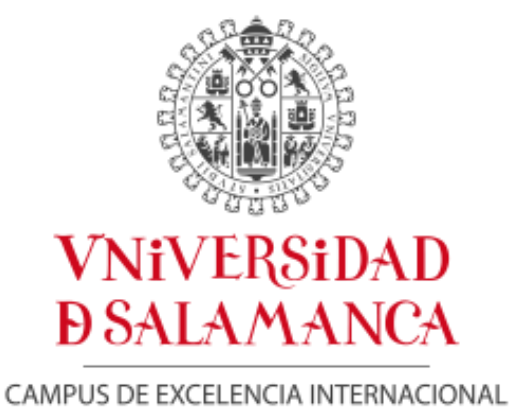

FACULTAD DE CIENCIAS QUÍMICAS

Departamento de Química Analítica, Nutrición y Bromatología

\title{
NANOPARTÍCULAS COMO HERRAMIENTAS EN PROCESOS BIO-QUÍMICOS. SÍNTESIS, CARACTERIZACIÓN, FUNCIONALIZACIÓN Y APLICACIONES
}

\author{
NANOPARTICLES AS TOOLS IN BIO-CHEMICAL PROCESSES. \\ SYNTHESIS, CHARACTERIZATION, FUNCTIONALIZATION AND \\ APPLICATIONS
}

Sara Sánchez Paradinas 



\section{UNIVERSIDAD DE SALAMANCA}

FACULTAD DE CIENCIAS QUÍMICAS

Departamento de Química Analítica, Nutrición y Bromatología

\section{NANOPARTÍCULAS COMO HERRAMIENTAS EN PROCESOS BIO-QUÍMICOS. SÍNTESIS, CARACTERIZACIÓN, FUNCIONALIZACIÓN Y APLICACIONES}

NANOPARTICLES AS TOOLS IN BIO-CHEMICAL PROCESSES. SYNTHESIS, CHARACTERIZATION, FUNCTIONALIZATION AND APPLICATIONS

Memoria que para optar al Grado de Doctor en Química presenta la Licenciada Sara Sánchez Paradinas

Salamanca, 27 de marzo de 2013

Fdo: Sara Sánchez Paradinas 

D. Ángel Alonso Mateos y D. a María Jesús Almendral Parra, Profesores Titulares de la Universidad de Salamanca

\section{AUTORIZAN}

A la Licenciada D. - Sara Sánchez Paradinas la presentación de la Memoria titulada 'NANOPARTÍCULAS COMO HERRAMIENTAS EN PROCESOS BIO-QUÍMICOS. SÍNTESIS, CARACTERIZACIÓN, FUNCIONALIZACIÓN Y APLICACIONES', que se ha realizado bajo nuestra dirección en el Departamento de Química Analítica, Nutrición y Bromatología de la Facultad de Ciencias Químicas de la Universidad de Salamanca, para optar al grado de Doctor en Química.

Y para que así conste, firmamos la presente autorización en Salamanca, a 27 de marzo de 2013. 

D. Bernardo Moreno Cordero, Catedrático y Director del Departamento de Química Analítica, Nutrición y Bromatología de la Universidad de Salamanca

\section{INFORMA}

Que la Memoria titulada 'NANOPARTÍCULAS COMO HERRAMIENTAS EN PROCESOS BIO-QUÍMICOS. SÍNTESIS, CARACTERIZACIÓN, FUNCIONALIZACIÓN Y APLICACIONES' que, para optar al grado de Doctor presenta la Licenciada D. a Sara Sánchez Paradinas, ha sido realizada bajo la dirección de los Doctores D. Ángel Alonso Mateos y D. - María Jesús Almendral Parra en el Departamento de Química Analítica, Nutrición y Bromatología de la Universidad de Salamanca.

Y para que así conste, firmo el presente informe en Salamanca, a 27 de marzo de 2013.

Fdo.: D. Bernardo Moreno Cordero 

Con la elaboración y defensa de esta Memoria se pretende optar a la obtención de Doctorado Europeo, teniendo en cuenta que la doctoranda reúne los requisitos para optar a tal mención:

- La doctoranda ha realizado una estancia de tres meses en Fachbereich Physik AG Biophotonik en Marburg (Alemania), donde ha realizado una parte del trabajo experimental.

- El resumen y las conclusiones se han redactado en una de las lenguas oficiales de la Unión Europea distinta a las de España, y parte de la defensa se realizará en ese mismo idioma.

- La tesis cuenta con los informes favorables de dos doctores expertos pertenecientes a instituciones de Educación Superior de países miembros de la Unión Europea distintos a España.

- Uno de los miembros que ha de formar parte del tribunal evaluador de la tesis es un experto perteneciente a una institución de Educación Superior de un Estado miembro de la Unión Europea distinto de España, con el título de doctor, y distinto del responsable de la estancia. 

Mi agradecimiento a la Junta de Castilla y León por la concesión de una beca predoctoral y a la Universidad de Salamanca por las ayudas concedidas.

Este trabajo ha sido financiado por los proyectos SA060A08 de la Junta de Castilla y León y GR 108: Convocatoria especial para Grupos de Investigación de Excelencia de la Junta de Castilla y León. 

Mi más sincero agradecimiento a mis tutores, Dra. María Jesús Almendral Parra y Dr. Ángel Alonso Mateos, por su apoyo incondicional, por la confianza depositada en mí y por tantas otras cosas que han servido para mi formación, tanto en lo personal como en lo profesional.

Gracias al Dr. Julio J. Criado Talavera, Dr. Emilio Rodríguez Fernández, Dr. Manuel Fuentes García y Dr. Martín Pérez Andrés por su ayuda, sus consejos, sus ánimos y por todo lo que me han enseñado en las últimas etapas de la tesis.

Mi agradecimiento al Dr. Miguel Valcárcel Cases por la oportunidad de trabajar en su grupo de investigación en la Universidad de Córdoba durante cuatro meses. Gracias al resto de compañeros por su ayuda y amabilidad durante la estancia.

También expreso mi gratitud al Dr. Wolfgang Parak por ofrecerme la oportunidad de trabajar en su grupo en la Philipps-Universität de Marburg (Alemania) durante tres meses. Estoy muy agradecida por su apoyo y ayuda en cualquier situación y por el tiempo dedicado. Gracias a los otros compañeros por su ayuda y amistad durante esta estancia.

Finalmente, agradecer a la Dra. Susana Carregal Romero y al Dr. Rene Kizek sus informes y comentarios sobre este trabajo. 

A los miembros del Departamento de Analítica, las viejas glorias con las que coincidí, los que han pasado por él y he tenido el placer de conocer, los que están y ya son algo más que compañeros de trabajo...

A los de otros Departamentos, que hacen que la interdepartamentalidad merezca la pena...

A los que han aparecido en la última etapa...

A mis niñas...

A mis padres, mi hermana, mi abuela...

Formáis parte de esta Tesis, igracias a todos! 

TABLA DE CONTENIDO 



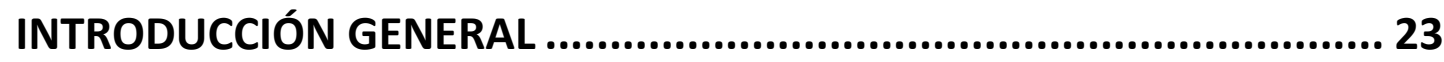

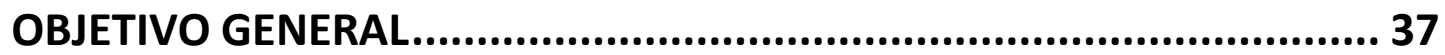

BLOQUE I: QUANTUM DOTS. SÍNTESIS EN MEDIO ACUOSO Y

ESTUDIO ESPECTROSCÓPICO ............................................................ 41

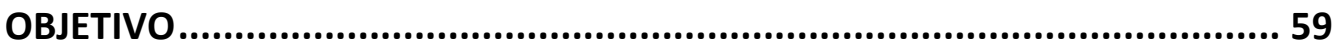

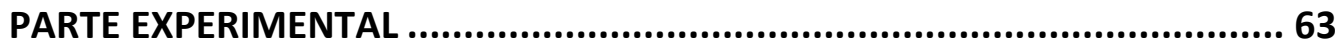

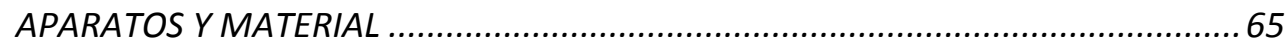

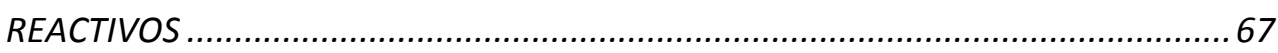

OBTENCIÓN DE NANOPARTÍCULAS DE CdS EN FASE HETEROGÉNEA ........... 69

MÉTODO EXPERIMENTAL PARA LA OBTENCIÓN DE QDS DE CdS EN

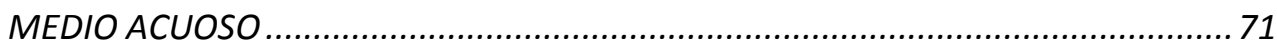

MÉTODOS PARA EL CÁLCULO DEL DIÁMETRO MEDIO DE LAS

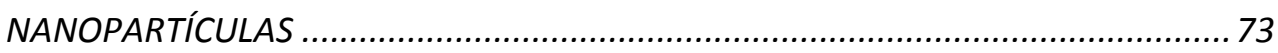

ESTIMACIÓN DEL NÚMERO DE MOLÉCULAS DE CdS CONTENIDAS

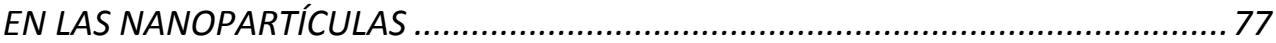

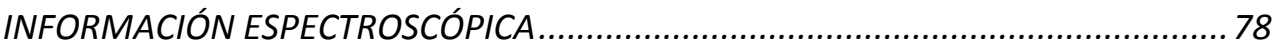

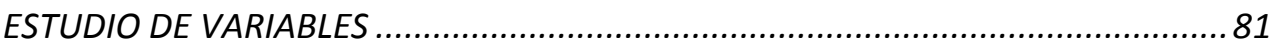

INFLUENCIA DEL pH ....................................................................................

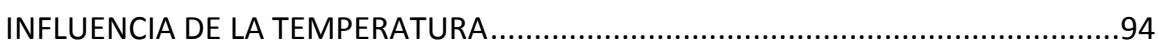

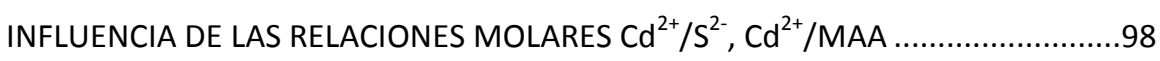

FOTOGRAFÍAS DE LA FLUORESCENCIA DE LOS QDS OBTENIDOS

EN EL LABORATORIO EN DIFERENTES CONDICIONES …...................................... 107

OBTENCIÓN DE NANOPARTÍCULAS DE CdS EN FASE HOMOGÉNEA............ 109

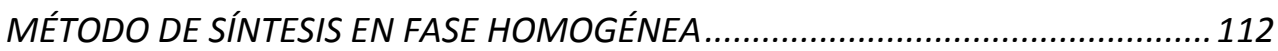

OBTENCIÓN DE NANOPARTÍCULAS DE CdS EN FASE HETEROGÉNEA

(A PARTIR DE SULFURO) COMO TESTIGO PARA LOS ESTUDIOS

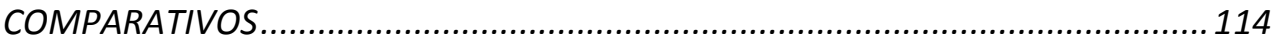

EVOLUCIÓN DE LOS ESPECTROS DE ABSORCIÓN ……………………….........115

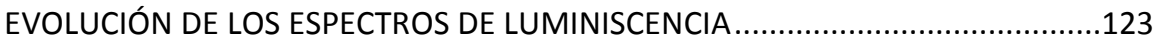

ESTUDIO DE VARIABLES QUE AFECTAN A LA OBTENCIÓN DE 


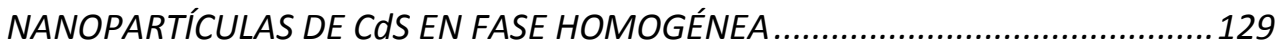

INFLUENCIA DEL pH DE LA DISOLUCIÓN ACUOSA.............................................129

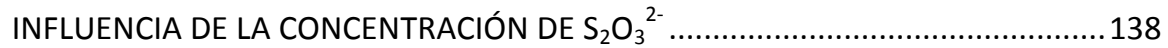

INFLUENCIA DE LA CONCENTRACIÓN DE TIOGLICEROL ....................................151

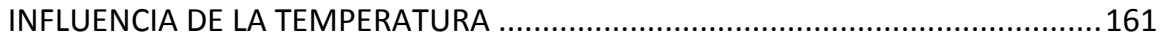

CONCLUSIONES GENERALES DEL ESTUDIO COMPARATIVO....................... 173

BLOQUE II: NANOPARTÍCULAS METÁLICAS. AUNPS Y FeNPS

COMO TRANSPORTADORES DE FÁRMACOS .................................179

NANOPARTÍCULAS DE ORO COMO TRANSPORTADORES DE FÁRMACOS... 181

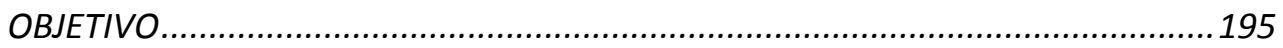

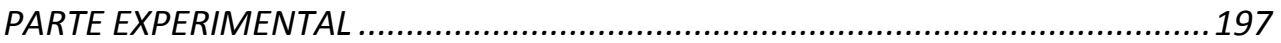

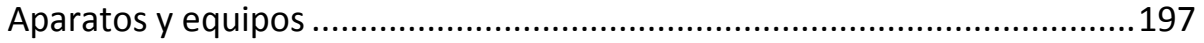

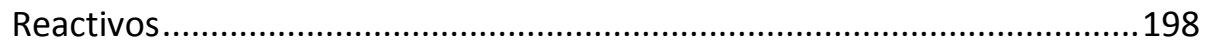

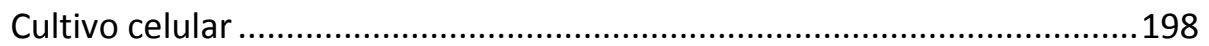

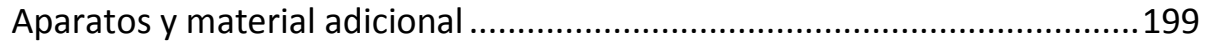

Síntesis y caracterización de los compuestos utilizados..............................199

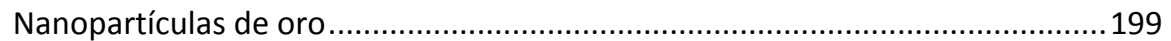

Bisursodeoxicolato(etilendiamino)platino (II), [Pt(UDC) $\left.)_{2}(e n)\right]$, PtU2 .................... 199

Estudio de la citotoxicidad del nuevo compuesto de platino PtU2 .............202

Compuesto conjugado de AuNPs y PtU2: PtU2-AuNP................................204

Estudio de la actividad transportadora de las AuNPs (captación

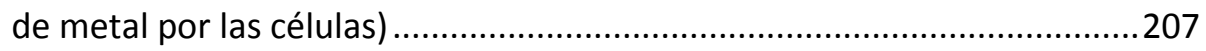

Estudio de la actividad citotóxica ............................................................209

\section{NANOPARTÍCULAS DE ÓXIDO DE HIERRO COMO TRANSPORTADORAS}

DE FÁRMACOS Y AGENTES DE CONTRASTE EN MRI ................................ 217

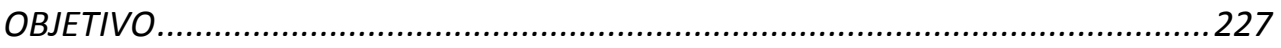

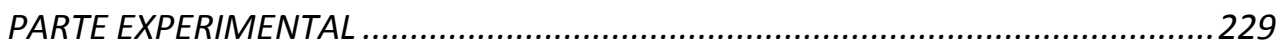

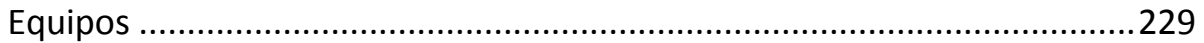

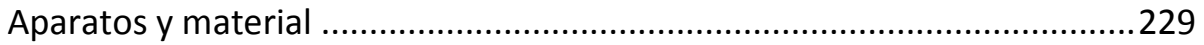

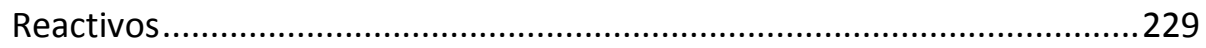


MÉTODO EXPERIMENTAL PARA LA OBTENCIÓN DE NANOPARTÍCULAS

$\mathrm{DE} \mathrm{Fe} \mathrm{O}_{3}$

RECUBRIMIENTO POLIMÉRICO DE LAS NANOPARTÍCULAS DE Fe $\mathrm{O}_{3} \ldots \ldots \ldots . . .232$

MODIFICACIÓN DE LA SUPERFICIE DE LAS NANOPARTICULAS CON PEG....236

UNIÓN DE METOTREXATO A LAS NANOPARTÍCULAS $\mathrm{Fe}_{2} \mathrm{O}_{3}$-PEG 238

CONCLUSIÓN GENERAL 245

SUMMARY IN ENGLISH .249

INTRODUCTION. .253

GENERAL AIMS 261

QUANTUM DOTS. Synthesis in aqueous medium and spectroscopy study. 265

METAL NANOPARTICLES. AuNPs as drug carriers 269 NANOPARTICLES IN PROTEOMICS .273 CONCLUSIONS .277

ANEXOS- APPENDIX 281

ANEXO I: ARTÍCULOS PUBLICADOS

(APPENDIX I: PUBLISHED ARTICLES)

ANEXO II: INFORMES SOBRE EL TRABAJO REALIZADO (APPENDIX II: REPORTS ON THE DEVELOPED WORK) 

Introducción general 

La esencia de la ciencia química encuentra su expresión más plena en las palabras de Leonardo da Vinci: "Donde la naturaleza termina de producir sus propias especies, los hombres comienzan, usando cosas naturales y con la ayuda de esta naturaleza, a crear una infinidad de nuevas especies". El laureado con el premio nobel Jean-Marie Lehn utilizó estas palabras para ofrecer su punto de vista sobre el futuro y las perspectivas de la química supramolecular ${ }^{1}$. La química supramolecular investiga los principios de la naturaleza para producir extraordinarios complejos y uniones moleculares funcionales y potencialmente útiles como sensores, catalizadores, medios de transporte y otras aplicaciones en medicina e ingeniería ${ }^{2,3}$. Otro ejemplo de los modernos logros técnicos se refiere al desarrollo de materiales avanzados, funcionalizados e incluso de diseño para aplicaciones en dispositivos mecánicos, ópticos o electrónicos altamente integrados, sensores o catalizadores ${ }^{4}$.

Comenzando con el descubrimiento de la estructura de doble hélice del ADN la Biología ha crecido, pasando de ser una disciplina puramente descriptiva y fenomenológica a una ciencia molecular. Todos estos desarrollos revolucionarios han llevado a fusionar la Biotecnología con la Ciencia de los Materiales, como podemos apreciar en la Figura 1.

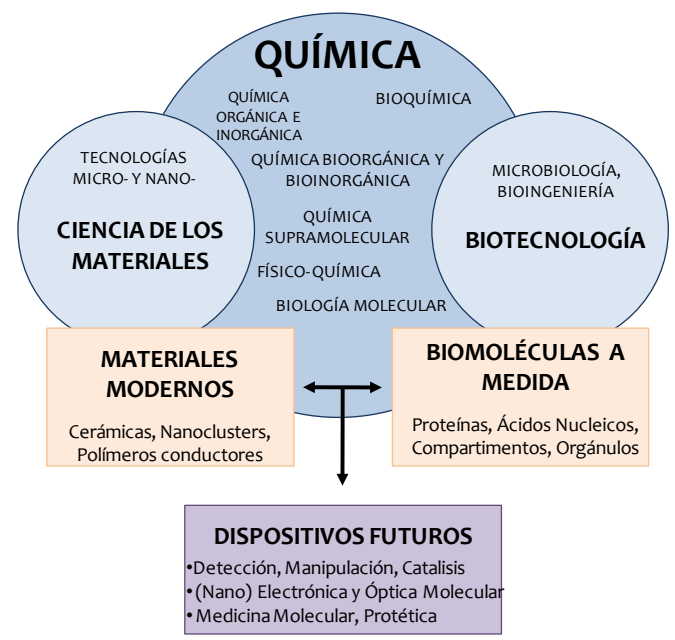

Figura 1. La Química como Ciencia central para el desarrollo de disciplinas como la investigación en materiales y la Biotecnología. La Ciencia de los Materiales, que está basada en campos de investigación de la Química Clásica y en tecnologías de ingeniería, ha conducido a enormes avances en la fabricación de avanzados materiales modernos hechos a medida. Modificada de [4]

\footnotetext{
${ }^{1}$ J.M. Lehn. Supramolecular Chemistry. Concepts and Perspectives. VCH, Weinheim, 1995.

${ }^{2}$ F. Vögtle. Supramolecular Chemistry. Wiley, Chichester, 1991.

${ }^{3}$ J.L. Atwood, J.E.D. Davies, D.D. MacNicol, F. Vögtle. Comprehensive Supramolecular Chemistry. Elsevier, Oxford, 1996.

${ }^{4}$ C.M. Niemeyer. Nanoparticles, Proteins and Nucleic Acids: Biotechnology Meets Materials Science. Angew. Chem. Int. Ed. 40 (2001) 4128-4158.
} 
La unión de estas disciplinas nos da la indudable ventaja de utilizar componentes biológicos en evolución para generar nuevos materiales de diseño y, a la inversa, aplicar estos materiales avanzados y nuevas técnicas fisicoquímicas a resolver problemas biológicos.

Ambas, Biotecnología y Ciencia de los Materiales, pueden verse en la misma escala de longitud (Fig. 2). Por una parte, los componentes biomoleculares tienen dimensiones en el rango de 5 a $200 \mathrm{~nm}$. Por otra parte, los requerimientos comerciales para producir dispositivos microelectrónicos cada vez más miniaturizados motivan fuertemente la elaboración de sistemas a nanoescala, con partes significativamente más pequeñas que los $100 \mathrm{~nm}$.

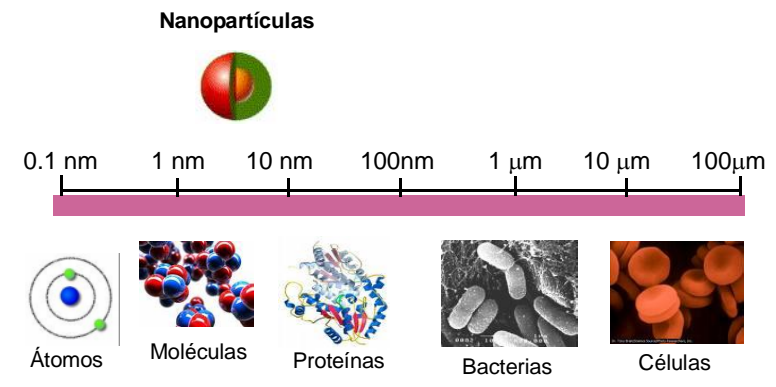

Figura 2. Tamaño de nanopartículas en relación con otros objetos biológicos ${ }^{5}$.

Para explotar y utilizar todos los conceptos implicados en los sistemas naturales a escala nanométrica es crucial el desarrollo de la Nanociencia y de la Nanoquímica ${ }^{6}$. Podemos definir la Nanociencia como la Ciencia que se ocupa del análisis y de la manipulación de materiales a nivel atómico o molecular, donde las características o propiedades físicas o químicas se diferencian significativamente de las presentadas a una escala mayor (Phantoms Foundation).

En este sentido se define un Nanomaterial como un material consistente en una sustancia o estructura que tiene una dimensión al menos menor que $100 \mathrm{~nm}$. Estas estructuras tienen, debido a su tamaño, nuevas propiedades y un comportamiento diferente al exhibido por el grueso de la materia de la misma composición. Son los objetos llamados de dimensión cero, que exhiben importantes propiedades tamaño-dependientes. Los más importantes podemos verlos representados esquemáticamente en la Figura 3.

\footnotetext{
${ }^{5}$ J.M. de la Fuente, S. Penadés. Glyconanoparticles: Types, synthesis and applications in glycoscience, biomedicine and material science. Biochimica et Biophysica Acta 1760 (2006) 636-651.

${ }^{6}$ D. Philp, J.F. Stoddart. Self-Assembly in Natural and Unnatural Systems. Angew. Chem. 108 (1996) 1242-1286. 


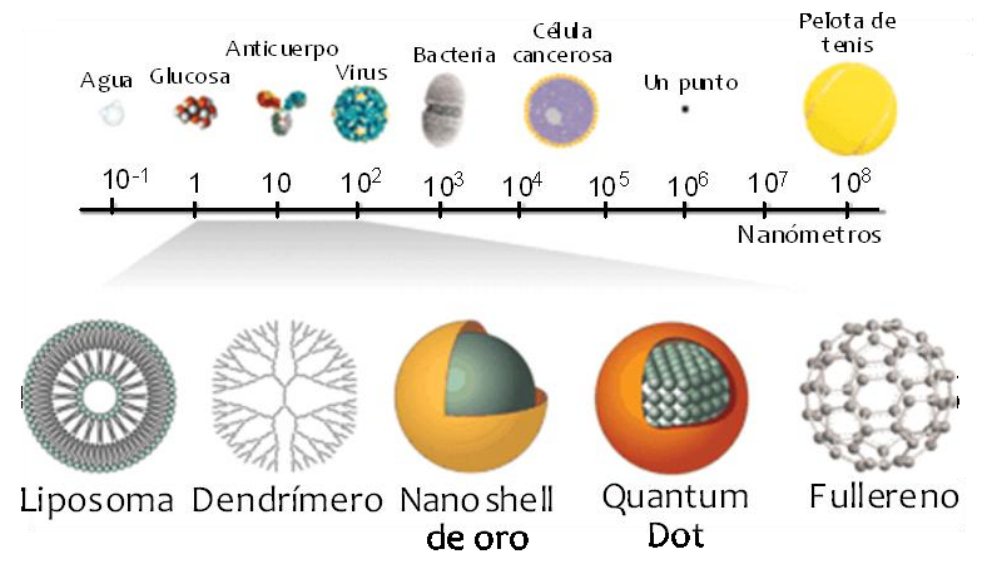

Figura 3. Tipos y tamaños relativos de nanopartículas en comparación con elementos familiares. Modificada $\mathrm{de}^{7}$.

Según la definición de la Unión Europea, la Nanotecnología es una ciencia multidisciplinar que se refiere a las actividades científicas y tecnológicas llevadas a cabo a escala atómica y molecular, así como a los principios científicos y a las nuevas propiedades que pueden ser comprendidas y controladas cuando se interviene a dicha escala.

Si consideramos la definición de la National Nanotechnology Initiative (NNI), la Nanotecnología se define como la investigación y el desarrollo tecnológico en la escala atómica, molecular y macromolecular, dirigida a la creación controlada y el uso de estructuras, dispositivos y sistemas de tamaño entre 1 y 100 nanómetros.

El Premio Nobel Richard Feynman (Fig. 4), en su conferencia con visión de futuro There is plenty of room at the bottom (Hay mucho espacio al fondo) ${ }^{8}$, inspiró los conceptos para la investigación sobre la Nanotecnología. Aunque el término Nanotecnología no había aparecido aún en el horizonte, Feynman dijo: "What I want to talk about is the problem of manipulating and controlling things on a small scale... What I have demonstrated is that there is room - that you can decrease the size of things in a practical way... I will not discuss how we are going to do it, but only what is possible in principle... We are not doing it simply because we haven't yet gotten around to it" (De lo que quiero hablar es del problema de manipular y controlar cosas a pequeña escala... Lo que he demostrado es que hay espacioque puedes reducir el tamaño de las cosas de una manera práctica... No voy a discutir cómo vamos a hacerlo, solo que es posible, en principio... No lo estamos haciendo simplemente porque aún no hemos llegado a hacerlo). Cuatro décadas más tarde los científicos han aprendido que la manipulación de átomos, moléculas y agrupaciones sobre superficies es

\footnotetext{
${ }^{7}$ S.E. McNeil. Nanotechnology for the biologist. Journal of Leukocyte Biology 78 (2005) 585-594.

${ }^{8}$ R. Feynman. There is Plenty of Room at the Bottom, in The Pleasure of Finding Things Out. Ed.: J. Robbins, Perseus Books (1999).
} 
factible y que la nueva física fundamental gobierna las propiedades de los nanoobjetos. Siguiendo la visión de Feynman pueden emplearse átomos y moléculas como unidades de construcción para uniones de "abajo hacia arriba" para la fabricación de arquitecturas de dimensiones nanométricas.

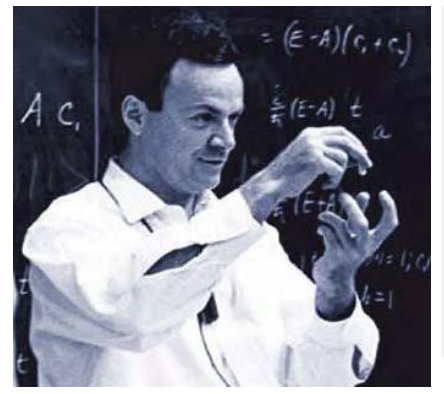

There is plenty of room at the bottom

"What I want to talk about is the problem of manipulating and controlling things on a small scale... What I have demonstrated is that there is room-that you can decrease the size of things in a practical way... I will not discuss how we are going to do it, but only what is possible in principle... We are not doing it simply because we haven't yet gotten around to it."

Figura 4. Richard Feynman, Premio Nobel de Física en 1965.

La Nanotecnología es un campo en rápida expansión que abarca el desarrollo de materiales hechos por el hombre con tamaños en el rango citado. Esta dimensión sobrepasa ampliamente la de las moléculas orgánicas estándar, pero es de rango más bajo que muchas proteínas y macromoléculas biológicas ${ }^{9}$ (Fig. 5). Tales construcciones deben tener propiedades y funciones nuevas debido a su pequeño tamaño. Por ejemplo, los nanotubos de carbono y las nanoconchas de oro, dos tipos diferentes de materiales, tienen propiedades físicas diferentes del carbono ${ }^{10,11}$ o del oro ${ }^{12,13}$ a macroescala. Otros ejemplos de nanotecnología incluyen dendrímeros ${ }^{14,15}$, liposomas ${ }^{16,17}$ y quantum dots semiconductores $^{18}$. Por otro lado, partículas como DNA, bacteriófagos y anticuerpos monoclonales $(\mathrm{mAb})$ pueden tener dimensiones nanométricas pero no deben ser considerados estrictamente ejemplos de nanotecnología.

${ }^{9}$ A.H. Faraji, P. Wipf. Nanoparticles in cellular drug delivery. Bioorganic \& Medicinal Chemistry 17 (2009) 29502962.

${ }^{10}$ A.S. Wu, T.W. Chou. Carbon nanotube fibers for advanced composites. Materials Today 15(7-8) (2012) 302-310.

${ }^{11}$ B.J. Leroy, S.G. Lemay, J. Kong, C. Dekker. Electrical generation and absorption of phonons in carbon nanotubes. Nature 432 (2004) 371-374.

${ }^{12}$ K. Saha, S.S. Agasti, C. Kim, X. Li, V.M. Rotello. Gold Nanoparticles in Chemical and Biological Sensing. Chem. Rev.112(5) (2012) 2739-2779.

${ }^{13}$ J.L. West, N.J. Halas. Engineered nanomaterials for biophotonics applications: improving sensing, imaging and therapeutics. Annu. Rev. Biomed. Eng. 5 (2003) 285-292.

${ }^{14}$ M. Malkoch, E. Malmström, A.M. Nyström. Dendrimers: Properties and Applications. Volume 6: Macromolecular Architectures and Soft Nano-Objects. Polymer Science: A Comprehensive Reference (2012) 113-176.

${ }^{15}$ M.J. Cloninger. Biological applications of dendrimers. Curr. Opin. Chem. Biol. 6 (2002) 742-748.

${ }^{16}$ M. Fathi, M.R. Mozafari, M. Mohebbi. Nanoencapsulation of food ingredients using lipid based delivery systems. Trends in Food Science \& Technology 23(1) (2012) 13-27.

${ }^{17}$ A.D. Miller. Nonviral liposomes. Methods Mol. Med. 90 (2004) 107-137.

${ }^{18}$ W.C. Chan, D.J. Maxwell, X. Gao, R.E. Bailey, M. Han, S. Nie. Luminescent quantum dots for multiplexed biological detection and imaging. Curr. Opin. Biotechnol. 13 (2002) 40-46. 

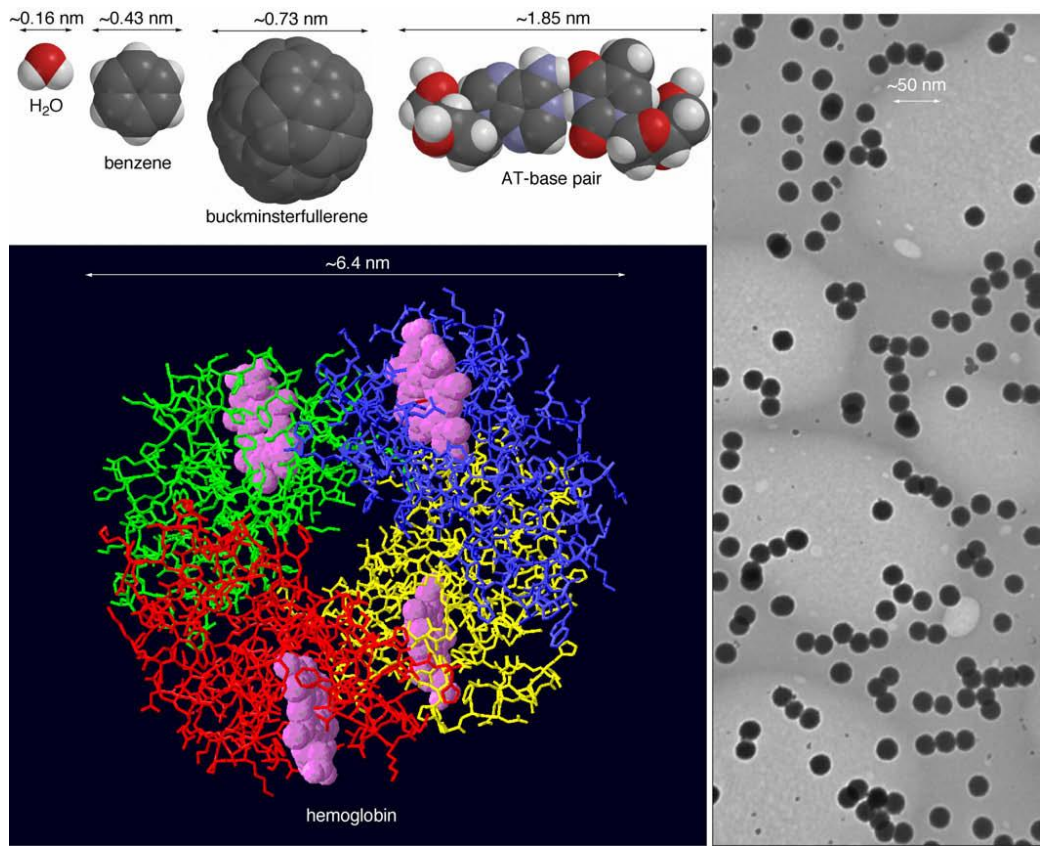

Figura 5. Tamaño de algunas moléculas orgánicas y macromoléculas biológicas (izquierda) en relación con nanopartículas de sílice (derecha) ${ }^{9}$.

Las nanopartículas (NPs) inorgánicas son particularmente atractivas como componentes básicos para la construcción de grandes superestructuras ${ }^{19,20,21,22}$. Estas nanopartículas pueden ser preparadas de forma sencilla a partir de diversos materiales. Sus dimensiones pueden ser controladas desde uno a varios cientos de nanómetros, con una distribución muy estrecha de tamaños. En la mayoría de los casos están formadas por metales $^{23}$ (por ejemplo, $\mathrm{Au}, \mathrm{Ag}$, Pt y $\mathrm{Cu}$ ) u óxidos metálicos y materiales semiconductores, tales como $\mathrm{Ag}_{2} \mathrm{~S}, \mathrm{CdS}, \mathrm{CdSe}$ y $\mathrm{TiO}_{2}{ }^{24}$. Tienen propiedades ópticas, electrónicas y catalíticas muy interesantes que dependen fuertemente del tamaño de la partícula. Como ejemplo podemos citar que la longitud de onda de emisión de luz de nanocristales semiconductores puede ser utilizada para el biomarcaje ${ }^{25,26,27}$ o en láseres ${ }^{28,29}$ entre otras aplicaciones.

19 C.C. Berry. Applications of Inorganic Nanoparticles for Biotechnology. Nanobiotechnology-Inorganic Nanoparticles vs Organic Nanoparticles. Chapter 6. Frontiers of Nanoscience 4 (2012) 159-180.

${ }^{20}$ A.P. Alivisatos. Semiconductor Clusters, Nanocrystals and Quantum Dots. Science 271 (1996) 933-937.

${ }^{21}$ D.L. Feldheim, C.D. Keating. Self-assembly of single electron transistors and related devices. Chem. Soc. Rev. 27 (1998) 1-12.

${ }^{22}$ A.N. Shipway, E. Katz, I. Willner. Nanoparticle Arrays on Surfaces for Electronic, Optical and Sensor Applications. Chem. Phys. Chem. 1 (2000) 19-52.

${ }^{23}$ D.L. Feldheim, C.A. Foss Jr. Metal Nanoparticles: Synthesis, Characterization and Applications. Marcel Dekker, New York, 2002.

${ }^{24}$ D.L. Klein, R. Roth, A.K.L. Lim, A.P. Alivisatos, P.L. McEuen. A Single-electron Transistor from Cadmium Selenide Nanocrystal. Nature 389 (1997) 699-701.

${ }^{25}$ P. Rivera-Gil, F. Yang, H. Thomas, L. Li, A. Terfort, W.J. Parak. Development of an assay based on cell counting with quantum dot labels for comparing cell adhesion within cocultures. Nano Today 6(1) (2011) 20-27. 
Además, ciertos tipos de nanopartículas pueden ser consideradas como átomos artificiales $^{30}$ ya que son obtenidos como nanocristales muy perfectos, que pueden utilizarse como componentes básicos para el ensamblaje de estructuras de dos o tres dimensiones ${ }^{31}$.

\section{Las Químicas Bioorgánica, Bioinorgánica y Bioanalítica son campos} interdisciplinarios que proporcionan la base para la unión de la Biotecnología con la Ciencia de los Materiales. La Bioinorgánica nos permite desarrollar procedimientos químicos para el atrapamiento y manipulación de componentes biológicos ${ }^{32,33}$ y, de forma análoga, las interacciones, que son abundantes en numerosos centros activos de enzimas, entre las cadenas laterales de los aminoácidos y los centros metálicos o la interacción entre ligandos orgánicos y la superficie de una nanopartícula inorgánica, facilitan el camino para acoplar sistemas de reconocimiento molecular a la generación de nuevos materiales.

Durante los últimos 20 años se ha producido un creciente interés en la fabricación de materiales híbridos entre nanopartículas inorgánicas y biomoléculas. Como las nanopartículas y las biomoléculas están en una escala similar de longitud, parece lógico que la combinación de biomoléculas con nanomateriales pueda dar lugar a interesantes herramientas de imitación de las biomoléculas que están presentes en los sistemas celulares, demostrando los mecanismos de los procesos biológicos y desarrollando medios químicos para manejar y manipular los componentes biológicos ${ }^{34,35}$. En la actualidad es sencillo controlar y modificar las propiedades de las nanoestructuras para conseguir su integración con sistemas biológicos; por ejemplo, controlando su tamaño, modificando su capa superficial para aumentar su solubilidad acuosa, su biocompatibilidad o su capacidad de biorreconocimiento.

Una gran variedad de metodologías sintéticas para la preparación de NPs con una estrecha distribución de tamaños ha sido descrita en bibliografía. En la fabricación de

\footnotetext{
${ }^{26}$ M. Bruchez Jr., M. Moronne, P. Gin, S. Weiss, A.P. Alivisatos. Semiconductor nanocrystals as fluorescent biological labels. Science 281 (1998) 2013-2015.

${ }^{27}$ W.C.W. Chan, S.M. Nie. Quantum dot bioconjugates for ultrasensitive nonisotopic detection. Science 281 (1998) 2016-2018.

${ }^{28}$ B.A. Ghali, S.J. Al-Obaidi, A.H. Al-Khursan. Modeling of synchronization in quantum dot semiconductor lasers. Optics \& Laser Technology 48 (2013) 453-460.

${ }^{29}$ M. Grundmann. The present status of quantum dot lasers. Physica E 5 (1999) 169.

${ }^{30}$ A. Eychmüller. Structure and Photophysics of Semiconductor Nanocrystals. J. Phys. Chem. B 104 (2000) 65146528.

${ }^{31}$ A.P. Alivisatos. Biomineralization: Enhanced: Naturally Aligned Nanocrystals Science 289 (2000) 736-737.

${ }^{32}$ H. Dugas. A Chemical Approach to Enzyme Action. Bioorganic Chemistry, Springer, New York, 1989.

${ }^{33}$ U. Diederichsen, T.K. Lindhorst, B. Westermann, L.A. Wessjohann. Bioorganic Chemistry: Highlights and New Aspects. Bioorganic Chemistry, Wiley-VCH, Weinheim, 1999.

${ }^{34}$ S. Kango, S. Kalia, A. Celli, J. Njuguna, Y. Habibi, R. Kumar. Surface Modification of Inorganic Nanoparticles for Development of Organic-Inorganic Nanocomposites - A Review. Progress in Polymer Science (2013) In Press, Accepted Manuscript.

${ }^{35}$ E. Katz, I. Willner. Integrated nanoparticle-biomolecule hybrid systems: synthesis, properties and applications. Angew. Chem. Int. Ed. 33 (2004) 6042-6108.
} 
nanomateriales se pueden distinguir dos aproximaciones: a) top-down (de arriba a abajo), y b) bottom-up (de abajo hacia arriba) (Fig. 6). La primera se basa en métodos en los que se busca lo pequeño a partir de lo grande, táctica usualmente empleada ya en las industrias. La segunda aproximación, la verdaderamente revolucionaria es la que busca crear complejidad a partir de elementos funcionales atómicos y moleculares, de un modo similar a la creación de la vida en nuestro planeta. En este sentido el área de los nanomateriales está estrechamente relacionada con la Nanoquímica ya que la preparación de materiales por rutas sintéticas ascendentes ó bottom-up, permite un grado de control de tamaño y propiedades muy difícil de conseguir, e inalcanzable en algunos casos, con técnicas más físicas de reducción de tamaño, top-down.

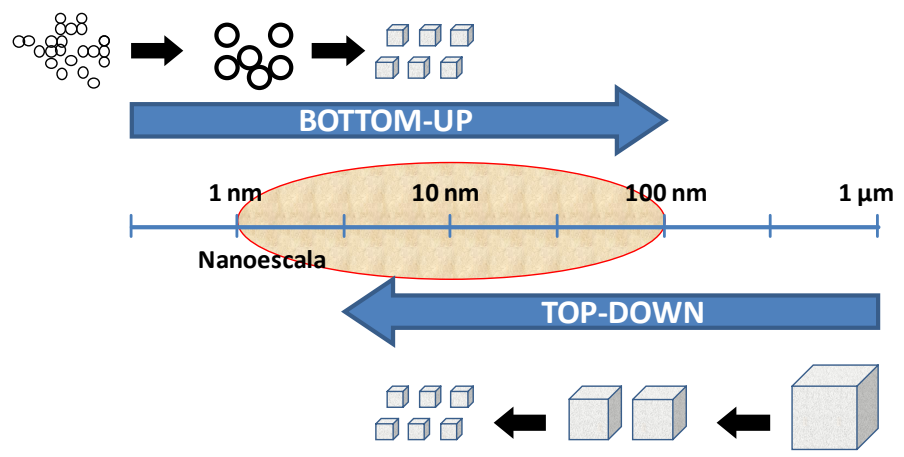

Figura 6. Representación esquemática de las dos aproximaciones en la fabricación de nanomateriales, top-down y bottom-up.

Con frecuencia, las nanopartículas se preparan por procedimientos de química húmeda, en los cuales se forman agrupaciones de átomos metálicos o moléculas semiconductoras en presencia de agentes estabilizantes (frecuentemente citratos, fosfatos o tioles) que se unen a los átomos sobre la superficie de la nanopartícula. Este recubrimiento conduce a la estabilización y previene el crecimiento incontrolado y la agregación de las NPs.

Las primeras aplicaciones prácticas de la nanotecnología fueron para avances en las comunicaciones, ingeniería, física, química, biología, robótica y medicina. La nanotecnología ha sido utilizada en Medicina para el suministro de fármacos y el desarrollo de tratamientos para una gran variedad de enfermedades y desórdenes. El aumento en la fabricación de nanomateriales está correlacionado con posteriores avances en estas disciplinas.

Las nanopartículas llaman a los científicos a través de muchas disciplinas debido a la oportunidad de intervenir en muchas propiedades que pueden de otra manera ser incompatibles en un dispositivo simple. Los dispositivos relevantes incluyen moléculas 
biológicamente activas, secuencias marcadoras, dispositivos fluorescentes y de imagen entre otros.

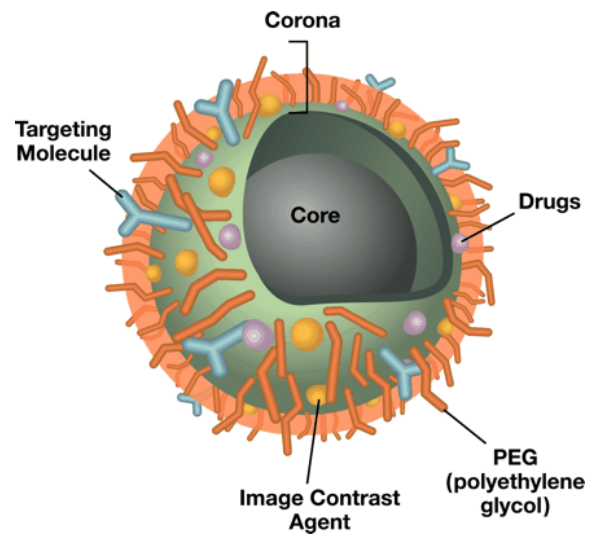

Figura 7. Nanopartícula multifuncional. La "corona" de la nanopartícula puede ser funcionalizada con polímeros hidrofílicos, moléculas marcadoras, agentes terapéuticos y agentes de contraste de imagen. El núcleo interior puede ser sólido (ej: quantum dots) o líquido (ej: liposomas). Las moléculas no se muestran a escala. PEG: polietilenglicol ${ }^{7}$.

Además, la ingeniería de la estructura de la partícula y su capa externa y el tamaño y forma del núcleo de la nanopartícula nos colocan en otra dimensión del control físico que puede ser ejercido hacia una función hecha a medida. Resultan particularmente interesantes sus aplicaciones en el suministro celular e intracelular de agentes terapéuticos ${ }^{36}$. Diversos tipos de nanopartículas usadas ya en la investigación biomédica y suministro de fármacos, pueden verse en la Figura 8.

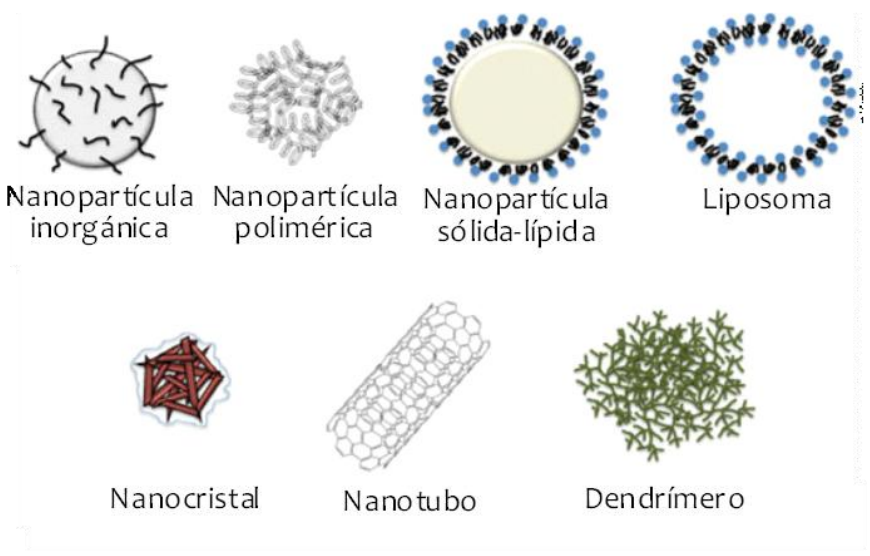

Figura 8. Varios tipos de nanopartículas usadas en investigación biomédica y suministro de fármacos ${ }^{9}$.

${ }^{36}$ S. Naahidia, M. Jafaria, F. Edalatc, K. Raymonda, A. Khademhosseinic, P. Chen. Biocompatibility of engineered nanoparticles for drug delivery. Journal of Controlled Release Volume 166 (2013) 182-194. 
Los parámetros farmacocinéticos y las estrategias específicas para el marcaje con estas nanopartículas nos muestran sugerencias sobre los mecanismos de aceptación celular e intracelular. A causa del extraordinario reto del suministro de fármacos al sistema nervioso central atravesando la blood-brain barrier (BBB), se abren grandes perspectivas en el tratamiento del cáncer neurológico, desórdenes neurovasculares y otras enfermedades neurodegenerativas.

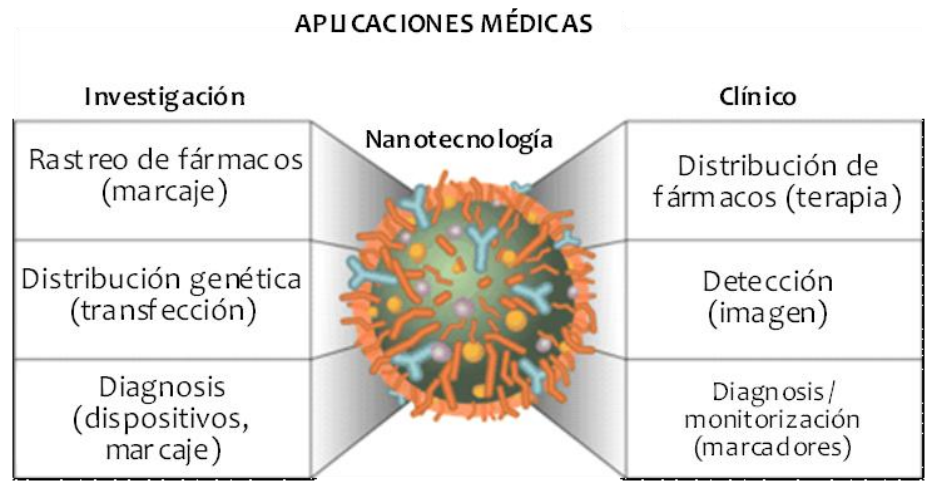

Figura 9. Aplicaciones médicas de la nanotecnología. El tamaño y la versatilidad de las nanopartículas hacen que sean ampliamente usadas en una gran variedad de aplicaciones médicas. Modificada de ${ }^{7}$.

Las terapias médicas se han vuelto cada vez mas adaptadas a enfermedades y pacientes específicos en los últimos años. La mayoría de los agentes farmacéuticos tienen sus objetivos primarios en células y tejidos; idealmente, estos agentes pueden ser preferentemente suministrados a los sitios de interacción con la célula. El suministro celular selectivo parece tener grandes beneficios terapéuticos. Este tipo de suministro es deseable para fármacos que sufren exportación extensiva desde la célula vía transportadores de flujo, como múltiples proteínas de resistencia a los medicamentos y las glicoproteínas- $\mathrm{P}^{37}$. Estos mecanismos de flujo reducen de forma continua la concentración intracelular terapéutica del fármaco. Una nanopartícula intracelular puede consecuentemente actuar como un depósito de droga dentro de la célula. La Nanotecnología puede ser utilizada para alcanzar dosis terapéuticas, vía terapias dirigidas, estableciendo perfiles de liberación sostenida de fármacos y proporcionando un santuario intracelular para proteger los compuestos terapéuticos de flujos o degradación.

En los últimos años, la Nanotecnología ha realizado un avance muy significativo, convirtiéndose en un área con gran aplicabilidad en diversos campos científicos, destacando entre éstos, de manera importante, el campo de la Proteómica.

\footnotetext{
${ }^{37}$ J. Panayam, V. Labhasetwar. Targeting Intracellular targets. Curr. Drug Deliv. 1 (2004) 235-247.
} 
El término proteómica apareció en 1997 como una analogía con genómica, el estudio de los genes. La palabra "proteoma" es la fusión de "proteína" y "genoma", y fue acuñada por Marc Wilkins en 1994, mientras trabajaba en ese concepto como estudiante de doctorado. El proteoma es la dotación completa de proteínas, incluyendo las modificaciones hechas a un conjunto particular de proteínas, producidas por un organismo o sistema. Esto varía con el tiempo, condiciones ambientales y con requisitos diferentes, o debido al estrés, que sufre una célula o un organismo. De ahí que se hable del carácter dinámico del proteoma. En el caso concreto del análisis proteómico asociado a patologías concretas, es posible identificar proteínas que permitirían diagnosticar la enfermedad o pronosticar la evolución de la misma. Dichas proteínas se conocen con el nombre genérico de biomarcadores.

La proteómica es una ciencia relativamente reciente. Su máximo desarrollo coincide con la consolidación de técnicas como la electroforesis en geles de poliacrilamida (introducida en 1970, es la técnica más eficaz para resolver mezclas complejas de proteínas, en dos modalidades, mono y bidimensional), HPLC y espectrometría de masas.

La Proteómica es el estudio y caracterización de todo el conjunto de proteínas expresadas de un genoma (proteoma), que permite identificar, categorizar y clasificar las proteínas con respecto a su función y a las interacciones que establecen entre ellas. El estudio del proteoma humano requiere el manejo de gran cantidad de datos generados por el elevado número de proteínas, producidas por alrededor de 25000 genes $^{38}$. En este sentido surgieron los arrays de proteínas como una plataforma que permite el análisis masivo, en paralelo y simultáneo de interacciones proteína-proteína ${ }^{39}$. El principio general en el que se basa un array de proteínas es la captura de proteínas por medio de moléculas de diversa naturaleza (agentes de captura) que permanecen ancladas a la superficie del microarray (Fig. 10).

\footnotetext{
${ }^{38}$ G. Marko-Varga, T. E. Fehninger. Proteomics and disease- the challenges for technology and discovery. J Proteome Research 3 (2004) 167-178.

${ }^{39}$ J. LaBaer, N. Ramachandran. Protein microarrays as tools for functional proteomics. Curr Opin Chem Biol 9 (2005) 14-19. 


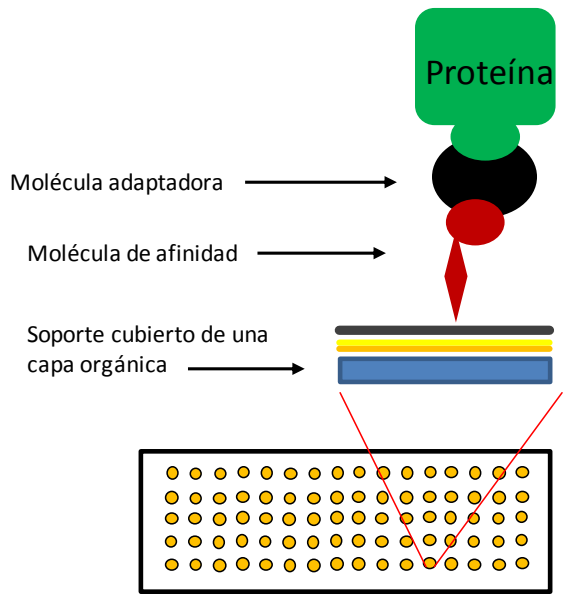

Figura 10. Inmobilización de proteínas en un microarray. Las moléculas de afinidad ancladas en la superficie del microarray mantienen unidas las proteínas por medio de una segunda molécula adaptadora.

Junto con los avances desarrollados en los arrays de proteínas se han realizado importantes avances en los métodos de detección que éstos utilizan. Últimamente, ha habido una transición de los sistemas de detección basados en etiquetas a los sistemas de detección libre de etiquetas (label-free).

Los sistemas basados en etiquetas generalmente se centran en el empleo de biomoléculas como sondas fluorescentes, radioisótopos, etc. Recientemente, la nanotecnología propone nuevos elementos como Quantum dots y nanopartículas de oro $^{40,41}$. Así, por ejemplo, los QDs se pueden conjugar con moléculas de biorreconocimiento, tales como péptidos o anticuerpos, para su utilización como etiquetas biológicas o marcadores fluorescentes, proporcionando ventajas como una alta fluorescencia y excelente fotoestabilidad. De esta manera se ha descrito la utilización de Quantum dots unidos a estreptavidina para la detección de citoquinas con un array de anticuerpos $^{42}$.

${ }^{40}$ Miguel Larguinhoa, Pedro V. Baptista. Gold and silver nanoparticles for clinical diagnostics-From genomics to proteomics. Journal of Proteomics 75 (2012) 2811-2823.

${ }^{41}$ S. Ray, G. Mehta, S. Srivastava. Label-free detection techniques for protein microarrays: prospects, merits and challenges. Proteomics 10 (2010) 731-748.

${ }^{42}$ A. Zajac, A. D. Song, W. Qian, T. Zhukov. Protein microarrays and quantum dot probes for early cancer detection. Colloids Surf B Biointerfaces 58 (2007) 309-314. 

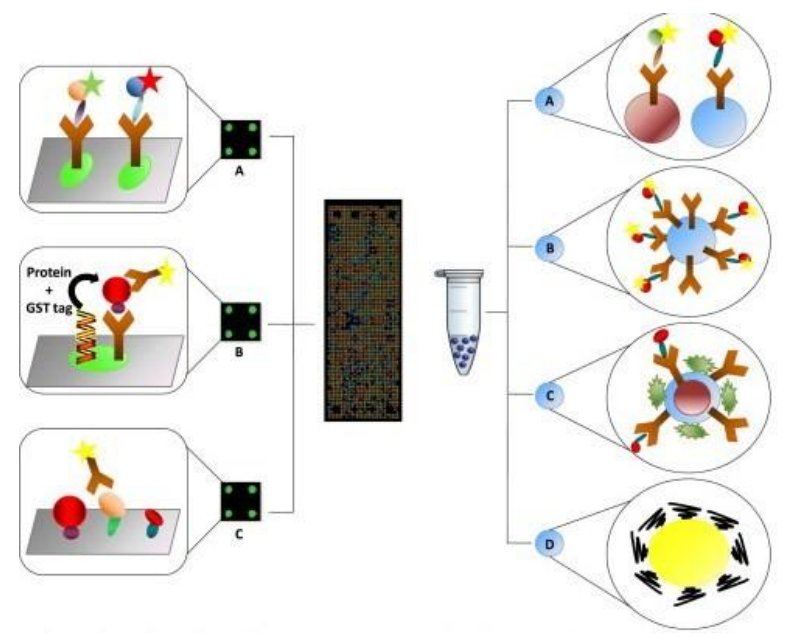

Figura 11. Métodos de detección de proteínas basados en etiquetas. Izquierda: Esquema del marcaje fluorescente convencional en microarrays de proteínas: A) arrays de proteínas diana; B) NAPPA; C) microarrays en fase reversa. Derecha: Arrays de proteínas basados en esferas: A) arrays de anticuerpos para detection por citometría de flujo; B) arrays de anticuerpos en microesferas magnéticas; C) Quantum dots; D) nanopartículas magnéticas.

Por otro lado, las técnicas sin marcaje (label-free) incluyen metodologías como la resonancia de plasmón de superficie (SPR, Surface Plasmon Resonance), nanotubos de carbono, cantilevers, etc.

Por tanto, el acoplamiento con éxito de la Nanotecnología con la Proteómica puede proporcionar una novedosa plataforma conocida como Nanoproteómica, que permita el estudio dinámico de proteínas en muestras biológicas complejas.

Junto con la detección de proteínas y el estudio de sus interacciones, la Nanotecnología también encuentra aplicación en el descubrimiento de biomarcadores, ofreciendo una serie de ventajas respecto a las técnicas clásicas, tales como la miniaturización y un mínimo consumo de reactivos, traduciéndose en una mayor sensibilidad y menor complejidad.

Esta última parte expuesta, dio lugar a un estudio bibliográfico que, a su vez, dio como resultado dos publicaciones mostradas en el Anexo I: Nanotechniques in proteomics: Protein microarrays and novel detection platforms en European Journal of Pharmaceutical Sciences 45 (2012) 499-506; y Biomarker Discovery by Novel Sensors Based on Nanoproteomics Approaches en Sensors 2012, 12, 2284-2308; doi:10.3390/s120202284. 
Objetivo general 

Con esta Tesis Doctoral se pretende realizar nuevas aportaciones al papel de las nanopartículas en la Nanociencia, Nanotecnología Analítica y Nanomedicina. Este propósito general se concreta en dos objetivos específicos que a continuación señalamos:

$>$ Contribuir al conocimiento de los Quantum dots, tanto en nuevos métodos para su síntesis, como en el estudio de sus características y fenómenos particulares, para fomentar y facilitar su empleo como herramientas analíticas.

Este primer bloque se centra en el estudio espectroscópico de nanopartículas semiconductoras de CdS, con el fin de mejorar los procedimientos de síntesis en medio acuoso y profundizar en el conocimiento del comportamiento de los QDS de CdS en diferentes condiciones.

Utilización de nanopartículas metálicas con fines biomédicos.

Funcionalizar nanopartículas de oro y de óxido de hierro, que actúen como transportadores de fármacos y ofrezcan nuevas oportunidades en el campo biomédico.

Por último, destacar que esta Tesis Doctoral se incluye dentro del pujante campo de investigación de la Nanociencia y Nanotecnología, tratándose de la primera Tesis Doctoral dedicada a nanopartículas realizada en el Departamento de Química Analítica, Nutrición y Bromatología de la Universidad de Salamanca, hecho que le otorga un grado de innovación importante. 



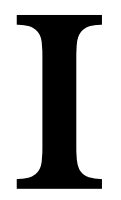

\section{Quantum dots}

Síntesis en medio acuoso $y$ estudio espectroscópico 



\section{QUANTUM DOTS (QDs)}

Los Quantum dots son un tipo de nanopartículas inorgánicas que ha recibido especial atención en los últimos años. Este interés se hace patente en el incremento de trabajos científicos que anualmente se registran con la palabra "quantum dot" en el buscador Scopus.com (Fig. 12).

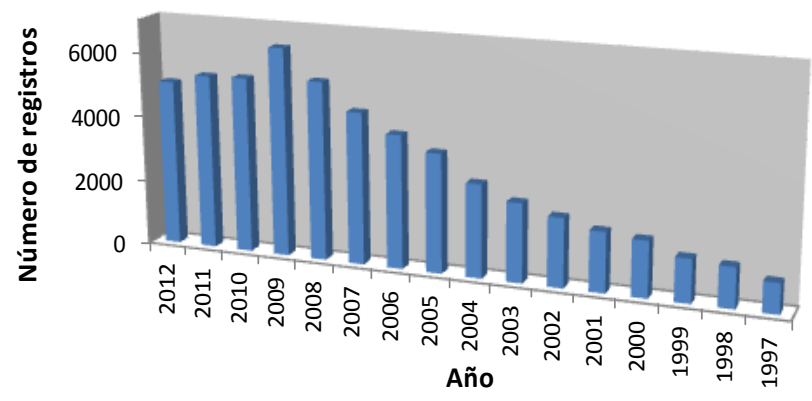

Figura 12. Registro de artículos científicos con la palabra clave "quantum dot" en la base de datos Scopus (enero 2013).

Existe una nomenclatura muy diversa para referirse a los Quantum dots: puntos cuánticos, nanopartículas semiconductoras, nanocristales semiconductores, semiconductores nanométricos, e incluso átomos artificiales. Sin embargo, el término por excelencia es sin duda el de "Quantum Dots" (abreviado con las siglas "QDs"), por lo que éste es el que emplearemos a lo largo de la presente Memoria.

Podemos definirlos como nanocristales semiconductores metálicos de tamaño entre 1 y 10 nanómetros, consistentes en unos pocos cientos o pocos miles de átomos, donde el movimiento de los electrones está confinado en tres dimensiones espaciales por barreras de potencial. Es un confinamiento cuántico, donde los electrones ya no se pueden mover libremente. El hecho de que se produzca este confinamiento cuántico es debido a que estas nanopartículas poseen un tamaño comparable al radio del excitón de Bohr, que es del orden de $10 \mathrm{~nm}$ en la mayoría de los semiconductores. Reduciendo las dimensiones del cristal semiconductor hasta tamaños del orden del radio del excitón de Bohr de dicho compuesto, los excitones se hallan confinados de manera similar al modelo cuántico de una

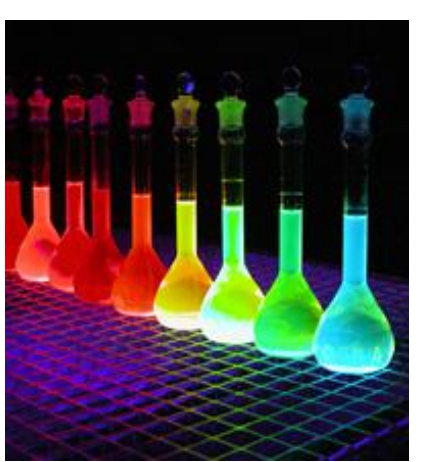

Figura 13. Luminiscencia de QDS de CdSe. partícula en una caja, y por tanto los niveles de energía pasan a ser discretos y finitos. Como consecuencia de este confinamiento cuántico, las propiedades ópticas de los QDs dependerán de su tamaño y estarán gobernadas por los efectos cuánticos resultantes de la 
cuantización de sus niveles energéticos, con un comportamiento que se asemeja al de los átomos y moléculas (Fig. 14).

(A)

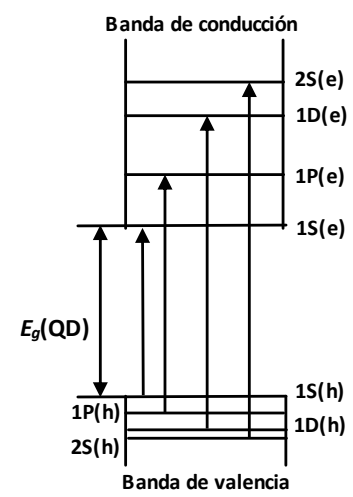

(B)

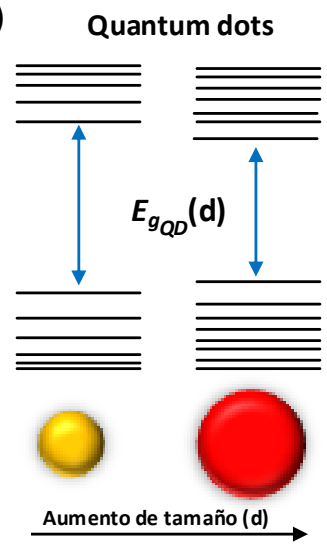

Semiconductor bulk
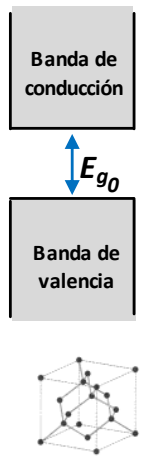

Figura 14. (A) Esquema de la estructura de bandas y niveles de energía de un quantum dot (QD). (B) Efecto de confinamiento cuántico en la estructura de bandas al aumentar el tamaño del QD.

La investigación en los Quantum dots comenzó con la comprensión de sus propiedades ópticas y electrónicas, las cuales, como ya se ha citado, eran fuertemente dependientes del tamaño de partícula, debido al confinamiento de la carga en un espacio tan pequeño. Debido al menor número de átomos en los QDs, contienen solamente unos pocos miles de átomos, la distancia entre las bandas de conducción y valencia es mayor que en el componente no nanoestructurado (Fig. 14), lo que provoca que la radiación emitida sea de un color más azulado (más energía). A medida que disminuye el tamaño del QD, aumenta su valor de $E g$ (bandgap energy), la radiación luminiscente emitida será de mayor energía, es decir de menor longitud de onda.

Están compuestos de los elementos de los grupos II-VI o III-V de la tabla periódica. Los QDs con elementos de los grupos III-V tienen núcleos de fosfuro de indio (InP), arseniuro de indio (InAs), arseniuro de galio (GaAs) y nitruro de galio (GaN). Los de elementos de los grupos II-VI tienen núcleos de sulfuro de zinc ( $\mathrm{ZnS})$, seleniuro de zinc ( $\mathrm{ZnSe}$ ), seleniuro de cadmio ( $\mathrm{CdSe}$ ) y telururo de cadmio (CdTe). Los nanocristales semiconductores pueden producirse con otras formas como por ejemplo en forma de barra, pero los de forma esférica son los más usados, fundamentalmente para aplicaciones biológicas.

Por tanto, uno de los rasgos más interesantes de los QDs es que el tamaño de la partícula y su composición determinan muchas de sus propiedades, la más importante: la longitud de onda de la emisión fluorescente (Fig. 15). 

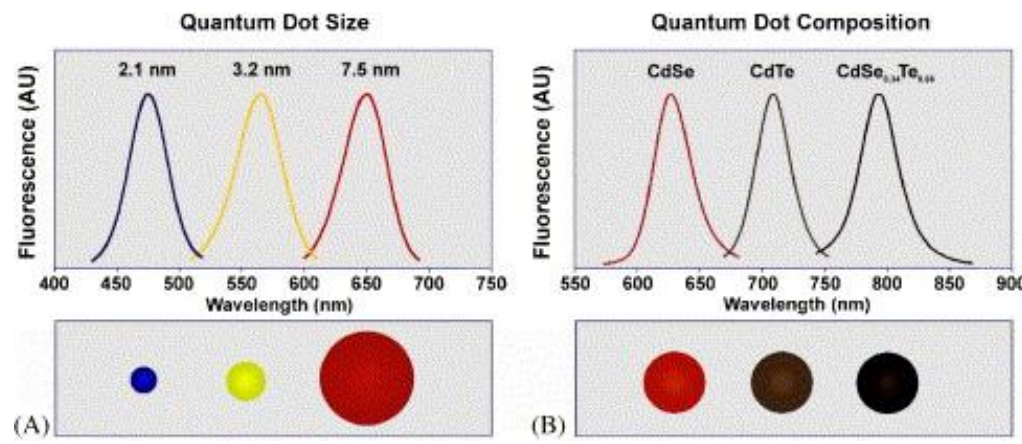

Figura 15. Modificación de la longitud de onda de emisión del QD con el cambio en el tamaño o la composición de la nanopartícula. (A) Emisión de un QD de CdSe en el espectro visible (450-650 nm) con diámetros entre 2.0 y $7.5 \mathrm{~nm}$. Los tamaños relativos de estas partículas de composición constante se muestran esquemáticamente debajo del espectro de fluorescencia. (B) Manteniendo constante el diámetro de la nanopartícula (5 nm) y cambiando la composición en $\mathrm{CdSe}_{\mathrm{x}} \mathrm{Te}_{1-\mathrm{x}}$, el máximo de emisión se modifica entre 610 y $800 \mathrm{~nm}$. La longitud de onda de emisión de esta aleación es mayor que la del quantum binario debido a una relación no linear entre la energía de "bandgap" y la composición $^{43}$.

Alterando el tamaño y la composición química del QD, la fluorescencia puede variar desde el UV cercano, a través del visible, hasta el IR cercano, abarcando un amplio rango de longitudes de onda de 400 a $2000 \mathrm{~nm}$. Los métodos corrientes de síntesis química de QDs permiten un excelente control del tamaño de partícula y su distribución, resultando en cantidades de QD de miligramos a gramos con picos de emisión estrechos y simétricos. Esto es mucho mejor que las características de emisión de típicas especies colorantes orgánicas, las cuales tienen perfiles de emisión más anchos y asimétricos. Esta propiedad particular es muy útil para marcar y detectar simultáneamente múltiples analitos.

Junto con las deseables propiedades de emisión, los QDs tienen buenas propiedades de absorción. Al contrario que los colorantes orgánicos, los cuales muestran grandes zonas de absorción cruzada sólo en una banda estrecha de frecuencias de resonancia, los QDs presentan absortividades molares altas y espectros de absorción anchos. Esta propiedad permite la excitación de los QDs con una fuente de luz única. La combinación de absortividades molares altas y rendimiento cuántico alto proporciona la base para una serie de marcadores fluorescentes basados en QDs. De hecho, estudios comparativos de luminosidad de QDs de CdSe/ZnS frente a Rodamina $6 \mathrm{G}$ indican que la fluorescencia de los QDs es de 10 a 100 veces mayor.

Muchas otras propiedades de los QDs tienen importantes implicaciones prácticas para su uso como marcadores fluorescentes. Su baja tasa de degradación hace posible un continuo seguimiento de lentos procesos biológicos, una característica que reta a los fluoróforos orgánicos tradicionales. Los largos tiempos de vida de fluorescencia de los QDs,

\footnotetext{
${ }^{43}$ R.E. Bailey, A.M. Smith, S. Nie. Quantum dots in biology and medicine. Physica E 25 (2004) 1-12.
} 
del orden de 10 a 50 ns, son ventajosos a la hora de distinguir las señales de los QDs de la fluorescencia base y permiten llevar a cabo una detección muy sensible.

Aunque el uso de QDs como marcadores es convincente, debe advertirse que no es probable que reemplacen a los colorantes orgánicos en todas las aplicaciones biológicas. Algunos de los retos que todavía no se han superado incluyen factores económicos: los QDs son caros en comparación con colorantes orgánicos, y esto requiere una previa inversión para los investigadores y un suministro de instrumentación para dar lugar a sistemas optimizados para usarlos con QDs. Se deberán hacer estudios de tamaño e impedimento estérico para decidir lo apropiado del uso de QDs como marcadores fluorescentes. Puesto que los QDs son un orden de magnitud mayores que los colorantes orgánicos, deberá ser determinada la extensión de la perturbación que produce su presencia en los procesos biológicos que se estén observando. Esto es importante en el diseño de experimentos multicolor, puesto que marcar varias biomoléculas con QDs de diferentes tamaños podría dar lugar a grados de perturbación diferentes debido a las grandes diferencias de tamaño de los QDs. En cualquier caso, este gran abanico de posibilidades de actuación confiere a los estudios de aplicación de los QDs en el mundo biológico, un enorme potencial de futuro.

\section{Síntesis química}

Históricamente, la síntesis de nanocristales coloidales de la familia de elementos semiconductores de los Grupos II a VI fue desarrollada usando técnicas similares a las usadas para producir nanopartículas coloidales de oro. Los nanocristales obtenidos por estos procedimientos pioneros tienen una amplia distribución de tamaño de partícula y bajos rendimientos cuánticos de fluorescencia. Debido a la polidispersión de estas muestras, las propiedades dependientes del tamaño de los QDs son difíciles de determinar. La situación cambia dramáticamente cuando Murray y col. ${ }^{44}$ desarrollan una síntesis coloidal usando medio orgánico y precursores organometálicos. Sintetizadas de esta manera las muestras presentaban un alto grado de monodispersidad, excelente cristalinidad y casi estaban libres de defectos estructurales. De todos modos, el rendimiento cuántico en la fluorescencia se situaba en torno al $10 \%$.

Fue descubierto con posterioridad que los defectos en la superficie de los QDs y una pasivación pobre de la misma eran los culpables de la baja fluorescencia. Este descubrimiento condujo a varios investigadores a inventar métodos eficientes para mejorar la calidad y pasivación de la superficie. Los primeros caminos con éxito involucran la pasivación vía deposición de una capa inorgánica (o shell- concha-) compuesta por un

\footnotetext{
${ }^{44}$ C.B. Murray, D.J. Norris, M.G. Bawendi. Synthesis and characterization of nearly monodisperse CdE $(E=s u l f u r$, selenium, tellurium) semiconductor nanocrystallites. J. Am. Chem. Soc. 115 (1993) 8706. 
material semiconductor de mayor bandgap energy (mínima energía requerida para excitar un electrón a un nivel de energía superior desde su estado fundamental) que el material interno.

Durante la década pasada se han desarrollado gran cantidad de procedimientos para la obtención de QDs de alta calidad, todos ellos basados en la variación de la alta temperatura de reacción introducida por Murray y col $^{44}$. Los elementos esenciales de estos procedimientos incluyen la combinación de un precursor metálico y organometálico apropiado (especies de zinc, cadmio o mercurio) con un precursor precipitante (especies sulfuro, seleniuro o telururo) en un disolvente de coordinación a altas temperaturas (Fig. 16).

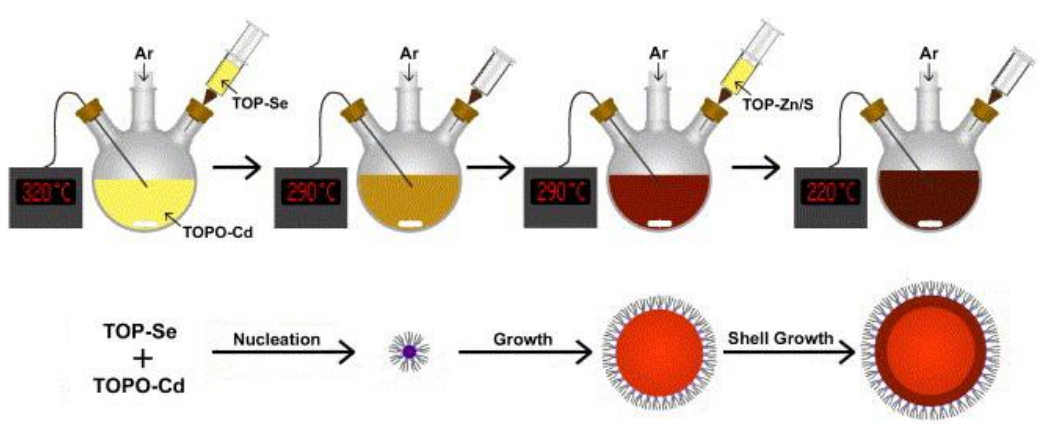

Figura 16. Síntesis de QDs coloidales de CdSe en disolventes coordinantes de alta temperatura. Para una reacción típica, un matraz de tres bocas se coloca en una manta calefactora y es equipado con un termopar y un controlador de temperatura. Un precursor de Cd (ej: óxido de $\mathrm{Cd}$ o acetato de $\mathrm{Cd}$ ) se disuelve en TOPO en atmósfera inerte (Ar o $\mathrm{N}$ ). Bajo continua agitación a alta temperatura (unos $320^{\circ} \mathrm{C}$ ), se inyecta rápidamente en el matraz el precursor de selenio disuelto en TOP, comenzando la rápida nucleación de las nanopartículas de CdSe. La nucleación cesa rápidamente en parte debido a la bajada rápida de la temperatura $\left(\mathrm{a} 290^{\circ} \mathrm{C}\right.$ ) causada por la inyección de la disolución a temperatura ambiente, y sobreviene el crecimiento de la partícula. Cuando se ha obtenido el tamaño deseado, la disolución debe ser enfriada $\left(220^{\circ} \mathrm{C}\right)$ para prevenir un mayor crecimiento. Se debe hace crecer una capa pasivante de ZnS por inyección de los precursores de Zn y S disueltos en TOP. Enfriando a temperatura ambiente, los QDs se aíslan vía precipitación ${ }^{43}$.

Se han obtenido QDs de alta calidad usando disolventes estables a alta temperatura, que actúan como moléculas surfactantes para la estabilización de la superficie del QD y así previenen la agregación de partículas. El TOPO (tri-n-octylphosphine oxide) es comúnmente usado debido a su alto punto de ebullición y su habilidad para coordinar el metal y el elemento precipitante. Frecuentemente, el TOPO se usa en combinación con otros surfactantes o co-disolventes como TOP (tri-n-octylphosphine), hexadecilamina o ácido esteárico ${ }^{45,46}$.

${ }^{45}$ D.V. Talapin, A.L. Rogach, A. Kornowski, M. Haase, H. Weller. Highly Luminescent Monodisperse CdSe and CdSe/ZnS Nanocrystals Synthesized in a Hexadecylamine-Trioctylphosphine Oxide-Trioctylphospine Mixture. Nano Lett. 1 (2001) 207. 
Bajo estas condiciones, la nucleación de las partículas tiene lugar rápidamente, seguida de crecimiento epitaxial y templado del cristal a temperaturas ligeramente más bajas.

Durante el periodo de crecimiento, el tamaño del QD puede ser monitorizado espectroscópicamente en el matraz de reacción o estudiando alícuotas tomadas a varios intervalos. Una vez obtenido el tamaño deseado, el crecimiento se para bajando la temperatura de la mezcla de reacción. La tasa de crecimiento y el tamaño máximo de partícula pueden ser manipulados hasta cierto punto controlando los siguientes parámetros: concentración del precursor inicial, temperatura de crecimiento y extensión del periodo de crecimiento. Es posible también introducir materiales precursores adicionales en el matraz de reacción durante el periodo de crecimiento para obtener QDs más grandes y mejorar la distribución de tamaños. Aunque la producción de QDs deba ser llevada a cabo en atmósfera inerte debido a la reactividad de las especies precursoras con el oxígeno y el agua, los QDs sintetizados son estables en aire, por ello, su manipulación puede llevarse a cabo de una manera sencilla.

Para cubrir el QD, se añade una mezcla apropiada de material precursor, gota a gota, a la mezcla cruda de reacción después del paso de enfriamiento (Fig. 16). Esta lenta adición del precursor para la capa exterior durante la fase de baja temperatura de la síntesis promueve la deposición epitaxial más que la nucleación de nuevos nanocristales. Durante este periodo de crecimiento de la capa exterior, se pueden ir analizando alícuotas para determinar cuándo se alcanza el espesor óptimo mediante la observación de la fluorescencia de las partículas. Los QDs obtenidos por estos procedimientos tienen alta fluorescencia, son fotoestables y suficientemente monodispersos para ser usados como marcadores en estudios biológicos, pero no son solubles en disoluciones acuosas ni se conjugan bien con biomoléculas.

Para hacer los QDs biocompatibles las moléculas superficiales de TOPO deben reemplazarse o modificarse con moléculas superficiales que permitan que los QDs se disuelvan en medio acuoso y se unan a biomoléculas. Aunque hay procedimientos asequibles para sintetizar QDs en disolución acuosa, sufren una marcada distribución de tamaños y poca eficiencia en la fluorescencia. Como consecuencia, el proceso de síntesis orgánica y capeado seguido de modificación de la superficie ha sido el camino preferido hasta la actualidad para la obtención de QDs solubles en agua con alta fluorescencia. Entre las técnicas para la modificación de la superficie, se han descrito dos procedimientos generales: (i) intercambio de moléculas surfactantes hidrofóbicas por moléculas

${ }^{46}$ L. Qu, Z.A. Peng, X.G. Peng. Alternative Routes toward High Quality CdSe Nanocrystals. Nano Lett. 1 (2001) 333- 
bifuncionales $^{27}$, y (ii) métodos de transferencia de fase usando moléculas anfifílicas que actúen como detergentes para solubilizar los QDs cubiertos con grupos hidrofóbicos ${ }^{47}$. Ambos procedimientos han sido empleados usando una amplia variedad de moléculas que actúan de manera similar para solubilizar los QDs y proporcionar los grupos funcionales (ácido carboxílico, amina, etc.) que son conjugados con biomoléculas utilizando protocolos establecidos. El último método ha sido particularmente ventajoso porque permite la retención de las moléculas surfactantes nativas, las cuales parecen incrementar la estabilidad y la fluorescencia respecto a aquellas muestras en las que la capa nativa se retira y reemplaza por una molécula bifuncional. A pesar de que las propiedades generales de la superficie parecen ser entendidas, la química superficial exacta de esos procesos continúa siendo debatida.

La espectroscopía de Resonancia Magnética Nuclear y los estudios de espectroscopía fotoelectrónica de Rayos $X$ se han usado para caracterizar las propiedades de la superficie de los QDs. De todos modos, se necesita más información para entender cómo las interacciones entre la superficie y las moléculas surfactantes o capeantes son responsables de las diferencias observadas en la eficacia de la pasivación/protección de la superficie del $Q D^{48,49,50,51}$. A diferencia de la superficie, el nanocristal interior ha sido caracterizado mucho más minuciosamente.

\section{Bioconjugación y aplicaciones biológicas}

Tras los estudios simultáneos acerca del uso de los QDs como marcadores en experimentos biológicos de Bruchez Jr. y col. y de Chan y Nie en $1998^{26,27}$, el número de estudios biológicos de QDs se ha incrementado exponencialmente, con especial atención a la utilización de grupos reactivos funcionales que faciliten la bioconjugación como ya se ha citado. Estos incluyen aminas primarias, ácidos carboxílicos, alcoholes y tioles y los métodos más comunes para llevar a cabo el proceso se muestran esquemáticamente en la Figura 17. Hay que resaltar que el área de un QD es lo suficientemente grande como para unirse a múltiples biomoléculas. Algunas proteínas y numerosas pequeñas biomoléculas (como oligonucleótidos y péptidos) pueden conjugarse a un QD de $4 \mathrm{~nm}$ por ejemplo.

\footnotetext{
${ }^{47}$ B. Dubertret, P. Skouride, D.J. Norris, V. Noireaux, A.H. Brivanlou, A. Libchaber. In Vivo Imaging of Quantum Dots Encapsulated in Phospholipid Micelles. Science 298 (2002) 1759.

${ }^{48}$ Archana Maurya, Pratima Chauhan. Structural and optical characterization of CdS/TiO2 nanocomposite. Materials Characterization 62(4) (2011) 382-390.

${ }^{49}$ L.R. Becerra, C.B. Murray, R.G. Griffin, M.G. Bawendi. Investigation of the surface morphology of capped CdSe nanocrystallites by ${ }^{31}$ P nuclear magnetic resonance. J. Chem. Phys. 100 (1994) 3297.

${ }^{50}$ J.E.B. Katari, V.L. Colvin, A.P. Alivisatos. X-ray photoelectron spectroscopy of CdSe nanocrystals with applications to studies of the nanocrystal surface. J. Phys. Chem. 98 (1994) 4109.

51 J.K. Lorenz, A.B. Ellis. Surfactant-Semiconductor Interfaces: Perturbation of the Photoluminescence of Bulk Cadmium Selenide by Adsorption of Tri-n-octylphosphine Oxide as a Probe of Solution Aggregation with Relevance to Nanocrystal Stabilization. J. Am. Chem. Soc. 120 (1998) 10970-10975.
} 
a Bifunctional linkage

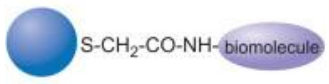

b Hydrophobic attraction

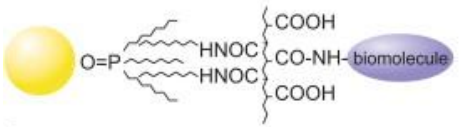

C Silanization

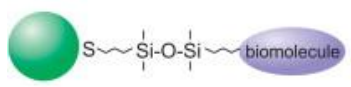

d Electrostatic attraction

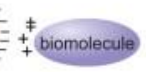

e Nanobeads

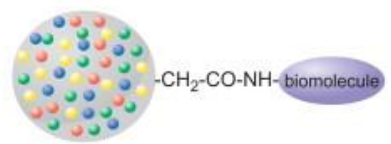

Figura 17. Ilustración esquemática de métodos de bioconjugación. (a) Uso de ligandos bifuncionales tales como ácido mercaptoacético para la unión de QDs a biomoléculas. (b) QD recubierto de TOPO unido a un polímero de ácido acrílico modificado por fuerzas hidrofóbicas. (c) Solubilización y bioconjugación del QD usando un compuesto mercaptosilano. (d) Biomoléculas cargadas positivamente unidas a QDs cargados negativamente por atracción electrostática. (e) Incorporación de QDs en microgotas o nanogotas ${ }^{52}$.

Alivisatos y Nie demostraron simultáneamente que los QDs podían hacerse solubles en medio acuoso y ser conjugados con moléculas biológicas. Los QDs bioconjugados han sido satisfactoriamente usados para muchos propósitos analíticos, con especial hincapié en la importancia de adecuadas modificaciones de la superficie, en el desarrollo de QDs luminiscentes como marcadores en bioanálisis y diagnóstico ${ }^{53}$, como marca en inmunoensayos de proteínas y ADN o como marcadores biocompatibles para estudios in vivo $^{54,55,56,57,58}$ tales como detección de hibridación del $A D N^{59}$, inmunoensayos ${ }^{60}$ y ensayos

${ }^{52}$ T. Jamieson, R. Bakhshi, D. Petrova, R. Pocock, M. Imani, A.M. Seifalian. Biological applications of quantum dots. Biomaterials 28 (2007) 4717-4732.

${ }^{53}$ Z. Jin, N. Hildebrandt. Semiconductor quantum dots for in vitro diagnostics and cellular imaging. Trends Biotechnol. 30(7) (2012) 394-403.

${ }^{54}$ C.M. Niemeyer. Functional hybrid devices of proteins and inorganic nanoparticles. Angew. Chem. Int. Ed. 42 (2003) 5796-5800.

${ }^{55}$ A.J. Sutherland. Quantum dots as luminescent probes in biological systems. Curr. Opin. Solid State Mater. Sci. 6 (2002) 365-370.

${ }^{56}$ A.M. Smith, S.Nie. Chemical analysis and cellular imaging with quantum dots. Analyst 129 (2004) 672-677.

57 J. Riegler, T. Nann. Application of luminescent nanocrystals as labels for biological molecules. Analytical and Bioanalytical Chemistry 379 (2004) 913-919.

${ }^{58}$ J.M. Costa-Fernández, R. Pereiro, A. Sanz-Medel. The use of luminescent quantum dots for optical sensing. Trends in Analytical Chemistry 25 (2006) 207-218.

${ }^{59}$ W.J. Parak, D. Gerion, D. Zanchet, A.S. Woerz, T. Pellegrino, C. Micheel, S.C. Williams, M. Seitz, R.E. Bruehl, Z. Bryant, C. Bustamante, C.R. Bertozzi, A.P. Alivisatos. Conjugation of DNA to silanized colloidal semiconductor nanocrystalline quantum dots. Chem. Mater. 14 (2002) 2113-2119.

${ }^{60}$ E.R. Goldman, G.P. Anderson, P.T. Tran, H. Mattoussi, P.T. Charles, J.M. Mauro. Conjugation of luminescent quantum dots with antibodies using an engineered adaptor protein to provide new reagents for fluoroimmunoassays. Anal. Chem. 74 (2002) 841-847. 
de unión usando FRET (transferencia de energía resonante fluorescente) ${ }^{61}$. Estas aplicaciones han empleado colorantes orgánicos con buenos resultados, no obstante, el uso de QDs podría permitir métodos de detección múltiple de alta sensibilidad debido a sus espectros de emisión estrechos e intensos. Se han hecho avances significativos en el uso de QDs como herramientas bioanalíticas para trabajos in vitro en las áreas de inmunoensayos y biosensores ${ }^{62,63,64,65}$.

Los inmunoensayos de fluorescencia detectan la unión de un anticuerpo marcado con un fluoróforo a un analito que ha sido unido a un sustrato. Tras un breve periodo de incubación, el anticuerpo que no se ha unido se elimina con lavados y se determina la cantidad de anticuerpo unido. En estos ensayos se han usado anticuerpos marcados con QDs y demostraron ser aplicables generalmente ${ }^{66}$. En otro estudio, los beneficios de usar QDs como marcadores en inmunoensayos se pusieron de manifiesto aprovechando las múltiples capacidades de estos nanocristales fluorescentes, por ejemplo, su capacidad para excitar y detectar varias especies marcadas simultáneamente, usando una única fuente de luz ${ }^{64}$.

En el área de los biosensores los QDs son particularmente atractivos debido a su duradera fotoestabilidad, permitiendo una monitorización continua y en tiempo real. Un método de utilización de los QDs en procedimientos de detección es crear una función on/off vía FRET a través de la cual tiene lugar una transferencia de energía entre el QD (donante) y una molécula aceptora ${ }^{67,68,69}$. Los QDs son donantes prometedores para aplicaciones basadas en FRET debido a su emisión continua tuneable (sintonizable) que puede ser combinada con cualquier aceptor, y a su banda ancha de absorción, permitiendo una excitación a una longitud de onda corta que no excita directamente al aceptor. Ha sido estudiado recientemente que los QDs pueden actuar como donantes muy eficientes para FRET cuando se emparejan con gran variedad de aceptores tales como fluoróforos

${ }^{61}$ D.M. Willard, L.L. Carrillo, J. Jung, A. Van Orden. CdSe-ZnS quantum dots as resonance energy transfer donors in a model protein-protein binding assay. Nano Lett. 1 (2001) 469-474.

${ }^{62} \mathrm{H}$. Mattoussi, G. Palui,H. Bin Na. Luminescent quantum dots as platforms for probing in vitro and in vivo biological processes. Advanced Drug Delivery Reviews 64 (2) (2012) 138-166.

${ }^{63}$ A.R. Clapp, I.L. Medintz, J.M. Mauro, B.R. Fisher, M.G. Bawendi, H. Mattoussi. Fluorescence Resonance Energy Transfer Between Quantum Dot Donors and Dye-Labeled Protein Acceptors. J. Am. Chem. Soc. 126 (2004) 301-310.

${ }^{64}$ E.R. Goldman, A.R. Clapp, G.P. Anderson, H.T. Uyeda, J.M. Mauro, I.L. Medintz, H. Mattoussi. Multiplexed Toxin Analysis Using Four Colors of Quantum Dot Fluororeagents. Anal. Chem. 76 (2004) 684-688.

${ }^{65}$ B.M. Lingerfelt, H. Mattoussi, E.R. Goldman, J.M. Mauro, G.P. Anderson. Preparation of Quantum Dot-Biotin Conjugates and Their Use in Immunochromatography Assays. Anal. Chem. 75 (2003) 4043-4049.

${ }^{66}$ F.A. Esteve-Turrillas, A. Abad-Fuentes. Applications of quantum dots as probes in immunosensing of small-sized analytes. Biosensors and Bioelectronics 41 (2013) 12-29.

${ }^{67}$ C.H. Vannoy, L. Chong, C. Le, U.J. Krull. A competitive displacement assay with quantum dots as fluorescence resonance energy transfer donors. Analytica Chimica Acta 759 (2013) 92-99.

${ }^{68}$ R. Weissleder, C.H. Tung, U. Mahmood, A. Bogdanov Jr. In vivo imaging of tumors with protease-activated nearinfrared fluorescent probes. Nat. Biotechnol. 17 (1999) 375-378.

${ }^{69}$ D.M. Willard, A. Van Orden. Quantum dots: Resonant energy-transfer sensor. Nat. Mater. 2 (2003) 575-576. 
orgánicos y colorantes ${ }^{70}$, así como con otros QDs o nanopartículas metálicas ${ }^{71,72,73}$. Avances en el diseño de este tipo de mecanismos integrados, los cuales incorporan una unidad de emisión con una unidad quenching que puede ser modulada por un estímulo biológico, podrían llevarnos a la creación de sensores potentes y compactos.

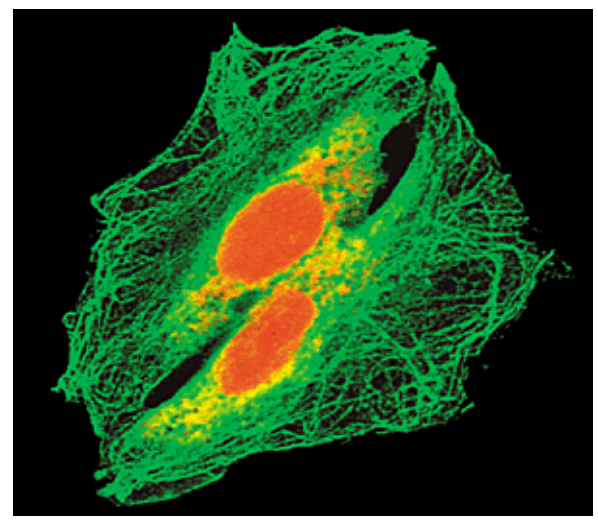

Figura 18. Imagen confocal de fibroblastos usando QDs verdes para marcar tubulina. Los núcleos están marcados en rojo con bromuro de etidio.

Se ha incrementado el uso de QDs como marcadores para receptores celulares y agentes de contraste para imágenes in vivo (Fig. 18) ${ }^{74,75}$. En estas aplicaciones, la alta fotoestabilidad de los QDs frente a los colorantes orgánicos permite el seguimiento a largo plazo de procesos biológicos ${ }^{76}$. Una demostración impresionante de esta capacidad fue mostrada por Dubertret y col. por microinyección de QDs bioconjugados en embrión de Xenopus y monitorizando su división en varias células durante el desarrollo del renacuajo a lo largo de varios días ${ }^{47}$. Además, el estrecho espectro de los QDs ha permitido la formación simultánea de imágenes de muchos marcadores dentro o en la superficie de células vivas, proporcionando la posibilidad de una temprana detección e identificación de tumores malignos. La formación de imágenes multicolor usando QDs podría también ser beneficiosa en el análisis de muestras de tejidos reduciendo el tiempo de análisis e incrementando el número de biomarcadores que pueden ser examinados ${ }^{77,78}$.

${ }^{70}$ I.L. Medintz, A.R. Clapp, H. Mattoussi, E.R. Goldman, B. Fisher, J.M. Mauro. Self-assembled nanoscale biosensors based on quantum dot FRET donors. Nat. Mater. 2 (2003) 630-638.

${ }_{71}$ M. Xue, X. Wang, L. Duan, W. Gao, L. Ji, B. Tang. A new nanoprobe based on FRET between functional quantum dots and gold nanoparticles for fluoride anion and its applications for biological imaging. Biosensors and Bioelectronics 36(1) (2012) 168-173.

${ }^{72}$ R. Wargnier, A.V. Baranov, V.G. Maslov, V. Stsiapura, M. Artemyev, M. Pluot, A. Sukhanova, I. Nabiev. Energy Transfer in Aqueous Solutions of Oppositely Charged CdSe/ZnS Core/Shell Quantum Dots and in Quantum Dot-Nanogold Assemblies. Nano Lett. 4 (2004) 451-457.

${ }^{73}$ S.P. Wang, N. Mamedova, N.A. Kotov, W. Chen, J. Studer. Antigen/Antibody Immunocomplex from CdTe Nanoparticle Bioconjugates. Nano Lett. 2 (2002) 817-822.

${ }^{74}$ M. Geszke-Moritza, M. Moritz. Quantum dots as versatile probes in medical sciences: Synthesis, modification and properties. Materials Science and Engineering: C 33(3) (2013) 1008-1021.

${ }^{75}$ M.E. Akerman, W.C.W. Chan, P. Laakkonen, S.N. Bhatia, E. Ruoslahti. Nanocrystal targeting in vivo. Proc. Natl. Acad. Sci. USA 99 (2002) 12617-12621.

${ }^{76}$ J.K. Jaiswal, H. Mattoussi, J.M. Mauro, S.M. Simon. Long-term multiple color imaging of live cells using quantum dot bioconjugates. Nat. Biotechnol. 21 (2003) 47-51.

77 X.L. Liu, C.W. Peng, C. Chen, X.Q. Yang, M.B. Hu, H.S. Xia, S.P. Liu, D.W. Pang, Y. Li. Quantum dots-based doublecolor imaging of HER2 positive breast cancer invasion. Biochemical and Biophysical Research Communications 409(3) (2011) 577-582.

${ }^{78}$ M. Dahan, T. Laurence, F. Pinaud, D.S. Chemla, A.P. Alivisatos, M. Sauer, S. Weiss. Time-gated biological imaging by use of colloidal quantum dots. Opt. Lett. 26 (2001) 825-827. 
Un método prometedor para la toma de imágenes de estructuras profundas en tejidos es el uso de QDs que absorban y emitan en la región del IR cercano (650-2000 nm), permitiendo una penetración más profunda de los fotones de la fuente de excitación, así como la salida de la señal de emisión de los QDs. Teóricamente los estudios muestran que sondas de largas longitudes de onda proporcionan baja dispersión y absorción por tejidos biológicos, así como un mínimo ruido de fondo ya que la autofluorescencia celular es reducida enormemente. Desafortunadamente, hay pocos colorantes orgánicos que emiten en esta región y aquellos que están disponibles son poco fotoestables y dan rendimientos cuánticos bajos en medio biológico. Por esta razón, los QDs son una alternativa deseable ya que hay varios materiales semiconductores disponibles los cuales pueden ser modificados para emitir en la región $\mathrm{NIR}^{79}$. Los QDs basados en estos materiales dan rendimientos de hasta el $50 \%$ a temperatura ambiente, son estables en disolución acuosa y compatibles con las técnicas de bioconjugación descritas previamente. Los QDs que emiten en NIR se han usado satisfactoriamente para tomar imágenes de la estructura vascular coronaria de ratas, así como nódulos linfáticos de cerdos con una profundidad de penetración en el tejido de un centímetro. Los QDs que emiten en el NIR serán idóneos para este tipo de estudios ya que tienen el potencial necesario para detección múltiple en tiempo real. Esto podría abrir una puerta para estudios que involucren la monitorización de complicados procesos biológicos in vivo.

Una ventaja adicional de los QDs consiste en que las sondas multicolor elaboradas con ellos pueden utilizarse para la imagen y el seguimiento de varios objetivos moleculares al mismo tiempo ${ }^{80,81}$. Ésta es una característica muy importante, porque la mayoría de las enfermedades humanas complejas, como el cáncer y la arterioesclerosis implican un gran número de genes y proteínas. El seguimiento de un panel de marcadores moleculares al mismo tiempo, permitirá a los científicos entender, clasificar y diferenciar enfermedades humanas complejas ${ }^{82}$. El uso de QDs para imágenes multicolor ha tenido importantes avances recientes, debido a las importantes mejoras en los procedimientos de síntesis, en la química de superficie y en la conjugación. Las imágenes in vivo con QDs se han utilizado para diferentes aplicaciones como puede verse en las Figuras 19 y 20.

\footnotetext{
${ }^{79}$ E. Cassette, M. Helle, L. Bezdetnaya, F. Marchal, B. Dubertret, T. Pons. Design of new quantum dot materials for deep tissue infrared imaging. Adv Drug Deliv Rev. (2012) Sep 6. pii: S0169-409X(12)00260-8.

80 J. Tian, L. Zhou, Y. Zhao, Y. Wang, Y. Peng, S. Zhao. Multiplexed detection of tumor markers with multicolor quantum dots based on fluorescence polarization immunoassay. Talanta 92 (2012) 72-77.

${ }^{81}$ X. Gao, L. Yang, J. A Petros, F.F Marshall, J.W Simons, S. Nie. In vivo molecular and cellular imaging with quantum dots. Current Opinion in Biotechnology 16 (2005) 63-72.

${ }^{82}$ X.H. Gao, S.M. Nie. Molecular profiling of single cells and tissue specimens with quantum dots. Trends Biotechnol 21 (2003) 371-373.
} 


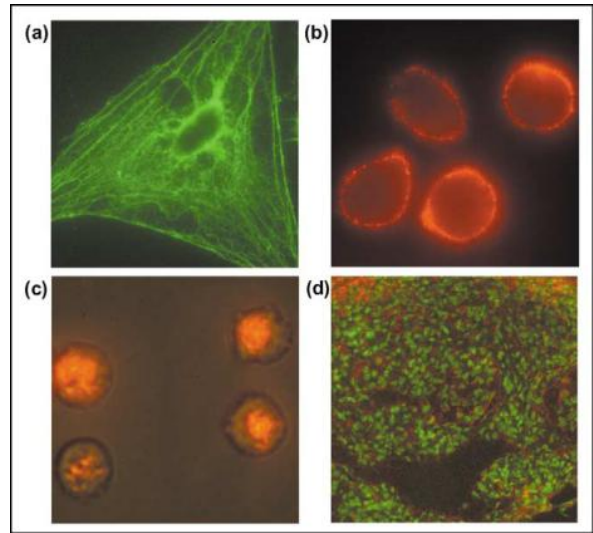

Figura 19. Microfotografías fluorescentes de células y tejidos teñidos con QDs. (a) Marcaje de Actina (QDs verdes) en fibroblastos 3T3. (b) Células mamarias tumorales MDA-MB231 marcadas con un conjugado rojo Anticuerpo-QD dirigido al receptor plasminogen uroquinasa. (c) Marcaje intracelular de células mamíferas vivas usando conjugados QD-Tat peptide. (d) Muestras de tejido marcado con QDs (marcaje de los receptores CXCR4 (rojo) y el núcleo (verde) ${ }^{81}$.

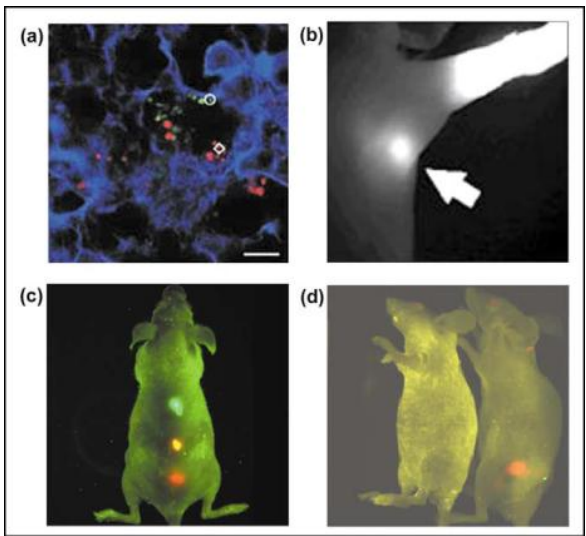

Figura 20. Marcaje e imagen in vivo con QDs. (a) Estudio de tejido ex vivo de células tumorales marcadas con QD en un pulmón de ratón. (b) Fluorescencia en el IR cercano de QDs soluble en agua del tipo II en ganglios linfáticos centinelas. (c) Imagen simultánea in vivo de QD-encoded-microbeads multicolor inyectados en ratón vivo. (d) Marcaje molecular e imagen in vivo de un tumor prostático en ratón usando un conjugado QD-anticuerpo (rojo) ${ }^{81}$.

Ballou y col. inyectan QDs recubiertos con PEG en la corriente sanguínea de un ratón e investigan cómo el recubrimiento superficial puede afectar a su tiempo de vida en circulación ${ }^{83}$. En contraste con los pequeños colorantes orgánicos, que son eliminados de la circulación pocos minutos después de la inyección, el QD-PEG permanece en la circulación sanguínea durante un largo periodo de tiempo (vida media de más de tres horas). Este largo tiempo de circulación característico puede explicarse por las propiedades estructurales conjuntas de las nanopartículas QDs con PEG. Los QDs recubiertos de PEG tienen un rango de tamaño intermedio: son lo bastante pequeños y suficientemente hidrofílicos como para frenar la opsonización y la captación reticuloendotelial, pero son lo suficientemente grandes como para evitar la filtración renal. Larson y col. se aprovecharon de esta propiedad, utilizando QDs para obtener imágenes de pequeños vasos sanguíneos ${ }^{84}$.

Para mejorar la penetración en los tejidos Kim y col. prepararon una nueva nanoestructura core-sell llamada QDs tipo II (II-QDs) $)^{85}$ con un pico de emisión bastante amplio a $850 \mathrm{~nm}$ y un rendimiento cuántico moderado del $13 \%$. En contraste con los QDs convencionales (tipo I), los materiales de la concha en los II-QDs tienen bandas de energía

\footnotetext{
${ }^{83}$ B. Ballou, B.C. Lagerholm, L.A. Ernst, M.P. Bruchez, A.S. Waggoner. Noninvasive imaging of quantum dots in mice. Bioconjug. Chem. 15 (2004) 79-86.

${ }^{84}$ D.R. Larson, W.R. Zipfel, R.M. Williams, S.W. Clark, M.P. Bruchez, F.W. Wise, W.W. Webb. Water-soluble quantum dots for multiphoton fluorescence imaging in vivo. Science 300 (2003) 1434-1436.

${ }^{85}$ S. Kim, Y.T. Lim, E.G. Soltesz, A.M. De Grand, J. Lee, A. Nakayama, J.A. Parker, T. Mihaljevic, R.G. Laurence, D.M. Dor et al. Near-infrared fluorescent type Il quantum dots for sentinel lymph node mapping. Nat. Biotechnol. 22 (2004) 93-97. 
de valencia y conducción más bajas que las del material del núcleo. Como resultado, los electrones y agujeros están separados físicamente y las nanopartículas emiten luz a energías reducidas (longitudes de onda más largas). Los resultados muestran una rápida captación de QDs desnudos en los nódulos linfáticos y una clara imagen y delineación de los nódulos centinelas implicados (que pueden entonces ser eliminados).

Este trabajo apunta a la posibilidad de que pueden utilizarse sondas de QD para obtener imágenes ópticas intraoperativas en tiempo real, proporcionando in situ una guía visual para que el cirujano pueda localizar y eliminar pequeñas lesiones (por ejemplo, tumores metastásicos) con rapidez y precisión.

\section{Toxicidad y potencial uso clínico}

Los potenciales efectos tóxicos de los QDs semiconductores se han convertido recientemente en un tópico de considerable importancia y discusión. De hecho, la toxicidad in vivo es posible que sea el factor clave para determinar si las sondas de imagen de QDs serán aprobadas por las agencias reguladoras para el uso clínico humano. Derfus y col. ${ }^{86}$ indicaron que el QD de CdSe es altamente tóxico en cultivos celulares bajo luz ultravioleta si se mantiene durante largos periodos de tiempo. Esto no es sorprendente, porque la energía de la radiación ultravioleta está cerca de la de un enlace covalente químico y disuelve las partículas semiconductoras en un proceso conocido como fotolisis, liberando iones cadmio tóxicos en el medio de cultivo. En ausencia de irradiación ultravioleta, se ha demostrado que los QDs con un recubrimiento polimérico estable son esencialmente no tóxicos para células y animales. Los estudios in vivo de Ballou y col. también han confirmado la naturaleza no tóxica de los QDs establemente protegidos ${ }^{83}$. En un estudio más reciente, Ju y col. ${ }^{87}$ probaron que QDs de CdSe/ZnS podrían inducir efectos citotóxicos, incluso inhibición del crecimiento celular, pero que esta genotoxicidad podría ser significativamente reducida con apropiadas modificaciones superficiales de las nanopartículas, como por ejemplo encapsulación con PEG. Sin embargo, hay aún una necesidad urgente de estudiar la toxicidad celular y los mecanismos de degradación in vivo de los QDs. Para los QDs encapsulados en polímeros la degradación química o enzimática de los núcleos semiconductores es poco probable que ocurra. Por tanto, los QDs protegidos por polímeros pueden ser eliminados del cuerpo por filtración lenta y excreción. Estos y otros mecanismos posibles deben ser cuidadosamente examinados antes de cualquier aplicación en humanos, tanto en tumores como en imagen vascular.

${ }^{86}$ A.M. Derfus, W.C.W. Chan, S.N. Bhatia. Probing the cytotoxicity of semiconductor quantum dots. Nano Lett. 4 (2004) 11-18.

${ }^{87}$ L. Ju, G. Zhang, Chen Zhang, L. Sun, Y. Jiang, C. Yan, P.J. Duerksen-Hughes, X. Zhang, X. Zhu, F.F. Chen, J. Yang. Quantum dot-related genotoxicity perturbation can be attenuated by PEG encapsulation. Mutation Research/Genetic Toxicology and Environmental Mutagenesis (2013) In Press, Corrected Proof. 
Podemos decir, como resumen de las posibilidades de futuro de los QDs, que estos ya han cumplido con algunas de sus expectativas como una nueva clase de agentes de imagen molecular. A través de sus versátiles recubrimientos poliméricos, los QDs proporcionan un bloque de construcción para ensamblar nanoestructuras multifuncionales y nanodispositivos. Pueden crearse sondas de imagen multimodalidad integrando QDs con agentes paramagnéticos y superparamagnéticos. Algunos investigadores han unido QDs a nanopartículas de $\mathrm{Fe}_{2} \mathrm{O}_{3}$ y $\mathrm{FePt}^{88,89,90}$, e incluso a quelatos paramagnéticos de gadolinio. En este sentido, correlacionando imágenes de resonancia magnética con imágenes ópticas ultrasensibles, un cirujano puede identificar visualmente tumores u otras pequeñas lesiones durante una operación y eliminar células y tejidos enfermos completamente. Otras modalidades de imágenes médicas, tales como la resonancia magnética y la tomografía por emisión de positrones pueden identificar enfermedades de una forma no invasiva, pero no suministran una guía visual durante la cirugía. El desarrollo de sondas de QDs magnéticas o radiactivas puede resolver este problema.

Otro dispositivo funcional de gran interés sería la combinación de un agente de imagen QD con un agente terapéutico. Esto no solamente permitiría el seguimiento de la farmacocinética, sino que el tejido enfermo puede ser tratado y monitorizado simultáneamente en tiempo real. Sorprendentemente, los QD pueden ser innatamente multimodales en este sentido, ya que han demostrado tener potencial actividad como agentes en terapias fotodinámicas ${ }^{91}$. Estas combinaciones ya nos muestran unos cuantos logros para el futuro. Las aplicaciones prácticas de estos dispositivos multifuncionales no llegarán sin una cuidadosa investigación, pero la naturaleza multidisciplinaria de la nanotecnología puede acelerar estos objetivos, combinando ideas y trabajos de investigadores en campos muy diferentes. El éxito logrado hasta ahora en el estudio de QDs apunta hacia el éxito de su aplicación en sistemas biológicos y predice el éxito de otras nanopartículas para aplicaciones biomédicas.

\section{QDs DE CdS}

Entre los diferentes nanocristales semiconductores, los QDs de CdS, los más importantes de los grupos II-VI, han sido ampliamente estudiados debido a su fotoluminiscencia tamaño-dependiente, tuneable a través del espectro visible y a los

${ }^{88}$ X. Wang, L. Wei, S. Dong, G. Chen, Y. Liu, Y. Gu. Synthesis of $\mathrm{Fe}_{3} \mathrm{O}_{4} / \mathrm{CdSe} / \mathrm{CdS}$ magnetic fluorescent nanocomposites by a stepwise heterocoagulation approach. Materials Letters 93(15) (2013) 92-94.

${ }^{89}$ D.S. Wang, J.B. He, N. Rosenzweig, Z. Rosenzweig. Superparamagnetic $\mathrm{Fe}_{2} \mathrm{O}_{3}$ beads-CdSe/ZnS quantum dots coreshell nanocomposite particles for cell separation. Nano Lett. 4 (2004) 409-413.

${ }^{90}$ H.W. Gu, R.K. Zheng, X.X. Zhang, B. Xu. Facile one-pot synthesis of bifunctional heterodimers of nanoparticles: a conjugate of quantum dot and magnetic nanoparticles. J. Am. Chem. Soc. 126 (2004) 5664-5665.

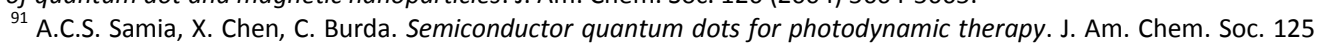
(2003) 15736-15737. 
diferentes avances en sus procedimientos de preparación ${ }^{44,92}$. De hecho, el principal interés en estudiar el QD de CdS está relacionado con los procedimientos de preparación y con sus propiedades fotoluminiscentes, que lo hacen utilizable en numerosas aplicaciones tales como marcador biológico ${ }^{92 g}$, procesos de conversión de energía solar ${ }^{93}$, optoelectrónica ${ }^{94}$, sondas iónicas, etc. El CdS es utilizado como un detector bio-orgánico de proteínas y $\operatorname{ADN}^{95}$.

La carencia de adecuados métodos de síntesis para la producción de la cantidad deseada de QDs de alta calidad es habitualmente el cuello de botella en este campo. Durante las pasadas dos décadas se han desarrollado numerosos métodos de química coloidal (o de química en disolución) para la preparación de NPs de CdS. La síntesis en disolución normalmente utiliza estabilizadores orgánicos para recubrir los átomos superficiales de las nanopartículas, en orden a controlar su proceso de crecimiento. El tipo de estabilizador es de gran importancia, ya que afecta a las propiedades físicas y químicas del nanocristal semiconductor, desde su estabilidad a su solubilidad o emisión de luz. Desde la introducción de la tecnología basada en la utilización de compuestos organometálicos de alta temperatura y su alternativa utilizando óxido de trioctilfosfina, aminas de cadenas largas o ácidos carboxílicos de cadenas largas, como agentes recubrientes ${ }^{44,92 a, b}$, se han

92 [a] W. Yu, X. Peng. Formation of High-Quality CdS and Other II-VI Semiconductor Nanocrystals in Noncoordinating Solvents: Tunable Reactivity of Monomers. Angew. Chem. Int. Ed. 41 (2002) 2368. [b] X. Zhong, S. Liu, W. Knoll et al. Synthesis of high-quality $C d S, Z n S$, and $\mathrm{Zn}_{x} C d_{1-x} S$ nanocrystals using metal salts and elemental sulfur. J. Mater. Chem. 14 (2004) 2790. [c] L. Spanhel, M. Haase, H. Weller et al. Photochemistry of colloidal semiconductors. 20. Surface modification and stability of strong luminescing CdS particles. J. Am. Chem. Soc. 109 (1987) 5649. [d] T. Vossmeyer, L. Katsikas, H. Weller et al. CdS Nanoclusters: Synthesis, Characterization, Size Dependent Oscillator Strength, Temperature Shift of the Excitonic Transition Energy, and Reversible Absorbance Shift. J. Phys. Chem. 98 (1994) 7665. [e] A. Chemseddine, H. Weller, B. Bunsen-Ges. Phys. Chem. 97 (1993) 636. [f] E.D. Spoerke, J.A. Voigt. Influence of Engineered Peptides Cadmium Sulfide Nanocrystals. Adv. Funct. Mater. 17 (2007) 2031. [g] Ch. Barglik-Chory, D. Buchold, G. Muller et al. Synthesis, structure and spectroscopic characterization of water-soluble CdS nanoparticles. Chem. Phys. Lett. 379 (2003) 443. [h] C. Jiang, S. Xu, W. Wang et al. Luminescence (2007) 22430. [i] S. Sapra, J. Nanda, G. Hodes et al. Blue emission from cysteine ester passivated cadmium sulfide nanoclusters. Chem. Commun. (2001) 2188. [j] Y.F. Chen, Z. Rosenzweig. Luminescent CdS Quantum Dots as Selective Ion Probes. Anal. Chem. 74 (2002) 5132. [k] L. Qi, H. Colfen, M. Antonietti. Synthesis and Characterization of CdS Nanoparticles Stabilized by Double-Hydrophilic Block Copolymers. Nano Lett. 1 (2001) 61. [I] R.B. Khomane, A. Manna, B.D. Kulkarni et al. Synthesis and Characterization of Dodecanethiol-Capped Cadmium Sulfide Nanoparticles in a Winsor II Microemulsion of Diethyl Ether/AOT/Water. Langmuir 18 (2002) 8237. [m] J. Yang, C. Xue, Y. Qian et al. General Synthesis of Semiconductor Chalcogenide Nanorods by Using the Monodentate Ligand n-Butylamine as a Shape Controller. Angew. Chem. Int. Ed. 41 (2002) 4697. [n] N. Pradhan, S. Efrima. Single-Precursor, One-Pot Versatile Synthesis under near Ambient Conditions of Tunable, Single and Dual Band Fluorescing Metal Sulfide Nanoparticles. J. Am. Chem. Soc. 125 (2003) 2050. [o] L. Zou, Z. Fang, Z. Gu,X. Zhong. Aqueous phase synthesis of biostabilizer capped CdS nanocrystals with bright emission. Journal of Luminescence 129 (2009) 536-540. [p] X. Liua, Y. Jianga, X. Lana, S. Lia, D. Wua, T. Hana, H. Zhonga, Z. Zhang. Synthesis of high quality and stability CdS quantum dots with overlapped nucleation-growth process in large scale. Journal of Colloid and Interface Science 354(1) (2011) 15-22.

${ }^{93}$ S. Guha, B.J. Wu, J.M. Depuydt et al. Microstructure and pseudomorphism in molecular beam epitaxially grown ZnCdS on GaAs(001). Appl. Phys. Lett. 63 (1993) 2129.

${ }_{94}$ J.H. Warner, R.D. Tilley. Synthesis and Self-Assembly of Triangular and Hexagonal CdS Nanocrystals. Adv. Mater. 17 (2005) 2997.

${ }^{95}$ [a] K.K. Caswel, R. Mahtab, C.J. Murphy. Optical Detection of Thymine Dinucleoside Monophosphate and its cissyn Photodimer by Inorganic Nanoparticles. J. Fluorescence 14 (2004) 407-415. [b] X. Chen, X. Wang, L. Liu, D. Yang, L. Fan. Functionalized semiconductor nanocrystals for ultrasensitive detection of peptides. Anal. Chim. Acta 542 (2005) 144. [c] N. Tessler, V. Medvedev, M. Kazes, S.H. Kan, U. Banin. Efficient Near-Infrared Polymer Nanocrystal Light-Emitting Diodes. Science 295 (2002) 1506. 
desarrollado de forma considerable metodologías de síntesis de NPs de CdS. A pesar del gran éxito de esta ruta de inyección organometálica en caliente, debido a su elevado precio y a sus delicadas y rigurosas condiciones experimentales, el método tiene algunas limitaciones inherentes. Por ejemplo, los QDs así preparados no pueden ser utilizados en aplicaciones biológicas debido a su carácter hidrofóbico. Deben ser ligados con moléculas hidrofílicas para hacerlos solubles en agua y, por tanto, biocompatibles. En este sentido, el tipo de moléculas hidrofílicas es de gran importancia ${ }^{96}$, ya que afecta a las propiedades físicas y químicas del semiconductor, desde su estabilidad a su solubilidad o emisión de luz ${ }^{97}$.

En paralelo al éxito de las rutas de síntesis orgánica, se han desarrollado algunos caminos para preparar QDs de CdS mediante procedimientos en medio acuoso ${ }^{92 c-0}$. Comparados con los procedimientos de síntesis en medio no acuoso, la síntesis acuosa es más reproducible, de coste más bajo, más respetuosa con el medioambiente y las muestras preparadas de esta forma son solubles en agua y biocompatibles. En la síntesis en fase acuosa de NPs de CdS la fase convencionalmente homogénea detiene la precipitación con el uso de fosfatos, tioles o varios polímeros hidrofílicos como agentes recubrientes ${ }^{92 c-k}$. Además también se han adoptado otros procedimientos basados en técnicas micelares inversas o termólisis de precursor simple ${ }^{921-n}$.

${ }^{96}$ J. Mao, S. Lai, X. Chang, W. Liu. Interaction among Cadmium Sulfide Nanoparticles, Acridine Orange and Deoxyribonucleic Acid in Fluorescence Spectra and a Method for Deoxyribonucleic Acid Determination. J. Fluoresc. 18 (2008) 727-732.

${ }^{97}$ C. Barglik-Chory, A.F. Müunster, H. Strohm, C. Remenyi. Influence of synthesis parameters on the growth of CdS nanoparticles in colloidal solution and determination of growth kinetics using Karhunen-Loeve decomposition. Chem. Phys. Lett. 374 (2003) 319-325. 
Objetivo 

Como ha podido observarse en lo descrito hasta ahora en la introducción, existe en la actualidad un gran interés en proponer nuevos avances en los procedimientos de síntesis de QDs de CdS de alta calidad. Hasta la actualidad, la mayoría de los métodos descritos son de elevado precio, altamente tóxicos y requieren unas condiciones de reacción extremas. Por otra parte, en muchos de estos procedimientos se observan lagunas en cuanto al estudio en profundidad de las características de la nanopartícula obtenida, base de los posteriores procesos de recubrimiento y funcionalización, y a lo crucial que resulta para su mantenimiento con el tiempo (objetivo importante para su fabricación y comercialización) la influencia de diferentes variables implicadas en el proceso. Es este un campo de gran actualidad en el que se mezclan intereses múltiples, dado el amplio espectro de posibles aplicaciones, por lo que resulta una línea de investigación de interés en la actualidad. Esta es la razón por la que, en este trabajo de investigación abordamos nuevos procedimientos de fácil preparación de QDs de CdS recubiertos con ácido mercaptoacético en disolución acuosa, a temperatura ambiente, profundizando en su caracterización y en su comportamiento en disolución en diferentes condiciones, con el fin de utilizarlos como marcadores biológicos y en otras aplicaciones de interés analítico. 



\section{Parte experimental}





\section{APARATOS Y MATERIAL}

\section{DETECCIÓN FOTOMÉTRICA}

Espectrofotómetro Shimadzu UV/Vis-160, con unidad de procesado y registro, y equipado con una célula de cuarzo Suprasil de $1 \mathrm{~cm}$ de paso óptico.

\section{DETECCIÓN FLUORIMÉTRICA}

Espectrofluorímetro Shimadzu RF-5000, provisto de una unidad de procesado y registro DR-15 y una unidad de almacenamiento de datos FDU-13.

MICROSCOPÍA ELECTRÓNICA DE TRANSMISIÓN (TEM, Transmission Electron Microscopy)

Para la toma de imágenes de las muestras se utilizó un Microscopio Electrónico de Transmisión, modelo ZEISS EM-900.

\section{DIFRACCIÓN DE RAYOSX}

Para el estudio de Rayos X se ha utilizado un difractómetro para muestras en polvo, marca Siemens, modelo D500, dotado con filtro de níquel y monocromador de grafito, lo que le da una eficacia para la radiación de cobre $K_{\alpha}(\lambda=154.050 \mathrm{pm})$ superior al $90 \%$.

Se dispone también de un sistema DIFRACC AT para control, adquisición de datos, con microprocesador DACO MP, e impresora gráfica con software específicamente desarrollado para el tratamiento de los datos de difracción de Rayos X. El voltaje empleado fue de $40 \mathrm{kV}$ y la intensidad de $30 \mathrm{~mA}$, lo que supone una potencia total de 1200 vatios.

\section{REFRACTOMETRÍA}

Se utilizó un Refractómetro Abbé para la determinación de índices de refracción en el estudio de la eficacia cuántica.

\section{MATERIAL ADICIONAL}

- $\quad$ pHmetro Crison 501

- Lámpara de vapor de $\mathrm{Hg}$

- Material usual de laboratorio 



\section{REACTIVOS}

Ácido mercaptoacético, $\mathrm{HSCH}_{2} \mathrm{COOH}, 98 \%$ (Acros Organics)

Cloruro de cadmio, $\mathrm{CdCl}_{2}$, 99\% (Acros Organics)

Sulfuro sódico, $\mathrm{Na}_{2} \mathrm{~S}, 90 \%$ (Acros Organics)

Tiosulfato sódico pentahidratado, $\mathrm{Na}_{2} \mathrm{~S}_{2} \mathrm{O}_{3} 5 \mathrm{H}_{2} \mathrm{O}, 99.5 \%$ (Scharlau)

3-Mercapto-1,2-propanodiol, $\alpha$-Tioglicerol, $\mathrm{C}_{3} \mathrm{H}_{8} \mathrm{O}_{2} \mathrm{~S}$, $\geq 97 \%$ (Sigma)

Hidróxido sódico, $\mathrm{NaOH}$

Sulfato de quinina, $\left(\mathrm{C}_{20} \mathrm{H}_{24} \mathrm{~N}_{2} \mathrm{O}_{2}\right)_{2} \cdot \mathrm{H}_{2} \mathrm{SO}_{4} \cdot 2 \mathrm{H}_{2} \mathrm{O}$

Ácido sulfúrico, $\mathrm{H}_{2} \mathrm{SO}_{4}$ 



\section{Obtención de nanopartículas de CdS en fase heterogénea}





\section{MÉTODO EXPERIMENTAL PARA LA OBTENCIÓN DE QDs DE CdS EN MEDIO} ACUOSO

El procedimiento general para la obtención de nanopartículas de CdS en medio acuoso, sin especificar las concentraciones reales de cada estudio experimental, ha seguido los siguientes pasos:

1. Se parte siempre de $100 \mathrm{~mL}$ de disolución acuosa que contiene el ion $\mathrm{Cd}^{2+}$ en concentración deseada, preparada por pesada de $\mathrm{CdCl}_{2}$ y disolución con el fin de que en cada experiencia la disolución sea recién preparada. Esta disolución inicial es colocada en un erlenmeyer topacio, para evitar procesos de fotosensibilización. Tiene inicialmente el típico color rosa pálido de las sales de cadmio hidratadas.

2. Con agitación, se añaden con micropipeta los microlitros deseados de disolución de ácido mercaptoacético $1.41 \mathrm{M}$. El pH de la disolución resultante está comprendido en el margen 2.8-3.0 (dependiendo de la cantidad añadida de ácido, $K_{1}=2.1 \times 10^{-4}$ ) y en presencia de $\mathrm{Cd}^{2+}$ aparece una turbidez blanquecina de naturaleza coloidal ya descrita en bibliografía y no explicada, que quizás pueda atribuirse a la formación de mercaptoacetato de cadmio, moderadamente insoluble.

3. Se ajusta el pH de trabajo con una disolución de $\mathrm{NaOH} 1 \mathrm{M}$ y la turbidez blanquecina desaparece. En este momento se comienza a burbujear nitrógeno y se mantiene el burbujeo mientras dura todo el procedimiento.

4. Cuando se vaya a trabajar a temperatura diferente a la del ambiente (al estudiar dicha variable), es en este momento cuando por calentamiento controlado se ajusta dicha variable (la temperatura). Es necesario mantener el burbujeo de nitrógeno para evitar la oxidación del ácido mercaptoacético, así como la posible formación posterior de CdO sobre las nanopartículas.

5. A continuación, y siempre burbujeando nitrógeno, se añaden muy lentamente y con agitación (para evitar sobresaturaciones locales) $50 \mathrm{~mL}$ de una disolución de $\mathrm{Na}_{2} \mathrm{~S}$ en la concentración deseada (siempre preparada en el momento). La presencia de nitrógeno evita la oxidación del $\mathrm{S}^{2-}$. El tiempo de adición de la disolución de sulfuro oscila entre 8 y 10 minutos y cuando se acaba de añadir la última porción de reactivo se anota la hora y se considera en ese momento el $t=0$, como tiempo de partida para los estudios cinéticos. 
Tras añadir la disolución de $\mathrm{Na}_{2} \mathrm{~S}$ se comprueba el $\mathrm{pH}$ final para controlar las posibles modificaciones. Al añadir el anión $\mathrm{S}^{2-}$, dependiendo de las condiciones experimentales, se observa que la disolución adquiere tonalidad amarilla, más o menos

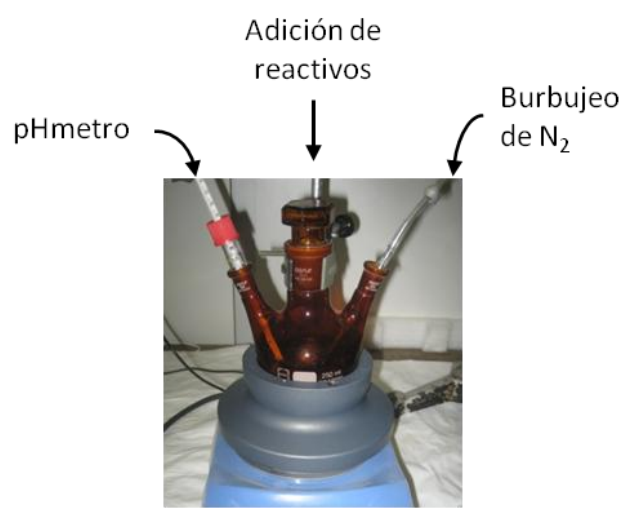

Figura 21 Fotografía del sistema de síntesis en el laboratorio. fuerte, transparente o turbia, debido a la formación de nanopartículas de CdS de diferente tamaño.

6. Terminado el proceso de obtención de las nanopartículas y manteniendo la temperatura fijada, durante al menos 12 horas, se registran periódicamente los espectros de absorción y los espectros de excitación y emisión de fluorescencia. Para el control de tiempos se considera $\mathrm{t}=0$ el momento en que se termina la adición de la disolución de $\mathrm{Na}_{2} \mathrm{~S}$.

Con el fin de ir conociendo cómo afectan las diferentes variables al proceso de obtención de nanopartículas (NPs) de CdS, se fijan unas condiciones iniciales de partida para, a partir del método de precipitación coloidal, obtener unas nanopartículas cuyas características físicas y ópticas serán estudiadas, así como su estabilidad con el tiempo.

Se parte de $100 \mathrm{~mL}$ de disolución acuosa de cloruro de cadmio $\left(\mathrm{CdCl}_{2}\right) 1.12 \times 10^{-3} \mathrm{M}$ sobre la que se añaden $8 \mu \mathrm{L}$ de ácido mercaptoacético $14.1 \mathrm{M}$ (en ese momento la disolución alcanza un valor de $\mathrm{pH}=2.9$ ). A continuación se ajusta el $\mathrm{pH}$ con disolución de $\mathrm{NaOH} 0.5 \mathrm{M}$ hasta un valor de 11 . Se burbujea nitrógeno durante unos 15 minutos y seguidamente, con agitación constante de $380 \mathrm{rpm}$, se añaden lentamente y nunca por las paredes del balón $50 \mathrm{~mL}$ de una disolución acuosa de sulfuro sódico $\left(\mathrm{Na}_{2} \mathrm{~S}\right) 1.5 \times 10^{-3} \mathrm{M}$, tardando en esta etapa unos cinco minutos. Para el control de tiempos se considera $t=0$ el momento en que se termina la adición de la disolución de $\mathrm{Na}_{2} \mathrm{~S}$. Terminada la adición de la disolución de $\mathrm{Na}_{2} \mathrm{~S}$, se mantiene la agitación durante 4.5 horas, momento en el que se empiezan a realizar las primeras medidas. Todo el proceso se lleva a cabo a temperatura ambiente y las concentraciones finales, teniendo en cuenta un volumen total de $150 \mathrm{~mL}$ son: $\left[\mathrm{Cd}^{2+}\right]_{\mathrm{f}}=0.747 \times 10^{-3} \mathrm{M} ;[\mathrm{MAA}]_{\mathrm{f}}=0.752 \times 10^{-3} \mathrm{M} ;\left[\mathrm{s}^{2-}\right]_{\mathrm{f}}=0.50 \times 10^{-3} \mathrm{M}$; por lo que se mantienen las siguientes relaciones molares: $\left[\mathrm{Cd}^{2+}\right] /[\mathrm{MAA}] \approx 1$ y $\left[\mathrm{Cd}^{2+}\right] /\left[\mathrm{S}^{2-}\right] \approx 1.5$.

Uno de los fenómenos observados durante la síntesis es la formación de una ligera turbidez en la disolución inicial de $\mathrm{Cd}^{2+}$ al añadir sobre ella el ácido mercaptoacético, debido probablemente a la formación de una sal ligeramente insoluble. Esta turbidez desaparece al 
ajustar el pH a 11 con $\mathrm{NaOH}$, quedando de nuevo la disolución transparente y de color rosa pálido.

Tras añadir lentamente la disolución de $\mathrm{Na}_{2} \mathrm{~S}$ no se observa ningún cambio apreciable en la disolución, mientras que cuando han transcurrido 4.5 horas, ésta, siendo aparentemente transparente, ha cambiado su color hasta un amarillo verdoso (Fig. 22), lo que indica que el proceso de formación de nanopartículas, en estas condiciones, es de cinética lenta a pesar de trabajar en condiciones de sobresaturación. El MAA enlazado a los núcleos de CdS frena su crecimiento, predominando la velocidad de nucleación sobre la velocidad de crecimiento.

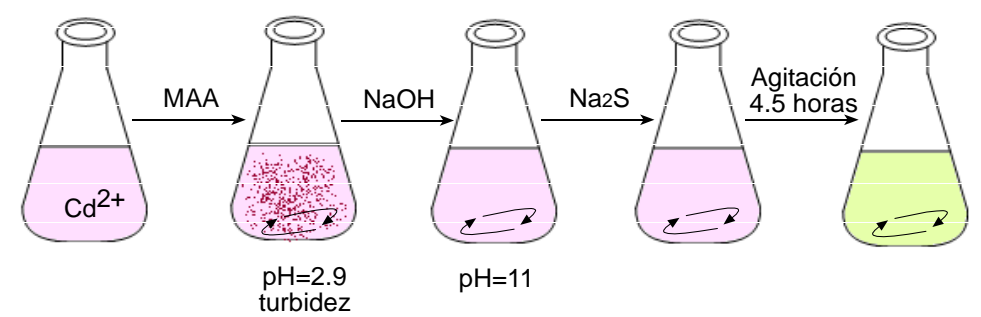

Figura 22 Fenómenos observados en el proceso de obtención de nanopartículas de CdS.

\section{MÉTOdOS PARA EL CÁLCULO DEL DIÁMETRO MEDIO DE LAS NANOPARTÍCULAS}

Tres son los métodos que aparecen en bibliografía para el cálculo del diámetro medio de las nanopartículas:

\section{a) A partir del difractograma de Rayos $X$}

A partir del difractograma de Rayos $\mathrm{X}$ de las nanopartículas aisladas de la disolución, es posible determinar su tamaño medio basándonos en la expresión de DebyeScherrer $^{98}$ :

$$
d=\frac{0.9 \lambda}{\beta \cos \theta}
$$

siendo $d$ : diámetro medio de la nanopartícula; $\lambda$ : longitud de onda de la fuente de Rayos $X$, en $n m ; \beta$ : anchura del pico de difracción en la mitad del máximo; $\theta$ : ángulo de difracción.

${ }^{98}$ B. D. Cullity. Elements of X-Ray Diffraction. $2^{\text {nd }}$ ed, Addison-Wesley, London, 1978. 


\section{b) A partir de la longitud de onda de corte del espectro de absorción de las} nanopartículas

A partir del espectro de absorción de la disolución que contiene las nanopartículas es posible estimar su tamaño medio utilizando una expresión empírica deducida por Henglein $^{99}$, y que lo relaciona con la longitud de onda de corte de la parte baja del espectro con la línea base $\left(\lambda_{\text {edge, }} \lambda_{e} \circ \lambda_{\text {corte }}\right)$, expresada en $\mathrm{nm}$.

$$
d=\frac{0.1}{(0.138-0.0002345 \lambda \mathrm{e})}
$$

Esta expresión empírica que ha sido utilizada por numerosos investigadores ${ }^{100,101}$, plantea el problema práctico de la determinación del valor correcto de $\lambda_{\mathrm{e}}$. En la Figura 23 se muestra el espectro de absorción de una disolución conteniendo nanopartículas de CdS obtenidas en unas condiciones experimentales que ahora no tienen interés. Si la $\lambda_{\mathrm{e}}$ se obtiene trazando la tangente en la parte más próxima al pico excitónico se obtiene $d_{1}=2.39$ $\mathrm{nm}$, un valor inferior al obtenido trazando la tangente en el tramo inicial del espectro, $\mathrm{d}_{2}=$ $2.87 \mathrm{~nm}\left(\lambda_{2}=440 \mathrm{~nm}\right)$.
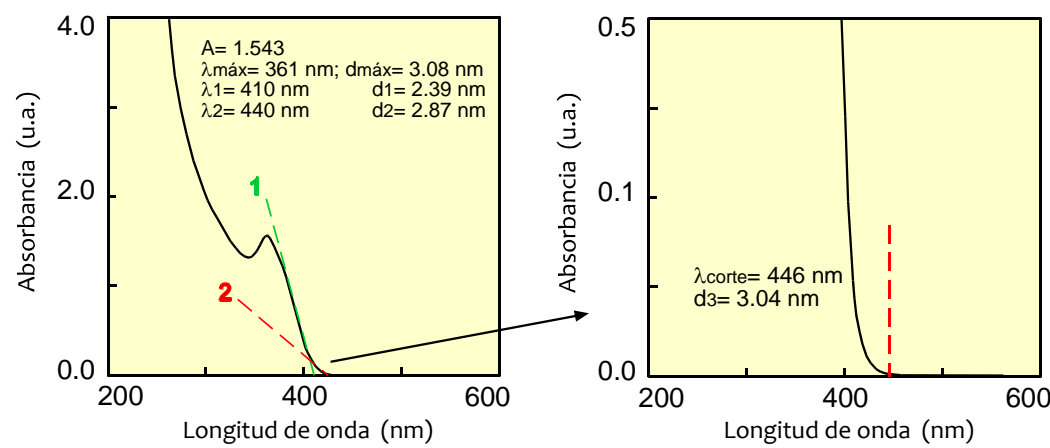

Figura 23. Espectro de absorción de una disolución acuosa conteniendo nanopartículas de CdS. Obtención de $\lambda_{\mathrm{e}}$. A la derecha, espectro anterior a otra escala de absorbancias.

El segundo valor es más correcto pues en realidad se busca la longitud de onda en la cual el valor de la absorbancia comienza a ser diferente de cero. Este valor se puede encontrar de una manera más exacta registrando la parte baja del espectro de absorción en una escala más amplificada de absorbancia (Fig. 23) y midiendo la longitud de onda a la cual

\footnotetext{
99 A. Henglein. Small-Particle Research: Physicochemical Properties of Extremely Small Colloidal Metal and Semiconductor Particles. Chem. Rev. 89 (1989) 1861-1873.

${ }^{100}$ M. Moffitt, E. Aisenberg. Size Control of Nanoparticles in Semiconductor-Polymer Composites. 1. Control via Multiplet Aggregation Numbers in Styrene-Based Random lonomers. Chem. Mater. 7 (1995) 1178-1184.

${ }^{101}$ R. He, X. Qian, J. Yin, H. Xi, L. Bian, Z. Zhu. Formation of monodispersed PVP-capped ZnS and CdS nanocrystals under microwave irradiation. Colloids Surf. A 220 (2003) 151-157. 
el valor de absorbancia comienza a ser distinto de cero (0.005 u.a.). Este caso concreto ocurre para $\lambda=446 \mathrm{~nm}$, lo que conduce a un valor de $d=3.04 \mathrm{~nm}$ a partir de la expresión [2].

Por lo tanto, cuando se estime el valor del tamaño medio de las NPs mediante este procedimiento, el valor de $\lambda_{\mathrm{e}}$ será determinado a partir del corte entre la tangente en la parte inicial del espectro y el origen del valor de absorbancia. Mediante este procedimiento la precisión de la medida es del orden de $\pm 0.1 \mathrm{~nm}$, si bien los resultados se indicarán con tres cifras significativas con fines simplemente comparativos.

\section{c) A partir de la longitud de onda del máximo del pico excitónico del espectro de absorción de las nanopartículas}

Una de las consecuencias de la disminución del tamaño de un cristal semiconductor a medida que sufre un confinamiento cuántico (su tamaño se aproxima al radio de Bohr) es que la energía de la banda hueca (bandgap energy) se va modificando precisamente con el tamaño. Esta modificación transcurre hacia valores más energéticos cuanto menor es el tamaño.

El incremento de energía de la banda hueca del semiconductor está relacionado con el tamaño de la nanopartícula según la expresión [3] ${ }^{102,103,104,105}$.

$$
\mathrm{E}_{\text {efc }}=\mathrm{E}^{0}+\frac{\mathrm{h}^{2}}{8 \mathrm{r}^{2} \mathrm{~m}_{\mathrm{er}}}-\frac{1.8 \mathrm{e}^{2}}{4 \pi \varepsilon_{0} \varepsilon \mathrm{r}}
$$

donde $E_{e f c}$ es la energía efectiva de la banda hueca del nanocristal (eV); $E^{O}$ es la energía de la banda hueca de la celdilla unitaria del cristal; $r$ es el radio de la nanopartícula; $h$ es la constante de Planck; $m_{e r}$ es la masa reducida efectiva del electrón; $e$ es la carga del electrón en reposo y $\varepsilon_{0}$ y $\varepsilon$ son las constantes dieléctricas del cristal y del nanocristal, respectivamente.

El último de los términos de la ecuación es despreciable numéricamente respecto a los otros dos, por lo que la expresión [3] para fines prácticos de cálculo se simplifica en:

$$
E_{e f c}=E^{0}+\frac{h^{2}}{8 r^{2} m_{e r}}
$$

\footnotetext{
${ }^{102}$ H. Su, J. Han, Q. Dong, D. Zhang, Q. Guo. In situ synthesis and photoluminescence of QD-CdS on silk fibroin fibers at room temperature. Nanotechnology 19 (2008) 025601.

${ }^{103}$ G.A.M. Castanon, M.G.S. Loredo, J.R.M. Mendoza, F. Ruiz. Synthesis of CdS nanoparticles: a simple method in aqueous media. Adv. Technol. Mater. Proc. 7 (2005) 171-174.

${ }^{104}$ Y. Wang, N. Herron. Nanometer-Sized Semiconductor Clusters: Materials Synthesis, Quantum Size Effects, and Photophysical Properties. Phys. Chem. 95 (1991) 525-532.

105 L.E. Brus. Electron-electron and electron-hole interactions in small semiconductor crystallites: The size dependence of the lowest excited electronic state. J. Chem. Phys. 80 (1984) 4403.
} 
La energía efectiva de la banda hueca del nanocristal se calcula a partir de la longitud de onda del máximo del pico excitónico $\left(\lambda_{\text {máx }}\right)$, a partir de la relación $E_{\text {efec }}=\mathrm{h} c / \lambda_{\text {máx}}$.

$E_{0}$ para el caso de CdS es $2.4 \mathrm{eV}^{106,107,108}$, lo que equivale a una longitud de onda de $515 \mathrm{~nm}$, que en el caso del cristal unitario corresponde a la longitud de onda de corte de su espectro de absorción (comienzo de la absorción). A esta longitud de onda la denominaremos $\lambda_{\text {cristal. }}$.

La masa reducida efectiva del electrón se relaciona con las masas efectivas del electrón y del hueco según la expresión:

$$
m_{e r}=\frac{m_{\mathrm{e}} m_{\mathrm{h}}}{m_{\mathrm{e}}+\mathrm{m}_{\mathrm{h}}}
$$

donde $m_{e}$ es la masa efectiva del electrón y $m_{h}$ es la masa efectiva del hueco. Para el caso de CdS, $\mathrm{m}_{\mathrm{e}}=0.19 \mathrm{~m}_{0}$ y $\mathrm{m}_{\mathrm{h}}=0.80 \mathrm{~m}_{0}$ (siendo $\mathrm{m}_{0}$ la masa del electrón en reposo).

A partir de la expresión [4] es posible obtener el valor de r:

$$
\mathrm{r}=\sqrt{\frac{\mathrm{h}^{2}}{\left(\text { Eefec- }-\mathrm{E}^{0}\right) 8 \mathrm{~m}_{\mathrm{er}}}}
$$

Como el dato experimental obtenido a partir del espectro de absorción es la $\lambda_{\text {máx, }}$ es posible transformar la expresión [6] en otra en función de $\lambda_{\text {máx }}$ teniendo en cuenta que:

$$
h=6.6252 \times 10^{-27} \mathrm{erg} \mathrm{s} ; 1 \mathrm{eV}=1.602 \times 10^{-12} \mathrm{erg} ; m_{0}=9.1096 \times 10^{-28} \mathrm{~g} ; c=3.0 \times 10^{10} \mathrm{~cm} \mathrm{~s}^{-1} ;
$$

$1 \mathrm{~nm}=10^{-7} \mathrm{~cm} ; \lambda_{\text {cristal }}=515 \mathrm{~nm}$;

que junto con el radio de las nanopartículas y la $\lambda_{\text {máx }}$ resulta:

$$
r(\mathrm{~nm})=0.0444 \sqrt{\frac{515 \lambda \text { máx }}{515-\lambda m a ́ x}}
$$

Para el espectro de la Figura 23 el pico del máximo excitónico se localiza a 361 nm, por lo que a partir de la expresión [7] se obtiene un valor de $r=1.54 \mathrm{~nm}$, siendo $d=3.08 \mathrm{~nm}$. La fluctuación en la obtención de $\lambda_{\text {máx }}$ en máximos de absorción bien definidos es de $\pm 2 \mathrm{~nm}$, por lo que el valor de $r$ tiene una fluctuación de $\pm 0.02 \mathrm{~nm}$ y el de $d \pm 0.04 \mathrm{~nm}$.

${ }^{106}$ A.I. Kryukov, S.Y. Kuchmii, V.D. Pokhodenko. Energetics of electron processes in semiconductor photocatalytic systems. Theor. Exp. Chem. 36 (2000) 63-81.

${ }^{107}$ S.V. Gaponenko. Optical properties of semiconductor nancrystals. Cambridge Univ. Press. Cambridge, 1996.

${ }^{108}$ Handbook, Physico-Chemical properties of semiconductor compounds. Nauka, Moscow, 1979. 
El valor obtenido a partir de $\lambda_{\text {máx }}$ es similar al obtenido a partir de $\lambda_{\mathrm{e}}$ (Fig. 23) y muy parecido al obtenido a partir de la tangente en la parte baja del espectro $\left(d_{2}=2.87 \mathrm{~nm}\right)$ si se tiene en cuenta su precisión.

En el ejemplo concreto del espectro de la Figura 23, la disolución acuosa de las nanopartículas de CdS que muestran un máximo de absorción bien definido con un pico a $361 \mathrm{~nm}$ conducen a un valor de $\mathrm{E}_{\mathrm{efec}}=3.4 \mathrm{eV}$ frente $\mathrm{a} \mathrm{E}_{0}=2.4 \mathrm{eV}$ debido al confinamiento cuántico de electrones y huecos en el nanosemiconductor debido a su tamaño de $3.08 \mathrm{~nm}$ de diámetro.

Este último método para calcular el tamaño medio de las nanopartículas plantea problemas de cálculo exacto cuando el espectro de las NPs no presenta un máximo de absorción bien definido. En estos casos resulta más práctico obtener el valor de $\mathrm{d}$ a partir de la $\lambda_{\mathrm{e}}$.

\section{ESTIMACIÓN DEL NÚMERO DE MOLÉCULAS DE CdS CONTENIDAS EN LAS NANOPARTÍCULAS}

Conocido el tamaño medio de las nanopartículas es posible estimar el número de moléculas de CdS contenidas en cada QD. Este cálculo es posible por la morfología esférica de las NPs obtenidas.

Como el volumen de la esfera es $4 / 3 \pi r^{3}$, el número de moléculas de $\mathrm{CdS}$ en el interior de cada partícula se puede estimar mediante la expresión:

$$
N_{C d S}=\frac{4}{3} \pi r^{3} \frac{\rho_{C d S} N_{0}}{M_{C d S}}
$$

donde $N_{C d S}$ es el número de moléculas de $C d S ; r$ es el radio de la nanopartícula; $\rho_{C d S}$ es la densidad de CdS (4.82 $\left.\mathrm{g} \mathrm{cm}^{-3}\right) ; N_{0}$ es el número de Avogadro $\left(6.023 \times 10^{23}\right.$ moléculas $\left.\mathrm{mol}^{-1}\right) ; M_{C d S}$ es la masa molecular de CdS (144.46 $\left.\mathrm{g} \mathrm{mol}^{-1}\right)$.

Para el caso de las nanopartículas de CdS, la expresión [8], sustituyendo el valor de las constantes en unidades coherentes, se transforma en:

$$
\mathrm{N}_{\mathrm{CdS}}=81.8 \mathrm{r}^{3}(r \text { en } \mathrm{nm})
$$

Así, para las nanopartículas responsables del espectro de la Figura 24 en la que $r=$ $1.61 \mathrm{~nm}$, se obtiene a partir de la expresión [9] que $\mathrm{N}_{\mathrm{Cds}}=341$, lo que da una idea clara del confinamiento cuántico por tamaño. 


\section{INFORMACIÓN ESPECTROSCÓPICA}

\section{ESPECTRO DE ABSORCIÓN}

En la Figura 24 se muestra un espectro de absorción típico entre 200 y 600 nm de la disolución amarillo-verdosa con nanopartículas.

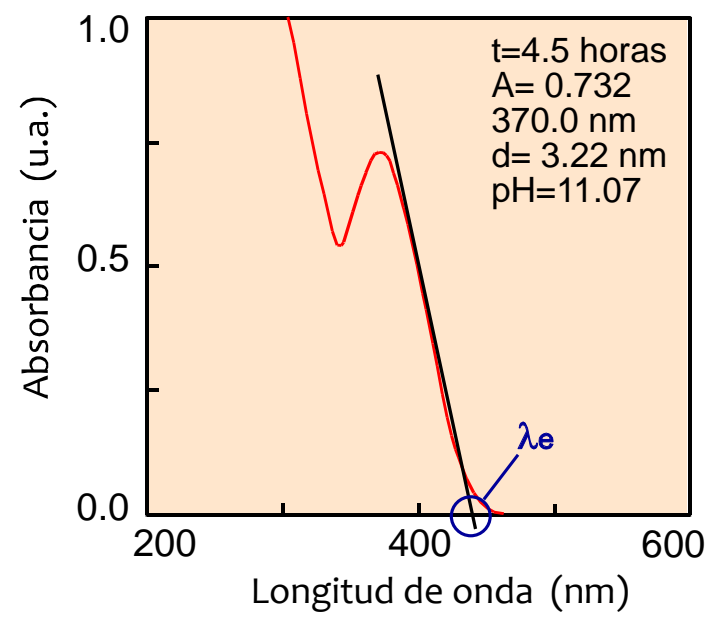

Figura 24 Espectro de absorción de las nanopartículas de CdS a las 4.5 horas una vez terminado el proceso de obtención.

En este caso, el espectro muestra una banda de absorción a partir de los $450 \mathrm{~nm}$ con un máximo, en este caso a $370 \mathrm{~nm}$. En la obtención de nanopartículas el máximo de la banda de absorción se encuentra mejor definido cuanto mayor es su cantidad en disolución y cuanto menor es la distribución del tamaño de partícula alrededor de su tamaño medio. El valor de la absorbancia a $370 \mathrm{~nm}, \mathrm{~A}=0.732$, es proporcional, a esa longitud de onda, a la cantidad o concentración de NPs; si bien el coeficiente de absorción depende del diámetro de la partícula. Para longitudes de onda menores de 360-370 nm se observa una banda inespecífica debida a transiciones electrónicas más energéticas. Aplicando la ecuación de Henglein para el cálculo del diámetro de estas nanopartículas se obtiene un valor de $d=$ $2.85 \mathrm{~nm}$.

\section{ESPECTRO DE FLUORESCENCIA}

El comportamiento luminiscente, característico de este tipo de nanopartículas semiconductoras, será estudiado a través de los espectros de excitación y emisión.

La longitud de onda de emisión depende, como se irá viendo a lo largo de las experiencias, del diámetro de la nanopartícula y muy posiblemente, la intensidad del 
proceso de emisión, además de las energías de los procesos de relajación electrónica entre las bandas del semiconductor, depende del estado de la superficie de la nanopartícula.

La forma simétrica del espectro de emisión indica, como iremos señalando en su momento, que las pérdidas de energía por procesos no radiantes son independientes de la longitud de onda de emisión en ese margen, lo que es indicativo de una superficie muy homogénea en las NPs, sin grandes imperfecciones.

El valor de la anchura del espectro de emisión a la mitad del valor máximo de la intensidad de fluorescencia, denominado $\triangle$ o FWHM, es indicativo de la mayor o menor distribución del tamaño de las nanopartículas alrededor del diámetro medio. Cuanto menor sea (banda de emisión más estrecha), menor será la distribución de tamaño (gaussiana con una desviación estándar más pequeña); lo que quiere decir que las partículas son más uniformes en cuanto a su tamaño se refiere.

Este valor, $\Delta$, nos permite comparar la distribución de tamaños en las diferentes condiciones experimentales y en las diferentes etapas de la vida de las nanopartículas. A título informativo se puede indicar que el valor de $\Delta$ para NPs obtenidas en medio orgánico oscila entre 30 y $90 \mathrm{~nm}^{109}$.

\section{EVOLUCIÓN TEMPORAL}

Terminado el tiempo de agitación de la disolución tras la síntesis, ésta se deja evolucionar con el tiempo, a la temperatura ambiente del laboratorio, en ausencia de irradiación con luz (frasco topacio) y sin agitación.

En estas condiciones las NPs de CdS estabilizadas con ácido mercaptoacético se encuentran dispersadas en una disolución que contiene iones $\mathrm{S}^{2-}$ y fundamentalmente $\mathrm{Cd}^{2+}$, por inicialmente estar en exceso, que se mueven según su coeficiente de difusión y teóricamente pueden interaccionar entre sí para generar más núcleos de precipitación o incorporarse a los ya formados para incrementar el tamaño de los cristales.

Por otra parte, los iones $\mathrm{Cd}^{2+}$, que se encuentran en exceso frente a los iones $\mathrm{S}^{2-}$, pueden intervenir en otras reacciones parásitas diferentes a la formación de nanopartículas, como son, al pH inicial de 11, la formación de óxidos hidratados, que de ocurrir se depositarán sobre la superficie de las NPs, ya que no se observa turbidez en la disolución y, por tanto, no existe precipitado de hidróxido de cadmio $\mathrm{Cd}(\mathrm{OH})_{2}$ en la disolución.

\footnotetext{
${ }^{109}$ K. Yu, B. Zaman, R. Taal, J.A. Ripmeester. Colloidal CdSe nanocrystals from tri-n-octylphosphine with various Cd sources: control of a slow growth for high-quality and large-scale production. Journal of Crystal Growth 283 (2005) 115-123.
} 
No debe olvidarse que las nanopartículas de CdS no se encuentran estáticas, son dinámicas en el sentido de que intervienen en equilibrio con las especies en disolución en procesos de solubilización y crecimiento del tamaño de partícula.

En gran parte de las experiencias realizadas, los fenómenos hasta ahora comentados vienen acompañados por un descenso en el valor de $\mathrm{pH}$ de la disolución. Parece indicar este hecho el consumo de iones $\mathrm{OH}^{-}$por parte de los iones $\mathrm{Cd}^{2+}$ de la disolución para formar óxidos hidratados sobre la superficie de las nanopartículas, si bien a estos valores de $\mathrm{pH}$ no puede despreciarse la transformación de dichos óxidos hidratados de la superficie en especies hidroxiladas, por ejemplo $\mathrm{Cd}(\mathrm{OH})_{3}{ }^{-}$, o bien la solubilización de los iones $\mathrm{Cd}^{2+}$ del nanocristal para transformarse en $\mathrm{CdOH}^{+}$principalmente:

$$
\begin{array}{ll}
\mathrm{Cd}^{2+}+\mathrm{OH}^{-} \leftrightarrow \mathrm{CdOH}^{+} & \log \beta_{1}=4.1 \\
\mathrm{Cd}^{2+}+2 \mathrm{OH}^{-} \leftrightarrow \mathrm{Cd}(\mathrm{OH})_{2} & \log \beta_{2}=7.7 \\
\mathrm{Cd}^{2+}+3 \mathrm{OH}^{-} \leftrightarrow \mathrm{Cd}(\mathrm{OH})_{3}^{-} & \log \beta_{3}=10.3 \\
\mathrm{Cd}^{2+}+4 \mathrm{OH}^{-} \leftrightarrow \mathrm{Cd}(\mathrm{OH})_{4}{ }^{2-} & \log \beta_{4}=12.0
\end{array}
$$

Se observa además, que la evolución de los valores de intensidad de fluorescencia con el tiempo tiene una morfología que se repite a lo largo de las experiencias que posteriormente comentaremos (Fig. 25). Para tiempos de evolución iniciales, la intensidad de emisión de fluorescencia disminuye, no por descender la cantidad de nanopartículas pues el valor de la absorbancia se mantiene constante, sino que este fenómeno puede deberse a procesos físicos y químicos en la superficie de las NPs modificando su morfología.

Esta alteración de la superficie provoca el aumento de emisión no radiante por lo que la luz fluorescente emitida disminuye en intensidad. Por otra parte, esta alteración superficial no es homogénea para todas las nanopartículas. Parece depender de su tamaño, pues la anchura del espectro de emisión a la mitad de su altura máxima, $\Delta$, aumenta con el tiempo, aumentando la distribución de tamaños alrededor del valor medio, $d$, que permanece prácticamente constante.

Pasadas unas horas, las nanopartículas más pequeñas crecen en tamaño, solubilizándose las más grandes, razón por la cual la distribución de tamaños se vuelve a estrechar hasta valores próximos al inicial. Este proceso va acompañado de una modificación paulatina y lenta de la superficie que hace que la intensidad de emisión de fluorescencia aumente considerablemente con el tiempo, a partir del cual hay un descenso ligero que normalmente va acompañado de un incremento en el tamaño medio de partícula. 


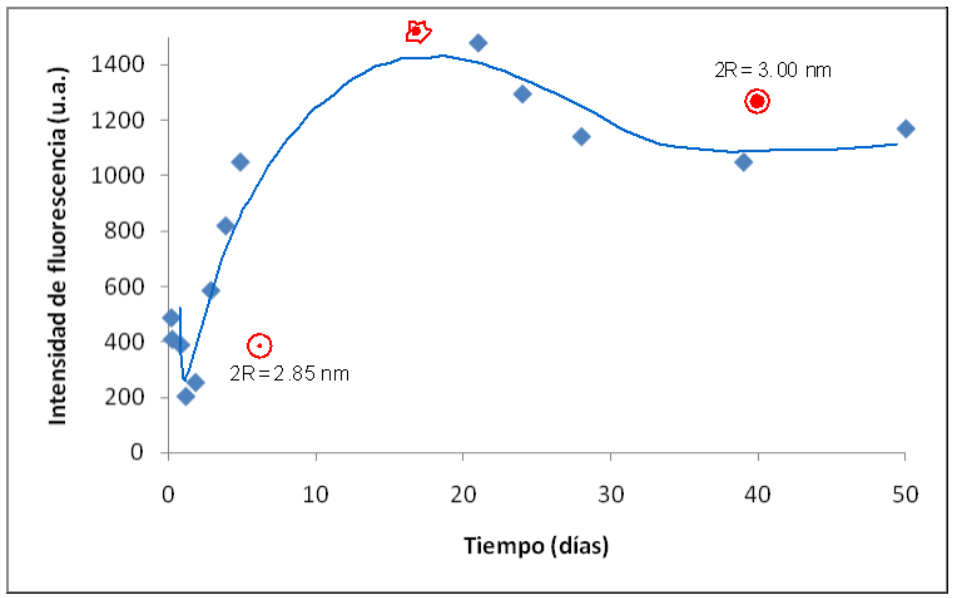

Figura 25 Evolución de la intensidad de fluorescencia con el envejecimiento de las nanopartículas. $\lambda$ ex $=392.0 \mathrm{~nm} ; \lambda$ em $=524.8 \mathrm{~nm} ; \operatorname{Rex}=\operatorname{Rem}=5 \mathrm{~nm}$.

Un hecho importante es que a pesar de la compleja evolución de las nanopartículas en estas condiciones experimentales, éstas permanecen dispersadas en la disolución hasta al menos 50 días de su obtención, manteniendo incluso al final sus propiedades fotoluminiscentes; si bien los valores máximos de intensidad de fluorescencia se obtienen a partir de los 15 días de terminado su proceso de obtención.

\section{ESTUDIO DE VARIABLES}

\section{INFLUENCIA DEL $p H$}

Como se acaba de comentar, en las propiedades luminiscentes de las nanopartículas de CdS tiene influencia fundamental el estado de la superficie, no sólo en el aspecto físico sino también en su composición. Las especies que se adsorben sobre la superficie son dependientes del $\mathrm{pH}$, esto es, son numerosos los equilibrios ácido-base que controlan su existencia. El tamaño de nanopartícula y las propiedades luminiscentes son, por tanto, dependientes del $\mathrm{pH}$ de la disolución conteniendo $\mathrm{Cd}^{2+}$ y $\mathrm{MAA}$ antes de la adición lenta de $\mathrm{S}^{2-}$.

Para de alguna manera comprobar estas hipótesis, se realiza la siguiente experiencia: sobre $100 \mathrm{~mL}$ de disolución conteniendo 0.20 mmoles de $\mathrm{Cd}^{2+}$ se añaden 105 $\mu \mathrm{L}$ de MAA $1.41 \mathrm{M}(0.148 \mathrm{mmoles})$ bajo agitación a $380 \mathrm{rpm}$. El pH de esta disolución, que es ácido, se ajusta con $\mathrm{NaOH} 0.5 \mathrm{M}$ en seis experiencias desde 5.2 hasta 11.0. A continuación, se burbujea nitrógeno durante 15-20 minutos y posteriormente se añade, lentamente y en porciones de volumen pequeñas, los $50 \mathrm{~mL}$ de disolución de $\mathrm{Na}_{2} \mathrm{~S}(0.075$ mmoles). El tiempo de adición de esta disolución es de 15 minutos. 
Las experiencias se realizan a temperatura ambiente (en el tiempo que duran las medidas ésta se mantiene entre 21 y $24^{\circ} \mathrm{C}$ ). La agitación se para a las seis horas de terminada la adición del $\mathrm{S}^{2-} \mathrm{y}$ este tiempo lo consideraremos $\mathrm{t}=0$.

En estas condiciones de trabajo las concentraciones finales y sus relaciones molares son: $\left[\mathrm{Cd}^{2+}\right]_{\mathrm{f}}=1.33 \times 10^{-3} \mathrm{M} ;\left[\mathrm{S}^{2-}\right]_{\mathrm{f}}=0.5 \times 10^{-3} \mathrm{M} ;[\mathrm{MAA}]_{\mathrm{f}}=0.987 \times 10^{-3} \mathrm{M} ;\left[\mathrm{Cd}^{2+}\right]_{\mathrm{f}} /\left[\mathrm{S}^{2-}\right]_{\mathrm{f}}=2.7$; $\left[\mathrm{Cd}^{2+}\right]_{\mathrm{f}} /[\mathrm{MAA}]_{\mathrm{f}}=1.3$.

Al ser la disolución de $\mathrm{Na}_{2} \mathrm{~S}$ muy alcalina ( $\mathrm{pH}$ prácticamente 11 ), sólo al principio de su adición hay diferencias claras de $\mathrm{pH}$, entre las experiencias, siendo la diferencia muy pequeña cuando ya se han añadido los $50 \mathrm{~mL}$ de disolución. Las diferencias de $\mathrm{pH}$ inicial van a afectar fundamentalmente a la concentración inicial de $\mathrm{S}^{2-}$ disponible para formar los nanonúcleos, así como a la formación de una nanocorteza de $\mathrm{Cd}(\mathrm{OH})_{2}$ que termodinámicamente será más favorable cuanto mayor sea el pH (Fig. 26).

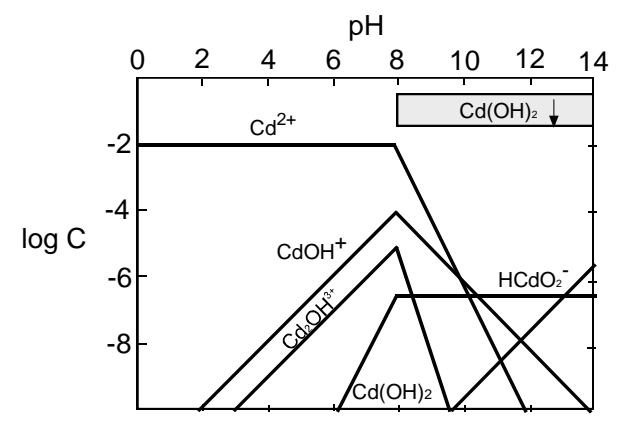

Figura 26. Diagrama log $\mathrm{C}-\mathrm{pH}$ para $\mathrm{Cd}$ (II) $10^{-2} \mathrm{M}$.

En conclusión, los diferentes pHs iniciales van a afectar fundamentalmente a las primeras etapas de formación de las NPs que condicionarán posteriormente la etapa de crecimiento, el estado de su superficie y, por tanto, sus propiedades luminiscentes y estabilidad en disolución. En definitiva, las reacciones parásitas para el $\mathrm{S}^{2-}$ serán más importantes cuanto menor sea el $\mathrm{pH}$ mientras que las de $\mathrm{Cd}^{2+}$ lo serán cuanto mayor sea el $\mathrm{pH}$.

En primer lugar debemos comentar que se observa un fenómeno curioso en las disoluciones y trasladado a los espectros de absorción nada más medir terminada la agitación (Fig. 27). 

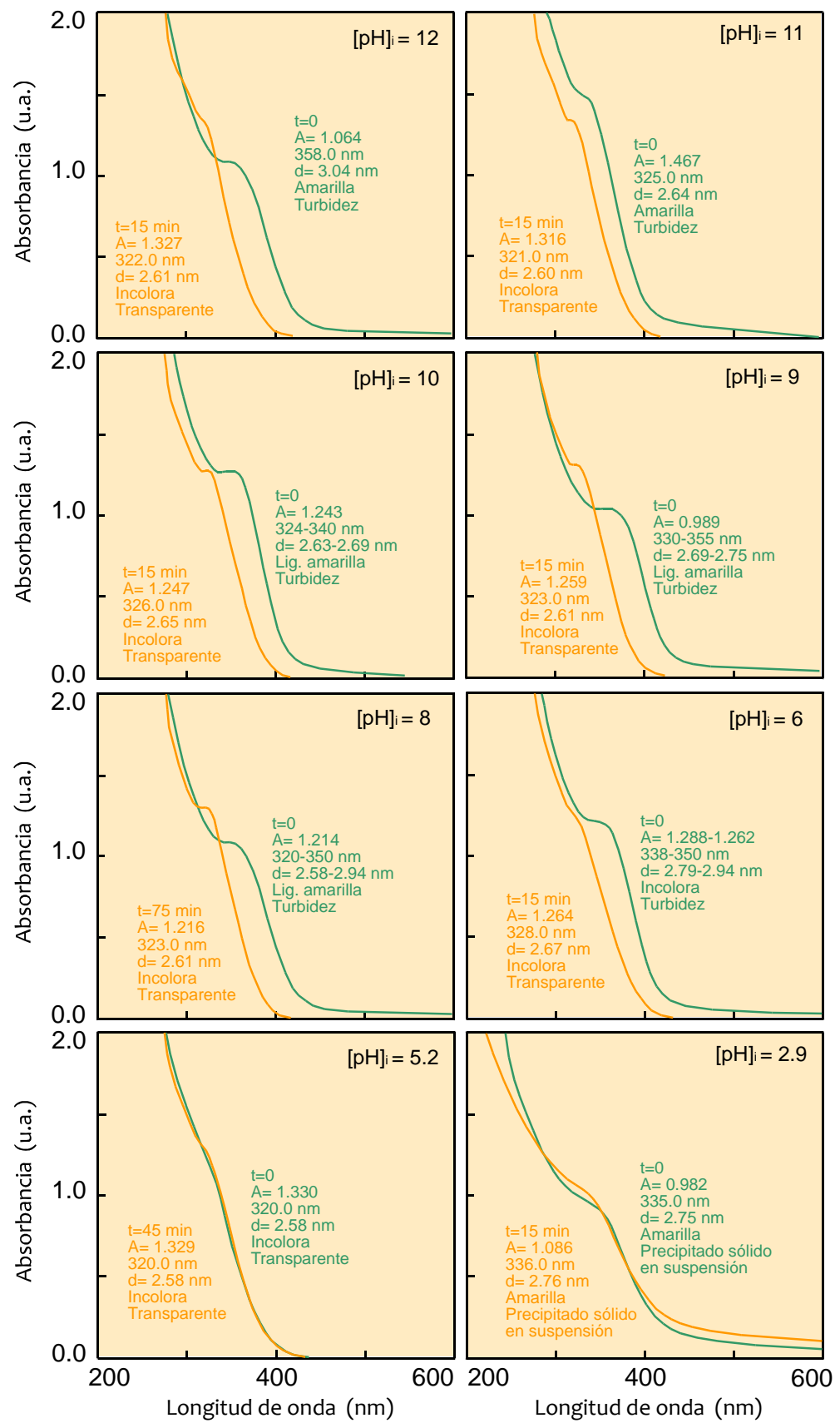

Figura 27. Evolución de los espectros de absorción con el tiempo, nada más terminar el periodo de agitación. Influencia del pH inicial antes de añadir la disolución de $\mathrm{Na}_{2} \mathrm{~S}$. Tiempo de agitación: 7 horas.

Puede comprobarse en dicha figura cómo nada más parar la agitación y medir el espectro de absorción se deduce a partir de él que el diámetro medio de la partícula es mayor cuanto más alto fue el $\mathrm{pH}$ inicial de la disolución antes de añadir el $\mathrm{S}^{2-}$. Debemos 
excluir la disolución en la que el pH inicial fue el del ácido mercaptoacético, pues a ese valor de $\mathrm{pH}$, en las adiciones iniciales de reactivos, la concentración de mercaptoacetato, que se enlaza al CdS, es tan pequeña que no existe suficiente cantidad de dispersante, por lo que en la disolución y en el fondo del recipiente aparece un precipitado amarillo de CdS. No obstante, en disolución quedan NPs de un tamaño medio de $2.75 \mathrm{~nm}$ que generan un espectro de absorción con un hombro entre 320 y $350 \mathrm{~nm}$, correspondiente a los procesos solapados de transiciones electrónicas $1 \mathrm{Sh}-1 \mathrm{Se}$ y $1 P \mathrm{P}-1 \mathrm{Pe}$. Esta disolución medida a los 15 minutos no experimenta ningún cambio. En ambos casos, al tener la disolución sólido en suspensión, el espectro de absorción para longitudes de onda largas, presenta un valor de absorbancia diferente a cero que hay que tener en cuenta a la hora de medir el valor de la absorbancia en el hombro, restando el valor de absorbancia de la línea base (línea recta tangente al valor de absorbancia a los $600 \mathrm{~nm}$ ).

El fenómeno curioso que queríamos comentar es que las mismas disoluciones medidas 15 minutos después de cortada la agitación, evolucionan espontáneamente, rompiéndose los agregados, hasta NPs que en todos los casos tienen un diámetro medio idéntico de $2.6 \mathrm{~nm}$, salvo la de $\mathrm{pH}=5.2$, que no experimenta modificación. Este cambio espontáneo va acompañado del correspondiente cambio de color de la disolución, de amarillo más o menos intenso hasta incoloro (está relacionado con el tamaño).

Parece, por lo tanto, que la agitación y el tiempo que ésta dura afectan al estado en que se encuentran las NPs, favoreciendo la agregación (no confundir con el crecimiento del tamaño de las nanopartículas). En este estudio se deduce que el pH inicial de la disolución afecta a este proceso de agregación, haciéndolo más favorable cuanto más alcalino es, esto es, cuanto mayor es la concentración inicial de $\mathrm{S}^{2-}$. Parece que los nanonúcleos iniciales se forman de manera diferente según sea el pH inicial de la disolución acuosa antes de añadir el $\mathrm{S}^{2-}$.

Cuando se ha terminado de añadir los $50 \mathrm{~mL}$ de la disolución de $\mathrm{Na}_{2} \mathrm{~S}$, en ese momento el $\mathrm{pH}$ de las disoluciones se diferencia menos, estrechándose el margen entre 11.85 y 9.86 , siendo en este medio en el que evolucionan las NPs, pero recordemos que en las primeras adiciones de $\mathrm{S}^{2-}$ el margen de $\mathrm{pH}$ es más amplio.

Tras parar la agitación, las NPs evolucionan con el tiempo creciendo de tamaño desde los $2.6 \mathrm{~nm}$ a diferentes tamaños dependiendo del pH y a diferentes velocidades, lo que confirma una vez más los posibles reacciones parásitas con los $\mathrm{OH}^{-}$.

En las Figuras 28 a 34 se muestran algunos de los espectros de absorción a lo largo del tiempo y para los diferentes $\mathrm{pHs}$. La experiencia a $\mathrm{pH}=12$ sólo muestra espectros hasta 
los 36 días, debido a que a partir de dicho tiempo las nanopartículas ya no tienen interés por no ser fluorescentes.

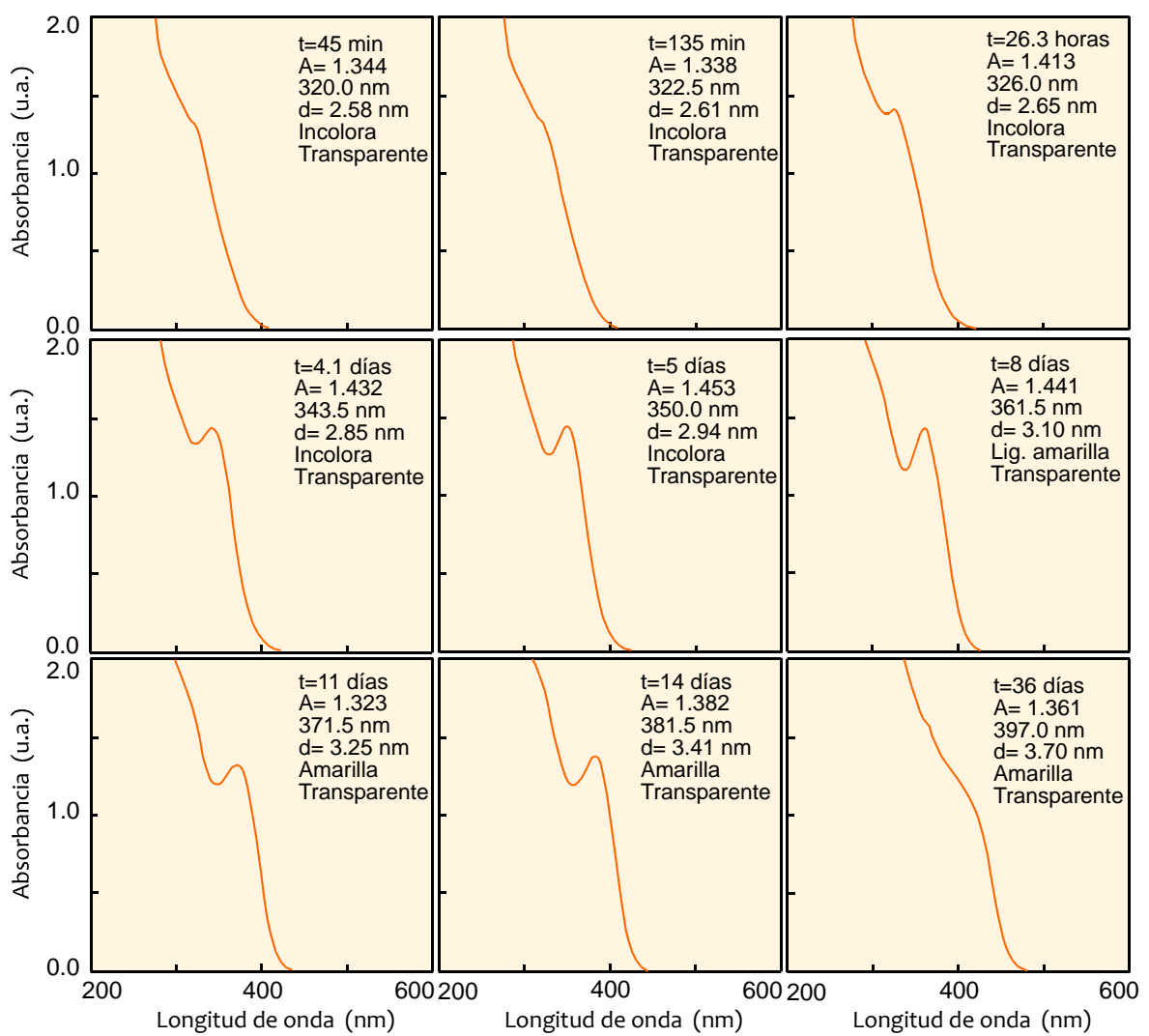

Figura 28. Evolución de los espectros de absorción con el tiempo tras parar la agitación. pH de la disolución antes de añadir $\mathrm{S}^{2-}$ $=12$. 


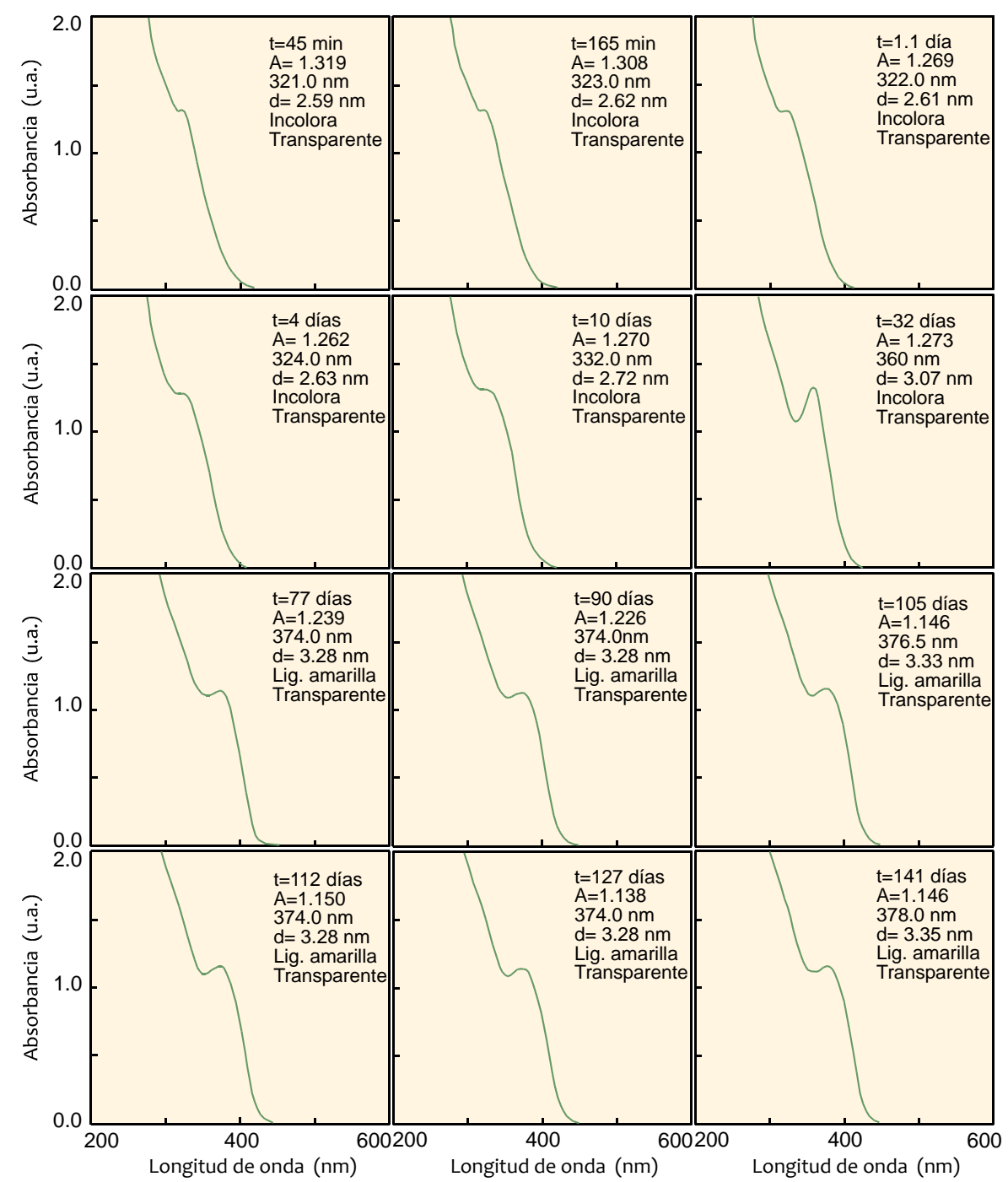

Figura 29. Evolución de los espectros de absorción con el tiempo tras parar la agitación. pH de la disolución antes de añadir $\mathrm{S}^{2-}$ $=11$. 


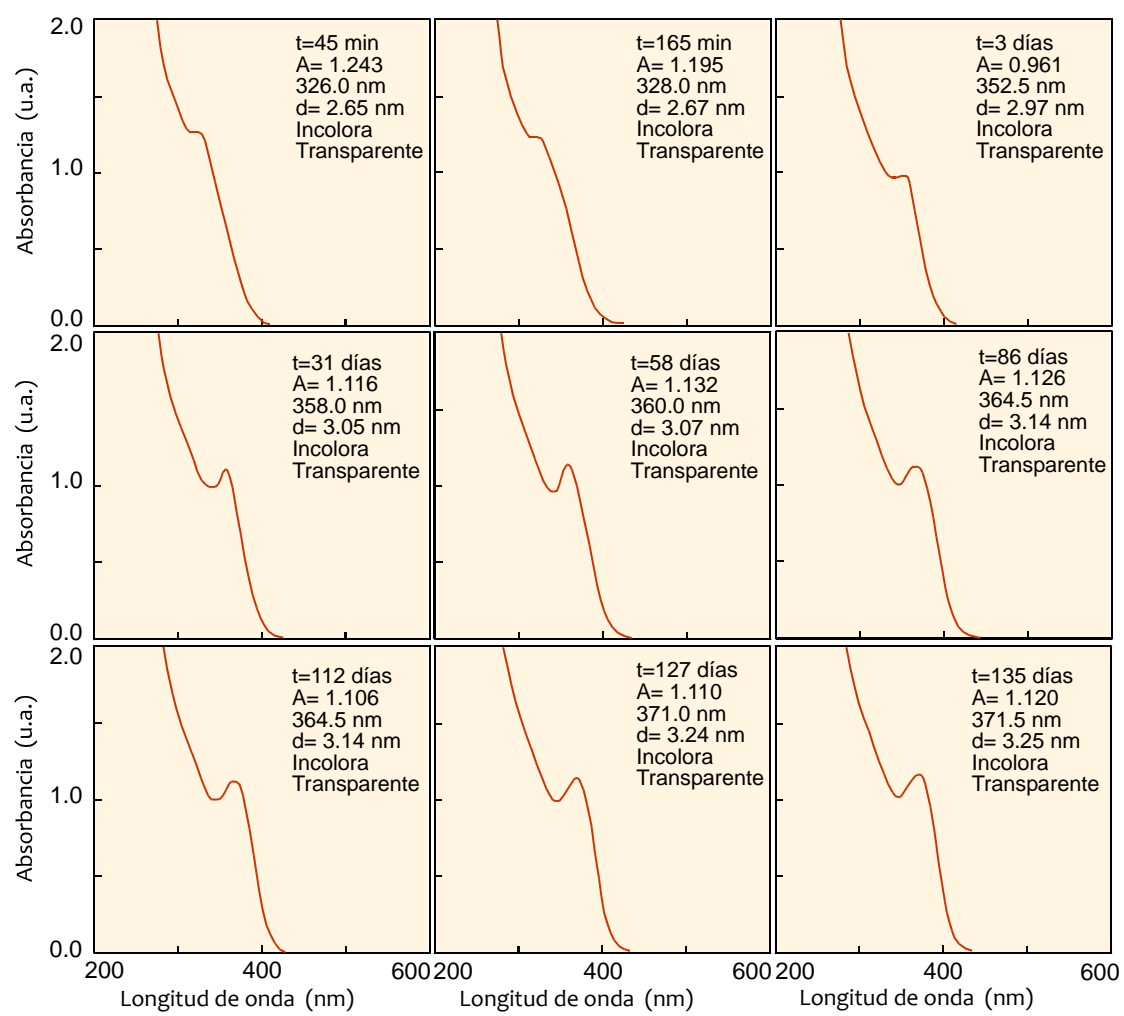

Figura 30. Evolución de los espectros de absorción con el tiempo tras parar la agitación. pH de la disolución antes de añadir $\mathrm{S}^{2-}$ $=10$. 


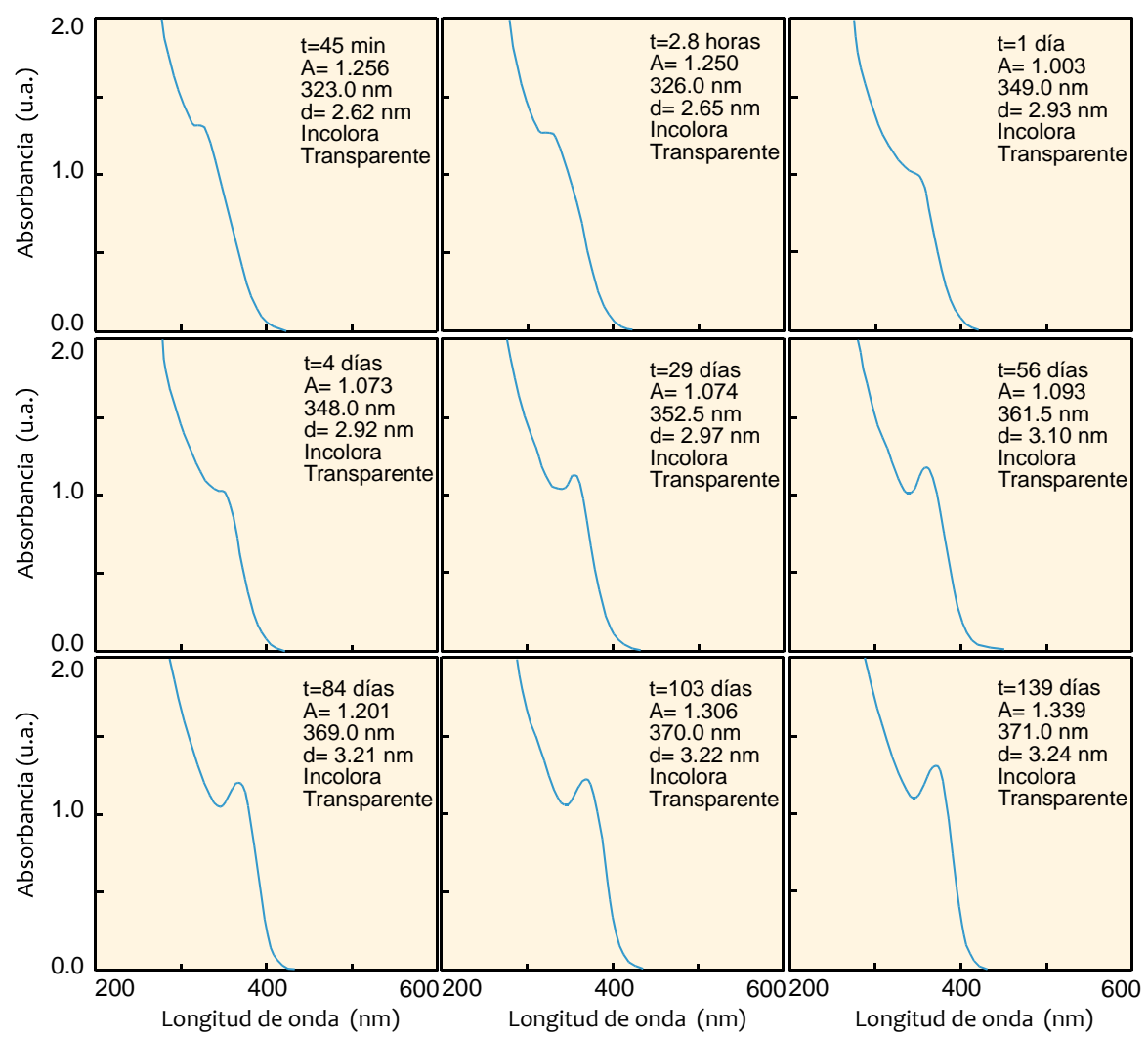

Figura 31. Evolución de los espectros de absorción con el tiempo tras parar la agitación. pH de la disolución antes de añadir $\mathrm{S}^{2-}$ $=9.0$. 


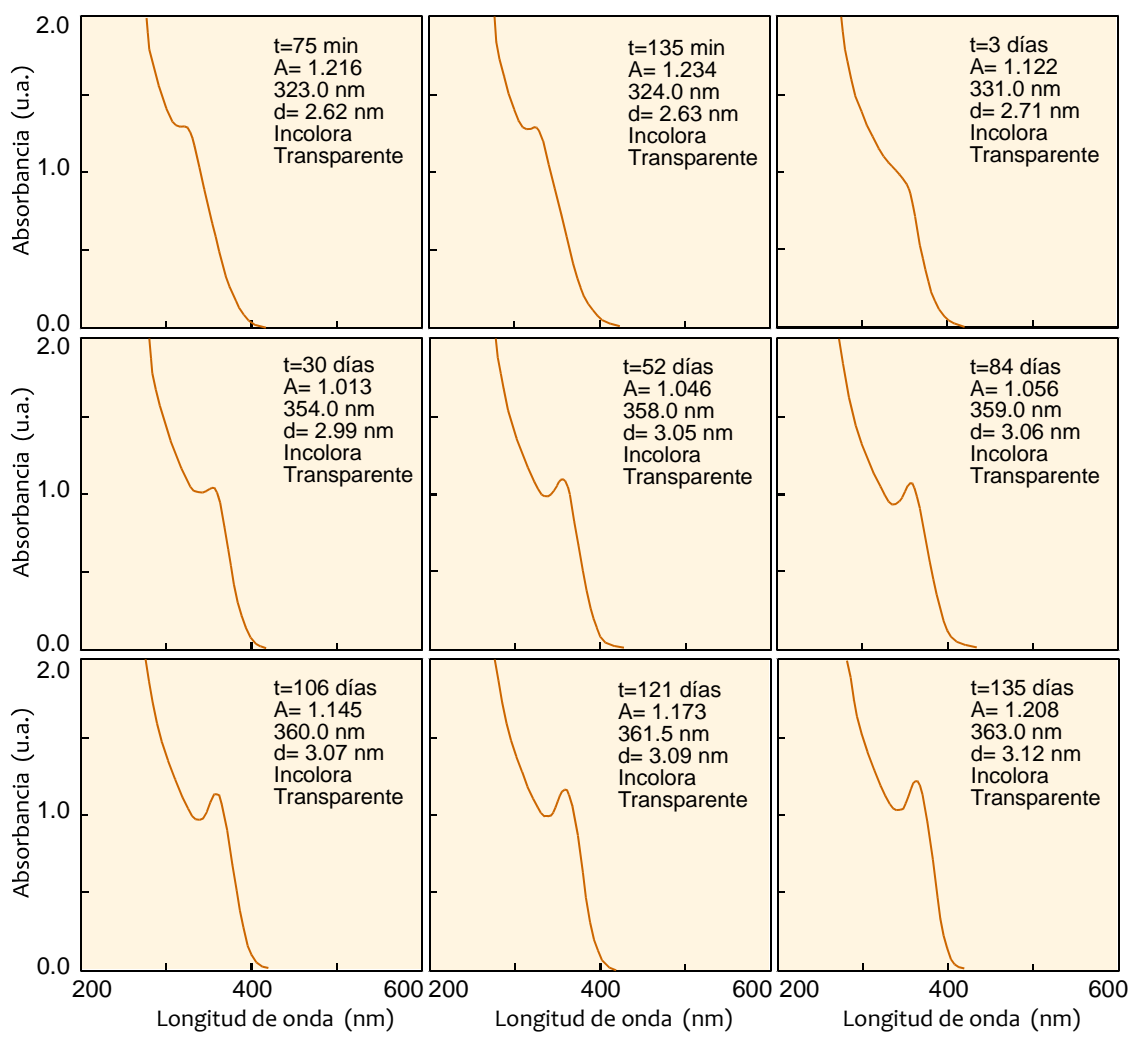

Figura 32. Evolución de los espectros de absorción con el tiempo tras parar la agitación. pH de la disolución antes de añadir $\mathrm{S}^{2-}$ $=8.0$. 


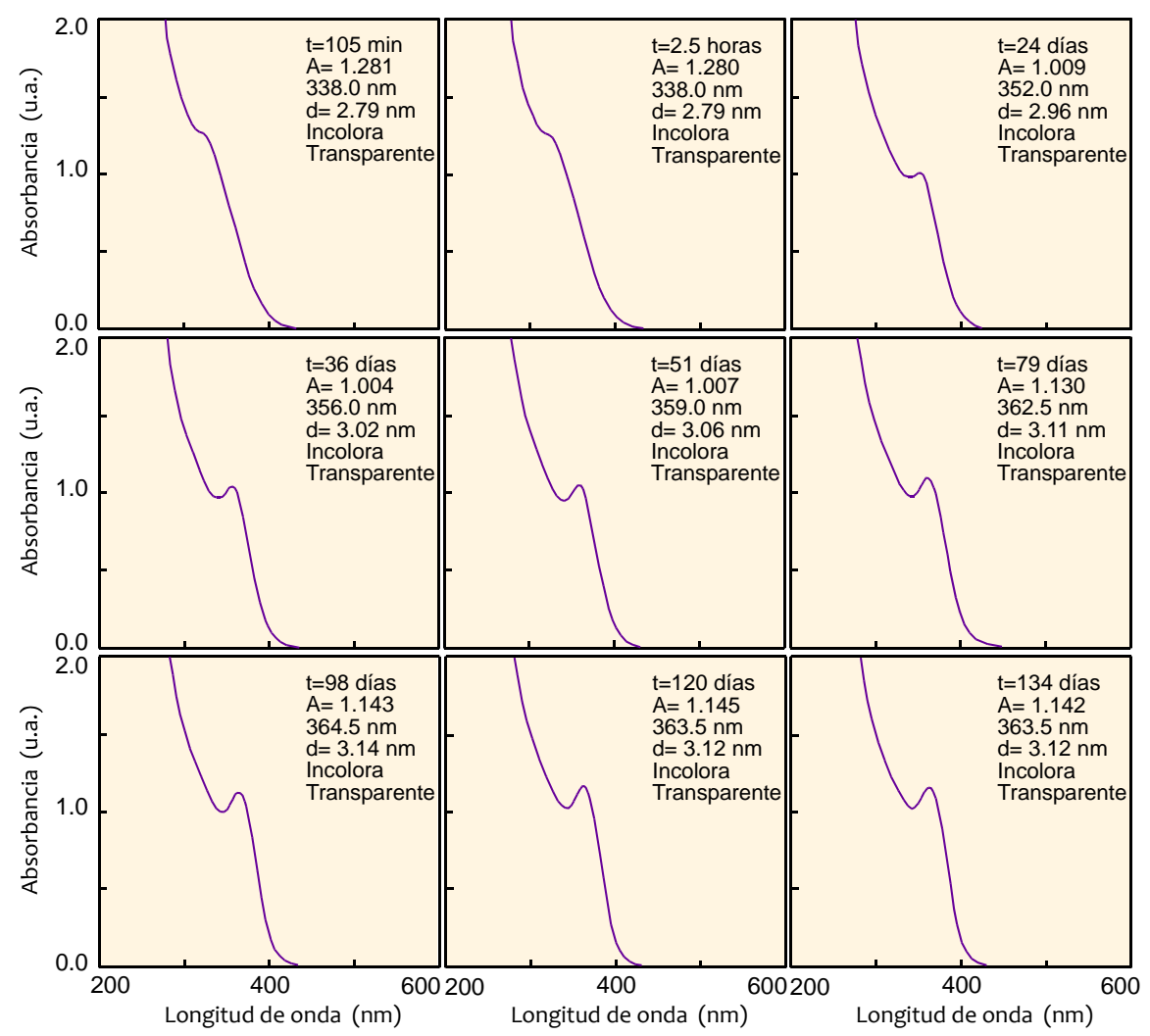

Figura 33. Evolución de los espectros de absorción con el tiempo tras parar la agitación. pH de la disolución antes de añadir $\mathrm{S}^{2-}$ $=6.0$. 


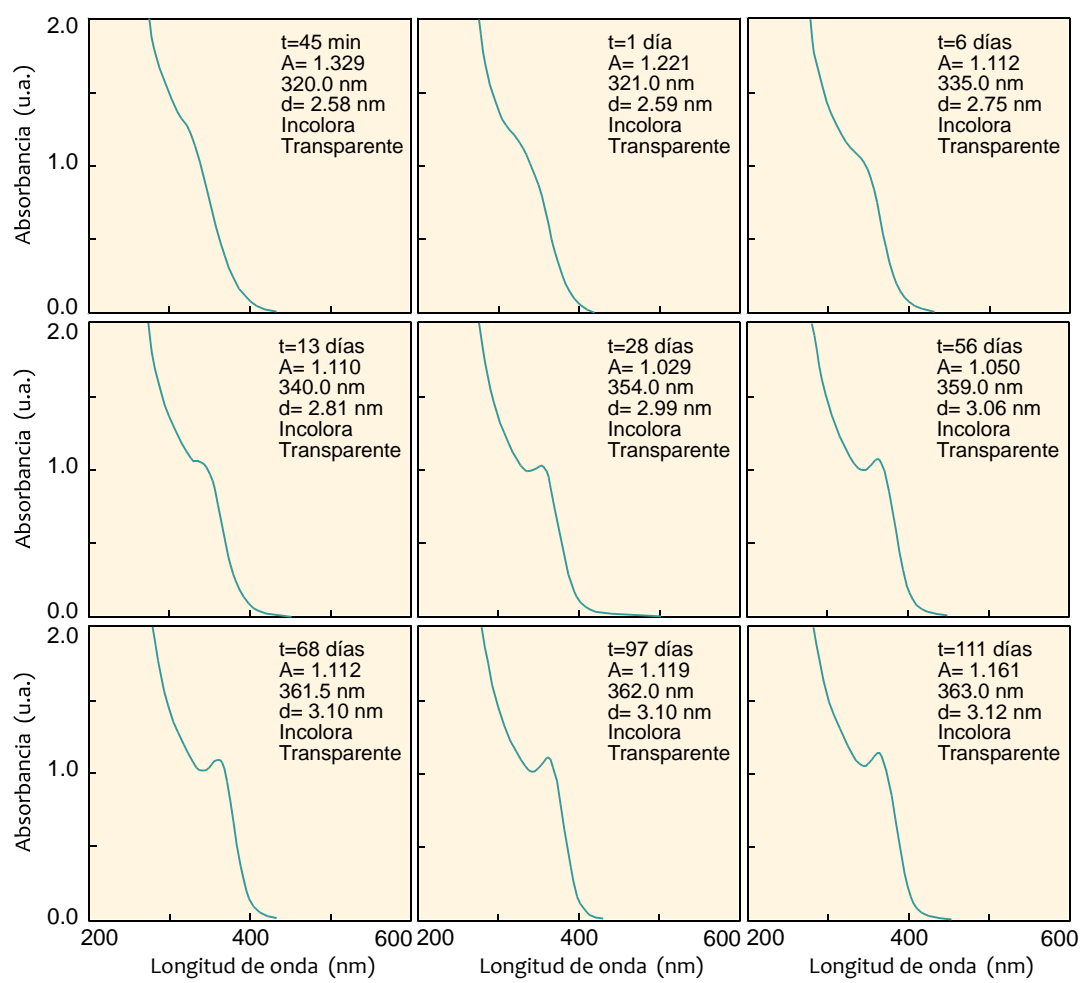

Figura 34. Evolución de los espectros de absorción con el tiempo tras parar la agitación. pH de la disolución antes de añadir $\mathrm{S}^{2-}$ $=5.2$.

Desde un punto de vista general se observa que la velocidad de crecimiento es mayor cuanto más alcalino es el $\mathrm{pH}$, lo que puede estar relacionado con el hecho de que la nanocorteza de $\mathrm{Cd}(\mathrm{OH})_{2}$ forme parte efectiva del tamaño de la nanopartícula a la hora de calcular el diámetro medio de la misma por el método de Henglein. Así, por ejemplo, para $\mathrm{pH}=12.0$ el diámetro medio de las NPs crece desde $2.58 \mathrm{~nm}$ hasta $3.70 \mathrm{~nm}$ a los 36 días.

A medida que la nanopartícula evoluciona con el tiempo, llega un momento, diferente para cada $\mathrm{pH}$, que el tamaño es el adecuado para que se observen clara y diferenciadamente ambos procesos energéticos; esto ocurre a partir del quinto día para $\mathrm{pH}=12.0$ y a partir del día 46 para $\mathrm{pH}=5.2$. Este hecho parece confirmar la teoría de la formación de una nanocorteza sobre la nanopartícula cuya relación de diámetros conduce a una nanopartícula ideal en la que los procesos de absorción y emisión de radiación sean óptimos. Esta relación óptima se alcanza antes con el tiempo cuanto más alcalino es el pH.

El color de las disoluciones acuosas a la luz ambiental está relacionado con el tamaño medio de las partículas siendo incoloras hasta los $2.3 \mathrm{~nm}$, aproximadamente, y amarillas por encima de este valor, y más intenso el color cuanto mayor es el tamaño. Este 
hecho visual coincide con el desplazamiento del máximo de absorción hacia longitudes de onda mayores cuanto más se incrementa el tamaño.

Los factores de evolución del tamaño de las NPs, formación de la nanocorteza de $\mathrm{Cd}(\mathrm{OH})_{2}$ sobre la superficie y concentración de dispersante (mercaptoacetato) a los diferentes valores de $\mathrm{pH}$ estudiados, hacen que la intensidad de emisión de fluorescencia en su valor máximo, frente al tiempo, presente una evolución como la representada en la Figura 35.

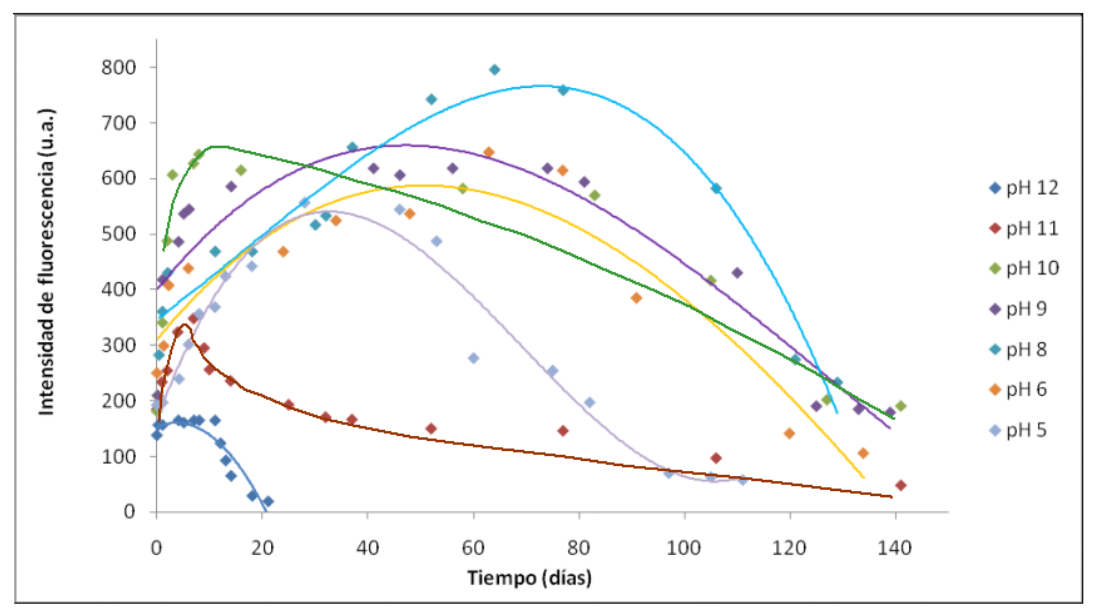

Figura 35. Evolución de los valores de intensidad de fluorescencia en el máximo de emisión en función del tiempo y para diferentes pHs.

Recordemos, tal y como se ha demostrado, que las NPs a los 15 minutos de terminado el proceso de agitación, tienen el mismo diámetro medio, $2.6 \mathrm{~nm}$, independientemente del pH inicial de la disolución. Con el tiempo crecen de manera diferente a la vez que se enfrentan a una reacción competitiva que ocurre en su superficie como consecuencia de la formación de la nanocorteza de $\mathrm{Cd}(\mathrm{OH})_{2}$ que termodinámica y cinéticamente ocurriría de manera más favorable cuanto más alcalino es el pH (Fig. 35). (Se recuerda que la disolución acuosa inicial de ion $\mathrm{Cd}(\mathrm{II})$ contiene una concentración de $0.7 \times 10^{-3} \mathrm{M}$ menor que la considerada para la construcción del diagrama de la Figura 26, por lo que el $\mathrm{pH}$ de precipitación se encuentra a valores ligeramente más alcalinos, prácticamente a $\mathrm{pH}=9 ; \mathrm{K}_{\mathrm{s}}=10^{-14.4}$ ).

En las experiencias a $\mathrm{pH}=11$ y 12 , el crecimiento de las NPs y el depósito de $\mathrm{Cd}(\mathrm{OH})_{2}$ es más favorable. La nanocorteza crece más que el núcleo de la nanopartícula, por lo que la intensidad de fluorescencia es poco favorable (por tamaño) y disminuye rápidamente en el tiempo (por crecimiento rápido de la nanocorteza) por ser cada vez mayor la radiación no dispersiva (pérdida de eficacia cuántica). 
Existe un momento en el tiempo en el que, para cada $\mathrm{pH}$, se alcanza la relación óptima de tamaños entre nanopartícula y nanocorteza, momento en que el conjunto alcanza el máximo rendimiento cuántico, apareciendo un máximo en el valor de la intensidad de fluorescencia que coincide en el tiempo con el momento en el cual el espectro de absorción presenta un pico perfectamente definido, correspondiente al proceso electrónico $1 S_{\mathrm{h}}-1 S_{\mathrm{e}}$.

El máximo de intensidad de fluorescencia con el tiempo se retarda cada vez más cuanto menos alcalino es el pH inicial (compárese en la Fig. 35 la evolución a pH=12, 11, 10, 9 y 8$)$.

Cuanto menos alcalino es el medio en el que se forman las NPs, más lento es su crecimiento con el tiempo y también menor es su tamaño, lo que junto con el hecho de que el depósito de $\mathrm{Cd}(\mathrm{OH})_{2}$ sea menos favorable termodinámica y cinéticamente, hace que la relación óptima de tamaños permanezca constante más tiempo (Fig. 35, valores de $\mathrm{pH}=9 \mathrm{y}$ 10).

Para valores de $\mathrm{pH}$ inferiores a 9, la velocidad de crecimiento de las NPs es menor que la velocidad de formación de la nanocorteza, alcanzándose una relación óptima para un tiempo determinado que genera de nuevo un máximo en el valor de intensidad de fluorescencia; pero como la cantidad de $\mathrm{Cd}(\mathrm{OH})_{2}$ depositada disminuye con el pH (cuanto menos alcalino es), la intensidad de fluorescencia máxima es menor a $\mathrm{pH}=5.2$ que a $\mathrm{pH}=6$.

Observando la Figura 35 se deduce que las condiciones óptimas para formar NPs con alta eficacia cuántica (alto valor de intensidad de fluorescencia) y estables durante más tiempo, corresponden a fijar el pH inicial en 9 ó 10.

No obstante, y de cara a estudios futuros, NPs obtenidas a $\mathrm{pH}$ inicial $=8$ pueden ser aisladas de la disolución (por ultracentrifugación) entre los días 56 y 78, presentando la fluorescencia más alta.

Para terminar el estudio de esta variable queremos recordar que la bajada con el tiempo del valor de intensidad de fluorescencia no quiere decir que las nanopartículas vayan creciendo y alcancen un tamaño coloidal, llegando a depositarse en el fondo del recipiente (eso ocurre a $\mathrm{pH}=2.9$ ); es simplemente que disminuye la eficacia cuántica. La estabilidad de las disoluciones con las NPs dispersadas supera los 6 meses. 


\section{INFLUENCIA DE LA TEMPERATURA}

Es bien conocida la relación entre temperatura, sobresaturación y solubilidad. Por este motivo se estudia la influencia que tiene esta variable sobre las características de las NPs de CdS.

Para ello se preparan siete disoluciones siguiendo en todas el mismo método de obtención. En erlenmeyer topacio se mezclan $100 \mathrm{~mL}$ conteniendo 0.15 milimoles de $\mathrm{Cd}^{2+}$ con $105 \mu \mathrm{L}$ de MAA $1.41 \mathrm{M}$ y se ajusta el pH a 11 con $\mathrm{NaOH}$, quedando una disolución transparente e incolora. En ese momento se deja que la disolución alcance la temperatura deseada, colocando el erlenmeyer en el interior de un cristalizador con hielo para la temperatura de $4^{\circ} \mathrm{C}$ o calentando en el agitador térmico a las otras temperaturas. Cuando se alcanza la temperatura deseada (controlándola en todo momento con termómetro) y bajo burbujeo de nitrógeno, se añaden lentamente y en agitación los $50 \mathrm{~mL}$ de disolución conteniendo 0.075 milimoles de $\mathrm{Na}_{2} \mathrm{~S}$ (la adición duró cinco minutos).

En estas condiciones las concentraciones de reactivos en la disolución final son: $\left[\mathrm{Cd}^{2+}\right]_{\mathrm{f}}=1.0 \times 10^{-3} \mathrm{M} ;\left[\mathrm{S}^{2-}\right]_{\mathrm{f}}=0.5 \times 10^{-3} \mathrm{M} ;[\mathrm{MAA}]_{\mathrm{f}}=0.99 \times 10^{-3} \mathrm{M}$; por lo que en este caso las relaciones molares son: $\left[\mathrm{Cd}^{2+}\right]_{\mathrm{f}} /\left[\mathrm{S}^{2-}\right]_{\mathrm{f}}=2 ;\left[\mathrm{Cd}^{2+}\right]_{\mathrm{f}} /[\mathrm{MAA}]_{\mathrm{f}}=1$.

Concluido el tiempo de agitación de 15 horas se registran los espectros de absorción y luminiscencia, para comparar los resultados obtenidos. Entre medida y medida las disoluciones se conservan en la nevera a $4^{\circ} \mathrm{C}$. En estas condiciones se obtiene información sobre las características de las NPs obtenidas al mantener las disoluciones empleadas en el procedimiento de obtención a diferentes temperaturas; la evolución posterior transcurre en todos los casos a $4^{\circ} \mathrm{C}$, en nevera y sin agitación.

En la Figura 36 se representan los espectros de absorción de las nanopartículas obtenidas a diferentes temperaturas y terminado el tiempo de agitación de 15 horas (el $\mathrm{t}=$ 0 en este caso se considera desde este momento). Todas las medidas se realizan dejando alcanzar a las disoluciones la temperatura ambiente. 

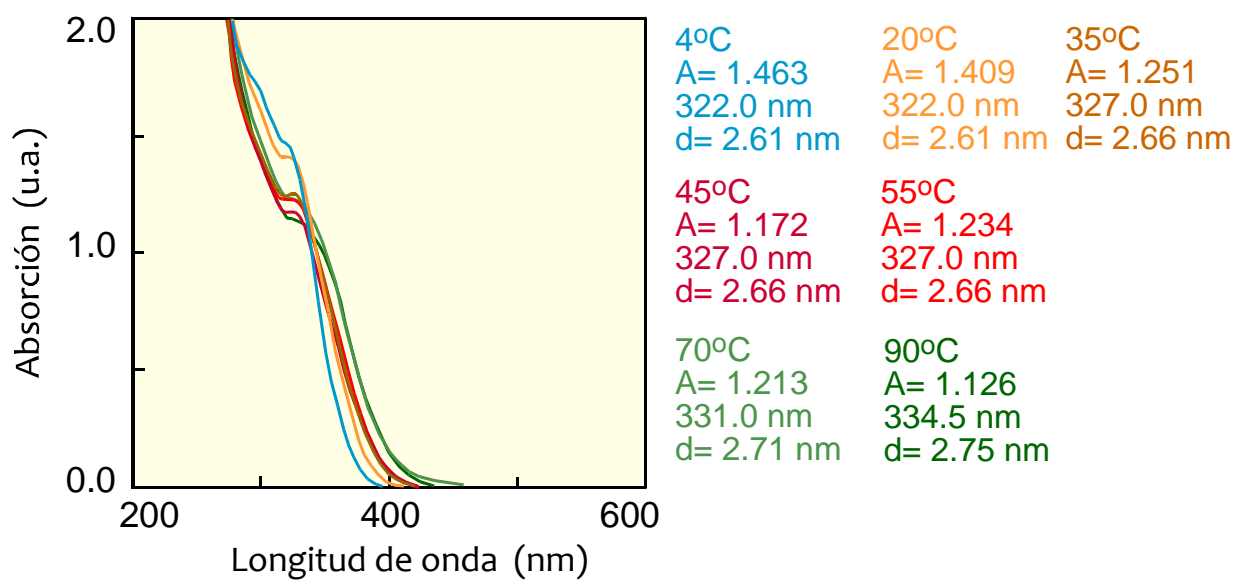

Figura 36. Espectros de absorción en el momento de terminar el proceso de obtención $(t=0)$ a diferentes temperaturas. Las medidas se realizan a temperatura ambiente.

Puede comprobarse cómo cuanto menor es la temperatura de la disolución, a menor longitud de onda aparece el pico de absorción correspondiente al proceso de transferencia electrónica $1 \mathrm{Sh}-1 \mathrm{Se}$, la misma relación que mantiene el diámetro medio de la nanopartícula, $d$, que varía desde $2.61 \mathrm{~nm}$ a $4^{\circ} \mathrm{C}$ hasta $2.75 \mathrm{~nm}$ a $90^{\circ} \mathrm{C}$. A medida que se incrementa el tamaño medio de partícula, el color de la disolución pasa de incoloro a amarillo, intensificándose esta tonalidad a medida que se incrementa la temperatura.

El valor de la absorbancia en el máximo de absorción disminuye al aumentar la temperatura, por hacerlo la solubilidad de las nanopartículas de CdS.

Recordemos que la evolución sucede, en todos los casos, manteniendo las disoluciones a $4^{\circ} \mathrm{C}$, y lógicamente depende de las características de la partícula inicial.

Para cada temperatura estudiada la longitud de onda del máximo de absorción se desplaza hacia valores más altos a la vez que lo hace el diámetro de la partícula. El desplazamiento es mayor cuanto más alta es la temperatura, siendo muy apreciable a los $90^{\circ} \mathrm{C}$. Los valores de absorbancia para una misma temperatura permanecen prácticamente constantes a lo largo del periodo de evolución.

En cuanto a las características luminiscentes se refiere, en la Figura 37 se muestran los espectros de emisión de las disoluciones obtenidas a diferentes temperaturas una vez terminadas las 15 horas de agitación, lo que corresponde al instante que hemos denominado $\mathrm{t}=0$. 

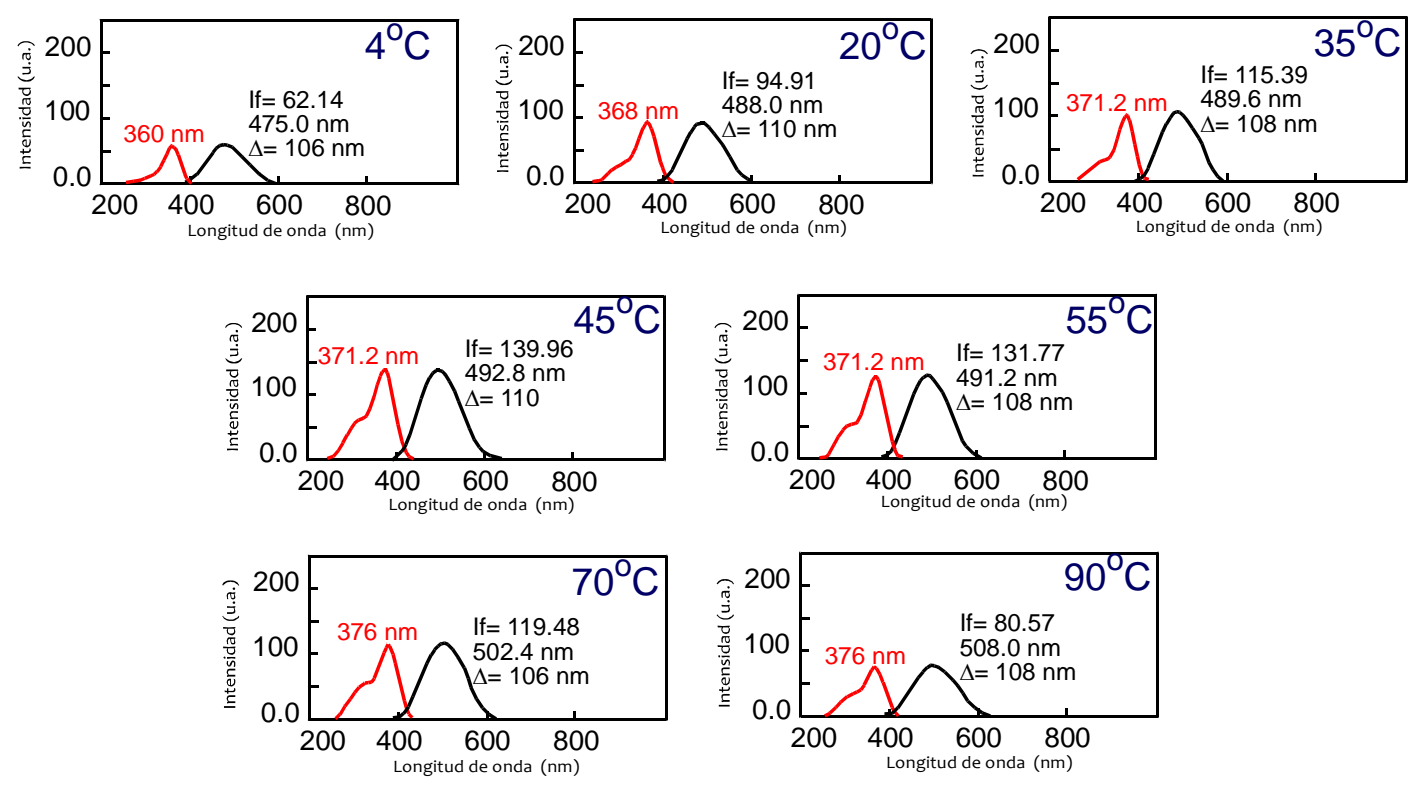

Figura 37. Espectros de excitación (rojo) y emisión (negro) de las nanopartículas obtenidas a diferentes temperaturas (desde $4^{\circ} \mathrm{C}$ a $90^{\circ} \mathrm{C}$ ), a las $15 \mathrm{~h}$ de su obtención ( $\mathrm{t}=0$ ). $R$ ex $=\operatorname{Rem}=3 \mathrm{~nm}$.

Las disoluciones son incoloras excepto a 70 y $90^{\circ} \mathrm{C}$ que presentan un color amarillo. La fluorescencia de las disoluciones es verde para 4,20 y $35^{\circ} \mathrm{C}$; amarillo-verdosa para 45 y $55^{\circ} \mathrm{C}$; amarilla para $70^{\circ} \mathrm{C}$ y amarilla-anaranjada para $90^{\circ} \mathrm{C}$.

La intensidad de fluorescencia en el máximo de emisión aumenta inicialmente con la temperatura hasta los $45^{\circ} \mathrm{C}$, disminuyendo posteriormente al hacerlo esta variable; todo ello para el mismo tiempo de evolución. Esto indica que la forma y el estado de la superficie está muy influenciada por la temperatura de la disolución, influyendo ésta no sólo sobre aspectos cinéticos de la nucleación y el crecimiento, sino también sobre la formación de la nanocorteza de $\mathrm{Cd}(\mathrm{OH})_{2}$. Una vez más se vuelve a confirmar que debe de existir un tamaño óptimo de esta nanocorteza relacionado con los procesos de emisión radiante y no radiante.

En cuanto a la evolución de las características luminiscentes para cada temperatura, comentaremos los resultados obtenidos para las temperaturas extremas de $4^{\circ} \mathrm{C}$ y $90^{\circ} \mathrm{C}$ (Fig. 38 y 39$)$. 


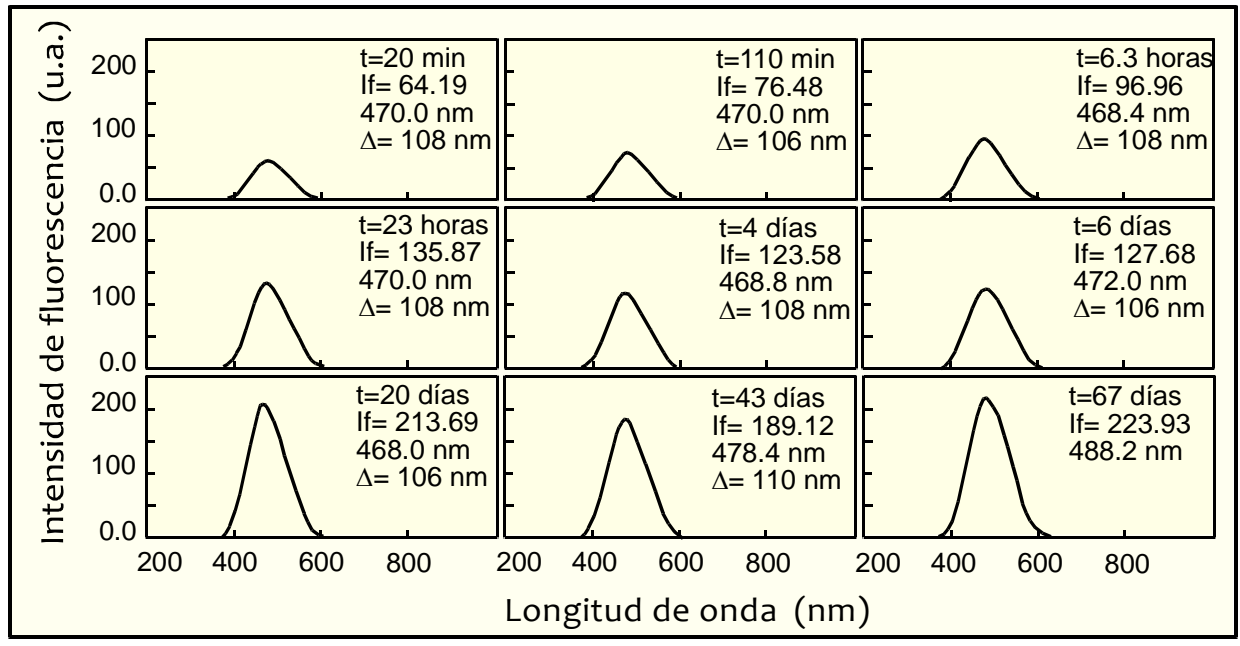

Figura 38. Evolución de los espectros de emisión con el tiempo. Temperatura: $4^{\circ} \mathrm{C}$. Tiempo de agitación: 15 horas. Disolución incolora. Fluorescencia verde (Fotografía 3). Rex= Rem= $3 \mathrm{~nm}$. $\lambda$ ex $=360.0 \mathrm{~nm}$.

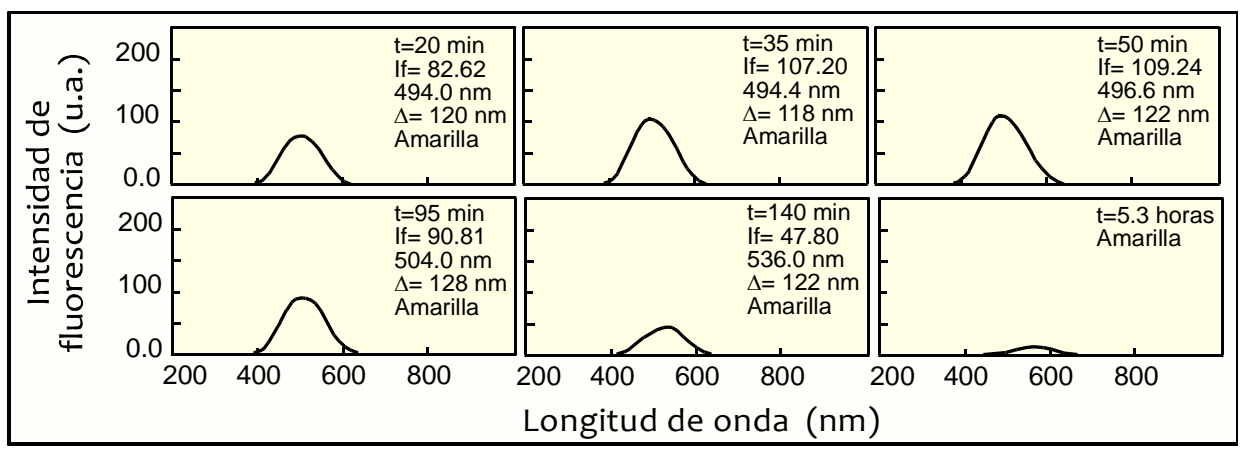

Figura 39. Evolución de los espectros de emisión con el tiempo. Temperatura: $90^{\circ} \mathrm{C}$. Tiempo de agitación: 15 horas. $\operatorname{Rex}=\operatorname{Rem}=3 \mathrm{~nm}$. $\lambda$ ex $=376.0 \mathrm{~nm}$. Fluorescencia amarilla similar a la de la Fotografía 4.

Como puede observarse en la Figura 38 en la experiencia de $4^{\circ} \mathrm{C}$, desde que pasan las 15 horas de agitación, la longitud de onda óptima de excitación y emisión permanece constante incluso hasta los 67 días; la intensidad de fluorescencia se incrementa paulatinamente y de manera lenta con el tiempo. El tamaño de partícula sólo varía desde $2.61 \mathrm{~nm}$ hasta $2.85 \mathrm{~nm}$, así que el incremento de fluorescencia se atribuye a la modificación de la superficie en un proceso que a $4^{\circ} \mathrm{C}$ es de cinética lenta.

Cuando la temperatura de la disolución en el método de obtención es de $90^{\circ} \mathrm{C}$, Figura 39, sólo en los tiempos iniciales la longitud de onda óptima de emisión se mantiene prácticamente constante, al igual que ocurre con el diámetro medio; posteriormente se incrementa a longitudes de onda hacia el rojo. La intensidad de fluorescencia aumenta ligeramente hasta la siguiente hora decayendo posteriormente de manera muy rápida, de modo que a las 5.3 horas prácticamente las NPs no presentan fluorescencia. 
A temperaturas elevadas en el método de obtención de las NPs, éstas evolucionan muy rápidamente en tamaño y en características superficiales, de forma que su estabilidad es pequeña. No puede descartarse que a $90^{\circ} \mathrm{C}$ parte del MAA (en forma de mercaptoacetato) se vaporice dejando la superficie de las nanopartículas con menos cantidad de dispersante.

Para las temperaturas intermedias, el comportamiento de las nanopartículas es intermedio a estas dos experiencias comentadas, incrementándose la intensidad de fluorescencia tanto más rápidamente cuanto mayor fue la temperatura, y disminuyendo antes en el tiempo en el mismo sentido.

En la Figura 40 se ha representado la evolución de la intensidad de fluorescencia con el tiempo para que se comprendan mejor las explicaciones dadas.

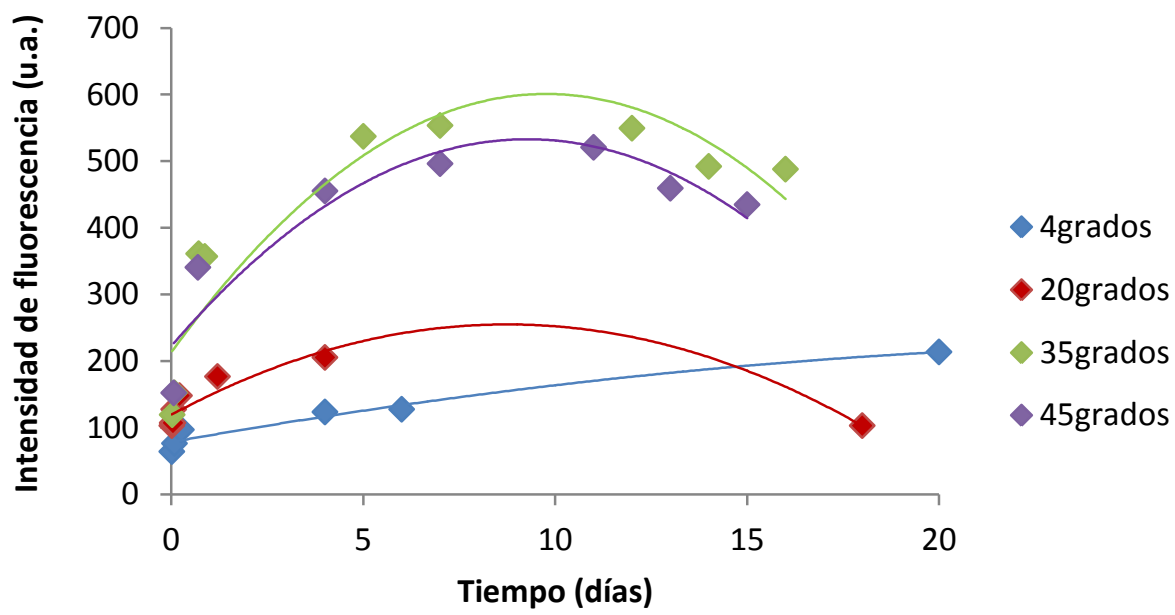

Figura 40. Evolución con el tiempo de la intensidad de emisión de fluorescencia para nanopartículas de CdS obtenidas a diferentes temperaturas (en grados centígrados). Tiempo de agitación: 15 horas.

Los mejores resultados en cuanto a intensidad máxima de fluorescencia y mayor estabilidad de dicho parámetro se consigue a $35^{\circ} \mathrm{C}$. Por otra parte, controlando la temperatura en el método de obtención y su tiempo de evolución se pueden obtener nanopartículas de diferente tamaño y con diferentes propiedades luminiscentes.

\section{INFLUENCIA DE LAS RELACIONES MOLARES $\mathrm{Cd}^{2+} / \mathrm{S}^{2-}, \mathrm{Cd}^{2+} / \mathrm{MAA}$}

Al ser estas las tres especies principales implicadas en la formación de nanopartículas de CdS y en su estabilidad o dispersión, y en vista de los resultados obtenidos en los estudios previos, es necesario conocer la influencia que tienen sus 
relaciones molares sobre las características de las NPs. Esta influencia ha sido estudiada con dos tipos de experiencias.

Influencia de la concentración de ácido mercaptoacético. $\mathrm{Cd}^{2+} / \mathrm{S}^{2-}$ constante. $\underline{\mathrm{Cd}^{2+} / \mathrm{MAA} \text { variable. }}$

Se preparan seis disoluciones conteniendo todas ellas 0.112 mmoles de $\mathrm{Cd}^{2+}$ en 100 $\mathrm{mL}$ de disolución acuosa. Se añaden a continuación entre 20 y $240 \mu \mathrm{L}$ de MAA $1.41 \mathrm{M}$ con lo que el pH de la disolución se acidifica. A continuación, en todos los casos se ajusta el pH a 11 con $\mathrm{NaOH}$ y en presencia de burbujeo de nitrógeno se añaden en todos los casos $50 \mathrm{~mL}$ de disolución acuosa de $\mathrm{Na}_{2} \mathrm{~S}$ (0.075 mmoles). La adición se realiza por el procedimiento lento y con agitación, que se mantiene durante 15 horas. Se utilizaron erlenmeyer topacio y la temperatura fue la del laboratorio $\left(22-25^{\circ} \mathrm{C}\right)$.

En todas las disoluciones la concentración final de $\mathrm{Cd}^{2+}$ y $^{2-}$ es constante, $0.747 \times 10^{-3} \mathrm{M}$ y $0.5 \times 10^{-3} \mathrm{M}$, respectivamente. Los volúmenes de MAA añadido fueron 20,40 , $80,120,160$ y $240 \mu \mathrm{L}$; por lo que las concentraciones finales de MAA varían entre $0.19 \times 10^{-3}$ $\mathrm{M}$ y $1.50 \times 10^{-3} \mathrm{M}$.

En las condiciones de trabajo las relaciones molares son: $\left[\mathrm{Cd}^{2+}\right]_{f} /\left[\mathrm{S}^{2-}\right]_{\mathrm{f}}=1.49 \mathrm{y}$ $\left[\mathrm{Cd}^{2+}\right]_{\mathrm{f}} /[\mathrm{MAA}]_{\mathrm{f}}$ entre 3.97 y 0.33 .

A las 15 horas de terminado el proceso de obtención se realizan las medidas de absorción y luminiscencia; las disoluciones se conservan en frascos topacio a la temperatura del laboratorio $\left(22-25^{\circ} \mathrm{C}\right)$.

La disolución a la que se añadieron $20 \mu \mathrm{L}$ de MAA $1.41 \mathrm{M}$, la menor cantidad, nada más ajustar el pH a 11 mostraba turbidez, y su espectro de emisión registrado a las 15 horas, el cual hemos denominado $\mathrm{t}=0$ (por ser el instante en que se corta la agitación), no genera ninguna señal con $\lambda_{\mathrm{ex}}=392 \mathrm{~nm}$. Las partículas de CdS responsables de la turbidez no tienen características de nanopartícula por su tamaño. Una relación $\left[\mathrm{Cd}^{2+}\right]_{f} /[\mathrm{MAA}]_{\mathrm{f}}=0.33$ no es suficiente para la obtención de NPs.

Al aumentar la cantidad de dispersante en disolución, la turbidez desaparece y aparecen NPs de CdS que muestran espectros de absorción y luminiscencia. En todos los casos las disoluciones acuosas a las 15 horas, al suprimir la agitación, son incoloras, salvo la de $240 \mu \mathrm{L}$ que es ligeramente amarilla (la concentración de $\mathrm{Cd}^{2+}$ en esta experiencia es inferior a las de otras). 
Los espectros de absorción a diferentes tiempos de evolución aparecen en la Figura 41, para las distintas concentraciones de MAA, donde también se indica el color de las diferentes disoluciones obtenidas.
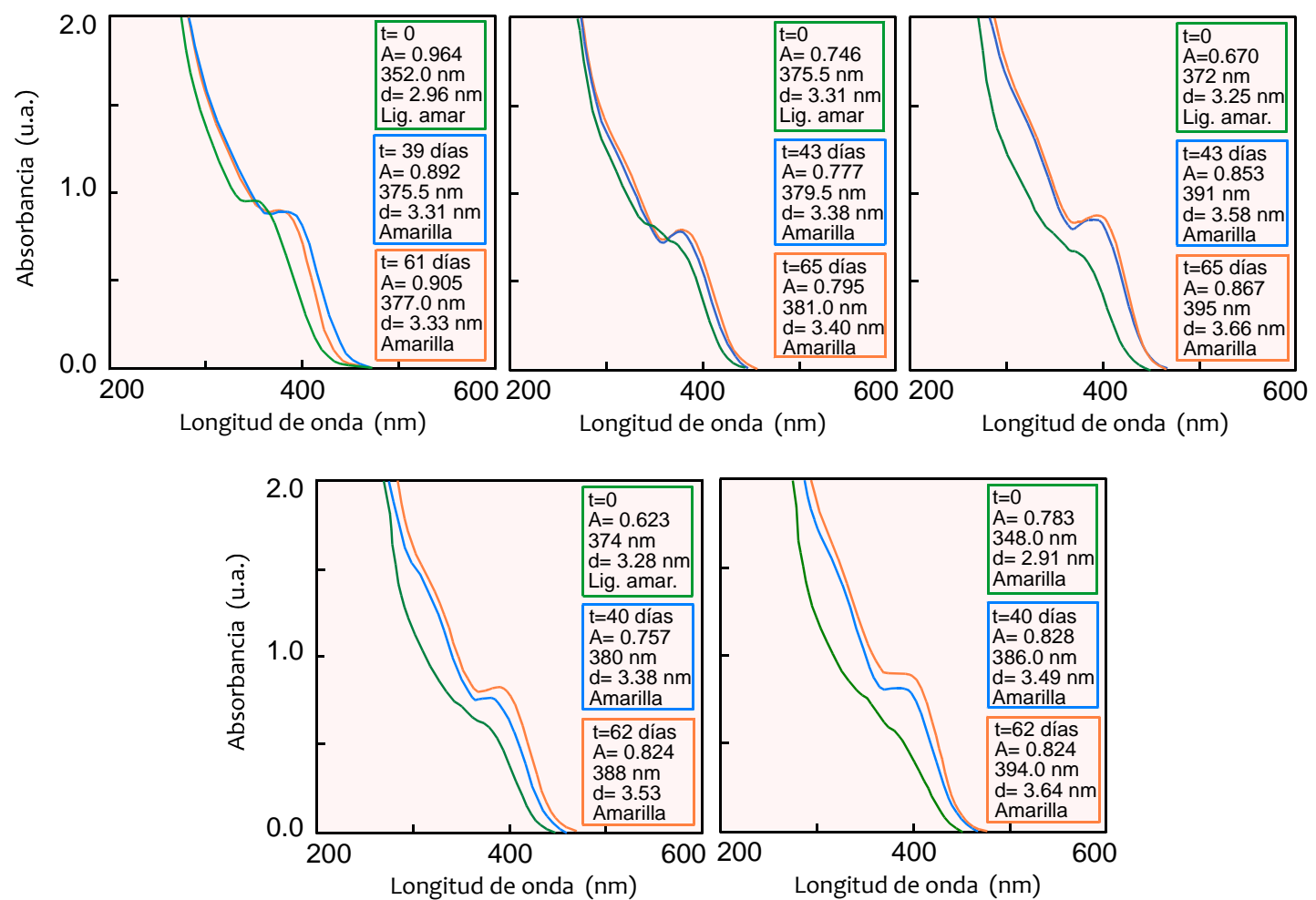

Figura 41. Espectros de absorción a diferentes tiempos de las NPs obtenidas en presencia de diferentes concentraciones de MAA (40-240 $\mu \mathrm{L})$. Tiempo de agitación: $15 \mathrm{~h}$.

Cabría esperar que cuanto mayor fuera la concentración de MAA, menor sería el tamaño de partícula o menor su evolución, sobre todo si el mercaptoacetato se enlaza al $\mathrm{Cd}^{2+}$ en los núcleos de CdS e frena su crecimiento.

Por el contrario se observa que para $\mathrm{t}=0$ (tras 15 horas de agitación) el diámetro medio de las partículas es independiente de la cantidad inicial de MAA, salvo cuando la cantidad de dispersante es elevada $(240 \mu \mathrm{L})$. Este resultado experimental, contrario al esperado, parece indicar que si bien el MAA impide que el CdS alcance tamaños coloidales inhibiendo procesos de crecimiento de núcleos (nanonúcleos) a tiempos elevados, favorece la formación de agregados entre nanocristales incrementando el tamaño medio de las NPs.

Desde el punto de vista de la constancia en el tamaño medio, los mejores resultados se obtienen para cantidades de MAA de 40 a $120 \mu \mathrm{L}$ (ambos inclusive) 
(relaciones $\mathrm{Cd}^{2+} / \mathrm{MAA}$ entre 1.39 y 0.66). Cantidades superiores generan incrementos de tamaño mayores a lo largo del proceso de evolución.

Por otra parte, los valores de absorbancia para longitudes de onda similares, no son significativamente diferentes; este hecho indica que la cantidad de NPs por unidad de volumen es independiente de la cantidad de dispersante MAA.

La intensidad de fluorescencia de emisión a su $\lambda_{\mathrm{em}}$ óptima, para cada disolución en particular, pero en todos los casos, se incrementa con el tiempo de evolución hasta alcanzar un valor constante (Fig. 42) que se mantiene durante unos días (más días cuanto mayor es la relación $\left[\mathrm{Cd}^{2+}\right] /[\mathrm{MAA}]$, por ser menor la concentración de MAA), para posteriormente comenzar a descender más rápidamente cuanto mayor es la concentración de MAA.

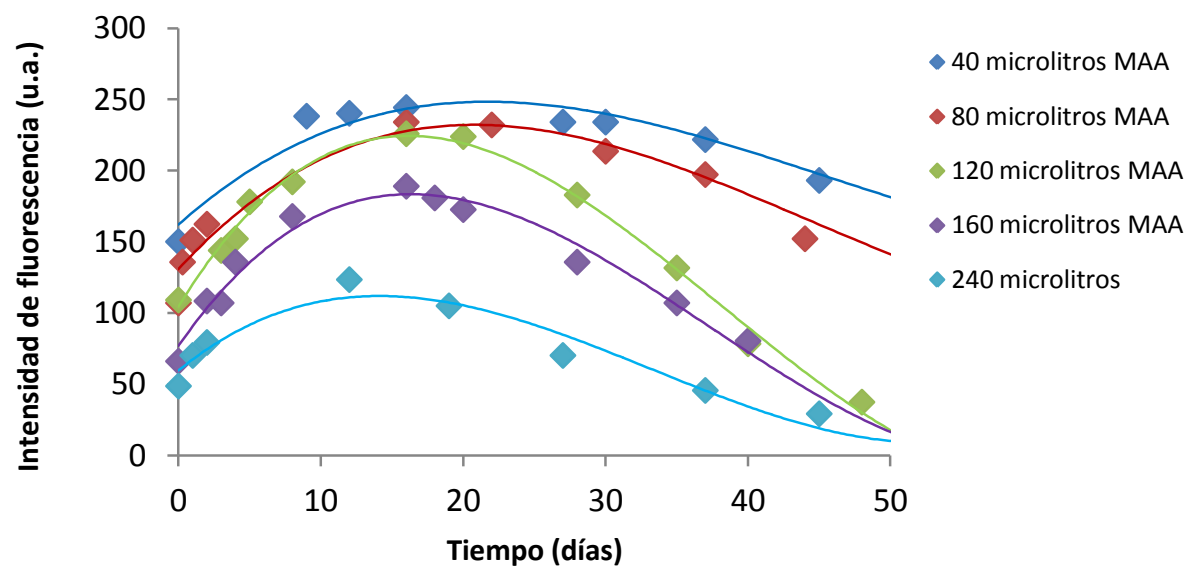

Figura 42. Evolución de la intensidad de fluorescencia con el tiempo para diferentes relaciones $\left[\mathrm{Cd}^{2+}\right] /[\mathrm{MAA}]$. Rex $=$ Rem $=3 \mathrm{~nm}$.

Este hecho, junto con la evolución con el tiempo del diámetro medio de las NPs, muestra que a la vez que crecen las nanopartículas de $\mathrm{CdS}$, perdiendo eficacia cuántica, también su forma y superficie se modifican contribuyendo a este descenso.

Como puede comprobarse en la Figura 42, el valor de intensidad de fluorescencia es mayor cuanto menor es la concentración de dispersante, pero siempre superior a $20 \mu \mathrm{L}$ de MAA, por lo que parece indicar que el dispersante, al enlazarse sobre la superficie de las NPs inhibe su fluorescencia (efecto quenching) por ocupar sitios activos de la misma.

En ninguna de las disoluciones, sea cual sea la concentración de MAA, en el tiempo de estudio (80 días) aparece precipitado, lo que indica que el dispersante actúa con eficacia estabilizando el nanotamaño de las partículas de CdS. El hecho de que la fluorescencia disminuya a medida que aumenta el tamaño, puede también estar relacionado con el 
incremento de MAA en exceso y libre en disolución. En la disolución en la que hay mucho más $\mathrm{Cd}^{2+}$ que MAA, no sólo la nanopartícula, también la disolución, es diferente a las disoluciones en las que la situación es contraria. El entorno en el que se forma la NP es importante en los procesos de nucleación y crecimiento y en el estado y la forma de la superficie.

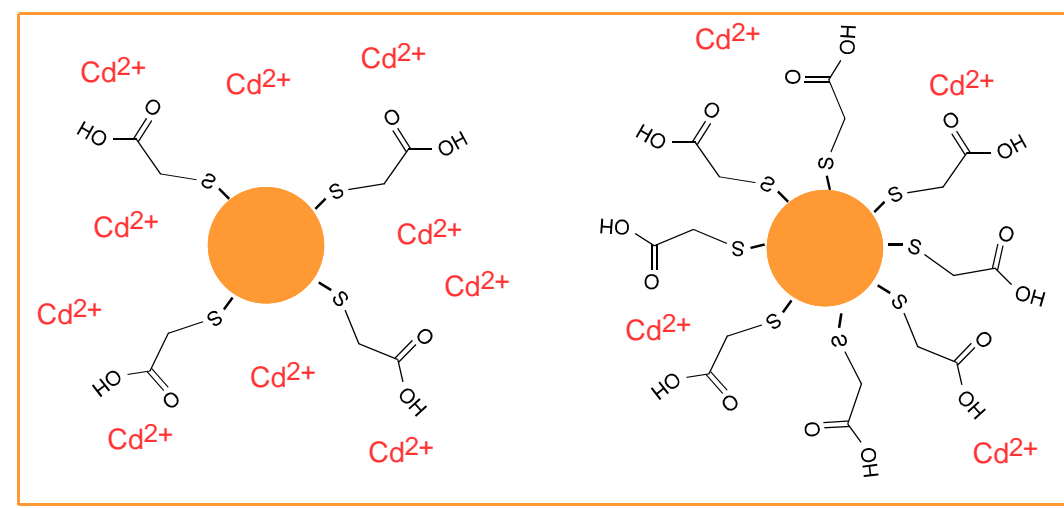

Nanopartícula en una relación $\left[C d^{2+}\right] /[M A A]$ alta

Nanopartícula en una relación

$\left[C d^{2+}\right] /[M A A]$ baja

El hecho de que las nanopartículas tengan mayor tamaño en medios en los que la relación $\left[\mathrm{Cd}^{2+}\right] /[\mathrm{MAA}]$ es baja (exceso de $\mathrm{MAA}$ ), cuando cabría esperar lo contrario, indica que el proceso de nucleación no es un simple acercamiento de iones $\mathrm{Cd}^{2+}$ y $\mathrm{S}^{2-}$, puede que intervengan también iones Cd-MAA, con lo que la cinética de formación depende de la concentración de dispersante.

De los valores de anchura en la mitad del pico de máxima emisión, $\Delta$, parece deducirse que la distribución de tamaños alrededor del diámetro medio se incrementa a medida que aumenta la concentración de dispersante, siendo del orden de $124 \mathrm{~nm}$ para 240 $\mu L$ de $M A A\left(\left[\mathrm{Cd}^{2+}\right] /[M A A]=0.33\right)$ frente a $104 \mathrm{~nm}$ para $40 \mu \mathrm{L}\left(\left[\mathrm{Cd}{ }^{2+}\right] /[\mathrm{MAA}]=1.99\right)$. El exceso de MAA en el medio provoca esta heterogeneidad.

Desde un punto de vista práctico, los mejores resultados en cuanto a valores de fluorescencia se refiere y tiempo en el que las NPs mantienen dicha fluorescencia, se deduce que en el proceso de obtención de nanopartículas la relación óptima $\left[\mathrm{Cd}^{2+}\right] /[\mathrm{MAA}]$ está comprendida entre 1 y 2. 
Influencia de la relación de concentraciones de los formadores de nanopartículas. $\mathrm{Cd}^{2+} /$ MAA constante. $\mathrm{Cd}^{2+} / \mathrm{S}^{2-}$ variable.

Se preparan seis disoluciones de $100 \mathrm{~mL}$ conteniendo entre 0.05 y 0.30 milimoles de $\mathrm{Cd}^{2+}$ en erlenmeyer topacio. Sobre todas ellas se agregan entre 35 y $215 \mu \mathrm{L}$ de MAA 1.41 $\mathrm{M}$, con lo que el pH de las disoluciones es próximo a 3. Se ajusta el pH a 11 con $\mathrm{NaOH}$ y con burbujeo de nitrógeno y por el procedimiento lento se añaden $50 \mathrm{~mL}$ de disolución de $\mathrm{Na}_{2} \mathrm{~S}$ (0.075 mmoles). Todas las operaciones anteriores se realizan con agitación y ésta se mantiene 15 horas, tras las cuales se considera el tiempo como punto de partida para la medida de los espectros de absorción y luminiscencia $(\mathrm{t}=0)$. Se trabaja a temperatura ambiente.

En todas las disoluciones la relación $\left[\mathrm{Cd}^{2+}\right]_{f} /[\mathrm{MAA}]_{\mathrm{f}}$ es constante y prácticamente 1 , variando la relación $\left[\mathrm{Cd}^{2+}\right]_{f} /\left[\mathrm{S}^{2-}\right]_{\mathrm{f}}$ entre 0.66 y 4.

La concentración de $\mathrm{Cd}^{2+}$ varía entre $0.33 \times 10^{-3}$ y $2 \times 10^{-3} \mathrm{M}$, manteniéndose constante la de $\mathrm{S}^{2-}$ en $0.5 \times 10^{-3} \mathrm{M}$. La de MAA varía entre $0.33 \times 10^{-5} \mathrm{M}$ y $2 \times 10^{-5} \mathrm{M}$. Como puede observarse, la concentración de $\mathrm{Cd}^{2+}$ en estas experiencias es inferior a la utilizada en las experiencias anteriores y la relación $\left[\mathrm{Cd}^{2+}\right] /[\mathrm{MAA}]$ se mantiene en un valor considerado óptimo, 1. La temperatura del método de obtención y conservación es la del laboratorio, con pequeñas fluctuaciones durante el estudio comparativo.
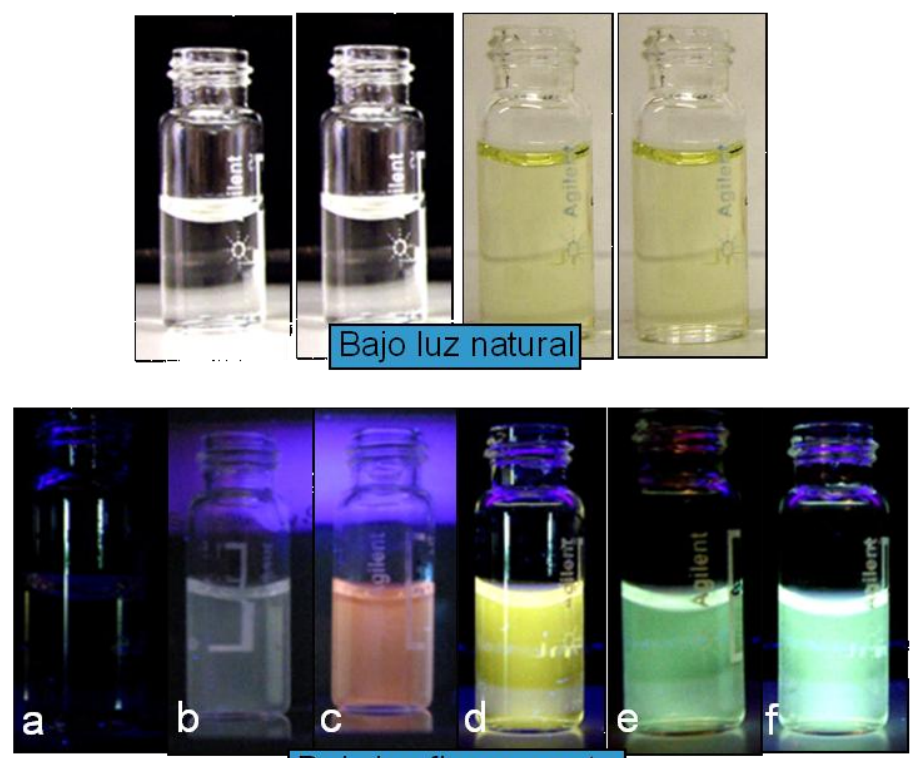

Bajo luz fluorescente

Figura 43. Influencia de la relación molar $\left[\mathrm{Cd}^{2+}\right] /\left[\mathrm{S}^{2-}\right]$. Aspectos cualitativos de las experiencias a $\left.\mathrm{t}=0 .\left[\mathrm{Cd}^{2+}\right] /\left[\mathrm{S}^{2-}\right]=\mathrm{a}\right)$ 0.67 ; b) 1.07 ; c) 1.33 ; d) 2.0 ; e) 2.7 ; f) 4.0 . 
Las dos primeras disoluciones, en las que la relación $\left[\mathrm{Cd}^{2+}\right] /\left[\mathrm{S}^{2-}\right]$ tiene un valor de 0.67 y 1.07 respectivamente, tienen un comportamiento diferente al resto: ambas disoluciones desde un principio son fuertemente amarillas (Fig. 43) y transparentes. Ambas, terminadas las 15 horas de agitación, presentan espectros de absorción con picos o zonas de inflexión correspondientes a los procesos de transición electrónica $1 \mathrm{Sh}-1 \mathrm{Se}$ y $1 \mathrm{Ph}-1 \mathrm{Pe}$ a $335 \mathrm{~nm}$ y $364 \mathrm{~nm}$ en la disolución donde hay más exceso de $\mathrm{S}^{2-}$ frente a $\mathrm{Cd}^{2+}$, y a $380 \mathrm{~nm}$ y $430 \mathrm{~nm}$ en la que se igualan. En ambos casos el tamaño de la nanopartícula es grande, 3.9 y $4.0 \mathrm{~nm}$, y éstas no son fluorescentes o lo son muy poco perdiendo al día siguiente esta característica.

Las nanopartículas obtenidas en estas condiciones experimentales en las que en la disolución no hay exceso de $\mathrm{Cd}^{2+}$, no son fluorescentes, lo que confirma la hipótesis de la relación entre fluorescencia y la corteza de $\mathrm{Cd}(\mathrm{OH})_{2}$, de un tamaño determinado, depositada sobre su superficie.

Para el resto de disoluciones en las que cada vez hay más $\mathrm{Cd}^{2+}$ que $\mathrm{S}^{2-}$, variando las relaciones molares desde 1.33 hasta 4 , el aspecto de las mismas también va variando, siendo cada vez menos amarillas, de modo que las dos últimas son prácticamente incoloras, con ligera tonalidad amarillo-verdosa. El color de las disoluciones (Fig. 43) está relacionado con el diámetro medio de las NPs, que va disminuyendo a medida que aumenta la relación $\left[\mathrm{Cd}^{2+}\right] /\left[\mathrm{S}^{2-}\right]$ (Fig. 44). 

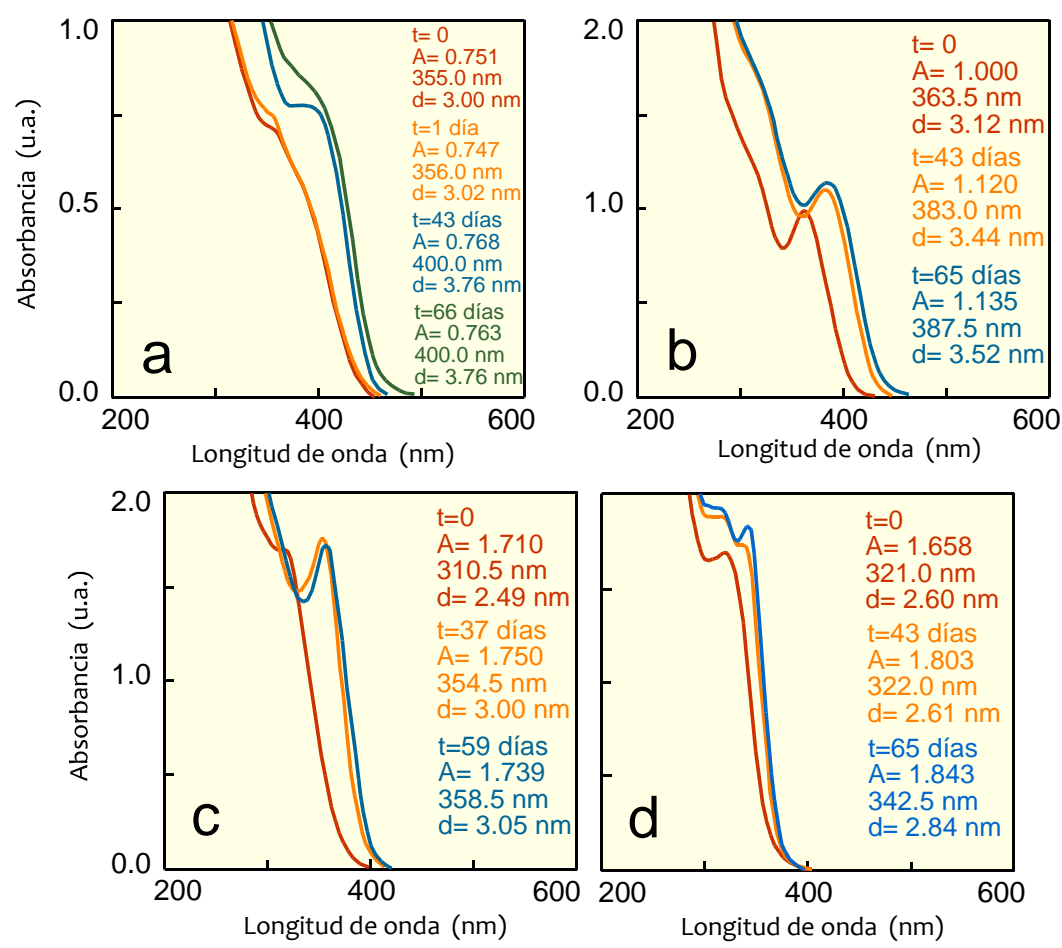

Figura 44. Evolución de los espectros de absorción con el tiempo. Disolución en la que $\left[\mathrm{Cd}^{2+}\right] /\left[\mathrm{S}^{2-}\right]=$ a)1.33; b) 2.0; c) 2.7; d) 4.0. Tiempo de agitación: 15 horas.

Dependiendo del diámetro medio la transición electrónica 1 Sh-1Se requiere de una determinada energía que es menor cuanto mayor es $d$, razón por la que el máximo de absorción se encuentra en este sentido a longitudes de onda mayores.

En todas las experiencias, las NPs crecen en tamaño con el tiempo, siendo mayor el incremento cuanto menor es la relación $\left[\mathrm{Cd}^{2+}\right] /\left[\mathrm{S}^{2-}\right]$, de modo que cuando esta relación tiene un valor de 4.0, el diámetro medio es prácticamente constante, $2.6 \mathrm{~nm}$. El exceso de $\mathrm{Cd}^{2+}$ sobre $\mathrm{S}^{2-}$ afecta a la velocidad de crecimiento siendo ésta menor cuanto mayor es este exceso. La cinética del proceso de nucleación es más rápida cuanto mayor es el exceso de $\mathrm{Cd}^{2+}$ sobre $\mathrm{S}^{2-}$.

La longitud de onda a la que ocurren la transición electrónica 1 Sh-1Se se desplaza hacia valores más pequeños (procesos más energéticos) a medida que aumenta la relación $\left[\mathrm{Cd}^{2+}\right] /\left[\mathrm{S}^{2-}\right]$, apareciendo a $400 \mathrm{~nm}$ para $\left[\mathrm{Cd}^{2+}\right] /\left[\mathrm{S}^{2-}\right]=1.33$ (43 días), a $383 \mathrm{~nm}$ cuando la relación vale 2.0 (43 días), a $354.5 \mathrm{~nm}$ cuando su valor es 2.7 (37 días) y $322 \mathrm{~nm}$ cuando vale 4.0 (43 días).

Si se comparan, en todas las experiencias los valores de absorbancia, para un mismo proceso electrónico, a longitudes de onda similares, aumentan a medida que lo hace 
la relación $\left[\mathrm{Cd}^{2+}\right] /\left[\mathrm{S}^{2-}\right]$, por lo que parece deducirse que cuanto mayor es el exceso de $\mathrm{Cd}^{2+}$ sobre $\mathrm{S}^{2-}$, no sólo se obtiene una nanopartícula más pequeña, cuyo tamaño prácticamente no evoluciona con el tiempo, sino también parece obtenerse un mayor número de NPs por unidad de volumen. Cabría esperar, por lo tanto, que la fluorescencia mostrada por estas NPs fuera la máxima, pero se va a comprobar que el resultado experimental es más complejo que esta previsión teórica.

En cuanto a la intensidad de fluorescencia se refiere, If, si bien comparativamente con otras experiencias crece inicialmente hasta alcanzar un valor máximo alrededor de los 6 días, disminuye posteriormente de modo paralelo a como aumenta el diámetro medio de la partícula y, por lo tanto, la $\lambda_{\mathrm{em}}$ óptima (Fig. 45).

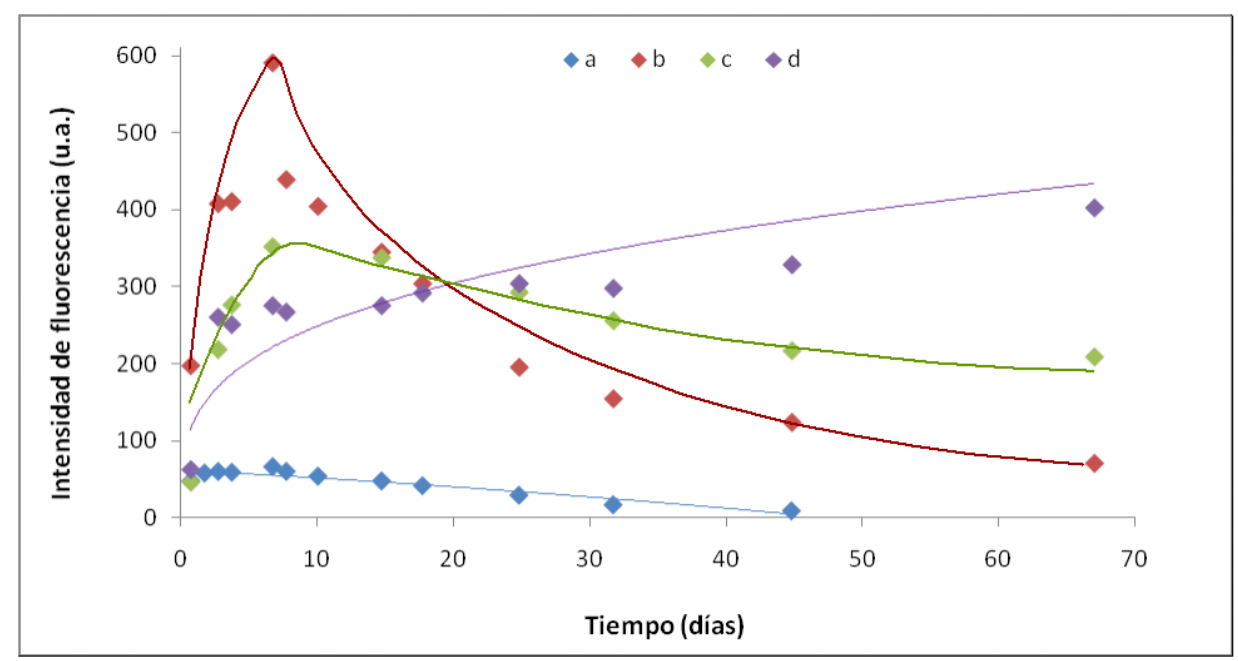

Figura 45. Evolución de la intensidad de fluorescencia para cada $\lambda$ ex óptima. Valores obtenidos para cada relación $\left.\left[\mathrm{Cd}^{2+}\right]_{\mathrm{f}} /\left[\mathrm{S}^{2-}\right]_{\mathrm{f}}\left[\mathrm{Cd}^{2+}\right]_{\mathrm{f}} /\left[\mathrm{S}^{2-}\right]_{\mathrm{f}}=\mathrm{a}\right) 1.33$; b) 2.0 ; c) 2.7 ; d) 4.0 .

Comparando los valores de If se comprueba cómo son más altos en la experiencia en la que $\left[\mathrm{Cd}^{2+}\right]_{f} /\left[\mathrm{S}^{2-}\right]_{f}=2.0$ frente a la de 1.33. La primera de las experiencias contiene mayor cantidad de $\mathrm{Cd}^{2+}$ libre en disolución que la segunda. Una vez más este hecho indica además de la influencia del exceso de $\mathrm{Cd}^{2+}$ en disolución sobre la velocidad de crecimiento, inhibiéndola, la relación entre fluorescencia y la formación de la nanocorteza de $\mathrm{Cd}(\mathrm{OH})_{2}$. $\mathrm{La}$ intensidad de fluorescencia máxima se alcanzaría para una relación óptima entre la anchura de la nanocorteza y el diámetro medio de las NPs. Si la nanocorteza constituye un depósito muy estrecho frente al diámetro medio, se mejora sólo la transferencia de electrones a través de ella, aumentando ligeramente la eficacia cuántica en el proceso excitación-emisión. Cuando la nanocorteza es grande respecto al diámetro de la partícula, la transferencia de electrones a través de ella en el proceso de excitación se incrementa, pero en el proceso de emisión de la radiación se incrementa la fracción energética no 106 
dispersiva, no radiante. La situación intermedia, relación óptima entre anchura de nanocorteza y diámetro medio, conduce a la eficacia cuántica más alta.

En la tercera de las experiencias, en la que la relación $\left[\mathrm{Cd}^{2+}\right]_{f} /\left[\mathrm{S}^{2-}\right]_{f}$ es mayor, 2.7 , el exceso de $\mathrm{Cd}^{2+}$ es mayor que en las experiencias anteriores, por lo que al ser el diámetro inicial de las NPs más pequeño se alcanzan antes las relaciones óptimas entre nanocorteza y diámetro de nanopartícula.

Los resultados obtenidos en esta última experiencia son muy interesantes, pues permiten tener unas nanopartículas que, teniendo un tamaño medio muy pequeño, tienen una fluorescencia elevada y constante durante un período de tiempo grande.

\section{FOTOGRAFÍAS DE LA FLUORESCENCIA DE LOS QDS OBTENIDOS EN EL LABORATORIO EN DIFERENTES CONDICIONES}

Como se ha hecho referencia a lo largo del texto a las diferentes longitudes de onda de emisión y su color, a modo de resumen exponemos unas fotografías (Fig. 46) de la fluorescencia de los QDs obtenidos en el laboratorio en diferentes condiciones experimentales.

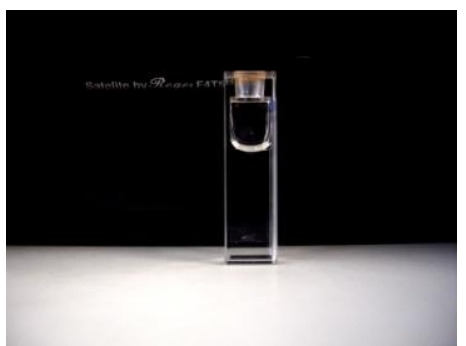

Fotografía 1

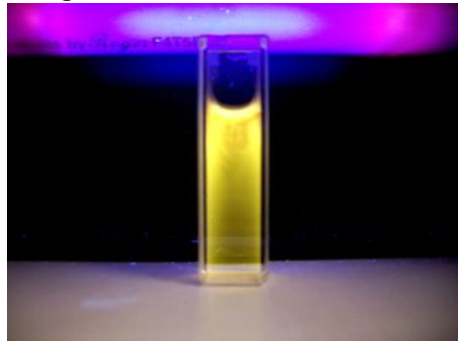

Fotografía 4

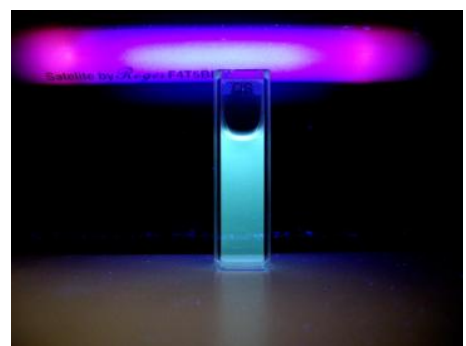

Fotografía 2

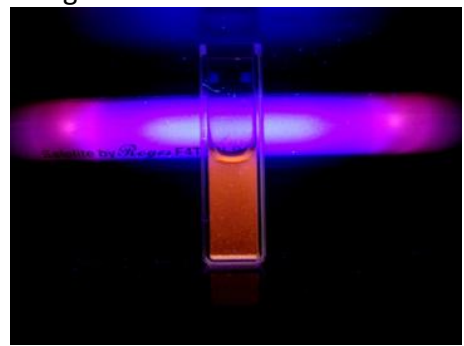

Fotografía 5

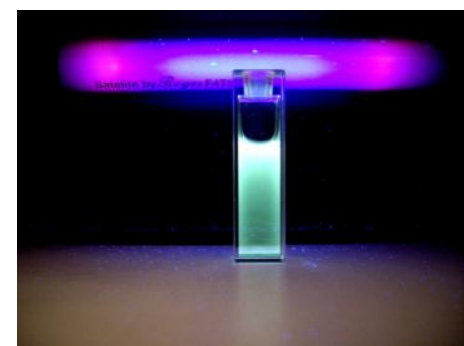

Fotografía 3

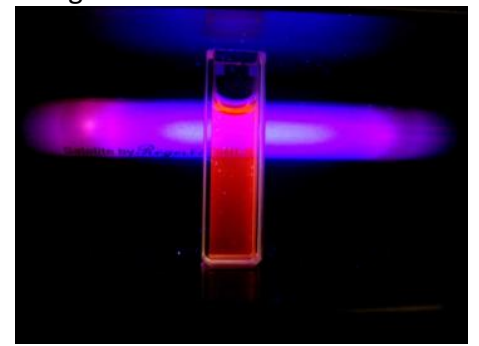

Fotografía 6

Figura 46. Fluorescencia de las disoluciones de QDs de CdS en distintas condiciones, referidas en el texto. 


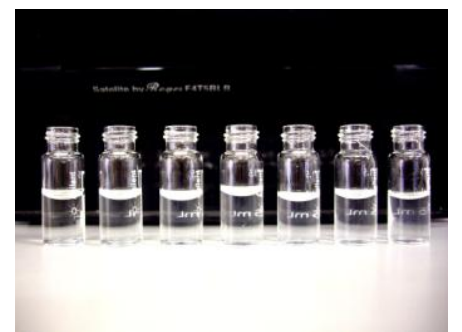

Fotografía 7

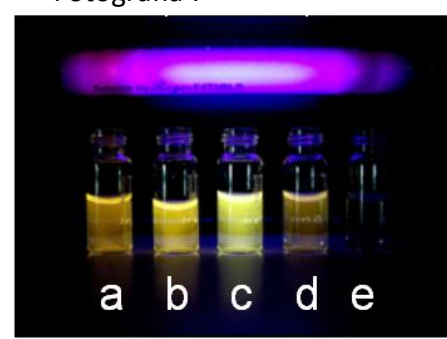

Fotografía 9

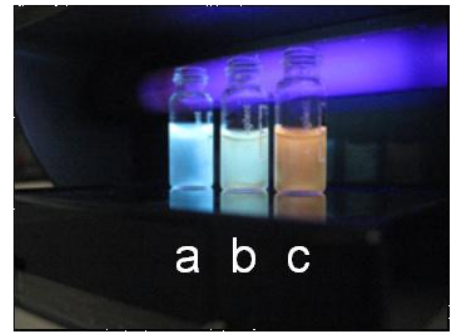

Fotografía 11

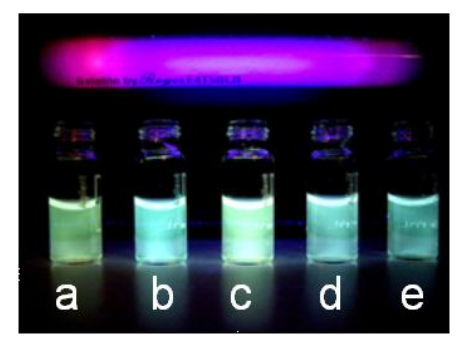

Fotografía 8

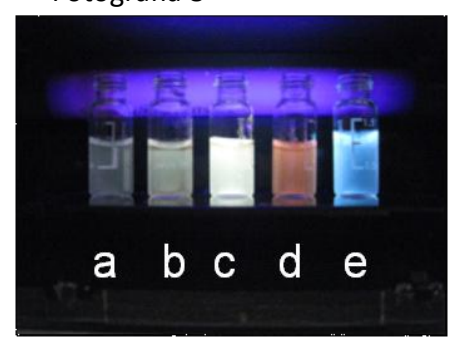

Fotografía 10

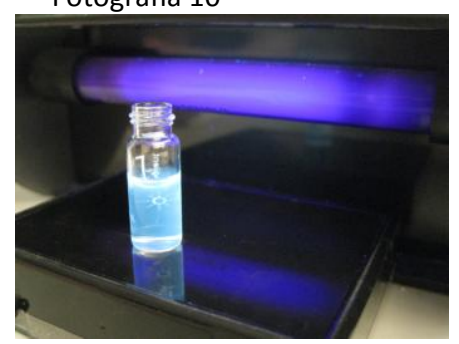

Fotografía 12

Figura 46, continuación. 


\section{Obtención de nanopartículas de CdS en fase homogénea}



En el estudio anterior, obtención de nanopartículas de CdS, de tamaño inferior a 5 $\mathrm{nm}$, en medio acuoso y utilizando como precursores $\mathrm{CdCl}_{2}$ y $\mathrm{Na}_{2} \mathrm{~S}$, se ha podido comprobar la influencia de las diferentes variables que afectan al tamaño y luminiscencia de los nanocristales finales.

De entre todas las variables que afectan a la velocidad de nucleación y crecimiento de los nanocristales hay una que resulta difícil de controlar, que es la concentración de ion $\mathrm{S}^{2-}$ en disolución. Este ion reacciona con los iones $\mathrm{Cd}^{2+}$ en presencia de ácido mercaptoacético como dispersante, añadiéndose lentamente a la disolución (para evitar sobresaturaciones) hasta completar en un tiempo dado la concentración final deseada.

A pesar de la agitación de la disolución, mediante este procedimiento es difícil evitar las sobresaturaciones locales que afectan a la velocidad de la nucleación. Por otra parte, se ha comprobado que las propiedades luminiscentes de las nanopartículas de CdS dependen fundamentalmente de la naturaleza de su superficie, razón por la cual la relación inicial $\left[\mathrm{Cd}^{2+}\right] /\left[\mathrm{S}^{2-}\right]$ es una de las variables más influyentes, obteniéndose los mejores resultados para condiciones experimentales en las que esta relación es $>1$.

Uno de los procedimientos químicos para evitar las sobresaturaciones del ion $\mathrm{S}^{2-}$ consiste en generarlo in situ añadiendo inicialmente a la disolución donde se desea formar los nanocristales una sal que lentamente se hidrolice generando dicho anión. Este tipo de procedimiento lo hemos denominado obtención de nanocristales en fase homogénea, por su similitud con el método de obtención de precipitados que lleva dicho nombre.

El reactivo precursor del anión $\mathrm{S}^{2-}$ escogido ha sido $\mathrm{Na}_{2} \mathrm{~S}_{2} \mathrm{O}_{3} 5 \mathrm{H}_{2} \mathrm{O}$, que se hidroliza en agua (fundamentalmente en medio básico) según la reacción:

$$
\mathrm{S}_{2} \mathrm{O}_{3}{ }^{2-}+\mathrm{H}_{2} \mathrm{O}=\mathrm{SO}_{4}{ }^{2-}+\mathrm{H}_{2} \mathrm{~S}
$$

La velocidad de dicha reacción se acelera en presencia de iones metálicos que forman sulfuros, con el incremento de $\mathrm{OH}^{-}$, con el incremento de la temperatura y con la presencia de tioglicerol $\left(\mathrm{HOH}_{2} \mathrm{C}-\mathrm{CHOH}-\mathrm{CH}_{2} \mathrm{HS}\right)$ que actúa de catalizador/dispersante ${ }^{110,111}$.

Son escasos los trabajos que aparecen en bibliografía que utilicen la generación in situ de un reactivo para la obtención de nanocristales con características cuánticas. Yang y Xiang ${ }^{110}$ dan a conocer la síntesis acuosa de nanocristales de CuS utilizando $\mathrm{CuSO}_{4}$ y $\mathrm{Na}_{2} \mathrm{~S}_{2} \mathrm{O}_{3}$ como precursores en presencia de tioglicerol, que actúa como dispersante. No obstante, en

\footnotetext{
${ }^{110}$ Y.J. Yang, J.W. Xiang. Template-free synthesis of CuS nanorods with a simple aqueous reaction at ambient conditions. Appl. Phys. A: Mater. Sci. Proc. 81 (2005) 1351-1353.

${ }^{111}$ Z. Sedaghat, N. Tagavinia, M. Marandi. Thermal control of the size and crystalline phase of CdS nanoparticles. Nanotechnology 17 (2006) 3812.
} 
dicho trabajo experimental no se estudian los cambios de tamaño del nanocristal en función de diferentes condiciones y además, la capacidad dispersante del tioglicerol es pequeña, pues se obtienen disoluciones coloidales de CuS con escasa estabilidad.

Los mismos precursores y el mismo dispersante han sido utilizados por Unni y col. ${ }^{112}$ para la síntesis de nanocristales de $\mathrm{CdS}$ dopados con $\mathrm{Zn}^{2+} \circ \mathrm{Cu}^{2+}$ con el inconveniente ya mencionado de la baja capacidad del dispersante para estabilizar las disoluciones en las que se forman los nanocristales.

En la primera parte de este capítulo se ha dado a conocer la preparación de nanocristales de $\mathrm{CdS}$ en medio acuoso partiendo de los precursores $\mathrm{CdCl}_{2}$ y $\mathrm{Na}_{2} \mathrm{~S}$, utilizando como dispersante ácido mercaptoacético. Se ha realizado un estudio en profundidad sobre las diferentes variables que afectan al tamaño, estado de la superficie (fluorescencia) y estabilidad de las disoluciones acuosas que contienen los nanocristales de CdS.

En esta segunda parte se realiza un estudio similar, con la diferencia fundamental que el anión $\mathrm{S}^{2-}$ se genera in situ a partir del precursor $\mathrm{Na}_{2} \mathrm{~S}_{2} \mathrm{O}_{3}$, que se hidroliza lentamente en disolución acuosa básica. Se mantiene el $\mathrm{CdCl}_{2}$ como precursor de $\mathrm{Cd}^{2+}$ y se emplea ácido mercaptoacético como dispersante que se enlaza a los iones cadmio sobre la superficie de los nanocristales.

Se pretende profundizar en el estudio de las variables que afectan a la velocidad de hidrólisis del $\mathrm{Na}_{2} \mathrm{~S}_{2} \mathrm{O}_{3}(\mathrm{pH}$, temperatura, concentración de tioglicerol como dispersante/catalizador) sin olvidar que para un tiempo dado la concentración de ión $\mathrm{S}^{2-}$, fijando el resto de variables, dependerá de la concentración inicial de $\mathrm{S}_{2} \mathrm{O}_{3}{ }^{2-}$ en disolución. Para estas tres variables se seguirá la evolución a lo largo del tiempo del tamaño de las NPs, sus características superficiales condicionantes de sus propiedades luminiscentes, así como la estabilidad de las nanopartículas. Se compararán las características antes mencionadas de las NPs de CdS obtenidas por ambos métodos para poder deducir las mejoras que introduce la obtención en fase homogénea.

\section{MÉTODO DE SÍNTESIS EN FASE HOMOGÉNEA}

El procedimiento empleado para la obtención de nanopartículas de CdS en fase acuosa utilizando $\mathrm{Na}_{2} \mathrm{~S}_{2} \mathrm{O}_{3}$ como precursor del anión $\mathrm{S}^{2-}$, es similar al utilizado cuando el precursor era directamente dicho anión en forma de sal sódica.

\footnotetext{
${ }^{112}$ C. Unni, D. Philip, S.L. Smitha, K.M. Nissamudeen, K.G. Gopchandran. Aqueous synthesis and characterization of CdS, CdS: $\mathrm{Zn}^{2+}$ and CdS:Cü quantum dots. Spectrochimica Acta Part A 72 (2009) 827-832. 
En todos los casos se parte de $100 \mathrm{~mL}$ de disolución acuosa de concentración en $\mathrm{Cd}^{2+} 1.0 \times 10^{-2} \mathrm{M}(1 \mathrm{mmol})$ contenidos en matraz erlenmeyer topacio sobre los que se añaden, con agitación $714 \mu \mathrm{L}$ de MAA $1.41 \mathrm{M}(1 \mathrm{mmol})$. El pH de la mezcla, como ya hemos comentado, oscila entre 2.3 y 2.9 , dependiendo de la cantidad añadida de MAA. En la disolución se observa una ligera turbidez blanquecina que hemos atribuido a la formación de un posible complejo de $\mathrm{Cd}(\mathrm{MAA})_{2}$ moderadamente insoluble a estos valores de $\mathrm{pH}$.

Es en ese momento cuando, manteniendo la agitación, se ajusta con $\mathrm{NaOH} 1 \mathrm{M}$ el $\mathrm{pH}$ de la disolución al valor deseado. Salvo cuando se estudie la influencia de esta variable, el valor escogido de $\mathrm{pH}$ es de 10.

A continuación y durante 15 minutos se burbujea nitrógeno sobre la disolución para evitar la posible oxidación del anión $\mathrm{S}^{2-}$. Transcurrido este tiempo se agregan lentamente y con agitación vigorosa $50 \mathrm{~mL}$ de disolución de $\mathrm{S}_{2} \mathrm{O}_{3}{ }^{2-}$, preparada en ese momento a partir del reactivo sólido $\mathrm{Na}_{2} \mathrm{~S}_{2} \mathrm{O}_{3} 5 \mathrm{H}_{2} \mathrm{O}$ en la concentración deseada. El tiempo de adición de este reactivo se mantiene constante en todas las experiencias $(10 \mathrm{~min})$ y terminada dicha operación se considera en este momento $t=0$ como punto de partida para el seguimiento temporal de la formación de nanopartículas de CdS.

Salvo cuando se estudie su influencia, la temperatura a la cual se realiza la síntesis es la ambiental $\left(22-25^{\circ} \mathrm{C}\right)$.

Como veremos en la descripción de los resultados experimentales, el valor de $\mathrm{pH}$ de la disolución final una vez añadido el precursor $\mathrm{S}_{2} \mathrm{O}_{3}{ }^{2-}$, sólo se modifica ligeramente respecto al valor impuesto con $\mathrm{NaOH}$.

Periódicamente, con el ritmo deseado, se sacan alícuotas de la disolución de síntesis y se registran los correspondientes espectros de absorción y fluorescencia.

Respecto al método de obtención de nanopartículas de CdS en medio acuoso partiendo de $\mathrm{Na}_{2} \mathrm{~S}$ como precursor del anión $\mathrm{S}^{2-}$, en el presente método se introduce un precursor nuevo que es la sal $\mathrm{Na}_{2} \mathrm{~S}_{2} \mathrm{O}_{3}$. Como se van a utilizar los espectros de absorción de las disoluciones que contienen nanocristales para obtener información sobre ellos, es preciso conocer el comportamiento espectrofotométrico de este nuevo reactivo.

En la Figura 47 se muestra el espectro de absorción de una disolución de $\mathrm{S}_{2} \mathrm{O}_{3}{ }^{2-}$ recién preparada, en concentración $6.67 \times 10^{-3} \mathrm{M}$ y a dos valores de $\mathrm{pH}(8$ y 11 , respectivamente). Puede comprobarse cómo hasta los $275 \mathrm{~nm}$ estas disoluciones no absorben y permiten la medida de absorbancia de otros analitos en un amplio margen de longitudes de onda sin que existan interferencias. 


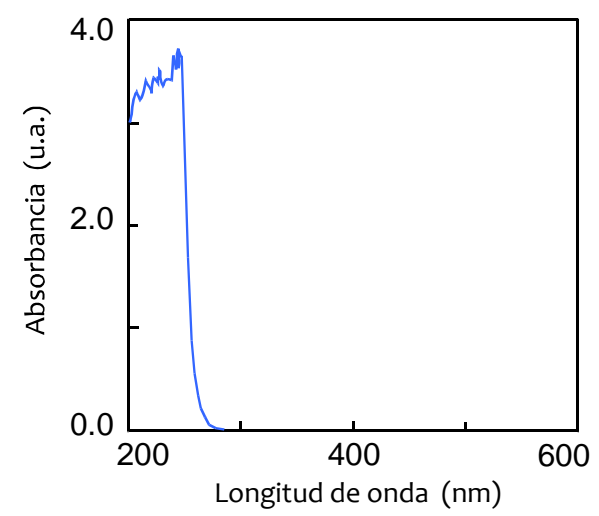

Figura 47. Espectro de absorción de disoluciones acuosas conteniendo $\mathrm{S}_{2} \mathrm{O}_{3}{ }^{2-} 6.67 \times 10^{-3} \mathrm{M}$ a dos valores de $\mathrm{pH}(8$ y 11$)$.

\section{OBTENCIÓN DE NANOPARTÍCULAS DE CdS EN FASE HETEROGÉNEA (A PARTIR DE SULFURO) COMO TESTIGO PARA LOS ESTUDIOS COMPARATIVOS}

Con el fin de poder comparar los resultados obtenidos por los dos métodos de síntesis mencionados, en primer lugar se obtienen nanopartículas de CdS mediante la utilización de $\mathrm{Na}_{2} \mathrm{~S}$ como precursor de ión $\mathrm{S}^{2-}$ en las condiciones experimentales en las que se estudiará el método de síntesis en fase homogénea utilizando $\mathrm{Na}_{2} \mathrm{~S}_{2} \mathrm{O}_{3}$ como precursor.

Se pretende así disponer de disoluciones acuosas conteniendo nanopartículas de CdS obtenidas de manera heterogénea y que van a ser utilizadas como "testigos de comparación".

Para ello se parte en todos los casos de $100 \mathrm{~mL}$ de disolución de $\mathrm{Cd}^{2+} 1.0 \times 10^{-2} \mathrm{M}(1$ mmol), sobre la que se añaden $715 \mu \mathrm{L}(1 \mathrm{mmol})$ de MAA $1.41 \mathrm{M}$, y posteriormente se ajusta el pH con $\mathrm{NaOH}$ hasta 9, 10 y 11, respectivamente, en las tres experiencias realizadas.

Tras el burbujeo con $\mathrm{N}_{2}$, durante el tiempo ya comentado, se añaden lentamente (a lo largo de 15 minutos) $50 \mathrm{~mL}$ de disolución de $\mathrm{Na}_{2} \mathrm{~S} 1 \times 10^{-2} \mathrm{M}(0.5 \mathrm{mmol})$ con agitación constante $\mathrm{y}$ considerando $\mathrm{t}=0$ el momento en el que termina este proceso. Las tres experiencias se realizan a temperatura ambiente y tras añadir la disolución de $\mathrm{Na}_{2} \mathrm{~S}$ el valor de $\mathrm{pH}$ de las disoluciones finales resulta ser $9.22,10.18$ y 10.51 , respectivamente.

En estas condiciones experimentales las concentraciones finales de los reactivos son: $\left[\mathrm{Cd}^{2+}\right]_{\mathrm{f}}=6.64 \times 10^{-3} \mathrm{M} ;\left[\mathrm{S}^{2-}\right]_{\mathrm{f}}=3.32 \times 10^{-3} \mathrm{M} ;[\mathrm{MAA}]_{\mathrm{f}}=6.64 \times 10^{-3} \mathrm{M}$; siendo sus relaciones molares: $\left[\mathrm{Cd}^{2+}\right] /\left[\mathrm{S}^{2-}\right]=2.0$ y $\left[\mathrm{Cd}^{2+}\right] /[\mathrm{MAA}]=1.0$. 


\section{EVOLUCIÓN DE LOS ESPECTROS DE ABSORCIÓN}

En las Figuras 48 a 50 se muestran algunos espectros de absorción de las tres disoluciones a medida que evolucionan con el tiempo. Estos espectros han sido registrados a partir de alícuotas de las disoluciones, pero diluidas con agua desionizada en una proporción 1:5 debido a la alta concentración de nanopartículas de CdS obtenidas en estas condiciones experimentales al ser mayor la concentración de reactivos utilizados.
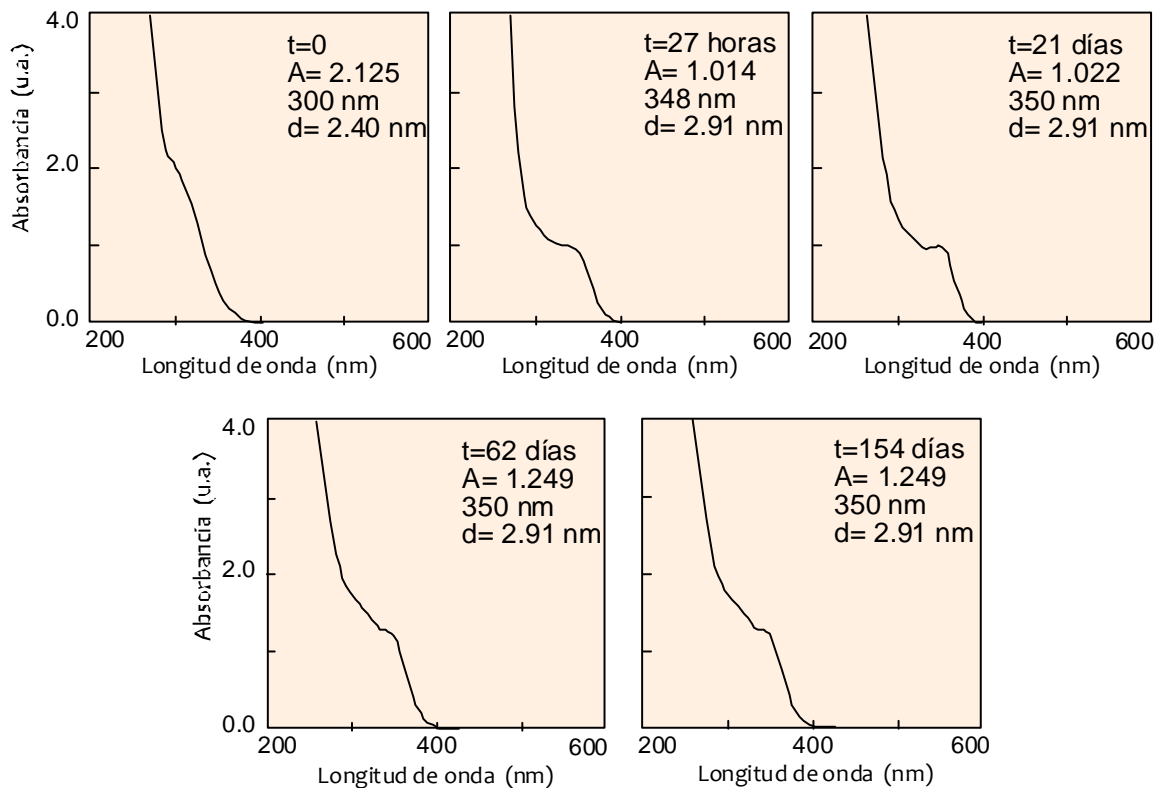

Figura 48. Espectros de absorción a diferentes tiempos de evolución de las NPs de $\mathrm{CdS}$ utilizando $\mathrm{S}^{2-}$ como precursor. $\mathrm{pH}=9$ (fijado antes de añadir $\mathrm{S}^{2-}$ ). $\left[\mathrm{Cd}^{2+}\right]_{\mathrm{f}}=6.64 \times 10^{-3} \mathrm{M} ;\left[\mathrm{S}^{2}\right]_{\mathrm{f}}=3.32 \times 10^{-3} \mathrm{M} ;[\mathrm{MAA}]_{\mathrm{f}}=6.64 \times 10^{-3} \mathrm{M} ;\left[\mathrm{Cd}^{2+}\right] /\left[\mathrm{S}^{2}\right]=2.0 ;\left[\mathrm{Cd}^{2+}\right] /[\mathrm{MAA}]=$ 1.0. Temperatura ambiente. Dilución 1:5. La disolución es transparente e incolora. 

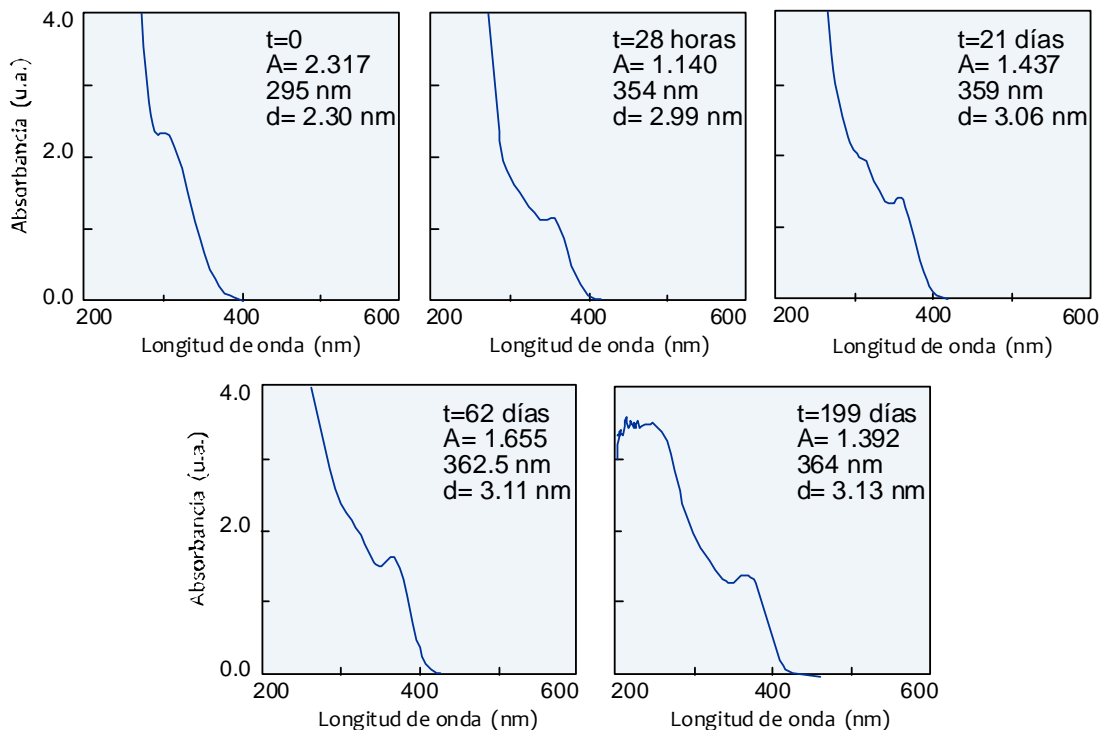

Figura 49. Espectros de absorción a diferentes tiempos de evolución de las $\mathrm{NPs}$ de $\mathrm{CdS}$ utilizando $\mathrm{S}^{2-}$ como precursor. $\mathrm{pH}=10$ (fijado antes de añadir $\mathrm{S}^{2-}$ ). $\left[\mathrm{Cd}^{2+}\right]_{\mathrm{f}}=6.64 \times 10^{-3} \mathrm{M} ;\left[\mathrm{S}^{2-}\right]_{\mathrm{f}}=3.32 \times 10^{-3} \mathrm{M} ;[\mathrm{MAA}]_{\mathrm{f}}=6.64 \times 10^{-3} \mathrm{M} ;\left[\mathrm{Cd}^{2+}\right] /\left[\mathrm{S}^{2-}\right]=2.0 ;\left[\mathrm{Cd}^{2+}\right] /\left[\mathrm{MAA}^{-}\right]=1.0$. Temperatura ambiente. Dilución 1:5. Disolución transparente-ligeramente amarilla a partir de los 40 días de evolución.
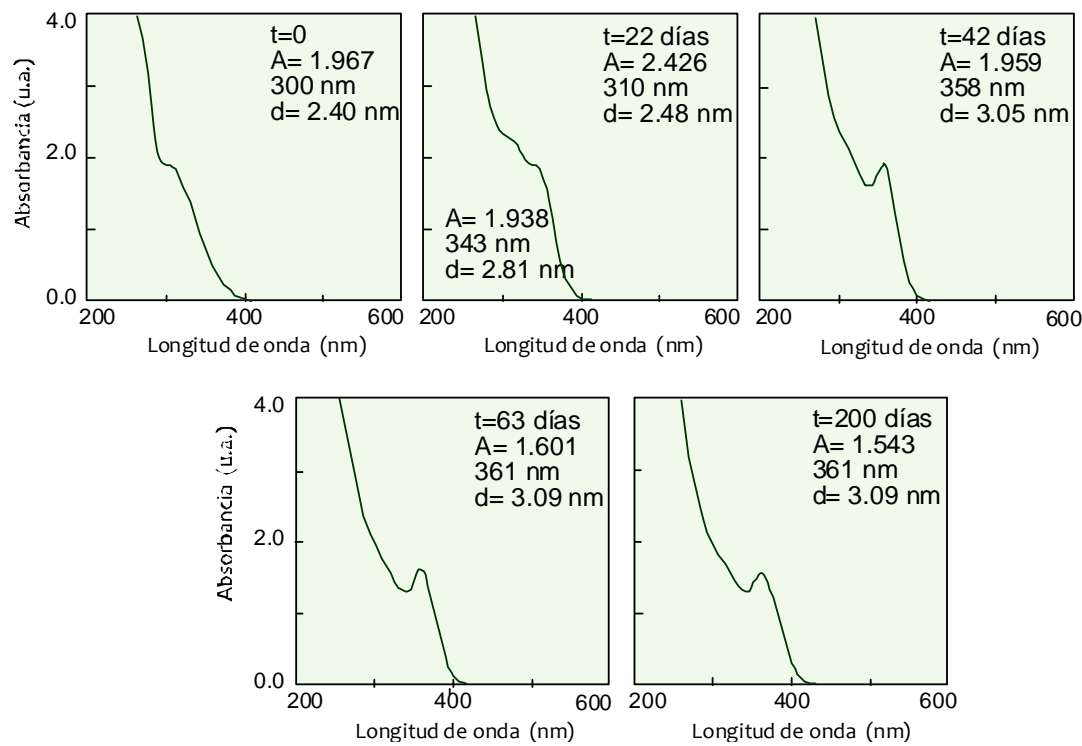

Figura 50. Espectros de absorción a diferentes tiempos de evolución de las NPs de CdS utilizando $\mathrm{S}^{2-}$ como precursor. $\mathrm{pH}=11$ (fijado antes de añadir $\mathrm{S}^{2-}$ ). $\left[\mathrm{Cd}^{2+}\right]_{\mathrm{f}}=6.64 \times 10^{-3} \mathrm{M} ;\left[\mathrm{S}^{2-}\right]_{\mathrm{f}}=3.32 \times 10^{-3} \mathrm{M} ;[\mathrm{MAA}]_{\mathrm{f}}=6.64 \times 10^{-3} \mathrm{M} ;\left[\mathrm{Cd}^{2+}\right] /\left[\mathrm{S}^{2-}\right]=2.0 ;\left[\mathrm{Cd}^{2+}\right] /[\mathrm{MAA}]=1.0$. Temperatura ambiente. Dilución 1:5. Disolución transparente-ligeramente amarilla a partir de los 42 días de evolución.

En dichos espectros se indica, además de las características de la disolución (transparencia o turbidez, color), la longitud de onda a la cual aparece el máximo correspondiente al primer estado excitónico, así como el diámetro medio (d) de las nanopartículas, calculado a partir de la energía de las bandas correspondiente a la longitud 
de onda del máximo de absorción y teniendo en cuenta la energía de las bandas del cristal de CdS (calculada a partir de la $\lambda_{\mathrm{e}}$ de dicho cristal).

Recordemos también que el valor de absorbancia en el máximo del pico excitónico está relacionado con la concentración de nanopartículas de CdS en disolución, así como con su coeficiente de extinción molar, $\varepsilon$, que, como ya se ha comentado, depende del tamaño de las nanopartículas.

Yu y col. ${ }^{113}$ tras la obtención, en medio orgánico, de nanocristales de CdTe, CdSe y CdS y su aislamiento por precipitación, preparan disoluciones de concentración conocida, registran sus espectros de absorción y deducen los valores de $\varepsilon$ en el primer pico excitónico. Tras medir el valor de $d$ a partir del difractograma correspondiente, obtienen ecuaciones empíricas que relacionan $\varepsilon$ con el diámetro medio del nanocristal. Para el caso de las nanopartículas de CdS esta relación empírica resultó ser:

$$
\varepsilon=21536 d^{2.3}(d \text { en } \mathrm{nm})
$$

Si se aplica dicha relación empírica a nuestros valores experimentales se obtienen valores no coherentes. Así, por ejemplo, partiendo de los datos experimentales de la disolución a $\mathrm{pH}$ inicial= 9 (Fig. 48) a las 27 horas de terminar de añadir la disolución de $\mathrm{S}^{2-}$, se obtiene un valor de $\varepsilon=2.5 \times 10^{5}$ u.a. $\mathrm{mol}^{-1} \mathrm{~L}(d=2.9 \mathrm{~nm})$ a partir de la relación empírica [10]. Con este valor de $\varepsilon$ y teniendo en cuenta el valor de la absorbancia $(A=1.014)$ así como el factor de dilución efectuada (1:5), se obtendría un valor para la concentración de nanopartículas de $\mathrm{CdS} \mathrm{C}_{\mathrm{CdS}}=2.03 \times 10^{-5} \mathrm{~mol} \mathrm{~L}^{-1}$. Calculado el valor de $\mathrm{N}$ (número de moléculas de CdS en cada nanopartícula), resulta ser para este caso concreto $N=252$, por lo que se deduce que la concentración de $\mathrm{CdS}$ en disolución es $[\mathrm{CdS}]=5.1 \times 10^{-3} \mathrm{M}$, siendo el dato incoherente pues se partió de una concentración de reactivo limitante $\left[\mathrm{S}^{2-}\right]=3.32 \times 10^{-3} \mathrm{M}$.

Queda demostrado que la relación empírica [10] deducida por Yu y col. para nanopartículas de CdS obtenidas en medio orgánico no se cumple para las mismas nanopartículas obtenidas en medio acuoso.

Si se tiene en cuenta el producto de solubilidad del $\mathrm{CdS}\left(\mathrm{pK}_{\mathrm{CdS}}=27\right)$ y que el $\mathrm{pH}$ en el que se obtienen las nanopartículas ( $\mathrm{pH}$ entre 9 y 11) es la zona de mínima solubilidad del CdS (Fig. 51), no es descabellado considerar que la concentración de CdS que interviene en la formación de nanopartículas es similar a la concentración de reactivo limitante añadido.

${ }^{113}$ W.W. Yu, L. Qu, W. Guo, X. Peng. Experimental determination of the extinction coefficient of CdTe, CdSe and CdS nanocrystals. Chem. Mater. 15 (2003) 2854-2860. 


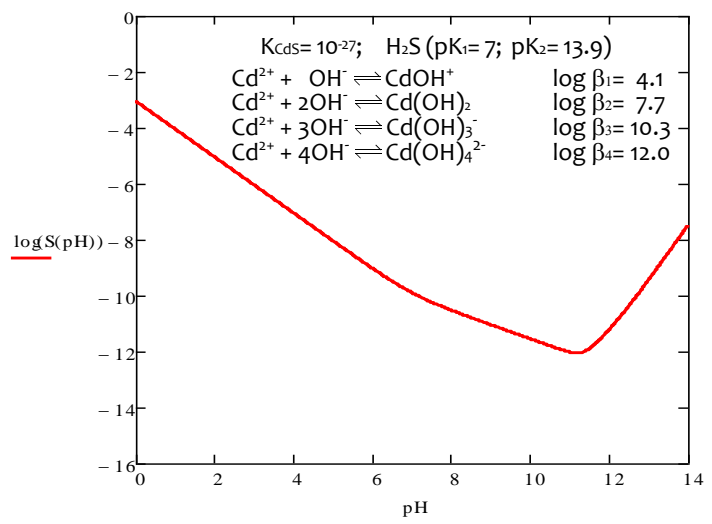

Figura 51. Diagrama de solubilidad del CdS en función del $\mathrm{pH}$.

Siguiendo este razonamiento, la concentración de NPs en disolución se podría calcular teniendo en cuenta el valor de $\mathrm{N}_{\text {cds }}$ deducido a partir del tamaño medio de la nanopartícula:

$$
\mathrm{C}_{\mathrm{CdS}}=[\mathrm{CdS}] / \mathrm{N}=\left[\mathrm{S}^{2-}\right]_{\mathrm{f}} / \mathrm{N}
$$

Pudiéndose deducir el valor de $\varepsilon$ para cada caso a partir del valor del máximo de absorción del espectro:

$$
\varepsilon=\frac{A_{\text {máx }}}{\frac{\mathrm{C}_{\mathrm{CdS}}}{5}}
$$

teniendo en cuenta la dilución efectuada de 1:5.

En cuanto a la morfología de los espectros, (Fig. 48-50), en todos los casos el comienzo en el proceso de absorción transcurre a valores de longitud de onda inferiores a $515 \mathrm{~nm}$ ( $\lambda$ de comienzo de absorción de la celdilla unidad del cristal de CdS), lo que indica que en todos los casos en disolución se obtienen nanopartículas de CdS de pequeño tamaño donde el desplazamiento es debido al confinamiento cuántico.

En general, como puede observarse en las figuras antes comentadas, cuanto mayor es el tamaño medio de las nanopartículas mayor es la longitud de onda a la que aparece el primer proceso excitónico $\left(\lambda_{\operatorname{máx}}\right)$, por lo que en este mismo sentido mejor está definido el máximo del proceso de absorción.

En todos los espectros alrededor de los $325 \mathrm{~nm}$ aparece una distorsión que en bibliografía algunos autores atribuyen a un proceso excitónico $1 P_{\mathrm{e}}-1 P_{\mathrm{h}}$, pero que como hemos podido comprobar en estudios previos corresponde a una banda de absorción 
debida a la formación de especies complejas entre $\mathrm{Cd}^{2+}$ y MAA (Fig. 52) que presenta su máximo a $325 \mathrm{~nm}$.

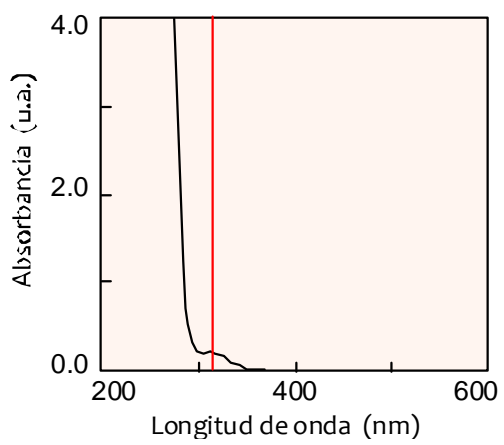

Figura 52. Espectro de absorción en un periodo de 7 días de una disolución que contiene $\mathrm{Cd}^{2+}$ $1.0 \times 10^{-2} \mathrm{M}$ sobre la que se han añadido $715 \mu \mathrm{L}$ de MAA $1.41 \mathrm{M}$ y se ha ajustado el $\mathrm{pH}$ a 10.

Como en el proceso de obtención de nanopartículas existe exceso de $\mathrm{Cd}^{2+}$ respecto a $\mathrm{S}^{2-}$, estas especies complejas con MAA siempre están presentes. Esta es la razón por la cual los espectros se distorsionan a esta $\lambda$. Algunos autores han llegado a utilizar esta zona de inflexión del espectro para el cálculo del diámetro medio de las nanopartículas lo que conduce a valores por defecto.

Por ello, el pico del máximo de absorción de las nanopartículas de CdS está perfectamente definido cuando su tamaño es tal que el máximo aparece por encima de los $350 \mathrm{~nm}$.

En cuanto al tamaño medio de las NPs, para los tres valores de $\mathrm{pH}$ estudiados, a medida que evolucionan con el tiempo, éste aumenta, si bien el incremento es distinto. A $\mathrm{t}=0$ el tamaño de las nanopartículas es prácticamente independiente del $\mathrm{pH}$ inicial de la disolución acuosa (fijado antes de añadir $\mathrm{S}^{2-}$ ) si se tiene en cuenta la dificultad experimental de determinar correctamente la $\lambda_{\text {máx }}$ por la interferencia ya comentada. Este valor inicial de $d$ se encuentra entre $2.3 \mathrm{~nm}$ y $2.4 \mathrm{~nm}$.

Cuando el pH inicial es 9 el tamaño evoluciona desde $2.4 \mathrm{~nm}(\mathrm{t}=0)$ hasta 2.9 ( $\mathrm{t}=$ $27 \mathrm{~h}=1.1$ días) y se mantiene en dicho valor sin evolución posterior hasta el último día estudiado (154 días).

Cuando el pH inicial es 10 (Fig. 49) el incremento de tamaño en el mismo período es similar pasando de $2.3 \mathrm{~nm}(\mathrm{t}=0)$ a $2.9 \mathrm{~nm}(\mathrm{t}=28 \mathrm{~h}=1.2$ días). Pero a diferencia del caso anterior, sigue creciendo aunque a ritmo menor a lo largo de los días de evolución, alcanzando un tamaño de $3.1 \mathrm{~nm}$ a los 199 días.

En cuanto a la tercera de las experiencias, a $\mathrm{pH}=11$, se obtiene un comportamiento intermedio entre las otras dos. A tiempos iniciales hay un incremento de tamaño inferior a 
los dos casos anteriores, desde $2.4 \mathrm{~nm}(\mathrm{t}=0)$ hasta 2.5 a las $23 \mathrm{~h}$. El incremento posterior es muy lento, de modo que pasa desde $2.8 \mathrm{~nm}$ ( $\mathrm{t}=22$ días) a $3.0 \mathrm{~nm}$ ( $\mathrm{t}=63$ días), manteniéndose posteriormente constante hasta el último día en que se midió ( $t=200$ días).

Este comportamiento del tamaño de las nanopartículas en función del pH inicial de la disolución acuosa antes de añadir $\mathrm{S}^{2-}$, en las experiencias comentadas, difiere ligeramente del observado al estudiar en profundidad esta variable.

La diferencia entre ambas series de experiencias estriba en las relaciones $\left[\mathrm{Cd}^{2+}\right]_{f} /\left[\mathrm{S}^{2-}\right]_{\mathrm{f}}$ y $\left[\mathrm{Cd}^{2+}\right]_{\mathrm{f}} /[\mathrm{MAA}]_{\mathrm{f}}$, así como en las concentraciones iniciales de $\left[\mathrm{Cd}^{2+}\right]$ y $\left[\mathrm{S}^{2-}\right]$, que en el presente caso son claramente superiores. Creemos que el diferente comportamiento se debe a la última de las diferencias comentadas.

En el pie de las Figuras 48-50 se indica el color de la disolución (antes de efectuar la dilución) y como puede comprobarse cuando el tamaño de las NPs alcanza el valor de $3 \mathrm{~nm}$, aproximadamente, la disolución correspondiente presenta color amarillo por ser la luz de dicha longitud de onda más dispersada por dicho tamaño.

En las Tablas 1 a 3 se muestran los valores para $\mathrm{N}_{\mathrm{cds}}$, calculado a partir de la expresión [9], así como el de $\mathrm{C}_{\text {cds }}$ (concentración de NPs en disolución) calculado a partir de [11], y por último el valor de $\varepsilon_{\text {CdS }}$ calculado a partir de $A_{\text {máx }}[12]$.

Tabla 1. Obtención de nanopartículas de CdS utilizando $\mathrm{S}^{2-}$ como precursor. Valores deducidos a partir del espectro de absorción. $\mathbf{p H}=\mathbf{9}$ (fijado antes de añadir $\mathrm{S}^{2-}$ ). Temperatura ambiente. Disoluciones diluídas (1:5). $[\mathrm{CdS}]_{\mathrm{f}}=3.32 \times 10^{-3} \mathrm{M}$.

\begin{tabular}{|c|c|c|c|c|c|}
\hline t / días & d / nm & Ncds/moléculas & $\mathrm{C}_{\mathrm{CdS}} / \mathrm{mol} \mathrm{L}^{-1}$ & Amáx & $\varepsilon /$ u.a. mol$^{-1} \mathbf{L}$ \\
\hline $\mathbf{0}$ & 2.40 & 141 & $2.35 \times 10^{-5}$ & 2.125 & $4.5 \times 10^{5}$ \\
\hline 1.1 & 2.91 & 252 & $1.31 \times 10^{-5}$ & 1.014 & $3.9 \times 10^{5}$ \\
\hline 2 & 2.91 & 252 & $1.31 \times 10^{-5}$ & 0.923 & $3.5 \times 10^{5}$ \\
\hline 3 & 2.91 & 252 & $1.31 \times 10^{-5}$ & 0.998 & $3.8 \times 10^{5}$ \\
\hline 7 & 2.91 & 252 & $1.31 \times 10^{-5}$ & 1.013 & $3.9 \times 10^{5}$ \\
\hline 15 & 2.91 & 252 & $1.31 \times 10^{-5}$ & 1.005 & $3.8 \times 10^{5}$ \\
\hline 21 & 2.91 & 252 & $1.31 \times 10^{-5}$ & 1.022 & $3.9 \times 10^{5}$ \\
\hline 30 & 2.91 & 252 & $1.31 \times 10^{-5}$ & 1.026 & $3.9 \times 10^{5}$ \\
\hline 41 & 2.91 & 252 & $1.31 \times 10^{-5}$ & 1.062 & $4.0 \times 10^{5}$ \\
\hline 55 & 2.91 & 252 & $1.31 \times 10^{-5}$ & 1.220 & $4.7 \times 10^{5}$ \\
\hline 62 & 2.91 & 252 & $1.31 \times 10^{-5}$ & 1.249 & $4.8 \times 10^{5}$ \\
\hline 130 & 2.91 & 252 & $1.31 \times 10^{-5}$ & 1.242 & $4.7 \times 10^{5}$ \\
\hline 154 & 2.91 & 252 & $1.31 \times 10^{-5}$ & 1.239 & $4.7 \times 10^{5}$ \\
\hline 199 & 2.91 & 252 & $1.31 \times 10^{-5}$ & 1.240 & $4.7 \times 10^{5}$ \\
\hline
\end{tabular}


Tabla 2. Obtención de nanopartículas de CdS utilizando $\mathrm{S}^{2-}$ como precursor. Valores deducidos a partir del espectro de absorción. $\mathbf{p H}=\mathbf{1 0}$ (fijado antes de añadir $\mathrm{S}^{2-}$ ). Temperatura ambiente. Disoluciones diluídas (1:5). $[\mathrm{CdS}]_{\mathrm{f}}=3.32 \times 10^{-3} \mathrm{M}$.

\begin{tabular}{|l|c|c|c|c|c|}
\hline $\mathbf{t} /$ días & $\mathbf{d} / \mathbf{n m}$ & $\mathbf{N}_{\text {Cds }} / \mathbf{m o l e ́ c u l a s ~}$ & $\mathbf{C}_{\text {Cds }} / \mathbf{~ m o l ~ L}^{-1}$ & $\mathbf{A}_{\text {máx }}$ & $\boldsymbol{\varepsilon} / \mathbf{u . a . ~} \mathbf{~ m o l}^{-1} \mathbf{L}$ \\
\hline $\mathbf{0}$ & 2.30 & 124 & $2.67 \times 10^{-5}$ & 2.317 & $4.3 \times 10^{5}$ \\
\hline $\mathbf{1 . 2}$ & 2.99 & 273 & $1.22 \times 10^{-5}$ & 1.140 & $4.7 \times 10^{5}$ \\
\hline $\mathbf{2}$ & 3.03 & 284 & $1.17 \times 10^{-5}$ & 1.147 & $4.9 \times 10^{5}$ \\
\hline $\mathbf{3}$ & 3.03 & 284 & $1.17 \times 10^{-5}$ & 1.142 & $4.9 \times 10^{5}$ \\
\hline $\mathbf{7}$ & 3.04 & 287 & $1.16 \times 10^{-5}$ & 1.148 & $5.0 \times 10^{5}$ \\
\hline $\mathbf{1 5}$ & 3.06 & 293 & $1.13 \times 10^{-5}$ & 1.432 & $6.3 \times 10^{5}$ \\
\hline $\mathbf{2 1}$ & 3.06 & 293 & $1.13 \times 10^{-5}$ & 1.437 & $6.4 \times 10^{5}$ \\
\hline $\mathbf{3 0}$ & 3.07 & 296 & $1.12 \times 10^{-5}$ & 1.445 & $6.5 \times 10^{5}$ \\
\hline $\mathbf{4 1}$ & 3.09 & 302 & $1.10 \times 10^{-5}$ & 1.621 & $7.4 \times 10^{5}$ \\
\hline $\mathbf{4 9}$ & 3.09 & 302 & $1.10 \times 10^{-5}$ & 1.630 & $7.4 \times 10^{5}$ \\
\hline $\mathbf{6 2}$ & 3.11 & 308 & $1.08 \times 10^{-5}$ & 1.655 & $7.6 \times 10^{5}$ \\
\hline $\mathbf{1 3 3}$ & 3.12 & 311 & $1.06 \times 10^{-5}$ & 1.679 & $7.9 \times 10^{5}$ \\
\hline $\mathbf{1 5 4}$ & 3.12 & 311 & $1.06 \times 10^{-5}$ & 1.676 & $7.9 \times 10^{5}$ \\
\hline $\mathbf{1 9 9}$ & 3.13 & 314 & $1.06 \times 10^{-5}$ & 1.392 & $6.6 \times 10^{5}$ \\
\hline
\end{tabular}

Tabla 3. Obtención de nanopartículas de CdS utilizando $\mathrm{S}^{2-}$ como precursor. Valores deducidos a partir del espectro de absorción. $\mathbf{p H}=\mathbf{1 1}$ (fijado antes de añadir $\mathrm{S}^{2-}$ ). Temperatura ambiente. Disoluciones diluídas (1:5). $[\mathrm{CdS}]_{\mathrm{f}}=3.32 \times 10^{-3} \mathrm{M}$.

\begin{tabular}{|c|c|c|c|c|c|}
\hline t / días & d / nm & Ncds/moléculas & $\mathrm{C}_{\mathrm{CdS}} / \mathrm{mol} \mathrm{L}^{-1}$ & Amáx & $\varepsilon /$ u.a. mol $^{-1} \mathbf{L}$ \\
\hline $\mathbf{0}$ & 2.40 & 141 & $2.35 \times 10^{-5}$ & 1.967 & $4.2 \times 10^{5}$ \\
\hline 1 & 2.46 & 152 & $2.18 \times 10^{-5}$ & 1.943 & $4.5 \times 10^{5}$ \\
\hline 2 & 2.48 & 156 & $2.13 \times 10^{-5}$ & 1.964 & $4.6 \times 10^{5}$ \\
\hline 8 & 2.60 & 180 & $1.84 \times 10^{-5}$ & 1.972 & $5.4 \times 10^{5}$ \\
\hline 16 & 2.81 & 227 & $1.46 \times 10^{-5}$ & 1.993 & $6.8 \times 10^{5}$ \\
\hline 22 & 2.81 & 227 & $1.46 \times 10^{-5}$ & 1.938 & $6.6 \times 10^{5}$ \\
\hline 31 & 3.00 & 276 & $1.20 \times 10^{-5}$ & 1.940 & $8.1 \times 10^{5}$ \\
\hline 42 & 3.05 & 290 & $1.15 \times 10^{-5}$ & 1.959 & $8.5 \times 10^{5}$ \\
\hline 50 & 3.07 & 296 & $1.12 \times 10^{-5}$ & 1.618 & $7.2 \times 10^{5}$ \\
\hline 63 & 3.09 & 302 & $1.12 \times 10^{-5}$ & 1.601 & $7.1 \times 10^{5}$ \\
\hline 133 & 3.09 & 302 & $1.12 \times 10^{-5}$ & 1.556 & $6.9 \times 10^{5}$ \\
\hline 155 & 3.09 & 302 & $1.12 \times 10^{-5}$ & 1.528 & $6.8 \times 10^{5}$ \\
\hline 162 & 3.09 & 302 & $1.12 \times 10^{-5}$ & 1.546 & $6.9 \times 10^{5}$ \\
\hline 200 & 3.09 & 302 & $1.12 \times 10^{-5}$ & 1.569 & $7.0 \times 10^{5}$ \\
\hline
\end{tabular}

En cuanto al valor de $\mathrm{C}_{\mathrm{Cds}}$ para las tres experiencias, disminuye claramente desde $\mathrm{t}=0$ hasta el valor obtenido una vez que ha transcurrido alrededor de un día. A pesar de que el valor de absorbancia a $\mathrm{t}=0\left(\lambda_{\operatorname{máx}}=300 \mathrm{~nm}\right)$ no sólo depende de la $\mathrm{C}_{\mathrm{cds}}$ (pues en esta zona absorben también los complejos formados entre $\mathrm{Cd}^{2+}$ y MAA) y su valor experimental tiene un error determinado por exceso, la disminución en el valor de la concentración de NPs indica que a tiempos iniciales, nada más añadir la disolución de $\mathrm{S}^{2-}$, hay en disolución un elevado número de núcleos de nanocristales de tamaño muy pequeño que en las primeras 24 horas se reagrupan entre sí para generar otros de tamaño superior (proceso Ostwald), por lo que la concentración de nanopartículas disminuye. Este proceso es muy parecido 
cuando el pH de la disolución inicial es 9 o 10, pero es menos acusado para pH 11. Parece, por lo tanto, que la velocidad de crecimiento es mayor que la velocidad de nucleación cuanto más alcalino es el medio, lo que estaría de acuerdo con los datos termodinámicos para la formación de CdS.

El número de NPs de CdS par unidad de volumen, $\mathrm{C}_{\mathrm{Cds}}$, se hace constante cuando lo hace el tamaño medio. Esto ocurre a los 1.1 días para $\mathrm{pH}=9$; a los 50 días para $\mathrm{pH}=11$, mientras que a $\mathrm{pH}=10$ su comportamiento es aparentemente anómalo, pues crecen de tamaño aunque muy lentamente, pero de manera constante hasta el día 199 (última medida experimental), si bien desde el día 133 parecen estabilizarse.

En estas condiciones experimentales, elevada concentración de $\mathrm{Cd}^{2+} \mathrm{y} \mathrm{S}^{2-}$, el diferente valor de $\mathrm{pH}$ inicial de la disolución acuosa, entre 9 y 11, no parece influir de manera decisiva, cuantitativamente hablando, sobre el tamaño medio de las nanopartículas y su concentración en disolución pasados los primeros días de evolución.

Sí se observan diferencias, ya comentadas, en cuanto a la manera de alcanzar estos valores, en función del pH inicial de la disolución acuosa, lo que indica que esta variable además de afectar a la velocidad de nucleación y crecimiento de las nanopartículas, influye en los equilibrio ácido-base que tienen lugar en la propia disolución o sobre la superficie de las nanopartículas. Tampoco se debe descartar que estos procesos generen especies que quedan incrustadas en el interior de las nanopartículas. Lo más probable es que los procesos a los que nos referimos estén relacionados con la formación de especies hidroxiladas de $\mathrm{Cd}^{2+}$ sobre la superficie de las NPs que ocurriría con mayor extensión cuanto más alcalino es el pH de la disolución.

Este proceso químico que estamos comentando conduciría a nanopartículas que manteniendo el tamaño, tendrían alteraciones superficiales que afectarían a los procesos de absorción de radiación. Este efecto parece ser positivo cuando la alteración superficial es mínima, lo que ocurre a pH 9 y sería negativa cuando el tamaño de depósito supera un valor crítico $(\mathrm{pH}=11)$.

Esta alteración química en forma de depósito (nanodepósito) interviniendo en los procesos de absorción de radiación sería lo que explicaría que en la experiencia a $\mathrm{pH}$ inicial= 9, aun manteniendo las NPs el tamaño desde el día 1.2 (Tabla 1), el valor de la absorbancia se incrementa ligeramente con el tiempo. A este valor de $\mathrm{pH}$, la formación de especies hidroxiladas es termodinámicamente poco favorable.

En el otro extremo se encuentran los resultados obtenidos cuando el $\mathrm{pH}$ de la disolución inicial es 11. Desde un principio la formación de nanodepósitos es 
termodinámicamente muy favorable y su extensión superaría un valor crítico haciendo que el valor de absorbancia, en el pico excitónico, disminuya a pesar de que aumente el tamaño medio de las nanopartículas con el tiempo.

La experiencia a pH 10 sería una situación intermedia entre las otras dos. El tamaño crítico de la nanocorteza se superaría sólo a tiempos muy elevados (199 días).

En medio acuoso y en presencia de exceso de $\mathrm{Cd}^{2+}$ la relación entre el tamaño medio de las nanopartículas $(d)$ y el coeficiente de absortividad molar $(\varepsilon)$ no es similar a la obtenida en medio no acuoso, siendo más compleja. De los resultados obtenidos (Tablas 13 ) se deduce que, en general, cuanto mayor es $d$, mayor es $\varepsilon$, pero también para un mismo tamaño de NP el valor de $\varepsilon$ depende de la contaminación por especies hidroxiladas.

\section{EVOLUCIÓN DE LOS ESPECTROS DE LUMINISCENCIA}

De manera paralela al registro de los espectros de absorción y con las mismas alícuotas, pero sin diluir, se registran los espectros de luminiscencia de las nanopartículas en disolución acuosa. El procedimiento de registro siempre se realiza de la misma manera: inicialmente, mediante el multiespectro (barrido de $\lambda_{\mathrm{em}}$ con diferentes $\lambda_{\mathrm{ex}}$ ) se obtienen los valores óptimos de las $\lambda_{\mathrm{em}}$ y $\lambda_{\mathrm{ex}}$. Para cada alícuota se registra posteriormente el espectro de excitación (a la $\lambda_{\text {em }}$ óptima) y el espectro de emisión (a la $\lambda_{\text {ex }}$ óptima).

El color de la luz emitida, si bien puede ser observado con el espectrofluorímetro en ausencia de luz ambiental, también ha sido seguido iluminando la disolución con lámpara de mercurio. En este segundo caso, al no ser una fuente de radiación monocromática, el color de la fluorescencia observado está desplazado hacia $\lambda$ más altas.

En las Figura 53 se muestran los espectros de excitación y emisión de las disoluciones de las tres experiencias mencionadas a $\mathrm{t}=0$ (momento en el que se acaba de añadir la disolución de $\mathrm{S}^{2-}$ ). 

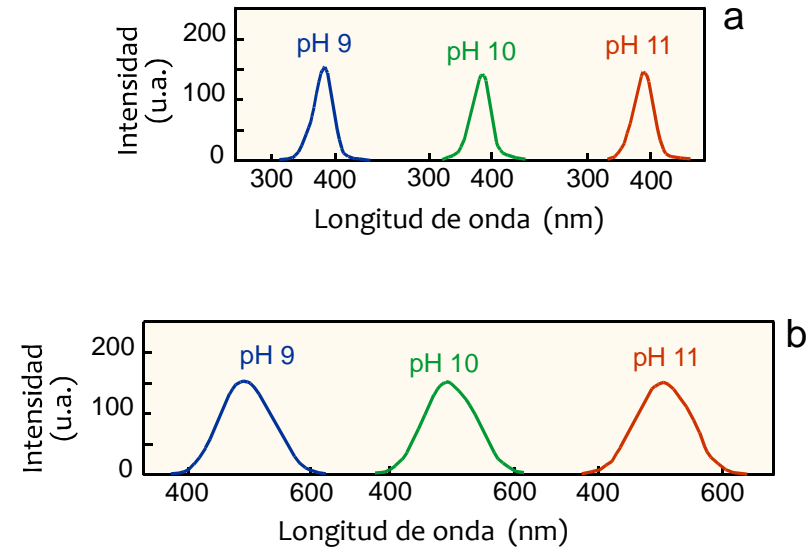

Figura 53. Espectros de excitación (a) y emisión (b) de las nanopartículas obtenidas a $\mathrm{pH} \mathrm{9,10} \mathrm{y} 11$ (fijados antes de añadir el ión $\mathrm{S}^{2-}$ ), a $\mathrm{t}=0 .\left[\mathrm{Cd}^{2+}\right]_{\mathrm{f}}=$ $6.64 \times 10^{-3} \mathrm{M} ;\left[\mathrm{S}^{2-}\right]_{\mathrm{f}}=3.32 \times 10^{-3} \mathrm{M} ;[\mathrm{MAA}]_{\mathrm{f}}=6.64 \times 10^{-3} \mathrm{M} ;\left[\mathrm{Cd}^{2+}\right]_{\mathrm{f}} /\left[\mathrm{S}^{2-}\right]_{\mathrm{f}}=2$; $\left[\mathrm{Cd}^{2+}\right]_{\mathrm{f}} /[\mathrm{MAA}]_{\mathrm{f}}=1$. Rendijas de $5 \mathrm{~nm}$. Temperatura ambiente.

Puede comprobarse en dichas figuras cómo al tratarse de nanopartículas recién obtenidas y tener prácticamente el mismo diámetro medio, las características luminiscentes son similares. Las longitudes de onda de excitación y emisión óptimas son similares $\left(\lambda_{\mathrm{ex}}=380 \mathrm{~nm} ; \lambda_{\mathrm{em}}=484 \mathrm{~nm}\right.$ ), así como el valor de intensidad de fluorescencia en el máximo ( $\left(\mathrm{f}_{\text {máx }}=147-148\right.$ u.a.). En los tres casos la fluorescencia emitida es de color verde.

La distribución de tamaños también resulta similar, encontrándose $\mathrm{If}_{\text {máx }} / 2$ entre 98 y $100 \mathrm{~nm}$.

En las Figuras 54-56 se muestran los espectros de emisión de las NPs de CdS a medida que evolucionan con el tiempo, para las tres experiencias ya mencionadas. Dentro de cada gráfica se muestran el tiempo de evolución, el valor de $I_{\text {máx, la }} \lambda_{\text {em }}$ óptima, la $\lambda_{\text {ex }}$ óptima y $\Delta$. 

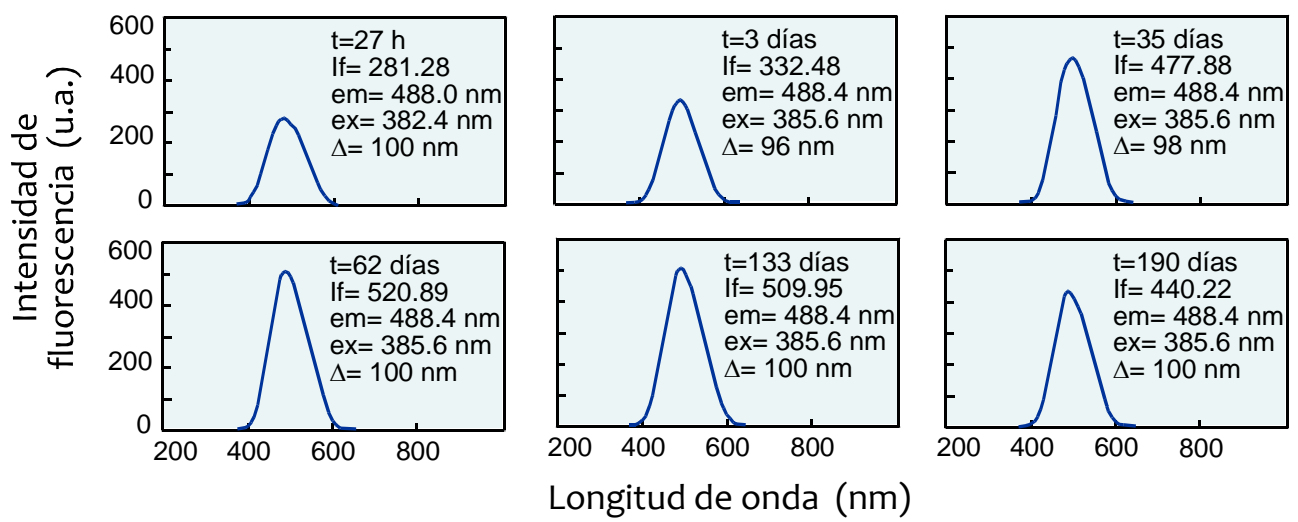

Figura 54. Espectros de emisión a diferentes tiempos de las nanopartículas obtenidas a pH 9 (fijado antes de añadir el ión $\mathrm{S}^{2-}$ ). Rendijas de $5 \mathrm{~nm}$. El resto de las variables experimentales se especifica en la Figura 53.
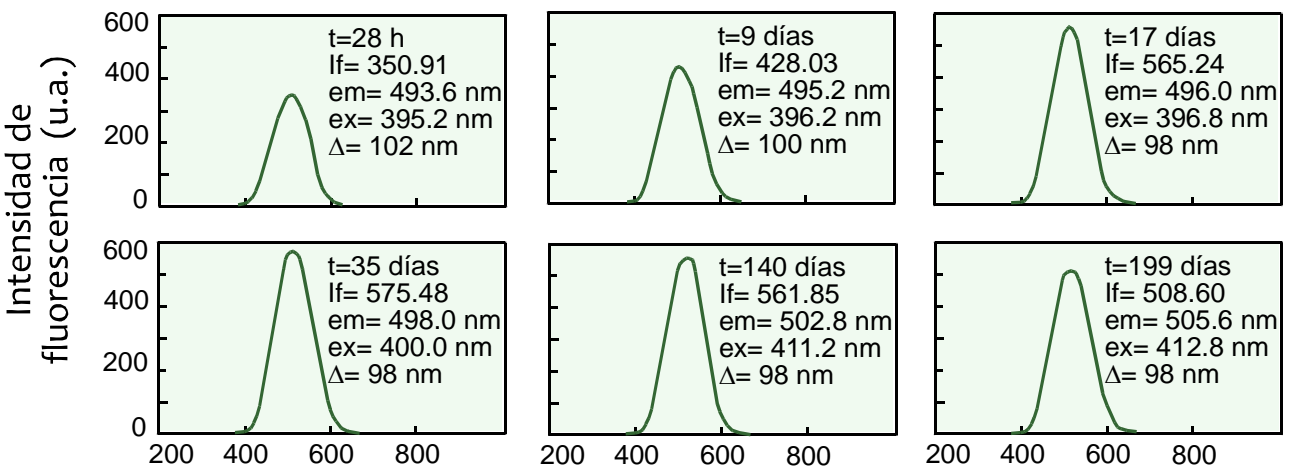

\section{Longitud de onda (nm)}

Figura 55. Espectros de emisión a diferentes tiempos de las nanopartículas obtenidas a pH 10 (fijado antes de añadir el ión $\mathrm{S}^{2-}$ ). Rendijas de $5 \mathrm{~nm}$. El resto de las variables experimentales se especifica en la Figura 53.
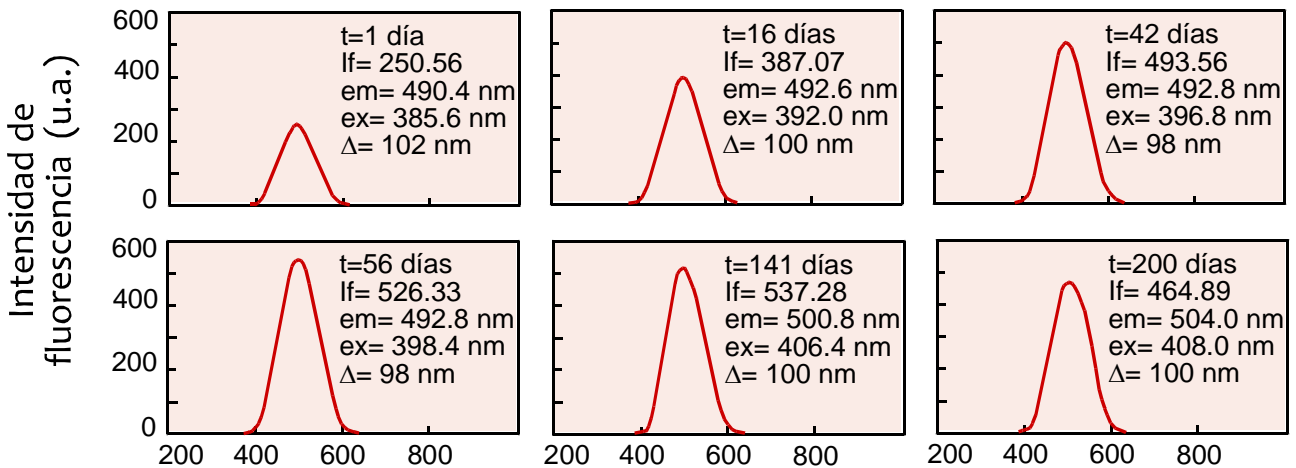

Longitud de onda (nm)

Figura 56. Espectros de emisión a diferentes tiempos de las nanopartículas obtenidas a pH 11 (fijado antes de añadir el ión $\left.\mathrm{S}^{2-}\right)$. Rendijas de $5 \mathrm{~nm}$. El resto de las variables experimentales se especifica en la Figura 53. 
Los valores de $\lambda_{\text {em }}$ y de If $_{\text {máx }}$ que muestran las nanopartículas a lo largo de su evolución para las tres experiencias se indican en las Tablas 4 a 6.

\begin{tabular}{|lcc|}
\hline$t /$ días & $\lambda_{\text {em }} / n m$ & If $_{\text {máx }} /$ u.a. \\
\hline $\mathbf{0}$ & 484.8 & 148.48 \\
\hline 1.1 & 480.4 & 281.28 \\
\hline $\mathbf{2}$ & 480.4 & 293.56 \\
\hline $\mathbf{3}$ & 480.4 & 332.48 \\
\hline $\mathbf{7}$ & 480.4 & 404.64 \\
\hline $\mathbf{1 5}$ & 480.4 & 428.73 \\
\hline $\mathbf{2 1}$ & 480.4 & 447.12 \\
\hline $\mathbf{3 0}$ & 480.4 & 471.96 \\
\hline $\mathbf{4 1}$ & 480.4 & 498.20 \\
\hline $\mathbf{4 9}$ & 480.4 & 506.32 \\
\hline $\mathbf{6 2}$ & 480.4 & 520.89 \\
\hline 130 & 480.4 & 520.06 \\
\hline 154 & 480.4 & 501.18 \\
\hline 199 & 480.4 & 432.43 \\
\hline
\end{tabular}

Tabla 4. Obtención de nanopartículas de CdS utilizando $\mathrm{S}^{2-}$ como precursor. Valores de longitud de onda de emisión $\left(\lambda_{\text {em }}\right)$ e intensidad de fluorescencia máxima ( $\left(\mathrm{If}_{\text {máx }}\right)$ de los espectros de emisión a diferentes tiempos. Nanopartículas obtenidas a pH 9 (fijado antes de añadir el ión $\mathrm{S}^{2-}$ ). Rex $=$ Rem $=5 \mathrm{~nm}$.

\begin{tabular}{|l|r|r|}
\hline \multicolumn{1}{|c|}{$\mathrm{t} /$ días } & $\lambda_{\mathrm{em}} / \mathrm{nm}$ & $\mathrm{If} \mathrm{f}_{\operatorname{máx}} /$ u.a. \\
\hline $\mathbf{0}$ & 484.4 & 147.45 \\
\hline $\mathbf{1 . 2}$ & 493.6 & 350.91 \\
\hline $\mathbf{2}$ & 494.4 & 387.07 \\
\hline $\mathbf{3}$ & 495.2 & 428.03 \\
\hline $\mathbf{7}$ & 496.0 & 524.28 \\
\hline $\mathbf{1 5}$ & 496.0 & 560.13 \\
\hline $\mathbf{2 1}$ & 496.0 & 567.45 \\
\hline $\mathbf{3 0}$ & 498.0 & 586.43 \\
\hline $\mathbf{4 1}$ & 498.2 & 579.32 \\
\hline $\mathbf{4 9}$ & 498.2 & 579.58 \\
\hline $\mathbf{6 2}$ & 500.4 & 590.52 \\
\hline $\mathbf{1 3 3}$ & 502.8 & 565.84 \\
\hline $\mathbf{1 5 4}$ & 502.8 & 548.60 \\
\hline $\mathbf{1 6 1}$ & 504.2 & 538.62 \\
\hline $\mathbf{1 9 9}$ & 505.6 & 508.60 \\
\hline
\end{tabular}

Tabla 5. Obtención de nanopartículas de CdS utilizando $\mathrm{S}^{2-}$ como precursor. Valores de longitud de onda de emisión $\left(\lambda_{\mathrm{em}}\right)$ e intensidad de fluorescencia máxima ( $\left(\mathrm{f}_{\text {máx }}\right)$ de los espectros de emisión a diferentes tiempos. Nanopartículas obtenidas a pH 10 (fijado antes de añadir el ión $\mathrm{S}^{2-}$ ). Rex $=\mathrm{Rem}=5 \mathrm{~nm}$.

\begin{tabular}{|lcc|}
\hline $\mathbf{t} /$ días & $\lambda_{\mathrm{em}} / \mathbf{n m}$ & If $_{\text {máx }} /$ u.a. \\
\hline $\mathbf{0}$ & 484.4 & 147.13 \\
\hline $\mathbf{1}$ & 490.4 & 250.56 \\
\hline $\mathbf{2}$ & 490.8 & 268.28 \\
\hline $\mathbf{4}$ & 490.8 & 282.62 \\
\hline $\mathbf{8}$ & 492.0 & 325.63 \\
\hline $\mathbf{1 6}$ & 492.6 & 387.07 \\
\hline $\mathbf{2 2}$ & 492.8 & 417.79 \\
\hline $\mathbf{3 1}$ & 492.8 & 458.34 \\
\hline $\mathbf{4 2}$ & 492.8 & 493.56 \\
\hline $\mathbf{5 0}$ & 492.8 & 520.19 \\
\hline $\mathbf{6 3}$ & 494.4 & 538.90 \\
\hline $\mathbf{1 3 3}$ & 499.2 & 544.16 \\
\hline $\mathbf{1 5 5}$ & 500.8 & 521.08 \\
\hline $\mathbf{1 6 2}$ & 504.0 & 504.51 \\
\hline $\mathbf{2 0 0}$ & 504.0 & 464.89 \\
\hline
\end{tabular}

Tabla 6. Obtención de nanopartículas de CdS utilizando $\mathrm{S}^{2-}$ como precursor. Valores de longitud de onda de emisión $\left(\lambda_{\text {em }}\right)$ e intensidad de fluorescencia máxima ( $\left(\mathrm{f}_{\text {máx }}\right.$ ) de los espectros de emisión a diferentes tiempos. Nanopartículas obtenidas a pH 11 (fijado antes de añadir el ión $\left.\mathrm{S}^{2-}\right)$. Rex $=$ Rem $=5 \mathrm{~nm}$. 
Lo primero que se comprueba es que el comportamiento luminiscente de las nanopartículas de CdS obtenidas a partir de elevadas concentraciones de $\mathrm{Cd}^{2+}$ y $\mathrm{S}^{2-}$ es muy similar al observado para disoluciones más diluidas.

La longitud de onda del proceso de excitación guarda una relación directa con el tamaño medio de las nanopartículas, desplazándose a valores más altos cuanto más aumenta el tamaño. Así, para la experiencia a $\mathrm{pH}=9$, la $\lambda_{\mathrm{ex}}$ varía desde $379 \mathrm{~nm}(\mathrm{t}=0)$ hasta $385.6 \mathrm{~nm}$ ( $\mathrm{t}=3$ días), permaneciendo posteriormente constante por hacerlo el tamaño. A $\mathrm{pH}=10$ la situación es ligeramente distinta, pues al incrementarse en el tiempo el tamaño medio de las nanopartículas la $\lambda_{\text {ex }}$ evoluciona desde $380 \mathrm{~nm}(\mathrm{t}=0)$ hasta $413 \mathrm{~nm}$ ( $\mathrm{t}=199$ días). Un fenómeno similar ocurre en la experiencia a $\mathrm{pH}=11$ los 133 primeros días de evolución, pasando la $\lambda_{\mathrm{ex}}$ desde $380 \mathrm{~nm}(\mathrm{t}=0)$ hasta $400 \mathrm{~nm}$, si bien posteriormente y a pesar de que el tamaño de las NPs se mantiene constante, la $\lambda_{\text {ex }}$ se desplaza ligeramente hasta los $408 \mathrm{~nm}$ a los 200 días. Esto indica la dependencia de la $\lambda_{\mathrm{ex}}$ no sólo con el diámetro medio de las nanopartículas, sino también con el estado de su superficie, debido a otras especies relacionadas con $\mathrm{Cd}^{2+}$.

En cuanto a la emisión (Fig. 54-56), los espectros de dicho proceso luminiscente mantienen su morfología a lo largo del tiempo de evolución y a los diferentes valores de pH estudiados. Son espectros muy simétricos, sin deformaciones en la cola y cabeza, lo que indica que la naturaleza de la superficie de las NPs es muy homogénea. La longitud de onda de emisión óptima lógicamente está relacionada con el tamaño medio de las nanopartículas, observándose un desplazamiento batocrómico a medida que aumenta el valor de $d$. Esta es la razón por la cual en la experiencia a pH 9 (Fig. 54 y Tabla 4) la $\lambda_{\text {em }}$ se mantiene constante desde las 27 horas hasta los 199 días, por hacerlo también el tamaño. En la experiencia a pH 10 (Fig. 55 y Tabla 5) la $\lambda_{\text {em }}$ óptima pasa desde $484 \mathrm{~nm}(\mathrm{t}=0$ ) hasta $506 \mathrm{~nm}$ ( $\mathrm{t}=199$ días), por evolucionar de manera continua el tamaño de las NPs. En la experiencia a pH 11 (Fig. 56 y Tabla 6) la $\lambda_{\text {em }}$ sigue el comportamiento mencionado aumentando a medida que lo hace el tamaño, pasando de $484 \mathrm{~nm}(\mathrm{t}=0)$ hasta $499 \mathrm{~nm}(\mathrm{t}=$ 133 días), pero posteriormente no se mantiene constante a pesar de que sí lo hace el tamaño, moviéndose hasta $504 \mathrm{~nm}$ a los 200 días.

Este hecho parece indicar que sobre la $\lambda_{\text {em }}$ óptima además del tamaño influye, aunque sea ligeramente, el proceso de formación de la nanocorteza de $\mathrm{Cd}(\mathrm{OH})_{2}$ y otras especies hidroxiladas. Esta influencia será mayor cuanto más alto sea el valor de $\mathrm{pH}$ de la disolución, entre otras variables. Nanopartículas de CdS de tamaño idéntico pero obtenidas en condiciones experimentales diferentes tienen propiedades luminiscentes ligeramente diferentes. 
A pesar de las diferencias comentadas en las experiencias descritas, la mayor diferencia entre los valores de $\lambda_{\text {em }}$ medidos es de $25 \mathrm{~nm}$, lo que explica que el color de la luz fluorescente observada varíe desde el verde hasta tonalidades amarillo-verdosas en las diferentes disoluciones medidas.

La intensidad de emisión de fluorescencia depende fundamentalmente de la eficacia cuántica del proceso de luminiscencia a una $\lambda_{\text {ex }}$ y $\lambda_{\text {em }}$ dadas, así como de la concentración de nanopartículas presentes en disolución en un tiempo dado. Los valores de intensidad de las tres experiencias han sido representados frente al tiempo en la Figura 57 para una mejor comprensión visual.

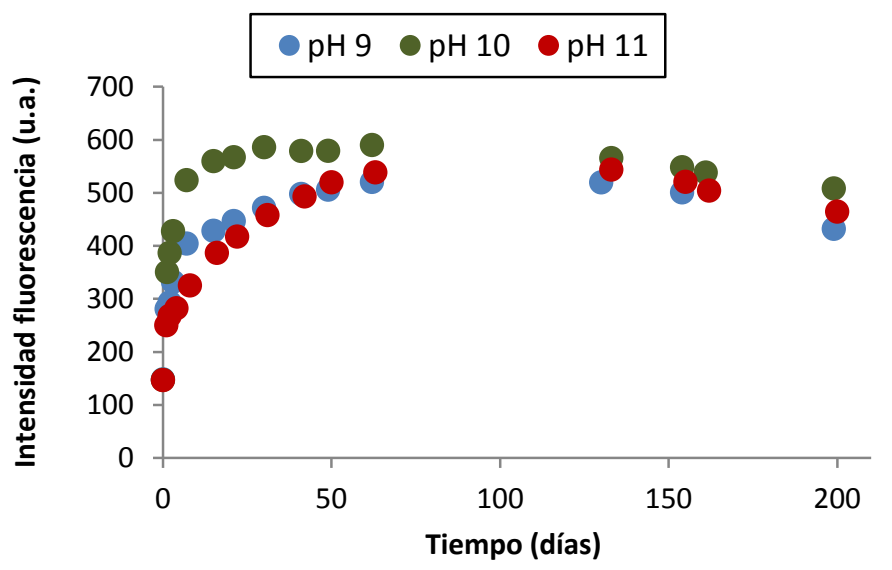

Figura 57. Evolución de la intensidad de fluorescencia máxima con el tiempo para diferentes valores de $\mathrm{pH}$ fijados antes de añadir el ion $\mathrm{S}^{2-}$. $\left[\mathrm{Cd}^{2+}\right]_{\mathrm{f}}=6.64 \times 10^{-3} \mathrm{M} ;\left[\mathrm{S}^{2-}\right]_{\mathrm{f}}=3.32 \times 10^{-3} \mathrm{M} ;[\mathrm{MAA}]_{\mathrm{f}}=$ $6.64 \times 10^{-3} \mathrm{M} ;\left[\mathrm{Cd}^{2+}\right]_{\mathrm{f}} /\left[\mathrm{S}^{2-}\right]_{\mathrm{f}}=2 ;\left[\mathrm{Cd}^{2+}\right]_{\mathrm{f}} /[\mathrm{MAA}]_{\mathrm{f}}=1$. Temperatura ambiente. Rex $=$ Rem $=5 \mathrm{~nm}$.

Al comprobar la evolución del valor de ${ } f_{\text {máx }}$ con el tiempo se observa que el comportamiento en las tres experiencias es cualitativamente parecido. En los primeros días de evolución de las nanopartículas existe un incremento importante en If $_{\text {máx }}$ hasta alcanzar un valor máximo que se mantiene constante durante un periodo de tiempo elevado para posteriormente comenzar a disminuir transcurridos aproximadamente 133 días. Este comportamiento cualitativo ya había sido observado en los estudios de la primera parte de la memoria.

Las pequeñas diferencias de concentración y del valor de $\varepsilon$ no explican por sí solas las diferencias observadas para las variaciones cuantitativas de la eficacia cuántica y, por lo tanto, del valor de If. Solo cabe la explicación de que en el caso de las nanopartículas de CdS obtenidas en medio acuoso en presencia de exceso de ion $\mathrm{Cd}^{2+}$, la formación de una nanocorteza de $\mathrm{Cd}(\mathrm{OH})_{2}$ u otras especies hidroxiladas favorezca la eficacia cuántica cuando su extensión sea pequeña, y afecte negativamente cuando su extensión supere un valor 
crítico. Para poder explicar la razón por la cual los mayores valores de If y su constancia se alcancen a pH 10, solo cabe suponer que la eficacia cuántica además depende de una relación óptima entre tamaño de nanocorteza y tamaño de nanopartícula. Relaciones superiores al valor crítico hacen que la nanocorteza de $\mathrm{Cd}(\mathrm{OH})_{2}$ contribuya al incremento de la energía no dispersiva de la nanopartícula.

\section{ESTUDIO DE VARIABLES QUE AFECTAN A LA OBTENCIÓN DE NANOPARTÍCULAS DE CdS EN FASE HOMOGÉNEA}

\section{INFLUENCIA DEL PH DE LA DISOLUCIÓN ACUOSA}

De entre las variables que pueden afectar a la reacción de hidrólisis del $\mathrm{S}_{2} \mathrm{O}_{3}{ }^{2-}$ para generar ion $\mathrm{S}^{2-}$, la primera estudiada fue el $\mathrm{pH}$ de la disolución acuosa antes de añadir la disolución de precursor de $\mathrm{S}^{2-}$.

El método experimental seguido fue descrito anteriormente, pero interesa destacar las concentraciones de los reactivos y sus relaciones molares. Se parte de $100 \mathrm{~mL}$ de una disolución de $\mathrm{Cd}^{2+} 1.0 \times 10^{-2} \mathrm{M}(1 \mathrm{mmol})$ sobre la que se añaden $714 \mu \mathrm{L}$ de MAA $1.41 \mathrm{M}(1$ $\mathrm{mmol}$ ) y se ajusta el $\mathrm{pH}$ a 8,10 y 11 respectivamente en las tres experiencias realizadas. Tras el borboteo con $\mathrm{N}_{2}$ se añaden rápidamente $50 \mathrm{~mL}$ de una disolución de $\mathrm{S}_{2} \mathrm{O}_{3}{ }^{2-} 2.0 \times 10^{-2}$ $\mathrm{M}(1 \mathrm{mmol})$. Ese momento se considera $\mathrm{t}=0$.

Las concentraciones finales en la disolución inicial, así como sus relaciones molares son: $\left[\mathrm{Cd}^{2+}\right]_{\mathrm{f}}=6.64 \times 10^{-3} \mathrm{M} ;\left[\mathrm{S}_{2} \mathrm{O}_{3}{ }^{2-}\right]_{\mathrm{f}}=6.64 \times 10^{-3} \mathrm{M} ;[\mathrm{MAA}]_{\mathrm{f}}=6.64 \times 10^{-3} \mathrm{M} ;\left[\mathrm{Cd}^{2+}\right] /\left[\mathrm{S}_{2} \mathrm{O}_{3}{ }^{2-}\right]=1$; $\left[\mathrm{Cd}^{2+}\right] /[\mathrm{MAA}]=1$.

Tras la adición de la disolución de $\mathrm{S}_{2} \mathrm{O}_{3}{ }^{2-}$ el pH varía ligeramente $(7.80 ; 9.87 ; 10.81$, respectivamente).

Antes de empezar a comentar los resultados experimentales es el momento de recordar que en este método de obtención del ion $\mathrm{S}^{2-}$ en fase homogénea, éste se va generando lentamente, por lo que la relación $\left[\mathrm{Cd}^{2+}\right] /\left[\mathrm{S}^{2-}\right]$ inicialmente es muy elevada y a medida que transcurre el tiempo va disminuyendo paulatinamente, lo que hace que las condiciones experimentales en cuanto a esta relación varíen con el tiempo y el medio en el que se forman las nanopartículas difiera del medio en el que se obtienen en fase heterogénea.

En las tres experiencias la temperatura durante el método de obtención y durante el tiempo de evolución es la del medio ambiente del laboratorio. 


\section{Evolución de los espectros de absorción}

En las Figuras 58-60 se muestran algunos de los espectros de las nanopartículas de CdS obtenidas fijando el pH inicial de 8 a 11, a diferentes tiempos desde $t=0$. En todos los casos los disoluciones son diluidas con agua bidestilada en proporción 1:5 para obtener valores de absorbancia medibles y poder comparar todas las disoluciones.
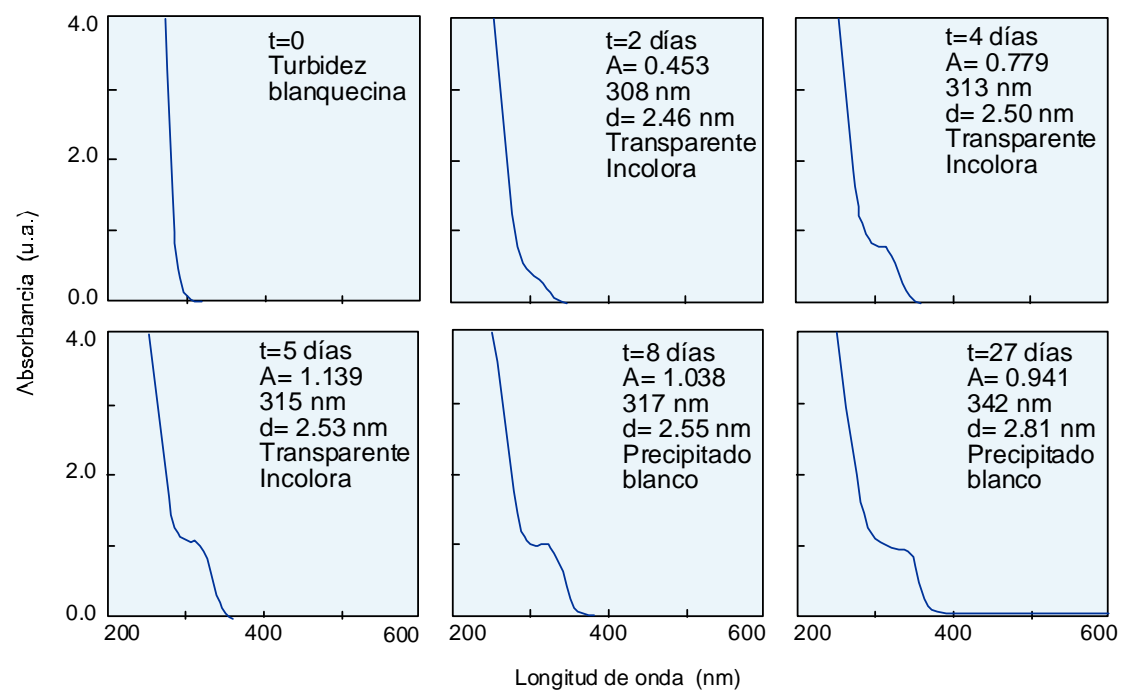

Figura 58. Espectros de absorción a diferentes tiempos de evolución. $\mathrm{pH}=8$ (fijado antes de añadir $\mathrm{S}_{2} \mathrm{O}_{3}{ }^{2-}$ ). $\left[\mathrm{Cd}^{2+}\right]_{\mathrm{f}}=6.64 \times 10^{-3}$ $\mathrm{M} ;\left[\mathrm{S}_{2} \mathrm{O}_{3}{ }^{2-}\right]_{\mathrm{f}}=6.64 \times 10^{-3} \mathrm{M} ;[\mathrm{MAA}]_{\mathrm{f}}=6.64 \times 10^{-3} \mathrm{M} ;\left[\mathrm{Cd}^{2+}\right] /\left[\mathrm{S}_{2} \mathrm{O}_{3}{ }^{2-}\right]=1 ;\left[\mathrm{Cd}^{2+}\right] /[\mathrm{MAA}]=1$. Temperatura ambiente. Factor dilución 1:5. 


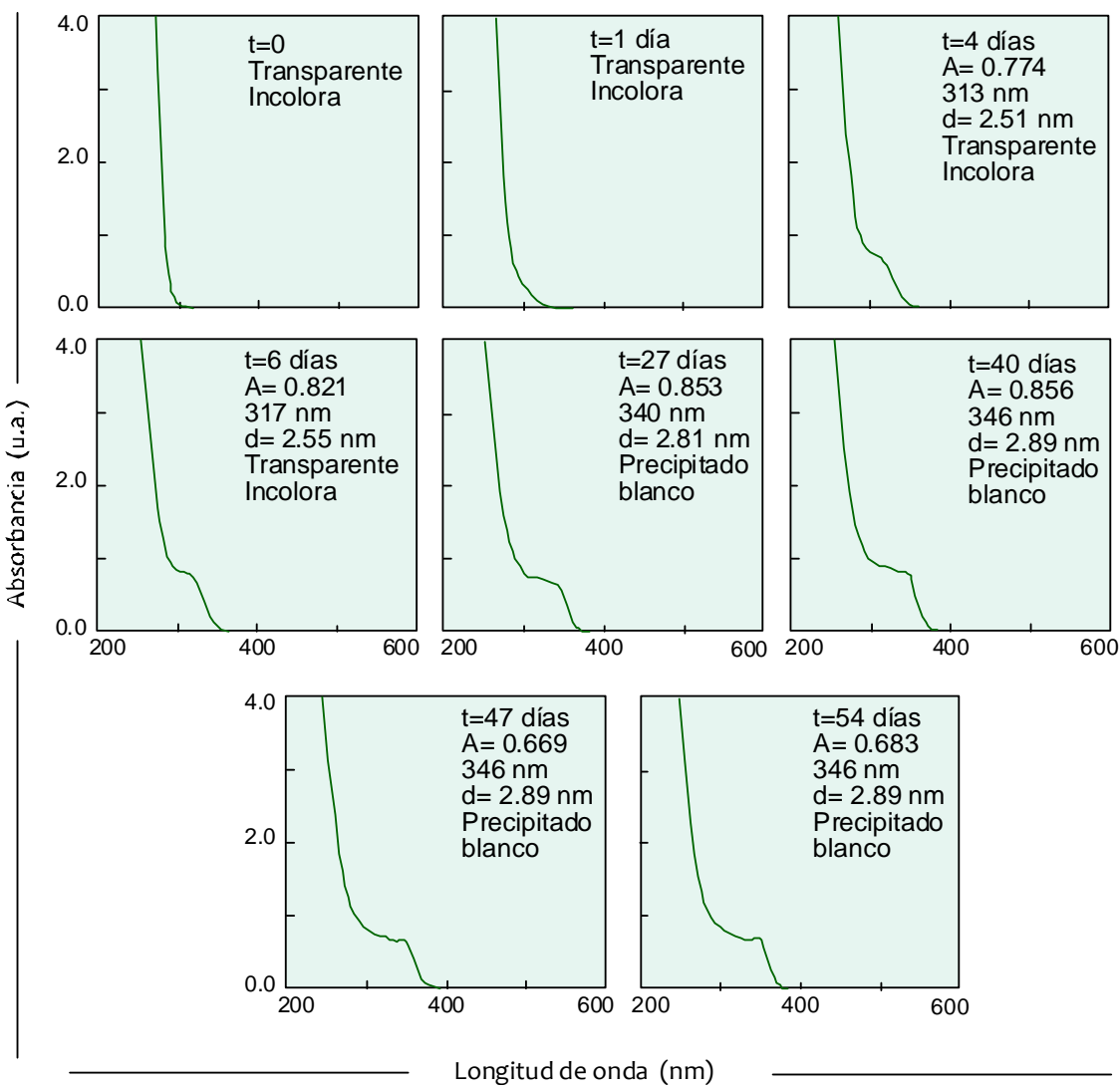

Figura 59. Espectros de absorción a diferentes tiempos de evolución. $\mathrm{pH}=10$ (fijado antes de añadir $\mathrm{S}_{2} \mathrm{O}_{3}{ }^{2-}$ ). $\left[\mathrm{Cd}^{2+}\right]_{\mathrm{f}}=6.64 \times 10^{-3}$ $\mathrm{M} ;\left[\mathrm{S}_{2} \mathrm{O}_{3}{ }^{2-}\right]_{\mathrm{f}}=6.64 \times 10^{-3} \mathrm{M} ;[\mathrm{MAA}]_{\mathrm{f}}=6.64 \times 10^{-3} \mathrm{M} ;\left[\mathrm{Cd}^{2+}\right] /\left[\mathrm{S}_{2} \mathrm{O}_{3}{ }^{2-}\right]=1 ;\left[\mathrm{Cd}^{2+}\right] /[\mathrm{MAA}]=1$. Temperatura ambiente. Factor dilución 1:5.
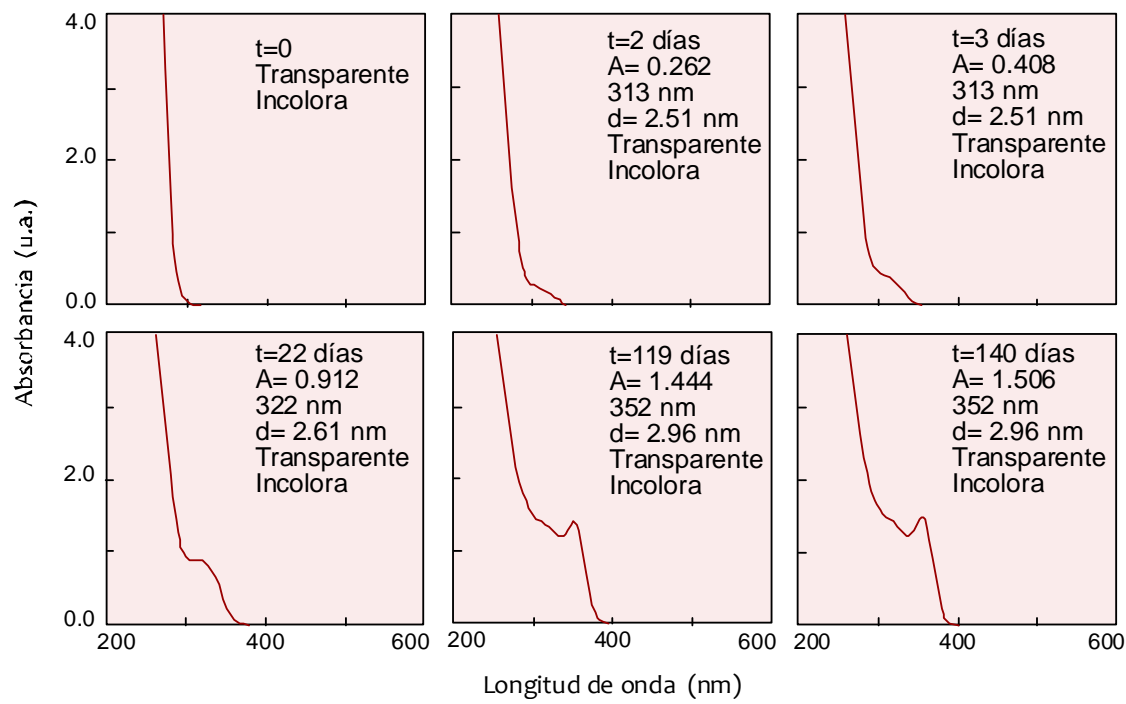

Figura 60. Espectros de absorción a diferentes tiempos de evolución. $\mathrm{pH}=11$ (fijado antes de añadir $\mathrm{S}_{2} \mathrm{O}_{3}{ }^{2-}$ ). $\left[\mathrm{Cd}^{2+}\right]_{\mathrm{f}}=6.64 \times 10^{-3}$ $\mathrm{M} ;\left[\mathrm{S}_{2} \mathrm{O}_{3}{ }^{2-}\right]_{\mathrm{f}}=6.64 \times 10^{-3} \mathrm{M} ;[\mathrm{MAA}]_{\mathrm{f}}=6.64 \times 10^{-3} \mathrm{M} ;\left[\mathrm{Cd}^{2+}\right] /\left[\mathrm{S}_{2} \mathrm{O}_{3}{ }^{2-}\right]=1 ;\left[\mathrm{Cd}^{2+}\right] /[\mathrm{MAA}]=1$. Temperatura ambiente. Factor dilución 1:5. 
En cada uno de los espectros se indica el tiempo transcurrido, el color y aspecto de la disolución antes de diluir y otros fenómenos químicos observados, como la aparición de precipitado. Además se indica la longitud de onda del máximo excitónico al comienzo de su aparición aunque tenga una zona plana, salvo en los casos en que el pico esté bien definido. A partir de este valor de $\lambda\left(\lambda_{\text {máx }}\right)$ se calcula el diámetro medio de las nanopartículas por el procedimiento ya mencionado.

Centrándonos ya en el comentario de los resultados, puede observarse cómo en los tres valores de $\mathrm{pH}$, a $\mathrm{t}=0$ el único espectro que se obtiene corresponde a la absorción del $\mathrm{S}_{2} \mathrm{O}_{3}{ }^{2-}$ y del complejo entre $\mathrm{Cd}^{2+}$ y MAA (comparar con Fig. 47 y 52, teniendo en cuenta la dilución), no apareciendo ningún hombro antes de $300 \mathrm{~nm}$ (tomando como referencia el barrido desde longitudes de onda largas). Esto indica que a $\mathrm{t}=0$ aún no se ha formado ninguna nanopartícula de $\mathrm{CdS}$, pues el $\mathrm{S}_{2} \mathrm{O}_{3}{ }^{2-}$ no ha comenzado a hidrolizarse.

Para la experiencia a pH 8, solo al cabo de 2 días de evolución se registra un espectro de absorción con un hombro cuya absorción comienza a $308 \mathrm{~nm}$ y que corresponde a nanopartículas de $2.46 \mathrm{~nm}$ de diámetro medio (Fig. 58). Cuando el pH es más alcalino, pH 10 (Fig. 59), ya al cabo de un día se registra un espectro de absorción medible desde las $340 \mathrm{~nm}$, lo que indica que aunque en pequeña concentración, ya existen nanopartículas de CdS en disolución, si bien no es posible determinar su diámetro. Este resultado es lógico si se tiene en cuenta que a pH 10 la velocidad de hidrólisis del $\mathrm{S}_{2} \mathrm{O}_{3}{ }^{2-}$ debe ser mayor que a pH 8 por incrementarse la concentración de $\mathrm{OH}^{-}$. Cabría esperar, por lo tanto, que a pH más alcalino, pH 11 (Fig. 60), al ser mayor la velocidad de hidrólisis del precursor debería detectarse antes la presencia de nanopartículas. Como puede comprobarse en la figura, sólo se detecta a partir de los 2 días de evolución y con un valor de absorbancia inferior al obtenido a pH 8 en el mismo periodo de tiempo.

Este hecho indica que el proceso de formación de las nanopartículas es más complejo de lo esperado en este método, en el que la concentración del ion $\mathrm{S}^{2-}$ aparece influenciada por el pH de la disolución pero también por el proceso químico de aparición de especies hidroxiladas (que ya comentamos en el método en fase heterogénea). El efecto conjunto de ambas influencias afecta a la velocidad de nucleación (a tiempos iniciales), de modo que el primero de ellos es favorable y el segundo desfavorable.

Independientemente del $\mathrm{pH}$ inicial de la disolución acuosa, desde $\mathrm{t}=0$ en adelante, como el $\mathrm{S}_{2} \mathrm{O}_{3}{ }^{2-}$ se hidroliza en mayor extensión generando mayor concentración de ion $\mathrm{S}^{2-}$, se incrementa la concentración de NPs lentamente así como el tamaño medio de las mismas, lo que se traduce en incrementos pequeños del valor de la absorbancia en el proceso de evolución (recuérdese que $\varepsilon$ aumenta al hacerlo el valor del diámetro medio). 
A diferencia de la experiencia en fase heterogénea, en fase homogénea no es posible calcular la concentración de nanopartículas en disolución, pues el reactivo $\mathrm{S}^{2-}$ se va generando lentamente siendo imposible conocer su concentración a cada instante. Sí es posible hacer un cálculo aproximado que nos da una idea de las concentraciones implicadas. En la experiencia de la Figura 60, las nanopartículas obtenidas a los 119 días tienen un tamaño de $d=2.96 \mathrm{~nm}$ y muestran un valor de absorbancia de 1.444 u.a. Una nanopartícula de CdS similar en tamaño se encuentra en la experiencia en fase heterogénea obtenida a las 28 horas ( $d=2.99 \mathrm{~nm}$; Fig. 49), que tiene un valor de $\varepsilon=4.7 \times 10^{5} \mathrm{~mol}^{-1} \mathrm{~L}$ (Tabla 2). Si aplicamos este valor de $\varepsilon$ a las nanopartículas de $2.96 \mathrm{~nm}$, teniendo en cuenta su valor de absorbancia así como el factor de dilución, y calculamos la concentración de nanopartículas se obtiene un valor de $1.6 \times 10^{-5} \mathrm{M}\left(\mathrm{C}_{\mathrm{cds}}\right)$, que con el valor de $\mathrm{N}=265$ conduce a una concentración de $\mathrm{CdS}$ que forma parte de las nanopartículas de $4.2 \times 10^{-3} \mathrm{M}$. Si se tiene en cuenta que la concentración inicial de $\mathrm{S}_{2} \mathrm{O}_{3}{ }^{2-}$ en disolución era $6.64 \times 10^{-3} \mathrm{M}$, quiere decir que se ha hidrolizado un $63 \%$ del reactivo inicial (a los 126 días).

En las condiciones experimentales en las que se ha trabajado, entre $\mathrm{pH}$ final $7.80 \mathrm{y}$ 10.81 , las nanopartículas que se obtienen a lo largo del proceso de evolución difieren poco en su tamaño medio (menos que por el método heterogéneo) variando desde $2.5 \mathrm{~nm}$ hasta 3.0. El número de moléculas de $\mathrm{CdS}$ contenidas en su interior varía desde $\mathrm{N}=152$ hasta $\mathrm{N}=$ 265. El tamaño de las NPs explica que todas sus disoluciones sean incoloras.

Se observa otro fenómeno que es necesario comentar y que ocurre en las experiencias realizadas a pH 8 y pH 10. En tales condiciones experimentales se observa en el proceso de evolución de las nanopartículas la aparición de una turbidez que genera un precipitado blanco. Dicho precipitado es perfectamente observable para la primera experiencia ( $\mathrm{pH} 8$ ) a los 8 días del proceso de evolución y en la experiencia a pH 10 a los 27 días, no ocurriendo nada en la experiencia a pH 11 ni siquiera a los 140 días.

Ya se había comentado que en ausencia de $\mathrm{S}_{2} \mathrm{O}_{3}{ }^{2-}$ este fenómeno también es observado y ya ha sido mencionado por otros investigadores. Al ser un proceso químico dependiente del $\mathrm{pH}$ y de la concentración inicial de $\mathrm{Cd}^{2+}$ y $\mathrm{MAA}$, parece que está relacionado con la solubilidad de especies intermedias como $\mathrm{Cd}(\mathrm{MAA})^{+}$y/o $\mathrm{Cd}(\mathrm{MAA})_{2}$, que sería mayor cuanto más alcalino es el medio en el que se encuentran. Además, la formación de estas especies compite con la reacción en la que se forman las nanopartículas de CdS, por lo que el fenómeno de precipitación de una especie blanca es también dependiente de la presencia o no del ion $\mathrm{S}^{2-}$ en disolución. Como la velocidad de generación del ion $\mathrm{S}^{2-}$ por hidrólisis del $\mathrm{S}_{2} \mathrm{O}_{3}{ }^{2-}$ es mayor a $\mathrm{pH} 10$, el precipitado aparece en estas condiciones más tarde en el tiempo que a pH 8 y no aparece a pH 11. 
Este proceso altera los espectros de absorción de las nanopartículas pues la concentración de los reactivos en disolución varía y afecta al valor de la absorbancia. Este proceso no se refleja en la línea base de los espectros de absorción por ser un precipitado que queda depositado en el fondo del recipiente.

\section{Evolución de los espectros de luminiscencia}

Paralelamente a los espectros de absorción, a lo largo del proceso de evolución de las nanopartículas de CdS se obtienen los espectros de luminiscencia a partir de alícuotas sacadas de la disolución inicial.

De la disolución a pH 8 nada más añadir la disolución de $\mathrm{S}_{2} \mathrm{O}_{3}{ }^{2-}$ la cantidad de nanopartículas generada es tan pequeña al cabo de un día de evolución, que no se observa fluorescencia con rendijas de $5 \mathrm{~nm}$. A los 4 días de evolución (Fig. 61) la luminiscencia ya es medible y las NPs generadas, aunque en pequeña concentración, muestran un espectro con un pico de excitación muy simétrico y un pico de emisión a $422.4 \mathrm{~nm}$ que corresponde a luz añil, pero que no es observable con la lámpara de mercurio.

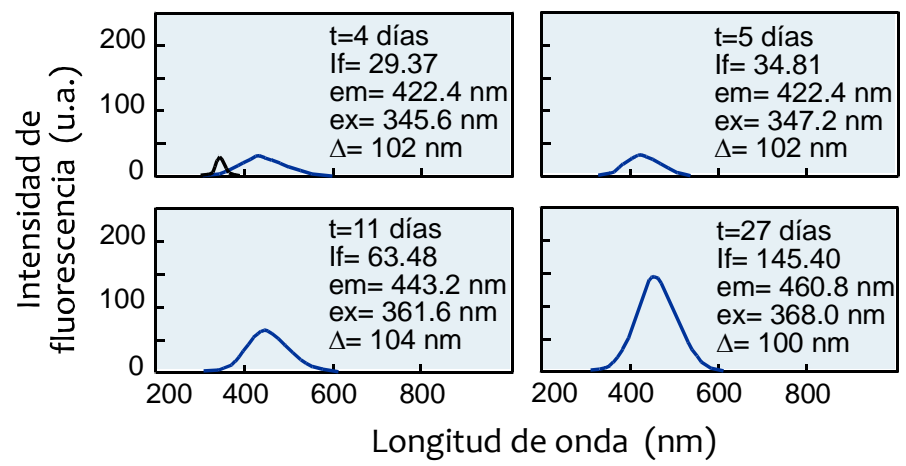

Figura 61. Espectros de luminiscencia de las nanopartículas obtenidas a $\mathrm{pH} 8$ (fijado antes de añadir el $\left.\mathrm{S}_{2} \mathrm{O}_{3}{ }^{2-}\right)$. Rendijas de $5 \mathrm{~nm}$. $\left[\mathrm{Cd}^{2+}\right]_{\mathrm{f}}=6.64 \times 10^{-3} \mathrm{M} ;\left[\mathrm{S}_{2} \mathrm{O}_{3}{ }^{2-}\right]_{\mathrm{f}}=6.64 \times 10^{-3} \mathrm{M} ;[\mathrm{MAA}]_{\mathrm{f}}=6.64 \times 10^{-3} \mathrm{M} ;\left[\mathrm{Cd}^{2+}\right] /\left[\mathrm{S}_{2} \mathrm{O}_{3}{ }^{2-}\right.$ ]$=1 ;\left[\mathrm{Cd}^{2+}\right] /[\mathrm{MAA}]=1$. Temperatura ambiente. Factor dilución 1:5.

Los espectros de excitación y emisión tienen una morfología similar a los obtenidos en el método heterogéneo, lo que muestra que las características superficiales de las nanopartículas son similares.

En la Figura 61 se muestran además algunos de los espectros de emisión registrados a lo largo de la evolución de estas nanopartículas obtenidas a pH inicial= 8 . Recordemos que a partir del día 8 aparece el precipitado blanco que retira el ion $\mathrm{Cd}^{2+}$ de la disolución, por lo que los espectros a partir de ese día corresponden a la disolución sobrenadante. 
La longitud de onda de excitación óptima sufre un desplazamiento batocrómico desde $345.6 \mathrm{~nm}$ (día 4) hasta $368.0 \mathrm{~nm}$ (día 27) como consecuencia del aumento del diámetro medio de las nanopartículas en el proceso de evolución. El mismo desplazamiento lo sufre la $\lambda_{\text {em }}$ óptima desde $422.4 \mathrm{~nm}$ hasta $460.8 \mathrm{~nm}$.

La intensidad de fluorescencia correspondiente al máximo de emisión se incrementa con el tiempo por hacerlo la concentración de NPs y el valor de $\varepsilon$ (por incrementarse el tamaño), no obstante, este incremento no es elevado. La fluorescencia a los 27 días es visible con la lámpara de mercurio (azulada).

En cuanto al valor de $\Delta$, no se observan diferencias significativas en la distribución de tamaños a lo largo del proceso de evolución y son valores similares a los observados en el método de obtención a partir de $\mathrm{S}^{2-}$ como precursor.

Para la experiencia a pH 10 el comportamiento cualitativo de las nanopartículas (propiedades luminiscentes) es muy similar al de las NPs a pH 8. Para tiempos iniciales no muestran fluorescencia medible. A los 4 días muestran espectros de excitación y emisión similares, siendo la If $_{\text {máx }}$ ligeramente menor, lo que demuestra la influencia del pH de la disolución acuosa inicial sobre su formación. Comparando ambas experiencias a este tiempo de 4 días, a pesar de tener el mismo tamaño $(2.5 \mathrm{~nm})$ las NPs obtenidas a pH 10 no muestran una fluorescencia mayor pese al aumento de la velocidad de hidrólisis del $\mathrm{S}_{2} \mathrm{O}_{3}{ }^{2-}$.

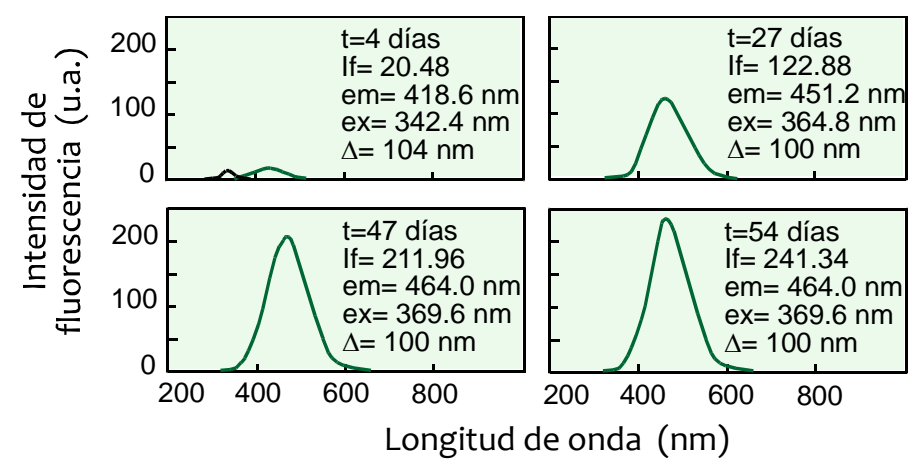

Figura 62. Espectros de luminiscencia de las nanopartículas obtenidas a $\mathrm{pH} 10$ (fijado antes de añadir el $\left.\mathrm{S}_{2} \mathrm{O}_{3}{ }^{2-}\right)$. Rendijas de $5 \mathrm{~nm}$. $\left[\mathrm{Cd}^{2+}\right]_{\mathrm{f}}=6.64 \times 10^{-3} \mathrm{M} ;\left[\mathrm{S}_{2} \mathrm{O}_{3}{ }^{2-}\right]_{\mathrm{f}}=6.64 \times 10^{-3} \mathrm{M} ;[\mathrm{MAA}]_{\mathrm{f}}=6.64 \times 10^{-3} \mathrm{M} ;\left[\mathrm{Cd}^{2+}\right] /\left[\mathrm{S}_{2} \mathrm{O}_{3}{ }^{2-}\right]=$ $1 ;\left[\mathrm{Cd}^{2+}\right] /[\mathrm{MAA}]=1$. Temperatura ambiente. Factor dilución 1:5.

A partir del día 27 aparece el precipitado blanco ya comentado, pero en menor cantidad, lo que permite registrar los espectros de fluorescencia hasta el día 54 (Fig. 62) y comprobar que además del desplazamiento hacia el rojo de las $\lambda_{\text {ex }}$ y $\lambda_{\text {em }}$ óptimas, la ${ } f_{\text {máx }}$ aumenta con el tiempo alcanzando el valor de 241 u.a. a los 54 días. 
La distribución de tamaños alrededor del diámetro medio, $\Delta$, no muestra diferencias significativas ni en el proceso de evolución ni respecto a la experiencia a pH 8.

La experiencia a pH 11 es más reveladora en el sentido de que hasta el día 154 permite el control de las propiedades luminiscentes de las nanopartículas debido a que en ningún momento aparece el precipitado blanco ya mencionado.

A pesar de que la velocidad de hidrólisis del $\mathrm{S}_{2} \mathrm{O}_{3}{ }^{2-}$ es mayor a $\mathrm{pH} 11 \mathrm{y}$, por lo tanto, se genera mayor cantidad de $\mathrm{S}^{2-}$ por unidad de tiempo, los resultados experimentales indican que la concentración de nanopartículas obtenida, medida por el valor de la absorbancia en el máximo (Fig. 60), y sus propiedades superficiales no superan a las NPs obtenidas inicialmente a $\mathrm{pH} 8$ y 10.

En la Figura 63 se muestran algunos de los espectros de emisión a lo largo de la evolución de las nanopartículas. Se observa de nuevo el desplazamiento batocrómico de la $\lambda_{\text {ex }}$ y $\lambda_{\text {em }}$ óptimas; en este último caso pasa de $428.8 \mathrm{~nm}$ a los 4 días hasta $475.8 \mathrm{~nm}$ a los 119 días, y después prácticamente permanece constante como el tamaño de las nanopartículas.

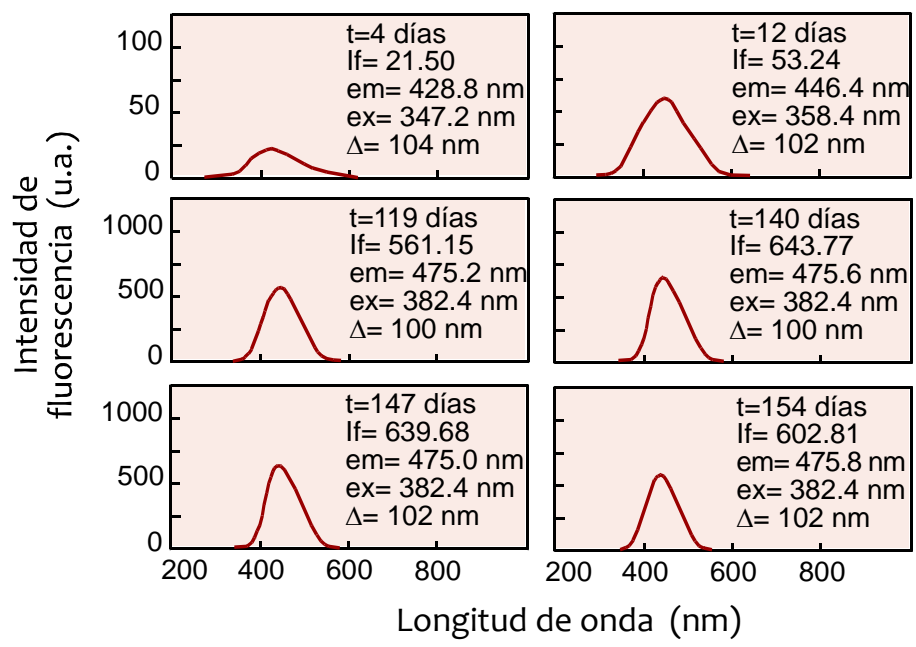

Figura 63. Espectros de luminiscencia de las nanopartículas obtenidas a pH 11 (fijado antes de añadir el $\left.\mathrm{S}_{2} \mathrm{O}_{3}{ }^{2-}\right)$. Rendijas de $5 \mathrm{~nm}$. $\left[\mathrm{Cd}^{2+}\right]_{\mathrm{f}}=6.64 \times 10^{-3} \mathrm{M} ;\left[\mathrm{S}_{2} \mathrm{O}_{3}{ }^{2-}\right]_{\mathrm{f}}=6.64 \times 10^{-3} \mathrm{M} ;[\mathrm{MAA}]_{\mathrm{f}}=6.64 \times 10^{-3} \mathrm{M} ;\left[\mathrm{Cd}^{2+}\right] /\left[\mathrm{S}_{2} \mathrm{O}_{3}{ }^{2-}\right]=1$; $\left[\mathrm{Cd}^{2+}\right] /[\mathrm{MAA}]=1$. Temperatura ambiente. Factor dilución 1:5.

Desde el día 25 del proceso de evolución la fluorescencia es visible bajo la lámpara de mercurio y, como puede comprobarse en la Figura 64, se incrementa con el tiempo hasta los 140 días, disminuyendo posteriormente. 
Para comentar esta evolución se han representado en la Figura 64 los valores de If $_{\text {máx }}$ a diferentes días desde su obtención. En la figura aparecen además los datos mostrados en la Tabla 7.

Tabla 7. Valores de intensidad de fluorescencia máxima de las nanopartículas obtenidas a $\mathrm{pH}=11$ (fijado antes de añadir $\mathrm{S}_{2} \mathrm{O}_{3}{ }^{2-}$ ). Rendijas de $5 \mathrm{~nm}$.

\begin{tabular}{ll}
\hline t (días) & If $_{\text {máx }}$ (u.a.) \\
\hline 4 & 21.50 \\
\hline 12 & 53.24 \\
27 & 143.51 \\
42 & 199.80 \\
68 & 328.14 \\
85 & 401.05 \\
119 & 561.15 \\
140 & 643.77 \\
147 & 639.68 \\
\hline 154 & 602.81 \\
\hline
\end{tabular}

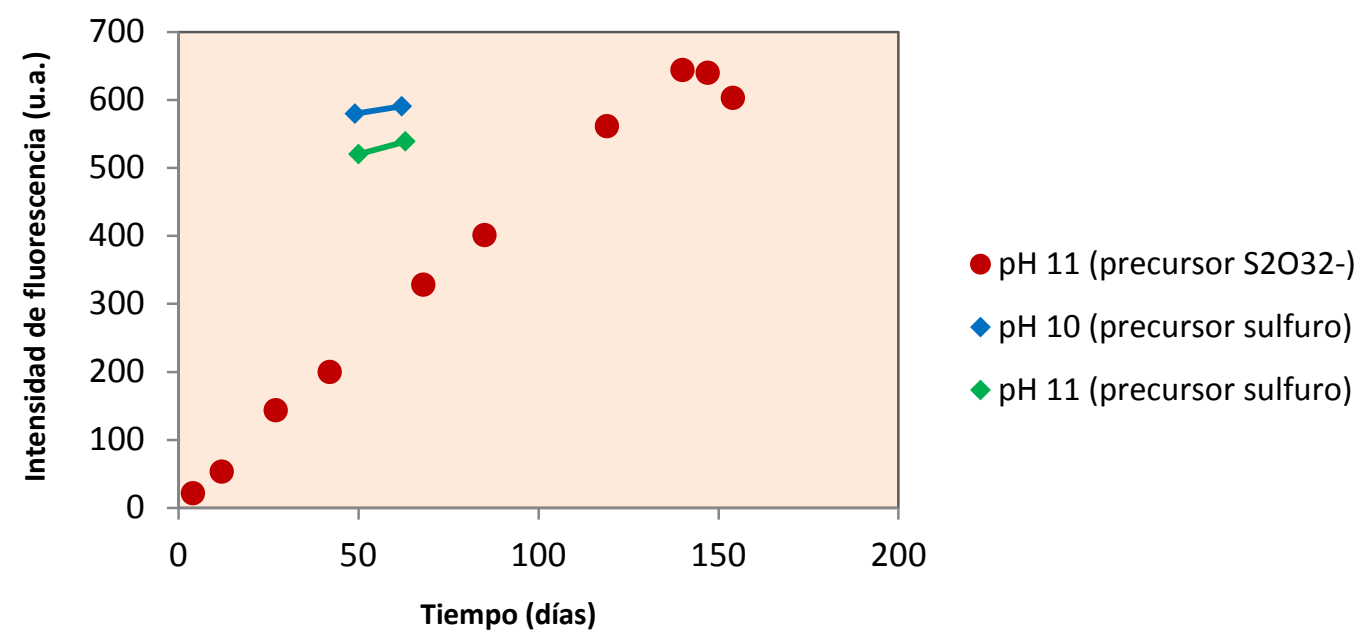

Figura 64. Evolución de la intensidad en el máximo de emisión de las nanopartículas obtenidas a pH=11 (fijado antes de añadir $\left.\mathrm{S}_{2} \mathrm{O}_{3}{ }^{2-}\right) .\left[\mathrm{Cd}^{2+}\right]_{\mathrm{f}}=6.64 \times 10^{-3} \mathrm{M} ;\left[\mathrm{S}_{2} \mathrm{O}_{3}{ }^{2-}\right]_{\mathrm{f}}=6.64 \times 10^{-3} \mathrm{M} ;[\mathrm{MAA}]_{\mathrm{f}}=6.64 \times 10^{-3} \mathrm{M} ;\left[\mathrm{Cd}^{2+}\right] /\left[\mathrm{S}_{2} \mathrm{O}_{3}{ }^{2-}\right]=1 ;\left[\mathrm{Cd}{ }^{2+}\right] /[\mathrm{MAA}]=1$. Temperatura ambiente. Factor dilución 1:5.

Puede comprobarse cómo la intensidad de fluorescencia de las nanopartículas aumenta los 140 primeros días por hacerlo su concentración junto con el proceso de formación de la nanocorteza de $\mathrm{Cd}(\mathrm{OH})_{2}$, que es más favorable a este valor de $\mathrm{pH}$. El valor máximo de If $_{\text {máx }}$ supera al obtenido en el método heterogéneo, no sólo para el mismo valor de $\mathrm{pH}$, también para el más favorable a pH 10. Transcurridos los 140 primeros días, aún manteniéndose el tamaño de las nanopartículas, la intensidad de fluorescencia comienza a disminuir por un proceso distinto al crecimiento de la nanocorteza, pues es más rápido y 
evidente. Este descenso es debido a que en ese instante se ha alcanzado la concentración máxima de $\mathrm{S}^{2-}$ necesaria para formar la máxima concentración de nanopartículas de CdS y entonces el $\mathrm{S}^{2-}$ generado por la hidrólisis de $\mathrm{S}_{2} \mathrm{O}_{3}{ }^{2-}$ se deposita sobre la superficie de las nanopartículas formando auténticas trampas para el proceso de emisión.

Como conclusión de los estudios sobre la influencia del $\mathrm{pH}$ inicial sobre las características de las nanopartículas de $\mathrm{CdS}$ obtenidas utilizando $\mathrm{S}_{2} \mathrm{O}_{3}{ }^{2-}$ como precursor, se puede enunciar que:

En las condiciones experimentales empleadas no se observan grandes diferencias en la velocidad de hidrólisis del $\mathrm{S}_{2} \mathrm{O}_{3}{ }^{2-}$, si bien el estudio se ha visto alterado pues a $\mathrm{pH} 8$ y 10 aparece un precipitado blanco atribuido a la inestabilidad de especies entre $\mathrm{Cd}^{2+}$ y MAA. Para los primeros días de evolución de las NPs no se observan grandes diferencias al variar el pH de la disolución acuosa sobre la que se añade el precursor. El diámetro medio de las nanopartículas para los tiempos iniciales es muy similar y no se observan diferencias en cuanto a la distribución de tamaños alrededor del valor medio.

Las nanopartículas de CdS obtenidas a estos tres valores de $\mathrm{pH}$ utilizando una concentración inicial de $\mathrm{S}_{2} \mathrm{O}_{3}{ }^{2-}$ de $6.64 \times 10^{-3} \mathrm{M}$ tienen propiedades luminiscentes similares los primeros días de su evolución. En la experiencia a pH 11 las NPs alcanzan valores de fluorescencia más elevados el día 140 que los que muestran las nanopartículas obtenidas por el método de adición directa de los iones $S^{2-}$. Esta fluorescencia en días posteriores disminuye más rápidamente que en el caso de las NPs obtenidas en medio heterogéneo, debido a la aparición de trampas sobre su superficie.

\section{INFLUENCIA DE LA CONCENTRACIÓN DE $\mathrm{S}_{2} \mathrm{O}_{3}{ }^{2-}$}

Otra de las variables que lógicamente influyen sobre la generación de ion $\mathrm{S}^{2-}$ a partir de $\mathrm{S}_{2} \mathrm{O}_{3}{ }^{2-}$ es precisamente la concentración puesta en disolución de este último reactivo.

Para estudiar la influencia de esta variable sobre el proceso de obtención de nanopartículas de $\mathrm{CdS}$ en fase homogénea se preparan disoluciones de $\left[\mathrm{Cd}^{2+}\right]_{\mathrm{f}}=6.64 \times 10^{-3} \mathrm{M}$ y $[\mathrm{MAA}]_{\mathrm{f}}=6.64 \times 10^{-3} \mathrm{M}$, que se ajustan con $\mathrm{NaOH}$ a $\mathrm{pH}=10$ y tras burbujear nitrógeno se agregan $50 \mathrm{~mL}$ de disolución de $\mathrm{S}_{2} \mathrm{O}_{3}{ }^{2-}$ desde $4.0 \times 10^{-2} \mathrm{M}$ hasta $8.0 \times 10^{-1} \mathrm{M}$. En estas condiciones experimentales la concentración final de $\mathrm{S}_{2} \mathrm{O}_{3}{ }^{2-}$ está comprendida entre $13.3 \times 10^{-3} \mathrm{M}$ y $4.0 \times 10^{-1} \mathrm{M}$, por lo que la relación $\left[\mathrm{Cd}^{2+}\right]_{\mathrm{f}} /[\mathrm{MAA}]_{\mathrm{f}}$ se mantiene constante en $1 \mathrm{y}$ la relación $\left[\mathrm{S}_{2} \mathrm{O}_{3}{ }^{2-}\right]_{\mathrm{f}} /\left[\mathrm{Cd}^{2+}\right]_{\mathrm{f}}$ varía desde 2 hasta 60 .

Al igual que en el estudio de la variable anterior, todo el proceso se realiza a temperatura ambiente. 
El motivo de escoger el $\mathrm{pH}$ de 10 para la experiencia $\left(\mathrm{pH}_{\text {final }}=9.87\right)$ estriba en que se quiere comprobar si en presencia de mayores cantidades de $\mathrm{S}^{2-}$ generado (mayor concentración inicial de $\mathrm{S}_{2} \mathrm{O}_{3}{ }^{2-}$ ) desaparece o no la formación del precipitado blanco que es interferente en el método de obtención de nanopartículas de CdS.

\section{Evolución de los espectros de absorción}

A lo largo del proceso de evolución se sacan alícuotas de las cuales, tras ser diluídas en proporción 1:5 con agua bidestilada, se registran los correspondientes espectros de absorción que se muestran en las Figuras 65-71.

En dichos espectros se indican además del tiempo transcurrido desde el momento en que se terminó de añadir la disolución de $\mathrm{S}_{2} \mathrm{O}_{3}{ }^{2-}$, la longitud de onda del máximo y/o de otras bandas del espectro, el tamaño medio de las nanopartículas calculado a partir de la longitud de onda del primer pico excitónico, los valores de absorbancia correspondientes, así como las características físicas de la disolución y si aparece o no precipitado.

En vez de hacer un comentario particular de cada una de las experiencias hemos preferido comentar los resultados en general y, cuando sea necesario, comparativamente.

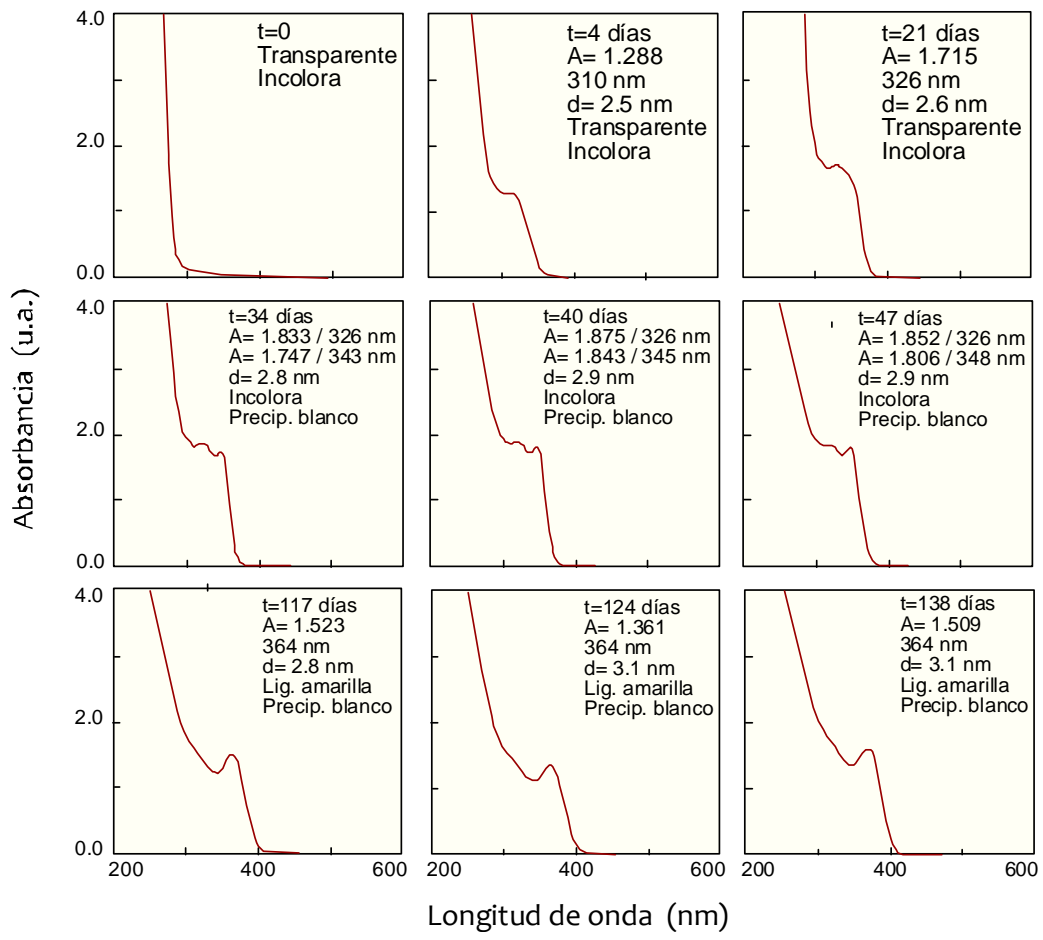

Figura 65. Espectros de absorción a diferentes tiempos de evolución. Influencia de la concentración de $\mathrm{S}_{2} \mathrm{O}_{3}{ }^{2-}$. $\left[\mathrm{S}_{2} \mathrm{O}_{3}{ }^{2-}\right]_{\mathrm{f}}=$ $13.3 \times 10^{-3} \mathrm{M} ;\left[\mathrm{Cd}^{2+}\right]_{\mathrm{f}}=6.64 \times 10^{-3} \mathrm{M} ;[\mathrm{MAA}]_{\mathrm{f}}=6.64 \times 10^{-3} \mathrm{M} ;\left[\mathrm{S}_{2} \mathrm{O}_{3}{ }^{2-}\right] /\left[\mathrm{Cd}^{2+}\right]=2 ;\left[\mathrm{Cd}^{2+}\right] /[\mathrm{MAA}]=1 . \mathrm{pH}=10$ (fijado antes de añadir $\mathrm{S}_{2} \mathrm{O}_{3}{ }^{2-}$ ). Temperatura ambiente. Dilución 1:5. 


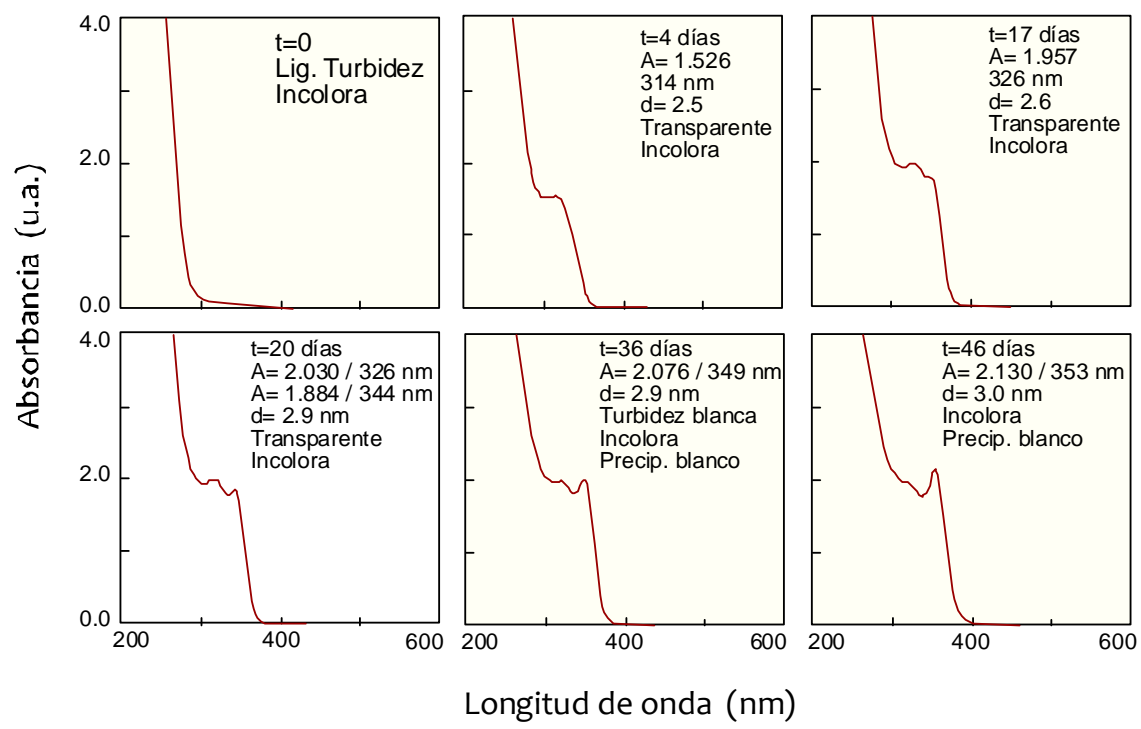

Figura 66. Espectros de absorción a diferentes tiempos de evolución. Influencia de la concentración de $\mathrm{S}_{2} \mathrm{O}_{3}{ }^{2-}$. $\left[\mathrm{S}_{2} \mathrm{O}_{3}{ }^{2-}\right]_{\mathrm{f}}=$ $19.9 \times 10^{-3} \mathrm{M} ;\left[\mathrm{Cd}^{2+}\right]_{\mathrm{f}}=6.64 \times 10^{-3} \mathrm{M} ;[\mathrm{MAA}]_{\mathrm{f}}=6.64 \times 10^{-3} \mathrm{M} ;\left[\mathrm{S}_{2} \mathrm{O}_{3}{ }^{2-}\right] /\left[\mathrm{Cd}^{2+}\right]=3 ;\left[\mathrm{Cd}^{2+}\right] /[\mathrm{MAA}]=1 . \mathrm{pH}=10$ (fijado antes de añadir $\mathrm{S}_{2} \mathrm{O}_{3}{ }^{2-}$ ). Temperatura ambiente. Dilución 1:5.
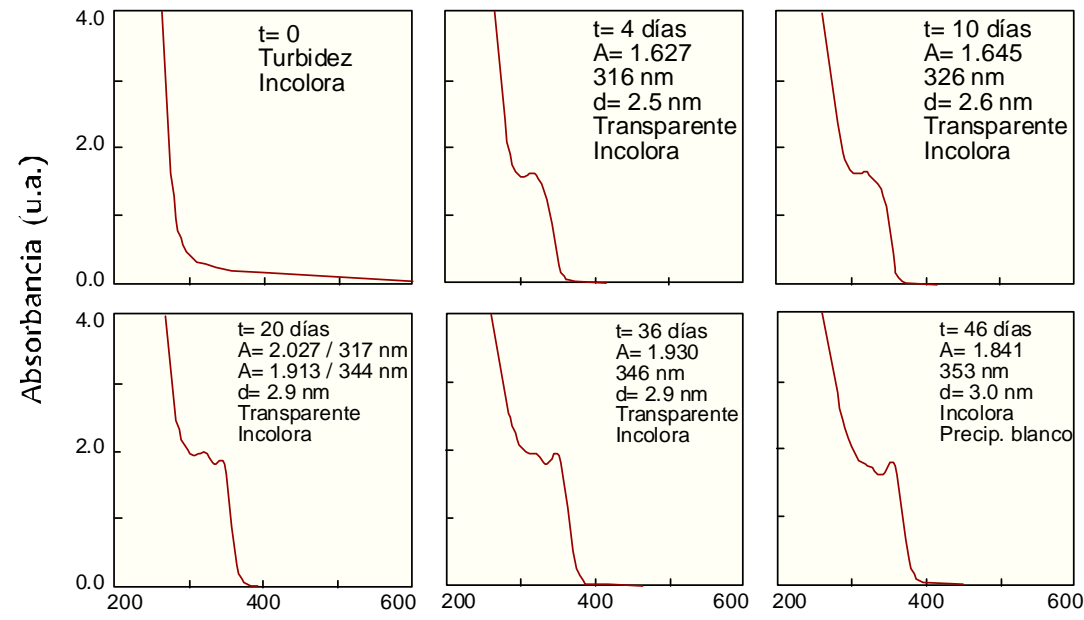

Longitud de onda (nm)

Figura 67. Espectros de absorción a diferentes tiempos de evolución. Influencia de la concentración de $\mathrm{S}_{2} \mathrm{O}_{3}{ }^{2-}$. $\left[\mathrm{S}_{2} \mathrm{O}_{3}{ }^{2-}\right]_{\mathrm{f}}=$ $26.5 \times 10^{-3} \mathrm{M} ;\left[\mathrm{Cd}^{2+}\right]_{\mathrm{f}}=6.64 \times 10^{-3} \mathrm{M} ;[\mathrm{MAA}]_{\mathrm{f}}=6.64 \times 10^{-3} \mathrm{M} ;\left[\mathrm{S}_{2} \mathrm{O}_{3}{ }^{2-}\right] /\left[\mathrm{Cd}^{2+}\right]=4 ;\left[\mathrm{Cd}^{2+}\right] /[\mathrm{MAA}]=1 . \mathrm{pH}=10$ (fijado antes de añadir $\mathrm{S}_{2} \mathrm{O}_{3}{ }^{2-}$ ). Temperatura ambiente. Dilución 1:5. 

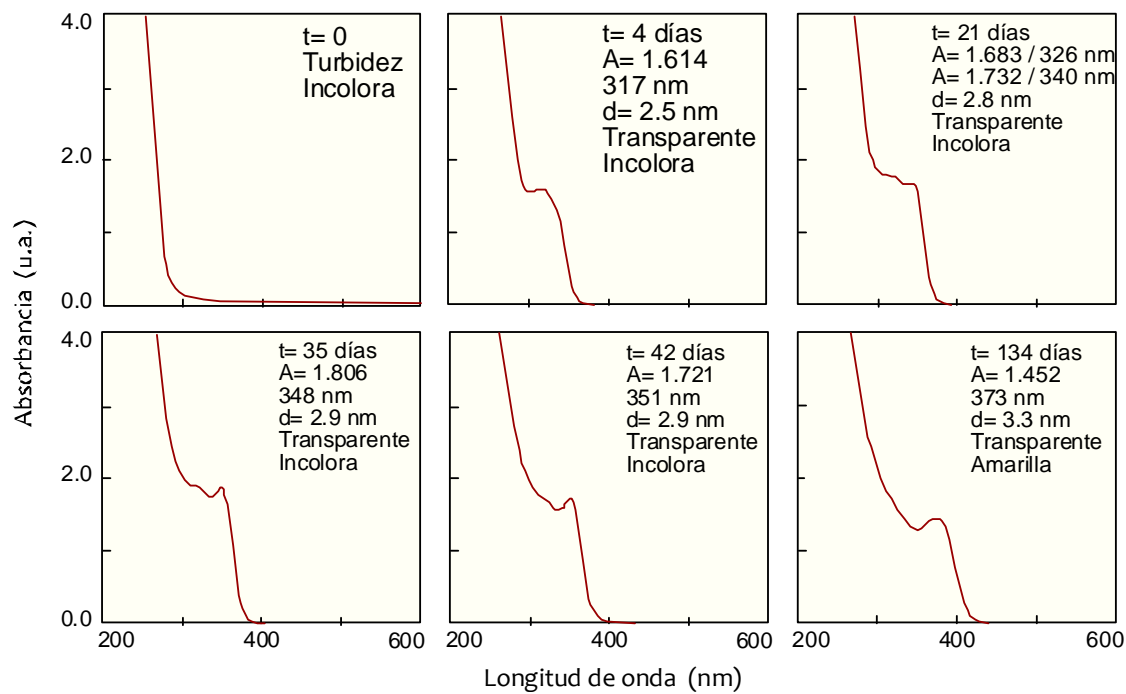

Figura 68. Espectros de absorción a diferentes tiempos de evolución. Influencia de la concentración de $\mathrm{S}_{2} \mathrm{O}_{3}{ }^{2-}$. $\left[\mathrm{S}_{2} \mathrm{O}_{3}{ }^{2-}\right]_{f}=$ $33.2 \times 10^{-3} \mathrm{M} ;\left[\mathrm{Cd}^{2+}\right]_{\mathrm{f}}=6.64 \times 10^{-3} \mathrm{M} ;[\mathrm{MAA}]_{\mathrm{f}}=6.64 \times 10^{-3} \mathrm{M} ;\left[\mathrm{S}_{2} \mathrm{O}_{3}{ }^{2-}\right] /\left[\mathrm{Cd}^{2+}\right]=5 ;\left[\mathrm{Cd}^{2+}\right] /[\mathrm{MAA}]=1 . \mathrm{pH}=10$ (fijado antes de añadir $\left.\mathrm{S}_{2} \mathrm{O}_{3}{ }^{2-}\right)$. Temperatura ambiente. Dilución 1:5.
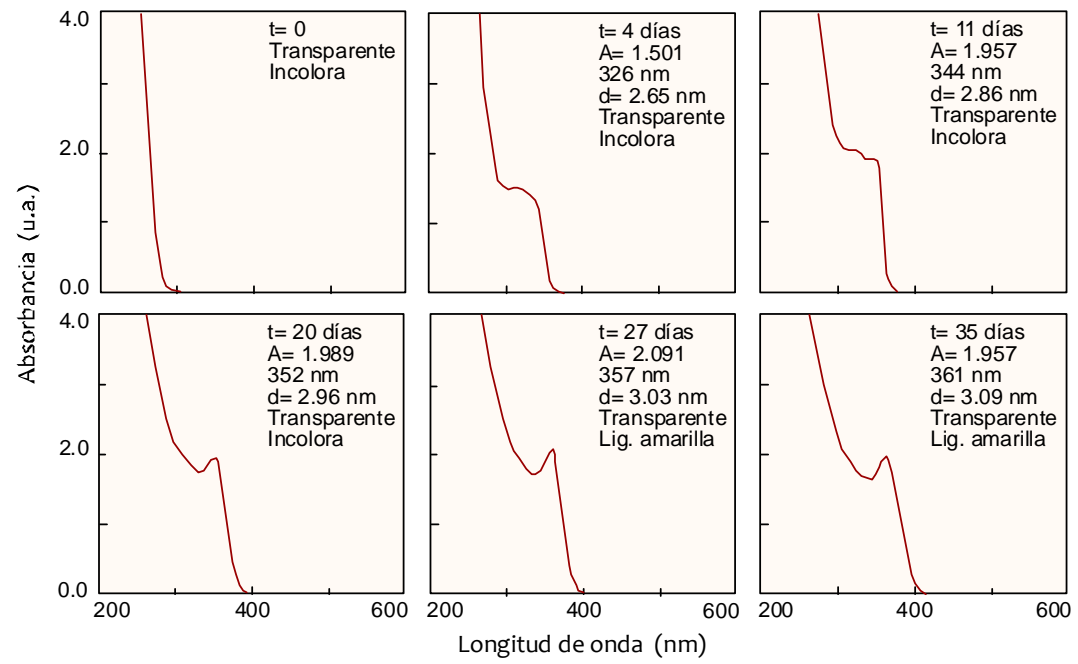

Figura 69. Espectros de absorción a diferentes tiempos de evolución. Influencia de la concentración de $\mathrm{S}_{2} \mathrm{O}_{3}{ }^{2-}$. $\left[\mathrm{S}_{2} \mathrm{O}_{3}{ }^{2-}\right]_{f}=$ $66.4 \times 10^{-3} \mathrm{M} ;\left[\mathrm{Cd}^{2+}\right]_{\mathrm{f}}=6.64 \times 10^{-3} \mathrm{M} ;[\mathrm{MAA}]_{\mathrm{f}}=6.64 \times 10^{-3} \mathrm{M} ;\left[\mathrm{S}_{2} \mathrm{O}_{3}{ }^{2-}\right] /\left[\mathrm{Cd}^{2+}\right]=5 ;\left[\mathrm{Cd}^{2+}\right] /[\mathrm{MAA}]=1 . \mathrm{pH}=10$ (fijado antes de añadir $\left.\mathrm{S}_{2} \mathrm{O}_{3}{ }^{2-}\right)$. Temperatura ambiente. Dilución 1:5. 

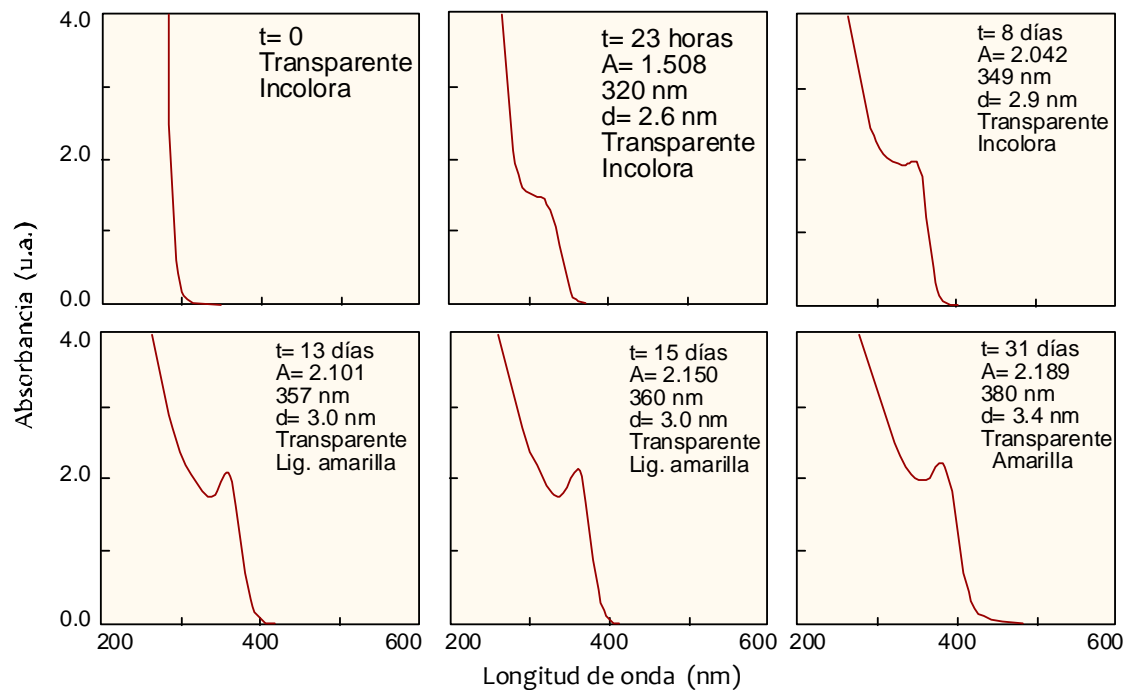

Figura 70. Espectros de absorción a diferentes tiempos de evolución. Influencia de la concentración de $\mathrm{S}_{2} \mathrm{O}_{3}{ }^{2-}$. $\left[\mathrm{S}_{2} \mathrm{O}_{3}{ }^{2-}\right]_{\mathrm{f}}=$ $132.7 \times 10^{-3} \mathrm{M} ;\left[\mathrm{Cd}^{2+}\right]_{\mathrm{f}}=6.64 \times 10^{-3} \mathrm{M} ;[\mathrm{MAA}]_{\mathrm{f}}=6.64 \times 10^{-3} \mathrm{M} ;\left[\mathrm{S}_{2} \mathrm{O}_{3}{ }^{2-}\right] /\left[\mathrm{Cd}^{2+}\right]=20 ;\left[\mathrm{Cd}^{2+}\right] /[\mathrm{MAA}]=1 . \mathrm{pH}=10$ (fijado antes de añadir $\left.\mathrm{S}_{2} \mathrm{O}_{3}{ }^{2-}\right)$. Temperatura ambiente. Dilución 1:5.

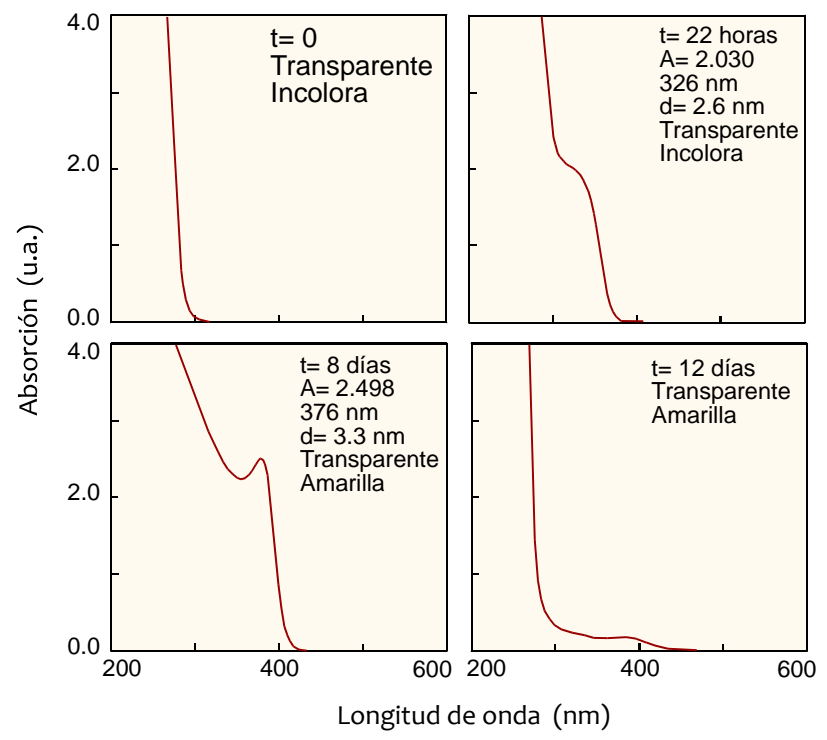

Figura 71. Espectros de absorción a diferentes tiempos de evolución. Influencia de la concentración de $\mathrm{S}_{2} \mathrm{O}_{3}{ }^{2-} .\left[\mathrm{S}_{2} \mathrm{O}_{3}{ }^{2-}\right]_{\mathrm{f}}=400 \times 10^{-3} \mathrm{M} ;\left[\mathrm{Cd}^{2+}\right]_{\mathrm{f}}=6.64 \times 10^{-3} \mathrm{M} ;[\mathrm{MAA}]_{\mathrm{f}}=6.64 \times 10^{-3} \mathrm{M} ;\left[\mathrm{S}_{2} \mathrm{O}_{3}{ }^{2-}\right] /\left[\mathrm{Cd}^{2+}\right]=60$; $\left[\mathrm{Cd}^{2+}\right] /[\mathrm{MAA}]=1 . \mathrm{pH}=10$ (fijado antes de añadir $\mathrm{S}_{2} \mathrm{O}_{3}{ }^{2-}$ ). Temperatura ambiente. Dilución 1:5.

En todas la experiencias se observa la siguiente evolución en cuanto a la morfología de los espectros de absorción: el espectro obtenido a $\mathrm{t}=0$ indica en todos los casos que en el tiempo que se tarda en añadir la disolución de $\mathrm{S}_{2} \mathrm{O}_{3}{ }^{2-}$ no existe formación de nanopartículas. En alguna de las experiencias se observa que la línea base del espectro se desvía del valor cero de absorbancia, lo que indica la presencia de una pequeña turbidez 
blanquecina al ajustar el pH de la disolución acuosa a 10, pero que desaparece a los pocos minutos. Pasadas unas horas o incluso días, dependiendo de la concentración de $\mathrm{S}_{2} \mathrm{O}_{3}{ }^{2-}$, el espectro de la disolución muestra ya un hombro entre $300 \mathrm{~nm}$ y $330 \mathrm{~nm}$ que indica la presencia de nanopartículas de CdS en concentración apreciable (se debe recordar que las disoluciones medidas han sido diluidas de las originales en proporción 1:5). A medida que las NPs evolucionan creciendo en tamaño, el hombro antes mencionado se va deformando generando en el espectro otro hombro que aparece siempre a $326 \mathrm{~nm}$, independientemente del tiempo de evolución y de la concentración de $\mathrm{S}_{2} \mathrm{O}_{3}{ }^{2-}$, y que no corresponde a un proceso excitónico de las nanopartículas sino a la presencia de especies complejas entre $\mathrm{Cd}^{2+}$ y MAA (Fig. 52). A su derecha aparece un pico de absorción que con el tiempo se diferencia cada vez más y que corresponde al proceso excitónico de las NPs.

La morfología comentada tiene lugar más o menos rápidamente dependiendo de la concentración inicial de $\mathrm{S}_{2} \mathrm{O}_{3}{ }^{2-}$, siendo lenta para las experiencias con menores concentraciones de reactivo precursor o transcurriendo en 12 días cuando la concentración de reactivo es alta.

En los casos en los que aparece el hombro a $326 \mathrm{~nm}$ y el pico próximo, puede que el valor de la absorbancia del primero sea mayor, en cuyo caso a esa longitud de onda la hemos denominado $\lambda_{\text {máx }}$ pero no se utiliza, como es lógico, para el cálculo del tamaño de la nanopartícula. En estos casos el tamaño se calcula a partir de la $\lambda$ del pico excitónico.

El precipitado blanco aparece de nuevo en las experiencias en las que la concentración de $\mathrm{S}_{2} \mathrm{O}_{3}{ }^{2-}$ es inferior a $33.2 \times 10^{-3} \mathrm{M}$, y aparece más tarde cuanto mayor es la concentración inicial de $\mathrm{S}_{2} \mathrm{O}_{3}{ }^{2-}$. Cuando el $\mathrm{S}_{2} \mathrm{O}_{3}{ }^{2-}$ inicial es $13.3 \times 10^{-3} \mathrm{M}$ el precipitado blanco aparece a los 34 días; si el $\mathrm{S}_{2} \mathrm{O}_{3}{ }^{2-}$ es $19.9 \times 10^{-3} \mathrm{M}$ lo hace a los 36 días y si se eleva hasta $26.5 \times 10^{-3} \mathrm{M}$ su aparición, en pequeña cantidad, es observable a los 46 días. En las experiencias en las que la concentración de $\mathrm{S}_{2} \mathrm{O}_{3}{ }^{2-}$ es más elevada no se observa la aparición de dicho precipitado en el periodo de tiempo estudiado.

Lo comentado anteriormente indica que la aparición de precipitado blanco está influenciada por el $\mathrm{pH}$ (como vimos en la experiencia anterior), así como por la concentración de $\mathrm{Cd}(\mathrm{MAA})^{+}$y/o $\mathrm{Cd}(\mathrm{MAA})_{2}$ en disolución (menor cuanto más alta sea la concentración de $\mathrm{S}^{2-}$ disponible para formar las nanopartículas, esto es, cuanto mayor sea la concentración de $\mathrm{S}_{2} \mathrm{O}_{3}{ }^{2-}$ inicial).

En las disoluciones en las que aparece el precipitado blanco, éste decanta rápidamente y permite medidas de la disolución restante. Si bien en estos casos esas medidas no son cuantitativamente correctas, sí nos proporcionan una idea de la evolución con el tiempo de algunos parámetros de interés. 
En la experiencia en la que la concentración de $\mathrm{S}_{2} \mathrm{O}_{3}{ }^{2-}$ es elevada $\left(400 \times 10^{-3} \mathrm{M}\right.$, Fig. 71) a los 12 días de evolución aparece un precipitado cuajoso de color amarillo debido a la aglomeración de nanopartículas de CdS por pérdida de capacidad dispersiva del mercaptoacetato, debido a interacciones electrostáticas competitivas.

El tamaño medio de las nanopartículas, al ser disoluciones diluidas, ha sido calculado a partir de la longitud de onda a la que aparece el hombro o pico excitónico. Los valores obtenidos se muestran en cada espectro de absorción de las Figuras 65-71. En todos los casos el diámetro medio de las NPs se incrementa con el tiempo, en cada experiencia, a mayor velocidad cuanto mayor es la concentración de $\mathrm{S}_{2} \mathrm{O}_{3}{ }^{2-}$. No obstante, para concentraciones inferiores a $33.2 \times 10^{-3} \mathrm{M}$ existen pocas diferencias en la evolución del tamaño con el tiempo. En la Tabla 8 se muestran los valores de $d$ a lo largo del tiempo para las diferentes concentraciones estudiadas incluyendo la experiencia del estudio anterior $\left(\mathrm{pH}=10,\left[\mathrm{~S}_{2} \mathrm{O}_{3}{ }^{2-}\right]=6.64 \times 10^{-3} \mathrm{M}\right)$.

Tabla 8. Valor del tamaño medio de las nanopartículas. Influencia de la concentración de $\mathrm{S}_{2} \mathrm{O}_{3}{ }^{2-}$. $\left[\mathrm{Cd}^{2+}\right]_{\mathrm{f}}=$ $6.64 \times 10^{-3} \mathrm{M} ;[\mathrm{MAA}]_{\mathrm{f}}=6.64 \times 10^{-3} \mathrm{M} ;\left[\mathrm{Cd}^{2+}\right] /[\mathrm{MAA}]=1 . \mathrm{pH}=10$ (fijado antes de añadir $\mathrm{S}_{2} \mathrm{O}_{3}{ }^{2-}$ ). Temperatura ambiente. Dilución 1:5.

\begin{tabular}{|c|c|c|c|c|c|c|c|c|}
\hline \multirow{4}{*}{$t$ (días) } & \multicolumn{8}{|c|}{ Diámetro medio $(\mathrm{nm})$} \\
\hline & \multicolumn{8}{|c|}{$\left[\mathrm{S}_{2} \mathrm{O}_{3}{ }^{2-}\right] \times 10^{-3} \mathrm{M}$} \\
\hline & $a$ & b & c & d & e & $f$ & g & $\mathbf{h}$ \\
\hline & 6.64 & 13.3 & 19.9 & 26.5 & 33.2 & 66.4 & 132.7 & 400.0 \\
\hline 0.83 & & & & & & 2.5 & & \\
\hline 0.95 & & & & & 2.5 & & 2.6 & 2.6 \\
\hline 2 & & & 2.5 & 2.5 & 2.5 & & 2.6 & \\
\hline 4 & 2.5 & 2.5 & 2.5 & 2.5 & 2.5 & 2.6 & & \\
\hline 5 & & & & & & & & 2.9 \\
\hline 6 & 2.5 & 2.5 & & & & 2.8 & 2.8 & \\
\hline 7 & & & & & & & & 3.1 \\
\hline 8 & & & & & & & 2.9 & 3.3 \\
\hline 10 & & & 2.6 & 2.6 & 2.6 & & & \\
\hline 11 & & & & & & 2.9 & & \\
\hline 12 & & & & & & & & 3.7 \\
\hline 13 & & & & & & & 3.0 & \\
\hline 19 & & & & & & & 3.0 & \\
\hline 20 & & & 2.9 & 2.9 & & 3.0 & 3.13 & \\
\hline 21 & & 2.6 & & & 2.8 & & & \\
\hline 25 & & & & & & 3.0 & & \\
\hline 27 & 2.8 & & & & & 3.0 & 3.3 & \\
\hline 28 & & & 3.0 & 2.9 & 2.9 & & & \\
\hline 31 & & & & & & & 3.4 & \\
\hline 32 & & & & & & 3.0 & & \\
\hline 35 & & 2.8 & 2.9 & 2.9 & 2.9 & 3.0 & & \\
\hline 40 & 2.9 & 2.9 & & & & & & \\
\hline 42 & 2.9 & & & & 2.9 & & & \\
\hline 47 & 2.9 & 2.9 & 3.0 & 3.0 & & & & \\
\hline
\end{tabular}


El tamaño de las nanopartículas obtenidas en las experiencias mencionadas varía desde $2.5 \mathrm{~nm}$ hasta $3.7 \mathrm{~nm}$, lo que corresponde a valores de $\mathrm{N}$ comprendidos entre $156 \mathrm{y}$ 526.

Los valores de algunas de las experiencias en la Tabla 8 han sido representados en la Figura 72 para una mejor visualización. Puede comprobarse cómo cuanto mayor es la concentración de $\mathrm{S}_{2} \mathrm{O}_{3}{ }^{2-}$ inicial, mayor es la velocidad de generación de ion $\mathrm{S}^{2-}$ y mayor es el tamaño de las nanopartículas.

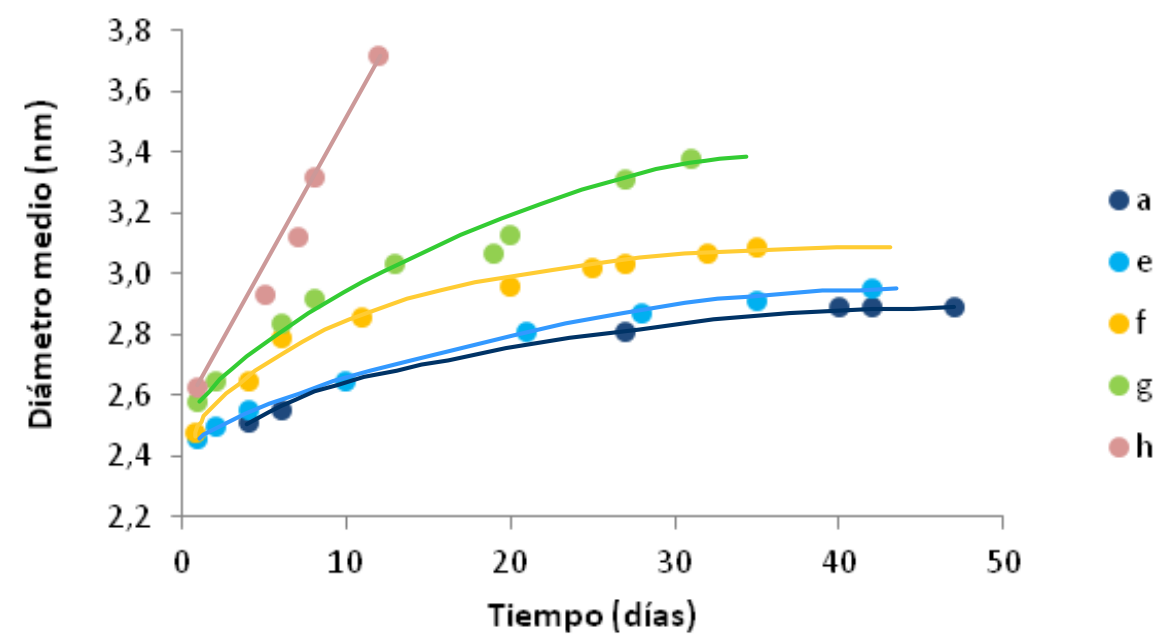

Figura 72. Influencia de la concentración de $\mathrm{S}_{2} \mathrm{O}_{3}^{2-}$. Evolución del tamaño medio de las nanopartículas. $\left[\mathrm{Cd}^{2+}\right]_{\mathrm{f}}=6.64 \times 10^{-3} \mathrm{M} ;[\mathrm{MAA}]_{\mathrm{f}}=6.64 \times 10^{-3} \mathrm{M} ;\left[\mathrm{Cd}^{2+}\right] /[\mathrm{MAA}]=1 . \mathrm{pH}=10$ (fijado antes de añadir $\mathrm{S}_{2} \mathrm{O}_{3}{ }^{2-}$ ). Temperatura ambiente. Dilución 1:5. $\left[\mathrm{S}_{2} \mathrm{O}_{3}{ }^{2}\right]=$ a) $6.64 \times 10^{-3} \mathrm{M}$; e) $33.2 \times 10^{-3} \mathrm{M}$; f) 66.4 $\times 10^{-3} \mathrm{M}$; g) $132.7 \times 10^{-3} \mathrm{M} ;$ h) $400 \times 10^{-3} \mathrm{M}$.

Para cada experiencia existe una relación lineal entre $d$ y $t$ fundamentalmente en los primeros días de evolución, lo que indica que el mecanismo básico de crecimiento de las nanopartículas es el mismo que el descrito para nanocristales coloidales: mecanismo de maduración de Oswald, que consiste en el crecimiento de partículas a partir de otras más pequeñas (núcleos) por transferencia de masa. Según Dushxin y col. ${ }^{114}$, el mecanismo de Oswald conduce a una velocidad de crecimiento recogida por la expresión:

$$
\mathrm{R}^{3}-\mathrm{R}_{0}^{3}=k \mathrm{t}
$$

donde $R_{0}$ es el radio inicial del nanocristal; $R$ es el radio en un instante dado y $k$ es la constante de velocidad de crecimiento.

${ }^{114}$ C.D. Dushkin, S. Saita, K. Yoshie, Y. Yamaguchi. The kinetics of growth of semiconductor nanocrystals in a hot amphiphile matrix. Adv Colloid Interface Sci. 88(2000) 37-78. 
Como puede comprobarse en la Figura 72, los valores de $d$ se desvían de esta linealidad transcurrido un tiempo de evolución y dependiendo de la concentración de $\mathrm{S}_{2} \mathrm{O}_{3}{ }^{2-}$ para alcanzar un valor constante. Este hecho indica la intervención de otros mecanismos diferentes al de Oswald a partir de un tiempo dado.

El valor de la absorbancia a la longitud de onda del pico excitónico depende de la concentración de NPs en ese momento así como del valor de $\varepsilon$ que es dependiente del tamaño de la nanopartícula. Ésta es la razón por la cual el valor de absorbancia se incrementa inicialmente con el tiempo para, llegado un momento (dependiendo del tamaño), comenzar a disminuir, pues a medida que aumenta el tamaño de las nanopartículas disminuye su concentración en disolución.

No obstante, de la observación de los valores de absorbancia entre las experiencias, comparando a un mismo tiempo, se deduce que es mayor cuanto más elevada es la concentración inicial de $\mathrm{S}_{2} \mathrm{O}_{3}{ }^{2-}$ por generarse mayor concentración del ion $\mathrm{S}^{2-}$.

En la experiencia a mayor concentración de $\mathrm{S}_{2} \mathrm{O}_{3}{ }^{2-}$ los valores de absorbancia a pesar de estar diluida la disolución, son los más elevados, si bien a medida que disminuye la concentración por hacerlo el tamaño, el valor de absorbancia disminuye drásticamente a los 12 días (Fig. 71) por precipitar entonces las nanopartículas de CdS debido a la neutralización del dispersante.

\section{Evolución de los espectros de luminiscencia}

Paralelamente a la absorción se registran los espectros de fluorescencia de las alícuotas sin diluir y a diferentes tiempos de evolución. No se muestran los espectros de excitación pues su morfología es idéntica en todos los casos, no así su intensidad, y es similar a los mostrados en la experiencia anterior salvo la $\lambda_{\text {ex }}$ óptima que varía según el momento temporal de la nanopartícula.

En la Tabla 9 se muestran los datos de los espectros de emisión a medida que las NPs evolucionan para las diferentes concentraciones de $\mathrm{S}_{2} \mathrm{O}_{3}{ }^{2-}$ estudiadas. En cada experiencia se vuelve a comprobar que, a medida que aumenta el diámetro medio de la nanopartícula, las $\lambda_{\mathrm{ex}}$ y $\lambda_{\mathrm{em}}$ óptimas sufren un desplazamiento batocrómico. Se indica además el color de la fluorescencia observada bajo la lámpara de mercurio, recordando que el color real correspondería a una luz de menor longitud de onda (hacia el violeta). La fluorescencia con lámpara de mercurio solo es apreciable para valores de intensidad aproximadamente superiores a 120 u.a. 
Tabla 9. Datos de los espectros de emisión de fluorescencia de las nanopartículas de CdS obtenidas utilizando $\mathrm{S}_{2} \mathrm{O}_{3}{ }^{2-}$ como precursor. Influencia de la concentración de $\mathrm{S}_{2} \mathrm{O}_{3}{ }^{2-}$. [ $\left.\mathrm{Cd}^{2+}\right]_{\mathrm{f}}=$ $6.64 \times 10^{-3} \mathrm{M} ;[\mathrm{MAA}]_{\mathrm{f}}=6.64 \times 10^{-3} \mathrm{M} ;\left[\mathrm{Cd}^{2+}\right] /[\mathrm{MAA}]=1 . \mathrm{pH}=10$ (fijado antes de añadir $\mathrm{S}_{2} \mathrm{O}_{3}{ }^{2-}$ ). Temperatura ambiente.

\begin{tabular}{|c|c|c|c|c|c|c|}
\hline$\left[\mathrm{S}_{2} \mathrm{O}_{3}{ }^{2-}\right]$ & $\begin{array}{c}\text { Tiempo } \\
\text { (días) }\end{array}$ & If (u.a.) & $\lambda$ em (nm) & $\lambda \operatorname{ex}(n m)$ & $\Delta$ & $\begin{array}{c}\text { Color } \\
\text { fluorescencia }\end{array}$ \\
\hline \multirow[t]{11}{*}{$13,3 \times 10^{-3} \mathrm{M}$} & 4 & 34,81 & 425,6 & 348,8 & 108 & \\
\hline & 6 & 53,24 & 435,2 & 356,8 & 104 & \\
\hline & 15 & 92,16 & 438,4 & 361,6 & 102 & \\
\hline & 21 & 112,64 & 444,8 & 363,2 & 100 & \\
\hline & 34 & 219,13 & 460,8 & 374,4 & 100 & Azul-verde \\
\hline & 40 & 276,48 & 460,8 & 374,4 & 102 & Azul-verde \\
\hline & 117 & 742,08 & 491,2 & 398,4 & 100 & Verde-amarilla \\
\hline & 124 & 733,88 & 492,8 & 401,6 & 100 & Verde-amarilla \\
\hline & 131 & 664,25 & 497,6 & 408 & 102 & Verde-amarilla \\
\hline & 138 & 627,39 & 496 & 404,8 & 98 & Verde-amarilla \\
\hline & 145 & 619,2 & 494,4 & 403,2 & 102 & Verde-amarilla \\
\hline \multirow[t]{9}{*}{$19,9 \times 10^{-3} \mathrm{M}$} & 2 & 30,72 & 424,4 & 347,2 & 106 & \\
\hline & 4 & 55,29 & 428,8 & 355,2 & 104 & \\
\hline & 10 & 86,01 & 443,2 & 358,4 & 100 & \\
\hline & 17 & 129,02 & 449,6 & 366,4 & 100 & Azul \\
\hline & 20 & 156,67 & 449,6 & 366,4 & 102 & Azul \\
\hline & 29 & 215,04 & 457,6 & 374,4 & 100 & Azul-verde \\
\hline & 36 & 296,96 & 465,6 & 376 & 98 & Azul-verde \\
\hline & 42 & 385,72 & 464 & 377,6 & 100 & Azul-verde \\
\hline & 46 & 426,68 & 465,6 & 380,8 & 100 & Azul-verde \\
\hline \multirow[t]{9}{*}{$26,5 \times 10^{-3} \mathrm{M}$} & 2 & 36,86 & 436,8 & 353,6 & 106 & \\
\hline & 4 & 61,44 & 436,8 & 356,8 & 104 & \\
\hline & 10 & 110,59 & 444,8 & 363,2 & 102 & \\
\hline & 14 & 122,88 & 448 & 366,4 & 100 & Azulada \\
\hline & 20 & 177,15 & 452,8 & 372,8 & 100 & Azulada \\
\hline & 28 & 258,04 & 464 & 374,4 & 102 & Azul-verde \\
\hline & 36 & 303,1 & 465,6 & 377,6 & 98 & Azul-verde \\
\hline & 42 & 365,24 & 465,6 & 377,6 & 100 & Azul-verde \\
\hline & 46 & 401,4 & 467,2 & 380,8 & 100 & Azul-verde \\
\hline
\end{tabular}


Tabla 9, continuación.

\begin{tabular}{|c|c|c|c|c|c|c|}
\hline$\left[\mathrm{S}_{2} \mathrm{O}_{3}{ }^{2-}\right]$ & $\begin{array}{c}\text { Tiempo } \\
\text { (días) }\end{array}$ & If (u.a.) & $\lambda$ em (nm) & $\lambda \operatorname{ex}(\mathrm{nm})$ & $\Delta$ & $\begin{array}{c}\text { Color } \\
\text { fluorescencia }\end{array}$ \\
\hline \multirow[t]{12}{*}{$33,2 \times 10^{-3} \mathrm{M}$} & 2 & 35,52 & 430,4 & 355,2 & 104 & \\
\hline & 4 & 62,14 & 440 & 358,4 & 102 & \\
\hline & 10 & 108,54 & 448 & 364,8 & 100 & \\
\hline & 16 & 167,93 & 459,2 & 369,6 & 100 & Azul \\
\hline & 21 & 210,94 & 464 & 372,8 & 102 & Azul-verde \\
\hline & 28 & 283,62 & 470,4 & 377,6 & 100 & Azul-verde \\
\hline & 35 & 333,82 & 468,8 & 379,2 & 100 & Azul-verde \\
\hline & 45 & 358,4 & 476,8 & 382,4 & 100 & Verde \\
\hline & 113 & 445,12 & 508,8 & 409,6 & 98 & Verde-amarilla \\
\hline & 120 & 422,59 & 508,8 & 411,2 & 98 & Verde-amarilla \\
\hline & 134 & 374,78 & 512 & 412,8 & 100 & Verde-amarilla \\
\hline & 141 & 348,86 & 512 & 414,4 & 100 & Verde-amarilla \\
\hline \multirow[t]{8}{*}{$66,4 \times 10^{-3} \mathrm{M}$} & 0,83 & 39,61 & 449,6 & 355,2 & 106 & \\
\hline & 4 & 96,96 & 451,2 & 364,8 & 104 & \\
\hline & 6 & 133,12 & 452,8 & 366,4 & 104 & Azul \\
\hline & 13 & 208,89 & 468,8 & 379,2 & 102 & Azul-verde \\
\hline & 20 & 356,35 & 476,8 & 385,6 & 100 & Verde \\
\hline & 25 & 432,12 & 483,2 & 392 & 100 & Verde \\
\hline & 32 & 488,12 & 489,6 & 396,3 & 102 & Verde \\
\hline & 35 & 475,84 & 489,6 & 396 & 102 & Verde \\
\hline \multirow[t]{10}{*}{$132,7 \times 10^{-3} \mathrm{M}$} & 0,96 & 47,8 & 443,2 & 355,2 & 104 & \\
\hline & 2 & 81,92 & 448 & 364,8 & 102 & \\
\hline & 6 & 194,56 & 464 & 377,6 & 100 & Azul-verde \\
\hline & 8 & 251,9 & 472 & 382,4 & 100 & Azul-verde \\
\hline & 13 & 443,07 & 489,6 & 393,6 & 100 & Verde \\
\hline & 15 & 456,7 & 489,6 & 396,8 & 98 & Verde \\
\hline & 17 & 428,73 & 494,4 & 400 & 98 & Verde-amarilla \\
\hline & 20 & 418,49 & 497,6 & 403,2 & 98 & Verde-amarilla \\
\hline & 27 & 205,5 & 508,8 & 411,2 & 100 & Verde-amarilla \\
\hline & 31 & 83,96 & 512 & 417,6 & 100 & Verde-amarilla \\
\hline \multirow[t]{5}{*}{$400 \times 10^{-3} \mathrm{M}$} & 0,99 & 68,28 & 456 & 364,8 & 104 & \\
\hline & 5 & 407,55 & 484,8 & 393,6 & 100 & Verde-amarilla \\
\hline & 7 & 323,58 & 505,6 & 406,4 & 100 & Verde-amarilla \\
\hline & 8 & 210,94 & 513,6 & 412,8 & 102 & Verde-amarilla \\
\hline & 12 & 14,01 & 520,4 & 420 & 104 & \\
\hline
\end{tabular}


La velocidad de generación del ion $\mathrm{S}^{2-}$, la formación con el tiempo de la nanocorteza de $\mathrm{Cd}(\mathrm{OH})_{2}$, el enlace de $\mathrm{S}^{2-}$ sobre la superficie de las nanopartículas cuando se genera a partir de una velocidad dada, condicionan no sólo la concentración de NPs, también la naturaleza de su superficie que, en definitiva, son las dos variables que afectan a la fluorescencia de las nanopartículas.

En la Figura 73 se ha representado la evolución del valor de $\mathrm{If}_{\text {máx }}$ para las NPs obtenidas a diferentes concentraciones iniciales de precursor $\mathrm{S}_{2} \mathrm{O}_{3}{ }^{2-}$. En dicha representación se han incluido los valores de la experiencia del estudio anterior en la que, siendo el $\mathrm{pH}=10$, la concentración de $\mathrm{S}_{2} \mathrm{O}_{3}{ }^{2-}$ es de $6.64 \times 10^{-3} \mathrm{M}$; así como los valores de $\mathrm{If}_{\text {máx }}$ de las nanopartículas obtenidas a $\mathrm{pH}=10$ por el método heterogéneo (añadiendo directamente el ion $\mathrm{S}^{2-}$ ) (Fig. 55, Tabla 5), en la que la concentración de $\mathrm{Cd}^{2+}$ es idéntica a la de la experiencia actual, así como la de MAA, siendo solo distinta la concentración de $\mathrm{S}^{2-}$ $\left(3.32 \times 10^{-3} \mathrm{M}\right)$.

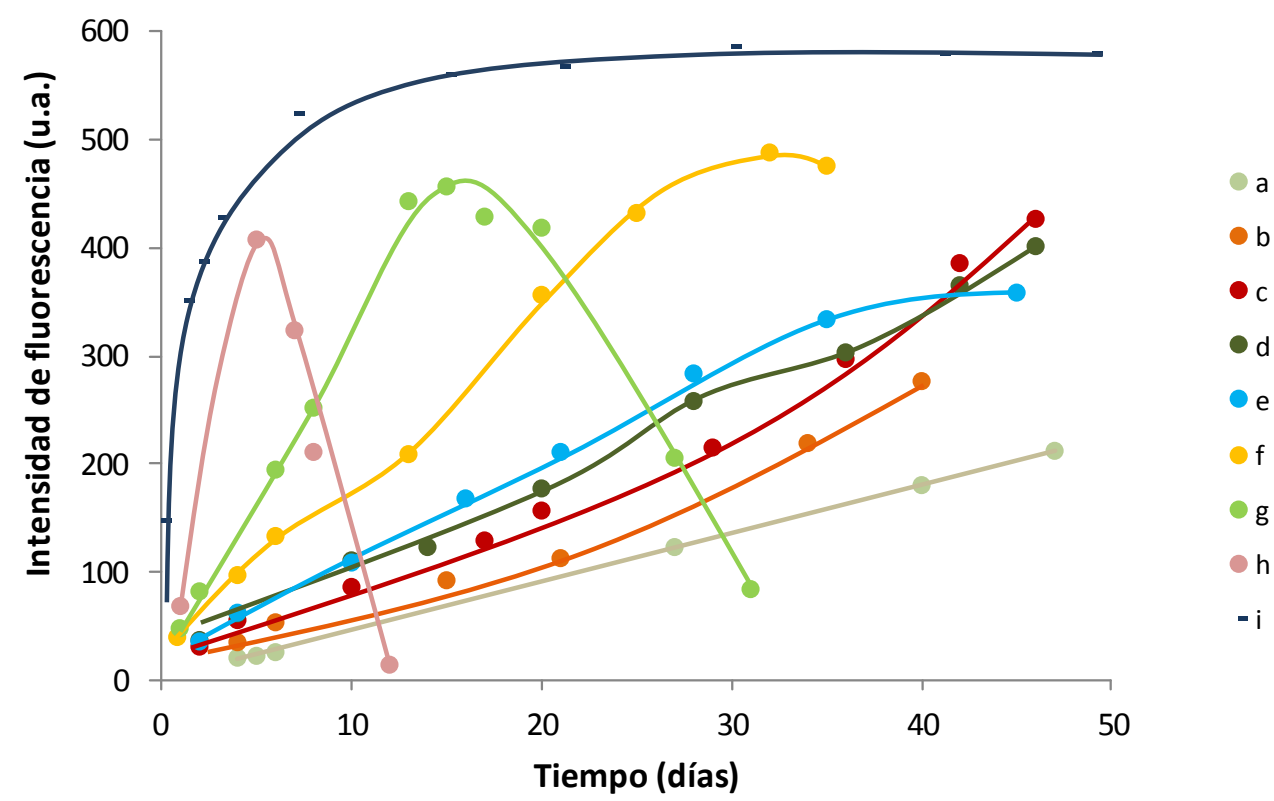

Figura 73. Evolución de la intensidad de fluorescencia máxima de las nanopartículas. Influencia de la concentración de precursor. $\left[\mathrm{Cd}^{2+}\right]_{\mathrm{f}}=6.64 \times 10^{-3} \mathrm{M} ;[\mathrm{MAA}]_{\mathrm{f}}=6.64 \times 10^{-3} \mathrm{M} ;\left[\mathrm{Cd}^{2+}\right] /[\mathrm{MAA}]=1 . \mathrm{pH}=10$ (fijado antes de añadir $\mathrm{S}_{2} \mathrm{O}_{3}{ }^{2-}$ ). Temperatura ambiente. $\left[\mathrm{S}_{2} \mathrm{O}_{3}{ }^{2-}\right]=$ a) $6.64 \times 10^{-3} \mathrm{M}$; b) $13.3 \times 10^{-3} \mathrm{M}$; c) $19.9 \times 10^{-3} \mathrm{M}$; d) $26.5 \times 10^{-3} \mathrm{M}$; e) $33.2 \times 10^{-3} \mathrm{M}$; f) $66.4 \times 10^{-3} \mathrm{M}$; g) $132.7 \times 10^{-3} \mathrm{M}$; h) $400 \times 10^{-3} \mathrm{M}$; i) fase heterogénea.

En la Figura 74 se han representado solo los valores de fluorescencia los primeros 47 días de evolución. Se comprueba que cuanto mayor es la concentración de $\mathrm{S}_{2} \mathrm{O}_{3}{ }^{2-}$ más rápida es la evolución de la fluorescencia de las nanopartículas, alcanzando valores máximos más rápidamente cuanto mayor es la concentración inicial de reactivo. Para 
concentraciones de $\mathrm{S}_{2} \mathrm{O}_{3}{ }^{2-}$ de $66.4 \times 10^{-3} \mathrm{M}$ el valor máximo de fluorescencia se alcanza aproximadamente a los 32 días y a los 5 días cuando la concentración es de $400 \times 10^{-3} \mathrm{M}$. En esta experiencia, junto con la de $\mathrm{S}_{2} \mathrm{O}_{3}{ }^{2-} 132.7 \times 10^{-3} \mathrm{M}$, la generación de ion $\mathrm{S}^{2-}$ por hidrólisis de $\mathrm{S}_{2} \mathrm{O}_{3}{ }^{2-}$ transcurre a mayor velocidad que en el resto de experiencias en fase homogénea, lo que indica que una vez formados los núcleos de $\mathrm{CdS}$, el $\mathrm{S}^{2-}$ generado en el tiempo compite en dos procesos: formación de más núcleos y unión a los iones de $\mathrm{Cd}^{2+}$ de la superficie formando trampas para la energía radiante llegando un momento en que la cantidad de $\mathrm{S}^{2-}$ enlazado es tan alta que disminuye la intensidad de fluorescencia con el tiempo.

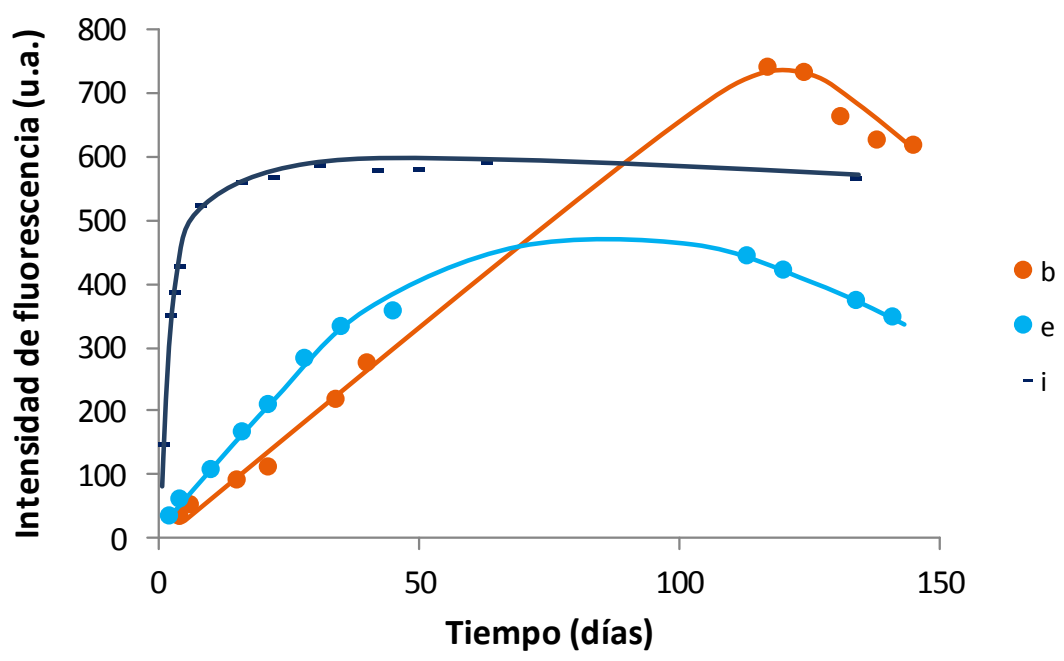

Figura 74. Evolución de la intensidad de fluorescencia máxima de las nanopartículas. Influencia de la concentración de precursor. $\left[\mathrm{Cd}^{2+}\right]_{\mathrm{f}}=6.64 \times 10^{-3} \mathrm{M} ;[\mathrm{MAA}]_{\mathrm{f}}=6.64 \times 10^{-3} \mathrm{M} ;\left[\mathrm{Cd}^{2+}\right] /[\mathrm{MAA}]=1 . \mathrm{pH}=10$ (fijado antes de añadir $\mathrm{S}_{2} \mathrm{O}_{3}{ }^{2-}$ ). Temperatura ambiente. $\left[\mathrm{S}_{2} \mathrm{O}_{3}{ }^{2-}\right]=$ b) $13.3 \times 10^{-3} \mathrm{M}$; e) $33.2 \times 10^{-3} \mathrm{M}$; i) fase heterogénea.

El hecho de que el valor máximo de If alcanzado sea menor cuanto mayor es la concentración de $\mathrm{S}_{2} \mathrm{O}_{3}{ }^{2-}$ inicial parece indicar que el proceso de predominio de la deposición de $\mathrm{S}^{2-}$ sobre las nanopartículas de $\mathrm{CdS}$ ocurre una vez que se alcanza una determinada concentración de ion $\mathrm{S}^{2-}$.

Esta suposición parece correcta si se observa la evolución de la fluorescencia de las nanopartículas de la experiencia con $\left[\mathrm{S}_{2} \mathrm{O}_{3}{ }^{2-}\right]=13.3 \times 10^{-3} \mathrm{M}$. Esta evolución ha sido representada en la Figura 74 junto con la experiencia en la que $\left[\mathrm{S}_{2} \mathrm{O}_{3}{ }^{2-}\right]=33.2 \times 10^{-3} \mathrm{M}$ y la experiencia en fase heterogénea.

Como la generación de ion $\mathrm{S}^{2-}$ es más lenta en el tiempo, el valor máximo de fluorescencia se alcanza a los 110 días y no solo es más alto que el de la experiencia $\left[\mathrm{S}_{2} \mathrm{O}_{3}{ }^{2-}\right]=33.2 \times 10^{-3} \mathrm{M}$ sino que supera el valor de fluorescencia de las NPs de $\mathrm{CdS}$ obtenidas 
en fase heterogénea. Transcurridos los 110 días la fluorescencia disminuye por la interferencia del ion $\mathrm{S}^{2-}$ que se invierte en enlazarse a la superficie provocando un efecto quenching.

Se deduce como conclusión de este estudio que la concentración inicial de $\mathrm{S}_{2} \mathrm{O}_{3}{ }^{2-}$ influye considerablemente sobre la concentración de $\mathrm{S}^{2-}$ generada. Si la velocidad de generación es muy lenta y la concentración de $S^{2-}$ generada es muy pequeña, el exceso de $\mathrm{Cd}^{2+}$ en disolución que se encuentra libre o complejado con MAA genera un precipitado blanco que interfiere en el método de obtención de nanopartículas de CdS. Si la velocidad de generación del ion $\mathrm{S}^{2-}$ y su concentración es más alta, desaparece el precipitado blanco y las NPs se van formando lentamente a expensas de los núcleos iniciales alcanzando un estado superficial óptimo que hace que su fluorescencia incluso supere a la mostrada por las nanopartículas de CdS obtenidas por el método heterogéneo.

Para velocidades de generación de ion $\mathrm{S}^{2-}$ mucho más altas, la concentración alta de dicho ion impurifica la superficie de las nanopartículas afectando a su fluorescencia, por lo que disminuye con el tiempo.

Sobre el control adecuado de la generación de ion $\mathrm{S}^{2-}$ afectan el $\mathrm{pH}$ de la disolución acuosa y la concentración inicial del portador, $\mathrm{S}_{2} \mathrm{O}_{3}^{2-}$.

\section{INFLUENCIA DE LA CONCENTRACIÓN DE TIOGLICEROL}

Como ya hemos comentado, el tioglicerol ( $\mathrm{TG}, \mathrm{HSCH}_{2}-\mathrm{CHOH}-\mathrm{CH}_{2} \mathrm{OH}$ ) ya ha sido utilizado como catalizador de la hidrólisis acuosa del $\mathrm{S}_{2} \mathrm{O}_{3}{ }^{2-}$ en la obtención de nanopartículas de CdS pero en ausencia de dispersante MAA. En dicho método se generan NPs de CdS de elevado tamaño y de muy baja estabilidad, pues a partir de los 30 minutos una vez terminada la adición de reactivos se obtienen disoluciones coloidales turbias. Se revela así que la capacidad dispersante del tioglicerol es muy pobre.

En el método que se estudia en esta parte el dispersante empleado es el ácido mercaptoacético, por lo que el uso de TG tiene como objetivo aumentar la velocidad de descomposición del $\mathrm{S}_{2} \mathrm{O}_{3}^{2-}$.

Para estudiar la influencia de esta variable se preparan cuatro disoluciones partiendo en todos los casos de $100 \mathrm{~mL}$ de disolución de $\mathrm{Cd}^{2+} 1 \times 10^{-2} \mathrm{M}(1 \mathrm{mmol})$ sobre la que se añaden $715 \mu \mathrm{L}$ de MAA $1.41 \mathrm{M}(1 \mathrm{mmol})$ y posteriormente cantidades crecientes de TG. A la primera disolución se añade $900 \mu \mathrm{L}$ de TG $1.118 \mathrm{M} \mathrm{(1} \mathrm{mmol),} \mathrm{a} \mathrm{la} \mathrm{segunda} 1.8 \mathrm{~mL}$ (2 $\mathrm{mmol})$, a la tercera $2.7 \mathrm{~mL}(3 \mathrm{mmol})$ y a la última $4.5 \mathrm{~mL}(5 \mathrm{mmol})$. En todos los casos el pH final de las disoluciones tras la adición de MAA y TG es del orden de 2.4, por lo que se 
observa turbidez que desaparece en todos los casos después de añadir $\mathrm{NaOH}$ y elevar el valor de $\mathrm{pH}$ hasta 10.

Tras el burbujeo de $\mathrm{N}_{2}$ se añaden en todos los casos $50 \mathrm{~mL}$ de disolución de $\mathrm{S}_{2} \mathrm{O}_{3}{ }^{2-}$ $1.0 \times 10^{-1} \mathrm{M}(5 \mathrm{mmol})$ (el pH final se mantiene prácticamente en el valor de 10). El momento en el que finaliza la adición de este reactivo se considera $t=0$, el origen del tiempo para los estudios de evolución.

Las operaciones se realizan y conservan a temperatura ambiente del laboratorio.

Debido al diferente volumen de TG añadido la concentración de $\mathrm{Cd}^{2+}$ en la disolución final varía desde $6.60 \times 10^{-3} \mathrm{M}$ hasta $6.44 \times 10^{-3} \mathrm{M}$, al igual que la de MAA. La de $\mathrm{S}_{2} \mathrm{O}_{3}{ }^{2-}$ varía desde $33.0 \times 10^{-3} \mathrm{M}$ hasta $32.2 \times 10^{-3} \mathrm{M}$, manteniéndose constantes las relaciones molares: $\left[\mathrm{Cd}^{2+}\right]_{\mathrm{f}} /[\mathrm{MAA}]_{\mathrm{f}}=1 ;\left[\mathrm{S}_{2} \mathrm{O}_{3}{ }^{2-}\right]_{\mathrm{f}} /\left[\mathrm{Cd}^{2+}\right]_{\mathrm{f}}=5$.

Las concentraciones de TG en las disoluciones finales son $6.60 \times 10^{-3} \mathrm{M} ; 13.11 \times 10^{-3}$ $\mathrm{M} ; 19.95 \times 10^{-3} \mathrm{M}$ y $32.2 \times 10^{-3} \mathrm{M}$, respectivamente. La relación molar $[\mathrm{TG}]_{\mathrm{f}} /\left[\mathrm{Cd}^{2+}\right]_{\mathrm{f}}$ varía por lo tanto de 1 hasta 5 .

Los resultados obtenidos en las cuatro experiencias se van a comparar con los de la experiencia del estudio anterior que contenía las mismas relaciones molares $\left[\mathrm{Cd}^{2+}\right]_{\mathrm{f}} /[\mathrm{MAA}]_{\mathrm{f}}$ $\mathrm{y}\left[\mathrm{S}_{2} \mathrm{O}_{3}{ }^{2-}\right]_{\mathrm{f}} /\left[\mathrm{Cd}^{2+}\right]_{\mathrm{f}} \mathrm{y}$ al mismo valor de $\mathrm{pH}$ y temperatura.

\section{Evolución de los espectros de absorción}

En las Figuras 75-78 se muestran los espectros de absorción de alícuotas diluídas (1:5) de las disoluciones finales de las cuatros experiencias a diferentes tiempos de evolución. En dichos espectros se indica el valor de $\lambda_{\text {máx }}$ del pico excitónico sin indicar ya el valor de absorbancia del pico a $326 \mathrm{~nm}$ que corresponde al complejo formado entre $\mathrm{Cd}^{2+} \mathrm{y}$ MAA. A partir de la longitud de onda del pico excitónico se calcula el diámetro medio de las NPs de CdS. Se indica además el aspecto físico de la disolución original en cuanto a su transparencia y color. 


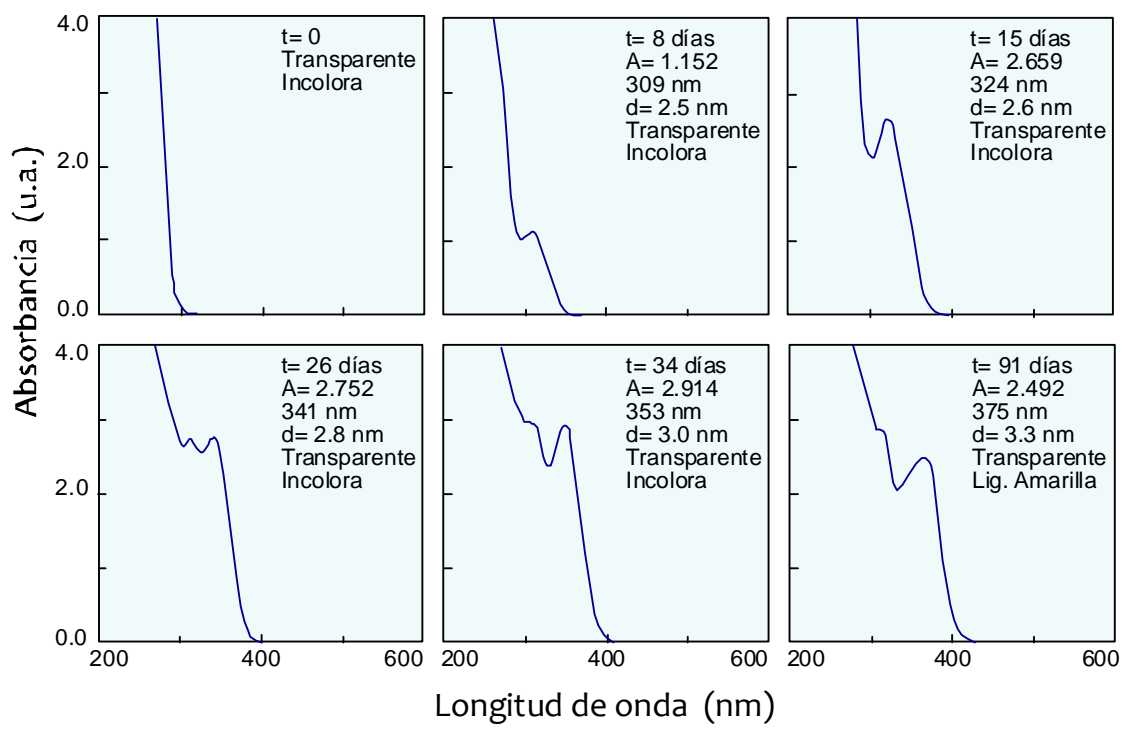

Figura 75. Espectros de absorción a diferentes tiempos de evolución de las NPs obtenidas utilizando $\mathrm{S}_{2} \mathrm{O}_{3}{ }^{2-}$ como precursor. Influencia de la concentración de TG. $\left[\mathrm{Cd}^{2+}\right]_{\mathrm{f}}=6.60 \times 10^{-3} \mathrm{M} ;\left[\mathrm{S}_{2} \mathrm{O}_{3}{ }^{2-}\right]_{\mathrm{f}}=33.0 \times 10^{-3} \mathrm{M} ;[\mathrm{MAA}]_{\mathrm{f}}=6.60 \times 10^{-3} \mathrm{M} ;[\mathrm{TG}]_{\mathrm{f}}=6.60 \times 10^{-3} \mathrm{M}$; $\left[\mathrm{Cd}^{2+}\right]_{\mathrm{f}} /[\mathrm{MAA}]_{\mathrm{f}}=1 ;\left[\mathrm{S}_{2} \mathrm{O}_{3}{ }^{2-}\right]_{\mathrm{f}} /\left[\mathrm{Cd}^{2+}\right]_{\mathrm{f}}=5 ;[\mathrm{TG}]_{\mathrm{f}} /\left[\mathrm{Cd}^{2+}\right]_{\mathrm{f}}=1 . \mathrm{pH}=10$ (fijado antes de añadir $\mathrm{S}_{2} \mathrm{O}_{3}{ }^{2-}$ ). Temperatura ambiente. Disoluciones diluídas (1:5).

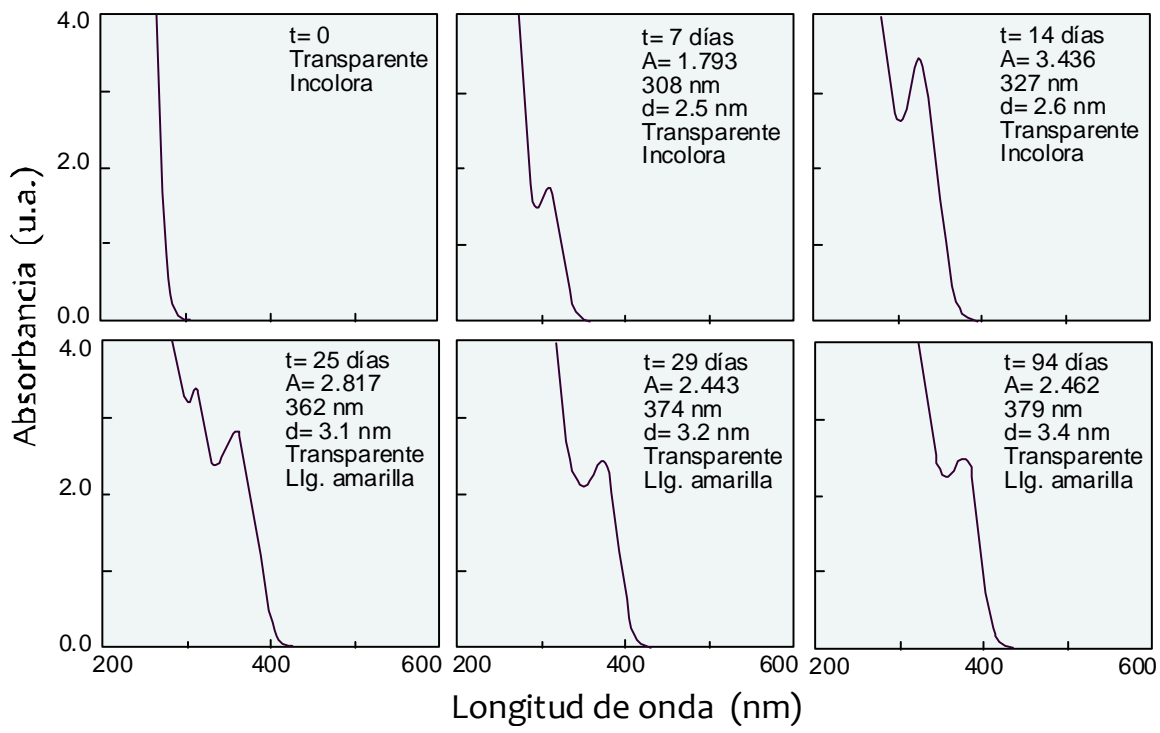

Figura 76. Espectros de absorción a diferentes tiempos de evolución de las NPs obtenidas utilizando $\mathrm{S}_{2} \mathrm{O}_{3}{ }^{2-}$ como precursor. Influencia de la concentración de TG. $\left[\mathrm{Cd}^{2+}\right]_{\mathrm{f}}=6.60 \times 10^{-3} \mathrm{M} ;\left[\mathrm{S}_{2} \mathrm{O}_{3}{ }^{2-}\right]_{\mathrm{f}}=33.0 \times 10^{-3} \mathrm{M} ;[\mathrm{MAA}]_{\mathrm{f}}=6.60 \times 10^{-3} \mathrm{M} ;[\mathrm{TG}]_{\mathrm{f}}=13.1 \times 10^{-3} \mathrm{M}$; $\left[\mathrm{Cd}^{2+}\right]_{\mathrm{f}} /[\mathrm{MAA}]_{\mathrm{f}}=1 ;\left[\mathrm{S}_{2} \mathrm{O}_{3}{ }^{2-}\right]_{\mathrm{f}} /\left[\mathrm{Cd}^{2+}\right]_{\mathrm{f}}=5 ;[\mathrm{TG}]_{\mathrm{f}} /\left[\mathrm{Cd}^{2+}\right]_{\mathrm{f}}=2 . \mathrm{pH}=10$ (fijado antes de añadir $\mathrm{S}_{2} \mathrm{O}_{3}{ }^{2-}$ ). Temperatura ambiente. Disoluciones diluídas (1:5). 


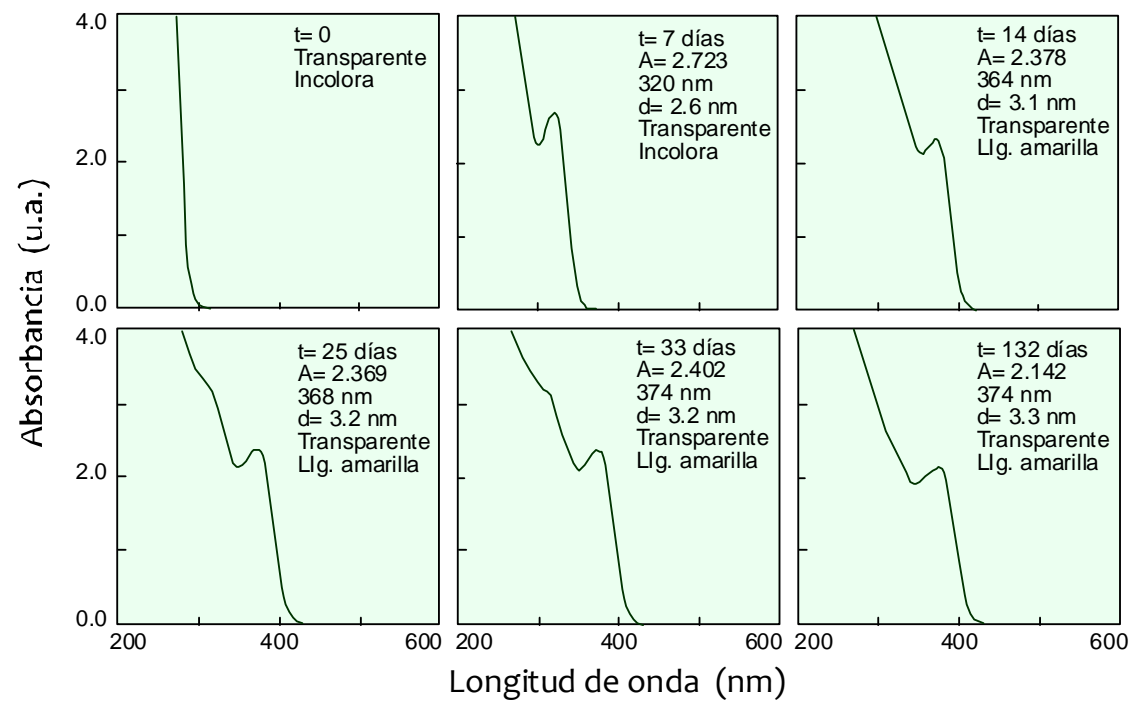

Figura 77. Espectros de absorción a diferentes tiempos de evolución de las NPs obtenidas utilizando $\mathrm{S}_{2} \mathrm{O}_{3}{ }^{2-}$ como precursor. Influencia de la concentración de TG. $\left[\mathrm{Cd}^{2+}\right]_{\mathrm{f}}=6.60 \times 10^{-3} \mathrm{M} ;\left[\mathrm{S}_{2} \mathrm{O}_{3}{ }^{2-}\right]_{\mathrm{f}}=33.0 \times 10^{-3} \mathrm{M} ;[\mathrm{MAA}]_{\mathrm{f}}=6.60 \times 10^{-3} \mathrm{M} ;[\mathrm{TG}]_{\mathrm{f}}=19.5 \times 10^{-3} \mathrm{M}$; $\left[\mathrm{Cd}^{2+}\right]_{\mathrm{f}} /[\mathrm{MAA}]_{\mathrm{f}}=1 ;\left[\mathrm{S}_{2} \mathrm{O}_{3}{ }^{2-}\right]_{\mathrm{f}} /\left[\mathrm{Cd}^{2+}\right]_{\mathrm{f}}=5 ;[\mathrm{TG}]_{\mathrm{f}} /\left[\mathrm{Cd}^{2+}\right]_{\mathrm{f}}=3 . \mathrm{pH}=10$ (fijado antes de añadir $\mathrm{S}_{2} \mathrm{O}_{3}{ }^{2-}$ ). Temperatura ambiente. Disoluciones diluídas (1:5).

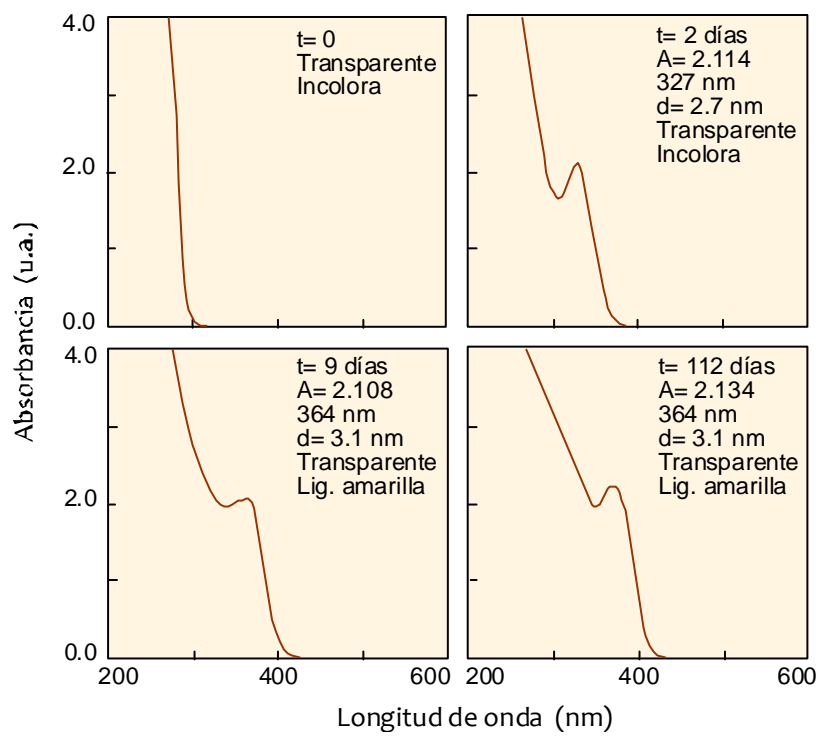

Figura 78. Espectros de absorción a diferentes tiempos de evolución de las NPs obtenidas utilizando $\mathrm{S}_{2} \mathrm{O}_{3}{ }^{2-}$ como precursor. Influencia de la concentración de TG. $\left[\mathrm{Cd}^{2+}\right]_{\mathrm{f}}=6.60 \times 10^{-3} \mathrm{M} ;\left[\mathrm{S}_{2} \mathrm{O}_{3}{ }^{2-}\right]_{\mathrm{f}}=33.0 \times 10^{-3} \mathrm{M} ;[\mathrm{MAA}]_{\mathrm{f}}=6.60 \times 10^{-3} \mathrm{M} ;[\mathrm{TG}]_{\mathrm{f}}=32.2 \times 10^{-3} \mathrm{M}$; $\left[\mathrm{Cd}^{2+}\right]_{\mathrm{f}} /[\mathrm{MAA}]_{\mathrm{f}}=1 ;\left[\mathrm{S}_{2} \mathrm{O}_{3}{ }^{2-}\right]_{\mathrm{f}} /\left[\mathrm{Cd}^{2+}\right]_{\mathrm{f}}=5 ;[\mathrm{TG}]_{\mathrm{f}} /\left[\mathrm{Cd}^{2+}\right]_{\mathrm{f}}=5 . \mathrm{pH}=10$ (fijado antes de añadir $\mathrm{S}_{2} \mathrm{O}_{3}{ }^{2-}$ ). Temperatura ambiente. Disoluciones diluídas (1:5).

Para comentar el efecto del TG en el proceso de obtención de NPs de CdS utilizando $\mathrm{S}_{2} \mathrm{O}_{3}{ }^{2-}$ como precursor de $\mathrm{S}^{2-}$ es necesario comparar los valores obtenidos en las cuatro experiencias con aquella que no contiene TG (Fig. 68). 
En cuanto a la morfología de los espectros, no se observan grandes diferencias y viene determinada por la longitud de onda del pico excitónico (que depende del tamaño de la nanopartícula) y del pequeño hombro debido a la presencia de especies entre $\mathrm{Cd}^{2+} \mathrm{y}$ MAA en disolución que aparece a una longitud de onda constante aproximada de $326 \mathrm{~nm}$. La aproximación o diferenciación de estas dos longitudes de onda explican la superposición de picos o su separación clara. La presencia de TG en disolución en el método de obtención de $\mathrm{CdS}$ a partir de $\mathrm{S}_{2} \mathrm{O}_{3}{ }^{2-}$ como precursor, no altera cualitativamente la morfología de los espectros de absorción de dichas NPs.

En las presentes experiencias se investiga el papel catalizador del tioglicerol en la descomposición del $\mathrm{S}_{2} \mathrm{O}_{3}{ }^{2-}$ así como el efecto que ejerce como dispersante de las nanopartículas, enlazándose sus átomos de azufre a los de cadmio en la superficie, y la posibilidad de que potencie la capacidad dispersante del MAA.

Una de las características de las NPs de CdS obtenidas a partir de $\mathrm{S}_{2} \mathrm{O}_{3}{ }^{2-}$ que se ve más afectada por la concentración inicial de esta última variable estudiada, es su tamaño medio. Como pudimos comprobar al estudiar la concentración de $\mathrm{S}_{2} \mathrm{O}_{3}{ }^{2-}$, cuanto mayor es ésta, para un tiempo dado, mayor es la concentración de $\mathrm{S}^{2-}$ generada y mayor es el tamaño medio de la nanopartícula.

Para comprobar la capacidad catalizadora del TG es útil comparar a tiempos similares los valores del tamaño de las NPs en función de su concentración en disolución. Esta es la razón por la que, para una mejor comprensión, en la Tabla 10 se han indicado los valores del diámetro medio de las nanopartículas a diferentes tiempos y a diferentes concentraciones de TG. En dicha tabla se muestran también los valores de $d$ para las NPs obtenidas en las mismas condiciones experimentales pero en ausencia de TG. 
Tabla 10. Influencia de la concentración de TG. Valor del tamaño medio de las nanopartículas.

\begin{tabular}{|c|c|c|c|c|c|}
\hline \multirow{3}{*}{ t (días) } & \multicolumn{5}{|c|}{ Diámetro medio (nm) } \\
\hline & \multicolumn{5}{|c|}{$[\mathrm{TG}] \times 10^{-3} \mathrm{M}$} \\
\hline & 0 & 6.60 & 13.11 & 19.55 & 32.20 \\
\hline 2 & 2.5 & & & & 2.7 \\
\hline 4 & 2.5 & & & & \\
\hline 6 & & & & & 3.0 \\
\hline 7 & & & 2.5 & 2.6 & \\
\hline 8 & & 2.5 & & & \\
\hline 9 & & & & & 3.1 \\
\hline 10 & 2.6 & & & & \\
\hline 14 & & & 2.7 & 3.1 & 3.1 \\
\hline 15 & & 2.6 & & & \\
\hline 20 & & & 2.8 & 3.1 & \\
\hline 21 & 2.8 & 2.6 & & & \\
\hline 23 & & & & & 3.1 \\
\hline 25 & & & 3.1 & 3.2 & \\
\hline 26 & & 2.8 & & & \\
\hline 27 & & & & 3.3 & \\
\hline 28 & 2.9 & & & & \\
\hline 29 & & & 3.3 & & \\
\hline 30 & & 2.9 & & & \\
\hline 33 & & & 3.3 & 3.3 & \\
\hline 34 & & 3.0 & & & \\
\hline 35 & 2.9 & & & & \\
\hline 42 & 2.9 & & 3.3 & 3.3 & \\
\hline 43 & & 3.3 & & & \\
\hline$>90$ & 3.1 & 3.3 & 3.4 & 3.3 & 3.1 \\
\hline
\end{tabular}

De los valores mostrados en la tabla se intuye que el TG desempeña varios papeles en la formación de NPs, interviniendo no sólo en el proceso de hidrólisis de $\mathrm{S}_{2} \mathrm{O}_{3}{ }^{2-}$. Que el TG cataliza la reacción de descomposición de $\mathrm{S}_{2} \mathrm{O}_{3}{ }^{2-}$ parece quedar confirmado si se comparan los valores de absorbancia en el pico excitónico de las experiencias en presencia de TG (Fig. 75-78) frente a la experiencia en ausencia de éste (Fig. 68).

Este fenómeno de catálisis se traduce en el tamaño de las NPs que claramente aumenta desde tiempos iniciales cuando la concentración de TG es igual o superior a $19.5 \times 10^{-3} \mathrm{M}$. No obstante, para concentraciones de TG inferiores este incremento sólo es apreciable para tiempos elevados de evolución siendo semejante o inferior para tiempos iniciales.

Este hecho indica que en el proceso de crecimiento de las NPs en presencia de TG, existe un proceso de inhibición (frente a la ausencia de TG) debido, probablemente, a que se enlaza a través de los átomos de cadmio sobre la superficie de las NPs, ralentizando el proceso de crecimiento de las mismas. 


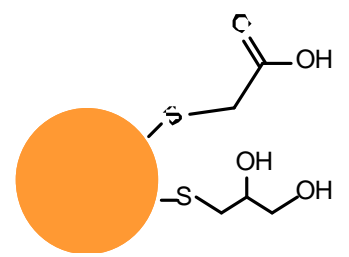

Figura 79. Representación esquemática de un QD con una molécula de ácido mercaptoacético y otra de tioglicerol.

Si el efecto de la catálisis no es muy acusado este proceso de inhibición tendrá cuantitativamente más importancia para bajas concentraciones de tioglicerol. Para concentraciones de dicho reactivo en disolución elevadas predominaría el efecto catalítico sobre el proceso de inhibición, siendo el crecimiento de las nanopartículas más apreciable.

El efecto catalítico del TG se traduce en que se alcanza un valor constante del tamaño de las NPs antes en el tiempo cuanto mayor es la concentración de catalizador (a los 27 días cuando $[\mathrm{TG}]=19.55 \times 10^{-3} \mathrm{M}$; a los 9 días para $[\mathrm{TG}]=32.20 \times 10^{-3} \mathrm{M}$ ). El número de moléculas de $\mathrm{CdS}$ contenidas en las NPs obtenidas varía entre $\mathrm{N}=152$ y $\mathrm{N}=391$.

\section{Evolución de los espectros de luminiscencia}

De manera paralela, de las alícuotas de las disoluciones de las cuatro experiencias sin ser diluidas, se registran los espectros de fluorescencia que se muestran en las Figuras 80-83. Para poder comprobar el efecto del TG sobre las propiedades luminiscentes de las NPs de CdS los resultados de las experiencias actuales se comparan con los resultados obtenidos en la experiencia en la que, manteniendo las mismas condiciones, no se añade TG (Tabla 9). 


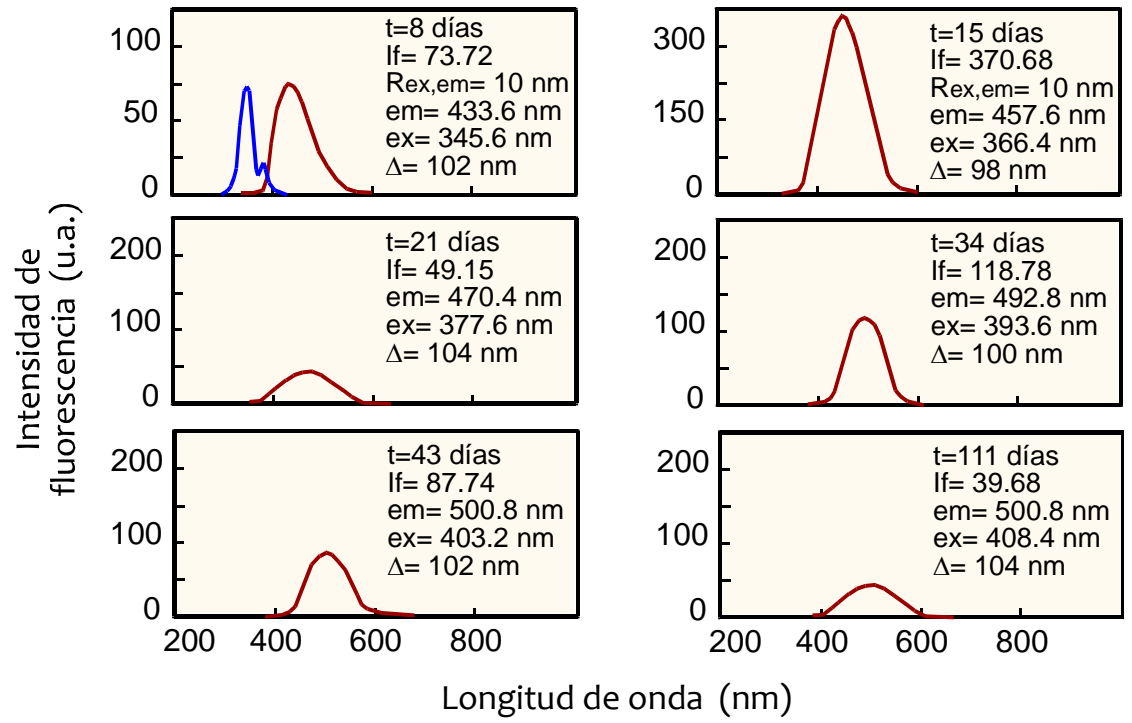

Figura 80. Espectros de emisión a diferentes tiempos de evolución. Influencia de la concentración de TG. $\left[\mathrm{Cd}^{2+}\right]_{\mathrm{f}}=6.60 \times 10^{-3} \mathrm{M}$; $\left[\mathrm{S}_{2} \mathrm{O}_{3}{ }^{2-}\right]_{\mathrm{f}}=33.0 \times 10^{-3} \mathrm{M} ;[\mathrm{MAA}]_{\mathrm{f}}=6.60 \times 10^{-3} \mathrm{M} ;[\mathrm{TG}]_{\mathrm{f}}=6.60 \times 10^{-3} \mathrm{M} ;\left[\mathrm{Cd}^{2+}\right]_{\mathrm{f}} /[\mathrm{MAA}]_{\mathrm{f}}=1 ;[\mathrm{TG}]_{\mathrm{f}} /\left[\mathrm{Cd}^{2+}\right]_{\mathrm{f}}=1 ;\left[\mathrm{S}_{2} \mathrm{O}_{3}{ }^{2-}\right]_{\mathrm{f}} /\left[\mathrm{Cd}^{2+}\right]_{\mathrm{f}}=5 . \mathrm{pH}=10$ (fijado antes de añadir $\mathrm{S}_{2} \mathrm{O}_{3}{ }^{2-}$ ). Temperatura ambiente. Sin diluir. En azul: espectro de excitación. Rem= Rex= $5 \mathrm{~nm}$ (excepto a $\mathrm{t}=8$ y 15 días).

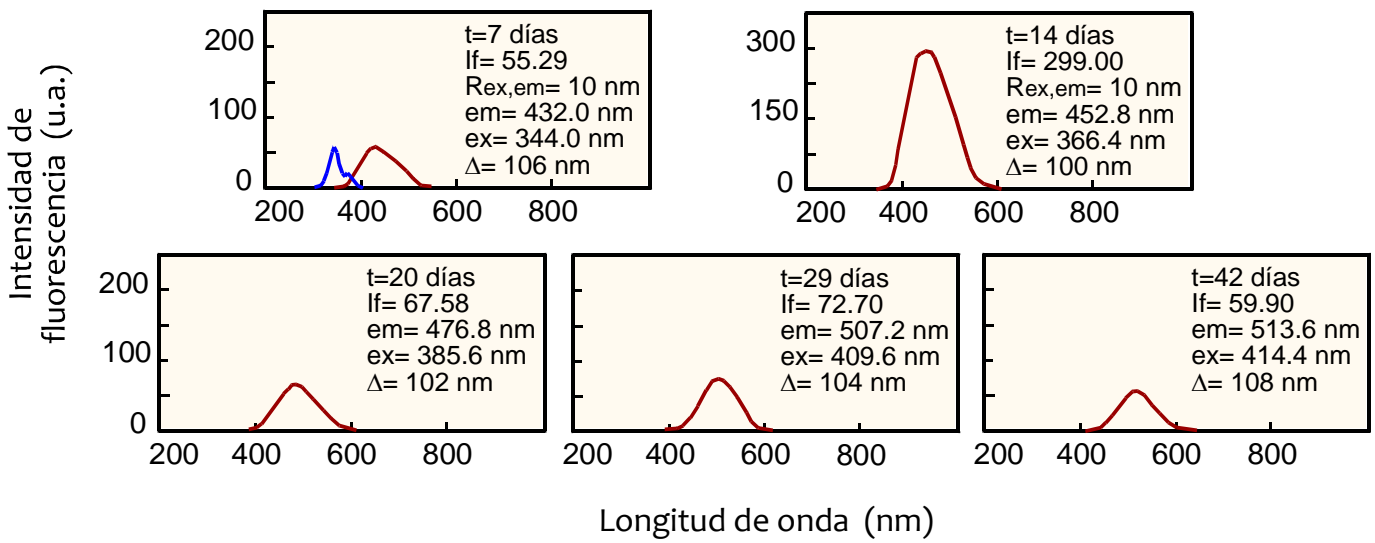

Figura 81. Espectros de emisión a diferentes tiempos de evolución. Influencia de la concentración de TG. $\left[\mathrm{Cd}^{2+}\right]_{\mathrm{f}}=6.60 \times 10^{-3} \mathrm{M}$; $\left[\mathrm{S}_{2} \mathrm{O}_{3}{ }^{2-}\right]_{\mathrm{f}}=33.0 \times 10^{-3} \mathrm{M} ;[\mathrm{MAA}]_{\mathrm{f}}=6.60 \times 10^{-3} \mathrm{M} ;[\mathrm{TG}]_{\mathrm{f}}=13.11 \times 10^{-3} \mathrm{M} ;\left[\mathrm{Cd}^{2+}\right]_{\mathrm{f}} /[\mathrm{MAA}]_{\mathrm{f}}=1 ;[\mathrm{TG}]_{\mathrm{f}} /\left[\mathrm{Cd}^{2+}\right]_{\mathrm{f}}=2 ;\left[\mathrm{S}_{2} \mathrm{O}_{3}{ }^{2-}\right]_{\mathrm{f}} /\left[\mathrm{Cd}^{2+}\right]_{\mathrm{f}}=5 . \mathrm{pH}=10$ (fijado antes de añadir $\mathrm{S}_{2} \mathrm{O}_{3}{ }^{2-}$ ). Temperatura ambiente. Sin diluir. En azul: espectro de excitación. Rem= Rex= $5 \mathrm{~nm}$ (excepto a $\mathrm{t}=7$ y 14 días). 


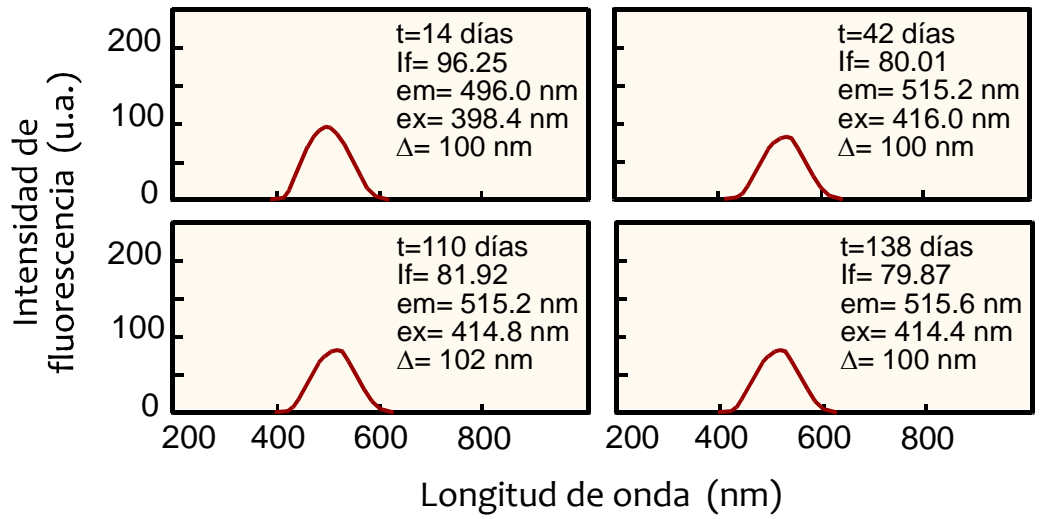

Figura 82. Espectros de emisión a diferentes tiempos de evolución. Influencia de la concentración de TG. $\left[\mathrm{Cd}^{2+}\right]_{\mathrm{f}}=6.60 \times 10^{-3} \mathrm{M} ;\left[\mathrm{S}_{2} \mathrm{O}_{3}{ }^{2-}\right]_{\mathrm{f}}=33.0 \times 10^{-3} \mathrm{M} ;[\mathrm{MAA}]_{\mathrm{f}}=6.60 \times 10^{-3} \mathrm{M} ;[\mathrm{TG}]_{\mathrm{f}}=$ $19.55 \times 10^{-3} \mathrm{M} ;\left[\mathrm{Cd}^{2+}\right]_{\mathrm{f}} /[\mathrm{MAA}]_{\mathrm{f}}=1 ;[\mathrm{TG}]_{\mathrm{f}} /\left[\mathrm{Cd}^{2+}\right]_{\mathrm{f}}=3 ;\left[\mathrm{S}_{2} \mathrm{O}_{3}{ }^{2-}\right]_{\mathrm{f}} /\left[\mathrm{Cd}^{2+}\right]_{\mathrm{f}}=5 . \mathrm{pH}=10$ (fijado antes de añadir $\mathrm{S}_{2} \mathrm{O}_{3}{ }^{2-}$ ). Temperatura ambiente. Sin diluir. $\mathrm{Rem}=\mathrm{Rex}=5 \mathrm{~nm}$.

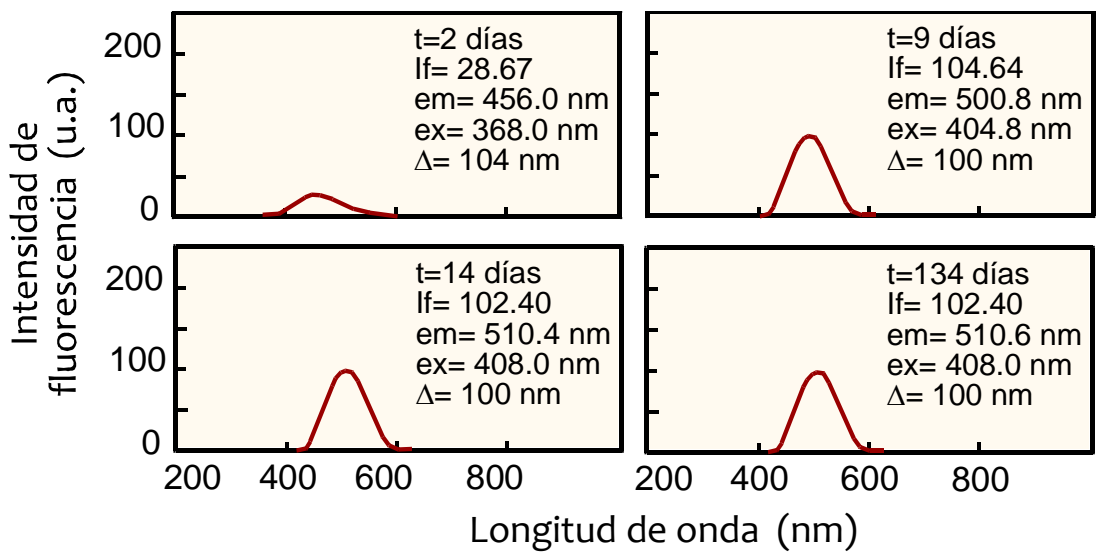

Figura 83. Espectros de emisión a diferentes tiempos de evolución. Influencia de la concentración de TG. $\left[\mathrm{Cd}^{2+}\right]_{\mathrm{f}}=6.60 \times 10^{-3} \mathrm{M} ;\left[\mathrm{S}_{2} \mathrm{O}_{3}{ }^{2-}\right]_{\mathrm{f}}=33.0 \times 10^{-3} \mathrm{M} ; \quad[\mathrm{MAA}]_{\mathrm{f}}=6.60 \times 10^{-3} \mathrm{M} ; \quad[\mathrm{TG}]_{\mathrm{f}}=32.20 \times 10^{-3} \mathrm{M}$; $\left[\mathrm{Cd}^{2+}\right]_{\mathrm{f}} /[\mathrm{MAA}]_{\mathrm{f}}=1 ;[\mathrm{TG}]_{\mathrm{f}} /\left[\mathrm{Cd}^{2+}\right]_{\mathrm{f}}=5 ;\left[\mathrm{S}_{2} \mathrm{O}_{3}{ }^{2-}\right]_{\mathrm{f}} /\left[\mathrm{Cd}^{2+}\right]_{\mathrm{f}}=5$. $\mathrm{pH}=10$ (fijado antes de añadir $\mathrm{S}_{2} \mathrm{O}_{3}{ }^{2-}$ ). Temperatura ambiente. Sin diluir. Rem $=\mathrm{Rex}=5 \mathrm{~nm}$.

Lo primero que llama la atención es que la fluorescencia a tiempos iniciales cuando existe TG es menor que la que presentan en ausencia de dicho reactivo cuando su concentración es inferior a $32.2 \times 10^{-3} \mathrm{M}$. Este hecho no está de acuerdo con las pequeñas diferencias de tamaño, pues la concentración de NPs es mayor en presencia de TG (como lo indica el valor de la absorbancia) y parece indicar un posible efecto quenching del TG sobre el proceso fluorescente. Para la experiencia en la que la concentración de TG es elevada $\left(32.2 \times 10^{-3} \mathrm{M}\right)$, el efecto catalítico hace que las NPs de CdS obtenidas, a tiempos iniciales, a pesar del efecto quenching, muestren mayor fluorescencia que las obtenidas en ausencia de TG. La mayor concentración de nanopartículas compensa el efecto quenching. 
Los espectros de excitación que presentan las NPs en presencia de TG (Fig. 80-81) son morfológicamente idénticos a los obtenidos en ausencia de dicho reactivo. Son muy simétricos y no muestran deformaciones ni en cabeza ni en cola, lo que indica un estado de superficie muy homogéneo.

Los espectros de emisión muestran desplazamiento batocrómico con el incremento de tamaño. Las longitudes de onda de emisión en todas las experiencias corresponden a luz desde color azul a verde.

Los valores de intensidad de fluorescencia se representan frente al tiempo en la Figura 84. Se muestran también los valores de la experiencia en la que no se añade TG.

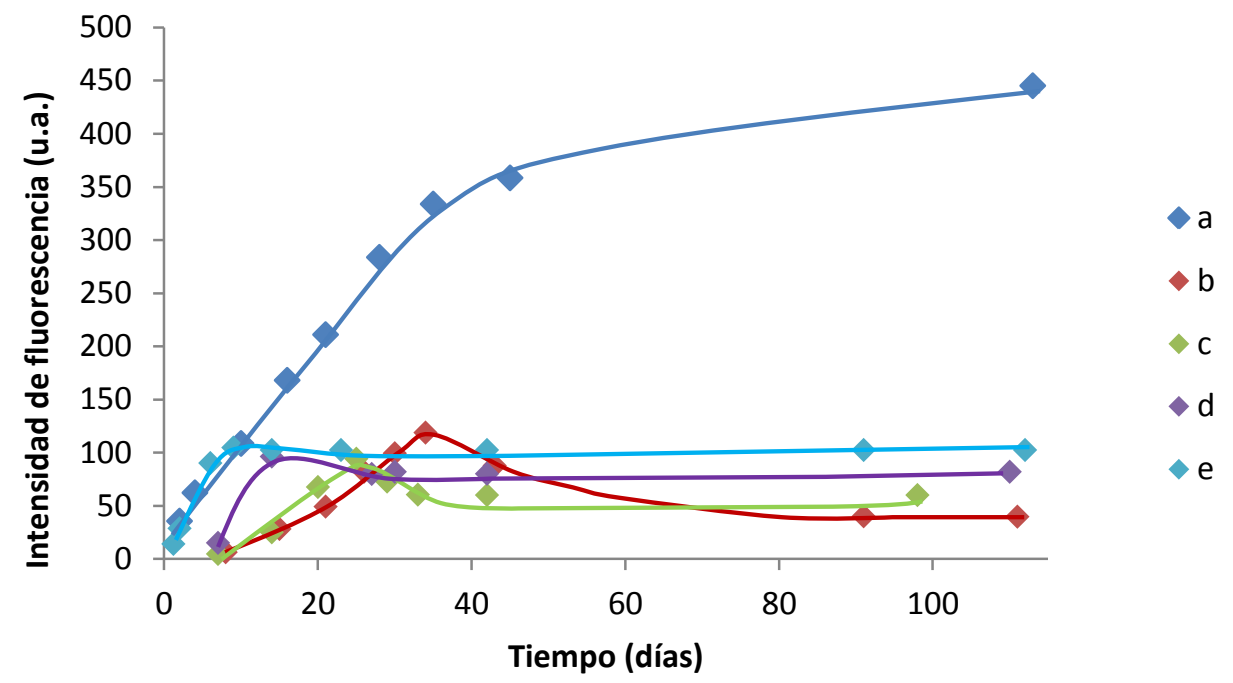

Figura 84. Evolución de la intensidad máxima de fluorescencia. Influencia de la concentración de TG. a) Ausencia de TG; b) $[\mathrm{TG}]_{\mathrm{f}}=6.60 \times 10^{-3} \mathrm{M}$; c) $\left.[\mathrm{TG}]_{\mathrm{f}}=13.11 \times 10^{-3} \mathrm{M} ; \mathrm{d}\right)[\mathrm{TG}]_{\mathrm{f}}=19.55 \times 10^{-3} \mathrm{M}$; e) $[\mathrm{TG}]_{\mathrm{f}}=32.20 \times 10^{-3} \mathrm{M}$. $\left[\mathrm{Cd}{ }^{2+}\right] /[\mathrm{MAA}]=$ $1 ;\left[\mathrm{S}_{2} \mathrm{O}_{3}{ }^{2-}\right] /\left[\mathrm{Cd}^{2+}\right]=5 . \mathrm{pH}=10$ (fijado antes de añadir $\mathrm{S}_{2} \mathrm{O}_{3}{ }^{2-}$ ). Temperatura ambiente. Rex= Rem= $5 \mathrm{~nm}$.

Puede observarse cómo, salvo para la experiencia donde TG es $32.2 \times 10^{-3} \mathrm{M}$ (y a tiempos iniciales), en el resto los valores de If máximos son inferiores a los obtenidos en la experiencia en ausencia de TG. El efecto catalítico del TG se plasma en la pendiente de la subida inicial: a mayor concentración de TG, mayor pendiente. El efecto quenching del TG, mayor cuanto más alta es su concentración, explica la razón por la cual el valor máximo de fluorescencia no supera al valor máximo obtenido en la experiencia en la que no hay TG.

En todos los casos, en presencia de TG se alcanza un valor de If constante, lo que indica que su papel dispersante refuerza al del MAA, obteniéndose nanopartículas menos fluorescentes pero más estables. Este valor constante se alcanza antes en el tiempo cuanto 
mayor es la concentración de TG por alcanzarse, en este sentido, una nanopartícula que ya no crece más.

Como conclusión del estudio de la influencia del TG sobre la obtención de NPs de CdS utilizando $\mathrm{S}_{2} \mathrm{O}_{3}{ }^{2-}$ como precursor, cabe destacar que, si bien dicho reactivo actúa como catalizador en el proceso de hidrólisis del precursor generando ión $S^{2-}$ a mayor velocidad, ejerce un efecto negativo que contrarresta al anterior por provocar quenching en la fluorescencia al depositarse sobre la superficie de las nanopartículas.

En cuanto al control del tamaño de las nanopartículas y su fluorescencia, el uso de $T G$ en presencia de $\mathrm{S}_{2} \mathrm{O}_{3}{ }^{2-}$ y $\mathrm{MAA}$ resulta negativo y no mejora el comportamiento de las nanopartículas de CdS obtenidas en ausencia de dicho reactivo.

Un aspecto positivo del TG es que mejora el poder dispersante del MAA, por lo que la estabilidad de las nanopartículas en disolución aumenta.

\section{INFLUENCIA DE LA TEMPERATURA}

La influencia de la temperatura de la disolución en el método de obtención de las NPs de CdS utilizando $\mathrm{S}^{2-}$ como reactivo formador ya fue estudiada en la primera parte de esta memoria.

En el método de obtención utilizando $\mathrm{S}_{2} \mathrm{O}_{3}{ }^{2-}$ como precursor de $\mathrm{S}^{2-}$, la temperatura puede jugar un papel importante en la reacción de hidrólisis de dicho reactivo por ser de cinética lenta. Para estudiar la influencia de dicha variable, en primer lugar se realiza la siguiente experiencia:

Sobre $100 \mathrm{~mL}$ de disolución de $\mathrm{Cd}^{2+} 1.0 \times 10^{-3} \mathrm{M}(1 \mathrm{mmol})$, termostatada a $40^{\circ} \mathrm{C}$, se añaden (cuando la temperatura se estabiliza en dicho valor) $714 \mu \mathrm{L}$ de MAA $1.41 \mathrm{M}$ (1 mmol) y se ajusta el $\mathrm{pH}$ a 10 con disolución de $\mathrm{NaOH}$. Se pasa corriente de nitrógeno durante el tiempo indicado en el procedimiento y se añaden $50 \mathrm{~mL}$ de disolución de $\mathrm{S}_{2} \mathrm{O}_{3}{ }^{2-}$ $40 \times 10^{-2} \mathrm{M}$ (20 mmoles), con lo que el pH final resulta 9.98. El momento de terminar de añadir el último reactivo se considera $\mathrm{t}=0$.

La disolución se sigue termostatando a $40^{\circ} \mathrm{C}$ durante $24 \mathrm{~h}$ y en ese momento se divide en dos partes. Una de ellas se sigue termostatando (Disolución 1) y la otra parte se conserva a temperatura ambiente (Disolución 2).

En las condiciones expuestas las concentraciones finales de los reactivos y su relación molar resultan: $\left[\mathrm{Cd}^{2+}\right]_{\mathrm{f}}=6.64 \times 10^{-3} \mathrm{M} ;\left[\mathrm{S}_{2} \mathrm{O}_{3}{ }^{2-}\right]_{\mathrm{f}}=132.7 \times 10^{-3} \mathrm{M}$; $[\mathrm{MAA}]_{\mathrm{f}}=6.64 \times 10^{-3} \mathrm{M}$; $\left[\mathrm{Cd}^{2+}\right]_{\mathrm{F}} /[\mathrm{MAA}]_{\mathrm{f}}=1 ;\left[\mathrm{S}_{2} \mathrm{O}_{3}{ }^{2-}\right]_{\mathrm{f}} /\left[\mathrm{Cd}^{2+}\right]_{\mathrm{f}}=20$. 
Desde $\mathrm{t}=0$, tanto en la Disolución 1 como en la 2 , se toman periódicamente alícuotas para registrar sus espectros de absorción (diluyendo en proporción 1:5) y de luminiscencia (sin diluir).

\section{Evolución de los espectros de absorción}

En la Figura 85 se representan los espectros de absorción de diferentes alícuotas durante las primeras $24 \mathrm{~h}$ de evolución de la Disolución 1, y en la Figura 86 se representan los espectros de esta disolución a partir de las $24 \mathrm{~h}$. Para comprobar el efecto de la temperatura se comprarán estas dos figuras con la Figura 70, que corresponde a NPs obtenidas en las mismas condiciones a temperatura ambiente.

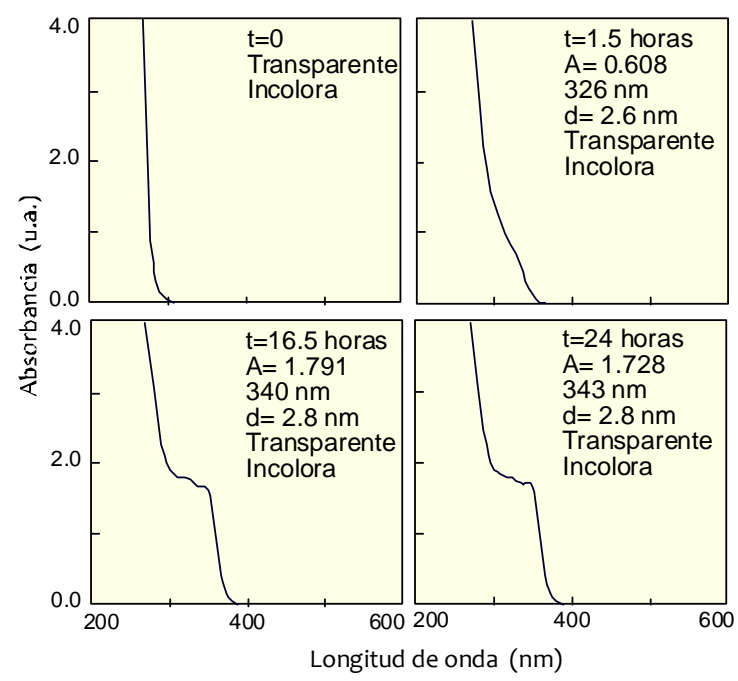

Figura 85. Espectros de absorción durante las primeras $24 \mathrm{~h}$. Influencia de la temperatura. Disolución 1. $\left[\mathrm{Cd}^{2+}\right]_{\mathrm{f}}=6.64 \times 10^{-3} \mathrm{M} ;\left[\mathrm{S}_{2} \mathrm{O}_{3}{ }^{2-}\right]_{\mathrm{f}}=132.7 \times 10^{-3} \mathrm{M}$; $[\mathrm{MAA}]_{\mathrm{f}}=6.64 \times 10^{-3} \mathrm{M} ;\left[\mathrm{Cd}^{2+}\right]_{\mathrm{f}} /[\mathrm{MAA}]_{\mathrm{f}}=1 ;\left[\mathrm{S}_{2} \mathrm{O}_{3}{ }^{2-}\right]_{\mathrm{f}} /\left[\mathrm{Cd}^{2+}\right]_{\mathrm{f}}=20 . \mathrm{pH}=10$ (fijado antes de añadir $\mathrm{S}_{2} \mathrm{O}_{3}{ }^{2-}$ ). Dilución 1:5. 


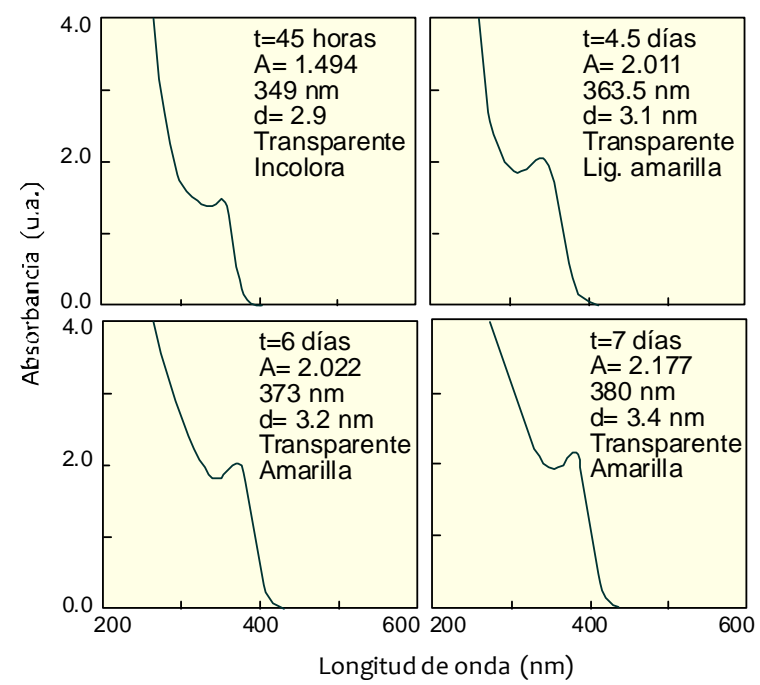

Figura 86. Espectros de absorción a tiempo superior a las $24 \mathrm{~h}$. Influencia de la temperatura. Disolución 1. $\left[\mathrm{Cd}^{2+}\right]_{\mathrm{f}}=6.64 \times 10^{-3} \mathrm{M} ;\left[\mathrm{S}_{2} \mathrm{O}_{3}{ }^{2-}\right]_{\mathrm{f}}=132.7 \times 10^{-3}$ $\mathrm{M} ;[\mathrm{MAA}]_{\mathrm{f}}=6.64 \times 10^{-3} \mathrm{M} ;\left[\mathrm{Cd}^{2+}\right]_{\mathrm{f}} /[\mathrm{MAA}]_{\mathrm{f}}=1 ;\left[\mathrm{S}_{2} \mathrm{O}_{3}{ }^{2-}\right]_{\mathrm{f}} /\left[\mathrm{Cd}^{2+}\right]_{\mathrm{f}}=20 . \mathrm{pH}=10$ (fijado antes de añadir $\mathrm{S}_{2} \mathrm{O}_{3}{ }^{2-}$ ). Dilución 1:5.

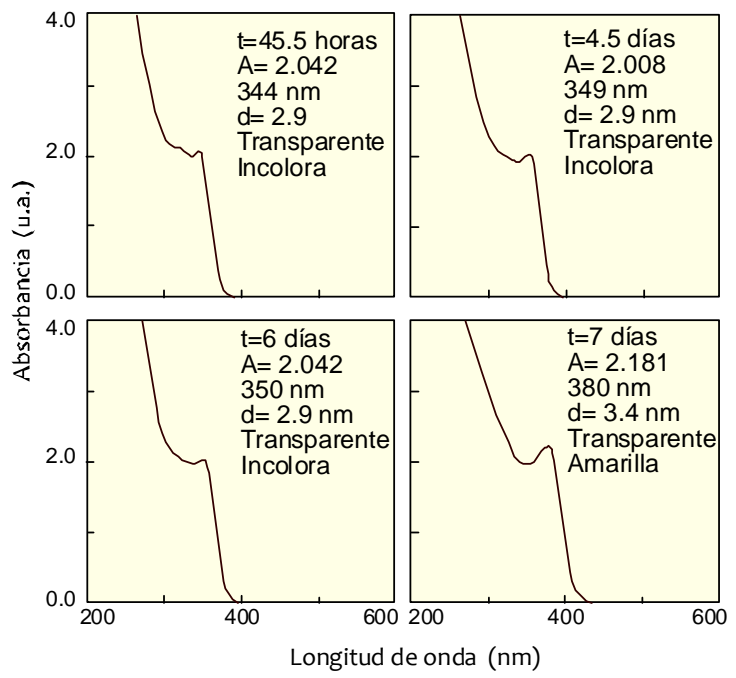

Figura 87. Espectros de absorción a tiempo superior a las $24 \mathrm{~h}$. Influencia de la temperatura. Disolución 2. $\left[\mathrm{Cd}^{2+}\right]_{\mathrm{f}}=6.64 \times 10^{-3} \mathrm{M} ;\left[\mathrm{S}_{2} \mathrm{O}_{3}{ }^{2-}\right]_{\mathrm{f}}=132.7 \times 10^{-3}$ $\mathrm{M} ;[\mathrm{MAA}]_{\mathrm{f}}=6.64 \times 10^{-3} \mathrm{M} ;\left[\mathrm{Cd}^{2+}\right]_{\mathrm{f}} /[\mathrm{MAA}]_{\mathrm{f}}=1 ;\left[\mathrm{S}_{2} \mathrm{O}_{3}{ }^{2-}\right]_{\mathrm{f}} /\left[\mathrm{Cd}^{2+}\right]_{\mathrm{f}}=20 . \mathrm{pH}=10$ (fijado antes de añadir $\mathrm{S}_{2} \mathrm{O}_{3}{ }^{2-}$ ). Dilución 1:5.

Comparando las dos experiencias se comprueba de manera fehaciente que la cinética de descomposición del $\mathrm{S}_{2} \mathrm{O}_{3}{ }^{2-}$ se acelera al incrementar la temperatura. A temperatura ambiente, a las $24 \mathrm{~h}$, el tamaño de la NP es de $2.6 \mathrm{~nm}$, mientras que en el mismo periodo de tiempo a $40^{\circ} \mathrm{C}$ el tamaño es de $2.8 \mathrm{~nm}$. Esto indica que a $40^{\circ} \mathrm{C}$ se ha generado una mayor concentración de $\mathrm{S}^{2-}$ y una mayor concentración de NPs. 
Si a las $24 \mathrm{~h}$ la termostatación a $40^{\circ} \mathrm{C}$ se para y se deja evolucionar la disolución a temperatura ambiente (Fig. 87), la generación de $\mathrm{S}^{2-}$ se frena y la nanopartícula crece a menor velocidad. Pero a partir de los 4 días las diferencias en el tamaño se van haciendo menores, igualándose en $3.4 \mathrm{~nm}$ a los 7 días.

Este hecho parece indicar que cuando se alcanza una concentración de $\mathrm{S}^{2-}$ que satisface una relación óptima $\left[\mathrm{Cd}^{2+}\right] /\left[\mathrm{S}^{2-}\right]$, sobre el tamaño de las NPs empieza a influir el posible depósito de $\mathrm{S}^{2-}$ generado sobre la superficie de las NPs modificando su modelo de crecimiento. Este fenómeno había sido observado al estudiar la obtención de NPs de CdS en fase heterogénea, y más concretamente al comprobar que siempre existe una relación óptima $\left[\mathrm{Cd}^{2+}\right] /\left[\mathrm{S}^{2-}\right]$ para obtener NPs con la máxima fluorescencia (con una características morfológicas y superficiales dadas).

\section{Evolución de los espectros de luminiscencia}

Para comentar la influencia de la temperatura sobre las propiedades luminiscentes de las NPs, los espectros se comparan con los obtenidos en las mismas condiciones pero a temperatura ambiente (Tabla 9).

Lo primero que queremos comentar es que el hecho de obtener las NPs a temperaturas superiores a la ambiental, en el presente caso a $40^{\circ} \mathrm{C}$, no modifica el aspecto morfológico del espectro de excitación. En la Figura 88 se muestran como ejemplo los espectros de excitación de las nanopartículas a las 45 h y a los 4.5 días de su evolución tras calentar y mantener la disolución a $40^{\circ} \mathrm{C}$ (Disolución 1). Son espectros muy simétricos y, además de estrechos, similares a los obtenidos en las experiencias a temperatura ambiente, que muestran una morfología superficial muy homogénea y que sobre la superficie de las NPs no parecen ocurrir procesos diferentes a los que ocurren a temperatura ambiente.
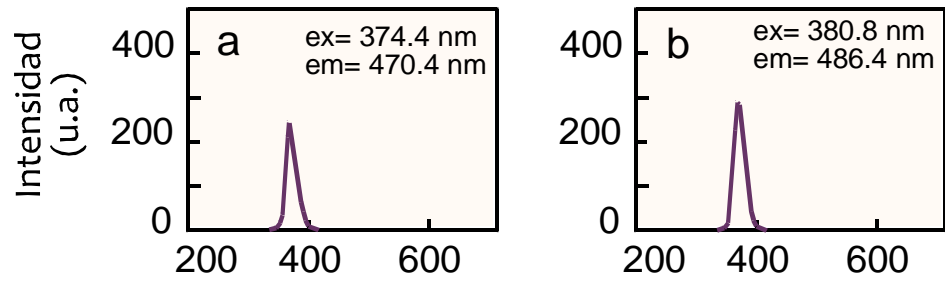

Longitud de onda ( $\mathrm{nm})$

Figura 88. Espectros de excitación a dos tiempos de evolución: a) 45 h; b) 4.5 días. Influencia de la temperatura. Disolución 1. $\left[\mathrm{Cd}^{2+}\right]_{\mathrm{f}}=6.64 \times 10^{-3} \mathrm{M} ;\left[\mathrm{S}_{2} \mathrm{O}_{3}{ }^{2-}\right]_{\mathrm{f}}=132.7 \times 10^{-3} \mathrm{M}$; $[\mathrm{MAA}]_{\mathrm{f}}=6.64 \times 10^{-3} \mathrm{M} ;\left[\mathrm{Cd}^{2+}\right]_{\mathrm{f}} /[\mathrm{MAA}]_{\mathrm{f}}=1 ;\left[\mathrm{S}_{2} \mathrm{O}_{3}{ }^{2-}\right]_{\mathrm{f}} /\left[\mathrm{Cd}^{2+}\right]_{\mathrm{f}}=20 . \mathrm{pH}=10$ (fijado antes de añadir $\mathrm{S}_{2} \mathrm{O}_{3}{ }^{2-}$ ). Rendijas de $5 \mathrm{~nm}$. 
En las Figuras 89 y 90 se muestran los espectros de emisión de las NPs obtenidas a $40^{\circ} \mathrm{C}$ hasta las $24 \mathrm{~h}$ y en periodos posteriores, respectivamente (Disolución 1). En la Figura 91 se muestran los espectros de emisión de las nanopartículas dejadas a temperatura ambiente tras las $24 \mathrm{~h}$ a $40^{\circ} \mathrm{C}$ (Disolución 2). En dichos espectros se indican las longitudes de onda de excitación y emisión óptimas, el valor de la intensidad de fluorescencia máxima y el valor de distribución del tamaño de las NPs alrededor del valor medio $(\Delta)$.
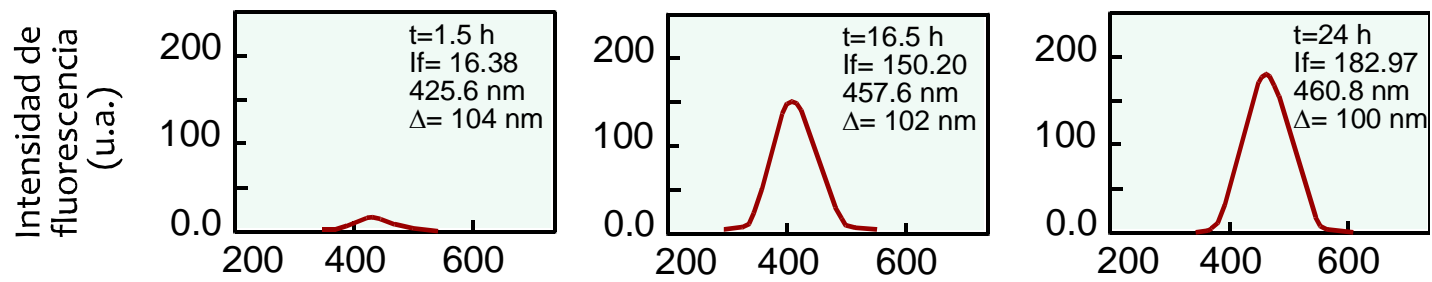

Longitud de onda (nm)

Figura 89. Espectros de emisión durante las primeras $24 \mathrm{~h}$. Influencia de la temperatura. Disolución $1 .\left[\mathrm{Cd}^{2+}\right]_{\mathrm{f}}=6.64 \times 10^{-3} \mathrm{M}$; $\left[\mathrm{S}_{2} \mathrm{O}_{3}{ }^{2-}\right]_{\mathrm{f}}=132.7 \times 10^{-3} \mathrm{M} ;[\mathrm{MAA}]_{\mathrm{f}}=6.64 \times 10^{-3} \mathrm{M} ;\left[\mathrm{Cd}^{2+}\right]_{\mathrm{f}} /[\mathrm{MAA}]_{\mathrm{f}}=1 ;\left[\mathrm{S}_{2} \mathrm{O}_{3}{ }^{2-}\right]_{\mathrm{f}} /\left[\mathrm{Cd}^{2+}\right]_{\mathrm{f}}=20 . \mathrm{pH}=10$ (fijado antes de añadir $\mathrm{S}_{2} \mathrm{O}_{3}{ }^{2-}$ ). Rendijas de $5 \mathrm{~nm}$. $\lambda$ ex $=347-376 \mathrm{~nm}$.

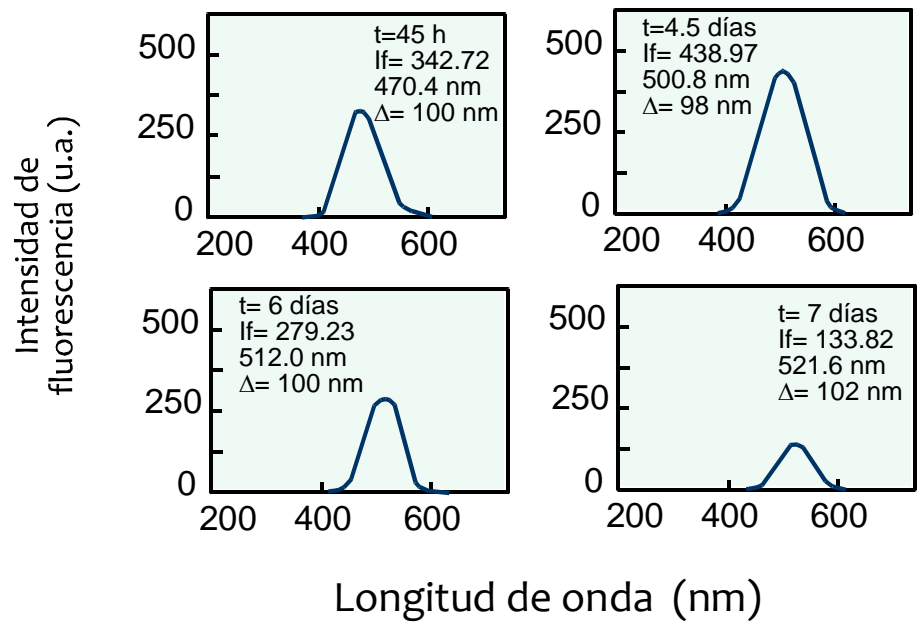

Figura 90. Espectros de emisión a tiempos superiores a las $24 \mathrm{~h}$. Influencia de la temperatura. Disolución 1. $\left[\mathrm{Cd}^{2+}\right]_{\mathrm{f}}=6.64 \times 10^{-3} \mathrm{M} ;\left[\mathrm{S}_{2} \mathrm{O}_{3}{ }^{2-}\right]_{\mathrm{f}}=132.7 \times 10^{-3} \mathrm{M} ;[\mathrm{MAA}]_{\mathrm{f}}=6.64 \times 10^{-}$

${ }^{3} \mathrm{M} ;\left[\mathrm{Cd}^{2+}\right]_{\mathrm{f}} /[\mathrm{MAA}]_{\mathrm{f}}=1 ;\left[\mathrm{S}_{2} \mathrm{O}_{3}{ }^{2-}\right]_{\mathrm{f}} /\left[\mathrm{Cd}^{2+}\right]_{\mathrm{f}}=20 . \mathrm{pH}=10$ (fijado antes de añadir $\mathrm{S}_{2} \mathrm{O}_{3}{ }^{2-}$ ).

Rendijas de $5 \mathrm{~nm}$. $\lambda$ ex $=382-417 \mathrm{~nm}$. 


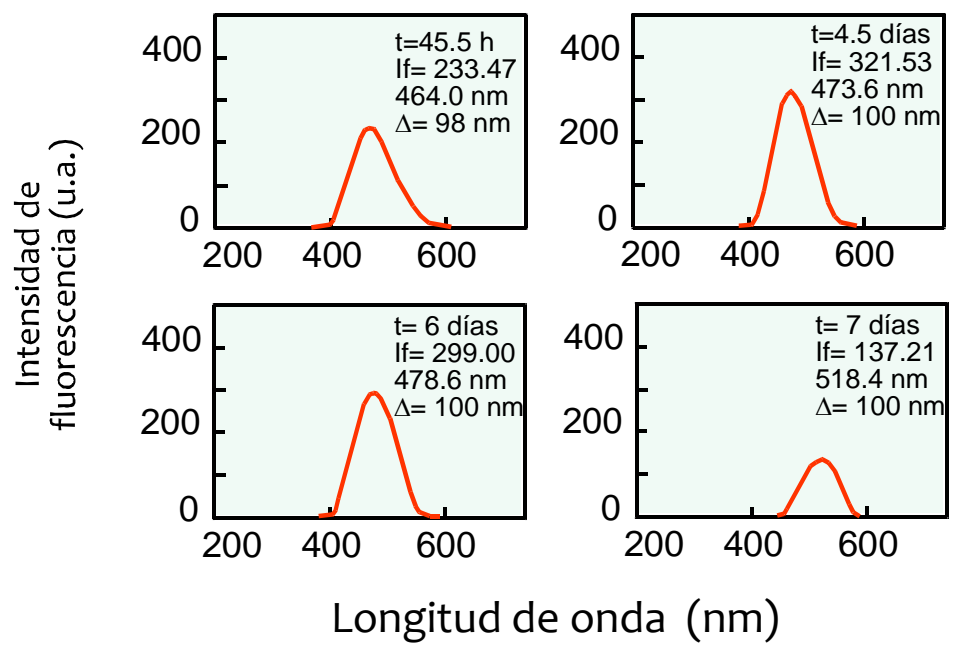

Figura 91. Espectros de emisión a tiempos superiores a las $24 \mathrm{~h}$. Influencia de la temperatura. Disolución 2. $\left[\mathrm{Cd}^{2+}\right]_{\mathrm{f}}=6.64 \times 10^{-3} \mathrm{M} ;\left[\mathrm{S}_{2} \mathrm{O}_{3}{ }^{2-}\right]_{\mathrm{f}}=132.7 \times 10^{-3} \mathrm{M} ;[\mathrm{MAA}]_{\mathrm{f}}=6.64 \times 10^{-}$

${ }^{3} \mathrm{M} ;\left[\mathrm{Cd}^{2+}\right]_{\mathrm{f}} /[\mathrm{MAA}]_{\mathrm{f}}=1 ;\left[\mathrm{S}_{2} \mathrm{O}_{3}{ }^{2-}\right]_{\mathrm{f}} /\left[\mathrm{Cd}^{2+}\right]_{\mathrm{f}}=20 . \mathrm{pH}=10$ (fijado antes de añadir $\mathrm{S}_{2} \mathrm{O}_{3}{ }^{2-}$ ).

Rendijas de $5 \mathrm{~nm}$. $\lambda$ ex $=374-417 \mathrm{~nm}$.

Al comparar estos espectros de emisión con los obtenidos en condiciones experimentales idénticas pero a temperatura ambiente (Tabla 9), se observa en todos los casos que a medida que aumenta el tamaño de las nanopartículas en el proceso de su evolución, tanto la $\lambda_{\mathrm{ex}}$ como la $\lambda_{\mathrm{em}}$ sufren un desplazamiento batocrómico. Este desplazamiento es más rápido para la experiencia a $40^{\circ} \mathrm{C}$ que para la experiencia a temperatura ambiente. Este hecho es una consecuencia del incremento en la velocidad de generación del $\mathrm{S}^{2-}$ que conduce a una mayor velocidad en el incremento del tamaño.

En cuanto a la distribución de tamaños no se observan diferencias significativas entre las experiencias realizadas a temperatura ambiente o a $40^{\circ} \mathrm{C}$.

El color de la fluorescencia, al ser el rango de tamaños similar e independiente de la temperatura, en ambos casos va desde añil a verde.

La evolución del valor de intensidad de fluorescencia para las tres experiencias se ha representado en la Figura 92. 


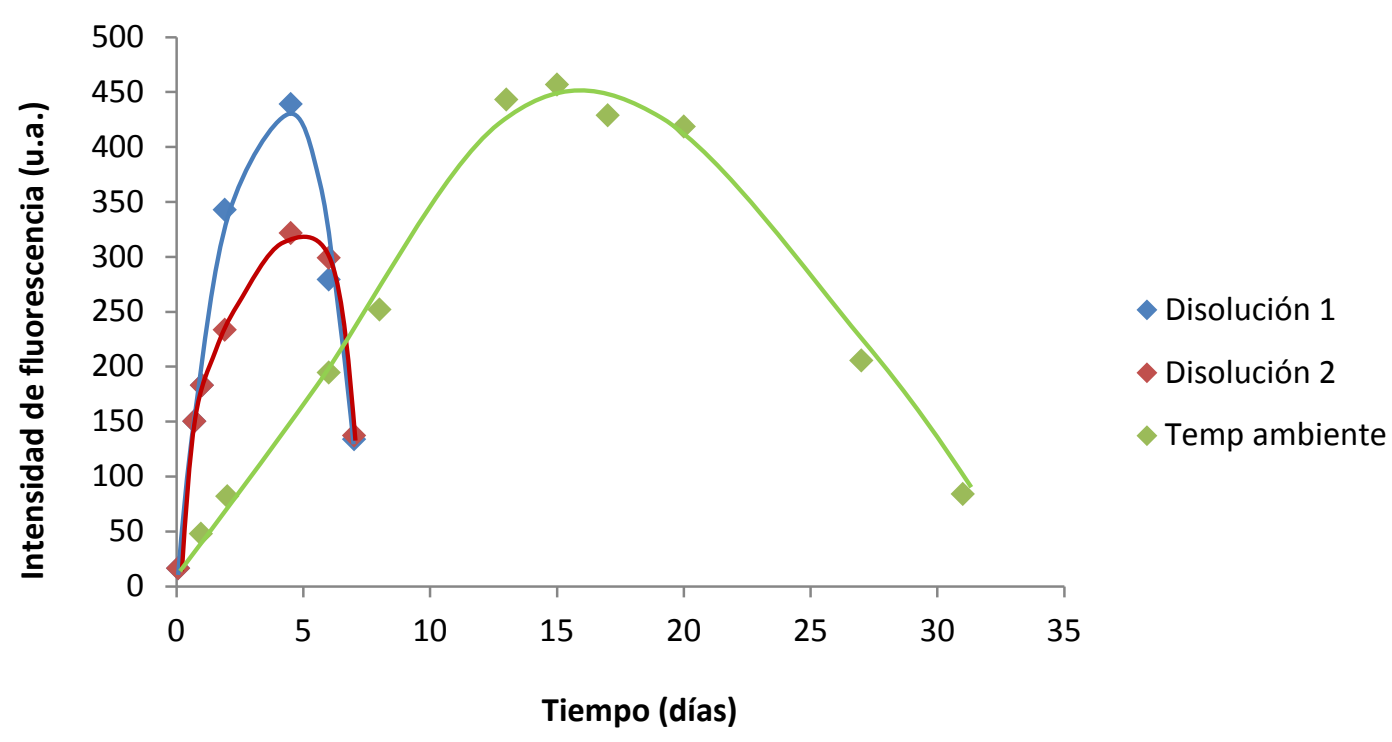

Figura 92. Evolución de la intensidad de fluorescencia. Influencia de la temperatura. $\left[\mathrm{Cd}^{2+}\right]_{\mathrm{f}}=6.64 \times 10^{-3} \mathrm{M} ;\left[\mathrm{S}_{2} \mathrm{O}_{3}{ }^{2-}\right]_{\mathrm{f}}=$ $132.7 \times 10^{-3} \mathrm{M} ;[\mathrm{MAA}]_{\mathrm{f}}=6.64 \times 10^{-3} \mathrm{M} ;\left[\mathrm{Cd}^{2+}\right]_{\mathrm{f}} /[\mathrm{MAA}]_{\mathrm{f}}=1 ;\left[\mathrm{S}_{2} \mathrm{O}_{3}{ }^{2-}\right]_{\mathrm{f}} /\left[\mathrm{Cd}^{2+}\right]_{\mathrm{f}}=20 . \mathrm{pH}=10$ (fijado antes de añadir $\mathrm{S}_{2} \mathrm{O}_{3}{ }^{2-}$ ). Rendijas de $5 \mathrm{~nm}$.

Como puede comprobarse, la morfología de la evolución es similar. A medida que las NPs evolucionan con el tiempo, su fluorescencia inicialmente se incrementa por hacerlo la concentración (pues se incrementa la concentración de $\mathrm{S}^{2-}$ generado) hasta alcanzar un valor de If $_{\text {máx }}$ que corresponde a una relación óptima $\left[\mathrm{Cd}^{2+}\right] /\left[\mathrm{S}^{2-}\right]$, que lógicamente se alcanza antes a $40^{\circ} \mathrm{C}$ por ser mayor la generación de $\mathrm{S}^{2-}$. Como puede verse en la Figura 92, el máximo se alcanza antes en la experiencia a $40^{\circ} \mathrm{C}$ (Disolución 1), posteriormente la experiencia en la que dicha temperatura sólo se mantiene 24 h (Disolución 2) y en último lugar en la experiencia donde el ión $\mathrm{S}^{2-}$ se genera a menor velocidad (experiencia a temperatura ambiente).

Tras alcanzar el máximo de intensidad de fluorescencia, relación óptima $\left[\mathrm{Cd}^{2+}\right] /\left[\mathrm{S}^{2-}\right]$, la intensidad de fluorescencia comienza a disminuir, más bruscamente cuanto mayor es la temperatura. Este descenso en la fluorescencia está relacionado con la formación de trampas en la superficie de las NPs por depósito de $\mathrm{S}^{2-}$, que se enlaza sobre átomos superficiales de cadmio. Es muy probable que en las condiciones experimentales utilizadas (exceso de $\mathrm{S}_{2} \mathrm{O}_{3}{ }^{2-}$ ) sea menos favorable termodinámicamente la formación de depósitos de especies hidroxiladas de cadmio.

El valor de $I_{\text {máx }}$ que se alcanza en la relación óptima $\left[\mathrm{Cd}^{2+}\right] /\left[\mathrm{S}^{2-}\right]$ es ligeramente menor a $40^{\circ} \mathrm{C}$ ( $\left(\mathrm{f}_{\text {máx }}=438\right.$ u.a.) que a temperatura ambiente ( $\left(\mathrm{f}_{\text {máx }}=457\right.$ u.a.), lo que indica que en las proximidades de dicho valor compiten dos procesos: uno, la formación de 
nuevas partículas de CdS y otro, el depósito de ión $\mathrm{S}^{2-}$; este último predominaría más cuanto mayor es la velocidad de generación del ión $\mathrm{S}^{2-}$. Este fenómeno también fue observado al estudiar otras variables.

Influencia de la temperatura a bajas concentraciones de $\mathrm{S}_{2} \mathrm{O}_{3}{ }^{2-}$

Como se ha podido comprobar al exponer los resultados experimentales de la influencia de la temperatura así como los deducidos al estudiar la influencia de la concentración de $\mathrm{S}_{2} \mathrm{O}_{3}{ }^{2-}$, el exceso de ion $\mathrm{S}^{2-}$ generado en su descomposición afecta negativamente a las propiedades fluorescentes de las NPs de CdS obtenidas. El descenso de fluorescencia parece depender, además, de la velocidad de generación de dicho ión $\mathrm{S}^{2-}$.

Para el empleo de las nanopartículas de CdS como biomarcadores es importante que tengan la mayor fluorescencia posible, por esta razón se estudia la influencia de la temperatura sobre las propiedades fluorescentes de las NPs generadas a partir de $\mathrm{S}_{2} \mathrm{O}_{3}{ }^{2-}$ como precursor y en concentraciones bajas.

Se preparan tres disoluciones en las mismas condiciones experimentales descritas al estudiar la influencia del $\mathrm{pH}$. En todos los casos se ajusta el $\mathrm{pH}$ a 11. Las concentraciones finales y las relaciones molares son: $\left[\mathrm{Cd}^{2+}\right]_{\mathrm{f}}=6.64 \times 10^{-3} \mathrm{M} ;\left[\mathrm{S}_{2} \mathrm{O}_{3}{ }^{2-}\right]_{\mathrm{f}}=6.64 \times 10^{-3} \mathrm{M}$; $[\mathrm{MAA}]_{\mathrm{f}}=$ $6.64 \times 10^{-3} \mathrm{M} ;\left[\mathrm{Cd}^{2+}\right]_{\mathrm{f}} /[\mathrm{MAA}]_{\mathrm{f}}=1 ;\left[\mathrm{Cd}^{2+}\right]_{\mathrm{f}} /\left[\mathrm{S}_{2} \mathrm{O}_{3}{ }^{2-}\right]_{\mathrm{f}}=1$.

Las tres disoluciones son termostatadas a $30^{\circ} \mathrm{C}, 40^{\circ} \mathrm{C}$ y $50^{\circ} \mathrm{C}$ durante todo el periodo de estudio y periódicamente se sacan alícuotas y, sin diluir, se registran los espectros de absorción y luminiscencia para estudiar las características de las NPs de CdS.

Los resultados se comparan con los obtenidos a partir de la misma disolución mantenida a temperatura ambiente, que ya fueron dados a conocer (Fig. 60 y 63).

A partir de los espectros de absorción se deduce que, en todos los casos, las NPs obtenidas crecen desde $2.5 \mathrm{~nm}$ hasta $3.0 \mathrm{~nm}$. El margen de tiempo del proceso de crecimiento es más corto cuanto mayor es la temperatura. Estos tamaños de nanopartícula corresponden a valores de $\mathrm{N}$ entre 160 y 270. Los valores de absorbancia en el pico excitónico oscilan entre 0.26 y 1.51.

Del estudio de los espectros de luminiscencia se deduce que, en todos los casos, el efecto batocrómico hace que la $\lambda_{\text {ex }}$ varíe desde $347 \mathrm{~nm}$ hasta $384 \mathrm{~nm}$, y la $\lambda_{\mathrm{em}}$ desde $427 \mathrm{~nm}$ hasta $480 \mathrm{~nm}$.

Los valores de intensidad de fluorescencia máximos obtenidos en las tres experiencias, conjuntamente con la experiencia a temperatura ambiente, se muestran en la 
Tabla 11. Dichos valores se representan frente al tiempo en la Figura 93. En dicha figura también se representa en forma de segmento continuo el valor más alto de fluorescencia y el periodo de tiempo en el que se mantiene constante de las NPs de CdS obtenidas por el método heterogéneo, usando directamente $S^{2-}$ (Tabla 6; $I_{\text {máx }}=540$ u.a.).

Tabla 11. Influencia de la temperatura a bajas concentraciones de $\mathrm{S}_{2} \mathrm{O}_{3}{ }^{2-}$. Valores de intensidad de fluorescencia máxima. $\left[\mathrm{Cd}^{2+}\right]_{\mathrm{f}}=\left[\mathrm{S}_{2} \mathrm{O}_{3}{ }^{2-}\right]_{\mathrm{f}}=[\mathrm{MAA}]_{\mathrm{f}}=6.64 \times 10^{-3} \mathrm{M}$; $\left[\mathrm{Cd}^{2+}\right]_{\mathrm{f}} /[\mathrm{MAA}]_{\mathrm{f}}=\left[\mathrm{S}_{2} \mathrm{O}_{3}{ }^{2-}\right]_{\mathrm{f}} /\left[\mathrm{Cd}^{2+}\right]_{\mathrm{f}}=1 . \mathrm{pH}=11$ (fijado antes de añadir $\mathrm{S}_{2} \mathrm{O}_{3}{ }^{2-}$ ). Rendijas de $5 \mathrm{~nm}$.

\begin{tabular}{|c|c|c|c|c|}
\cline { 2 - 5 } \multicolumn{1}{c|}{} & \multicolumn{4}{c|}{ Intensidad de fluorescencia máxima (u.a.) } \\
\cline { 3 - 5 } \multicolumn{1}{c|}{} & & $\mathbf{3 0}^{\circ} \mathbf{C}$ & $\mathbf{4 0}^{\circ} \mathbf{C}$ & $\mathbf{5 0}^{\circ} \mathbf{C}$ \\
\hline Tiempo (días) & $\mathbf{2 0 - 2 2}^{\circ} \mathbf{C}$ & 12.38 & 40.06 & 53.12 \\
\hline 1 & & & 50.13 & 61.07 \\
\hline 4 & 21.50 & 49.60 & 71.21 & 128.21 \\
10 & & 76.13 & 134.02 & 226.55 \\
12 & 53.24 & & & 254.67 \\
16 & & 120.77 & 210.78 & 309.44 \\
18 & & & & 318.90 \\
27 & 143.51 & 199.25 & 311.02 & 204.03 \\
30 & & & 350.31 & 150.13 \\
42 & 199.80 & 283.44 & 451.07 & \\
50 & & 345.91 & 511.43 & \\
58 & & & 483.90 & \\
68 & 328.14 & 455.32 & 379.75 & \\
85 & 401.05 & 560.11 & 189.32 & \\
98 & & 543.20 & & \\
119 & 561.15 & 422.88 & & \\
140 & 643.77 & & & \\
147 & 639.68 & & & \\
154 & 602.81 & & & \\
\hline
\end{tabular}




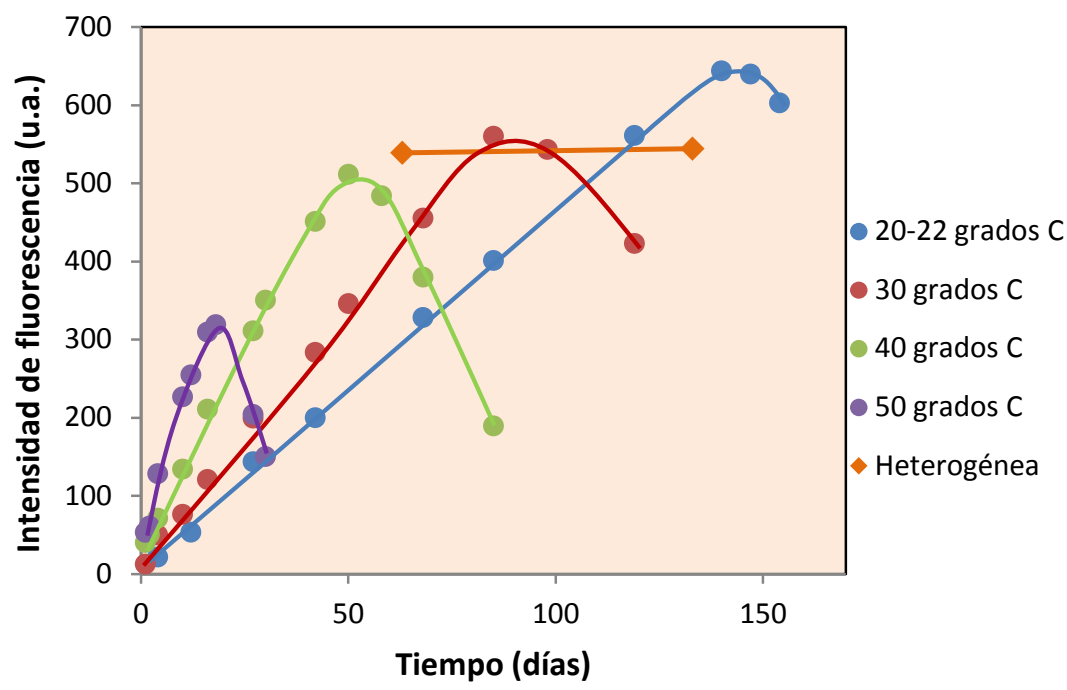

Figura 93. Influencia de la temperatura a bajas concentraciones de $\mathrm{S}_{2} \mathrm{O}_{3}{ }^{2-}$. Evolución temporal de los valores de intensidad de fluorescencia máxima. $\left[\mathrm{Cd}^{2+}\right]_{\mathrm{f}}=\left[\mathrm{S}_{2} \mathrm{O}_{3}{ }^{2-}\right]_{\mathrm{f}}=[\mathrm{MAA}]_{\mathrm{f}}=6.64 \times 10^{-3} \mathrm{M}$; $\left[\mathrm{Cd}^{2+}\right]_{\mathrm{f}} /[\mathrm{MAA}]_{\mathrm{f}}=\left[\mathrm{S}_{2} \mathrm{O}_{3}{ }^{2-}\right]_{\mathrm{f}} /\left[\mathrm{Cd}^{2+}\right]_{\mathrm{f}}=1 . \mathrm{pH}=11$ (fijado antes de añadir $\mathrm{S}_{2} \mathrm{O}_{3}{ }^{2-}$ ). Rendijas de $5 \mathrm{~nm}$.

Puede comprobarse en dicha figura cómo la evolución de la fluorescencia con el tiempo es cualitativamente igual e independiente de la temperatura. La diferencia estriba en que el tiempo en que se alcanza el valor máximo es más pequeño cuanto mayor es la temperatura (se necesita diferente tiempo para alcanzar la relación óptima $\left[\mathrm{Cd}^{2+}\right] /\left[\mathrm{S}^{2-}\right]$ ).

Cuanto mayor es la temperatura, menor es el valor máximo de fluorescencia, por ser mayor la velocidad de generación del ión $\mathrm{S}^{2-}$ y mayor la competitividad entre el proceso de formación de nanopartículas y el proceso de depósito de ión sulfuro sobre la superficie.

Para estas concentraciones de $\mathrm{S}_{2} \mathrm{O}_{3}{ }^{2-}$ se pueden obtener NPs de CdS que muestran una intensidad de fluorescencia similar $\left(30^{\circ} \mathrm{C}\right)$ o mayor $\left(20-22^{\circ} \mathrm{C}\right)$ que la que muestran las nanopartículas obtenidas empleando directamente ión $\mathrm{S}^{2-}$, si bien el tiempo requerido es mayor y su estabilidad en el tiempo menor.

Como conclusión del estudio de la influencia de la temperatura durante el proceso de formación de las nanopartículas de $\mathrm{CdS}$ utilizando $\mathrm{S}_{2} \mathrm{O}_{3}{ }^{2-}$ como precursor, se deduce que esta variable afecta de manera efectiva a la velocidad de descomposición del $\mathrm{S}_{2} \mathrm{O}_{3}{ }^{2-}$, por lo que a mayor temperatura mayor es la velocidad de generación de ion $S^{2-}$ y mayor es la concentración de NPs en disolución. Este incremento va acompañado del proceso de crecimiento de las nanopartículas desde $2.50 \mathrm{~nm}$ a $2.98 \mathrm{~nm}$ (para las condiciones experimentales ya mencionadas). 
La temperatura afecta a dos procesos cinéticos diferentes y competitivos. El ion $S^{2-}$ generado reacciona con $\mathrm{Cd}^{2+}$ para formar nuevas nanopartículas, pero también lo hace sobre la superficie de éstas, formando "trampas" que afectan a los procesos radiantes de energía luminiscente. La competitividad de la segunda reacción es más alta cuanto mayor es la temperatura. Por esta razón, se alcanzan mayores valores de intensidad de fluorescencia de las NPs cuanto menor es la temperatura. La estabilidad de las nanopartículas en cuanto al valor máximo de fluorescencia, es menor cuanto mayor es la temperatura. 



\section{Conclusiones generales del estudio comparativo}



Recordemos que el objetivo fundamental del estudio del nuevo método de obtención de nanopartículas de $\mathrm{CdS}$ en medio acuoso, utilizando $\mathrm{S}_{2} \mathrm{O}_{3}{ }^{2-}$ como precursor del ion $\mathrm{S}^{2-}$, consistía en comprobar si la generación en fase homogénea de uno de los reactivos introducía modificaciones favorables en las características de las nanopartículas frente a las obtenidas por el método llamado heterogéneo, consistente en la adición lenta del ion $\mathrm{S}^{2-}$.

Tras el estudio de todas las variables que influyen en ambos métodos de obtención se puede concluir:

El método denominado homogéneo (generación del ion $\mathrm{S}^{2-}$ a partir de $\mathrm{S}_{2} \mathrm{O}_{3}{ }^{2-}$ ) es mucho más reproducible por no estar sometido a la influencia de la adición lenta del reactivo (a la misma velocidad) sobre la disolución acuosa que contiene el ion $\mathrm{Cd}^{2+}$. No ocurren procesos locales de sobresaturación y la velocidad de agitación de la disolución es un factor poco influyente.

En cuanto el mecanismo por el cual se forman y crecen las nanopartículas, la diferencia entre los dos métodos estriba en la velocidad de los procesos de formación de nanonúcleos y nanocristales. En el método homogéneo la velocidad es menor, lo que supone una mayor lentitud en obtener NPs de un determinado tamaño, pero es más preciso su aislamiento (tras añadir acetona y ultracentrifugación) del resto de la disolución.

Los iones $\mathrm{Cd}^{2+}$ complejados por mercaptoacetato (MAA) interaccionan con los iones $\mathrm{S}^{2-}$ presentes en la disolución formando inicialmente nanonúcleos (constituídos solo por unos cuanto átomos de $\mathrm{Cd}$ y S). Estos nanonúcleos se reagrupan formando nanocristales según un proceso cinético dependiente del $\mathrm{pH}$ de la disolución, de la temperatura y de la concentración de reactivos.

En el método homogéneo, la aparición del ion $\mathrm{S}^{2-}$ en disolución está controlada por otro proceso cinético que es la hidrólisis del $\mathrm{S}_{2} \mathrm{O}_{3}{ }^{2-}$ y pasa a ser el proceso limitante de los otros dos ya mencionados. Por esta razón, en este método la evolución del tamaño y el incremento en la concentración de nanopartículas es más lento que en el denominado método heterogéneo.

Paralelamente a los procesos descritos, sobre la superficie de las NPs ocurren otros procesos químicos que modifican su naturaleza y repercuten en sus propiedades, fundamentalmente las luminiscentes. El exceso de ion $\mathrm{Cd}^{2+}$ a $\mathrm{pH}$ alcalino, contamina la superficie de las nanopartículas formando nanocorteza de compuestos hidroxilados. En el método homogéneo además, por encima de un valor crítico de reactivo generado, el ion $\mathrm{S}^{2-}$ se deposita sobre las NPs enlazándose a los átomos de cadmio formando zonas con trampas para los procesos energéticos de radiación electromagnética. 
Los espectros de absorción de las nanopartículas de CdS obtenidas por ambos métodos muestran hombros de inflexión o picos excitónicos como consecuencia del confinamiento. La morfología de estos espectros es independiente del método de obtención y evoluciona con el tiempo a medida que se modifica el tamaño de las NPs. La diferencia entre ambos estriba en el tiempo en que ocurre la evolución.

Independientemente del método de obtención y en condiciones experimentales muy parecidas, la evolución del tamaño de las nanopartículas es similar, pasando desde 2.4 $\mathrm{nm}$ a tiempos iniciales hasta $3.4 \mathrm{~nm}$ a tiempos elevados. Este margen es más corto en el tiempo para el método heterogéneo. Estos valores de $d$ indican que las NPs contienen inicialmente 141 moléculas de CdS y 395 para valores finales.

En ambos métodos de obtención, la longitud de onda del hombro de inflexión o del pico excitónico se desplaza hacia el rojo a medida que aumenta el tamaño medio de las NPs. El desplazamiento ocurre a diferente velocidad según sea el método de obtención empleado.

En el caso de que se deseen obtener nanopartículas de un determinado tamaño, aislándolas del resto de la disolución, el método de obtención más adecuado es el de fase homogénea, por provocar una evolución de tamaño más lenta en el tiempo.

La concentración de NPs obtenidas en condiciones experimentales similares es semejante, como se deduce de los valores de absorbancia en el pico excitónico de nanopartículas del mismo tamaño obtenidas por ambos métodos.

Una consecuencia del confinamiento cuántico es que las NPs de CdS muestran propiedades luminiscentes de interés práctico. El desplazamiento, con el tamaño, de la longitud de onda del pico excitónico en el proceso de absorción se traduce en un desplazamiento similar de la longitud de onda óptima de excitación y emisión. Este desplazamiento batocrómico con el tamaño de la nanopartícula es similar para los nanocristales obtenidos por los dos métodos comparados, si bien ocurren a diferente velocidad en el tiempo.

Las nanopartículas de CdS obtenidas por ambos métodos muestran espectros de excitación y emisión absolutamente simétricos, lo que indica una alta uniformidad en su constitución incluso en la superficial, incluidos los nanodepósitos o sitios trampa en forma de vacantes atómicas. No aparecen ni en la cola ni en la cabeza de los espectros las típicas deformaciones debidas a impurificaciones heterogéneas. 
La fluorescencia de las NPs de CdS, obtenidas por ambos métodos, está constituida por ondas electromagnéticas de $\lambda_{\mathrm{em}}$ entre $450 \mathrm{~nm}$ y $520 \mathrm{~nm}$, dependiendo del tamaño de las mismas. La intensidad del proceso de fluorescencia y su evolución muestran que por ambos métodos se incrementa inicialmente con el tiempo, aunque a diferente velocidad, hasta alcanzar un valor máximo. A partir de este instante es cuando existe una clara diferencia entre las nanopartículas obtenidas por los dos métodos que se están comparando. Las obtenidas por el método heterogéneo mantienen el valor máximo de fluorescencia durante meses (en las condiciones experimentales óptimas), mientras que las obtenidas por el método homogéneo sólo mantienen su valor máximo de intensidad de fluorescencia durante algunos días (menos cuanto mayor es la concentración inicial de $\left.\mathrm{S}_{2} \mathrm{O}_{3}{ }^{2-}\right)$.

Controlando el $\mathrm{pH}$, la temperatura y la concentración inicial de $\mathrm{S}_{2} \mathrm{O}_{3}{ }^{2-}$ se pueden obtener por el método homogéneo, nanopartículas de CdS con valores de intensidad de fluorescencia superiores (mayor eficacia cuántica) a los que presentan las NPs obtenidas por el método heterogéneo, en condiciones experimentales similares.

En cuanto a la distribución de tamaños alrededor del tamaño medio, no se observan diferencias significativas (a partir del valor de $\Delta$ ) entre las nanopartículas obtenidas por los dos métodos comparados.

En las condiciones experimentales óptimas, el mercaptoacetato se revela como un dispersante eficaz de las nanopartículas de CdS en ambos métodos. La estabilidad de las disoluciones (nanopartículas dispersadas) en las que se mantienen las NPs es muy alta, superando para ambos métodos los ocho meses. 



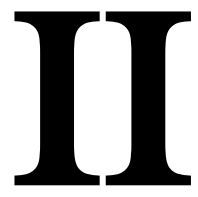

Nanopartículas metálicas AuNPs y FeNPs como transportadores de fármacos 



\section{Nanopartículas de oro como transportadores de fármacos}



Las nanopartículas de metales nobles han atraído la atención de los científicos desde la antigüedad debido a sus propiedades ópticas únicas dependientes de la forma y el tamaño de las mismas. En el siglo XVII, los colores brillantes de nanopartículas de Ag, Au y $\mathrm{Cu}$ fueron utilizados en la tinción de vidrio, e incluso ya en el siglo IV en obras de arte decorativas tan antiguas como la copa de Lycurgo $^{115}$.

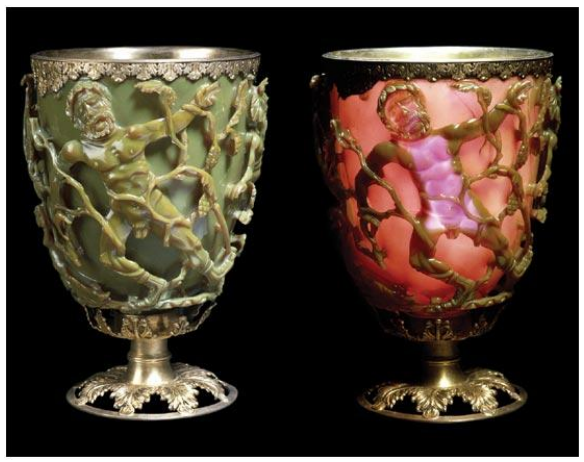

Figura 94. La copa de Lycurgo, una copa romana de cristal actualmente en el Museo Británico, fabricada con cristal dicroico, que muestra un color diferente dependiendo de si la luz pasa o no a través de él. Es rojo rubí con luz transmitida, y verde con luz reflejada (el rojo cuando se ilumina desde atrás y verde cuando está iluminado desde el frente).

En 1618, el filósofo y médico Francisci Antonii publicó el que se considera el primer libro a cerca del oro coloidal, que incluye información sobre su uso médico y algunos casos prácticos de éxito. Doscientos años después, en 1818, Jeremias Benjamin Richters sugirió una explicación para las diferencias en el color observadas en la preparación de disoluciones de oro bebibles ${ }^{116}$ : las disoluciones rosa o púrpura contienen oro en el mayor (más pequeño) grado de subdivisión, mientras que las disoluciones amarillas tienen lugar cuando las partículas pequeñas se han agregado. En 1857, Faraday escribió sobre la formación de disoluciones de color rojo intenso de oro coloidal por reducción de una disolución acuosa de cloroaurato $\left(\mathrm{AuCl}_{4}{ }^{-}\right)$utilizando fósforo en $\mathrm{CS}_{2}$ (un sistema de dos fases). Investigó las propiedades ópticas de películas delgadas preparadas a partir de disoluciones coloidales y observó cambios reversibles de color de las películas tras compresión mecánica (de azul púrpura a verde tras la presurización) ${ }^{117}$. Ya en el siglo XX han sido publicados varios métodos para la preparación de oro coloidal. En la última década, las disoluciones coloidales de oro han sido sujeto de un considerable número de libros y revistas, especialmente después de los avances de Schmid ${ }^{118,119}$ y Brust $^{120,121}$.

${ }^{115}$ I. Freestone, N. Meeks, M. Sax, C. Higgitt. The Lycurgus Cup-A Roman Nanotechnology. Gold Bulletin 40 (2007)

${ }^{116}$ W. Ostwald. Zur Geschichte des Colloiden Goldes. Kolloid Z 4 (1909) 5.

${ }^{117}$ M. Faraday. Experimental Relations of Gold (and other Metals) to Light. Philos. Trans. 147 (1857) 145-181.

${ }^{118}$ G. Schmid. Large Clusters and Colloids. Chem. Rev. 92 (1992) 1709-1727. 
Las nanopartículas de oro (AuNPs) han emergido recientemente como un atractivo candidato en el transporte de pequeñas moléculas de fármacos o biomoléculas como proteínas, DNA o RNA hacia un lugar concreto ${ }^{122}$. Se han explotado sus propiedades químicas y físicas para el transporte y descarga de productos farmacéuticos y en tratamientos fototérmicos con objetivo terapéutico. El núcleo de oro (core) es inerte, no tóxico y biocompatible, y su tamaño puede oscilar entre 1 y $150 \mathrm{~nm}$. El uso de AuNPs en la investigación de enfermedades como el cáncer se debe a su fácil síntesis y modificación de la superficie, sus propiedades ópticas sintonizables y su biocompatibilidad en entornos clínicos ${ }^{123,124,125}$.

Algunas de las características únicas de las nanopartículas metálicas en general, son evidentes simplemente fijándonos en el comportamiento de sus puntos de fusión cuando el tamaño del metal se reduce hasta unos pocos nanómetros. El oro tiene el punto de fusión en torno a $1064^{\circ} \mathrm{C}$. Al reducir el tamaño de una pieza del metal en estudio, el punto de fusión desciende constantemente y con un tamaño de aproximadamente $2 \mathrm{~nm}$ las AuNPs presentan un punto de fusión de alrededor de $200^{\circ} \mathrm{C}^{126}$. Este bajo punto de fusión puede atribuirse a la creciente relación de átomos superficiales respecto a átomos internos al disminuir el tamaño de partícula.

Otras propiedades características se hacen evidentes por el estudio de las propiedades ópticas. Las nanopartículas de metales nobles, conocidas también como nanopartículas plasmónicas, se distinguen de otras nanoplataformas como los Quantum dots semiconductores, las nanopartículas magnéticas o las nanopartículas poliméricas, por la Resonancia del Plasmón Superficial (SPR, Surface Plasmon Resonance). Esta SPR es el resultado del confinamiento de los fotones en un tamaño de partícula pequeño, y como consecuencia se genera un fuerte campo electromagnético en la superficie de la nanopartícula incrementándose todas sus propiedades radiativas y no radiativas. Las propiedades radiativas fuertemente incrementadas, como la absorción, la dispersion

${ }^{119}$ G. Schmid, L.F. Chi. Metal Clusters and Colloids. Adv. Mater. 10 (1998) 515-527.

${ }^{120}$ D. Bethell, M. Brust, D.J. Schiffrin, C. Kiely. From Monolayers to Nanostructured Materials: An Organic Chemist's View of Self-Assembly. J. Electroanal. Chem. 409 (1996) 137-143.

${ }^{121}$ M. Brust, C.J. Kiely. Some Recent Advances in Nanostructure Preparation from Gold and Silver: A Short Topical Review. Colloids Surf. A: Physicochem. Eng. Asp. 202 (2002) 175-186.

${ }^{122}$ S. Rana, A. Bajaj, R. Mout, V. Rotello. Monolayer coated gold nanoparticles for delivery applications. Advanced Drug Delivery Reviews 64 (2012) 200-216.

${ }^{123}$ S. Dhar, W.L. Daniel, D.A. Giljohann, C.A. Mirkin, S.J. Lippard. Polyvalent oligonucleotide gold nanoparticle conjugates as delivery vehicles for platinum (IV) washeads. J. Am. Chem. Soc. 131 (2009) 14652-14653.

124 J.R. Hwu, Y.S. Lin, T. Josephrajan, M.H. Hsu, F.Y. Cheng, C.S. Yeh, W.C. Su, D.B. Shieh. Targeted paclitaxel by conjugation to iron oxide and gold nanoparticles. J. Am. Chem. Soc. 131 (2008) 66-68.

${ }^{125}$ E.C. Dreaden, S.C. Mwakwari, Q.H. Sodji, A.K. Oyelere, M.A. El-Sayed. Tamoxifen poly(ethylene glycol) thiol gold nanoparticle conjugates: enhanced potency and selective delivery for breast cancer treatment. Bioconjugate Chem. 20 (2009) 2247-2253.

${ }^{126}$ Ph. Buffat, J.P. Borel. Size effect on the melting temperature of gold particles. Phys. Rev. A 13 (1976) 2287-2298. 
(scattering) y el campo plasmónico para el Raman amplificado de superficie de moléculas adyacentes, hacen que este tipo de nanopartículas sean muy útiles en imagen molecular y detección espectroscópica. A través de la conversión de radiación vía procesos no radiativos conseguimos propiedades fototérmicas para su uso en terapias ${ }^{127}$.

Cuando una partícula metálica es expuesta a la luz, el campo electromagnético oscilante de la radiación incidente induce una oscilación colectiva de los electrones libres (electrones de la banda de conducción) del metal. Esta oscilación electrónica alrededor de la superficie de la partícula origina una separación de carga dando lugar a una oscilación dipolar en la dirección del campo eléctrico de la radiación.

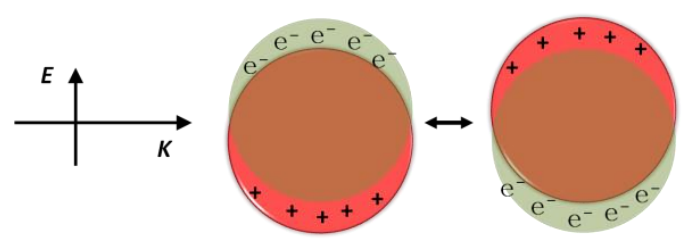

Figura 95. Ilustración esquemática del efecto de Resonancia del Plasmón Superficial. Modificada de ${ }^{104}$.

La amplitud de la oscilación alcanza el máximo a una frecuencia específica, llamada Resonancia del Plasmón Superficial (SPR). La oscilación dipolar está en resonancia con la radiación incidente a una frecuencia específica que depende del tamaño y forma de la nanopartícula. La banda SPR induce una fuerte absorción de la radiación incidente y así puede ser medida usando un espectrómetro de absorción UV-Vis. La banda SPR en nanopartículas plasmónicas (de metales nobles, especialmente $\mathrm{Au}$ y $\mathrm{Ag}$ ) se localiza en la región visible y es mucho mayor que en otros metales, con bandas menos intensas en la región UV.

La intensidad y la longitud de onda de la banda SPR dependen de los factores que afecten a la densidad electrónica sobre la superficie de la nanopartícula, como el tipo de metal, el tamaño y la forma de nanopartícula, estructura, composición y constante dieléctrica del medio, tal y como describe la teoría de $\mathrm{Mie}^{128,129}$.

\footnotetext{
${ }^{127}$ X. Huang, M.A. El-Sayed. Gold nanoparticles: Optical properties and implementations in cancer diagnosis and photothermal therapy. Journal of Advanced Research 1 (2010) 13-28.

${ }^{128}$ G. Mie. Beiträge zur Optik trüben Medien speziell kolloidaler Metalösungen. Annalen der Physik 25 (1908) 377452.

${ }^{129}$ J.A. Lock, G. Gouesbet. Generalized Lorenz-Mie theory and applications. Journal of Quantitative Spectroscopy and Radiative Transfer 110 (2009) 800-807.
} 


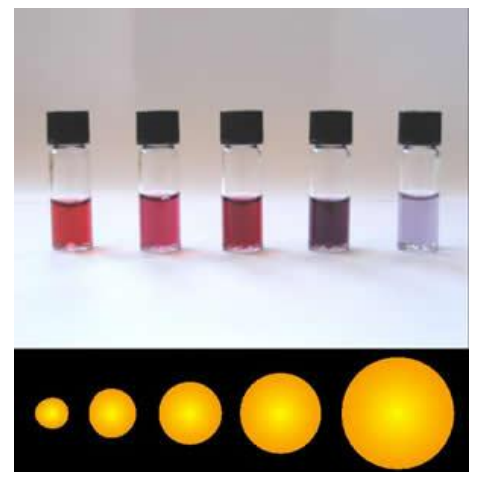

Figura 96. Disoluciones de nanopartículas de oro de distintos tamaños. El tamaño es uno de los responsables del color de la disolución.

Las AuNPs muestran una SPR en torno a $520 \mathrm{~nm}$ en la región visible. Aumentando el tamaño de partícula la longitud de onda de la banda del plasmón se desplaza hacia longitudes de onda mayores y además su intensidad aumenta. Debido a la oscilación de la SPR, la absorción y la dispersión de la radiación se ven fuertemente incrementadas, del orden de 5 a 6 veces mayor que la fuerte absorción de ciertos colorantes orgánicos y la fuerte emisión de ciertas moléculas fluorescentes, respectivamente. La pérdida de energía de las ondas electromagnéticas (total light extinction) al atravesar la materia es el resultado de dos contribuciones: absorción y scattering (dispersión). Ambos procesos, absorción y scattering, son fuertemente dependientes del tamaño de nanopartícula. Para la toma de imágenes, se prefieren nanopartículas de mayor tamaño debido a su alta eficacia en los procesos de dispersión, sin embargo en terapia fototérmica se prefieren nanopartículas de menor tamaño, debido a que en estas partículas el porcentaje de luz absorbida es muy elevado, la cual se convierte en calor para la destrucción celular y de tejidos.

\section{Métodos de síntesis de nanopartículas de oro}

En los trabajos existentes en bibliografía se han citado numerosos métodos de preparación de nanopartículas de oro, incluyendo métodos top-down (manipulación física) y métodos bottom-up (transformación química). Tanto los métodos de síntesis en disolución acuosa como en disolventes orgánicos están bien establecidos para este tipo de nanopartículas. Los esfuerzos en la síntesis de AuNPs están dirigidos a conseguir un mejor control del tamaño, forma, solubilidad, estabilidad y funcionalidad.

Un método general para la síntesis de nanopartículas de oro monodispersas y de tamaño controlable es la reducción de sales de oro en presencia de agentes estabilizantes, los cuales forman una monocapa (SAM, self-assembled monolayer) sobre la superficie de la nanopartícula que normalmente está cargada, de tal forma que las nanopartículas se 
repelen unas a otras, siendo estables coloidalmente. En la Tabla 12 se resumen algunos de los métodos de síntesis de AuNPs.

Tabla 12. Métodos de síntesis y agentes protectores de nanopartículas de oro de diferentes tamaños ${ }^{130}$.

\begin{tabular}{|c|c|c|c|}
\hline Tamaño $(d)$ & Método de síntesis & Agente protector & Referencias \\
\hline $1-2 \mathrm{~nm}$ & $\begin{array}{l}\text { Reducción de } \mathrm{AuCl}\left(\mathrm{PPh}_{3}\right) \text { con } \\
\text { diborano o borohidruro sódico }\end{array}$ & Fosfina & 131 \\
\hline $1.5-5 \mathrm{~nm}$ & $\begin{array}{l}\text { Reducción bifásica de } \mathrm{HAuCl}_{4} \\
\text { con borohidruro sódico en } \\
\text { presencia de agentes } \\
\text { protectores con grupos tiol }\end{array}$ & Alcanotiol & 132,133 \\
\hline $10-150 \mathrm{~nm}$ & $\begin{array}{l}\text { Reducción de } \mathrm{HAuCl}_{4} \text { con } \\
\text { citrato sódico en agua }\end{array}$ & Citrato & 134,135 \\
\hline
\end{tabular}

El método más utilizado consiste en la reducción de $\mathrm{HAuCl}_{4}$ con citrato, siendo el ácido cítrico el reductor e iniciador de la nucleación y el agente estabilizante (proporcionando estabilidad coloidal por sus cargas negativas) a la vez. Este método fue introducido por Turkevitch en 1951. Se obtienen de esta forma nanopartículas de alta calidad, alto rendimiento y tamaño coloidal controlable, de manera sencilla y rápida. Las nanopartículas producidas tienen un diámetro de $20 \mathrm{~nm}$, pero este tamaño se puede manipular alterando la relación sal de oro/sodio.

El método Brust-Schiffrin, publicado en 1994, es una estrategia de síntesis en dos fases utilizando las fuertes interacciones azufre-oro para proteger las AuNPs con ligandos tiol. En este método, $\mathrm{AuCl}_{4}{ }^{-}$es transferido desde la fase acuosa a tolueno usando bromuro de tetraoctilamonio (TOAB) como surfactante y reducido con borohidruro sódico $\left(\mathrm{NaBH}_{4}\right)$ en presencia de dodecanotiol ${ }^{133}$. Tras la adición de $\mathrm{NaBH}_{4}$, la fase orgánica sufre un rápido cambio de color de naranja a marrón oscuro. Se generan AuNPs en tolueno con diámetros comprendidos entre 1.5 y $5 \mathrm{~nm}$. Estas nanopartículas, protegidas por grupos tiol,

\footnotetext{
${ }^{130}$ P. Ghosh, G. Han, M. De, C.K. Kim, V.M. Rotello. Gold nanoparticles in delivery applications. Advanced Drug Delivery Reviews 60 (2008) 1307-1315.

${ }^{131}$ G. Schmid. Large clusters and colloids - metals in the embryonic state. Chem. Rev. 92 (1992) 1709-1727.

${ }^{132}$ A.C. Templeton, M.P. Wuelfing, R.W. Murray. Monolayer protected cluster molecules. Acc. Chem. Res. 33 (2000) 27-36.

${ }^{133}$ M. Brust, M. Walker, D. Bethell, D.J. Schiffrin, R. Whyman. Synthesis of thiol-derivatized goldnanoparticles in a 2phase liquid-liquid system. J. Chem. Soc., Chem. Commun. (1994) 801-802.

134 K.C. Grabar, R.G. Freeman, M.B. Hommer, M.J. Natan. Preparation and characterization of Au colloid monolayers. Anal. Chem. 67 (1995) 735-743.

135 J. Turkevich, P.C. Stevenson, J. Hillier. A study of the nucleation and growth processes in the synthesis of colloidal gold, discuss. Farad. Soc. 11 (1951) 55-57.
} 
demuestran una elevada estabilidad debido a la fuerte interacción entre el oro y los grupos tiol, pudiendo ser, de esta manera, manejadas, caracterizadas y funcionalizadas de forma sencilla.

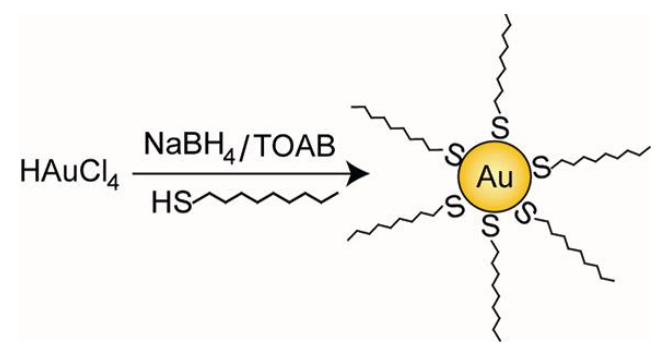

Figura 97. Esquema general de la síntesis de nanopartículas de oro por el método Brust-Schiffrin.

Además de los métodos químicos, la síntesis de AuNPs se ha llevado a cabo a través de métodos físicos, entre los que destacan métodos fotoquímicos ${ }^{136,137,138}$, sonoquímicos $^{139,140}$, radiólisis $^{141,142}$ y termólisis ${ }^{143,144}$.

\section{Modificación superficial y bioconjugación (Biofuncionalización)}

Las moléculas estabilizantes que rodean las nanopartículas, se adsorben o se unen químicamente a la superficie de las AuNPs por un extremo, quedando el otro extremo hacia la disolución, proporcionando estabilidad coloidal. Tras la síntesis, estas moléculas estabilizantes pueden ser reemplazadas por otras en una reacción de intercambio de ligando. De esta forma, escogiendo las moléculas surfactantes es posible modificar las propiedades superficiales de las nanopartículas.

Para aplicaciones en medios acuosos, una modificación típica es la utilización de tioles con grupos carboxílico en el otro extremo. Estas moléculas proporcionan estabilidad

\footnotetext{
${ }^{136}$ Y. Zhou, C.Y. Wang, Y.R. Zhu, Z.Y. Chen. A Novel Ultraviolet Irradiation Technique for Shape-Controlled Synthesis of Gold Nanoparticles at Room Temperature. Chem. Mater. 11 (1999) 2310-2312.

${ }^{137}$ Y. Niidome, A. Hori, T. Sato, S. Yamada. Enormous Size Growth of Thiol-passivated Gold Nanoparticles Induced by Near-IR Laser Light. Chem. Lett. (2000) 310-311.

${ }^{138}$ K. Mallick, Z.L. Wang, T. Pal. Seed-Mediated Successive Growth of Gold Particles Accomplished by UV Irradiation: a Photochemical Approach for Size-Controlled Synthesis. J. Photochem. Photobiol. 140 (2001) 75-80.

${ }^{139}$ W. Chen, W.P. Cai, C.H. Liang, L.D. Zhang. Synthesis of Gold Nanoparticles Dispersed Within Pores of Mesoporous Silica Induced by Ultrasonic Irradiation and its Characterization. Mater. Res. Bull. 36 (2001) 335-342.

${ }^{140}$ V.G. Pol, A. Gedanken, J. Calderro-Moreno. Deposition of Gold Nanoparticles on Silica Spheres: A Sonochemical Approach. Chem. Mater. 15 (2003) 1111-1118.

${ }^{141}$ A. Henglein, D. Meisel. Radiolytic Control of the Size of Colloidal Gold Nanoparticles. Langmuir 14 (1998) 73927396.

${ }^{142}$ A. Dawson, P.V. Kamat. Complexation of Gold Nanoparticles with Radiolytically Generated Thiocyanate Radicals $(\mathrm{SCN})_{2}$. J. Phys. Chem. B 104 (2000) 11842-11846.

${ }^{143}$ M. Nakamoto, M. Yamamoto, M. Fukusumi. Thermolysis of Gold (I) Thiolate Complexes Producing Novel Gold Nanoparticles Passivated by Alkyl Groups. Chem. Commun. (2002) 1622-1623.

${ }^{144}$ T. Shimizu, T. Teranishi, S. Hasegawa, M. Miyake. Size Evolution of Alkanethiol-Protected Gold Nanoparticles by Heat Treatment in the Solid State. J. Phys. Chem. B 107 (2003) 2719-2724. 
coloidal debido a las cargas negativas de los grupos carboxílico y además pueden ser utilizados como puntos de anclaje de otras moléculas biológicas. EI PEG (polietilenglicol) es otro de los ligandos más utilizadas ya que reduce las adsorciones inespecíficas de moléculas a la superficie de la nanopartícula. El recubrimiento de las nanopartículas con sílice ha sido otra de las técnicas utilizadas por varios autores ${ }^{145}$.

Las AuNPs de unos pocos nanómetros se encuentran en el mismo rango de tamaño que las proteínas, enzimas y $A D N$ y, por tanto, son adecuados para interaccionar con subunidades celulares o proteínas, permitiendo la preparación de nuevos híbridos biomolécula-nanopartícula. La unión de AuNPs a biomoléculas está atrayendo cada vez más atención debido a las posibles aplicaciones de estos nuevos materiales en los nuevos retos presentes en disciplinas como la Biología.

Una combinación de gran relevancia en la actualidad es la unión de AuNPs y ADN. La alta estabilidad físico-química de la molécula de $A D N$, los múltiples sitios de unión y un esqueleto cargado ofrecen gran cantidad de oportunidades para una modificación selectiva del ADN con AuNPs. Los dos grupos pioneros en diseñar estrategias para la funcionalización de nanopartículas de oro con ADN son el de Mirkin-Letsinger ${ }^{146}$ y Alivisatos-Schultz ${ }^{147}$. Estos últimos utilizaron ADN como plantilla para preparar "moléculas nanocristal" consistentes en dos o tres nanopartículas de $1.4 \mathrm{~nm}$ sobre un oligonucleótido de una única hebra.

\section{Aplicaciones biológicas}

La entrega de un medicamento en su lugar de acción terapeútica es una de las principales limitaciones de la industria farmacéutica y biotecnológica. Una liberación controlada de un fármaco en el sitio deseado mejora sustancialmente el potencial terapéutico del fármaco y reduce la dosis global y los efectos secundarios no deseados. La mayoría de los fármacos están limitados por su baja solubilidad y agregación consiguiente, su elevada toxicidad, la dosis alta, la entrega no específica, la degradación in vivo y corta vida media en circulación. Los sistemas de suministro de fármacos (Drug delivery systems) basados en nanopartículas proporcionan una mejor solubilidad, estabilidad in vivo, biodistribución y farmacocinética a un fármaco libre. Las nanopartículas de oro son uno de los materiales que se menciona con frecuencia al hablar de nanomedicina, debido a su importante papel en este tipo de aplicaciones. Las AuNPs pueden conjugarse directamente con antibióticos u otros fármacos por enlace covalente, enlace iónico o adsorción física. En

\footnotetext{
${ }^{145}$ L.M. Liz-Marzán, M. Giersig, P. Mulvaney. Synthesis of Nanosized Gold-Silica Core-Shell Particles. Langmuir 12 (1996) 4329-4335.

${ }^{146}$ C.A. Mirkin, R.L. Letsinger, R.C. Mucic, J.J. Storhoff. DNA-Based Method for Rationally Assembling Nanoparticles into Macroscopic Materials. Nature 382 (1996) 607-609.

${ }^{147}$ A.P. Alivisatos, K.P. Johnsson, X. Peng, T.E. Wislon, C.J. Loweth, M.P. Bruchez Jr., P.G. Schultz. Organization of Nanocrystal Molecules Using DNA. Nature 382 (1996) 609-611.
} 
bibliografía podemos encontrar varios ejemplos de esta conjugación directa ${ }^{148,149,150}$, y comprobar cómo la forma conjugada del antibiótico proporciona un mayor grado de inhibición en el crecimiento de bacterias y también mayor estabilidad respecto a la forma libre. La adsorción electrostática de biomoléculas a la superficie de la nanopartícula se emplea comúnmente para el recubrimiento de AuNPs con citrato o derivados similares de ácido carboxílico ${ }^{151}$. En otros casos se prefiere una modificación de la superficie de las nanopartículas. La estrategia general para modificar la superficie de las AuNPs puede dividirse en dos métodos basados en interacciones covalentes o no covalentes. Las interacciones no covalentes facilitan interesantes uniones de nanopartículas de oro con biomoléculas pero, por supuesto, más débiles que una interacción covalente. La union covalente proporciona vehículos estables para el suministro, pero esta elevada estabilidad puede resultar un inconveniente ya que para la liberación del fármaco se requiere un procesamiento intracelular del pro-fármaco.

Algunos de los ejemplos de lo expuesto anteriormente es la utilización de nanopartículas de oro funcionalizadas para la distribución celular y la liberación mediada por GSH del colorante hidrófobo BODIPY ${ }^{152}$ o la liberación de agentes terapéuticos diatómicos desde la superficie de AuNPs funcionalizadas con ftalocianinas, un fotosensibilizador para generar oxígeno singlete para la terapia fotodinámica de cáncer ${ }^{153}$.

Las AuNPs tienen también la capacidad para distribuir biomoléculas grandes, tales como péptidos, proteínas o ácidos nucleicos ${ }^{154}$. Las nanopartículas de oro son candidatos muy atractivos para la distribución de genes debido a su elevada relación superficie/volumen, la cual maximiza la relación carga/portador y la eficiencia en la transfección. Nagasaki y col. inmovilizaron siARN en nanopartículas de oro funcionalizadas con PEG, mostrando una actividad ARNi significativa en células HuH-7 ${ }^{155}$. Las AuNPs pueden, de la misma manera, ser nanocarriers de péptidos y proteínas de elevado interés,

\footnotetext{
${ }^{148}$ L. Rastogi, A.J. Kora, J. Arunachalam. Highly stable, protein capped gold nanoparticles as effective drug delivery vehicles for amino-glycosidic antibiotics. Materials Science and Engineering 32 (2012) 1571-1577.

${ }^{149}$ B. Saha, J. Bhattacharya, A. Mukherjee, A.K. Ghosh, C.R. Santra, A.K. Dasgupta, P. Karmakar. In vitro structural and functional evaluation of gold nanoparticles conjugated antibiotics. Nanoscale Res. Lett. 2 (2007) 614-622.

${ }^{150}$ H. Gu, P.L. Ho, L. Tong, L. Wang, B. Xu. Presenting vancomycin on nanoparticles to enhance antimicrobial activities. Nano Lett. 3 (2003) 1261-1263.

${ }^{151}$ E. Katz, I. Willner. Integrated Nanoparticle-Biomolecule Hybrid Systems: Synthesis, Properties, and Applications. Angewandte Chemie International Edition 43 (2004) 6042-6108.

${ }^{152}$ R. Hong, G. Han, J.M. Fernández, B.J. Kim, N.S. Forbes, V.M. Rotello. Glutathione-mediated delivey and release using monolayer protected nanoparticle carriers. J. Am. Chem. Soc. 128 (2006) 1078-1079.

${ }^{153}$ D.C. Hone, P.I. Walker, R. Evans-Gowing, S. FitzGerald, A. Beeby, I. Chambrier, M.J. Cook, D.A. Russell. Generation of cytotoxic singlet oxygen via phthalocyanine-stabilized gold nanoparticles: a potencial delivery vehicle for photodynamic therapy. Langmuir 18 (2002) 2985-2987.

${ }^{154}$ S. Rana, A. Bajaj, R. Mout, V.M. Rotello. Monolayer coated gold nanoparticles for delivery applications. Advanced Drug Delivery Reviews 64 (2012) 200-216.

${ }^{155}$ M. Oishi, J. Nakaogami, T. Ishii, Y. Nagasaki. Smart PEGylated gold nanoparticles for the cytoplasmic delivery of siRNA to induced enhanced gene silencing. Chem. Lett. 35 (2006) 1046-1047. 
como por ejemplo la insulina. Bhumkar y col. utilizaron nanopartículas de oro reducidas con chitosan para promover la penetración y absorción de esta hormona peptídica a través de la mucosa ${ }^{156}$.

Además de la química de la superficie, las propiedades físicas de las nanopartículas de oro también pueden ser explotadas. La elevada sección transversal dispersiva de las AuNPs, junto con su elevada fotoestabilidad (en comparación con los colorantes orgánicos), las hace extremadamente prometedoras en imagen celular. En los primeros intentos, Sokolov y col. describieron una nueva clase de agentes moleculares de contraste específicos para la formación de imágenes de reflectancia basados en nanopartíuclas de oro unidas a anticuerpos anti-EGFR con alta afinidad por EGFR, un biomarcador celular específico en células y tejidos de cáncer cervical ${ }^{157}$. AuNPs de $12 \mathrm{~nm}$ de diámetro fueron conjugadas con anticuerpos monoclonales anti-EGFR vía adsorción electrostática no covalente de los anticuerpos a la superficie de las nanopartículas, la cual estaba recubierta con moléculas de citrato cargadas negativamente. En este trabajo, las señales fuertemente dispersadas por parte de las nanopartículas unidas en la membrana de las células cancerosas permitieron la detección de tejidos anómalos en contraste con los tejidos normales, que presentaban una auto-dispersión débil.
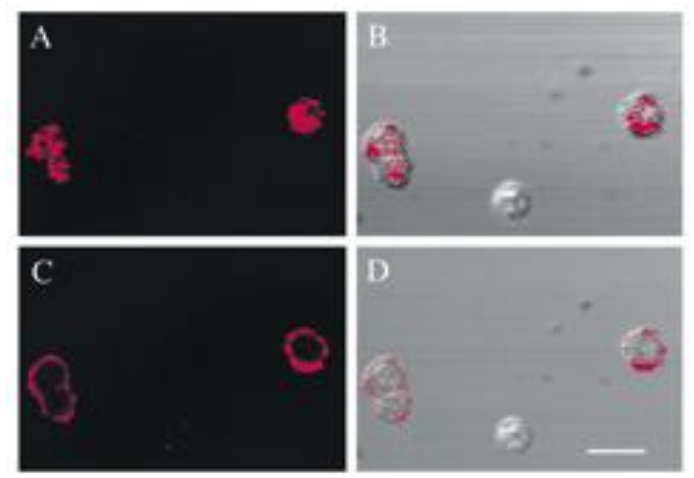

Figura 98. Imágenes ópticas de alta resolución de células SiHa marcadas con conjugados AuNP/anti-EGFR. Imágenes de reflectancia con laser confocal (A y C) y combinación de reflectancia/transmitancia (B y D) de las células marcadas, obtenidas con un objetivo x40. La dispersión de los conjugados está coloreada en rojo. En A y B, el plano focal está encima de las células. En C y D, la sección transversal media de las células está en el foco. Las imágenes de reflectancia y transmitancia confocal fueron obtenidas de forma independiente y luego superpuestas. Las imágenes de reflectancia fueron obtenidas con un láser de excitación en $647 \mathrm{~nm}$. La barra de escala es $\sim 20 \mu \mathrm{m}(A-D)$.

\footnotetext{
${ }^{156}$ D.R. Bhumkar, H.M. Joshi, M. Sastry, V.B. Pokharkar. Chitosan Reduced Gold Nanoparticles as Novel Carriers for Transmucosal Delivery of Insulin. Pharmaceutical Research 24 (2007) 1415-1426.

${ }^{157}$ K. Sokolov, M. Follen, J. Aaron, I. Pavlova, A. Malpica, R. Lotan, et al. Real-time vital optical imaging of precancer using anti-epidermal growth factor receptor antibodies conjugated to gold nanoparticles. Cancer Res. 63 (2003) 1999-2004.
} 
La extirpación quirúrgica del tumor, la quimioterapia y la radioterapia son los tratamientos principales para la mayoría de las formas de cáncer. Sin embargo, la cirugía se limita a los tumores accesibles, la quimioterapia causa efectos secundarios importantes, y la radioterapia es altamente invasiva para el tejido sano en el camino de la radiación. Para resolver estos inconvenientes, la hipertermia con láser ha surgido como una buena alternativa para el tratamiento del cáncer. La fuerte resonancia de plasmón con la luz que presentan las nanopartículas de oro las hace muy útiles en terapia fototérmica, porque pueden convertir la luz absorbida en calor a través de procesos no radiantes. Las AuNPs provocan calentamiento local cuando son irradiadas con luz entre 800 y $1200 \mathrm{~nm}$ (water window). El-Sayed y col. han utilizado nanopartículas de oro esféricas conjugadas con anticuerpos anti-EGFR para marcar específicamente células HSC de cáncer de boca y provocar su destrucción fototérmicamente ${ }^{158}$. El calentamiento plasmónico inducido por la luz también puede ser utilizado para liberar una carga química previamente unida a la nanopartícula.

La capacidad para suministrar medicamentos y genes, así como para inducir hipertermia, son dos de las propiedades de AuNPs que las hacen materiales nanoestructurados ideales para el tratamiento del cáncer ${ }^{159,160}$.

\section{Citotoxicidad}

Respecto a las aplicaciones biológicas, debe tenerse en cuenta un aspecto de crucial importancia: la citotoxicidad. De manera generalizada, las nanopartículas de oro mayores de $10 \mathrm{~nm}$ son consideradas no tóxicas. En 2006 se publicó que nanopartículas de oro estabilizadas con bromuro de cetiltrimetilamonio (CTAB) eran tóxicas para células HeLa ${ }^{161}$. No obstante, esta toxicidad probablemente sea debida a la toxicidad del agente estabilizante, el cual se desorbe de la superficie de las nanopartículas al entrar en la célula. Esto indica que, aparte de la toxicidad de la nanopartícula sola, la fuerza del enlace del ligando a la superficie de la nanopartícula y la toxicidad del mismo deben ser considerados.

En contraste con las nanopartículas de mayor tamaño, las nanopartículas de oro de tamaño inferior a $2 \mathrm{~nm}$ muestran elevada citotoxicidad en diferentes líneas celulares ${ }^{162}$.

\footnotetext{
${ }^{158}$ X. Huang, W. Qian, I.H. El-Sayed, M.A. El-Sayed. The potencial use of the enhanced nonlinear properties of gold nanospheres in photothermal cancer therapy. Laser Surg. Med. 39 (2007) 747-753.

${ }^{159}$ S. Das, P. Roy, S. Mondal, T. Bera, A. Mukherjee. One pot synthesis of gold nanoparticles and application in chemotherapy of wild and resistant type visceral leishmaniasis. Colloids and Surfaces B: Biointerfaces 107 (2013) 27-34.

${ }_{160}$ M. Espinoza-Castañeda, A. Escosura-Muñiz,G. González-Ortiz, S.M. Martín-Orúe, J.F. Pérez, A. Merkoçi. Casein modified gold nanoparticles for future theranostic applications. Biosensors and Bioelectronics 40 (2013) 271-276.

${ }^{161}$ T. Niidome, M. Yamagata, Y. Okamoto, Y. Akiyama, H. Takahashi, T. Kawano, Y. Katayama, Y. Niidome. PEGmodified gold nanorods with a stealth character for in vivo applications. J. Control. Release 114 (2006) 343-347.

${ }^{162}$ Y. Pan, S. Neuss, A. Leifert, M. Fischler, F. Wen, U. Simon, G. Schmid, W. Brandau, W. Jahnen-Dechent. Sizedependent cytotoxicity of gold nanoparticles. Small 3 (2007) 1941-1949. 
Pero es importante distinguir entre los efectos tóxicos relacionados con la naturaleza del material (en este caso, oro) y los efectos comunes a todas las nanopartículas incluso de material inerte.

En cultivos celulares, las nanopartículas de oro se consideran biocompatibles y hasta la fecha no se ha observado citotoxicidad aguda. Tampoco se ha observado ninguna liberación de iones tóxicos como la que puede observarse en nanopartículas de cadmio, de ahí que sean las preferidas para estudios biológicos.

Como ya hemos citado a lo largo de la introducción de este capítulo, los núcleos de oro son esencialmente inertes y no tóxicos en ensayos directos a corto y medio plazo ${ }^{163}$. En la mayor parte de los trabajos publicados hasta la fecha no muestran citotoxicidad severa, aunque en contadas ocasiones inducen daño en el ADN, probablemente a través de un mecanismo indirecto debido a estrés oxidativo.

En general, las nanopartículas de oro (con o sin recubrimiento) están demostrando ser adecuadas para aplicaciones terapéuticas debido a su absorción celular sintonizable y baja toxicidad.

${ }^{163}$ C. Di Guglielmo, J. De Lapuente, C. Porredon, D. Ramos-López, J. Sendra, M. Borràs. In vitro safety toxicology data for evaluation of gold nanoparticles-chronic cytotoxicity, genotoxicity and uptake. J Nanosci Nanotechnol. 12(8) (2012) 6185-6191. 



\section{OBJETIVO}

Las nanopartículas de oro son un vehículo ideal de transporte y liberación de fármacos debido a que se sabe que son no tóxicas y no immunogénicas. También son fácilmente funcionalizables con moléculas de diversa naturaleza, entre ellas, los compuestos de platino.

El objetivo de esta parte del trabajo se basa en la utilización de nanopartículas de oro para el transporte de nuevos fármacos antitumorales, como son los derivados del cisplatino con ácidos biliares. Más allá, se planteó estudiar la actividad del compuesto de Pt con ácidos biliares (PtU2) tras su unión a AuNPs, y comprobar si era posible de esta manera aumentar su potencial como fármaco antitumoral. 



\section{PARTE EXPERIMENTAL}

\section{Aparatos y equipos}

Detección fotométrica

Los espectros de absorción fueron realizados con un espectrofotómetro Helios Gamma UV-Visible (Thermo Electron Corporation).

Detección fluorimétrica

Las medidas de fluorescencia se llevaron a cabo en disolución, con un espectrofluorímetro Cary Eclipse (Varian) equipado con una lámpara de xenón de 150 W. Se fijó el ancho de las rendijas de excitación y emisión en $20 \mathrm{~nm}$. Todas las medidas se llevaron a cabo en una cubeta de cuarzo de $1 \mathrm{~cm}$ de paso óptico, a temperatura ambiente.

\section{Microscopía Electrónica}

Las imágenes TEM fueron tomadas con un equipo ZEISS EM-900. Las muestras fueron preparadas por deposición de una gota de la muestra sobre una rejilla de cobre de 3 $\mathrm{mm}$ de diámetro, y secado en horno a $30^{\circ} \mathrm{C}$ antes del análisis. Las imágenes SEM fueron tomadas con un equipo Microscope Zeiss DSM 940, conectado a un Scan Converter DSC1024 G Sony, gracias al cual las imágenes pueden ser digitalizadas.

Inductively Coupled Plasma-Mass Spectrometer (ICP-MS)

El análisis por ICP-MS fue Ilevado a cabo en un Elan 6000 modelo de Perkin-Elmer (Waltham, MA) calibrado de 10 a 1000 ppb con disoluciones estándar de oro y platino (Panreac, Barcelona, Spain) en el Servicio General de Análisis Químico (Universidad de Salamanca).

\section{Citometría de Flujo}

Para la adquisición de células apoptóticas se utilizó un citómetro de flujo FACSCalibur (BDBiosciences, San Jose, CA) del Servicio de Citometría, Departamento de Medicina, Centro de Investigación del Cáncer (CIC), Universidad de Salamanca. El porcentaje de células muertas fue analizado con el software Infinicyte 1.5 (Cytognos, Spain). 


\section{Reactivos}

Dicloro(etilendiamino)platino(II), $\mathrm{H}_{2} \mathrm{NCH}_{2} \mathrm{CH}_{2} \mathrm{NH}_{2}$ ) $\mathrm{PtCl}$, 99\% (Sigma-Aldrich)

Cisplatino, $\mathrm{Pt}\left(\mathrm{NH}_{3}\right)_{2} \mathrm{Cl}_{2}$, cristalino (Sigma-Aldrich)

Ácido ursodeoxicólico (HUDC), $\mathrm{C}_{24} \mathrm{H}_{40} \mathrm{O}_{4}, \geq 99 \%$ (Sigma-Aldrich)

Nanopartículas de oro (gold colloidal solution, $20 \mathrm{~nm}$ de diámetro, estabilizadas en tampón citrato) (Sigma-Aldrich)

Annexin V-FITC (Immunostep)

Propidium iodide Staining Solution (Immunostep)

Annexin V Binding Buffer 10X (Immunostep)

Penicilina/Estreptomicina (GIBCO)

Tripsina (GIBCO)

Medio de cultivo celular (RPMI, cell culture medium) (GIBCO)

Suero bovino fetal (Fetal bovine serum) (GIBCO)

L-glutamina (GIBCO)

Tampón fosfato (PBS, Phosphate buffered saline), pH= 7.4 (GIBCO)

Dimetilsulfóxido, $\left(\mathrm{CH}_{3}\right)_{2} \mathrm{SO}$ (Merck)

\section{Cultivo celular}

Línea celular humana MG-63 (osteosarcoma). Esta línea celular se cultivó en RPMI suplementado con $10 \%$ de suero bovino fetal (SBF), $1 \%$ de L-Glutamina y $2 \%$ de penicilina/estreptomicina, y se mantuvo en incubación a $37^{\circ} \mathrm{C}$ en una atmósfera húmeda con $5 \%$ de $\mathrm{CO}_{2}$. Durante los cambios de medio, éste se elimina por aspiración y se reemplaza por medio fresco. Para realizar un subcultivo de las células adheridas se debe proceder al levantamiento de las mismas por tripsinización. Tiempo de duplicación entre 24 y 36 horas. 


\section{Aparatos y material adicional}

Campana de flujo laminar

Incubador $\mathrm{CO}_{2}$

Microscopio

Centrífuga

\section{Síntesis y caracterización de los compuestos utilizados}

Nanopartículas de oro

Las nanopartículas de oro fueron caracterizadas por espectroscopía de absorción en UV-Vis y TEM. Estas nanopartículas tienen un tamaño medio de $20 \mathrm{~nm}$ y muestran una banda (ultraviolet-visible (UV-Vis) light extinction band) centrada en $520 \mathrm{~nm}$, característica del color rojo intenso.
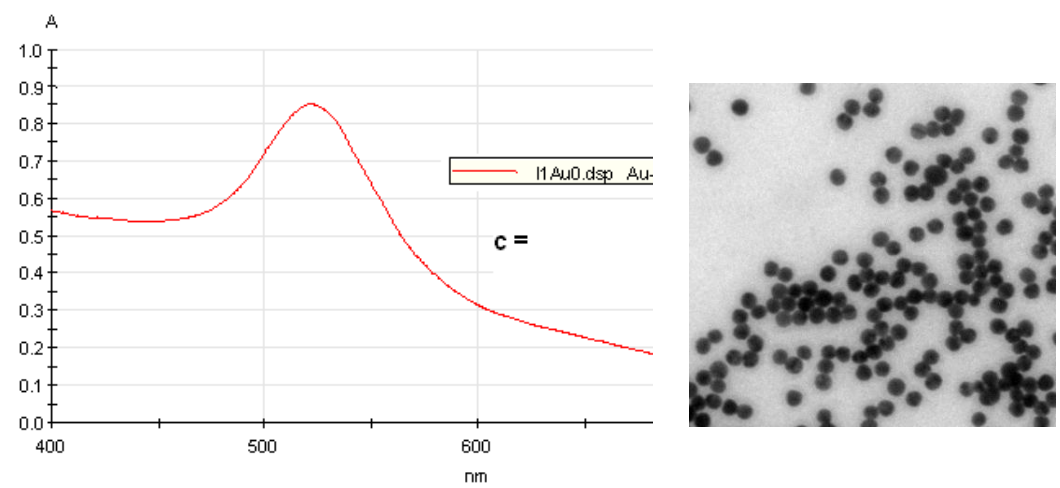

Figura 99. Espectro de absorción e imagen TEM de las AuNPs comerciales.

Son nanoestructuras de Au recubiertas de citrato, donde las moléculas de citrato sirven por una lado de agente reductor (durante la síntesis) y por otro lado sirven de agente protector, generando isotropía (tras la nucleación, el crecimiento se produce a través de todas las caras, formándose nanopartículas esféricas) y uniones (interacciones) al azar.

Bisursodeoxicolato(etilendiamino)platino (II), [Pt(UDC) $\left.{ }_{2}(e n)\right], \operatorname{PtU} 2$

Los compuestos de platino tienen utilidad clínica como fármacos antitumorales debido a su actividad citotóxica. Desde su introducción en ensayos clínicos en 1972, el cisdiaminodicloroplatino (II) (cisplatino) se ha convertido en uno de los agentes antitumorales 
más extendido en el tratamiento de muchos tumores sólidos, pero tiene dos grandes inconvenientes: uno, los efectos secundarios (nefrotoxicidad, mielotoxicidad, neurotoxicidad, nauseas, vómitos) y el segundo, el desarrollo de resistencia por parte de las células. De ahí que en los últimos años se haya trabajado en la búsqueda de nuevos compuestos derivados del cisplatino que solventen o atenúen estos problemas.<smiles>N[P+](N)(Cl)Cl</smiles>

Figura 100. Cisplatino (cis-diaminodicloroplatino II, Cis-DDP, CDDP)

Las investigaciones fueron dirigidas entonces hacia la búsqueda de agentes anticancerígenos menos tóxicos, apareciendo así los fármacos análogos del cisplatino de segunda y tercera generación. En 1986, la FDA aprobó el uso de Carboplatino, siendo el más utilizado en el tratamiento de cáncer de ovario. El Oxaliplatino fue incorporado en los protocolos hace unos veinte años, y es el más efectivo para tratar el cáncer de colon.
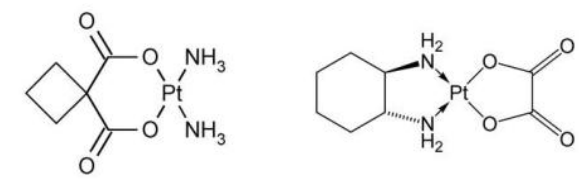

Figura 101. Fármacos anticancerosos análogos del cisplatino de segunda (Carboplatino, a la izquierda) y tercera (Oxaliplatino, a la derecha) generación.

Desde hace unos años, nuestro grupo ha trabajado en el desarrollo de derivados del cisplatino con ácidos biliares con potencial actividad citotóxica ${ }^{164,165,166}$. Estos compuestos poseen uno o dos ácidos biliares como ligandos intercambiables del platino (II) (grupos salientes). La baja labilidad, el carácter anfipático y la vectorialidad de estos grupos salientes podrían reducir tanto la toxicidad como la resistencia de las células.

El compuesto escogido para el presente estudio fue bisursodeoxicolato (etilendiamino)platino(II), PtU2 de manera abreviada. Es un complejo plano-cuadrado de $\mathrm{Pt}$ (II) con dos ligandos ursodeoxicolato como dos de los sustituyentes.

164 E. Rodriguez-Fernandez,J.L. Manzano,A. Alonso, M.J. Almendral, M. Perez-Andres, A. Orfao, J.J. Criado. Fluorescent Cisplatin Analogues and Cytotoxic Activity. Current Medicinal Chemistry 16 (2009) 4314-4327.

165 J.J. Criado, E.R. Fernández, J.L. Manzano, M. Medarde, A. Alonso, S. Barrena, R. Peláez, M.D. Tabernero, A. Orfao. Intrinsically Fluorescent Cytotoxic Cisplatin Analogues as DNA Marker Molecules. Bioconjugate Chem. 16 (2005) 275282.

${ }^{166}$ J.J. Criado, R.I.R. Macías, M. Medarde, M.J. Monte, M.A. Serrano, J.J.G. Marín. Synthesis and Characterization of the New Cytostatic Complex cis-Diammineplatinum(II)-Chlorocholylglycinate. Bioconjugate Chem. 8 (1997) 453-458. 


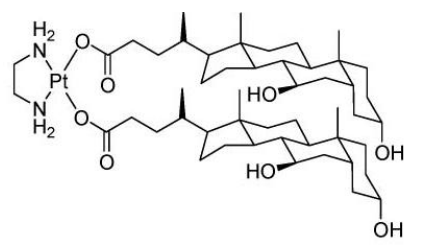

Figura 102. Bisursodeoxicolato(etilendiamino)-platino(II), $\left[\mathrm{Pt}(\mathrm{UDC})_{2}(\mathrm{en})\right], \mathrm{PtU} 2$.

El compuesto PtU2 fue sintetizado en una serie de pasos secuenciales, de acuerdo con el procedimiento previamente descrito por Pérez-Andrés y col. ${ }^{167} \mathrm{El}$ complejo fue preparado a partir de disoluciones acuosas de $\mathrm{PtI}_{2}(\mathrm{en})$ y la sal de plata del ácido ursodeoxicólico. En primer lugar, se preparó la sal de plata AgUDC mezclando HUDC en agua ultrapura con $\mathrm{Na}_{2} \mathrm{CO}_{3}$ y $\mathrm{AgNO}_{3}$. Una vez llevada a cabo la reacción a temperatura ambiente y en la oscuridad, el precipitado de AgUDC fue filtrado y lavado varias veces con agua. Para preparar $\mathrm{Ptl}_{2}(\mathrm{en})$, se disolvió $\mathrm{PtCl}_{2}(\mathrm{en})$ en agua ultrapura calentando a $50^{\circ} \mathrm{C}$ bajo agitación constante. Una vez que el complejo de platino se hubo disuelto, se añadió una disolución acuosa de $\mathrm{KI}$ gota a gota. La disolución resultante se calentó y agitó durante 2 horas a $50^{\circ} \mathrm{C}$ en la oscuridad. El precipitado de $\mathrm{PtI}_{2}(\mathrm{en})$ obtenido fue filtrado y lavado con agua. El compuesto PtU2 se obtuvo mezclando las disoluciones acuosas previamente obtenidas de AgUDC y $\mathrm{Ptl}_{2}$ (en) en una relación de 2:1, y dejándolas reaccionar durante tres días. El compuesto final se obtuvo tras extracción líquido-líquido en C18 (Waters Corporation, Massachusetts, USA), y purificado por cromatografía de capa fina (TLC) usando butilacetato/metanol a 35/65 (v/v). Los compuestos fueron caracterizados por NMR, FABMS, FT-IR, y espectroscopía UV. Los datos de NMR fueron consistentes con la estructura propuesta. El compuesto es un sólido amarillento, soluble en agua, en metanol y en DMSO.

167 M. Pérez-Andrés, J.J. Benito, E. Rodríguez-Fernández, B. Corradetti, D. Primo, J.L. Manzano, et al. Bisursodeoxycholate(ethylenediamine)platinum(II): a new autofluorescent compound. Cytotoxic activity and cell cycle analysis in ovarian and hematological cell lines. Dalton Trans. (2008) 6159-6164. 


\section{Estudio de la citotoxicidad del nuevo compuesto de platino PtU2}

En estudios anteriores publicados ${ }^{167}$, se demostró que el compuesto PtU2 era capaz de ejercer una fuerte inhibición del crecimiento in vitro de la línea celular HeLa, con un IC 50 a 24 y 48 horas con valores por debajo del obtenido por el cisplatino (Tabla 13).

Tabla 13. Inhibición del crecimiento in vitro debido a cisplatino y PtU2. Resultados de $\mathrm{IC}_{50}$ expresados en $\mu \mathrm{M}$ a diferentes periodos de exposición a la droga ( 24 y 48 horas).

\begin{tabular}{lcc}
\hline Compuesto & Tiempo de incubación/h & IC 5 (en HeLa)/ $\mu$ M \\
\multirow{2}{*}{ PtU2 } & 24 & 5.2 \\
& 48 & 3.7 \\
\hline \multirow{2}{*}{ CDDP } & 24 & 8.0 \\
& 48 & 6.2 \\
\hline
\end{tabular}

Se decidió probar este análogo del cisplatino frente a otras líneas celulares en las que el cisplatino muestra una clara actividad citotóxica. Para una prueba de concepto, seleccionamos la MG63 (línea celular de osteosarcoma), que en la actualidad representa un modelo para uno de los tumores malignos más intratables y doloroso, cuyo tratamiento estándar requiere cirugía radical y terapia neoadyuvante.

En un primer lugar, se decidió evaluar la actividad citotóxica del compuesto derivado del cisplatino escogido para este estudio en comparación con la mostrada por el propio cisplatino. Para ello se cultivó la línea celular MG63 en presencia de diferentes concentraciones (de 0 a $150 \mu \mathrm{M}$ ) del compuesto PtU2 o de cisplatino, en RPMI suplementado con suero bovino fetal al $10 \%$ y L-glutamina al $1 \%$. Las células fueron recogidas tras 24 y 48 horas en presencia de los compuestos, y se procedió al análisis de la apoptosis por citometría de flujo.

Los resultados obtenidos en cuanto a muerte celular provocada por los compuestos PtU2 y cisplatino tras 24 y 48 horas, se muestran en las siguientes gráficas de la Figura 103. 


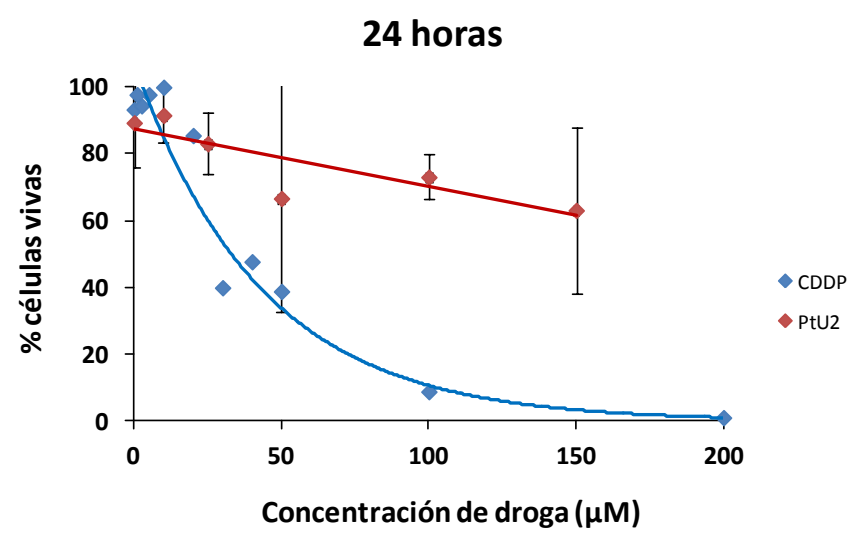

48 horas

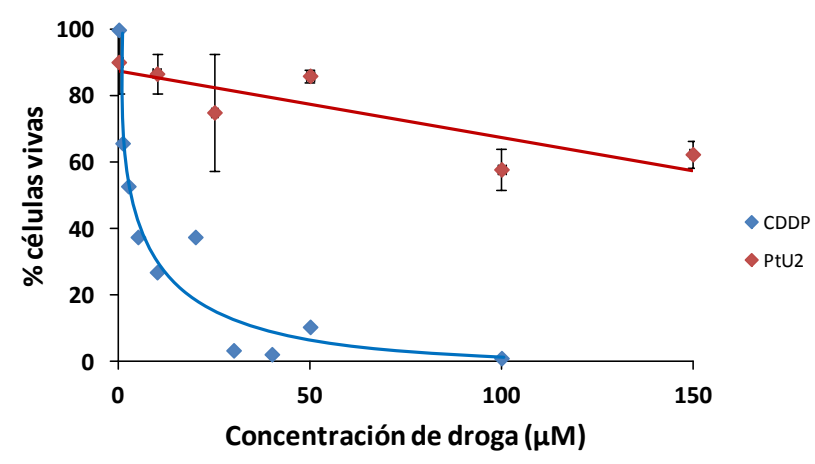

Figura 103. Actividad citotóxica del compuesto PtU2 comparado con el cisplatino frente a células MG63 tras 24 y 48 horas en cultivo.

A la vista de los resultados obtenidos, podemos afirmar que el compuesto PtU2 no ejerce actividad citotóxica importante frente a la línea celular MG63 para el margen de concentraciones estudiado. Tras 24 horas en cultivo, el compuesto PtU2 no llega al $40 \%$ de muerte celular para su concentración más alta $(150 \mu \mathrm{M})$, presentando el cisplatino en este caso un $\mathrm{IC}_{50}$ de $33 \mu \mathrm{M}$ (Ecuación exponencial: $\mathrm{y}=106.75 \mathrm{e}^{-0.023 x}$ ).

Tras 48 horas en incubación, PtU2 no ejerce una actividad citotóxica superior al $50 \%$ para la concentración más alta $(150 \mu \mathrm{M})$. Sin embargo, el cisplatino ve reducido su $\mathrm{IC}_{50}$ a $4 \mu \mathrm{M}$.

En el margen de concentraciones estudiado no se consigue una actividad citotóxica mayor del $40 \%$ por parte del compuesto PtU2. Este compuesto derivado del cisplatino, por sí solo no tiene efectos citotóxicos importantes en esta línea celular. No es capaz de ejercer efectos citotóxicos equivalentes a los del cisplatino para ninguna de las concentraciones estudiadas. 
El carácter anfipático de los ácidos biliares en el compuesto PtU2, permitiría a estos análogos una fácil difusión a través de las membranas celulares hasta el interior de las células, lo que les daría cierta ventaja frente al cisplatino, cuya entrada en la célula depende de la disponibilidad de transportadores de cobre. Esto se confirma en la línea celular HeLa, pues la actividad citotóxica que ejerce el análogo de cisplatino nos conduce a pensar que la entrada del compuesto hasta el núcleo ha tenido lugar. Pero en el caso de MG63, que el compuesto PtU2 no cause daños celulares importantes indicaría que, por algún motivo que aún desconocemos, no está atravesando la membrana celular. En este punto es donde se plantea la posibilidad de utilizar un transportador que facilite en la medida de lo posible la entrada en la célula.

Como se ha señalado a lo largo del trabajo, las nanopartículas están tomando cierta relevancia en aplicaciones biológicas. Ya ha sido probada en múltiples trabajos la capacidad de las nanopartículas de oro como transportadoras de moléculas de diversa naturaleza, y la importancia del desarrollo de metodologías para una adecuada funcionalización. Partiendo de esta premisa, se decidió estudiar la propiedad transportadora de las AuNPs para nuestros compuestos de platino, a través de la formación de un conjugado, evaluando posteriormente el efecto de la captación de metal por las células y la respuesta celular.

\section{Compuesto conjugado de AuNPs y PtU2: PtU2-AuNP}

El compuesto conjugado de PtU2 con AuNPs (PtU2-AuNP) fue preparado disolviendo el sólido directamente en la disolución coloidal de las nanopartículas. Todas las disoluciones fueron agitadas en vórtex durante al menos veinte minutos y después guardadas en nevera a $4^{\circ} \mathrm{C}$ hasta su uso en los cultivos celulares.

Las nanoestructuras AuNPs-citrato fueron recubiertas con el compuesto de platino a través de interacciones no covalentes entre las moléculas de citrato y los grupos funcionales del derivado con ácidos biliares. La formación de los complejos de manera no covalente es, en muchos casos, mucho más conveniente que una unión covalente debido a que la liberación del fármaco es más sencilla (no se requiere procesado intracelular del profármaco) e incluso la fabricación es más fácil y la carga (cantidad de fármaco) se puede controlar de una manera más eficaz. 

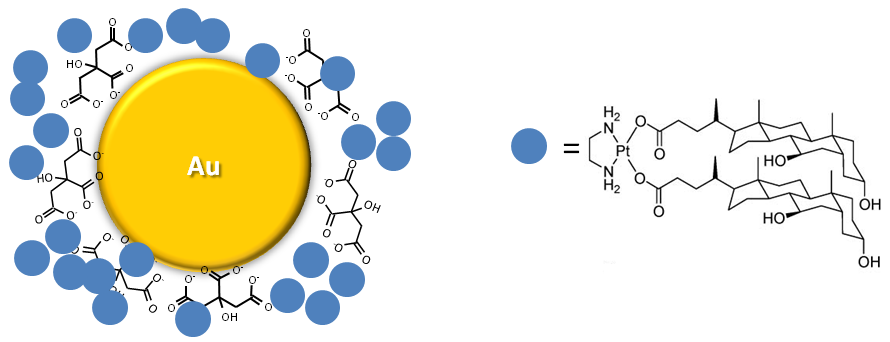

Figura 104. Estructura propuesta para el conjugado PtU2-AuNPs.

La caracterización morfológica de los conjugados se llevó a cabo por TEM y SEM (Fig. 105). En la imagen TEM es posible distinguir las AuNPs y una zona más clara alrededor de las mismas, que corresponde a un elemento con una menor densidad electrónica que el oro, en nuestro caso platino (Fig. 105-A). En la imagen SEM (Fig. 105-B) se observa la superficie de las nanopartículas con aspecto rugoso. Los ácidos biliares de este estudio tienen un carácter anfipático capaz de formar micelas. De este modo, se asume una interacción entre las micelas y la superficie hidrofóbica de las AuNPs.
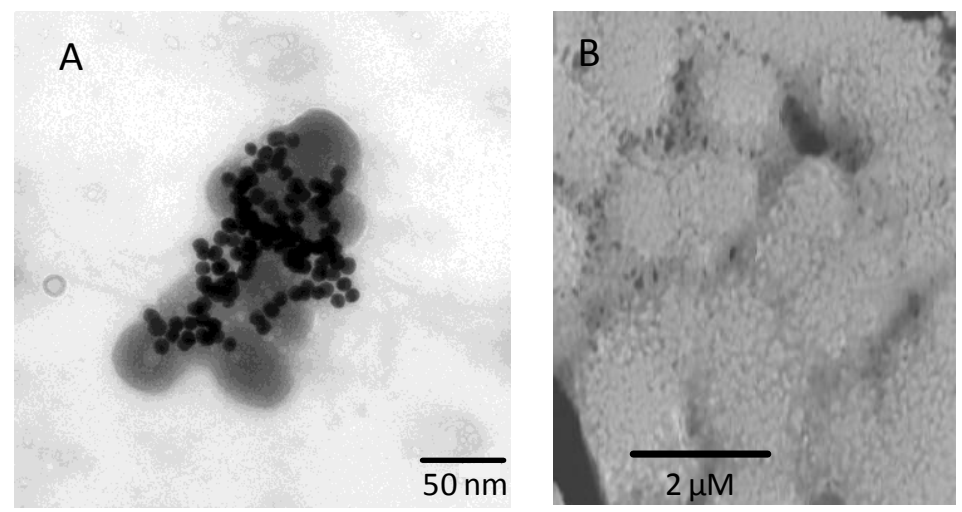

Figura 105. Imágenes TEM (A) y SEM (B) de los conjugados PtU2-AuNPs en agua.

A simple vista, en las imágenes TEM y SEM se observa agregación de las nanopartículas. Esto, en lugar de ser una limitación puede resultar beneficioso. Se ha descrito en algunas publicaciones que la mayor parte de los tumores presentan espacios intercelulares entre 100 y $1200 \mathrm{~nm}^{168,169}$. Las partículas de menor tamaño que $100 \mathrm{~nm}$ se extravasan a través del transporte transvascular. Teniendo esto en cuenta, parece lógico pensar que la agregación observada en los conjugados PtU2-AuNPs podría incrementar la

168 S.K. Hobbs, W.L. Monsky, F. Yuan F, et al. Regulation of transport pathways in tumor vessels: Role of tumor type and microenvironment. Proc. Natl. Acad. Sci. USA 95 (1998) 4607-4612.

${ }^{169}$ F. Yuan, M. Dellian, D. Fukumura, et al. Vascular Permeability in a Human Tumor Xenograft: Molecular Size Dependence and Cutoff Size. Cancer Research 55 (1995) 3752-3756. 
atracción por células neoplásicas en tumores sólidos en comparación con derivados no agregados.

Para el análisis NMR las muestras se prepararon de la siguiente forma: $500 \mu \mathrm{L}$ de la disolución coloidal de nanopartículas se mezclaron con $500 \mu \mathrm{L}$ de la disolución acuosa de PtU2 $\left(1 \times 10^{-4} \mathrm{M}\right)$ y la mezcla se incubó durante 24 horas. El sedimento se recogió por centrifugación a 7500 rpm y se resuspendió en agua destilada. La muestra se centrifugó de nuevo y el sólido obtenido se resuspendió en $\mathrm{D}_{2} \mathrm{O}$ para registrar el espectro.

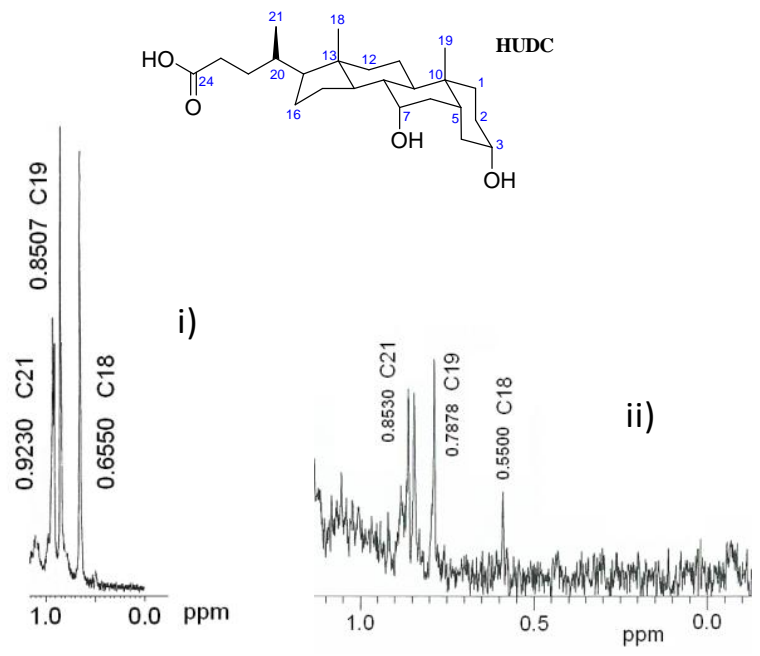

Figura 106. Espectro ${ }^{1} \mathrm{H}-\mathrm{NMR}$ en $\mathrm{D}_{2} \mathrm{O}$. i) PtU2 $\left(1 \times 10^{-4} \mathrm{M}\right)$; ii) Incubación de AuNPs $(500 \mu \mathrm{L})$ con PtU2 $\left(500 \mu \mathrm{L}, 1 \times 10^{-4} \mathrm{M}\right)$. HUDC = ácido ursodeoxicólico.

En la Figura 106-i se muestra parte del espectro RMN con señales a 0.9230, 0.8507 y 0.6550 ppm, atribuidas a los carbonos C21, C19 y C18 de los tres metilos del ácido biliar en PtU2. Las señales de estos grupos metilo se desplazan ligeramente cuando se carga el compuesto de platino sobre las AuNPs, encontrándose las señales de C21, C19 y C18 en $0.8530,0.7878$ y 0.5500 , respectivamente (Fig. 106-ii).

Para preparar la muestra para el registro del espectro IR, el sólido obtenido tras dos series de centrifugación a 7500 rpm y resuspensión en agua destilada, fue colocado en un desecador con $\mathrm{CaCl}_{2} \mathrm{y}$, una vez seco, fue disuelto en $\mathrm{KBr}$ y registrado su espectro. 


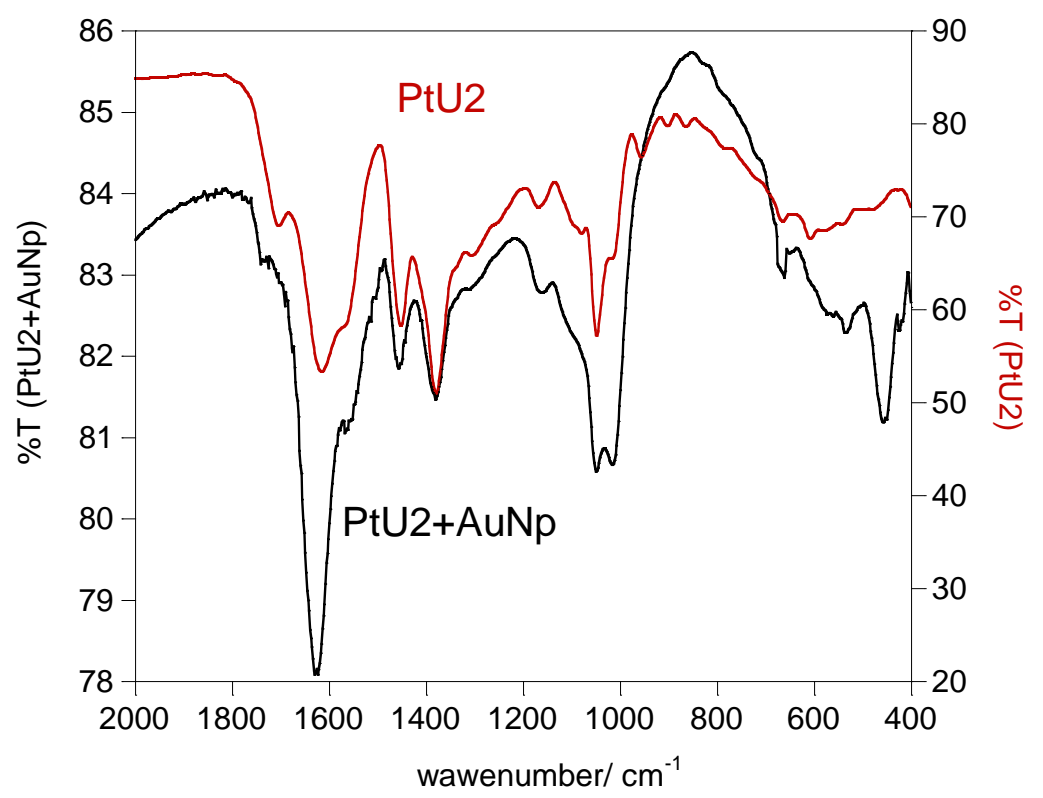

Figura 107. Espectro FT-IR del complejo de platino (rojo) y su conjugado tras incubación con nanopartículas de oro (negro).

El espectro IR del compuesto de platino contiene dos picos principales a 1413 y $1560 \mathrm{~cm}^{-1}$, los cuales se atribuyen al grupo $\mathrm{COO}^{-}$. Tras la formación del aducto, dichas bandas se desplazan ligeramente de 1413 a $1457 \mathrm{~cm}^{-1}$ y de 1560 a $1627 \mathrm{~cm}^{-1}$.

Estudio de la actividad transportadora de las AuNPs (captación de metal por las células)

Llegado este punto, y una vez caracterizado el compuesto conjugado, el siguiente paso fue su evaluación in vitro. Para comprobar que las nanopartículas de oro actúan como transportadores de nuestro compuesto de platino, se analizó y cuantificó el contenido de metal dentro de la célula, tras su incubación en presencia de los compuestos en estudio.

Para evaluar la captación de metal por las células, éstas fueron cultivadas en paralelo en presencia de diferentes concentraciones de PtU2, AuNPs y PtU2-AuNP. El rango de concentraciones de los compuestos en estudio fue de 0 a $150 \mu \mathrm{M}$. Las células se mantuvieron en cultivo en presencia de los compuestos evaluados durante 24 y 48 horas. Tras este tiempo, el medio y las células se recogieron por separado, y las distintas muestras fueron analizadas por ICP-MS para cuantificar Pt y Au.

Se utilizó holmio como patrón interno. Para la determinación cuantitativa los isótopos más abundantes de platino y oro fueron medidos a las relaciones masa/carga (m/z) 194.965 y 196.967, respectivamente. 
Todas las muestras fueron sometidas a disgregación ácida en reactores de alta presión cerrados. A las muestras con oro y platino se les añadieron $5 \mathrm{~mL}$ de $\mathrm{HNO}_{3}$ concentrado, el patrón interno (Ho: 20 ppb) y se llevaron a $10 \mathrm{~mL}$. Se utilizó un programa de microondas consistente en dos etapas:

Etapa 1: 5 minutos a $180^{\circ} \mathrm{C}$ y hasta $1000 \mathrm{~W}$ de potencia

Etapa 2: 10 minutos a $180^{\circ} \mathrm{C}$ y hasta $1000 \mathrm{~W}$ de potencia

Tras 15 minutos de tratamiento en horno microondas, las disoluciones fueron analizadas por ICP-MS para la cuantificación de oro y platino. Los valores de concentración se corrigieron respecto a la señal del holmio.

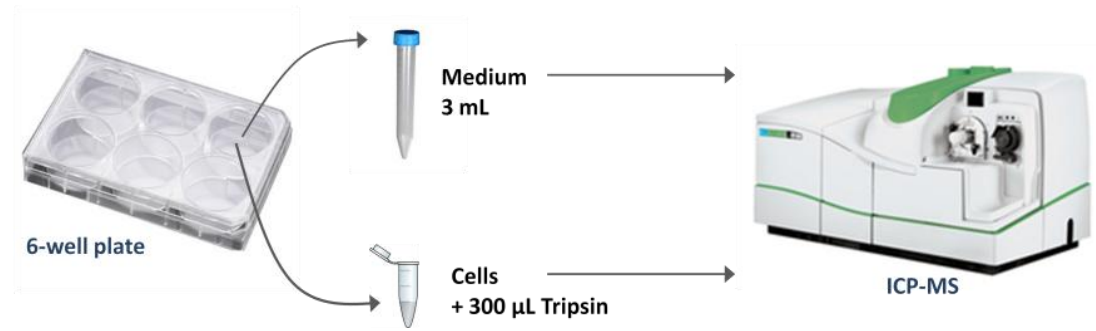

Figura 108. Metodología general para el análisis por ICP-MS.

MG63 es una línea celular que en cultivo crece adherida a la placa. Al separar el contenido de cada pocillo de la placa de cultivo en medio por un lado y células por otro (Fig. 108), se determinó el contenido de platino y oro fuera y dentro de las células, respectivamente.

En la Figura 109 se muestra el contenido intracelular y extracelular de oro y de platino tras 48 horas de incubación con PtU2 y PtU2-AuNPs, en función de la concentración de compuesto añadida. 

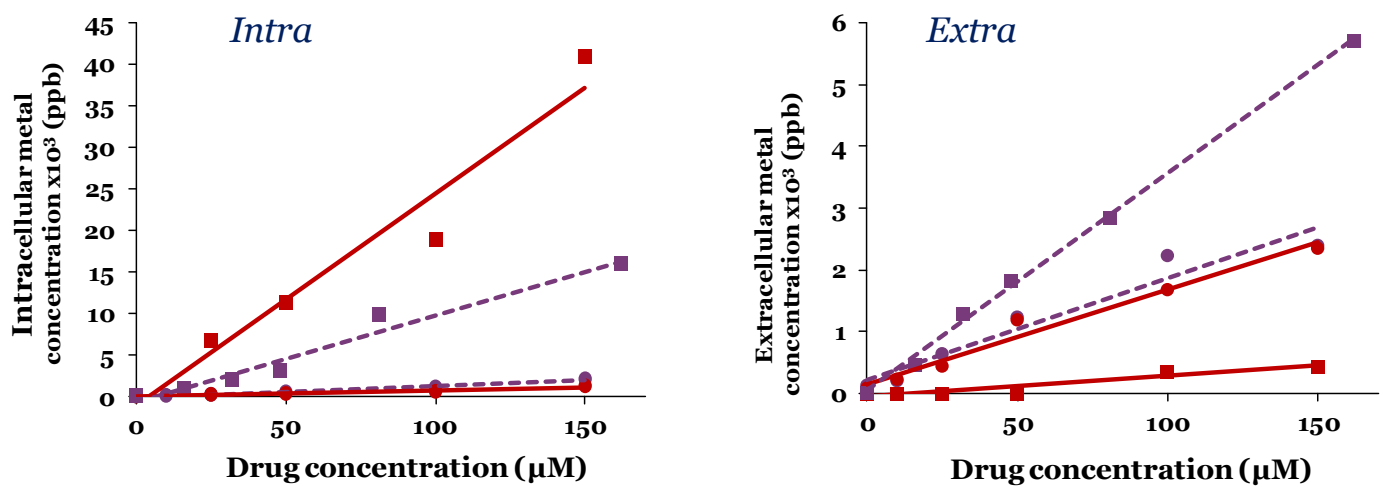

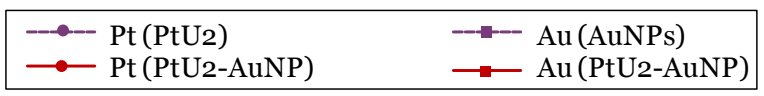

Figura 109. Cantidad de metal tras 48 horas de exposición continua a los compuestos en estudio (0-150 $\mu \mathrm{M})$ determinada por ICP-MS. Gráfica izquierda: Contenido intracelular de oro y platino. Gráfica derecha: Contenido extracelular de oro y platino.

En la gráfica de la izquierda de la Figura 109 se observa que hay una relación directa entre la cantidad de Au intracelular y la cantidad añadida de AuNPs o conjugado. A medida que incrementamos la concentración de compuesto añadido, la cantidad de metal dentro de las células aumenta. Sorprendentemente, la cantidad de oro dentro de las células fue mayor cuando éstas fueron incubadas con PtU2-AuNP en comparación con AuNPs (en las mismas condiciones). El valor más alto de relación [Au] intracelular procedente de PtU2AuNPs/[Au] intracelular procedente de AuNPs fue 2.5, alcanzado al valor más alto de concentración $(150 \mu \mathrm{M})$.

En cuanto al platino, la cantidad de este metal absorbida por las células también aumenta con la concentración de PtU2 y PtU2-AuNPs. Sin embargo, en este caso no se encontraron diferencias significativas en la cantidad de platino dentro de las células incubando con el conjugado o con el compuesto solo, ni en la cantidad de platino dentro y fuera de las células.

\section{Estudio de la actividad citotóxica}

Para la evaluación de la actividad citotóxica del conjugado PtU2-AuNPs, se incubaron las células con dicho compuesto durante 24 y 48 horas. Tras estos tiempos, se recogieron en conjunto las células con el propio medio y se centrifugaron durante 10 minutos a 1200 rpm. Se retiró el sobrenadante por aspiración y el sedimento se lavó con 2 $\mathrm{mL}$ PBS. Tras otra centrifugación y eliminación del sobrenadante se pasó al marcaje de las células para detección de apoptosis. Se utilizó un kit de detección de apoptosis de AnexinaV-FITC. A cada muestra procedente de cada pocillo se le añadieron $5 \mu \mathrm{L}$ de 
AnexinaV y $5 \mu \mathrm{L}$ de Yoduro de Propidio. Tras 15 minutos de incubación en oscuridad se añaden $400 \mu \mathrm{L}$ de Binding Buffer (PBS) y las muestras quedan listas para su análisis en el Citómetro de Flujo. De cada muestra fueron adquiridas $5 \times 10^{4}$ células, y analizado el porcentaje de células muertas con el software Infinicyte 1.5 .

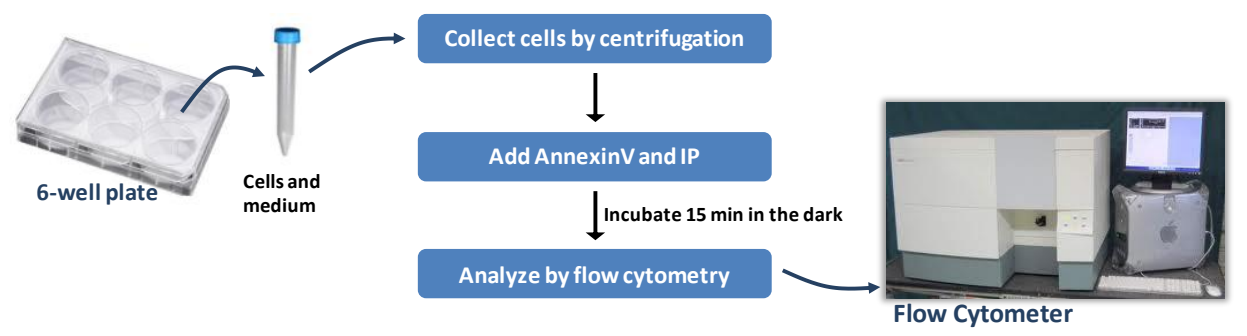

Figura 110. Esquema de la metodología utilizada para el ensayo con AnexinaV.

La Citometría de Flujo (CMF) representa un método rápido, objetivo y cuantitativo de análisis de células, núcleos, cromosomas, mitocondrias y otras partículas en suspensión. Es una técnica de análisis celular multiparamétrico que se basa en hacer pasar células u otras partículas en suspensión alineadas y de una en una por delante de un haz de láser focalizado. La interacción de las células o las partículas con el rayo luminoso genera señales que corresponden a diferentes parámetros de la célula y que son recogidos por distintos detectores. Éstos, convierten dichas señales luminosas en señales eléctricas que posteriormente serán digitalizadas para permitir la medida simultánea de varios parámetros en una misma célula. Estos parámetros son:

- Parámetros relacionados con características intrínsecas de la célula, como su tamaño y la complejidad de su núcleo y citoplasma.

- Parámetros relacionados con características antigénicas de cada célula (inmunofenotipo).

Por lo tanto, la CMF es capaz de identificar una célula por medio de sus características antigénicas $\mathrm{y} / \mathrm{o}$ por sus características morfológicas de tamaño $\mathrm{y}$ complejidad. (www.citometriadeflujo.com)

La interacción de las células con el haz luminoso produce dos tipos de señales: de dispersión y de fluorescencia. La dispersión resulta de la interacción de la luz con una partícula que produce un cambio de dirección (no de longitud de onda) en todas las direcciones del espacio. Las características celulares que contribuyen a la dispersión de la luz son el tamaño celular, la membrana celular, el núcleo y el material granular del interior 
de la célula. La luz dispersada hacia delante (forward scatter, FSC) es una medida del tamaño de la célula o la partícula que produce la dispersión. La luz dispersada en ángulo recto (side scatter, SSC) es proporcional a la complejidad de la estructura interna (densidad celular, granulosidad, etc) y no depende del tamaño.

Las señales de fluorescencia resultan de la emisión de luz por los fluorocromos presentes en la célula o partícula al ser impactados por el rayo luminoso. Un fluorocromo es una molécula química que absorbe luz a una determinada longitud de onda y emite a una longitud de onda superior (menor energía). Los Citómetros de Flujo permiten detectar señales de fluorescencia procedentes de los fluorocromos situados en una célula, siendo la cantidad de señal de fluorescencia emitida igual a la proporción de la cantidad de componentes fluorescentes de la partícula.

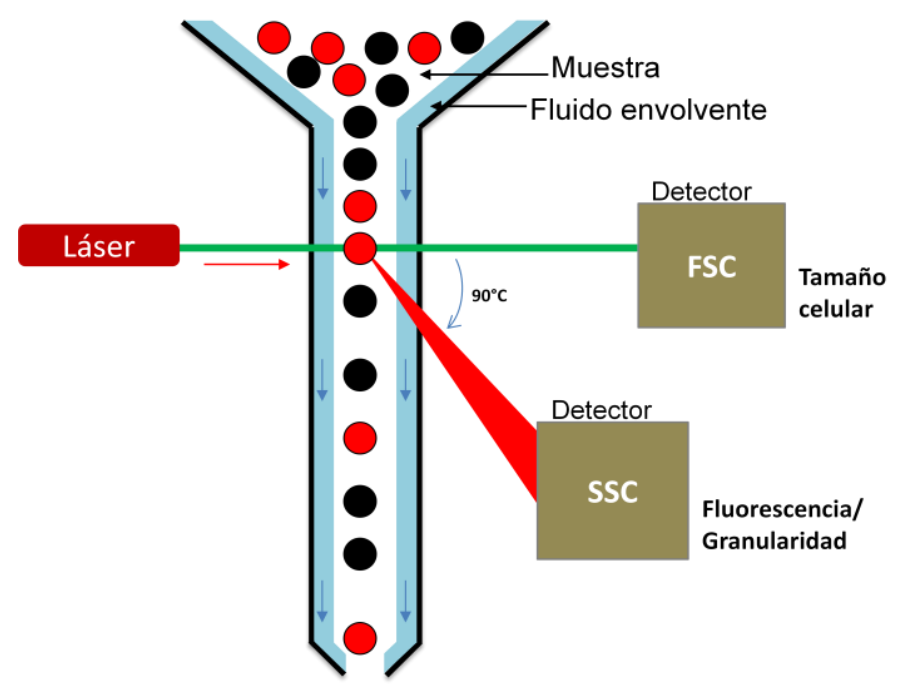

Figura 111. Representación esquemática de la detección en un CMF.

En esta parte del trabajo se utiliza esta técnica para la detección y cuantificación de células muertas. Como hemos mencionado anteriormente, las células presentes en cada muestra se marcaron con AnexinaV-FITC y yoduro de propidio (PI), una proteína que lleva un fluorocromo y un agente intercalante fluorescente, respectivamente. El marcaje se basa en una serie de fenómenos morfológicos en la célula ligados a la apoptosis. En células viables normales los fosfolípidos se distribuyen de forma simétrica a ambos lados de la membrana plasmática, con residuos de fosfatidilcolina y esfingomielina expuestos en la parte externa de la bicapa lipídica, y fosfatidilserina (PS) predominantemente en la parte interna hacia el citosol. La exposición de PS en la cara externa de la membrana celular es uno de los cambios morfológicos asociado a la apoptosis. La AnexinaV se une específicamente a la PS. La pérdida de integridad de membrana es otro de los fenómenos 
ligados a la apoptosis. De esta forma, la membrana se hace permeable al yoduro de propidio, una molécula fluorescente que se une al ADN celular. El marcaje con estos dos agentes, AnexinaV-FITC (fluorescencia verde) y PI (fluorescencia roja), nos permite clasificar las células en células vivas (AnexinaV-FITC negativo, PI negativo), células en apoptosis temprana (AnexinaV-FITC positivo, PI negativo) y células apoptóticas (AnexinaV-FITC positivo, PI positivo).

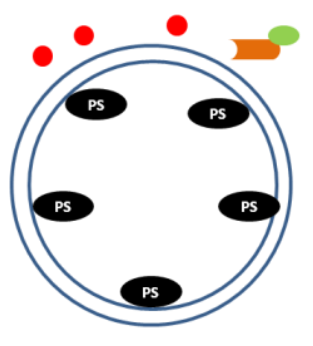

VIVA

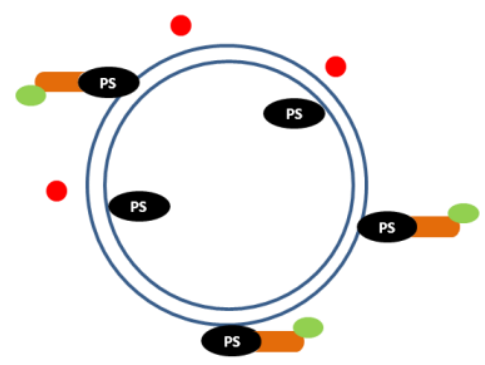

APOPTOSIS TEMPRANA

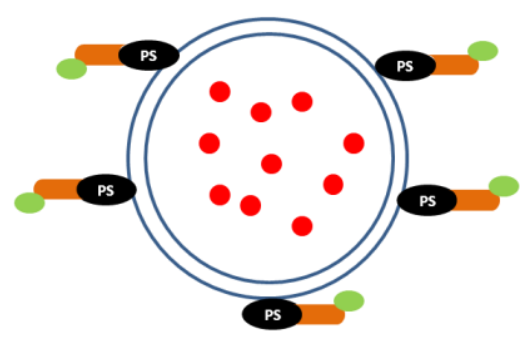

APOPTOSIS TARDÍA

Figura 112. Cambios morfológicos en la célula asociados a la apoptosis.

Los resultados en porcentaje de muerte celular obtenidos para las muestras en estudio, tras 24 y 48 horas de incubación con el conjugado PtU2-AuNPs, se muestran en laTabla 14 y en la Figuras 113-114. 
Tabla 14. Porcentaje normalizado de células vivas tras 24 y 48 horas de incubación con PtU2-AuNPs desde $0 \mu \mathrm{M}$ (blanco, ausencia de fármaco) a $150 \mu \mathrm{M}$.

\begin{tabular}{|c|c|c|c|c|c|c|c|c|c|c|}
\hline & & ELULAS & $\begin{array}{l}24 \text { hora } \\
\text { VAS (\% }\end{array}$ & malizac & & & ÉLLULAS & $\begin{array}{l}48 \text { hora } \\
\text { AS (\% }\end{array}$ & Imalizac & \\
\hline $\begin{array}{l}\text { Conc } \\
(\mu \mathrm{M})\end{array}$ & R1 & R2 & R3 & Media & SD & R1 & R2 & R3 & Media & SD \\
\hline 0 & 70,39 & 96,59 & 77,77 & 81,59 & 13,51 & 98,76 & 100,00 & 97,35 & 98,70 & 1,33 \\
\hline 10 & 92,28 & 95,29 & 100,00 & 95,86 & 3,89 & 75,74 & 78,43 & 43,07 & 65,75 & 19,69 \\
\hline 25 & 89,22 & 79,11 & 61,94 & 76,76 & 13,79 & 13,06 & 16,82 & 14,86 & 14,91 & 1,88 \\
\hline 50 & 71,52 & 81,80 & 72,70 & 75,34 & 5,63 & 11,70 & 28,47 & 12,02 & 17,39 & 9,59 \\
\hline 100 & 74,68 & 92,48 & 36,68 & 67,95 & 28,50 & 12,31 & 15,65 & 19,72 & 15,89 & 3,71 \\
\hline 150 & 48,37 & 63,42 & 31,57 & 47,79 & 15,93 & 15,56 & 17,39 & 16,96 & 16,64 & 0,96 \\
\hline
\end{tabular}

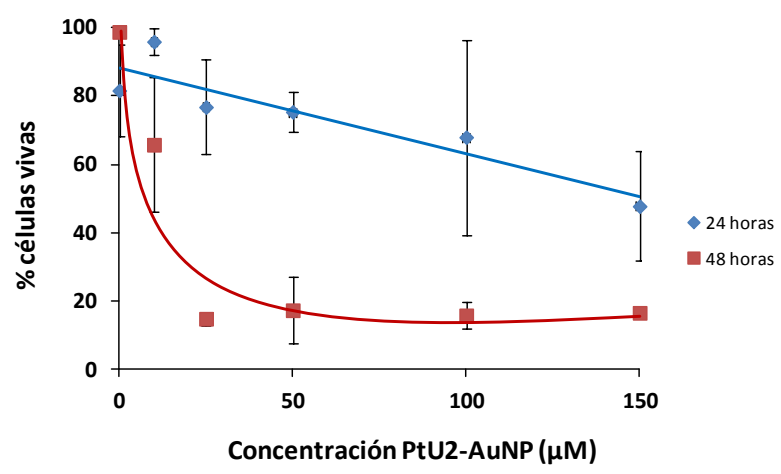

Figura 113. Porcentaje de células vivas frente a la concentración de conjugado añadido. Se representa la media de tres réplicas.

Observando la gráfica podemos decir que el conjugado a las 24 horas ejerce una actividad citotóxica que va en aumento a medida que incrementamos la concentración de PtU2-AuNPs, pero que apenas supera el $50 \%$ de muerte celular en el valor más alto de concentración. Por el contrario, para 48 horas de incubación con el compuesto conjugado observamos una importante actividad citotóxica que alcanza el 50\% de muerte celular ya en torno a una concentración de PtU2-AuNPs de $10 \mu \mathrm{M}$.

En la Figura 113 se muestra que el conjugado PtU2-AuNP ejerce una importante actividad citotóxica frente a células de osteosarcoma MG63, claramente detectable tras 48 horas. A este tiempo, la cantidad de células apoptóticas detectada tras la incubación con este nuevo compuesto fue significativamente elevada $(p<0.05)$ en concentraciones desde 10 a $150 \mu \mathrm{M}$, en comparación con los resultados obtenidos incubando con PtU2 (Fig. 103). Anteriormente ya se comprobó en los experimentos que se llevaron a cabo para evaluar la actividad del compuesto PtU2 libre, que éste no fue capaz de ejercer ninguna actividad inhibitoria. 


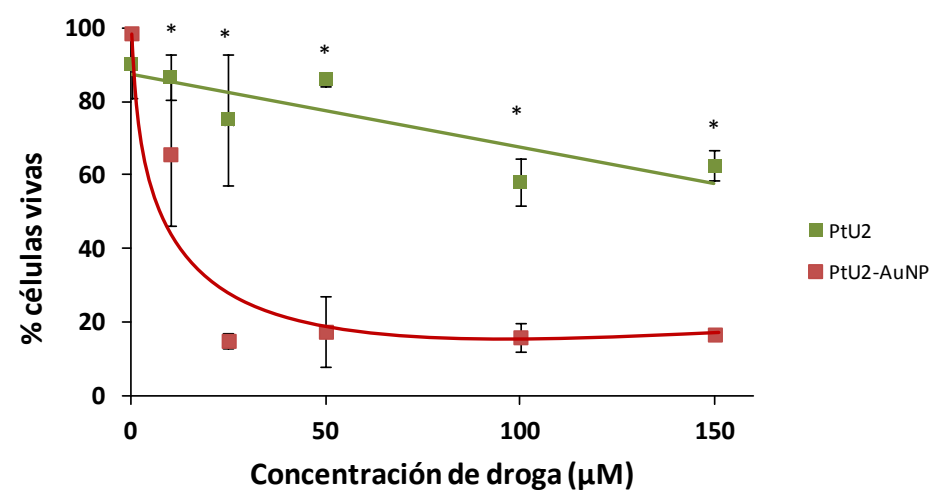

Figura 114. Comparación de la actividad citotóxica del compuesto PtU2 (línea verde) y del nuevo complejo PtU2-AuNP (línea roja) frente a células MG63 después de su cultivo en presencia de diferentes concentraciones de los compuestos durante 48 horas. Los resultados están expresados en porcentaje de células vivas. ${ }^{*} p<0.05$.

El porcentaje de células muertas causado por PtU2 y PtU2-AuNPs es significativamente diferente, sin embargo no hay diferencias significativas en la cantidad de platino en el interior de las células (Fig. 109), como se mencionó anteriormente. In vitro, los derivados de ácidos biliares unidos a AuNPs son más eficaces, en términos de actividad citotóxica que los compuestos de platino solos.

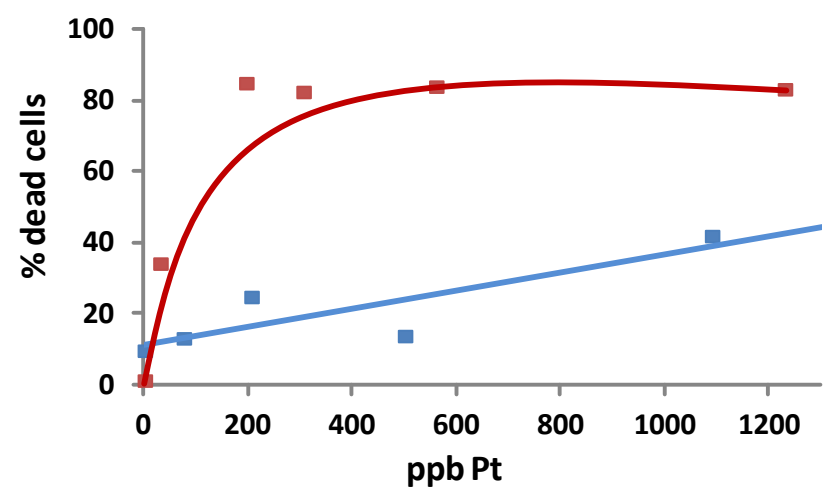

Figura 115. Porcentaje de células muertas respecto al contenido intracelular de platino, incubando con PtU2 (azul) y con PtU2-AuNPs (rojo).

La union de PtU2 a AuNPs hace que la actividad citotóxica se incremente sustancialmente. No se ha detectado actividad citotóxica incubando con AuNPs, en volúmenes equivalentes a los utilizados con el conjugado, para un margen de concentraciones de 0 a $30 \mu \mathrm{M}$. 
El mecanismo preciso a través del cual la presencia de AuNPs incrementa la actividad citotóxica del fármaco continua sin conocerse y requiere investigaciones más a fondo.

Es importante señalar que las nanopartículas que ejercen de transportadores de fármacos en general, aunque su presencia dé lugar a la misma actividad citotóxica que el compuesto aislado, sería un excelente resultado si el fármaco fuese distribuido de forma más eficaz al destino, disminuyendo los efectos secundarios sistémicos.

Los "nano-vehículos" pueden ser muy importantes si son capaces de incrementar la captación celular del fármaco (vía endocítica), incrementando los niveles de éste en células diana, y disminuyendo consecuentemente el $\mathrm{IC}_{50}$.

El compuesto PtU2, que presenta baja actividad citotóxica en ensayos anteriores frente a diferentes líneas celulares (entre ellas, osteosarcoma), una vez unido a un transportador (AuNPs) la actividad se acentúa de forma destacada, como así lo demuestra el I $C_{50}$ observado, comprobando a su vez que no sería necesaria una terapia combinada como es habitual en tratamientos con cisplatino (en el caso de osteosarcoma, cisplatino y doxorubicina). 

Nanopartículas de óxido de hierro como transportadoras de fármacos y agentes de contraste en MRI 

Las nanopartículas englobadas bajo el término SPIONs tienen núcleos de óxidos de hierro y diámetros comprendidos entre 1 y $100 \mathrm{~nm}$. Las dos formas principales en las que se presentan son magnetita $\left(\mathrm{Fe}_{3} \mathrm{O}_{4}\right)$ y su forma oxidada maghemita $\left(\gamma-\mathrm{Fe}_{2} \mathrm{O}_{3}\right)$. Este tipo de nanopartículas ha resultado muy atractiva debido a sus propiedades superparamagnéticas y su potencial uso en múltiples campos (a pesar de que $\mathrm{Cu}$, Co y Ni son también materiales altamente magnéticos, son tóxicos y fácilmente oxidables).

Algunas de las aplicaciones de las nanopartículas de óxido de hierro incluyen dispositivos de almacenamiento magnético (terabits), catálisis, sensores, siendo cada vez más relevantes las aplicaciones médicas como la imagen de resonancia magnética (MRI) biomolecular de alta sensibilidad. Estas aplicaciones requieren un recubrimiento de las nanopartículas por moléculas como ácidos grasos de cadena larga, aminas sustituidas con grupos alquilo y dioles.

Estructuralmente presentan dos configuraciones típicas: a) un núcleo magnético recubierto de un polímero biocompatible o b) un polímero biocompatible poroso en cuyos poros se encuentran precipitadas las nanopartículas. La configuración más típica es la formada por el núcleo y una cobertura biocompatible que permite la integración de distintas moléculas y agentes que aportan carácter multifuncional a la nanopartícula.

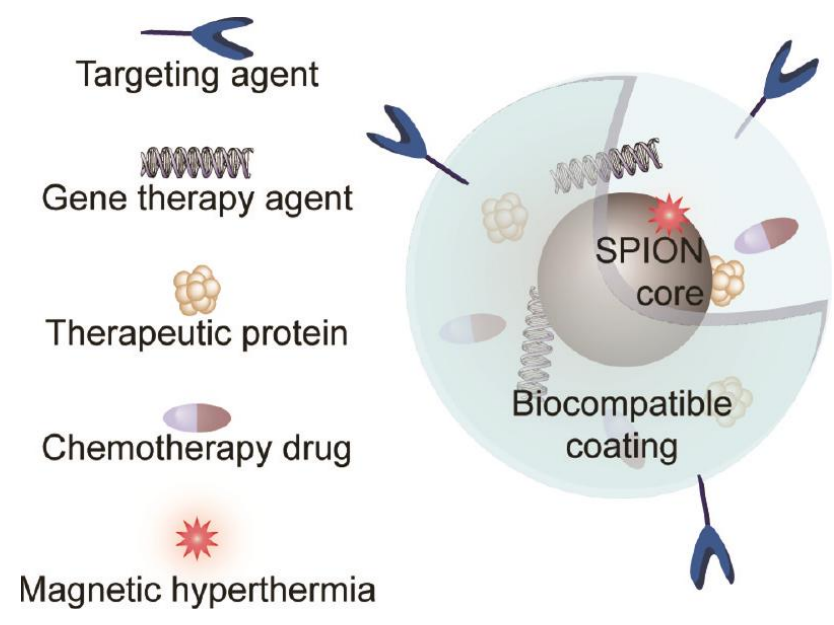

Figura 116. Arquitectura de una SPION nanoterapéutica.

La reducción de tamaño del óxido de hierro desde la macroescala a la nanoescala provoca la aparición de una nueva propiedad física importante: el superparamagnetismo. Las nanopartículas de óxido de hierro se vuelven superparamagnéticas cuando cada partícula tiene un único dominio magnético y la energía térmica es lo suficientemente 
elevada como para sobrepasar la barrera energética del flipping (volteo) magnético (normalmente, <20 nm). A escala nanométrica, la formación de paredes de Bloch (transiciones entre dominios) es termodinámicamente desfavorable, lo que conduce a la formación de cristales de dominio único, clasificados como superparamagnéticos. El término superparamagnético se refiere entonces a la característica naturaleza fuertemente paramagnética de las partículas a esta escala.

El pequeño tamaño de las SPIONs, y de todas las nanopartículas en general, facilita el movimiento por los tejidos, la endocitosis y el transporte al interior de las células. Además, la elevada relación área superficial/volumen permite una alta capacidad de carga del fármaco en la superficie de las nanopartículas. Los tamaños de las SPIONs varían de 2 a $3 \mathrm{~nm}$ para las recubiertas con moléculas de citrato, de decenas de nanómetros para las recubiertas de polímero, hasta el tamaño micrométrico de los agentes de contraste ingeribles por vía oral. En la Tabla 15 se muestra una clasificación de las SPIONs basada en su diámetro global.

Tabla 15. Categorías de SPION, basadas en su diámetro global.

\begin{tabular}{|ll|}
\hline Clase & Tamaño medio \\
\hline Oral SPIO & $>300 \mathrm{~nm}$ \\
\hline Standard SPIO (SSPIO) & $60-150 \mathrm{~nm}$ \\
\hline $\begin{array}{l}\text { Ultrasmall SPIO(USPIO) } \\
\text { MION (monocrystalline } \\
\text { iron oxide NPs) }\end{array}$ & $10-40 \mathrm{~nm}^{170}$ \\
\hline
\end{tabular}

\section{Procedimientos para la síntesis de nanopartículas de óxidos de hierro}

Han sido publicadas muchas rutas para la síntesis de SPIONs, siendo las más importantes las rutas físicas, químicas y biológicas (Tabla 16). El método de preparación influye directamente en la forma, la distribución de tamaños y la superficie de las nanopartículas. En gran medida también determina la distribución y el tipo de defectos estructurales e impurezas en las partículas. Todos estos factores afectan al comportamiento magnético. Recientemente, se han hecho grandes intentos por desarrollar procesos y técnicas que permitan generar "coloides monodispersos" con nanopartículas iguales en tamaño y forma.

\footnotetext{
${ }^{170}$ R. Weissleder, G. Elizondo, J. Wittenberg, A.S. Lee, L. Joseph-son, T.J. Brady. Ultrasmall superparamagnetic iron oxide: Characterization of a new class of contrast agents for MRI. Radiology 175 (1990) 489-493.

${ }^{171}$ T. Shen, R. Weissleder, M. Papisov, A. Bogdanov Jr., T.J. Brady. Monocrystalline iron oxide nanocompounds (MION): Physicochemical properties. Magn. Reson. Med. 29 (1993) 599-604. 
Tabla 16. Rutas para la síntesis de SPIONs.

\begin{tabular}{|l|l|}
\hline \multirow{5}{*}{ Físicas } & Deposición en fase gaseosa \\
\hline Litografía por haz de electrones \\
\hline Ablación con láser pulsado \\
\hline Pirolisis inducida por láser \\
\hline Polvo con molino de bolas \\
\hline Químicas & Coprecipitación \\
\hline Microemulsión \\
\hline Hidrotermal \\
\hline Deposición electroquímica \\
\hline Sonoquímica \\
\hline Descomposición térmica \\
\hline Mediada por hongos \\
\hline Mediada por bacterias \\
\hline Mediada por proteínas \\
\hline
\end{tabular}

El método más empleado para la producción de nanopartículas de magnetita es la coprecipitación de sales de hierro. Este método puede ser dividido en dos tipos, en función de la presencia o no de agentes superficiales complejantes. En el primero, las suspensiones de hidróxido de hierro son parcialmente oxidadas con diferentes agentes oxidantes. Por ejemplo, se pueden obtener partículas de magnetita esféricas con una distribución estrecha de tamaños entre 30 y $100 \mathrm{~nm}$ a partir de una sal de Fe(II), una base y un oxidante suave (iones nitrato $)^{172}$. Los agentes complejantes en este tipo de síntesis pueden ser dextrano, PEG o PVA, y tienen como función proporcionar estabilidad coloidal y biocompatibilidad. El otro método consiste en el envejecimiento de mezclas estequiométricas de hidróxidos ferrosos y férricos en medios acuosos, generando partículas de magnetita esféricas de tamaño homogéneo. En el segundo tipo, sucede la siguiente reacción:

$$
2 \mathrm{Fe}^{3+}+\mathrm{Fe}^{2+}+8 \mathrm{OH}^{-} \rightarrow \mathrm{Fe}_{3} \mathrm{O}_{4}+4 \mathrm{H}_{2} \mathrm{O}
$$

Las condiciones óptimas para esta reacción son $\mathrm{pH}$ entre 8 y 14 , relación $\mathrm{Fe}^{3+} / \mathrm{Fe}^{2+}$ de 2:1 y una atmósfera no oxidante. La magnetita $\left(\mathrm{Fe}_{3} \mathrm{O}_{4}\right)$, muy susceptible a la oxidación, se transforma en maghemita $\left(\gamma-\mathrm{Fe}_{2} \mathrm{O}_{3}\right)$ en presencia de oxígeno ${ }^{173}$ :

$$
\mathrm{Fe}_{3} \mathrm{O}_{4}+2 \mathrm{H}^{+} \rightarrow \nu \mathrm{Fe}_{2} \mathrm{O}_{3}+\mathrm{Fe}^{2+}+\mathrm{H}_{2} \mathrm{O}
$$

${ }^{172}$ T. Sugimoto, E. Matijević. Formation of uniform spherical magnetite particles by crystallization from ferrous hydroxide gels. Journal of Colloid and Interface Science 74 (1980) 227-243.

${ }^{173}$ S. Laurent, D. Forge, M. Port, A. Roch, C. Robic, L. Vander Elst, R.N. Muller. Magnetic Iron Oxide Nanoparticles: Synthesis, Stabilization, Vectorization, Physicochemical Characterizations, and Biological Applications. Chemical Reviews 108 (2008) 2064-110. 
El tamaño y la forma de las nanopartículas pueden ser contraladas ajustando el pH, la fuerza iónica, la temperatura, la naturaleza química de las sales (percloratos, cloruros, sulfatos, nitratos) o la relación de concentraciones $\mathrm{Fe}(\mathrm{II}) / \mathrm{Fe}(\mathrm{III})$.

La primera síntesis controlada de nanopartículas de óxido de hierro por precipitación alcalina de $\mathrm{FeCl}_{3}$ y $\mathrm{FeCl}_{2}$ fue realizada por Massart y $\mathrm{col}^{174}$.

Recientemente, las microemulsiones han sido adoptadas como nanoreactores para la síntesis de SPIONs debido a la capacidad de controlar el tamaño y la forma de las mismas. Una microemulsión es una dispersión isotrópica estable de dos líquidos inmiscibles, que consiste en dominios de tamaño nanométrico de uno de los líquidos en el otro estabilizados por una película interfacial de moléculas tensioactivas. Las microemulsiones además se pueden clasificar en oil-in-water (o/w) o water-in-oil (w/o), dependiendo de cuál sea la fase dispersa y cuál la continua. Water-in-oil es la más utilizada para la síntesis de muchos tipos de nanopartículas. El agua y el líquido orgánico se mezclan con un surfactante anfifílico. El surfactante rebaja la tensión superficial entre ambos líquidos, haciendo que la disolución se vuelva transparente. Las nanogotas de agua actúan como nanoreactores para sintetizar nanopartículas. Tendremos, de forma general, nanogotas de sales de hierro acuosas rodeadas de surfactante, el cual las separa de la disolución orgánica que las rodea formando micelas inversas. A esta mezcla añadimos nanogotas de una disolución alcalina, y las nanopartículas precipitan y se oxidan en el interior de las micelas de tamaño nanométrico. El tamaño de las nanopartículas esféricas puede ser modificado y ajustado cambiando el tamaño de las gotas de agua (cambiando la concentración de metal y de base). Salazar-Álvarez publicó la síntesis de nanopartículas de óxido de hierro utilizando emulsiones inversas ${ }^{175}$.

Existen métodos adicionales para una síntesis controlada de SPIONs, incluyendo ultrasonidos, spray pirolisis y láser pirolisis. Son métodos con alta tasa de producción de nanopartículas, pero exigen un exhaustivo control de las condiciones experimentales y equipos costosos.

La descomposición de precursores de hierro en presencia de surfactantes orgánicos a elevadas temperaturas proporciona muestras con buen control del tamaño, distribuciones estrechas (5-12 nm), buena cristalinidad y nanopartículas fácilmente dispersables. Las nanopartículas magnéticas sintetizadas de esta forma son muy útiles en aplicaciones biomédicas como MRI, separación celular magnética o magnetorelaxometría.

\footnotetext{
${ }^{174}$ R. Massart. Preparation of aqueous magnetic liquids in alkaline and acidic media. IEEE Trans. Magn. 17 (1981) 1247-1248.

${ }^{175}$ G. Salazar-Álvarez. Synthesis, characterization and applications of iron oxide nanoparticles. Doctoral Thesis, Stockholm, Sweden, 2004. 
Precursores de hierro para este tipo de síntesis son $\mathrm{Fe}(\mathrm{Cup})_{3}{ }^{176}, \mathrm{Fe}(\mathrm{CO})_{5}$ o $\mathrm{Fe}(\mathrm{acac})_{3}$, en disolventes orgánicos como el xileno y surfactantes como sodio dodecilbencenosulfonato. Estas estrategias de síntesis basadas en la reacción de precursores organometálicos a altas temperaturas, son muy efectivas y proporcionan nanopartículas magnéticas de alta calidad. Pero los nanocristales obtenidos por este procedimiento se encuentran dispersos en disoluciones hidrofóbicas, siendo de esta forma necesaria una etapa posterior de intercambio de ligando o encapsulación en micelas o copolímeros en bloque para transferir las nanopartículas a medio acuoso. En varios estudios recientes se muestra el uso de PEG como ligando de unión y recubrimiento de nanocristales de óxido de hierro, permitiendo su transferencia a medio acuoso. Estos segmentos de PEG formando parte de la nanopartícula mejoran sustancialmente la estabilidad del nanocristal en medio biológico ${ }^{177}$.

\section{Aplicaciones biológicas de las SPIONs}

Aunque las nanopartículas de óxidos de hierro han sido utilizadas como agentes de contraste magnéticos desde hace 45 años, el refinamiento de los procesos de síntesis y recubrimiento, especialmente en la última década, ha llevado al empleo de este tipo de nanopartículas en novedosas aplicaciones biológicas. De entre todos los tipos de nanopartículas, las SPIONs han surgido como uno de los candidatos más atractivos para el diagnóstico y terapia del cáncer, presentado la ventaja adicional de ser un material biodegradable.

En la Figura 117 se presentan las aplicaciones de las SPIONs en diagnóstico y terapia.

\footnotetext{
${ }^{176}$ J. Rockenberger, E.C. Scher, A.P. Alivisatos. A new nonhydrolytic single-precursor approach to surfactant-capped nanocrystals of transition metal oxides. J. Am. Chem. Soc. 121 (1999) 11595-11596.

${ }^{177}$ M.H. Stewart, K. Susumu, B.C. Mei, I.L. Medintz, J.B. Delehanty, J.B. Blanco-Canosa, P.E. Dawson, H. Mattoussi. Multidentate Poly(ethylene glycol) Ligands Provide Colloidal Stability to Semiconductor and Metallic Nanocrystals in Extreme Conditions. J. Am. Chem. Soc. 132 (2010) 9804-9813.
} 


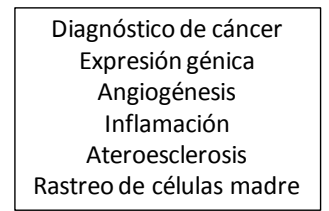

MRI

Diagnóstico
Quimioterapia Radiactividad Fotodinámica Hipertermia Antiinflamatoria Antiinfecciosa Antiartrítica Disolución de coágulos

Entrega dirigida de fármacos

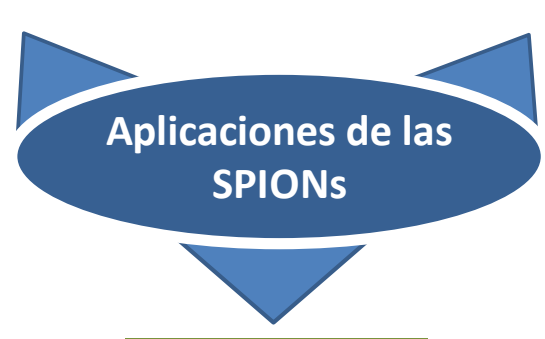

Terapia

Diagnóstico y

terapia

Marcaje magnético

Carriers magnéticos Separadores magnéticos Aislamiento magnéticos de ADN y proteínas Transfección génica

Figura 117. Aplicaciones recientes de las SPIONs en diagnóstico y terapia. Modificada de Mahmoudi y col. ${ }^{178}$

En numerosos artículos publicados hasta la fecha se expone la enorme utilidad de las SPIONs en imagen molecular. Las nanopartículas superparamagnéticas de óxidos de hierro han demostrado ser novedosas herramientas para ensalzar el contraste en resonancia magnética, permitiendo a los investigadores monitorizar no sólo cambios anatómicos sino también fisiológicos e incluso moleculares.

MRI es una técnica de imagen médica usada en radiología para visualizar estructuras internas del cuerpo con detalle. Es una modalidad de imagen que se utiliza para construir imágenes a partir de las señales de resonancia magnética nuclear, principalmente de los átomos de hidrógeno. El principio en el que se basa la MRI es el hecho de que el cuerpo contiene grandes cantidades de agua $y$, por tanto, protones que se alinean en presencia de un campo magnético grande. Cuando una persona se encuentra dentro del campo magnético del escáner, los momentos magnéticos de los protones se alinean en dirección del campo. Se activa brevemente una corriente de radio frecuencia generando un campo electromagnético variable, el cual tiene la frecuencia concreta, frecuencia de

${ }^{178}$ Morteza Mahmoudi, Shilpa Santc, Ben Wangc, Sophie Laurente, Tapas Sen. Superparamagnetic iron oxide nanoparticles (SPIONs): Development, surface modification and applications in chemotherapy. Advanced Drug Delivery Reviews 63 (2011) 24-46. 
resonancia, para ser absorbido e invertir el spin de los protones. Una vez apagado el campo electromagnético, el spin de los protones recuperan el equilibrio termodinámico y la magnetización se re-alinea con el campo magnético estático. Durante esta relajación, se genera una señal de radiofrecuencia (radiación electromagnética en el rango de radiofrecuencias), la cual se mide con bobinas receptoras.

Los protones de diferentes tejidos vuelven al estado de equilibrio a diferentes velocidades de relajación. Para construir las imágenes se pueden utilizar distintas variables características del tejido, como la densidad de spin, velocidades de relajación T1 y T2 y desplazamientos espectrales. Cambiando la configuración del escáner, se crea contraste entre diferentes tipos de tejido corporal.

MRI proporciona un buen contraste entre tejidos del cuerpo diferentes. En la práctica clínica, MRI se utiliza para distinguir el tejido patológico (como un tumor cerebral) del tejido normal. Una ventaja de la exploración por MRI es que es inofensiva para el paciente. Se utilizan fuertes campos magnéticos no ionizantes y campos electromagnéticos en el rango de frecuencias de radio, a diferencia de las tomografías y radiografías tradicionales, que ambas usan radiación ionizante.

Utilizadas en MRI, las SPIONs generan inhomogeneidades locales en el campo magnético que disminuyen la señal, apareciendo como zonas más oscuras las regiones del cuerpo que contienen estas nanopartículas. La capacidad de imagen proporcionada no es de las SPIONs intrínsecamente, sino a través de su influencia en la relajación longitudinal y transversal de los núcleos circundantes.

\section{Biocompatibilidad y citotoxicidad}

Los materiales componentes de un agente nanoterapéutico se escogen normalmente por biocompatibilidad, incluyendo la de los productos de degradación, manteniendo la capacidad de realizar las funciones para las que fue diseñado.

Una de las barreras fisiológicas a las que se tienen que enfrentar las nanopartículas con función terapéutica, es la sangre. El recubrimiento, bien sea con PEG o con otro tipo de moléculas, por ejemplo materiales zwitteriónicos, protegen la superficie de las SPIONs de la adsorción de componentes de la sangre, mejorando la estabilidad coloidal. Para sobrepasar las barreras fisiológicas que suponen el hígado y el bazo, las nanopartículas deben tener un tamaño hidrodinámico lo suficientemente pequeño para no ser eliminado por el sistema reticuloendotelial (RES), que reconoce y elimina todo aquello con un tamaño superior a 100 $\mathrm{nm}$, y lo suficientemente grande para no traspasar los poros del riñón, que filtran y eliminan todo aquello menos de $10 \mathrm{~nm}$. 
Los estudios hasta la fecha han demostrado que las nanopartículas recubiertas de polímero tienen un mínimo impacto sobre la viabilidad y función celular ${ }^{179,180}$. La biocompatibilidad de la magnetita ha sido probada en varios trabajos publicados hasta la fecha ${ }^{181,182}$. Tras la internalización, las SPIONs se acumulan generalmente en los lisosomas donde, a valores de $\mathrm{pH}$ bajos, los núcleos de óxido de hierro se rompen dando lugar a iones de hierro que son incorporados a las reservas de hemoglobina.

${ }^{179}$ A.K. Gupta, A.S. Curtis. Surface-modified superparamagnetic nanoparticles for drug delivery: interaction studies with human fibroblasts in culture. J. Mater. Sci. Mater. Med. 15 (2004) 493-496.

${ }^{180}$ M. Lewin, N. Carlesso, C.H. Tung, X.W. Tang, D. Cory, D.T. Scadden, R. Weissleder. Tat peptide-derivatized magnetic nanoparticles allow in vivo tracking and recovery of progenitor cells. Nat. Biotechnol. 18 (2000) 410-414.

${ }^{181}$ M. Mahmoudi, A. Simchi, M. Imani, M.A. Shokrgozar, A.S. Milani, U.O. Häfeli, P. Stroeve. A new approach for the in vitro identification of the cytotoxicity of superparamagnetic iron oxide nanoparticles. Colloids and Surfaces B: Biointerfaces 75 (2010) 300-309.

${ }^{182}$ U. Schwertmann, R.M. Cornell. Iron oxides in the laboratory, preparation and characterization. Cambridge: Wiley-VCH (2003). 


\section{OBJETIVO}

El objetivo perseguido en esta parte de la memoria fue la síntesis de nanopartículas de óxido de hierro y su funcionalización con un agente quimioterapéutico, el metotrexato. Esta parte experimental fue llevada a cabo en el laboratorio del Fachbereich Physik AG Biophotonik (Marburg, Alemania).

El objetivo más a largo plazo es la utilización de estas nanopartículas de óxido de hierro como vehículos para el transporte de fármacos, aprovechando además el superparamagnetismo de este tipo de nanopartículas, sirviendo por tanto de agentes de contraste en imagen por resonancia magnética. 



\section{PARTE EXPERIMENTAL}

\section{Equipos}

Detección fotométrica

Los espectros de absorción fueron realizados con un espectrofotómetro Agilent 8453 UV-visible Spectroscopy System (Agilent).

Microscopía electrónica

Las imágenes TEM fueron tomadas con un equipo JEM 3010 TEM, operando a $300 \mathrm{kV}$ (Joel Ltd).

\section{Aparatos y material}

- Rotavapor Laborota 400, Heidolph

- Sistema para reflujo

- Controlador de temperatura

- $\quad$ Syringe membrane filter (Roth \#P818.1, $0.22 \mu \mathrm{m}$ pore size)

- 100000 MWCO Centricon centrifuge filter (Millipore \#4424)

- $\quad$ Sub-Cell GT electrophoresis cells, Bio-Rad

- Dialysis membrane bag (3500 Da MWCO, Roth)

- Matraz de tres bocas de $50 \mathrm{~mL}$

\section{Reactivos}

- Dioctil éter (99\%, Sigma-Aldrich \#24.959-9)

- $\quad$ Ácido oleico (99+\%, Sigma-Aldrich \#75.090)

- Pentacarbonilo de hierro, $\mathrm{Fe}(\mathrm{CO})_{5}$ (99.999\%, Sigma-Aldrich \#48.171-8)

- $\quad \mathrm{N}$-óxido de trimetilamina $\left(\mathrm{CH}_{3}\right)_{3} \mathrm{NO}$ (98\%, Sigma-Aldrich \#31.759-4)

- Metanol

- Tolueno 
- Disolución de polímero, Poly(maleic anhydride alt-1-tetradecene)

- Cloroformo

- Sodium Borate Buffer (SBB, $\mathrm{pH}=9$ and $\mathrm{pH}=12$ )

- $\quad 0.5 \times$ Tris-Borate-EDTA (TBE) buffer (Sigma-Aldrich \#T-3913)

- Gel de agarosa $2 \%$ (Invitrogen \#15510027)

- Diamino-poli(etilenglicol) $\left(\mathrm{H}_{2} \mathrm{~N}-\mathrm{PEG}-\mathrm{NH}_{2}, \mathrm{Mw}^{\sim} 2000 \mathrm{~g} / \mathrm{mol}\right)$

- EDC (1-Etil-3-(3-dimetilaminopropil)carbodiimida)

- Metotrexato (MTX comercial, $5000 \mathrm{mg} / 200 \mathrm{~mL}, \mathrm{MW}: 454.44 \mathrm{~g} \mathrm{~mol}^{-1}$ )

\section{MÉTODO EXPERIMENTAL PARA LA OBTENCIÓN DE NANOPARTÍCULAS DE $\mathrm{Fe}_{2} \mathrm{O}_{3}$}

Los nanocristales de $\mathrm{Y}-\mathrm{Fe}_{2} \mathrm{O}_{3}$ fueron preparados siguiendo el método descrito por Hyeon y colaboradores ${ }^{183}$. De manera abreviada, $10 \mathrm{~mL}$ de éter octílico y $1.28 \mathrm{~g}$ de ácido oleico se desgasificaron en un matraz de $50 \mathrm{~mL}$ a $60{ }^{\circ} \mathrm{C}$ durante 20 minutos. La mezcla se calentó a $100{ }^{\circ} \mathrm{C}$, y una vez a esta temperatura se añadieron $0.29 \mathrm{~mL}$ de $\mathrm{Fe}(\mathrm{CO})_{5}$ para posteriormente calentar hasta reflujo $\left(\sim 295-300{ }^{\circ} \mathrm{C}\right)$ durante 1 hora. En caso de una refrigeración insuficiente, se desprenden gases de ácido oleico y la disolución se vuelve turbia, que puede ser revertida añadiendo una pequeña cantidad más de ácido oleico. A medida que la temperatura aumenta, la disolución inicial de color amarillo- anaranjado se vuelve amarillo pálido y a veces incluso incolora. Este cambio de color fue diferente al descrito por Hyeon y col. y lleva a pensar que la síntesis ha ido mal. Pero la disolución se vuelve negra rápidamente durante el reflujo, y se deja continuar la reacción durante el tiempo previsto (1 hora). Tras este tiempo se enfría el matraz a temperatura ambiente y se añaden $0.34 \mathrm{~g}$ de $\left(\mathrm{CH}_{3}\right)_{3} \mathrm{NO}$. La mezcla se calienta de nuevo a $130{ }^{\circ} \mathrm{C}$ durante dos horas, observando un nuevo cambio de color a marrón oscuro. Calentamos a reflujo durante una hora, y después dejamos enfriar la disolución a temperatura ambiente. Se añade metanol para precipitar los nanocristales, que fueron recuperados tras centrifugación y redisolución en tolueno. Esta síntesis genera nanocristales con una distribución residual de tamaños (residual distribution of sizes). Los nanocristales de mayor tamaño, apenas solubles en tolueno, se eliminaron por centrifugación de la disolución de tolueno a $3000 \mathrm{rpm}$ durante 30 minutos. Los nanocristales más pequeños se separaron por precipitación selectiva de

\footnotetext{
${ }^{183}$ T. Hyeon, S.S. Lee, J. Park, Y. Chung, H.B. Na. Synthesis of highly crystalline and monodisperse maghemite nanocrystallites without a size-selection process. J. Am. Chem. Soc. 123 (2001) 12798-12801. 
tamaños, desechando el sobrenadante, y redisolviendo el precipitado en tolueno. Esta precipitación selectiva resultó bastante sencilla porque los nanocristales pequeños apenas precipitan incluso tras la adición de varios $\mathrm{mL}$ de metanol. Los nanocristales del tamaño seleccionado fueron redisueltos en tolueno y re-precipitados con metanol dos veces más. Este procedimiento ayudó a eliminar el exceso de tensioactivo y de $\left(\mathrm{CH}_{3}\right)_{3} \mathrm{NO}$ residual. La eliminación de $\left(\mathrm{CH}_{3}\right)_{3} \mathrm{NO}$ debe llevarse a cabo cuidadosamente, ya que la adición de grandes cantidades de metanol para precipitar los nanocristales de la disolución con tolueno puede provocar también la precipitación de amina $\mathrm{N}$-óxido.

Terminado el proceso de síntesis obtenemos unos nanocristales de $\mathrm{Fe}_{2} \mathrm{O}_{3}$ con una dispersión de tamaños estrecha y disueltos en tolueno. Son disoluciones de color rojo muy intenso. La caracterización de estas nanopartículas se llevó a cabo por espectrofotometría de absorción y microscopía electrónica.

A través de las imágenes TEM se calcula la distribución de tamaños y el diámetro medio característico de las nanopartículas de la muestra.
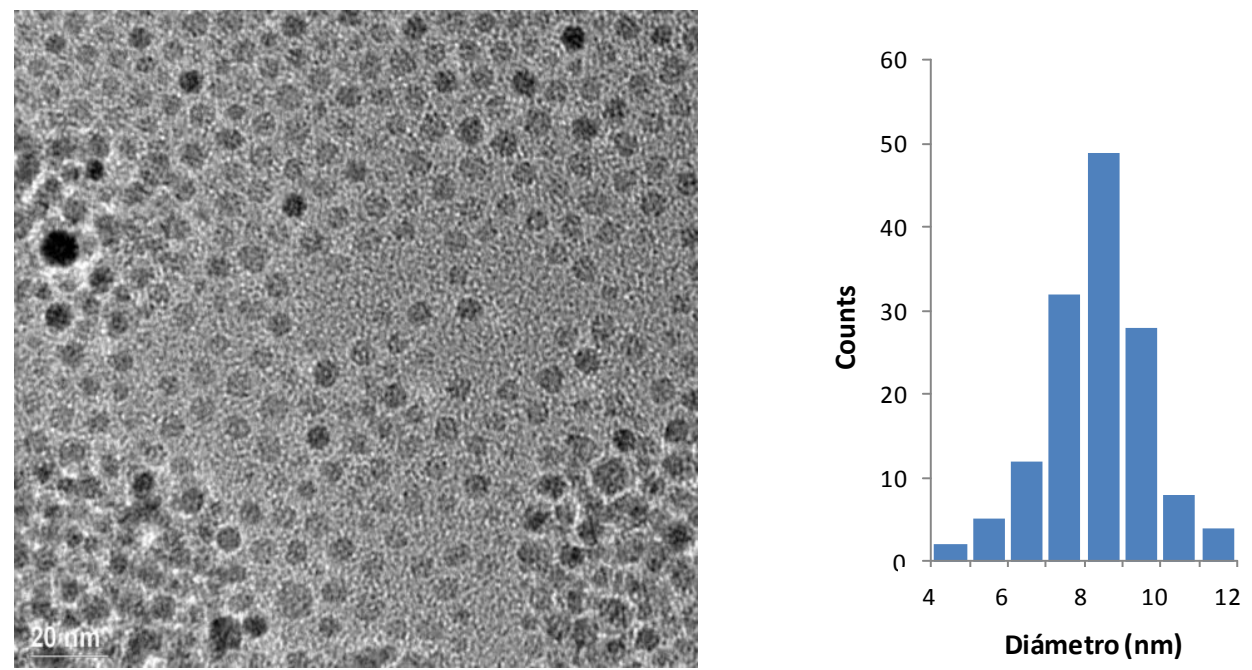

Figura 118 Imagen TEM de las nanopartículas de $\mathrm{Fe}_{2} \mathrm{O}_{3}$ (izquierda) y distribución de tamaños (derecha). La muestra presenta unas nanopartículas con un diámetro medio de $8.3 \mathrm{~nm}$ (desviación estándar= 1.2).

La muestra sintetizada contiene nanopartículas con un tamaño medio de $8.3 \mathrm{~nm}$.

Para el cálculo de la concentración de nanopartículas de $\mathrm{Fe}_{2} \mathrm{O}_{3}$ en la muestra se toma una alícuota y se mide su espectro de absorción. Dicha alícuota se diluye lo necesario para que el valor de absorbancia no supere el valor de 1 . Se anota el valor de absorbancia obtenido en el máximo y se calcula la concentración a partir de la siguiente ecuación:

$$
\text { Conc } \mathrm{Fe}_{2} \mathrm{O}_{3}(\mathrm{nM})=\mathrm{m} x+b
$$


Siendo $m=50.74562$ (pendiente); $x$ la absorbancia a $450 \mathrm{~nm} ; b=0.96947$ (ordenada en el origen).

Con una absorbancia de 0.02327, a través de la ecuación anterior y teniendo en cuenta un factor de dilución de 1000 en este caso, obtenemos una concentración de 2.1 $\mu \mathrm{M}$. Este cálculo se realiza cada vez que sea necesario, para cada muestra sintetizada.

\section{RECUBRIMIENTO POLIMÉRICO DE LAS NANOPARTÍCULAS DE $\mathrm{Fe}_{2} \mathrm{O}_{3}$}

Los polímeros anfifílicos pueden ser utilizados como recubrimiento de nanopartículas hidrofóbicas con el objetivo de transferirlas a medio acuoso. Esta clase de recubrimientos anfifílicos no sólo hace posible la transferencia de nanopartículas desde un medio orgánico a medio acuoso, sino que sirve además como una plataforma versátil para la modificación química y bioconjugación de la partícula a través de la unión covalente de moléculas biológicas a su superficie.

El polímero utilizado en nuestros experimentos para este propósito, poli(anhídrido maleico alt-1-tetradeceno $)^{184,185}$, tiene dos grandes elementos constitutivos: cadenas laterales hidrofóbicas compatibles con la superficie de las nanopartículas y un esqueleto principal hidrofílico que será expuesto a la disolución acuosa. Cada cadena de polímero tiene una longitud media de $\mathbf{3 0}$ monómeros (un monómero es la unidad constituida por el anillo anhídrido y la cadena alquílica).

Las cadenas alquílicas hidrofóbicas del polímero se intercalan con las moléculas que recubren la superficie de la nanopartícula, quedando los ácidos carboxílicos libres y los anillos anhídrido hacia el exterior, en la superficie de las nanopartículas recubiertas del polímero. Las nanopartículas se vuelven solubles en agua tras la adición de un tampón alcalino, pues en esta disolución acuosa los anillos de anhídrido maleico libres se hidrolizan dando lugar a dos ácidos carboxílicos libres cada uno. Estas cargas negativas del polímero estabilizan la nanopartícula en agua por repulsión electrostática. Los grupos carboxílicos expuestos servirán además como anclaje de moléculas con grupos amino (por ejemplo, PEG) a través de reacciones con carbodiimidas (EDC chemistry).

${ }^{184}$ C.J. Lin, R.A. Sperling, J.K. Li, T.Y. Yang, P.Y. Li, M. Zanella, W.H. Chang, W.J. Parak. Design of an Amphiphilic Polymer for Nanoparticle Coating and Functionalization. Small 4 (2008) 334-341.

${ }^{185}$ T. Pellegrino, L. Manna, S. Kudera, T. Liedl, D. Koktysh, A.L. Rogach, S. Keller, J. Radler, G. Natile, W.J. Parak. Hydrophobic Nanocrystals Coated with an Amphiphilic Polymer Shell: A General Route to Water Soluble Nanocrystals. Nanoletters 4 (2004) 703-707. 


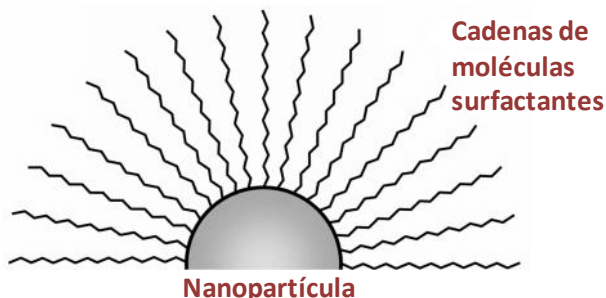

Nanopartícula

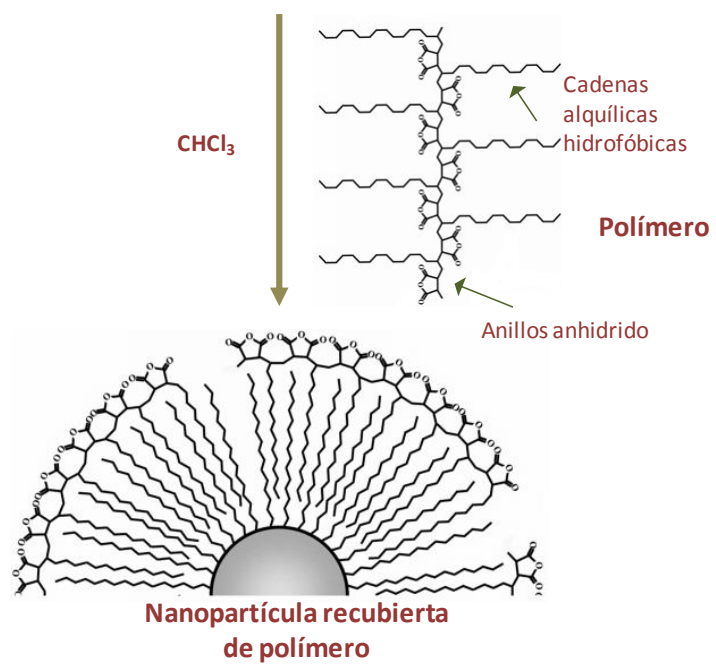

Figura 119. Recubrimiento polimérico de una nanopartícula.

\section{Metodología general}

A la disolución con nanopartículas se le añade la disolución con el polímero, ambas en cloroformo. Tras cinco minutos de agitación, el disolvente fue evaporado en un sistema rotavapor. Se redisuelve en cloroformo y se evapora otras dos veces. El sólido resultante fue disuelto en SBB12 y las nanopartículas ya recubiertas se disolvieron completamente en la disolución tampón. El exceso de polímero o los posibles agregados formados durante el proceso se eliminaron filtrando la disolución a través de una jeringa de filtro de membrana. Las nanopartículas, en SBB12 y lo suficientemente concentradas, se purificaron posteriormente por electroforesis en gel. Después de extraer las nanopartículas del gel, cambiamos el buffer por SBB9 en sucesivas rondas de dilución y reconcentración en centrífuga.

El protocolo general adoptado para el recubrimiento de las nanopartículas considera que se añade un volumen de polímero a la disolución de nanocristales equivalente a 100 unidades de polímero por $\mathrm{nm}^{2}$ de área de superficie de las nanopartículas. 
Recubrimiento polimérico para nanopartículas de $\mathrm{Fe}_{2} \mathrm{O}_{3}$

Para calcular la cantidad de polímero que añadir a nuestra disolución con nanopartículas es necesario conocer dos parámetros: el diámetro efectivo de una nanopartícula y la concentración de nanopartículas en disolución. Como hemos señalado anteriormente, el diámetro medio de las nanopartículas de óxido de hierro fue determinado por TEM y la concentración de las mismas en disolución fue determinada por espectroscopía de absorción.

El diámetro efectivo $\left(d_{\text {eff }}\right)$ es la suma del diámetro del núcleo inorgánico (core) y el espesor de la capa de surfactante, que se supone de $1 \mathrm{~nm}$. Éste diámetro se calcula a través de la ecuación [1].

$$
d_{\text {eff }}=d_{\text {core }}+2 I_{\text {surfactant }}(\mathrm{nm})
$$

siendo $d_{\text {eff }}$ el diámetro efectivo; $d_{\text {core }}$ el diámetro del núcleo de la nanopartícula y $I_{\text {surfactant }}$ el supuesto espesor de la capa de surfactant $\left(I_{\text {surfactant }}=1 \mathrm{~nm}\right)$.

Para nuestras nanopartículas de $8 \mathrm{~nm}$, utilizando la expresión anterior obtenemos un $d_{\text {eff }}=10 \mathrm{~nm}$.

El area superficial total (A) se calcula a través de la expresión [2]:

$$
\mathrm{A}=\mathrm{C} \cdot \mathrm{V} \mathrm{N} \mathrm{N}_{\mathrm{A}} \cdot \mathrm{A}_{0}=\pi \cdot \mathrm{C} \cdot \mathrm{V} \mathrm{N} \mathrm{N}_{\mathrm{A}} d_{\text {eff }}^{2}
$$

siendo $A_{0}$ el área superficial de una nanopartícula esférica $\left(\mathrm{nm}^{2}\right)=4 \pi\left(d_{\text {eff }} / 2\right)^{2}=\pi$ $d_{\text {eff }}^{2} ; A$ el área superficial total de todas las nanopartículas en la alícuota $\left(\mathrm{nm}^{2}\right) ; d_{\text {eff }}$ el diámetro efectivo de una nanopartícula $(\mathrm{nm})$; $C$ la concentración de nanopartículas en la alícuota (mol/L); $V$ el volumen de la alícuota (L); $N_{A}$ la constante de Avogadro, $6.02 \times 10^{23} / \mathrm{mol}$.

En una alícuota de disolución de FeNPs $(100 \mu \mathrm{L}, 2.1 \mu \mathrm{M})$, el área superficial total (A), calculada a través de la expresión [2], fue de $3.97 \times 10^{16} \mathrm{~nm}^{2}$. Si el número de monómeros de polímero (P) añadidos por unidad de área de superficie de nanopartículas quedó establecido en $100\left(R_{\mathrm{P} / \text { Area }}=100 \mathrm{~nm}^{-2}\right)$, significa que se deben añadir $3.97 \times 10^{18}$ unidades de monómero de polímero a la disolución con nanopartículas, que equivalen a $132 \mu \mathrm{l}$ de disolución madre de polímero $(0.05 \mathrm{M}$ en cloroformo, 25\%Anhydride$\left.75 \% \mathrm{C}_{12} \mathrm{COOH}\right)$.

Tras añadir a las nanopartículas la cantidad de polímero necesaria y agitar 15 minutos, el disolvente se evaporó lentamente en un sistema rotavapor durante 10 minutos, 
hasta completa sequedad de la muestra. El sólido con las FeNPs recubiertas de polímero se disolvió en $2 \mathrm{~mL}$ de tampón SBB (SBB, pH 12 ajustado con $\mathrm{NaOH}$ ).

\section{Electroforesis en gel}

La electroforesis en gel en esta etapa se utilizó para purificar las nanopartículas recubiertas, para estudiar su tamaño y la distribución de carga del polímero y para comprobar la presencia de agregados. La disolución concentrada con nanopartículas se mezcló con GLB (concentración final 20\%) y se desplazaron en gel de agarosa al $2 \%$ en tampón TBE $0.5 \mathrm{X}$, a $100 \mathrm{~V}$ durante 1 hora (AuNPs de $10 \mathrm{~nm}$ recubiertas de fosfina como referencia). En el caso de nanopartículas de $\mathrm{Fe}_{2} \mathrm{O}_{3}$, la toma de imágenes de los geles se lleva a cabo bajo luz visible. A continuación, se cortaron las bandas que contenían las nanopartículas y se introdujeron en bolsas de membrana de diálisis, sometiéndolas de nuevo a $100 \mathrm{~V}$ para expulsar las nanopartículas atrapadas.

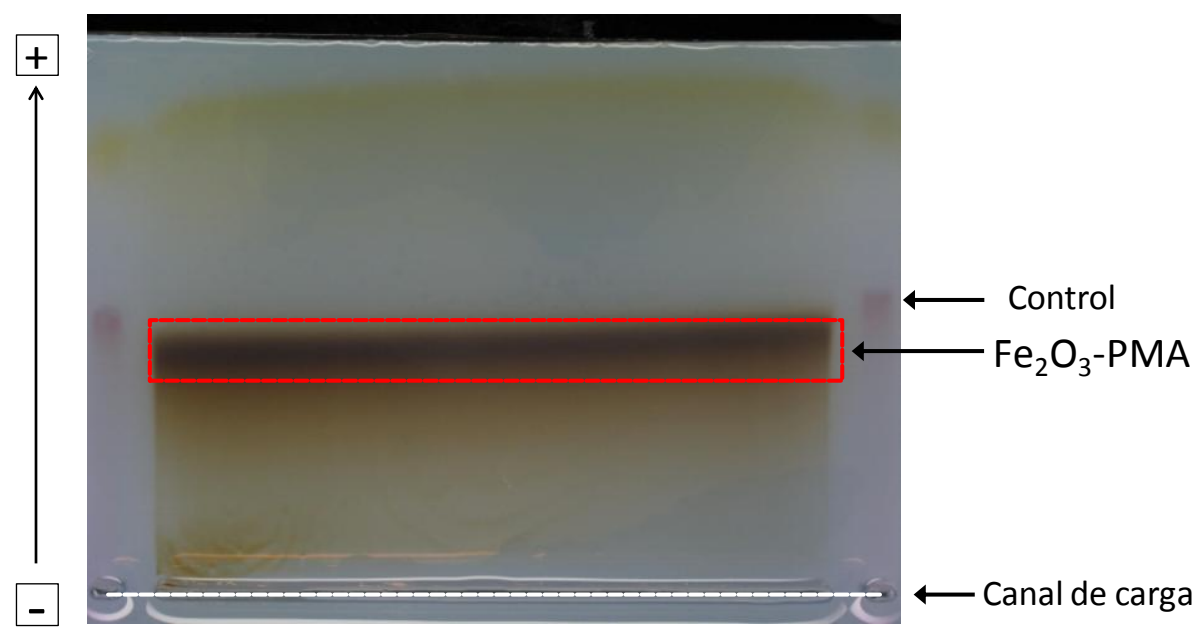

Figura 120. Gel de agarosa utilizado para purificar las nanopartículas de óxido de hierro recubiertas con polímero. La línea discontínua blanca indica los pocillos en el gel donde las nanopartículas fueron cargadas, y desde donde migraron hacia el polo positivo bajo la acción de un campo eléctrico. La banda discreta formada por las nanopartículas recubiertas de polímero ( $\mathrm{Fe}_{2} \mathrm{O}_{3}-\mathrm{PMA}$ ) se corta (línea roja discontínua) y se separa del gel para extraer dichas nanopartículas.

Finalmente, la disolución con las nanopartículas fue filtrada a través de un filtro (0.22 $\mu \mathrm{m}$ de tamaño de poro) para eliminar posibles trozos pequeños de gel y se concentró por ultrafiltración, quedando la disolución preparada para la siguiente etapa. Las nanopartículas recubiertas del polímero con grupos funcionales incorporados presentan propiedades coloidales que les permiten ser estables durante largos periodos de tiempo. 


\section{MODIFICACIÓN DE LA SUPERFICIE DE LAS NANOPARTICULAS CON PEG}

Para la siguiente etapa de modificación de la superficie de las nanopartículas ya solubles en medio acuoso, se escogió polietilenglicol (PEG) como molécula orgánica funcional. Las moléculas de PEG incrementan la estabilidad coloidal, reducen las interacciones inespecíficas en medios biológicos $y$, además, proporcionan grupos funcionales libres que preparan la superficie de las nanopartículas para reacciones posteriores con otras moléculas.

EI PEG utilizado en nuestros experimentos fue diaminopolietilenglicol (diaminoPEG) de peso molecular $2000 \mathrm{~g} / \mathrm{mol}$. Uno de sus extremos amino se unirá a un grupo carboxilo libre del polímero, y el otro extremo amino quedará libre hacia la disolución.

La estrategia de unión de las moléculas de PEG fue el acoplamiento mediado por EDC de estas moléculas funcionales a la cobertura de polímero. Las moléculas de EDC activan los grupos carboxílicos sobre la superficie del polímero, estimulando la reacción con los grupos amino terminal del PEG.
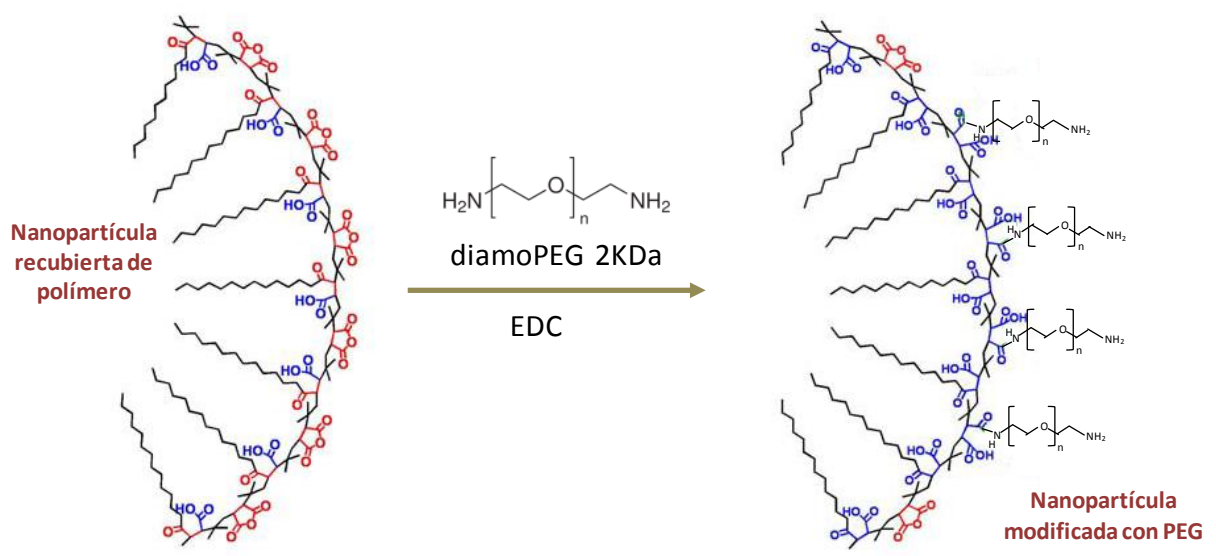

Figura 121. Estrategia de unión de las moléculas de diaminoPEG a los grupos carboxilo del polímero a través de activación con EDC.

\section{Metodología}

Las nanopartículas recubiertas de polímero $\left(\mathrm{Fe}_{2} \mathrm{O}_{3}-\mathrm{PMA}\right)$, diaminoPEG y EDC se mezclaron en una relación de 1:50000:128000, respectivamente. Previamente, se midió la concentración de $\mathrm{Fe}_{2} \mathrm{O}_{3}$-PMA y se prepararon disoluciones de diamino-PEG y EDC en SBB9 y agua MiliQ, respectivamente. 
Se utilizó PEG con grupos amino en los extremos, de bajo peso molecular y en elevada concentración para asegurar la unión a la NP y que esa unión sea solamente por uno de los grupos de cada PEG. De otro modo, un mayor tamaño de estas moléculas, facilitaría flexiones y plegamientos de la estructura que aumentarían la probabilidad de unión de los dos grupos amino a la NP y no quedarían aminos libre para funcionalizar.

Las disoluciones de EDC fueron preparadas en agua MiliQ, ya que este reactivo necesita una cantidad elevada de protones para ejercer su función. El EDC se pone en elevado exceso, pues cuanto más EDC se añade, más moléculas de PEG se unen a las nanopartículas.

La mezcla resultante se dejó a temperatura ambiente durante 2 horas, sin agitación. Tras dos horas de reacción, se centrifuga la mezcla y se purifica por electroforesis en gel $(10 \mathrm{~V} / \mathrm{m}, 1$ hora). Las bandas en el gel están retrasadas respecto a las bandas obtenidas con FeNP o FeNP-PMA. La unión de las moléculas de PEG a las nanopartículas recubiertas de polímero provoca cambios suficientes en el tamaño de partícula para que se resuelvan en el gel como una banda individual y perfectamente diferenciada de la banda originada por nanopartículas sin PEG.

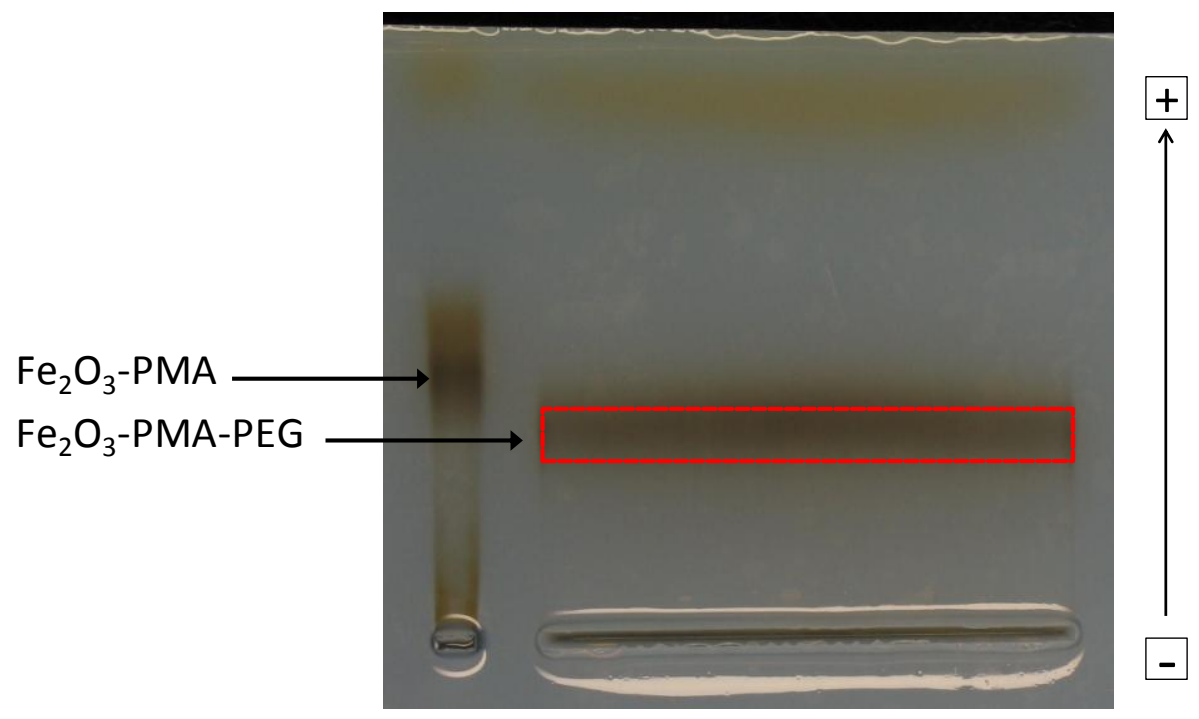

Figura 122. Separación por electroforesis en gel de nanopartículas de óxido de hierro recubiertas con PEG. La banda discreta formada por las nanopartículas recubiertas de PEG ( $\mathrm{Fe}_{2} \mathrm{O}_{3}-\mathrm{PEG}$ ) se corta (línea roja discontínua) y se separa del gel para extraer dichas nanopartículas.

Finalmente, las nanopartículas se extrajeron del gel, se concentraron en un volumen pequeño y se guardaron para la posterior reacción con MTX. 


\section{UNIÓN DE METOTREXATO A LAS NANOPARTÍCULAS $\mathrm{Fe}_{2} \mathrm{O}_{3}$-PEG}

El metotrexato (MTX), agente antineoplásico e inmunosupresor, antagonista del ácido fólico ${ }^{186}$, es uno de los fármacos más ampliamente utilizados en el tratamiento de diversos tipos de cáncer. Sin embargo, su aplicación clínica está limitada por los tóxicos efectos secundarios relacionados con la dosis y el desarrollo de resistencia a este fármaco por las células hacia las que va dirigido ${ }^{187}$. La falta de selectividad del MTX, una molécula de bajo peso molecular, está estrechamente relacionada con sus propiedades farmacocinéticas, es decir, un tiempo de vida media corto en el torrente sanguíneo y una rápida difusión por todo el cuerpo dando lugar a una distribución tisular uniforme ${ }^{188}$.

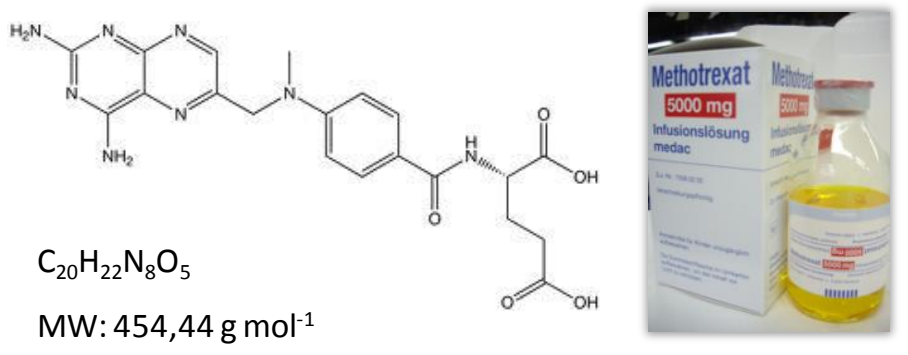

Figura 123. Estructura, fórmula, peso molecular del metotrexato (izquierda) y formato del envase para uso médico (derecha).

El metotrexato inhibe alostéricamente la dihidrofolato reductasa (DHFR), una enzima que participa en la síntesis de tetrahidrofolato ${ }^{186}$. La afinidad de la DHFR por el metotrexato es aproximadamente mil veces la del folato. La DHFR cataliza la conversion de dihidrofolato en su forma activa, tetrahidrofolato. El ácido fólico es necesario para la síntesis de timidina, nucleósido necesario para la síntesis de ADN. Además, el folato es necesario para la síntesis de purina, de modo que toda la síntesis de esta base nitrogenada será inhibida. El metotrexato, por tanto, inhibe la síntesis de ADN, ARN, timidilatos y proteínas.

Su actuación durante la síntesis de ADN y RNA hace que el MTX sea tóxico durante la fase $S$ del ciclo celular. Por ello, tiene un mayor efecto citotóxico en células que se dividen rápidamente, las cuales replican su ADN más frecuentemente, inhibiendo así el

${ }^{186}$ P.T.R. Rajagopalan, Z. Zhang, L. McCourt, M. Dwyer, S.J. Benkovic, G.G. Hammes. Interaction of dihydrofolate reductase with methotrexate: Ensemble and single-molecule kinetics. Proceedings of the National Academy of Sciences 99 (2002) 13481-13486.

187 D. Banerjee, P. Mayer-Kuckuk, G. Capiaux, T. Budak-Alpdogan, R. Gorlick, J.R. Bertino. Novel aspects of resistance to drugs targeted to dihydrofolate reductase and thymidylate synthase. Biochim. Biophys. Acta 1587 (2002) 164173.

${ }^{188}$ K. Wosikowski, E. Biedermann, B. Rattel, N. Breiter, P. Jank, R. Loser, G. Jansen, G.J. Peters. Methotrexate conjugate with branched polypeptide influences Leishmania donovani infection in vitro and in experimental animals. Clin. Cancer Res. 9 (2003) 1917-1926. 
crecimiento y la proliferación de células cancerosas, pero también en células no cancerosas que tienen estas características (células mieloides, mucosa gastrointestinal y oral), dando lugar a los conocidos efectos secundarios.

Un enfoque novedoso para mejorar la capacidad de dirigir y liberar fármacos de forma eficaz es conjugar nanopartículas con dichos reactivos químicos o biológicos, capaces de unirse a un determinado tipo de células. Por lo tanto, la unión de MTX a un sistema macromolecular alterará su comportamiento farmacocinético, mejorará la focalización hacia el sitio que va dirigido, reduciendo así su toxicidad y superando mecanismos de resistencia.

La reacción de conjugación del MTX puede ocurrir por cualquiera de los dos ácidos carboxílicos $(\alpha \circ \beta)$ del residuo de ácido glutámico. Estos grupos carboxílicos se unirán a los grupos amino libres de las moléculas de PEG sobre la superficie de la nanoparícula.

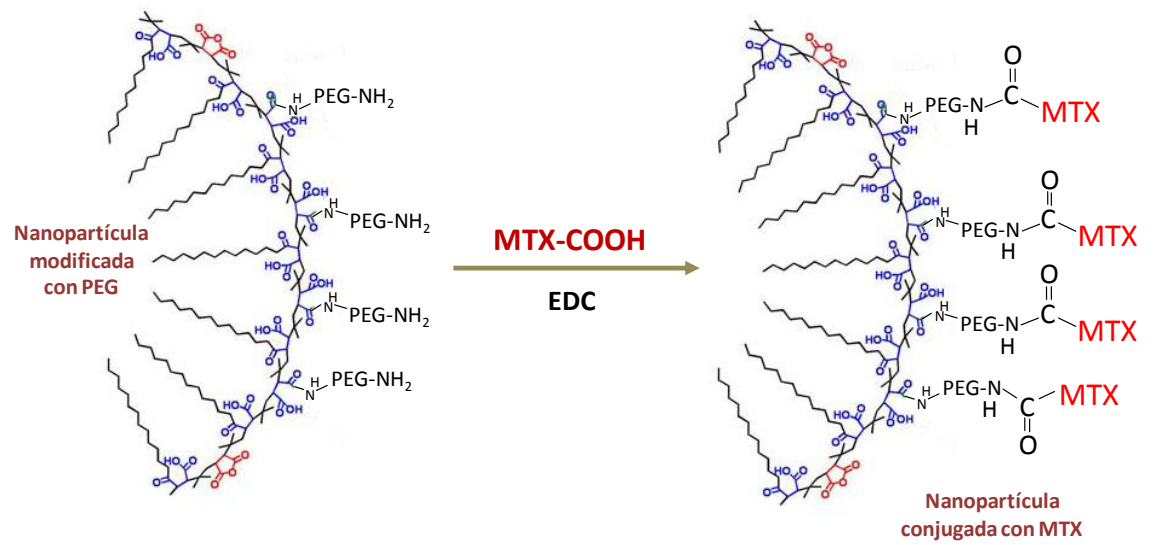

Figura 124. Estrategia de unión de las moléculas de metotrexato a los grupos amino del PEG a través de activación con EDC.

\section{Metodología}

Las nanopartículas modificadas con PEG $\left(\mathrm{Fe}_{2} \mathrm{O}_{3}\right.$-PMA-PEG-NH $\left.\mathrm{N}_{2}\right)$ fueron mezcladas con MTX y EDC en una relación de 1:50000:128000, respectivamente. Primeramente fue medida la concentración de la disolución de $\mathrm{Fe}_{2} \mathrm{O}_{3}$-PMA-PEG, y preparadas las disoluciones de MTX y EDC en SBB9 y agua MiliQ, respectivamente.

La mezcla resultante se dejó a temperatura ambiente durante 2 horas, sin agitación. Tras este tiempo, se centrifugó la muestra y se purificó por electroforesis en gel (10 V/cm, 1 hora, AuNPs de $10 \mathrm{~nm}$ recubiertas con fosfina como referencia). 


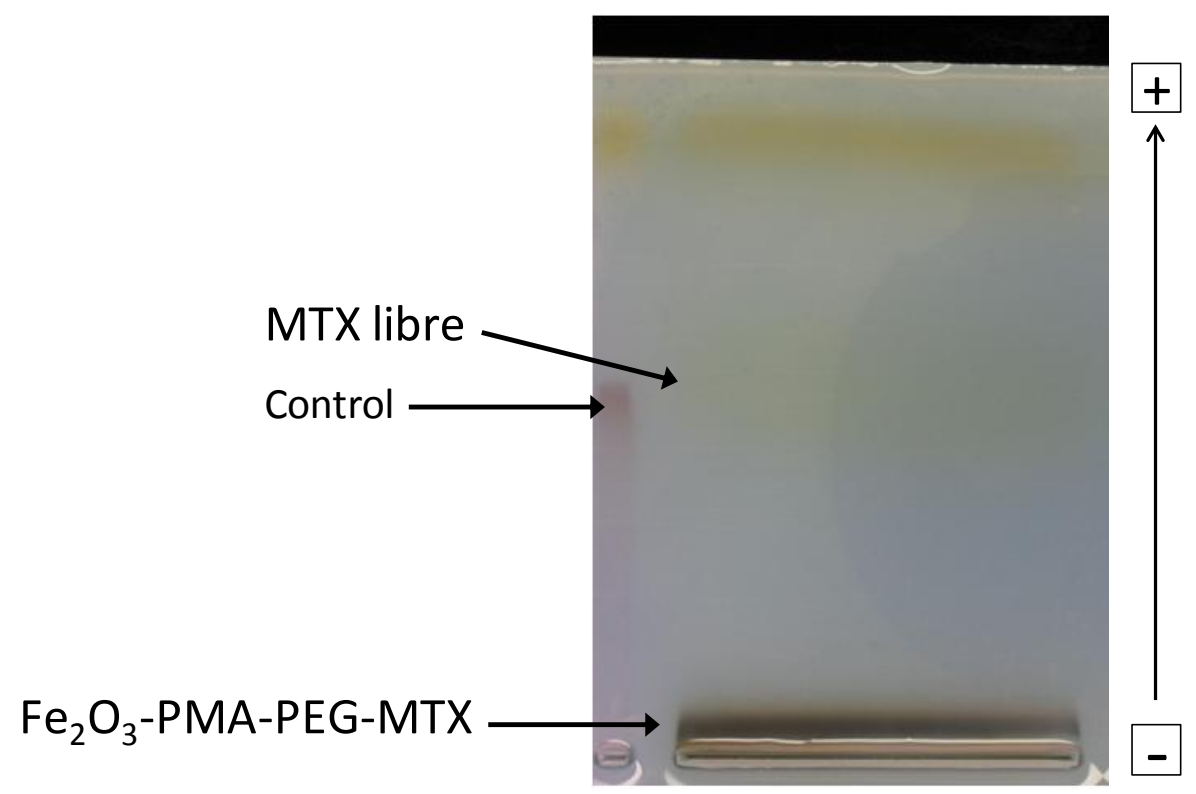

Figura 125. Separación por electroforesis en gel de nanopartículas de óxido de hierro funcionalizadas con MTX.

Las nanopartículas fueron extraídas del gel, reconcentradas y guardadas para su uso en cultivo celular.

\section{Captación por líneas celulares del conjugado $\mathrm{Fe}_{2} \mathrm{O}_{3}-\mathrm{MTX}$}

Como hemos podido ver a lo largo de esta parte, las moléculas bifuncionales de diaminoPEG fueron covalentemente unidas a los grupos carboxilo del polímero en la superficie de las nanopartículas de $\mathrm{Fe}_{2} \mathrm{O}_{3}$, dejando libre uno de los grupos amino terminal para la conjugación de MTX, a través de un enlace amida.

La captación celular del conjugado FeNP-MTX fue evaluada en dos líneas celulares: A375 y HeLa (proporcionadas por Institute of Molecular Biology and Tumor Research Marburg). El procedimiento experimental llevado a cabo constó de las siguientes etapas:

- Las células fueron sembradas en placas LabTek y cultivadas en RPMI 1640 libre de folato.

- Tras 24 horas el medio fue reemplazado por RPMI libre de folato conteniendo las nanopartículas conjugadas con MTX (FeNP-MTX; $0.1 \mathrm{mg} / \mathrm{mL}$ Fe; sólo medio en el caso de los controles).

- Tras 24 horas de incubación en presencia de las nanopartículas, las células se lavaron 5 veces con PBS y se fijaron con formaldehido al 4\% (10 min a temperatura ambiente). Tras lavar con PBS el hierro presente en las muestras fue teñido con 
Prussian Blue. Tras cinco lavados con agua las células fueron teñidas con Nuclear Fast Red y montadas con Dako Fluorescent Mounting Medium.

Las muestras fueron estudiadas por microscopía óptica, mostrándose en la Figura 126 las fotografías bajo luz visible.
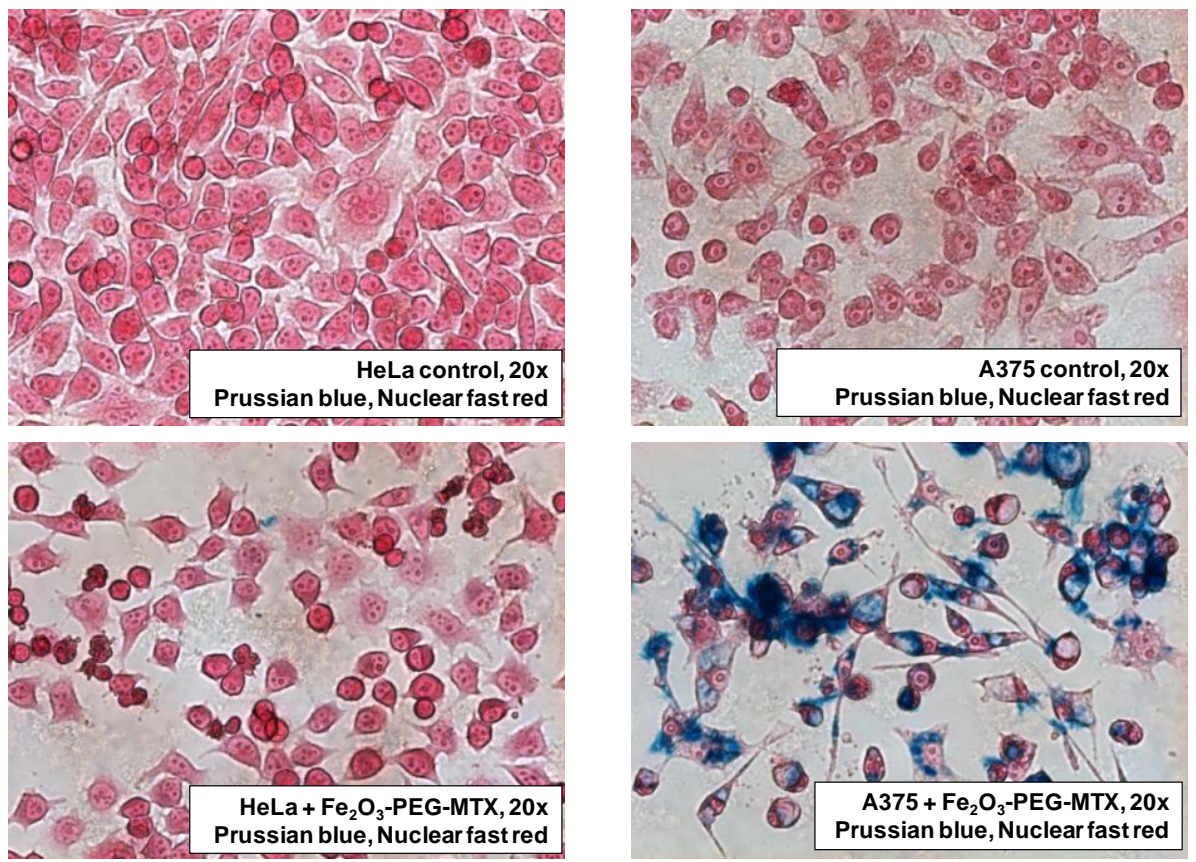

Figura 126. Fotografía bajo luz visible de las poblaciones celulares de A375 y HeLa en ausencia y presencia de FeNP-MTX.

Los experimentos mostraron que la captación de FeNP-MTX por parte de células A375 fue considerablemente mayor que la mostrada por HeLa.

Se llevó a cabo además un ensayo fotométrico para determinar la cantidad de hierro presente en cada muestra. El procedimiento experimental seguido fue el siguiente:

- $\quad$ Se cultivaron las células A375 y HeLa en RPMI 1640 libre de folato.

- A las 24 horas se reemplazó el medio por RPMI libre de folato conteniendo las nanopartículas conjugadas con MTX (FeNP-MTX; $0.1 \mathrm{mg} / \mathrm{mL}$ Fe; sólo medio en el caso de los controles).

- Tras 24 horas de incubación las células fueron lavadas 3 veces con PBS y fueron levantadas $\left(150 \mu \mathrm{L}\right.$ tripsina, $\left.10 \mathrm{~min} 37^{\circ} \mathrm{C}\right)$ y suspendidas en medio.

- $1 \mathrm{~mL}$ de la muestra fue centrifugado (6000rpm, 10min) y el sólido resultante fue sometido a digestión ácida (Triton $\mathrm{X}-100$ y $\mathrm{HCl}$ al $32 \%$ vol.; $14 \mathrm{~h}$ a $60^{\circ} \mathrm{C}$ y $\left.100 \mathrm{rpm}\right)$. Se utilizó hidroxilamina como agente reductor, y el 
hierro fue teñido con fenantrolina ( $3 \mathrm{~h}$, temperatura ambiente). Tras $5 \mathrm{~min}$ de centrifugación a $12000 \mathrm{rpm}$, se midió la absorbancia del sobrenadante a $492 \mathrm{~nm}$ con un lector de placas (Multiskan Platereader).

- $300 \mu \mathrm{L}$ de la suspensión celular se utilizaron para contabilizar el número de células.

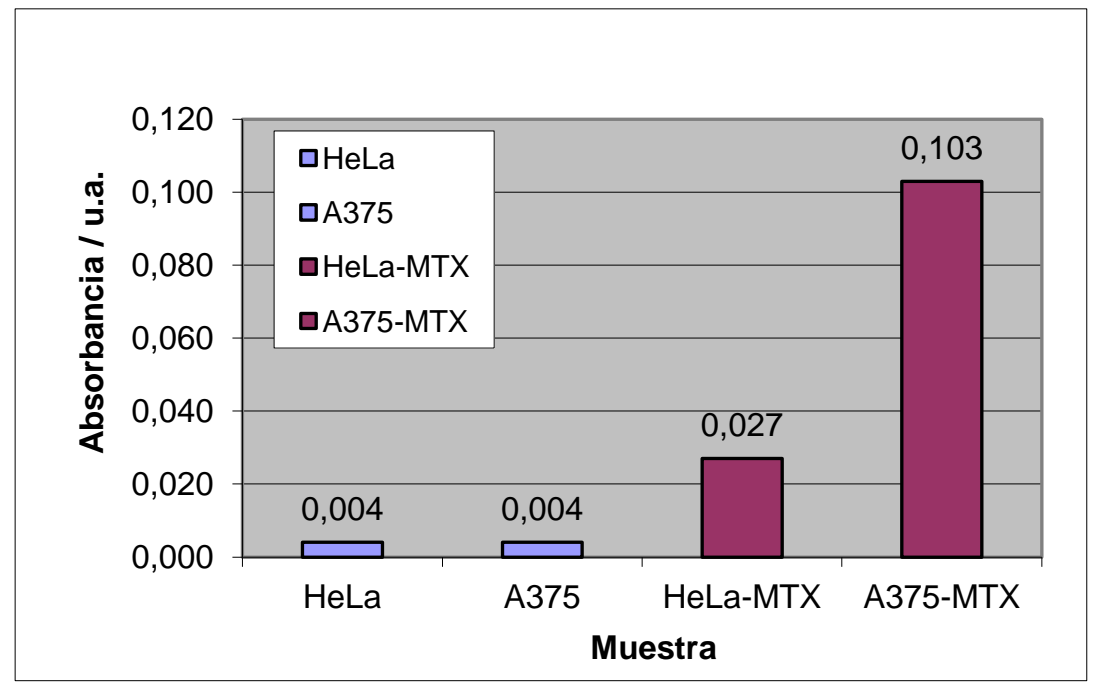

Figura 127. Absorbancia de las muestras tras 24 horas de incubación en ausencia o presencia de FeNP-MTX.

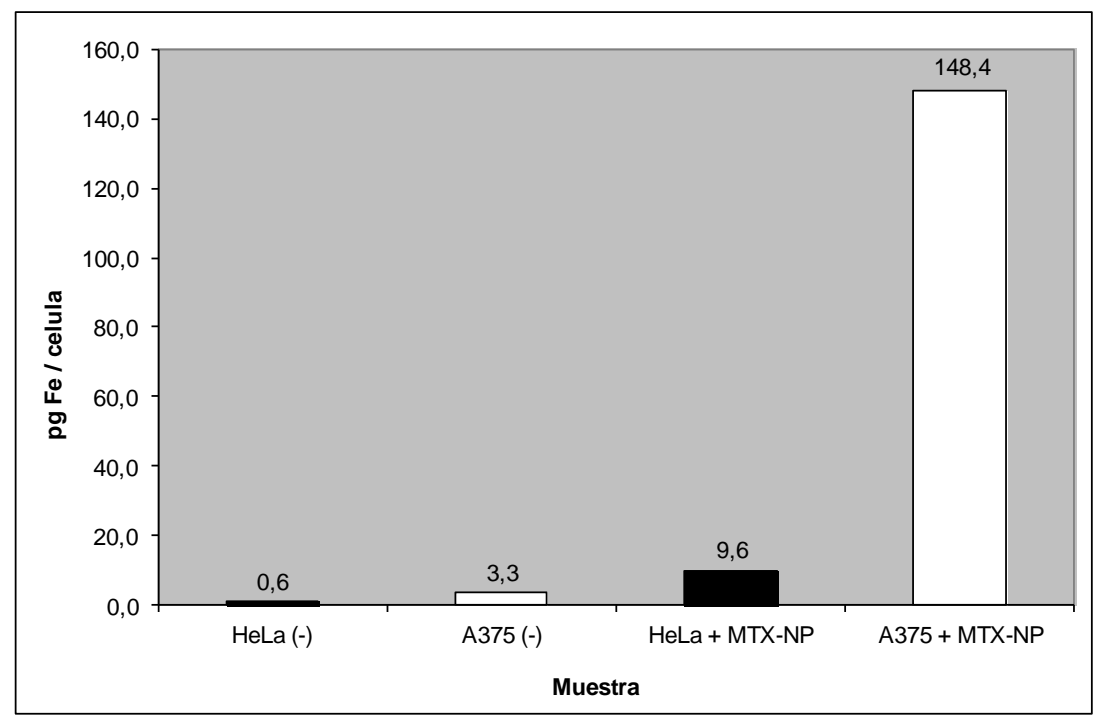

Figura 128. Captación intracelular de FeNP-MTX en A375 y HeLa tras 24 horas de incubación. 
En este estudio se comenzó la evaluación de la capacidad marcadora y la eficacia terapéutica del conjugado FeNP-MTX sobre células A375 y HeLa.

En esta parte experimental se han sintetizado y modificado nanopartículas de óxido de hierro para su conjugación con metotrexato, un fármaco quimioterapéutico que se une a células cancerosas cuyas superficies tienen los receptores del folato sobreexpresados. Estas nanopartículas superparamagnéticas podrán servir como agentes de mejora del contraste en imágenes por resonancia magnética y como transportadores de fármacos en terapias dirigidas.

Se ha desarrollado un conjugado que consiste en un núcleo superparamagnético, recubierto con PEG y con un fármaco inmovilizado covalentemente en la superficie, MTX. Este sistema de transporte de MTX permitirá una monitorización en tiempo real por MRI debido a la naturaleza superparamagnética de la nanopartículas. 

Conclusión general 

Para poder aplicar de modo práctico en Química Analítica, Bioquímica y Biomedicina nanopartículas de diferente naturaleza (semiconductoras, metálicas, etc.), es necesario en primer lugar conocer y dominar los métodos de obtención, bioconjugación y funcionalización de las mismas y profundizar en las variables que afectan a sus propiedades.

En todos estos aspectos se ha trabajado con nanopartículas semiconductoras, nanopartículas de oro y nanopartículas de óxido de hierro, abriendo un amplio campo de posibilidades a su utilización.

Estos son los objetivos que se han alcanzado en el trabajo que se presenta. 

Summary in English 

I would really like to thank my supervisors Dra. María Jesús Almendral Parra and Dr. Ángel Alonso Mateos for the opportunity to work with them and for their guidance throughout my PhD Thesis.

Thanks to Dr. Julio J. Criado Talavera, Dr. Manuel Fuentes García y Dr. Martín Pérez Andrés for their help and for all they have taught me in the last part of the Thesis.

I thank Dr. Miguel Valcárcel Cases for the chance to work within his research group at the Department of Analytical Chemistry at the University of Córdoba for four months. Thanks to the other colleagues for their valuable help and kindness during this stay.

I also thank Dr. Wolfgang Parak for offering me the opportunity to work within his group at the Philipps-Universität of Marburg (Germany) for three months. I am grateful for their support and help at any situation and for the time devoted to me. Thanks to other colleagues for their help and friendship during this stay.

Finally, Dra. Susana Carregal Romero and Dr. Rene Kizek are acknowledged for their reports on this work. 



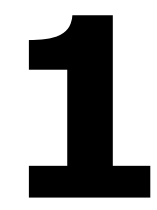

Introduction 

..."When nature finishes producing its own species, man begins using natural things in harmony with this very nature to create an infinity of species"... Jean-Marie Lehn used these words from Leonardo da Vinci to offer his views on the future prospects of supramolecular chemistry ${ }^{1}$. Supramolecular chemistry investigates the principles of nature to produce extraordinary complexes and functional molecular bonds, potentially useful as sensors, catalysts, transportation and other applications in medicine and engineering ${ }^{2}$. Starting with the discovery of the double helix structure of DNA, Biology has grown from being a purely descriptive and phenomenological discipline to a molecular science. All these revolutionary developments have led to merge Biotechnology and Materials Science, giving the undoubted advantage of using biological components to generate new design materials and, conversely, applying these advanced materials and new physicochemical techniques to solve biological problems ${ }^{3}$.

In order to exploit and use all concepts involved in natural systems at the nanoscale, development of Nanoscience and Nanochemistry is crucial. Nanoscience is the

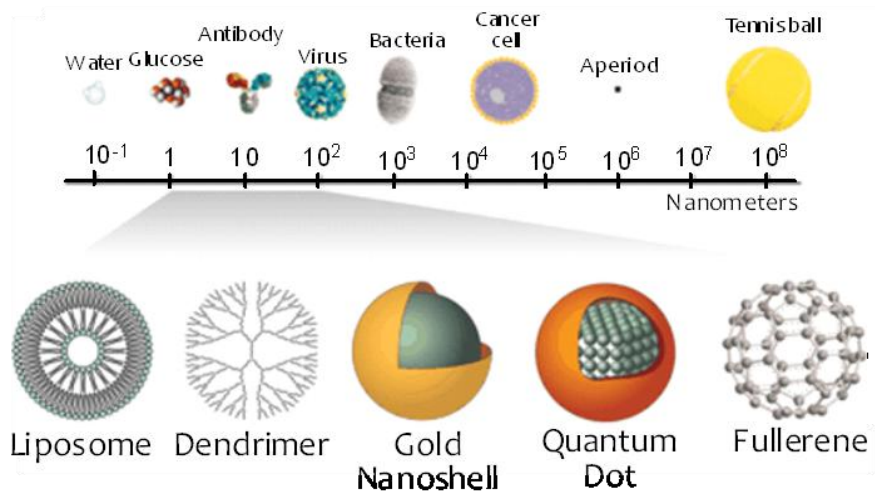

Figure 1. Types and relative sizes of nanoparticles compared with familiar elements. Modified from ${ }^{1}$. science that deals with the analysis and manipulation of materials at atomic or molecular level, where features or physical or chemical properties differ significantly from those presented on a larger scale. In this sense, a nanomaterial is defined as a material consisting of a substance or structure having at least one dimension less than $100 \mathrm{~nm}$. These structures have novel properties and a different behavior from the one exhibited by the bulk material of the same composition. The most notable nanomaterials are schematically represented in Figure 1.

Inorganic Nanoparticles are particularly attractive as building blocks for the construction of large superstructures ${ }^{4,5,6}$ and can be easily prepared from various materials.

\footnotetext{
${ }^{1}$ J.M. Lehn. Supramolecular Chemistry. Concepts and Perspectives. VCH, Weinheim, 1995.

2 J.L. Atwood, J.E.D. Davies, D.D. MacNicol, F. Vögtle. Comprehensive Supramolecular Chemistry. Elsevier, Oxford, 1996.

${ }^{3}$ C.M. Niemeyer. Nanoparticles, Proteins and Nucleic Acids: Biotechnology Meets Materials Science. Angew. Chem. Int. Ed. 40 (2001) 4128-4158.

${ }^{4}$ A.P. Alivisatos. Semiconductor Clusters, Nanocrystals and Quantum Dots. Science 271 (1996) 933-937.

${ }^{5}$ D.L. Feldheim, C.D. Keating. Self-assembly of single electron transistors and related devices. Chem. Soc. Rev. 27 (1998) 1-12.

${ }^{6}$ A.N. Shipway, E. Katz, I. Willner. Nanoparticle Arrays on Surfaces for Electronic, Optical and Sensor Applications. Chem. Phys. Chem. 1 (2000) 19-52.
} 
They have interesting optical, electronic and catalytic properties, which strongly depend on the particle size.

During the last twenty years there has been a growing interest in manufacturing inorganic hybrid materials between nanoparticles and biomolecules. As nanoparticles and biomolecules are in a similar scale length, it seems logical that the combination of biomolecules with nanomaterials could lead to some interesting imitation tools of biomolecules, demonstrating the mechanisms of biological processes ${ }^{7}$. At present, it is easy to control and modify the properties of the nanostructures to achieve their integration with biological systems, for example controlling their size or modifying their surface layer to increase their aqueous solubility or biocompatibility.

Nanotechnology is defined then as the understanding and control of matter at the nanoscale, at dimensions between approximately 1 and 100 nanometers, where unique phenomena enable novel applications. It is not just a new field of science and engineering, but a new way of looking at and studying. The first practical applications of Nanotechnology were to advances in Communications, Engineering, Physics, Chemistry, Biology, Robotics and Medicine. Nanotechnology in Medicine has been used, and is being used, for the delivery of drugs and developing treatments for a variety of diseases and disorders. The increase in the production of nanomaterials is correlated with subsequent advances in these disciplines.

Nanoparticles are used, or being evaluated for use, in many fields, being one of them the field of Proteomics. Nanotechnology in Proteomics has emerged as a promising technological platform for the challenging tasks of studying complex proteomes. Moreover, nanoparticles are a new generation of sensors playing an important role in biomarker discovery.

Biomarkers based on interactions with DNA form an important group in the study of, and advances in, the field of cancer and other diseases, and also in the development of treatments with different drugs. Among them, those with fluorescence characteristics are very promising, such that methods aimed at developing them and perfecting them are currently of extraordinary interest. One important field for the use of biomarkers in studies addressing anti-cancer compounds has been opened by the advent of new fluorophores called Quantum dots (QDs). QDs are semiconductor nanocrystals with a size of between 1 and 10 nanometers that are formed by elements of groups II-VI or III-V of the periodic table and that are able to surpass the limits of organic dyes.

\footnotetext{
${ }^{7}$ E. Katz, I. Willner. Integrated nanoparticle-biomolecule hybrid systems: synthesis, properties and applications. Angew. Chem. Int. Ed. 33 (2004) 6042-6108. 
Their main advantages in this field are as follows: the QD emission spectrum can be modified over a broad range by changing the size and composition of the core, which makes them highly amenable to biological detection.

Quantum Dot Size

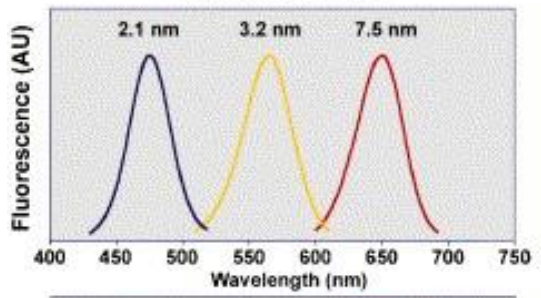

(A)

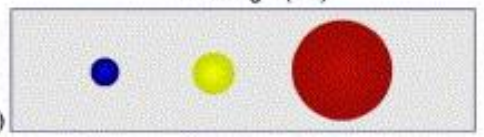

Quantum Dot Composition

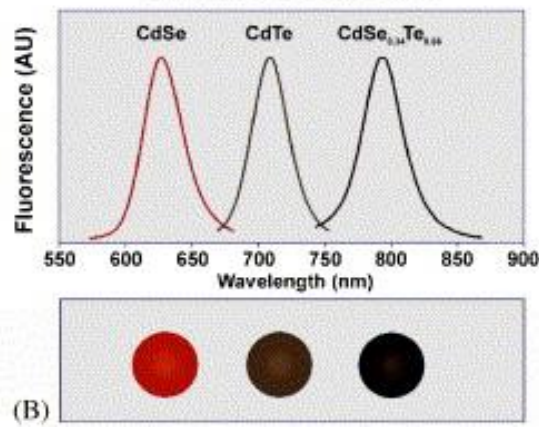

Figure 2. Effect on the emission spectra of $(A)$ the relative size of nanoparticles of constant composition and (B) the composition of the core while keeping the nanoparticle size constant $\left(5 \mathrm{~nm}\right.$ diameter). ${ }^{8}$

Their broad excitation and narrow emission spectra help to prevent spectral overlapping, thus increasing the possibility of distinguishing multiple fluorophores simultaneously. They also facilitate the use of a single excitation wavelength for QDs of different colours. These properties afford them an advantage over organic dyes, which have narrow excitation and broad emission spectra. The most important aspect to be considered, however, is their capacity for bioconjugation, allowing them to bind to proteins and other biomolecules containing primary amines and carboxylic acid as functional groups, as well as many other substances.

\footnotetext{
${ }^{8}$ R.E. Bailey, S.M. Nie. Alloyed Semiconductor Quantum Dots: Tuning the Optical Properties without Changing the Particle Size.
} J. Am. Chem. Soc. 125 (2003) 7100-7106. 
a Bifunctional linkage

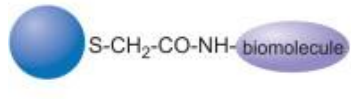

b Hydrophobic attraction

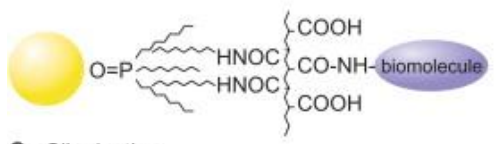

C Silanization

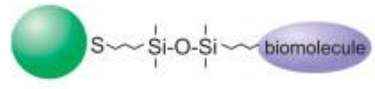

d Electrostatic attraction

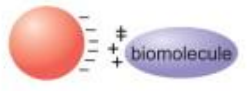

e Nanobeads

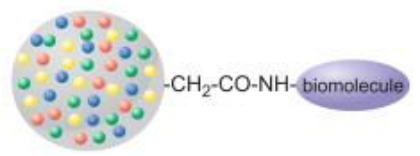

Figure 3. A schematic illustrating different approaches of conjugation of QDs to biomolecules: (a) Use of a bifunctional ligand such as mercaptoacetic acid for linking QDs to biomolecules. (b) TOPO-capped QDs bound to a modified acrylic acid polymer by hydrophobic forces. (c) QD solubilisation and bioconjugation using a mercaptosilane compound. (d) Positively charged biomolecules linked to negatively charged QDs by electrostatic attraction. (e) Incorporation of QDs into microbeads and nanobeads. ${ }^{9}$

There is a broad field of enquiry with many perspectives for the future in the study of QDs for biological applications. Although important advances have been made in certain aspects, there are many weak points as regards the procedures used for the synthesis of these nanoparticles, and their behaviour in different media must also receive more concerted attention. The QDs most widely used as biomarkers, such as CdS, are in most cases synthesized in organic phase, using high-boiling point solvents. The synthesis procedures in aqueous medium are an attractive alternative to the synthesis of QDs in organic medium and are now an active area of interest. Aqueous synthesis shows good reproducibility, low toxicity, low cost and, in particular, the products prepared in aqueous medium have excellent water solubility, stability and biological compatibility. The need to shed more light on the study of their structure and chemical behaviour is crucial if we are to optimize the bioconjugation processes involved, being one of the objectives of this work.

\footnotetext{
${ }^{9}$ T. Jamieson, R. Bakhshi, D. Petrova, R. Pocock, M. Imani, A.M. Seifalian. Biological applications of quantum dots. Biomaterials 28 (2007) 4717-4732. 
Gold nanoparticles (AuNPs) have recently emerged as an attractive candidate for delivery of small drug molecules or large biomolecules (proteins, DNA or RNA) into their targets ${ }^{10}$. Their chemical and physical properties have been exploited for transporting and unloading pharmaceuticals and in photothermal
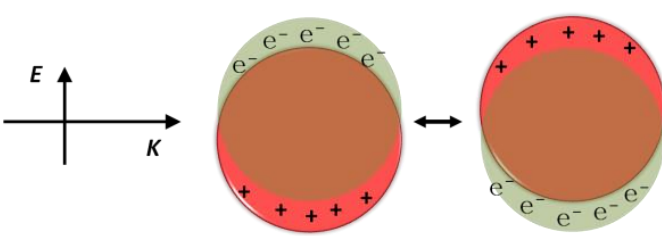

Figure 4. Schematic illustration of surface plasmon resonance in plasmonic nanoparticles. Modified from ${ }^{1}$. therapeutic contexts. The gold core is inert, non-toxic and biocompatible. They can be easily synthesized in a monodisperse way and core sizes ranging from $1 \mathrm{~nm}$ to $150 \mathrm{~nm}$. They have strong and tunable optical absorption. They are easy to modify to endow them with different functionalities, generally through thiol linkages, binding a wide range of organic molecules ${ }^{11,12,13}$. Additionally, AuNPs have unique optical properties, such as the characteristic excitation bands in the visible region, owing to the surface plasmon resonance. This property allows the use of AuNPs in many medical, biological and pharmaceutical applications.

Currently, AuNPs are attractive candidates for the delivery of a useful load to a particular target site. These useful loads range from being small drug molecules to large

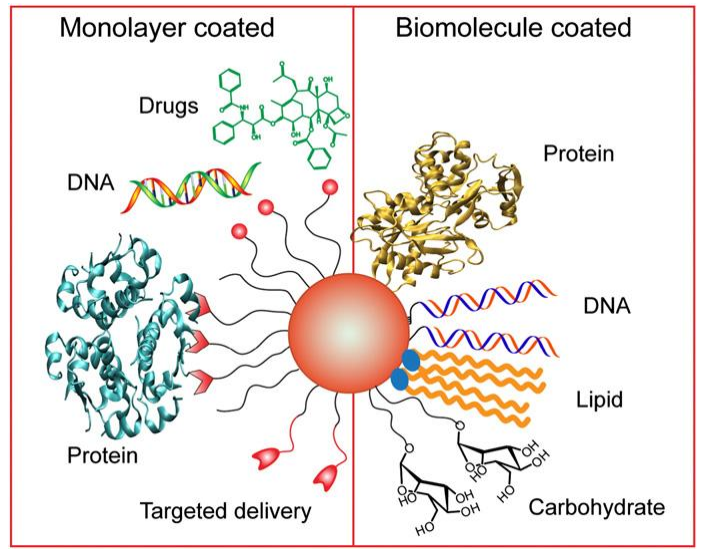

biomolecules, such as proteins, DNA and RNA. The efficient release of these therapeutic agents at the appropriate site is a prerequisite for effective therapy and is the basis of directed therapies, mainly in the most advanced fields of medicine.

Figure 5. Schematic presentation of the two AuNP surface structures commonly employed in delivery applications. From ${ }^{1}$.

\footnotetext{
${ }^{10}$ S. Rana, A. Bajaj, R. Mout, V. Rotello. Monolayer coated gold nanoparticles for delivery applications. Advanced Drug Delivery Reviews 64 (2012) 200-216.

${ }^{11}$ S. Dhar, W.L. Daniel, D.A. Giljohann, C.A. Mirkin, S.J. Lippard. Polyvalent oligonucleotide gold nanoparticle conjugates as delivery vehicles for platinum (IV) washeads. J. Am. Chem. Soc. 131 (2009) 14652-14653.

12 J.R. Hwu, Y.S. Lin, T. Josephrajan, M.H. Hsu, F.Y. Cheng, C.S. Yeh, W.C. Su, D.B. Shieh. Targeted paclitaxel by conjugation to iron oxide and gold nanoparticles. J. Am. Chem. Soc. 131 (2008) 66-68.

${ }^{13}$ E.C. Dreaden, S.C. Mwakwari, Q.H. Sodji, A.K. Oyelere, M.A, El-Sayed. Tamoxifen poly(ethylene glycol) thiol gold nanoparticle conjugates: enhanced potency and selective delivery for breast cancer treatment. Bioconjugate Chem. 20 (2009) 2247-2253.
} 



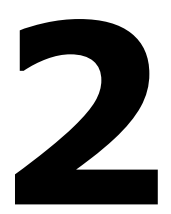

General aims 

The general aim of this Doctoral Thesis is to make new contributions to the role of nanoparticles in Chemistry. This general purpose focuses on the three specific objectives listed below:

$>$ To contribute to the knowledge of Quantum dots, develop new methods for their synthesis, and study their characteristics and particular phenomena, to encourage and facilitate their use as analytical tools.

This first section focuses on the spectroscopic study of CdS semiconductor nanoparticles, in order to improve the methods of synthesis in aqueous medium and go in depth in the knowledge of their behavior under different conditions.

$>$ The second section focuses on the use of gold nanoparticles as delivery vehicles. Gold nanoparticles (AuNPs) provide attractive delivery system for efficient transport of a wide variety of molecules, mainly due to the non-toxicity and biocompatibility of the gold core.

In this part of the work, the use of AuNPs as carriers for a new bile acid cisplatin derivative is exposed, in order to explore its potencial cytotoxic activity in vitro when conjugated with the nanoparticles.

$>$ The objective of the third part is to provide an overview about the use of nanoparticles as tags for target molecules and as novel sensors in biomarker discovery. This chapter describes the development of a new discipline, Nanoproteomics, arising from the coupling of Proteomics and Nanotechnology.

Finally, it is important to note that this thesis is included within the powerful research field of Nanoscience and Nanotechnology, being the first Doctoral Thesis on nanoparticles performed at the Department of Analytical Chemistry, Nutrition and Food Science, at the University of Salamanca, fact that gives a significant degree of innovation. 



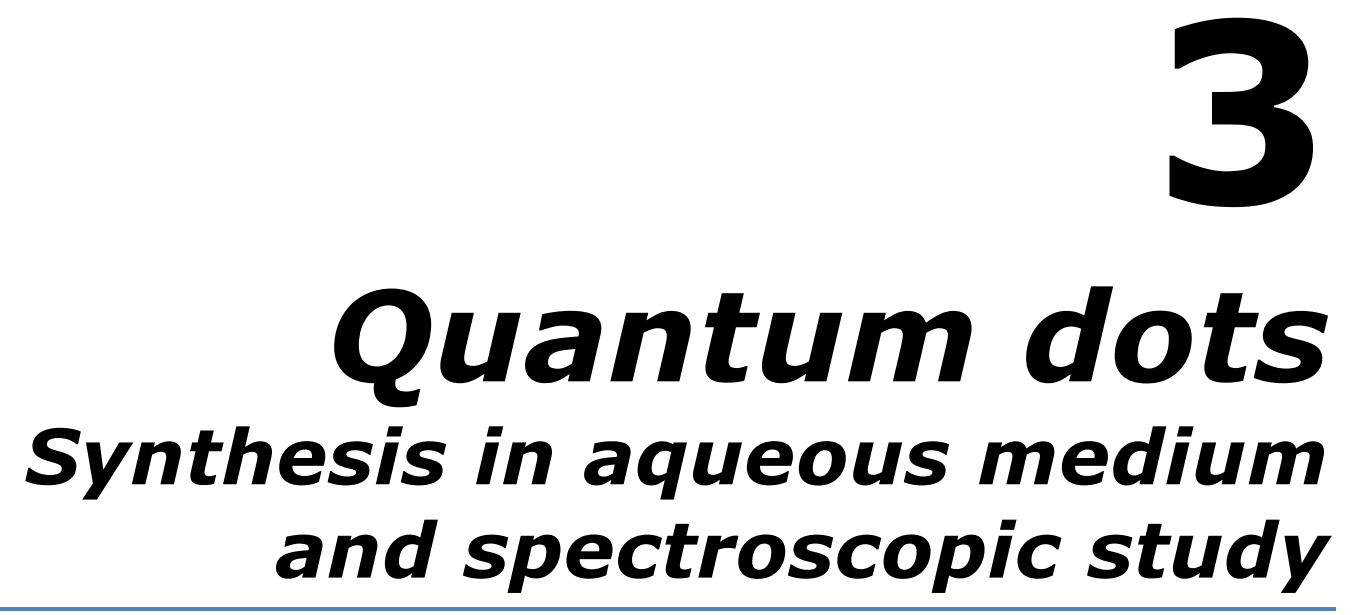



The aim of this chapter is to develop a new process for the preparation of Quantum dots in aqueous medium, in the presence of mercaptoacetic acid (MAA) as a capping reagent, under normal pressure and room temperature.

The influence of several experimental variables, including temperature, $\mathrm{pH}$, the $\mathrm{Cd} / \mathrm{S}$ ratio and the Cd/MAA ratio, on the optical properties of the QDs obtained was studied systematically. The experimental results indicate that these variables play an important role in determining the size and state of the surface of the nanoparticles, and hence their luminescent properties and temporal stability. Aspects like nanocrystal nucleation and growth during the synthesis are important to achieve the best conditions for the synthesis of high quality nanoparticles.

A deep study of the physical properties of the nanoparticles and their behavior in solution under different conditions will facilitate their use as biomarkers and in other applications of analytical interest. 
At room temperature, the mixture of aqueous solutions of $\mathrm{CdCl}_{2}$ and $\mathrm{Na}_{2} \mathrm{~S}$, in the presence of mercaptoacetic acid as a dispersant leads to the formation of a solution with a $\mathrm{pH}=11$, oversaturated in $\mathrm{CdS}$, in which -after stirring- first nuclei and then quantum-sized $(<10 \mathrm{~nm})$ particles of the $\mathrm{CdS}$ semiconductor are obtained.

The QDs obtained, subjected to X-ray diffraction studies, were confirmed to be nanoparticles of $\beta-C d S$, with a cubic mcrystalline network, no other crystalline phases being observed in their structure. Quantum size $(<10 \mathrm{~nm})$ was confirmed not only from the absorption spectra but also by Transmission Electron Microscopy.

At any given moment, the rate of nucleation and the growth rate govern nanoparticle size and also the state of their surface, although the importance of the excess of $\mathrm{Cd}^{2+}$ over $\mathrm{S}^{2-}$ was observed experimentally.

The size of the nanoparticles, their evolution with time, the state of their surface, and their stability depend on many variables, studied in depth in the present work. The mean diameter of QDs depends on the experimental conditions used to synthesize them. In the original solutions where they were synthesized, they were live particles that continued to evolve with time, not only their size but also the state of their surface and their stability as a dispersed phase being modified.

Regarding the fluorescence of the CdS QDs obtained in aqueous medium, both the emission wavelength (greenish blue light to orange light) and the maximum intensity were found to depend on the mean size of the QDs and on the state of their surface. Concerning this second characteristic, the presence of a nanoshell of $\mathrm{Cd}(\mathrm{OH})_{2}$ deposited on the nanoparticle seems to be very important, favouring the process of electronic excitation up to a maximum value of the nanoshell/nanoparticle size ratio, above which the processes of the emission of nondispersive light increases. This optimum size ratio depends on the experimental conditions employed and is reached at a given and variable time of development.

The fluorescence of the CdS QDs obtained in aqueous medium is sufficiently longlasting for them to be used as tracers of both inorganic and organic species that interact with them. 


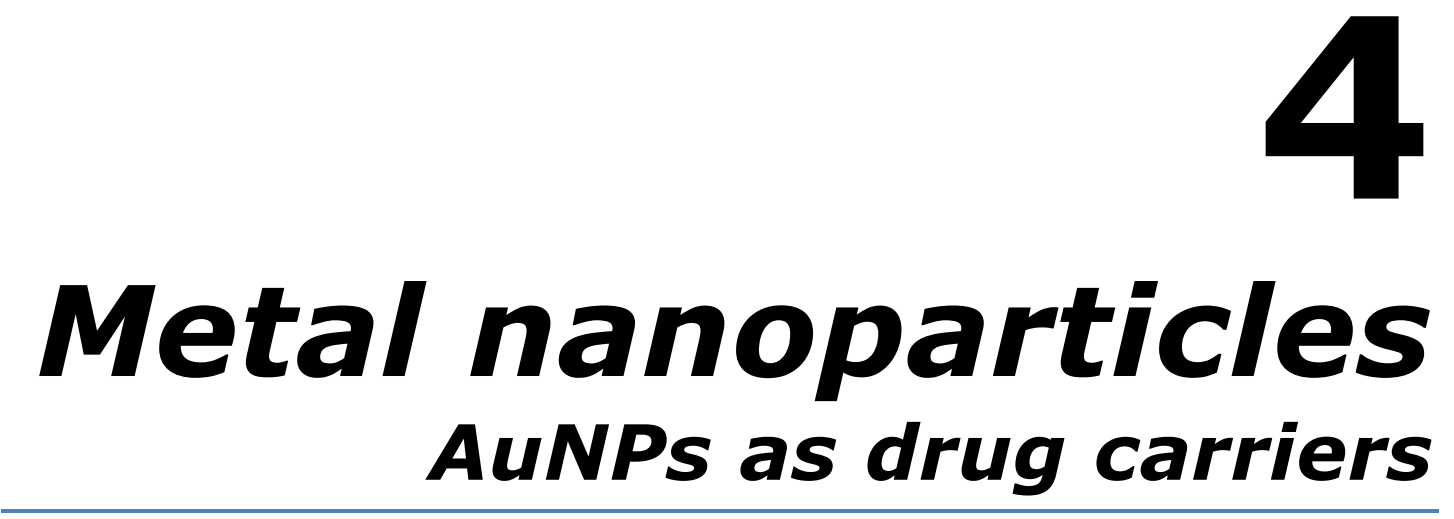



The aim of this chapter is to explore the potencial cytotoxic activity of Bile-acid cisplatin derivatives like bisursodeoxycholate(ethylenediamine)platinum(II), PtU2, when conjugated with gold nanoparticles. These derivatives have potential cytotoxic activity and reduced toxicity, owing to their lower lability and their amphipathic character, making them a suitable alternative for CDDP, as anti-tumoral drugs.

We analyzed the intracellular delivery ability of these compounds after conjugation with 20-nm gold nanoparticles (PtU2-AuNPs) in the MG63 (osteosarcoma) cell line, a model for one of the most untreatable and painful malignant tumors whose standard treatment requires radical surgery and neoadjuvant therapy. 
It could be concluded that under the same in vitro conditions, bile-acid derivatives attached to AuNPs are more efficient than the platinum compound alone in terms of their cytotoxic activity, e.g. as anticancer agents. Such increased cytotoxic activity is specific for the PtU2-AuNPs complex, since no cytotoxic activity was detected when the cells were incubated with the AuNPs alone in volumes of nanoparticle solution equivalent to those used with the PtU2-AuNPs complexes for a drug concentration between 0 and $30 \mu \mathrm{M}$.

Same platinum uptake after incubation with PtU2 and PtU2-AuNPs-derivatives is associated with a higher cytotoxic activity in case of the platinum-gold nanoparticle conjugate, the overall $\mathrm{IC}_{50}$ of PtU2 being reduced more than 10 fold for these new conjugates.

The precise mechanisms by which the presence of AuNPs increases the cytotoxic activity of the drug remain elusive and require further investigations. 


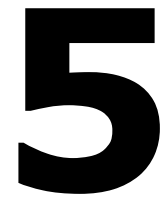

Nanoparticles in proteomics 

Protein microarrays are a platform for parallel and simultaneous analysis of proteinprotein interactions and protein profiling. Together with the advances in microarray technologies, increasingly sensitive and reliable detection methodologies are being currently developed. Such protein detection systems have progressively undergone a relevant transition from label-based to more sensitive label-free technologies, which are extremely useful to study the interactome and functions of large amounts of proteins on demand.

Overall, label-based systems are mainly focused on the use of specific tags for target molecules as conventional fluorescent dyes and radioisotopes, among others. More recently, other substances are being proposed, including inorganic quantum dots (QDs), gold nanoparticles (NPs), Raman dye-labeled carbon nanotubes or silica NPs. On the other hand, label-free detection techniques include surface plasmon resonance (SPR), carbon nanotubes, cantilever, etc.

The successful coupling of nanotechnology with proteomics over the last few years has led to the development of nanoproteomics, which provide a robust analytical platform for real-time and sensitive detection of low-abundande proteins.

A number of nanotechniques have been lately used for diverse applications such as biomarker discovery, label-free protein detection, study of protein interactions and printing of protein microarrays. Among all nanomaterials, Quantum dots, gold nanoparticles and carbon nanotubes have demonstrated potential to overcome the challenges of sensitivity faced by conventional proteomics for biomarker detection. However, many efforts are still required to explore the toxicity and biocompatibility of nanotechniques to ensure their safety for biological applications. 

General conclusions 

According to the objectives, the overall conclusions of this work are:

A Although QDs have been extensively described and exploited until now, we have developed a new method for the aqueous synthesis of CdS QDs of high stability over time.

The work has required a rigorous study of the obtained nanoparticles to find appropriate sizes, stabilities and fluorescence intensities for their future use as biomarkers.

$>$ We have succeeded in enhancing the cytotoxic activity of the cisplatin derivative compound [bisursodeoxycholate(ethylenediamine)platinum(II)] after conjugation to gold nanoparticles. It could be concluded that under the same in vitro conditions, our bile-acid derivative attached to AuNPs is more efficient than the platinum compound alone in terms of their cytotoxic activity.

In the third part of the work we have shown the state-of-the-art of a new discipline, born of the union of Proteomics and Nanotechnology. The last challenge in proteomics is to figure out, at high density and massively, relevant biological processes such as tumors. Nowadays, nanotechnology will anticipate a significant development that will make nanoproteomics a more robust, sensitive, reliable and biocompatible field. 

Anexos Appendix 

Anexo I: Artículos publicados

Appendix I: Published articles 



\title{
Procedures for Controlling the Size, Structure and Optical Properties of CdS Quantum Dots during Synthesis in Aqueous Solution
}

\author{
María-Jesús Almendral-Parra • Ángel Alonso-Mateos • \\ Sara Sánchez-Paradinas • Juán F. Boyero-Benito • \\ Emilio Rodríguez-Fernández • Julio J. Criado-Talavera
}

Received: 13 May 2011 / Accepted: 28 July 2011

(C) Springer Science+Business Media, LLC 2011

\begin{abstract}
We report an easy approach for the synthesis of CdS Quantum Dots (CdS QDs) with high luminescence and temporal stability through the reaction of $\mathrm{Cd}^{2+}$ and $\mathrm{S}^{2-}$ in the presence of mercaptoacetic acid (MAA) as a capping reagent in aqueous medium, under normal pressure and room temperature. The influence of several experimental variables, including temperature, $\mathrm{pH}$, the $\mathrm{Cd} / \mathrm{S}$ ratio and the $\mathrm{Cd} / \mathrm{MAA}$ ratio, on the optical properties of the QDs obtained was studied systematically. The experimental results indicate that these variables play an important role in determining the size and state of the surface of the nanoparticles, and hence their luminescent properties and temporal stability. The general aspects of nanocrystal nucleation and growth in the synthesis of nanocrystals were studied. The best conditions for the synthesis of nanoparticles of high quality are also reported. The CdS nanocrystals obtained exhibited a narrow PL band, with reproducible room-temperature quantum yields.
\end{abstract}

Keywords CdS quantum dots, Nanoparticles · Synthesis . Quantum yield·Photoluminescence enhancement

M.-J. Almendral-Parra $(\varangle) \cdot$ Á. Alonso-Mateos ·

S. Sánchez-Paradinas · J. F. Boyero-Benito

Department of Analytical Chemistry,

University of Salamanca,

37008 Salamanca, Spain

e-mail: almendral@usal.es

E. Rodríguez-Fernández $\cdot$ J. J. Criado-Talavera

Department of Inorganic Chemistry,

University of Salamanca,

37008 Salamanca, Spain

\section{Introduction}

Semiconductor Quantum Dots (QDs) are of outstanding importance owing to their extraordinary optical and electronic properties [1, 2]. Their composition and small size afford these dots extraordinary optical properties (high emission quantum yields, size-tuneable emission profiles, and narrow spectral bands) [3] that can be readily controlled by changing the size or composition of the dots in the synthesis procedure [4-7]. In addition, they possess excellent photostability (many orders of magnitude larger than conventional organic fluorophores) [8] and long fluorescence lifetimes ( $>10 \mathrm{~ns})$.

Alivisatos and Nie simultaneously demonstrated that semiconductor QDs can be rendered water-soluble and can be conjugated with biological molecules. Those prepared at high temperatures do not have intrinsic aqueous solubility and hence their transfer to the aqueous phase requires the functionalization of their surface with certain ligands, which in turn serve as anchorage sites for biomolecules [9]. Thus, a broad range of methods for bioconjugating colloidal quantum dots has been developed [10-15] in diverse areas of application: cell labelling [16], cell tracking $[17,18]$, in vivo imaging [19], DNA detection [20, 21], and multiplexed beads [22].

Among the different semiconductor nanocrystals, CdS QDs have been widely studied owing to their sizedependent photoluminescence [23], the advances gained in the procedures used to prepare them [24-31], and their important fields of application in different areas such as nanomedicine, optoelectronics, solar energy, etc. With proper surface modification, core-shell CdS nanoparticles can be obtained with enhanced luminescence properties. 
Despite the above, the lack of suitable synthesis methods for the production of the desired amount of high-quality QDs remained bottlenecked in this field [32]. Soumitra et al. [33] have shown that the nature of the solvent and the temperature and source of the CdS used play an important role in determining the morphology and size of $\mathrm{CdS}$ nanocrystals.

The synthesis in solution of these nanocrystals normally uses organic stabilizers to cover the surface atoms of the nanoparticles in order to control their rate of growth, but this method has some limitations because the QDs thus prepared cannot be used in biological applications owing to their hydrophobic nature. They must therefore be linked to hydrophilic molecules to render them water-soluble and hence biocompatible.

Parallel to the success in organic synthesis pathways, some alternatives have been developed for the preparation of CdS QDs using aqueous media [34]. In comparison with their synthesis in non-aqueous media, aqueous synthesis is more reproducible, less costly and the samples prepared in this way are soluble in water and, at the same time, biocompatible.

As may be seen from the above, there is currently great interest in proposing new advances in procedures aimed at the synthesis of high-quality CdS QDs. To date, most methods using aqueous media have resulted in lowquantum-yield products $[35,36]$. Also, in many such procedures, there are gaps in in-depth studies of the characteristics of the nanoparticles obtained, the basis of later processes of covering and functionalization, and in the importance afforded to the effect of different variables involved in the process as regards their maintenance with time (an important aim for their manufacture and commercialization). Thus, in view of the broad sphere of possible applications this field is of great importance and involves multiple interests.

Here we report an easy preparation of water-soluble and high-quantum-yield $\mathrm{CdS}$ quantum dots in aqueous solution at room temperature. The mean diameter of the QDs synthesized depended on the experimental conditions under which they were collected and on the time elapsed since their synthesis. In the original solutions where they were synthesized they were live particles; they continued to evolve over time, altering not only their size but also the state of their surface and their stability as a dispersed phase. It was observed that their formation at low temperatures $\left(4^{\circ} \mathrm{C}\right)$ showed slow kinetics, such that the size of the QDs remained almost constant at $2 \mathrm{~nm}$ for 2 months.

The intensity of fluorescence emission of QDs synthesized in aqueous medium depended on their size and the state of their surface. Regarding the latter characteristic, it appears that the presence of a nanocortex of $\mathrm{Cd}(\mathrm{OH})_{2}$ on the surface was very important, as reported in the experimental part. This fluorescence intensity is sufficiently long-lasting for the CQDs obtained to be used as tracers of species, both organic and inorganic, interacting with them. Quantum efficiency values higher than those reported in the literature for different synthesis procedures, in both aqueous and organic medium, were obtained

The QDs obtained were characterized by absorption spectrophotometry, fluorescence, X-ray and transmission electron microscopy studies, controlling all the variables affecting their size and properties in aqueous solution with a view to using them as biological markers and in other applications of interest. The results obtained allowed us to elucidate behavioral aspects in different media that could be attributed to the QDs themselves or other concurrent processes. In aqueous medium, it is possible to make CdS QDs of interest for any given specific application, follow their evolution under different conditions, know their manner of degradation in order to eliminate its or enhance it, depending on the aims pursued, and tailor-mold them to each specific bioconjugation application. All these aspects are crucial in the processes of applying QDs, among others in the rapidly emerging field of nanomedicine.

\section{Experimental}

Reagents and Solutions

All chemicals used were of analytical grade and were prepared with ultra-high quality deionized water.

Mercaptoacetic acid, $\mathrm{HSCH}_{2} \mathrm{COOH}, 98 \%$ (Acros Organics). Aqueous solutions of the following reagents, prepared by direct weighing of the species indicated and dissolution in water until the desired concentration was reached: $\mathrm{CdCl}_{2},\left(99 \%\right.$, Acros Organics), $\mathrm{Na}_{2} \mathrm{~S},(90 \%$, Acros Organics), $\mathrm{NaOH}$ (Scharlau), sodium hexametaphosphate (HMP), $0.022 \mathrm{M} \mathrm{Na}-\left(\mathrm{NaPO}_{3}\right)_{\mathrm{n}}-\mathrm{ONa}$ (Scharlau). Polyethylenimine (PEI), 50\%, $\mathrm{M}_{\mathrm{w}} 1300$ (Sigma-Aldrich). Quinine sulphate, $10^{-5} \mathrm{M}$ solution in $0.5 \mathrm{M} \mathrm{H}_{2} \mathrm{SO}_{4}$.

Instrumentation

Fluorescence spectra were measured using a Shimadzu Model RF-5000 spectrofluorophotometer, with a Model DR-15 controller unit and a $150 \mathrm{~W}$ Xenon lamp as a light source. The UV-visible absorption measurements of the samples were performed on a Shimadzu UV/Vis-160 spectrophotometer. The $\mathrm{pH}$ value of the solutions was measured with a Crison 501 pHmeter. Transmission electron microscopy (TEM) was performed on a ZEISS EM-900 device. X-ray powder diffraction (XRD) patterns were recorded on a Siemens D500 X-ray powder diffractometer equipped with graphite monochromatized high- 
intensity $\mathrm{Cu}-\mathrm{K} \alpha$ radiation $(\lambda=154.050 \mathrm{pm})$. The refraction index of the samples was determined with an Abbé refractometer.

Synthesis of CdS Quantum Dots in Aqueous Medium

The general procedure for the synthesis of CdS nanoparticles in aqueous medium was as follows: The starting volume was always $100 \mathrm{~mL}$ of a solution containing the $\mathrm{Cd}^{2+}$ ions at the desired concentration, prepared by weighing $\mathrm{CdCl}_{2}$ dissolved in distilled water. This mixture was placed in a round three-necked topaz flask subjected to stirring, and the desired microliter amounts of a solution of $1.14 \mathrm{M}$ mercaptoacetic acid were added. The $\mathrm{pH}$ of the resulting solution was in the 2.8-3.0 range (depending on the amount of acid added, $\mathrm{K}_{1}=2.1 \times 10^{-4}$ ).

The $\mathrm{pH}$ of the solution was adjusted with $1 \mathrm{M} \mathrm{NaOH}$. At that time, nitrogen was bubbled through the solution, maintaining this throughout the experiment, and temperature was adjusted. Under stirring conditions, $50 \mathrm{~mL}$ of $\mathrm{Na}_{2} \mathrm{~S}$ was added at the desired concentration. The time of addition of the sulphide ranged between 8 and $10 \mathrm{~min}$, considering this moment as $t=0$ for the kinetic studies. The final $\mathrm{pH}$ was checked to control possible modifications. After slow addition of $\mathrm{Na}_{2} \mathrm{~S}$ no appreciable change in the solution was observed, whereas after $4.5 \mathrm{~h}$ the solution, apparently transparent, changed to a green colour, indicating that the process of nanoparticle formation, under the conditions used, exhibited slow kinetics even though the conditions were supersaturating. The MAA bound to the $\mathrm{CdS}$ nuclei prevents their growth, the nucleation rate predominating over the growth rate.

Periodically, the absorption spectra and the fluorescence excitation and emission spectra were recorded.

\section{Results and Discussion}

\section{Absorption Spectrum}

Figure 1 shows the absorption spectrum of the yellowishgreen solution at $4.5 \mathrm{~h}$ after reagent addition.

The appearance of a band at $370 \mathrm{~nm}$ was due to the presence of $\mathrm{CdS}$ nanoparticles in which the electrons were confined quantically, being able to absorb electromagnetic waves of a given energy to carry out the electronic transitions through the empty bands of the semiconductor.

In the synthesis of QDs, the maximum of the absorption band is seen to better defined as their amount in solution increases and the distribution of the particle size around its mean size decreases. The value of the absorbance at $370 \mathrm{~nm}, A=0.732$, is proportional, at that wavelength, to the amount or concentration of CdS nanoparticles, although

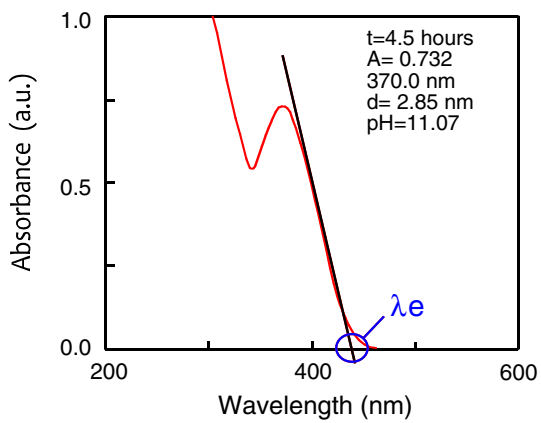

Fig. 1 Absorption spectra of the CdS QDs at $4.5 \mathrm{~h}$ after the collection process

the absorption coefficient depends on particle diameter. For wavelengths shorter than 360-370 nm, a non-specific band was seen, due to more energetic electronic transitions.

It is possible to obtain the mean value of the diameter of the QDs without using diffractograms by applying the HENGLEIN equation [37, 38], which relates it to the extrapolated wavelength, $\lambda_{\mathrm{e}}$, and is obtained by tracing the tangent to the absorption curve on the ascending segment and is clearly differentiated from the zero absorbance value (Fig. 1):

$2 R=d=\frac{0.1}{(0.138-0.0002345 \lambda \mathrm{e})}$

In the present case the value of $d$ obtained was $2.85 \mathrm{~nm}$.

\section{Fluorescence Spectra}

Figure 2 shows the excitation spectra of the CdS QDs at $4.5 \mathrm{~h}$ after synthesizing them at the optimum $\lambda_{\mathrm{em}}(528 \mathrm{~nm})$. An excitation band, not excessively broad, with a maximum at $392 \mathrm{~nm}$ was obtained.

Once the optimum $\lambda$ ex, determined experimentally at $392 \mathrm{~nm}$, had been obtained, the emission spectrum was recorded (Fig. 2); this determines the maximum emission intensity at $521.6 \mathrm{~nm}$ (optimum $\lambda \mathrm{em}$ ). As seen in ensuing experiments, the emission wavelength depended on nanoparticle diameter, on the intensity of the emission process, and on the state of the NP surface.

The completely symmetrical shape of the emission spectrum indicated that the losses of energy due to nonradiant processes were independent of the emission wavelength in that range, showing that the surface of the QDs was very homogeneous, with no large imperfections, at least during this period of the life-time of the NP.

The width of the emission spectrum at half the maximum value of the intensity of fluorescence emission (to If $=244$ u.f.), called $\Delta$, had a value of $104 \mathrm{~nm}$. This value is indicative of the greater or lesser size distribution of the NPs around the mean 

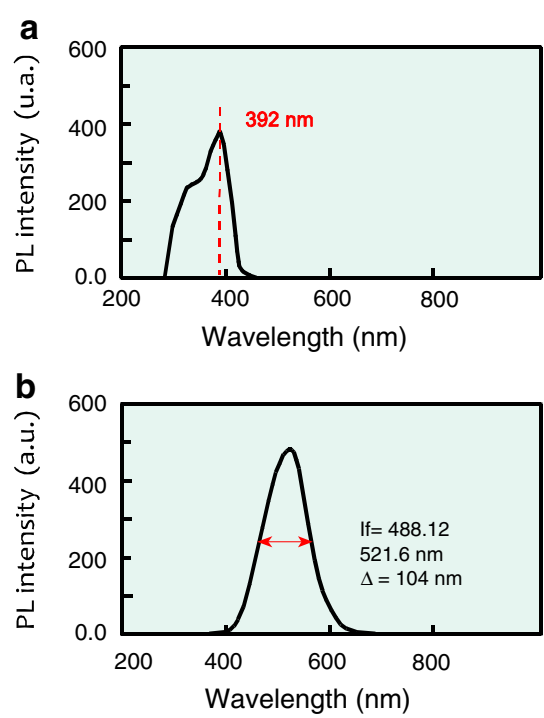

Fig. 2 Photoluminescence behaviour of the CdS QDs at $4.5 \mathrm{~h}$ after collection $\operatorname{Rex}=\operatorname{Rem}=5 \mathrm{~nm}$. a Excitation spectrum setting $\lambda$ em at 528 $\mathrm{nm}$. b Emission spectrum setting $\lambda$ ex at $390 \mathrm{~nm}$

diameter. The smaller it is (a narrower emission band), the smaller to size distribution (Gaussian, with a smaller standard deviation), indicating that the particles were more uniform as regards size.

This value, $\Delta$, allowed a comparison to be made of the size distribution under the different experimental conditions and in the different phases of the lifetimes of the QDs. It should be mentioned that the value of $\Delta$ for the QDs obtained in organic medium ranged between 50 and $90 \mathrm{~nm}$ [39]

Effect of different variables on the size and photoluminescence properties of the QDs synthesized

\section{Evolution of the QDS with time}

When stirring of the QDs had been completed, $4.5 \mathrm{~h}$ after the end of the process of synthesizing them at laboratory temperature they were allowed to evolve with time in the absence of irradiation with light (topaz flask) and no stirring. Under these conditions, the CdS QDs stabilized with mercaptoacetic acid were dispersed in a solution containing $\mathrm{S}^{2-}$, and mainly $\mathrm{Cd}^{2+}$, ions, because the latter were initially in excess and moved according to their diffusion coefficient and could (theoretically) interact with one another to generate more precipitation nuclei or join those already formed to increase the size of the crystals.

Additionally, the $\mathrm{Cd}^{2+}$ ions may participate in other parasitic reactions different from the formation of QDs, such as (at the initial pH of 11) the formation of hydrated oxides. When these appear, they are deposited on the surface of the QDs, since no turbidity was observed in the solution, and hence there was no precipitation of cadmium hydroxide, $\mathrm{Cd}(\mathrm{OH})_{2}$, in the solution.

It should not be forgotten that CdS QDs are not static but dynamic, in the sense that they are involved in the balance with the species in solution in the processes of solubilization and growth of particle size.

The absorption spectra of the CdS QDs were obtained at different times of evolution, observing that the maximum of the absorption bands with time was increasingly less pronounced, with a flat shoulder between 350 and $370 \mathrm{~nm}$. This cannot be attributed to the decrease in the amount of QDs in solution because the absorbance value in the zone of the maximum remained almost constant, with small variations between 0.695 (at 28 days) and 0.732 (at $4.5 \mathrm{~h}$ ).

Moreover, the mean diameter of the QDs, $d$, obtained with the method described above only increased slightly from $2.85 \mathrm{~nm}$ to $3.0 \mathrm{~nm}$, which is consistent with the fact that the wavelength of the absorption band maximum was not modified appreciably.

The phenomena addressed up to this point were accompanied by a decrease in the $\mathrm{pH}$ of the solution from 11.07 to 8.40 , which persisted until day 21 . This suggests the consumption of $\mathrm{OH}^{-}$ions by the $\mathrm{Cd}^{2+}$ ions of the solution, to form hydrated oxides on the surface of the QDs, although at such $\mathrm{pH}$ values it is not possible to rule out the transformation of such hydrated oxides from the surface into hydroxylated species (an example would be $\mathrm{Cd}(\mathrm{OH})_{3}{ }^{-}$) or the solubilization of $\mathrm{Cd}^{2+}$ ions from the nanocrystals to mainly $\mathrm{CdOH}^{+}$. The adsorption or co-precipitation processes occurring on the CdS surface could be of slow kinetics and could even cover the nanocrystal, forming a crust (nanocortex) of $\mathrm{Cd}(\mathrm{OH})_{2}$.

Regarding the emission spectra of the aqueous solution containing the CdS QDs, their evolution was studied over 50 days. Initially, up to $44 \mathrm{~h}$ the intensity of fluorescence emission decreased slightly, not because the amount of QDs decreased - since the absorbance value remained constantbut because this phenomenon could be due to physical and chemical processes occurring on the surface of the QDs, modifying their morphology.

This alteration to the surface elicited an increase in the non-radiant emission such that the intensity of the fluorescent light emitted decreased. Also, this surface alteration was not homogeneous for all of the QDs; it seemed to depend on their size, since the width of the emission spectrum at half height, $\Delta$, increased with time, size distribution with respect to the mean value, $\mathrm{d}$ (which remained almost constant), also increasing. As from $44 \mathrm{~h}$, the smallest QDs increased in size, the larger ones becoming solubilized, such that the size distribution was reduced to values close to $104 \mathrm{~nm}$. This was accompanied by a gradual and slow modification the surface of the QDs, leading the intensity of 
fluorescence emission to increase considerably as time progressed up to day 24 , after which a slight decrease was seen, accompanied by an increase in mean particle size up to $3.0 \mathrm{~nm}$. However, this increase in size was so small that it did not alter the luminescence properties of the QDs since the emission maximum remained constant at $524.8 \mathrm{~nm}$.

Influence of Temperature

The relationship between temperature, supersaturation and solubility is well known. Accordingly, a study was performed to determine the influence of this variable on the characteristics of the CdS QDs obtained. Seven solutions were prepared following the general procedure, allowing the solution to reach the desired temperature, When this temperature had been reached, and under nitrogen bubbling, $50 \mathrm{~mL}$ of a solution containing 0.075 millimoles of $\mathrm{Na}_{2} \mathrm{~S}$ were added. After a stirring time of $15 \mathrm{~h}$, the absorption and luminescence spectra were recorded to compare the results obtained. Between measurements, the solutions were kept at $4{ }^{\circ} \mathrm{C}$ in a refrigerator.

Under these conditions it was possible to obtain information about the QDs collected upon maintaining the solutions used in the collection procedure at different temperatures; in all cases, the later evolution of the NP solutions occurred at $4{ }^{\circ} \mathrm{C}$ in the refrigerator, with no stirring. The fluorescence intensity at maximum emission initially increased with temperature up to $35^{\circ} \mathrm{C}$ (Fig. 3), thereafter decreasing with the fall in temperature; all for the same time of evolution. This indicates that the shape and state of the surface is strongly influenced by the temperature of the solution, the latter affecting not only the kinetic aspects of the nucleation and growth but also the possible formation of a nanoshell of $\mathrm{Cd}(\mathrm{OH})_{2}$ on the nanoparticle. Thus, there must be an optimum size of this nanoshell related to the radiant and non-radiant emission processes.

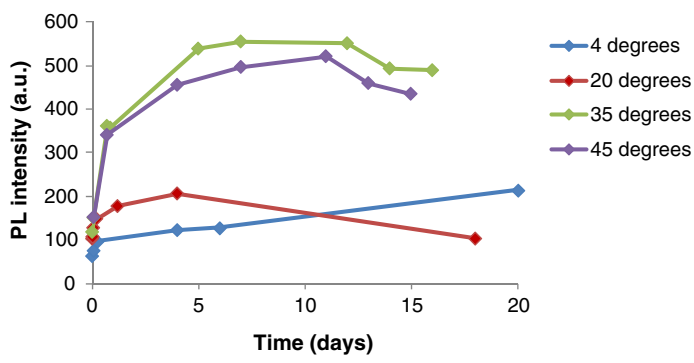

Fig. 3 Influence of temperature. Temporal evolution of PL intensity of CdS QDs synthesized at different temperatures (in degrees centigrade). The concentrations of reagents in the final solution were: $\left[\mathrm{Cd}^{2+}\right]_{\mathrm{f}}=1.0 \times 10^{-3} \mathrm{M} ;\left[\mathrm{S}^{2-}\right]_{\mathrm{f}}=0.5 \times 10^{-3} \mathrm{M} ;[\mathrm{MAA}]_{\mathrm{f}}=0.9 \times 10^{-3} \mathrm{M}$. The $f$ subindex indicates the final concentration of each species

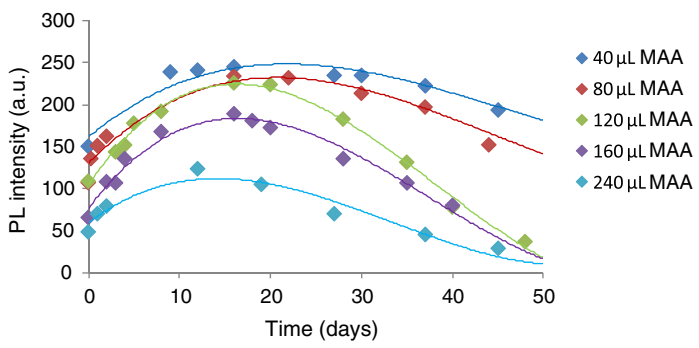

Fig. 4 Influence of the Cd/MAA ratio. Temporal evolution of PL intensity of CdS QDs synthesized with different Cd/MAA ratios

At temperatures higher than those shown in Fig. 3, according to the fluorescence spectra it was observed that the particles evolved rapidly in both size and their surface characteristics, such that their stability was low. It could not be ruled out that $90{ }^{\circ} \mathrm{C}$ some of the MAA (in the form of mercaptoacetate) could have been vaporized, leaving the nanoparticle surface with a lower amount of dispersant.

Regarding the maximum intensity of fluorescence and the stability of that parameter, the best results were obtained at $35^{\circ} \mathrm{C}$. Additionally, on controlling the temperature in the collection method and the time of evolution of the QDs it was possible to obtain nanoparticles of different sizes and with different luminescence properties.

Regarding the size distribution of the QDs with respect to the mean diameter, only at 70 and $90{ }^{\circ} \mathrm{C}$ was this clearly observed to increase, in agreement with the notion of the existence of aggregation processes.

\section{Influence of the Molar $\mathrm{Cd}^{2+} / \mathrm{S}^{2-}$ and $\mathrm{Cd}^{2+} / \mathrm{MAA}$ Ratios}

Since $\mathrm{Cd}^{2+}, \mathrm{S}^{2-}$, and MAA are the three main species involved in the formation of CdS nanoparticles and in their stability or dispersion, it is necessary to have knowledge of the influence of their molar ratios on the characteristics of the QDs. The influence was studied in two types of experiments:

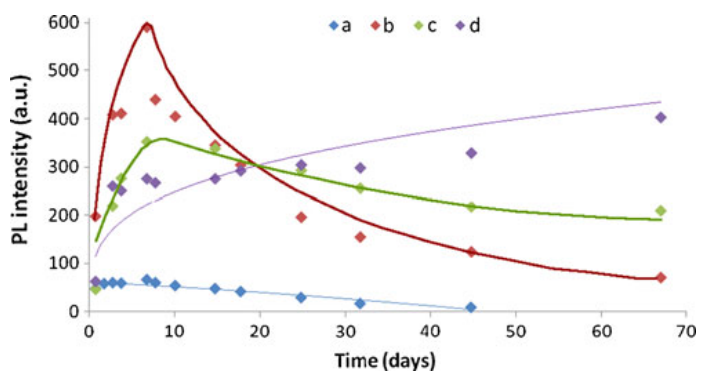

Fig. 5 Influence of the $\mathrm{Cd} / \mathrm{S}$ ratio. Temporal evolution of PL intensity of CdS QDs solutions with different $\mathrm{Cd} / \mathrm{S}$ ratios. a) $\mathrm{Cd} / \mathrm{S}=1.3$; b) $\mathrm{Cd} /$ $\mathrm{S}=2.0 ;$ c) $\mathrm{Cd} / \mathrm{S}=2.7 ;$ d) $\mathrm{Cd} / \mathrm{S}=4.0$ 
Fig. 6 Influence of the change in $\mathrm{pH}$ value during synthesis. Temporal evolution of the PL intensity at different $\mathrm{pH}$ values. Under the working conditions, the final concentrations and their molar ratios were as follows: $\left[\mathrm{Cd}^{2+}\right]_{\mathrm{f}}=1.3 \times 10^{-3} \mathrm{M} ;\left[\mathrm{S}^{2-}\right]_{\mathrm{f}}=$ $0.5 \times 10^{-3} \mathrm{M} ;[\mathrm{MAA}]_{\mathrm{f}}=1.0 \times$ $10^{-3} \mathrm{M} ;\left[\mathrm{Cd}^{2+}\right]_{\mathrm{f}}\left[\mathrm{S}^{2-}\right]_{\mathrm{f}}=2.7$; $\left[\mathrm{Cd}^{2+}\right]_{\mathrm{f}} /[\mathrm{MAA}]_{\mathrm{f}}=1.3$

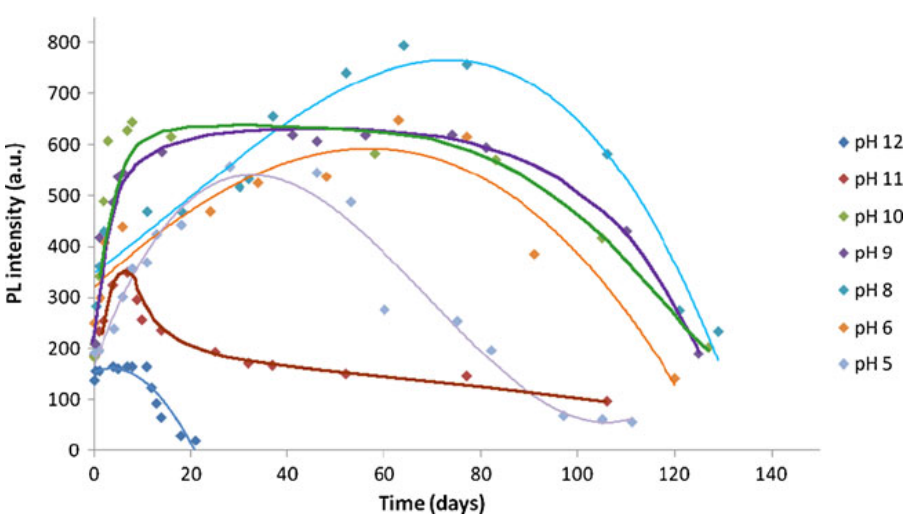

Influence of the Concentration of Mercaptoacetic Acid. $\mathrm{Cd}^{2}$ ${ }^{+} / \mathrm{S}^{2-}$ Constant $; \mathrm{Cd}^{2+} / \mathrm{MAA}$ Variable

Six solutions were prepared whose final concentrations of MAA varied between $0.2 \times 10^{-3} \mathrm{M}$ and $1.5 \times 10^{-3} \mathrm{M}\left(\mathrm{Cd}^{2+} /\right.$ MAA ratios between 4 and 0.3 ). The solution with the lowest concentration of MAA did not generate a fluorescence signal. A ratio of $\left[\mathrm{Cd}^{2+}\right]_{\mathrm{f}} /[\mathrm{MAA}]_{\mathrm{f}}=4$ was insufficient for the collection of fluorescent QDs.

In all cases, for each solution the emission intensity of fluorescence emission at its optimum excitation wavelength increased with the time of evolution until a constant value was reached (Fig. 4); this persisted for a few days (more days with increasing $\left[\mathrm{Cd}^{2+}\right] /[\mathrm{MAA}]$ ratios, because the MAA concentration was lower), thereafter decreasing progressively faster as the concentration of MAA was increased. This, together with the evolution of the mean diameter of the QDs over time, shows that at the same time as the $\mathrm{CdS}$ increased in size, losing quantum efficiency, their shape and surface were also modified, contributing to such a decrease in quantum efficiency.

From a practical point of view, the best results concerning the fluorescence values and the time during which the QDs maintained such fluorescence were obtained for a $\left[\mathrm{Cd}^{2+}\right] /[\mathrm{MAA}]$ ratio between 1 and 2 .

\section{Influence of the Concentration Ratios of the Formers of Nanoparticles, with $\mathrm{Cd}^{2+} / \mathrm{MAA}$ Constant and $\mathrm{Cd}^{2+} / \mathrm{S}^{2-}$ Variable}

For these experiments, we kept the $\left[\mathrm{Cd}^{2+}\right]_{\mathrm{f}} /[\mathrm{MAA}]_{\mathrm{f}}$ ratio constant and almost equal to 1 in all the solutions, varying the $\left[\mathrm{Cd}^{2+}\right]_{\mathrm{f}} /\left[\mathrm{S}^{2-}\right]_{\mathrm{f}}$ ratio between 0.7 and 4 . The $f$ subindex indicates the final concentration of each species.

The nanoparticles obtained under the conditions in which there was no excess of $\mathrm{Cd}^{2+}\left(\left[\mathrm{Cd}^{2+}\right]_{\mathrm{f}} /[\mathrm{MAA}]_{\mathrm{f}}=0.7\right.$ and 1) were large -between 3.9 and $4.0 \mathrm{~nm}$ - and were not fluorescent, which confirms the hypothesis that there must
Fig. 7 Influence of the change in the $\mathrm{pH}$ value on the already synthesized nanoparticles. Temporal evolution of PL intensity at different $\mathrm{pH}$ values

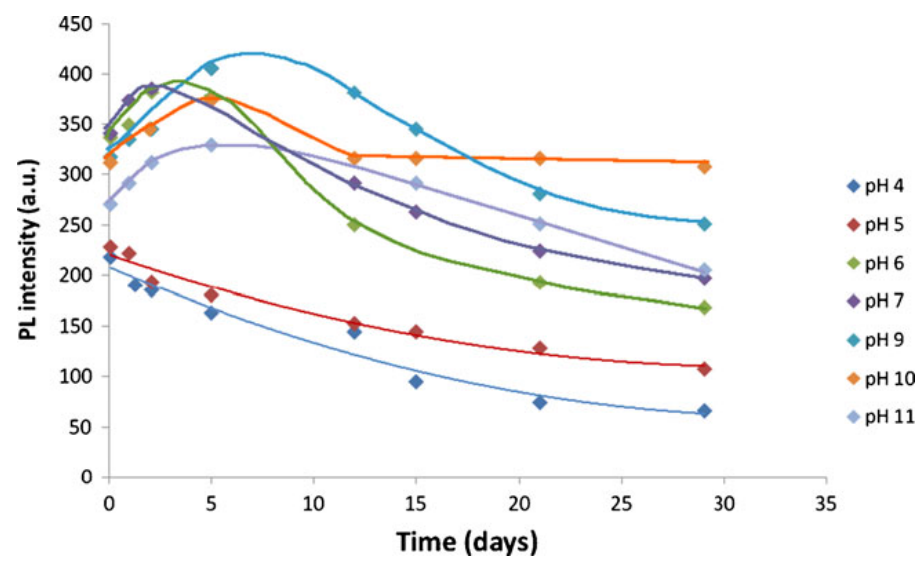


be a relationship between fluorescence and the $\mathrm{Cd}(\mathrm{OH})_{2}$ nanoshell of a given size deposited on their surface. The maximum intensity of fluorescence (Fig. 5) was attained for an optimum relationship between the thickness of the nanoshell and the mean diameter of the QDs. If the nanoshell is a very thin deposit as compared with the mean diameter, only the transfer of electrons through it is improved, the quantum efficiency in the excitationemission process being altered only slightly. When the nanoshell is thick in comparison with the particle diameter, the transfer of electrons through it in the excitation process increases, but in the process of the emission of radiation the non-energetic, non-radiant fraction increases. The intermediate situation - an optimum ratio between the thickness of the nanoshell and mean diameter- afforded the highest quantum efficiency.

Effect of the $\mathrm{pH}$ of the Medium in the Synthesis of CdS QDs

It was decided that this variable should be studied in two types of experiments:

\section{Influence of $p H$ in the Method Used for the Synthesis of CdS Nanoparticles}

The procedure and conditions used were as follows: $105 \mu \mathrm{L}$ of $1.41 \mathrm{M}$ (0.148 mmoles) of MAAwas added to a $100 \mathrm{~mL}$ solution containing 0.20 mmoles de $\mathrm{Cd}^{2+}$ under stirring conditions at $380 \mathrm{rpm}$. The $\mathrm{pH}$ of this solution, which was acid, was adjusted with $0.5 \mathrm{M} \mathrm{NaOH}$ in six experiments with a $\mathrm{pH}$ range from 5.2 to 11.0. Following this, nitrogen was bubbled through for 15-20 min, after which $50 \mathrm{~mL}$ of an $\mathrm{Na}_{2} \mathrm{~S}$ solution $(0.075$ mmoles $)$ was added slowly. Under these working conditions, the final concentrations of the 6 different species and their molar ratios are shown in Fig. 6. It was observed that the results regarding nanoparticle size and the luminescence properties depended on the $\mathrm{pH}$ of the

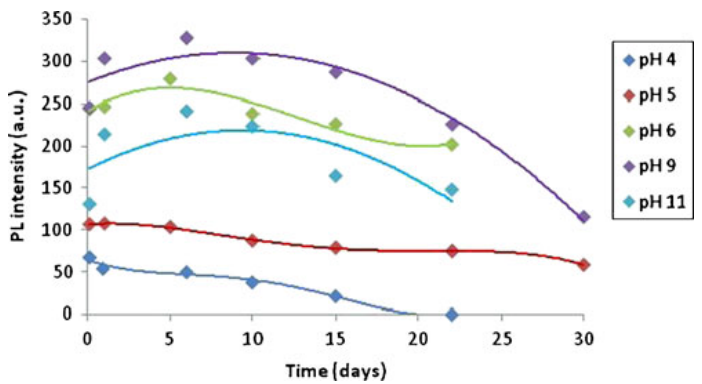

Fig. 8 Temporal evolution of PL intensity at different $\mathrm{pH}$ values of the nanoparticles synthesized with the recent $\mathrm{CdCl}_{2}$ solution

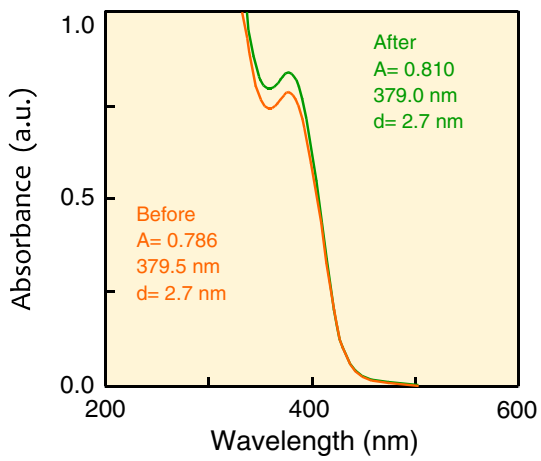

Fig. $9 \mathrm{UV}-$ vis spectra of CdS QDs grown in aqueous medium at $\mathrm{pH}=$ 11 , before and after the bubbling with oxygen

solution containing $\mathrm{Cd}^{2+}$ and MAA before the slow addition of $\mathrm{S}^{2-}$.

There is a point in time at which for each $\mathrm{pH}$ value an optimum size ratio between a nanoparticle and the nanoshell is reached, when the joint structure reaches the maximum quantum yield and a maximum of the intensity of fluorescence emission value is attained. Scrutiny of Fig. 6 suggests that the optimum conditions for the formation of QDs with such quantum efficiency (a high intensity of fluorescence emission value) and stable for longer correspond to setting the $\mathrm{pH}$ value at 9 or 10 .

\section{Influence of the $\mathrm{pH}$ of the Medium Once the CdS} Nanoparticles have been Formed

In the luminescent properties of CdS nanoparticles, a fundamental influence comes from the state of the surface, not only as regards their physical aspect but also their composition, and the species that are absorbed onto their surface are $\mathrm{pH}$-dependent. As mentioned in the Introduc-

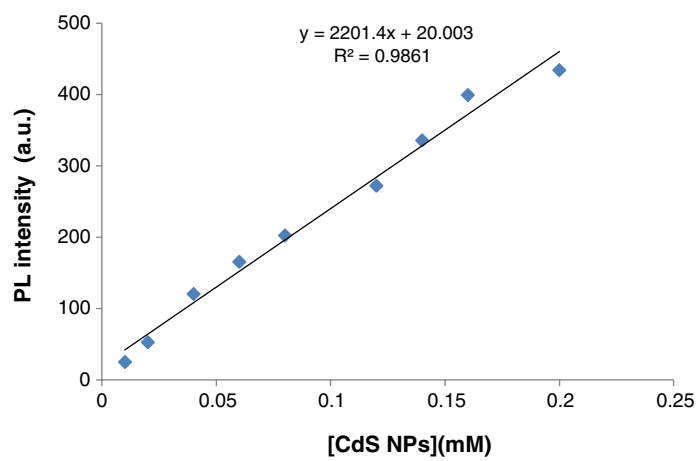

Fig. 10 Effect of NP concentration on the PL intensity $(\lambda \mathrm{em}=592 \mathrm{~nm}$; excitation and emission slit widths: $5 \mathrm{~nm}$ ) 


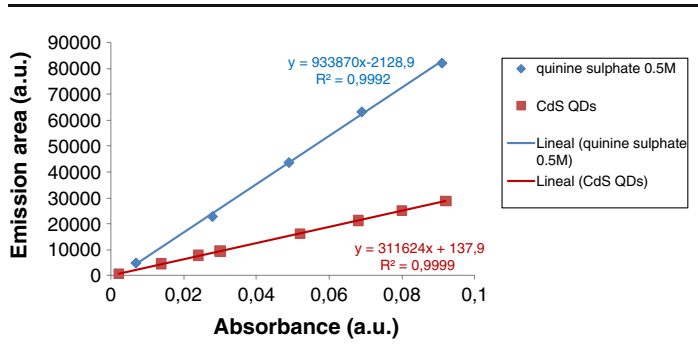

Fig. 11 Values of absorption against the values of integrated areas of the emission fluorescence spectra

tion, one future application is the use of nanoparticles obtained at the laboratory in biological media, which logically have $\mathrm{pH}$ values different from the medium used for collecting them.

It is important to know how the CdS nanoparticles obtained at the laboratory at elevated $\mathrm{pH}$ values above 10 will evolve when introduced into a medium with a different $\mathrm{pH}$.

With this in mind, we carried out the synthesis following the general procedure described. The experiment was conducted at room temperature and during the time taken for the measurements temperature was maintained between 20 and $23{ }^{\circ} \mathrm{C}$. Stirring was stopped at the exact moment of completing the addition of the $\mathrm{Na}_{2} \mathrm{~S}$ solution; the time considered $t=0$ for the studies of evolution. At that time, aliquots of $8 \mathrm{~mL}$ were collected and after adjusting $\mathrm{pH}$ from 4 to 10 with $0.1 \mathrm{M} \mathrm{HCl}$ volume was brought up to $10 \mathrm{~mL}$ topaz flasks.

According to the absorption spectra, the nanoparticles obtained under the above experimental conditions can be used in receptor media with $\mathrm{pH}$ values between 5 and 11 , with only small alterations in their size (mean diameter), and they remain dispersed in the solution for at least 4 months.

Regarding luminescence properties, the nanoparticles obtained under the experimental conditions described, with a half-life of one hour, added to aqueous media with $\mathrm{pH}$ values between 4 and 11 did not maintain their capacity for fluorescence emission in the case of the most acid media $(\mathrm{pH}=4$ and $\mathrm{pH}=5)$, while they did in less acid media; the most favourable range was $\mathrm{pH}=6$ and 11 (Fig. 7). In future experimental work addressing the markers of analytes in biological and biochemical media it will be necessary to take this kind of fluorescence behaviour over time into account in order not to commit certain experimental errors.

\section{Influence of the Age of the Reagent Solutions}

As indicated in the previous experimental studies, in all cases the $\mathrm{Na}_{2} \mathrm{~S}$ solution was prepared at the time of use in order to prevent the oxidation of $\mathrm{S}^{2-}$, whereas the $\mathrm{CdCl}_{2}$ solution was prepared and used as a stock solution for later studies lasting months. In order to check how the age of the $\mathrm{Cd}^{2+}$ solution affected the formation and development of $\mathrm{CdS}$ nanoparticles, the above experiment (exploring the influence of the $\mathrm{pH}$ of the medium once the CdS QDs had been formed) was performed, repeating all the steps of the procedure except the solution of $\mathrm{Cd}^{2+}$, which was prepared at the same concentration but was used immediately after its preparation, and is the one we shall refer to as the recent solution.

The morphology of those spectra was clearly different; on comparing the same $\mathrm{pH}$ values the mean diameter of the QDs obtained with the recent solution was greater than that of those obtained with the older solution. This difference can be attributed to the presence of nanocrystals of $\mathrm{CdCl}_{2}$ not dissolved in the recent solution, which acted as a support for the later growth of CdS nuclei.

The difference in size of the QDs and in their surface characteristics was reflected in differences in the luminescence properties of the nanoparticles obtained with the recent solution. Their fluorescence emission intensity values were lower (Fig. 8), although for each $\mathrm{pH}$ value they evolved in a way similar to the QDs obtained with the older solution (Fig. 7).

From this study it was concluded that, from the point of view of size and luminescence properties, in the process of nanoparticle synthesis it is preferable to use $\mathrm{CdCl}_{2}$ solutions prepared some time previously (older solutions).
Table 1 Evolution of the values of $\Phi$ for NPs obtained with different $\mathrm{Cd}^{2+} / \mathrm{S}^{2-}$ ratios

\begin{tabular}{lcccc}
\hline \multicolumn{1}{l}{$\Phi_{\text {CdS }}$} \\
\hline $\mathrm{t}$ (days) & $\mathrm{Cd}^{2+} / \mathrm{S}^{2-}=1.33$ & $\mathrm{Cd}^{2+} / \mathrm{S}^{2-}=2.00$ & $\mathrm{Cd}^{2+} / \mathrm{S}^{2-}=2.70$ & $\mathrm{Cd}^{2+} / \mathrm{S}^{2-}=4.00$ \\
\hline 1 & 7.0 & 19 & 24.0 & 29.0 \\
5 & 8.0 & 48 & 31.5 & 29.5 \\
12 & 7.5 & 31 & 30.0 & 29.0 \\
20 & 7.0 & 22 & 26.5 & 28.0 \\
40 & 4.5 & 15 & 21.5 & 28.0 \\
60 & $<1$ & 10 & 17.0 & 31.0 \\
\hline
\end{tabular}




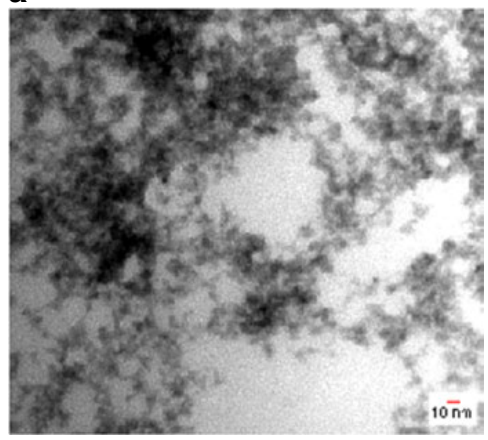

b

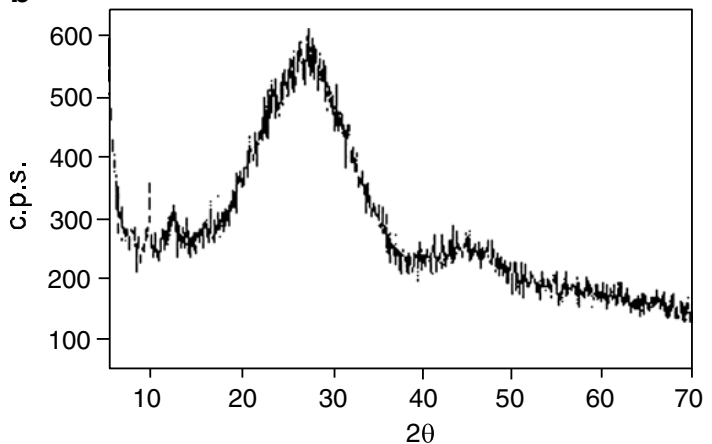

Fig. 12 a TEM image of the as-prepared CdS nanoparticles and b Powder XRD pattern of the CdS QDs

Influence of the presence of oxygen in the solutions on the evolution of QDs

Using aliquots of the $\mathrm{pH}=11$ solution, taken at different times of evolution, the effect of the presence of oxygen in the medium was assayed. $\mathrm{O}_{2}$ was introduced into the solution by bubbling air through it for $30 \mathrm{~min}$, to guarantee its saturation, using a membrane pump.

It may be seen (Fig. 9) that the presence of $\mathrm{O}_{2}$ (recall that in the solutions there was an excess of $\mathrm{Cd}^{2+}$ ) did not induce the formation of a nanoshell of $\mathrm{Cd}(\mathrm{OH})_{2}$. Particle size was not altered, even in the presence of vigorous and irregular stirring, as occurs during bubbling. Neither did the surface of the nanoparticles undergo any alteration, since both the excitation and emission spectra and the maximum intensity of fluorescence emission were similar after the bubbling.

Influence of the Amount of QD on Intensity of Fluorescence Emission

The aim of using CdS nanoparticles is based on their luminescent properties as fluorescent tracers in biological media with a view to measuring an analyte after its chemical bonding to such nanoparticles.

In order to check whether there was proportionality between the CdS QDs concentration and their luminescence intensity, CdS nanoparticles were obtained at the laboratory using $100 \mathrm{~mL}$ of an old solution of $1.2 \times 10^{-3} \mathrm{M} \mathrm{CdCl}_{2}$, to which $8 \mu \mathrm{L}$ of $14.1 \mathrm{M} \mathrm{MAA}$ was added, then adjusting $\mathrm{pH}$ to 11 . Under nitrogen bubbling and stirring conditions, $50 \mathrm{~mL}$ of $1.5 \times 10^{-3} \mathrm{M} \mathrm{Na}_{2} \mathrm{~S}$ was slowly added, after which the mixture was left to stand (maintaining the stirring) for $24 \mathrm{~h}$. Exactly $28 \mathrm{~h}$ after completing the mixture of the reagents, 10 solutions at different concentrations were prepared by dilution of the original solution, $\mathrm{pH}=10.89$, in which the mean size of the QDs was $2.9 \mathrm{~nm}$.
It may be seen (Fig. 10) that there was direct proportionality between the concentration of QD and fluorescence emission, with a linear regression coefficient of $\mathrm{R}^{2}=0.9861$ for a $95 \%$ confidence interval.

\section{Quantum Yield}

Room-temperature PL quantum yields (QYs) were determined by comparing the integrated emission of the QDs samples in water with that of a fluorescent organic molecule (such as quinine).

$\Phi_{\mathrm{x}}=\Phi_{\mathrm{s}}\left(\mathrm{K}_{\mathrm{x}} / \mathrm{K}_{\mathrm{s}}\right)\left(\eta_{\mathrm{x}} / \eta_{\mathrm{s}}\right)^{2}$

In Eq. 1, $x$ is the substance to be measured, $s$ is the fluorescence standard, $\Phi$ is the quantum yield in percentage, $\eta$ is the refraction index of the solvent employed in each solution, and $K$ is the proportionality constant between absorbance and the corrected integrated area of the emission spectrum (its ratio should be linear, such that the constant is the slope, Fig. 11).

A quantum yield of $18 \%$ was obtained for the aqueous solutions of CdS QDs. Unlike organic fluorophores, the $\Phi$ value in QDs or QDs depends on several variables such as the experimental conditions used to synthesize them, which determine mean size of the QDs and the greater or lesser

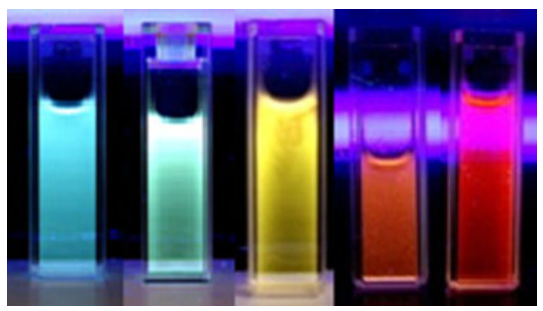

Fig. 13 Fluorescence of the CdS QDs of different sizes (from 2 to $5 \mathrm{~nm}$ ) 
capacity to form the nanocortex of $\mathrm{Cd}(\mathrm{OH})_{2}$, which in turn governs their luminescence properties. As confirmation of the above, Table 1 shows the values obtained in the calculation of $\Phi$ for solutions with different $\mathrm{Cd}^{2+} / \mathrm{S}^{2-}$ ratios at different times of evolution.

\section{Characterization of the CdS Quantum Dots}

The shape of the CdS nanoparticles was studied with Transmission Electron Microscopy (TEM) after evaporating off the solvent (Fig. 12, on the left), and X-ray diffraction was employed to study the morphology of the CdS nanocrystals (Fig. 12, on the right). It was observed that they were $\beta$-CdS nanocrystals with a cubic crystalline network.

\section{Conclusions}

At room temperature, the mixture of aqueous solutions of $\mathrm{CdCl}_{2}$ and $\mathrm{Na}_{2} \mathrm{~S}$, in the presence of mercaptoacetic acid as a dispersant leads to the formation of a solution with a $\mathrm{pH}=$ 11 , oversaturated in $\mathrm{CdS}$, in which -after stirring- first nuclei and then quantum-sized $(<10 \mathrm{~nm})$ particles of the CdS semiconductor are obtained.

The QDs obtained, subjected to X-ray diffraction studies, were confirmed to be nanoparticles of $\beta$-CdS, with a cubic crystalline network, no other crystalline phases being observed in their structure.

Quantum size $(<10 \mathrm{~nm})$ was confirmed not only from the absorption spectra but also by Transmission Electron Microscopy.

At any given moment, the rate of nucleation and the growth rate govern nanoparticle size and also the state of their surface, although the importance of the excess of $\mathrm{Cd}^{2+}$ over $\mathrm{S}^{2-}$ was observed experimentally.

The size of the nanoparticles, their evolution with time, the state of their surface, and their stability depend on many variables, studied in depth in the present work. The mean diameter of QDs depends on the experimental conditions used to synthesize them. In the original solutions where they were synthesized, they were live particles that continued to evolve with time, not only their size but also the state of their surface and their stability as a dispersed phase being modified.

Regarding the fluorescence of the CdS QDs obtained in aqueous medium (Fig. 13), both the emission wavelength (greenish blue light to orange light) and the maximum intensity were found to depend on the mean size of the QDs and on the state of their surface. Concerning this second characteristic, the presence of a nanoshell of $\mathrm{Cd}(\mathrm{OH})_{2}$ deposited on the nanoparticle seems to be very important, favouring the process of electronic excitation up to a maximum value of the nanoshell/nanoparticle size ratio, above which the processes of the emission of nondispersive light increases. This optimum size ratio depends on the experimental conditions employed and is reached at a given and variable time of development.

The fluorescence of the CdS QDs obtained in aqueous medium is sufficiently long-lasting for them to be used as tracers of both inorganic and organic species that interact with them.

The CdS QDs obtained under given experimental conditions and with different life-times behave as true analytical reagents, showing linear proportionality between intensity of fluorescence emission and the number of nanoparticles per unit volume.

The quantum yield of the luminescence process depends on the experimental conditions used to synthesize the QDs and their life-times, this being -for the best conditionsbetween 19 and $29 \%$ for a life-time of one day, and between 10 and $31 \%$ for 60 days. In general, higher quantum yields were obtained than those indicated in the literature for different procedures for the synthesis of nanoparticles in both aqueous and organic media.

Acknowledgements We thank the Council for Education and Culture of the Regional Government of Castilla y León for financial support.

\section{References}

1. Bailey RE, Smith AM, Nie S (2004) Quantum dots in biology and medicine. Physica E 25:1-12

2. Gao X, Yang L, Petros JA, Marshall FF, Simons JW, Nie S (2005) In vivo molecular and cellular imaging with quantum dots. Curr Opin Biotechnol 16:63-72

3. Costa JM, Rosario Pereiro R, Sanz-Medel A (2006) The use luminescent quantum dots for optical sensing. Trend Anal Chem $25: 207-218$

4. Liu T, Liu B, Zhang H, Wang Y (2005) The fluorescence bioassay platforms on quantum dots nanoparticles. J Fluoresc 15:729-733

5. Alivisatos AP (1996) Semiconductors clusters, nanocrystals and quantum dots. Science 271:933-937

6. Biju V, Itoh T, Anas A, Sujith A, Ishikawa M (2008) Semiconductor quantum dots and metal nanoparticle, syntheses, optical properties, and biological applications. Anal Bioanal Chem 391:2469-2495

7. Yu WW, Chang E, Drezek R, Colvin VL (2006) Water-soluble quantum dots for biomedical applications. Biochem Biophys Res Commun 348:781-786

8. Pinaud F, Michalet X, Bentolila LA, Tsay JM, Doose S, Li JJ, Iyer G, Weiss S (2006) Advances in fluorescence imaging with quantum dot bio-probes. Biomaterials 27:1679-1687

9. Jamieson T, Bakhshi R, Petrova D, Pocock R, Imani M, Seifalian AM (2007) Biological applications of quantum dots. Biomaterials 28:4717-4732

10. Alivisatos P (2004) The use of nanocrystals in biological detection. Nat Biotechnol 2:47-52

11. Tran PT, Goldman ER, Anderson GP, Mauro JM, Mattoussi H (2002) Use of luminescent CdSe-ZnS nanocrystal bioconjugates in 
quantum dot-based nanosensors. Physica Status Solidi B 229:427432

12. Gerion D, Pinaud F, Williams SC, Parak WJ, Zanchet D, Weiss S, Alivisatos AP (2001) Synthesis and properties of biocompatible water-soluble silica coated $\mathrm{CdSe} / \mathrm{ZnS}$ semiconductor quantum dots. J Phys Chem B 105:8861-8871

13. Parak WJ, Gerion D, Zanchet D, Woerz AS, Pellegrino T, Micheel C, Williams SC, Seitz M, Richard M, Bruehl E, Bryant Z, Bustamante C, Bertozzi CR, Alivisatos AP (2002) Conjugation of DNA to silanized colloidal semiconductor nanocrystalline quantum dots. Chem Mater 14:2113-2119

14. Wang SP, Mamedova N, Kotov NA, Chen W, Studer J (2002) Antigen/antibody immunocomplex from $\mathrm{CdTe}$ nanoparticle bioconjugates. Nano Letters 2:817-822

15. Guo W, Li JJ, Wang YA, Peng X (2003) Conjugation chemistry and bioapplications of semiconductor box nanocrystals prepared via dendrimer bridging. Chem Mater 15:3125-3133

16. Wu XY, Wu X, Liu H, Liu J, Kari N, Haley KN, Treadway JA, Larson JP, Nianfeng GN, Peale F, Bruchez MP (2003) Immunofluorescent labeling of cancer marker Her2 and other cellular targets with semiconductor quantum dots. Nat Biotechnol 21:41-46

17. Parak WJ, Boudreau R, Le Gros M, Gerion D, Zanchet D (2002) Cell motility and metastatic potential studies based on quantum dot imaging of phagokinetic tracks. Adv Mater 14:882-885

18. Hild WA, Breuning M, Goepferich A (2008) Quantum dots-Nanosized probes for the exploration of cellular and intracellular targeting. Eur J Pharm Biopharm 68:153-168

19. Dubertret B, Skourides P, Norris DJ, Noireaux V, Brivanlou AH, Libchaber A (2002) In vivo imaging of quantum dots encapsulated in phospholipid micelles. Science 298:1759-1762

20. Taylor JR, Fang MM, Nie SM (2000) Probing specific sequences on single DNA molecules with bioconjugated fluorescent nanoparticles. Anal Chem 72:1979-1986

21. Xu HX, Sha MY, Wong EY, Uphoff J, Xu YZ, Treadway JA, Truong A, O’Brien E, Asquith S, Stubbins M, Spurr NK, Lai EH, Mahoney W (2003) Multiplexed SNP genotyping using the Qbead $^{\mathrm{TM}}$ system: a quantum dot encoded microsphere-based assay. Nucleic Acids Res 31:1-10

22. Han MY, Gao XH, Su JZ, Nie S (2001) Quantum-dot-tagged microbeads for multiplexed optical coding of biomolecules. Nat Biotechnol 19:631-635

23. Zou L, Fang Z, Gu Z, Zhong X (2009) Aqueous phase synthesis of biostabilizer capped CdS nanocrystals with bright emission. J Lumin 129:536-540

24. Yu W, Peng X (2002) Formation of high-quality CdS and other II-VI semiconductor nanocrystals in noncoordinating solvents: tunable reactivity of monomers. Angew Chem Int Ed 41:2368

25. Zhong X, Liu S, Zhang Z, Li L, Weib Z, Knoll W (2004) Synthesis of high-quality $\mathrm{CdS}, \mathrm{ZnS}$, and $\mathrm{Zn}_{\mathrm{x}} \mathrm{Cd}_{1-\mathrm{x}} \mathrm{S}$ nanocrystals using metal salts and elemental sulfur. J Mater Chem 14:27902794

26. Barglik-Chory Ch, Buchold D, Muller G (2003) Synthesis, structure and spectroscopic characterization of water-soluble CdS nanoparticles. Chem Phys Lett 379:443-451

27. Chen YF, Rosenzweig Z (2002) Luminescent CdS quantum dots as selective ion probes. Anal Chem 74:5132-5138

28. Qi L, Colfen H, Antonietti M (2001) Synthesis and characterization of CdS nanoparticles stabilized by double-hydrophilic block copolymers. Nano Lett 1:61-65

29. Unni C, Philip D, Gopchandran KG (2008) Studies on optical absorption and photoluminescence of thioglycerol-stabilized CdS quantum dots. Spectrochim Acta A Mol Biomol Spectrosc $71: 1402-1407$

30. Murray CB, Norris DJ, Bawendi MG (1993) Synthesis and characterization of nearly monodisperse $\mathrm{CdE}(\mathrm{E}=$ sulfur, selenium, tellurium) semiconductor nanocrystallite. J Am Chem Soc 115:8706-8715

31. Unni C, Philip D, Smitha SL, Nissamudeen KM, Gopchandran $\mathrm{KG}$ (2009) Aqueous synthesis and characterization of CdS, $\mathrm{CdS}: \mathrm{Zn}^{2+}$ and $\mathrm{CdS}: \mathrm{Cu}$ quantum dots. Spectrochim Acta A $72: 827-832$

32. Gao XH, Chan WCW, Nie SM (2002) Quantum-dot nanocrystals for ultrasensitive biological labeling and multicolor optical encoding. J Biomed Opt 7:532-537

33. Kar S, Panda SK, Satpati B, Satyan PV, Chaudhuri SJ (2006) Morphology and size dependent optical properties of CdS in different nanoforms. Nanosci Nanotechnol 6:771-776

34. Pradhan N, Efrima S (2003) Single-precursor, one-pot versatile synthesis under near ambient conditions of tunable, single and dual band fluorescing metal sulfide nanoparticles. J Am Chem Soc 125:2050-2051

35. Zheng ChJ, Gao A, He Y, Wu C, Chen G, Kai Y, Zhu XC (2008) Functionalizad CdS quantum dots-based luminescence probe for detection of heavy and transition metal ions in aqueous solution. Spectrochim Acta A 69:1044-1052

36. Peng X, Schlamp MC, Kadavanich AV, Alivisatos AP (1997) Epitaxial growth of highly luminescent $\mathrm{CdSe} / \mathrm{CdS}$ core/shell nanocrystals with photostability and electronic accessibility. J Am Chem Soc 119:7019-7029

37. Moffitt M, Aisenberg E (1997) Size control of nanoparticles in semiconductor-polymer composites. 1. Control via multiplet aggregation numbers in styrene-based random ionomers. Chem Mater 7:1178-1183

38. He R, Qian X, Yin J, Xi H, Bian L, Zhu Z (2003) Formation of monodispersed PVP-capped $\mathrm{ZnS}$ and $\mathrm{CdS}$ nanocrystals under microwave irradiation. Colloids Surf A 220:151-155

39. Yu K, Zaman B, Taal R, Ripmeester JA (2005) Colloidal CdSe nanocrystals from tri-n-octylphosphine with various $\mathrm{Cd}$ sources: control of a slow growth for high-quality and large-scale production. J Cryst Growth 283:115-123 

Provided for non-commercial research and education use. Not for reproduction, distribution or commercial use.

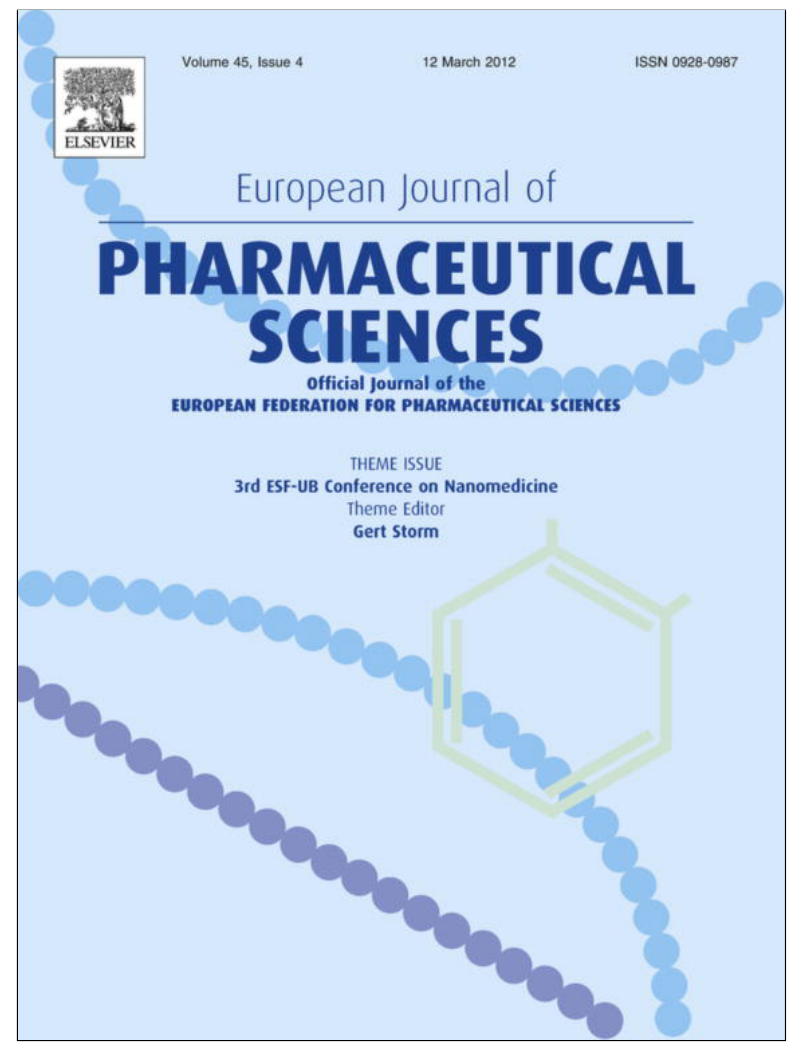

This article appeared in a journal published by Elsevier. The attached copy is furnished to the author for internal non-commercial research and education use, including for instruction at the authors institution and sharing with colleagues.

Other uses, including reproduction and distribution, or selling or licensing copies, or posting to personal, institutional or third party websites are prohibited.

In most cases authors are permitted to post their version of the article (e.g. in Word or Tex form) to their personal website or institutional repository. Authors requiring further information regarding Elsevier's archiving and manuscript policies are encouraged to visit:

http://www.elsevier.com/copyright 


\title{
Nanotechniques in proteomics: Protein microarrays and novel detection platforms
}

\author{
María Gonzalez-Gonzalez a , Ricardo Jara-Acevedo ${ }^{b}$, Sergio Matarraz ${ }^{a}$, María Jara-Acevedo ${ }^{a}$, \\ Sara Paradinas ${ }^{\mathrm{c}}$, J.M. Sayagües ${ }^{\mathrm{a}}$, Alberto Orfao ${ }^{\mathrm{a}}$, Manuel Fuentes ${ }^{\mathrm{a}, *}$ \\ a Centro de Investigación del Cáncer/IBMCC (USAL/CSIC), Departamento de Medicina and Servicio General de Citometría, University of Salamanca, 37007 Salamanca, Spain \\ ${ }^{\mathrm{b}}$ ImmunoStep, SL, Edificio Centro de Investigación del Cáncer, Avda. Coimbra s/n, Campus Miguel de Unamuno, University of Salamanca, 37007 Salamanca, Spain \\ ${ }^{c}$ Departamento de Química Analítica, Facultad de Cc. Químicas, University of Salamanca, 37008 Salamanca, Spain
}

\section{A R T I C L E I N F O}

\section{Article history:}

Received 1 April 2011

Received in revised form 7 July 2011

Accepted 14 July 2011

Available online 22 July 2011

\section{Keywords:}

Biomarkers

Drug discovery

Nanotechnology

Label-free

\begin{abstract}
A B S T R A C T
The field of proteomics has undergone rapid advancements over the last decade and protein microarrays have emerged as a promising technological platform for the challenging tasks of studying complex proteomes. Researchers have gone beyond traditional techniques and approached promising disciplines like nanotechnology to satisfy the growing demands of studying proteins in high-throughput format. Applications of nanotechnology in proteomics came from the need to detect low-abundant proteins in complex mixtures for sensitive, real-time and multiplexed detection platform. The scope of this article is to outline the current status and key technological advances of nanotechniques in protein microarrays.
\end{abstract} (c) 2011 Elsevier B.V. All rights reserved.

\section{Introduction}

The recent achievement of human genome sequencing has lead to worldwide opened scientific fields for the exploration of the potential applications of DNA-derived information. For this purpose, proteomics tools have witnessed rapid growth over the last decade, with increasing emphasis on development of robust and highthroughput (HT) technologies to understand the dynamic proteome changes derived from cell state and function (Matarraz et al., 2011).

The study of the human proteome, which encompasses the entire protein counterpart of the genome in a biological system can be a daunting task due to the extremely large number of proteins produced by around 40,000 genes (Marko-Varga and Fehninger, 2004). In an attempt to handle the large amount of data generated by mRNA splicing, post-translational modifications and protein complexes protein microarray technologies have lately undergone notable improvement.

Protein microarrays are miniaturized and parallelized array technology approaches for protein-protein interactions analysis and protein profiling (LaBaer and Ramachandran, 2005). Typically, thousands of proteins are printed and immobilized on functionalized glass slides, which that can be simultaneously studied and

\footnotetext{
* Corresponding author. Address: Centro de Investigación del Cáncer, Departamento de Medicina, Universidad de Salamanca-CSIC, Avda. Coimbra s/n, 37007 Salamanca, Spain. Tel.: +34 923294811; fax: +34 923294743.

E-mail address: mfuentes@usal.es (M. Fuentes).
}

analyzed in a HT fashion, thereby offering a high potential for characterizing the biology of a given cell of interest. To date, a number of microarray formats have been developed and recently implemented; all of them have tested as a versatile platform for many diverse applications, such as biomarker identification, protein interaction studies, immunological profiling and vaccine development, among others (Matarraz et al., 2011; LaBaer and Ramachandran, 2005; Hall et al., 2007).

Together with the advances in microarray technologies, increasingly sensitive and reliable detection methodologies are being currently developed. Such protein detection systems, have progressively undergone a relevant transition from label-based to more sensitive label-free technologies, which are extremely useful to study the interactome and functions of large amounts of proteins on demand. Overall, label-based systems are mainly focused on the use of specific tags for target molecules as conventional fluorescent dyes and radioisotopes, among others. More recently, other substances are being proposed, including inorganic quantum dots (QDs), gold nanoparticles (NPs), Raman dye-labeled carbon nanotubes or silica NPs (Espina et al., 2004; Ray et al., 2010; Chan et al., 2004).

On the other hand, label-free detection techniques include surface plasmon resonance (SPR), carbon nanotubes, microelectromechanical cantilevers and surface-enhanced laser desorption ionization (SELDI)-TOF-MS. Such approaches provide measurement of specific properties of the query molecule, such as mass, dielectric or optical properties. Several of these novel detection platforms have facilitated sensitive, specific, HT and 
rapid analysis of protein microarrays, thereby finding multiple applications in proteomics (Ray et al., 2010; Ramachandran et al., 2005).

So far, the scope of nanotechnology has widened over years to include pioneer applications in biological sciences. As the considerable interest in the development of highly specific and HT approaches in proteomics increases, the introduction of nanotechniques offers a broad spectrum of highly innovative methods to satisfy these demands. Thus, the successful coupling of nanotechnology with proteomics over the last few years has provided a novel analytical platform, which might be called "nanoproteomics", which has been increasingly investigated to developed innovative approaches for the study of the dynamic range of protein concentrations in complex biological samples in a HT. Therefore, the used nanotechniques provide multiple novel advantages over conventional proteomics approaches such as the miniaturization of platforms and assessment of real-time multiplexed analysis with low sample, time and reagents consumption translating into higher sensitivity and reduced complexity.

In the present review, we focus on the advantages, challenges, applications and promises of diverse current nanotechniques with interesting applications in proteomics.

\section{Overview of protein microarrays}

Protein microarrays allow the HT study of thousands of proteins simultaneously. Nevertheless, many challenges are linked to this technology, as compared to DNA microarrays. The majority arise from the need to maintain the structural integrity and physicochemical properties of proteins, derived from its complexity and variability (e.g. post-translational modifications, etc.). However, the central role of proteins in biological systems has motivated researchers to develop and improve new approaches to generate protein microarrays for multiple discipline application such as protein-protein interactions, biomarker discovery for early diagnostic and identifi- cation of targets for directed therapy (Matarraz et al., 2011; Ramachandran et al., 2009; Rifai et al., 2006; Sanchez-Carbayo, 2006).

Briefly, protein microarrays could basically be classified as target microarrays, reverse phase arrays (RPP) and in situ expressed arrays (Speer et al.,2005; Borrebaeck and Ohlin, 2002; Chandra and Srivastava, 2010) (Fig. 1). In target protein microarrays, capture agents of different nature and affinity properties (e.g.: antibodies or recombinant proteins) are immobilized onto a planar-solid surface and incubated with the test sample. Such approach is commonly used for the study of protein expression levels, also allowing evaluating its binding affinity or other specificity features, etc. However, target arrays have a several drawbacks such as crossreactivity and loss of proteins activity upon immobilization. In general, these arrays have found wide applicability in clinical and immunological studies (Ramachandran et al., 2009).

By contrast, RPP arrays are generated by immobilizing cellular or tissue lysates or even serum samples on the array surface, for further detection by an antibody against the target protein. Antigen-antibody interaction is then revealed by secondary tagging and further signal amplification (Ehrlich et al., 2002). Hence, the signal intensity would directly depend on the specificity, the binding affinity and sterical accessibility for interactions between the analyte and the antibody. Moreover, the scant analyte concentration within a spot in the search for low abundant proteins in a complex protein lysates increases the possibility to lack detection. RPP arrays have been successfully applied for analyzing posttranslational modifications and signal transduction ex vivo. Therefore, the possibility to generate a functional map for cell signaling pathways from individual cells or tissues by RPP arrays has translated into an increasing interest to examine the potential of this technology for developing personalized, patient-tailored therapies (Sheehan et al., 2005).

On the other hand, the protein in situ array format is mainly based on cell-free expression systems such as Escherichia coli 30s, rabbit reticulocyte lysates and wheat germ extracts. Regarding content for protein in situ arrays, a library of open reading frames
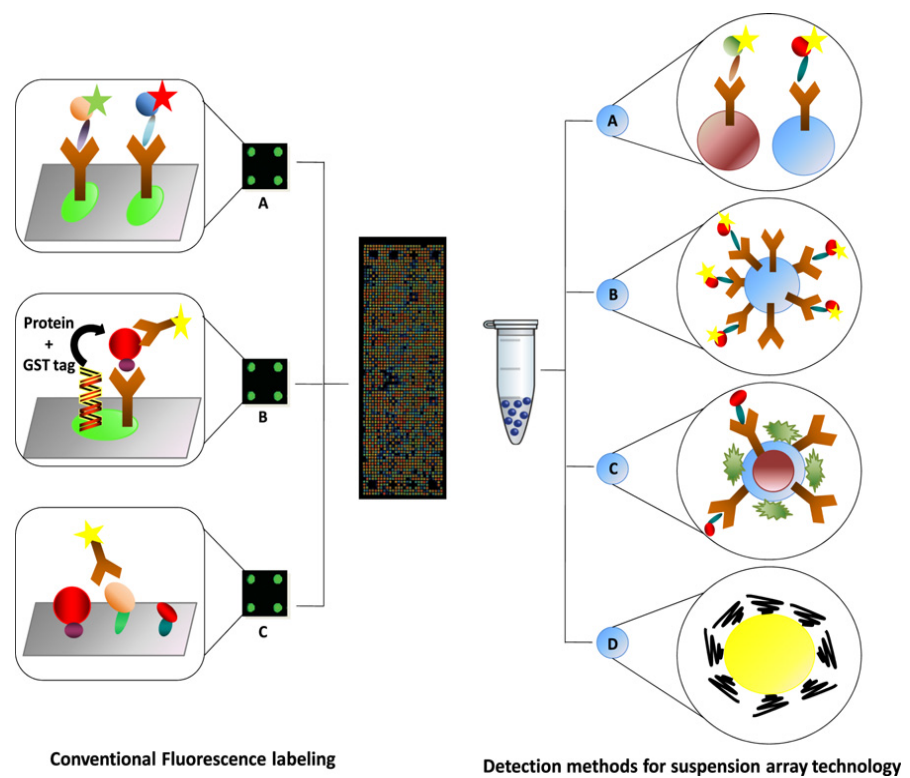

Conventional Fluorescence labeling

Detection methods for suspension array technology

Fig. 1. Label-based detection of protein microarrays used for proteomic studies. Scheme of standard label reagents and novel nano-approaches. (1) Fluorescent detection of conventional protein microarrays: (a) target protein arrays. (b) NAPPA protein arrays. (c) Reverse phase microarrays. (2) Beads suspension arrays: (a) beads suspension arrays and detection by flow-cytometry. (b) Magnetic beads. (c) Quantum-dots, (d) gold-nanoparticles. 
(ORFs) is required. Many different protein in situ arrays have been developed in the last years, for example: Protein in situ arrays (PISA) arrays, Printing protein arrays from DNA (DAPA) arrays and Nucleic Acids Programmable Protein Arrays (NAPPA) arrays (He and Taussig, 2001; Tao and Zhu, 2006; Ramachandran et al., 2008a,b).

\subsection{Detection techniques for protein microarrays}

So far, detection systems have been significantly improved allowing for rapid advancements in protein microarrays development.

In general, the ideal detection method should include critical parameters for the success of sensing technologies concerning sensitivity, detection limit, dynamic range, multiplexing capability and resolution.

\subsubsection{Label-based detection methods}

To date, the majority of microarray applications have employed label-based detection techniques due to their relative simplicity, wide availability of reagents and scanning instrument requirements. As mentioned, in addition to the conventional labeling strategies other molecules are being gradually introduced for the improvement of detection methods such as quantum-dots, gold nanoparticles, dye-doped silica or carbon nanotubes. Moreover, dye-bead-based techniques such as flow cytometry- and magnetic bead-based detection strategies are currently being explored with promising results (Fig. 1).

2.1.1.1. Conventional fluorescence labeling. Among the first detection procedures to be developed is the use of radioisotope molecules like ${ }^{32} \mathrm{P}$, which have been successfully employed to study protein interactions, between other applications. However, nowadays this methodology is unavoidably tending to disappear due to the inherent potentially damaging nature of such molecules. Soon after, the use of conventional dye (e.g.: fluorescein, rhodamine, nitrobenzoxadiazole, phycobiliproteins, bodipy and cyanines) compounds become most commonly used for protein detection in microarrays (Angenendt, 2005) However, it has to be considered that the appropriate choice of fluorophore molecules relies on many factors associated to the sample nature the substrate used, the light emission spectra of the dye and the number of target proteins in the sample. Furthermore, it is interesting to highlight that the detection of substrates with auto-fluorescence properties becomes tough as significantly decreases the signal-to-noise ratio.

In this regard, the use cyanine dyes (e.g.: Cy3 and Cy5) are among the most common fluorophores employed for protein microarray detection because of the limited dye interactions, brightness and the reduced complexity of labeling proteins with charged lysine residues.

Direct detection of fluorescent products can be assessed either by direct or indirect labeling methods. Thus, through direct labeling, the target protein is directly targeted with the fluorophore, which is absorbed by immobilized antibodies onto the solid array surface. Interestingly, dual fluorescence methods have been recently used for identification of biomarkers in prostate cancer, allowing the detection of nine differential proteins (Miller et al., 2003). Moreover Srivastava et al. (2006) used conventional Cy3 and $\mathrm{Cy} 5$ fluorophores for the identification of serum protein profiles in cystic fibrosis. Therefore, comparison of the protein expression patterns of pooled serum from these patients and controls revealed the former to depict selective protein expression patterns in lungs and intestine. Of note, detection limit of $6.25 \mathrm{pg}$ was achieved using the conventional dyes ( $\mathrm{Cy} 3$ or $\mathrm{Cy} 5$ ).

In the indirect detection method, target unlabeled proteins are captured by antibodies immobilized on the array surface. Thus, detection is based on a secondary antibody attached to a fluorophore molecule. Overall, this technique offers higher specificity due to binding of two target antibodies at different epitopes of the analyte of interest and high sensitivity because of low background labeling (Haab, 2003). The use of sandwich assay for multiplexed protein detection is usually limited to $30-50$ targets due to lack of specific antibodies available for all purified antigen targets. In addition, antibody microarrays were successfully used to monitor the activation, uptake and signal transduction of ErbB receptor kinases and also for the identification of small-molecule inhibitors of signal transduction pathways (Nielsen et al., 2003). Zhou et al. (2004) developed a innovative two-color protocol for the detection of different labeled proteins from parallel serum samples immobilized on antibody microarrays. By this approach up to 75 inflammatory cytokines (including macrophage inflammatory protein $1-\beta$, IL-8, interferon-inducible protein-10, eotaxin-2, I-309) were analyzed in a protein microarray, in which detection limits below femtomolar protein concentration range were achieved.

\subsubsection{Detection methods for suspension array technology}

2.1.2.1. Flow cytometry. Immunophenotypic studies by flow cytometry (FC), is a highly specific approach for fluorescent-based multiple protein detection providing an established platform for rapid, quantitative and multiplexed analysis of antigens of interest in biological samples.

Together with the widespread use of FC as key tool to evaluate phenotypic patters in basic and clinical research, FC allows for detection of soluble proteins using microspheres as a support for the assessment of immunoassay, nucleotide sequencing and molecular complex of transcription factors and related receptors. Although FC is a strongly validated technology, the use of microspheres have been largely restricted to calibration and absolute cell quantification. However, the full potential of this approach has been realized few years ago. Thus, among the newly proposed applications for microspheres by FC is multiplexed antibody capturing for cytokine quantification, single nucleotide polymorphism genotyping, phosphorylated protein detection, and characterization of molecular interactions of nuclear receptors (Edwards et al., 2004).

Briefly, microspheres of different colors and known sizes harboring orientated capture antibodies are incubated with target proteins from diverse samples, which are then revealed with fluorescent-tagged secondary antibodies Detection is further achieved by a flow cytometer that contains at least two laser sources for simultaneous quantitative and qualitative analysis of the analytes of interest. Of note, the number of lasers, the number of detectors, the setup of filters and data processing tools will affect the number of antibodies and the types of fluorochromes that can be simultaneously assessed (Edwards et al., 2004).

The advantages associated to FC over conventional fluorescence detection rely on the rapid and accurate assessment of multiple samples at a time with limited time consuming, scarce background signal, cost-effectiveness and high sensitivity, among others (Wu et al., 2009).

The study of the complexity of the human proteome strongly demands the development of specific antibodies against a wide spectrum of target proteins. In this sense, bead-based FC can be easily adapted to perform simultaneous analysis of a large number of antigens in one step (Morgan et al., 2004). In brief, the suspension array is based on the combination of beads with different ratios of red- and infrared-dyes, generating a set of 100 beads with differential color codes, generating individual fluorescent patterns. Each set of beads is used for the covalent immobilization of peptides of around 100-150 amino acids length with low homology with other proteins, excluding trans-membrane regions and signal 
transduction peptides. Such peptides are also used for immunization of rabbits. The bead mixture is further used to create a homogeneous array suspension for determining the antibody specificity within 85 purified polyclonal anti-sera with different affinities (Schwenk et al., 2007). The detection of specific antibodies recognizing the coupled peptide is performed by one anti-rabbit IgG antibody conjugated with a fluorochrome. The results from bead based specificity validation method are then confirmed by a high correlation with planar microarrays. This bead-based approach provides a HT tool for specificity analysis of binding molecules, with a great impact on antibody based proteomic field.

During the last years, additional assays based on multiplexed capture antibodies for the detection of analytes from several sources are developing. For example, a recently reported platform allows detection of the highest number of proteins achieved so far (Wu et al., 2009). This platform is based on a protein G-coated beads suspension array composed of about 300 unique particle subsets; in each subset antibodies are subsequently immobilized and orientated. In addition, this platform incorporates Western blotting basis, resolving the antibody specificity against protein size as a second parameter. The authors reported that most of the antibodies captured a single protein or a defined complex such as $\mathrm{MHCl} /$ beta 2 microglobulin (B2M) from protein fraction obtained by size exclusion chromatography from leukocytes and cell lines. The analysis of the results obtained for this two-dimensional platform provides information about complex elution profiles and illustrates its potential in large scale protein complex identification.

Molecular biology is another scientific field in which the introduction of suspension bead-based arrays would be particularly interesting, to achieve rapid and more sensitive and robust assays for diagnostic purposes. Accordingly, detection of several pestiviruses has been proposed as a model (LeBlanc et al., 2009). Thereby, four recognized species in the pestivirus genes of Flaviviridae family were identified by this approach. This family of pestivirus has a significant economical relevance in the livestock sector. By this multiplex method, the isolation and amplification of RNA from pestivirus is performed through the use of a pan-pestivirus RTPCR, in order to increase the signal. The biotinylated PCR products, were hybridized on a DNA capture suspension microarray with the matching oligonucleotides coupled to carboxylated microbeads The plates were carried out with streptavidin- $R$-phycoerythrin. Therefore, the combination of PCR amplification and multiplexed suspension bead-based array achieved high sensitivity. Thus, this approach provides a friendly HT detection and differential analysis of viral pathogens.

Other applications for bead-based array suspension are being currently developed for FC detection, as a versatile platform for assessment of diverse molecular interactions (Blazer et al., 2010; Wu et al., 2009). For example, screening of soluble compound libraries in drug discovery has been previously reported. Drug discovery, involves also binding analysis; therefore microbeads offer a solid-phase for combinatorial-chemistry improving the display of libraries and the analysis of these interactions. Other recent applications reported include the identification of molecules that inhibit interactions of the signaling $G \alpha$ subunit and the RGS protein, using a FC protein interaction assay (FCPIA) (Blazer et al., 2010).

This method is mainly based upon immobilization of proteins onto polystyrene beads for the quantitative analysis of proteinprotein interactions. Moreover bead-based arrays can also be used for the kinetic characterization of enzymatic cleavage mechanisms as well interaction of enzymes with multiple substrates in a multiplexed analysis (Blazer et al., 2010). Finally, antibody bead-based capture array are also being developed for determining phosphoprotein profiling, where phospho-specific antibodies coupled to microbeads are aimed for capturing phosphoproteins from cell lysates in order to be quantified by a secondary antibody.

2.1.2.2. Magnetic bead-based detection. This technology includes the use of magnetic beads coated with secondary antibodies to detect target proteins on the capture antibody, which represent an alternative to direct fluorescent staining. Thus, high sensitivity and reproducibility together with rapid detection, low background signal - due to removal of weakly bound beads - wide dynamic range high specificity and cost-effectiveness make this approach an ideal detection method for suspension array technologies (Gantelius et al., 2009). It has been recently reported a comparison of antibody-coated magnetic beads with the conventional fluorescence method for the detection of 12 auto-antigens from 21 serum samples from patients with auto-immune diseases and healthy controls on a single antigen microarray. This work revealed that magnetic bead-based detection is a highly sensitive and cost-effective method (Gantelius et al., 2009). However, this technique is still at proof-of-concept and requires further development before it becomes fully established.

Improving the sensitivity of techniques for isolation of malignant cells has a noteworthy relevance in clinical research, for improvement of diagnostic stratification of patients and identification of new targets for directed-therapy design in patients suffering from neoplastic diseases. In this regard, Song et al. (2011) reported fluorescent-magnetic-bio-targeting multifunctional nano-bioprobes (FMBMMs) to be useful for the detection and isolation of multiple target cells from complex cultures. Therefore, by fluorescent microscopy on cancer and apoptotic cells, an isolation efficiency of around $96-97 \%$ was reached, with such a high sensitivity that allowed for detecting neoplasic cells at concentrations of $0.01 \%$ within cultures (Song et al., 2011). Overall, these results suggest the potential utility of this technique for detection of cancer cells at early stages and low concentration.

\subsubsection{Quantum dots}

Quantum dots are nanometer-sized crystals composed of a semiconductor fluorescent core (cadmiun selenide) coated with another semiconductor shell (cadmiun sulfide or zinc sulfide) with a larger spectral band gap, and stable light-scattering or -emitting properties. These compounds display a wide range of applications in biological sciences such as diagnostic imaging, detection of cancer biomarkers, direct probing of human serum and tumor biopsy analysis (Sun et al., 2006; Jokerst et al., 2010).

This nanometer-sized semiconductor particles can be covalently linked with bio-recognition molecules such as peptides, antibodies or nucleic acids for use as biological labels. Introduction of quantum dots provide advantages compared with organic dyes with brighter fluorescence, an excellent photo-stability against photo-bleaching, multicolor fluorescence excitation, tunable emission spectra (even with single excitation wavelength), narrow emission spectra and greater quantum yield (Sun et al., 2006; Jokerst et al., 2010). Using streptavidin-coated quantum-dots for detection of six cancer-specific cytokines using antibody microarrays. By this approach, TNF- $\alpha$, IL-8, IL-6, macrophage inflammatory protein- $1 \beta$, IL-13 and IL- $1 \beta$ were successfully detected at picomolar concentrations (Zajac et al., 2007). Interesting comparative study of quantum-dots versus various organic fluorophores revealed that quantum-dots are 30-times more sensitive for identification of cancer biomarkers (carcinoembryonic antigen, cancer antigen 125 and her-27Neu) both in serum and saliva (Ghazani et al., 2006).

Despite these benefits, quantum-dots depict low stability and short time-of-life of due to its susceptibility to oxidation and photolysis. Moreover, and most importantly, undesirable hazards 
related to human health and environment are associated to the use of this technique.

\subsubsection{Gold nanoparticles}

The excitation of coherent electron oscillations that exits at the interface between two materials of different nature is known as surface plasmon resonance (SPR), which represents the benchmark for the use of gold nanoparticles as label-based detection systems. Gold nanoparticles, labeled with suitable capture biomolecules, exhibit a deviation in emission spectrum of scattered light due to effective binding of the analyte of interest from a protein mixture by specific biomolecular interactions (Ray et al., 2010; Yan et al., 2007).

Gold nanoparticles have been found to provide multiple applications for sensitive detection of standard proteins due to its optimal optical properties, higher quantum efficiency, compatibility with a wide range of wavelengths and chemical stability against photobleaching (Yan et al., 2007).

Scanometric immunoassay with gold nano-particles probes have been previously used for multiplexed detection of prostatespecific antigen (PSA) on protein microarray with improved sensitivity as compared with silver enhancement, with a detection limit of $300 \mathrm{amol}$ in buffer and $3 \mathrm{fmol}$ in 10\% serum (Liang et al., 2004). Colorimetric gold-nanoparticles conjugated with antibodies have been used for the detection of analytes on microarrays with sensitivity down to $1 \mathrm{pg}$ (Gao et al., 2008).

Interestingly, interactions between proteins and carbohydrates, which are more difficult to monitor than protein-protein interactions, have been studied using a microarray-based resonance light scattering approach. As additional proof of concept experiments, it has been successfully demonstrated the existence of carbohydrate-lectin and glycoprotein-lectin interactions by using gold-nanoparticles. In addition, this technique has also innovatily applied for the screening antibacterial drugs (Gao et al., 2010).

Interestingly, selective discrimination between various bacterial strains was achieved with sensitivity down to $10^{3}$ and a dynamic range covering nearly three orders of magnitude (Gao et al., 2008, 2010).

Although gold nanoparticles have been reported to be suitable for in vivo studies due to their biocompatibility and low cellular toxicity, systematic cytotoxicity studies must be performed when nanoparticles are functionalized with a different ligand.

\section{Label-free techniques}

At current, there is an increasing interest to overcome the limitations associated to label-based detection strategies such as the alteration of surface characteristics of the query molecule, time and effort required for labeling, the inherent difficulties of multiplexing and derived toxicity has which rely on the query molecule itself.

The label-free techniques are probed to be useful for the study of real-time kinetics of biomolecular interactions, which are not hindered by interaction with tag molecules.

In the field of protein microarrays, other remaining requirements for detection methods are related to compatibility to HT arraying procedures, the ability to detect binding of small molecules and achievement of a wide dynamic range. In this regard, a wide variety of technologies, at different stages of development are currently being tested as suitable label-free detection methods as briefly summarized below.

\subsection{Surface plasmon resonance (SPR)}

SPR technology is based on the generation of the so-called surface plasmons. These are oscillations of free electrons that propagate in parallel to a metal/dielectric interface, which allows measuring changes in refractive index close to the sensor surface (Ramachandran et al., 2005). Thus, the occurrence of associations or dissociations of molecules at the plasmon surface translates into the modification of the reflection intensity with respect to the incident angle which is further depicted in a sensorgram (Fig. 2). Therefore, SPR enables accurate determination of association to dissociation rate of the binding process between molecules as well as evaluate the strength of the binding and the specificity of the occurring interactions on large scale. Consequently, it is possible to measure biomolecular interactions in real-time with a very high sensitivity (Ramachandran et al., 2005).

On the basis of its unique characteristics and potential applicability, SPR is becoming of increasing relevance in biomedical research; for example in antibody screening, implementation of cancer diagnosis or for the innovative label-free detection of small molecules on a microarray chip.

In 2009, Ladd et al. made use of SPRi techniques for the detection of candidate diagnostic) biomarkers in cancer using antibody arrays. Interestingly, SPRi is showing to be a potentially useful technique for biomarker characterization in serum proteomic studies (Ladd et al., 2009). Noteworthy, additional studies have reported the combination of SPRi with a microfluidic chamber to obtain continuous flow of the analyte during the experiment.

\subsection{Microcantilevers \& AFM (atomic force microscopy)}

Microcantilevers are silicon-based, gold-coated surfaces associated to nanomechanics for biomolecular recognition (Braun et al., 2009). Cantilevers are mainly associated to atomic force microscopy (AFM). In this technology, a cantilever with a sharp tip in direct contact or oscillating (contact for a short time during the oscillation cycle), interacts with the sample surface scanning, thanks to a piezoelectric scanner. The bending of the cantilever is measured by optical detection of the position of a laser beam (Fig. 2). This method based on microscopical scanning of samples is the most powerful and versatile surface-characterization tool to provide information concerning surface topological variations at the molecular and atomic level. In this sense, the use of AFM finds applications in surface characterization of protein microarrays, immobilization of different biomolecules with micrometer resolution and for detection of protein-protein interactions (Breitenstein et al., 2010). Through this technology, Soultani-vigneron et al. (2005), developed a three-step technique for the immobilization of oligopeptides probed for protein microarray applications, using a combination of AFM, Fourier transform infrared spectroscopy and fluorescence scanning microscopy.

Other applications of cantilevers beyond the imaging surfaces are the cantilever-array sensors, for sensing proposes not required a sharp tip to contact the surface sample, only use an array of cantilevers beams, each coated with a sensitive layer for molecular recognition. The mechanical response of a sensitive layer applied onto one cantilever surface to the real recognition of molecules from the environment produce a signal such as static bending or differential deflection of the cantilever, that is measured by emitting lasers and a suitable electronic systems (Fig. 2). These devices, allow the translation of biomolecular recognition into a direct nanomechanical response, for detection of chemical and biochemical reactions in both gas-phase and liquid environments (Fritz et al., 2000). In a gaseous environment, this technology can be used such as an artificial nose to characterize odors and volatile chemicals. In this review, however, we focus on liquid environments, where cantilever sensors allow us a rapid, quantitative, qualitative and reproducible detection of non-labeled biomolecules such as specific DNA hybridization, antibody-antigen recognition or protein-protein interaction. For this purpose, either antibodies, 

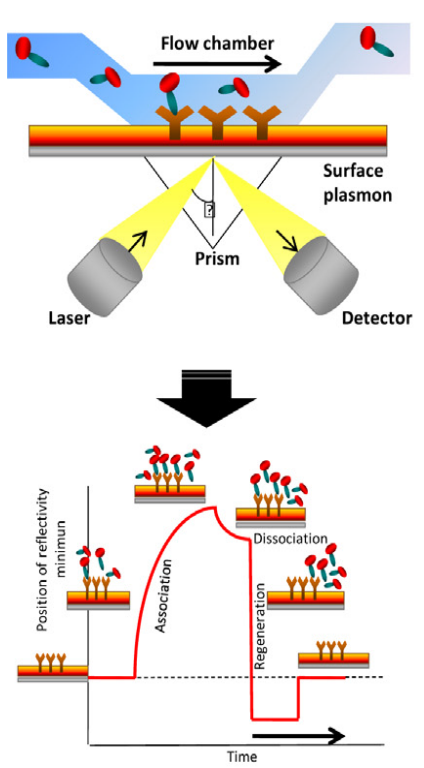

A. Surface Plasmon Resonance
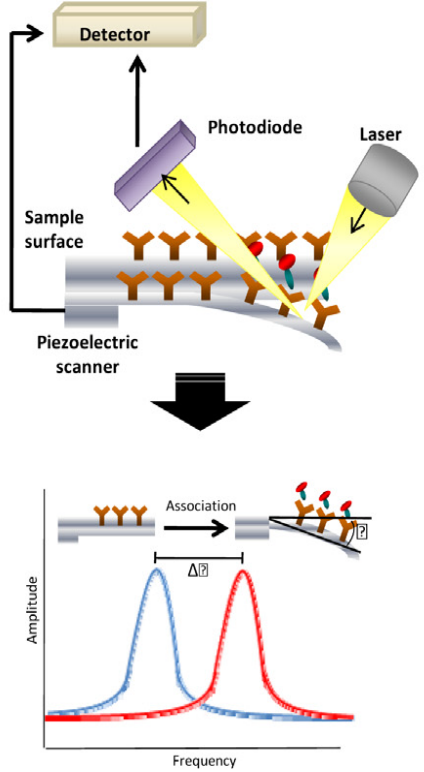

B. Microcantilevers
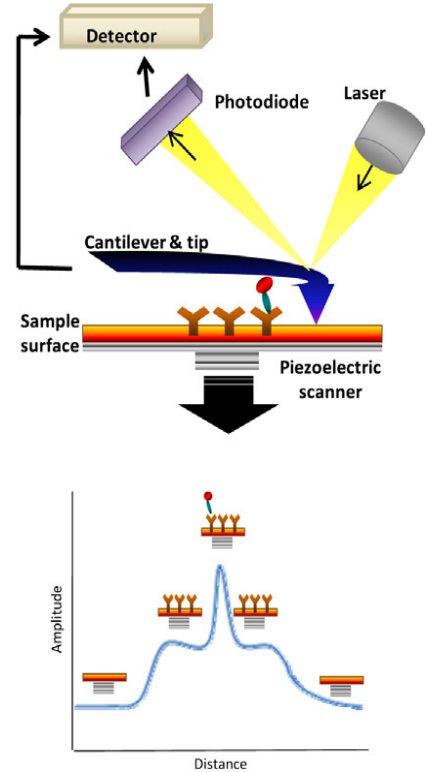

C. Atomic Force microscopy

Fig. 2. Label-free detection of protein microarrays used for proteomic studies. (a) Surface plasmon resonance: any changes in refractive index at the surface due to binding interactions between the probe and analyte are reflected in sensorgram by changes in reflection angle. (b) Microcantilevers: bending of the antibody-coated silicon cantilevers upon binding the target analyte is detected either by a change in an optical property, such as change in the angle of reflection, or by a change in an electronic property like change in mass. (c) Atomic force microscopy: scheme of AFM instrument. Surface topological changes on the microarray plate can be detected with picometer resolution by measuring any deflection of the cantilever.

proteins or DNA are immobilized at the end of silicon strips. For immobilization can be applied various techniques such as incubation in glass capillaries or coating using a ink-jet spotting device.

On the basis of this knowledge, interactions between molecules of different nature can also be assessed by microcantilevers, including antigen-antibody binding assays, detection of protein conformational changes and study of complex biological samples. Thus, several bioassays has been developed for the quantitative detection prostate-specific antigen (PSA) over a wide range of different concentrations using microcantilevers, demonstrating this label-free technique is sufficiently specific and sensitive to detect disease-related proteins at clinically relevant conditions and concentrations (Guanghua et al., 2001).

PSA was also chosen as the model analyte for the development of immunoassays with a two-dimensional (2D) microcantilever array. This allowed to the authors, explore different surfaces for label free antibody-antigen binding assay (Yue et al., 2008).

In a recent study reported by Braun et al. (2009) microcantilever sensors were used for label-free, time-resolved detection of membrane protein interactions with corresponding ligands in array format.

In the same way, piezoelectric cantilever arrays with an electrical readout have also been applied for protein detection using glutathione-S-transferase (GST) and the detection of GST antibodies down to a concentration compatible with an standard optical system (Daukasaite et al., 2007).

In addition, cantilevers biosensors offer interesting possibilities for label-free detection of specific protein conformations. By using the ligand-binding domain of the human estrogen receptor (ER $\alpha$ LDB) as the model to distinguish between the conformations of oestrogen receptors (ERs) in free and oestraidol (E2)-bound form (Mukhopadhyay et al., 2005).
Similarly, the cantilever array sensor can play a relevant role in the study of enormous complexity of the glycome. Kathrin Gruber et al. (2011) described the development of a cantilever array biosensor for the detection of clinically relevant carbohydrate-protein interactions with a picomolar sensitive and in a reliable, selective and reusable way.

Finally, other field where microcantilevers are an attractive label-free option is in the study of enzyme-substrate interactions. Digvijay et al. (2008) quantified the interaction between trypsin and fibronectin fragment, as a protease-substrate activity model, and its inhibition using SBTI substrate. Demonstrating that a microcantilever array can serve as a platform to quickly screen for inhibitors of known proteases, helping to identify biomarkers as well as therapeutic targets.

\section{Concluding remarks}

Over the last few years, nanotechniques have undergone a significant progress for reliable handling the complexity of cell proteome. Therefore a number of nanotechniques have been lately used for diverse applications such as biomarker discovery, label-free protein detection, study of protein interactions and printing of protein microarrays. The advantages offered by these approaches have allowed to be successfully coupled with the rapidly expanding field of proteomics. Among the most relevant emerging techniques, carbon nanotubes and nanowires, quantum dots and gold nanoparticles have drawn great attention due to its potential to minimize precious sample and reagent consumption.

Despite the advancement of these new and versatile technologies in proteomics, nanotechniques still face several limitations to be resolved for widespread application, including the lack of simple, well-established surface modification methods to enhance 
biocompatibility, the insufficient knowledge of the exact mechanisms involved and the incidence of cross-reactivity during multiplexed analysis.

Currently, new proteomics and nanotechnology disciplines are being progressively adopted by clinical research due to the availability of multiple-novel techniques and the wide spectrum of potential applications to deepen into the knowledge of the pathophysiology of unresolved diseases. Noteworthy, the multiple technologies and techniques briefly described above, might eventually lead to the characterization of new molecular entities and/ or disease-associated molecular modifications for improving diagnostic and prognostic stratification. Despite this, many efforts are still required to implement the current status of these approaches towards clinical standardization.

Finally, the application of these technologies to study at cells at the whole proteome level in HT format is the ultimate challenge of proteomics. Nowadays, it is possible to anticipate a significant development in near future that will make nano-proteomics field more robust, sensitive, reliable and above all, biocompatible and environment friendly.

\section{Acknowledgements}

We gratefully acknowledge financial support from Health Institute Carlos III of Spain (ISCIII, FIS PI081884) and JCYL-SAN10. María Gonzalez-Gonzalez is supported by a PhD scholarship of ISCIII FI08/00721.

\section{References}

Angenendt, P., 2005. Progress in protein and antibody microarray technology. Drug Discov. Today 10 (7), 503-511.

Blazer, L.L., Roman, D.L., Muxlow, M.R., Neubig, R.R., 2010. Use of flow cytometric methods to quantify protein-protein interactions. Curr. Protoc. Cytometry 13.11.1-13.11.15.

Borrebaeck, C.A., Ohlin, M., 2002. Antibody evolution beyond nature. Nat. Biotechnol. 20, 1189-1190.

Braun, T., Ghatkesar, M.K., Backman, N., Grange, W., Boulanger, P., Letellier, L., Lang, H.P., Bietsch, A., Gerber, C., Hegner, M., 2009. Quantitative time-resolved measurements of membrane protein-ligand interactions using microcantileve array sensors. Nat. Nanotechnol. 4 (3), 179-185.

Breitenstein, M., Hoelzl, R., Bier, F.F., 2010. Immobilization of different biomolecules by atomic force microscopy. J. Nanobiotechnol. 8, 10.

Chan, S.M., Ermann, J., Su, L., Fathman, C.G., Utz, P.J., 2004. Protein microarrays for multiplex analysis of signal transduction pathways. Nat. Med. 10 (2), 1390 1396.

Chandra, H., Srivastava, S., 2010. Cell-free synthesis-based protein microarrays and their applications. Proteomics 10 (4), 717-730.

Daukasaite, V., Lorentzen, M., Besenbacher, F., Kjems, J., 2007. Antibody-based protein detection using piezoresistive cantilever arrays. Nanotechnology 18 (18), 125503.

Edwards, B.S., Oprea, T., Prossnitz, E.R., Sklar, L.A., 2004. Flow cytometry for highthroughput, high-content screening. Curr. Opin. Chem. Biol. 8 (4), 392-398.

Ehrlich, J.R., Qin, S., Liu, B.C., 2002. The reverse-capture autoantibody microarray: a native antigen-based platform for autoantibody profiling. Nat. Protoc. 1 (1), 452-460.

Espina, V., Woodhouse, E.C., Wulfkuhle, J., Asmussen, H.D., Petricoin, E.F., Liotta, L.A 2004. Protein microarray detection strategies: focus on direct detection technologies. J. Immunol. Methods 290 (1-2), 121-133.

Fritz, J., Baller, M.K., Lang, H.P., Rothuizen, H., Vettiger, P., Meyer, E., Güntherodt, H., Gerber, C., Gimzewski, J.K., 2000. Translating biomolecular recognition into nanomechanics. Science 288 (5464), 316-318.

Gantelius, J., Hartman, M., Schwenk, J.M., Roeraade, J., Anderson-Svahn, H., Joos, T.O., 2009. Magnetic bead-based detection of auto-immune responses using protein microarrays. Nat. Biotechnol. 26 (6), 269-276.

Gao, J., Liu, D., Wang, Z., 2008. Microarray-based study of carbohydrate-protein binding by gold nanoparticles probes. Anal. Chem. 80 (22), 8822-8827.

Gao, J., Liu, C., Liu, D., Wang, Z., Dong, S., 2010. Antibody microarray-based strategies for detection of bacteria by lectin-conjugated gold nanoparticle probes. Talanta $81(4-5), 1816-1820$.

Ghazani, A.A., Lee, J.A., Klostranec, J., et al., 2006. High-throughput quantification of protein expression of cancer antigens in tissue microarray using quantum dot nanocrystals. Nano Lett. 6 (12), 2881-2886.

Guanghua, Wu., Datar, Ram.H., Hansen, Karolyn.M., Thundat, Thomas., Cote, Richard.J., Majumdar, Arun., 2001. Bioassay of prostate-specific antigen (PSA) using microcantilevers. Nat. Biotechnol. 19 (9), 856-860.
Haab, B.B., 2003. Methods and applications of antibody microarrays in cancer research. Proteomics 3 (11), 2116-2122.

Hall, D.A., Ptacek, J., Snyder, M., 2007. Protein microarray technology. Mech. Ageing Dev. 128 (1), 161-167.

He, M., Taussig, M.J., 2001. Single step generation of protein arrays from DNA by cell-free expression and in-situ immobilization (PISA method). Nucleic Acids Res. 29, E73-75.

Jokerst, J.V., Raamanathan, A., Christodoulides, N., et al., 2010. Nano-bio-chips for high performance multiplexed protein detection: determinations of cancer biomarkers in serum by using a quantum-dot-based microfluidic protein chip. ACS Nano. 4 (1), 488-494.

Gruber, Kathrin, Horlacher, Tim, Castelli, Riccardo, Mader, Andreas, Seeberger, Peter H., Hermann, Bianca A., 2011. Cantilever array sensors detect specific carbohydrate-protein interactions with picomolar sensitivity. ACS Nano. 5 (5), 3670-3678.

LaBaer, J., Ramachandran, N., 2005. Protein microarrays as tools for functional proteomics. Curr. Opin. Chem. Biol. 9 (1), 14-19.

LeBlanc, N., Gantelius, J., Schwenk, J.M., Andersson-Svahn, Blomberg J., Stahl, K., Belak, S., 2009. Development of magnetic bead microarray for simultaneous and simple detection of four pestiviruses. J. Virol. Methods 155, 1-9.

Liang, R.Q., Tan, C.Y., Ruan, K.C., 2004. Colorimetric detection of protein microarrays based on nanogold probe coupled with silver enhancement. J. Immunol. Methods 285 (6), 157-163.

Marko-Varga, G., Fehninger, T.E., 2004. Proteomics and disease - the challenges for technology and discovery. J. Proteome Res. 3 (2), 167-178.

Matarraz, S., González-González, M., Jara-Acevedo, M., Orfao, A., Fuentes, M., 2011. New technologies in cancer. Protein microarrays for biomarker discovery. Clin. Transl. Oncol. 13 (3), 156-161.

Miller, J.C., Zhou, H., Kwekel, J., et al., 2003. Antibody microarray profiling of human prostate cancer sera:antibody screening and identification of potential biomarkers. Proteomics 3 (1), 56-63.

Morgan, E., Varro, R., Sepulveda, H., Ember, J.A., Apgar, J., Wilson, J., Lowe, L., Chen, R., Shivraj, L., Agadir, A., Campos, R., Ernst, D., Gaur, A., 2004. Cytometric bead array: a multiplexed assay platform with applications in various areas of biology. Clin. Immunol. 110, 252-266.

Mukhopadhyay, R., Sumbayev, V.V., Lorentzen, M., Kjems, J., Andreasen, P.A., Besenbacher, F., 2005. Cantilever sensor for nanomechanical detection of specific protein conformations. Nano Lett. 5 (12), 2385-2388.

Nielsen, U.B., Cardone, M.H., Sinskey, A.J., McBeath, G., Sorger, P.L., 2003. Profiling receptor tirosin kinase activation by using Ab microarrays. Proc. Natl. Acad. Sci. USA 5, 299-307.

Ramachandran, N., Larson, D.N., Stark, P.R., Hainsworth, E., LaBaer, J., 2005. Emerging tools for real-time label-free detection of interactions on functional protein microarrays. FEBS J. 272 (21), 5412-5425.

Ramachandran, N., Raphael, J.V., Hainsworth, E., Demirkan, G., Fuentes, M.G., Rolfs, A., Hu, Y., Labaer, J., 2008a. Next-generation high-density self-assembling functional protein arrays. Nat. Methods

Ramachandran, N., Srivastava, S., Labaer, J., 2008b. Applications of protein microarrays for biomarker discovery Proteomics. Clin. Appl. (10/11), 14441459.

Raorane, Digvijay A., Lim, Mark D., Chen, Fanqing Frank, Craik, Charles S., Majumdar, Arun, 2008. Quantitative and label-free technique for measuring protease activity and inhibition using a microfluidic cantilever array. Nano Lett. 8 (9), 2968-2974.

Ray, S., Mehta, G., Srivastava, S., 2010. Label-free detection techniques for protein microarrays: prospects, merits and challenges. Proteomics 10 (4), 731-748.

Rifai, N., Gillete, M.A., Carr, S.A., 2006. Protein biomarkers discovery and validations: the long and uncertain path to clinical utility. Nat. Biotechnol. 24, 971-983.

Sanchez-Carbayo, M., 2006. Antibody arrays: technical considerations and clinical applications in cancer. Clin. Chem. 52 (2), 1651-1659.

Schwenk, J.M., Lindberg, J., Sundberg, J., Sundberg, M., Uhlen, M., Nilsson, P., 2007. Determination of binding specificities in highly multiplexed bead-based assays fro antibody proteomics. Mol. Cell. Proteomics 6.1,125-132.

Sheehan, K.M., Calvert, V.S., Kay, E.W., et al., 2005. Use of reverse-phase protein microarrays and reference standard development for molecular network analysis of metastatic ovarian carcinoma. Mol. Cell Proteomics 4 (4), 346355.

Song, E.Q., Hu, J., Wen, C.Y., Tian, Z.Q., Yu, X., Zhang, Z.L., Shi, Y.B., Pang, D.W 2011. Fluorescent-magnetic-biotargeting multifunctional nanobioprobes for detecting and isolating multiple types of tumor cells. ACS Nano. 5 (2), 761770

Soultani-Vigneron, S., Dugas, V., Rouillat, M.H., et al., 2005. Immobilization of oligopeptidic probes for microarray implementation: characterization by FTIR atomic force microscopy and 2D fluorescence. J. Chromatogr. B Analyt. Technol. Biomed. Life Sci. 822, 304-310.

Speer, R., Wulfkuhle, J.D., Liotta, L.A., 2005. Petricoin. Reverse-phase protein microarrays for tissue-based analysis. Curr. Opin. Mol. Ther. 7, 240-245.

Srivastava, M., Eidelman, O., Jozwik, C., et al., 2006. Serum proteomics signature for cystic fibrosis using an antibody microarray platform. Mol. Gent. Metab. 87 (4), 303-314.

Sun, Y.P., Zhou, B., Lin, Y., et al., 2006. Quantum-sized carbon dots for bright and colorful photoluminescence. J. Am. Chem. Soc. 128 (44), 7756-7757.

Tao, S.-C., Zhu, H., 2006. Protein chip fabrication by capture of nascent polypeptides. Nat. Biotechnol. 24, 1253-1254. 
Wu, W., Slastad, H., a Carrillo, D., Frey, T., Tjonnfjord, G., Boretti, E., Aasheim, H.C. Horejsi Lund-Johansen, F., 2009. Antibody array analysis with label-based detection and resolution of protein size. Mol. Cell Proteomics 8 (2), 245-257.

Yan, J., Estevez, M.C., Smith, H.E., et al., 2007. Dye-doped nanoparticles for bioanalysis. Nano Today 2 (3), 44-50.

Yue, M., Stachowiak, J.C., Lin, H., Datar, R., Cote, R., Majumdar, A., 2008. Label-free protein recognition two-dimensional array using nanomechanical sensors. Nano Lett. 8 (2), 520-524.
Zajac, A., Song, A.D., Qian, W., Zhukov, T., 2007. Protein microarrays and quantum dot probes for early cancer detection. Colloids Surf. B. Biointerfaces 58 (2), 309314.

Zhou, H., Bouwman, K., Schotanus, M., et al., 2004. Two-color, rolling-circle amplification on antibody microarrays for sensitive, multiplexed serumprotein measurements. Genome Biol. 5 (4), R28. 

Review

\title{
Biomarker Discovery by Novel Sensors Based on Nanoproteomics Approaches
}

\author{
Noelia Dasilva ${ }^{1, \dagger}$, Paula Díez ${ }^{1, \dagger}$, Sergio Matarraz ${ }^{1}$, María González-González ${ }^{1}$, \\ Sara Paradinas ${ }^{2}$, Alberto Orfao ${ }^{1}$ and Manuel Fuentes ${ }^{1, *}$
}

1 Centro de Investigación del Cáncer/IBMCC (USAL/CSIC), Departamento de Medicina and Servicio General de Citometría, University of Salamanca, Salamanca 37007, Spain; E-Mails: noeliadf@usal.es (N.D.); pauladg@usal.es (P.D.); smats@usal.es (S.M.); mariagg@usal.es (M.G.-G.); orfao@usal.es (A.O.)

2 Departamento de Química Analítica, Facultad de Ciencias Químicas, University of Salamanca, Salamanca 37008, Spain; E-Mail: ssparadinas@usal.es

$\dagger$ These authors contributed equally to this work.

* Author to whom correspondence should be addressed; E-Mail: mfuentes@usal.es; Tel.: +34-923-294-811; Fax: +34-923-294-743.

Received: 1 December 2011; in revised form: 20 January 2012 / Accepted: 14 February 2012 / Published: 16 February 2012

\begin{abstract}
During the last years, proteomics has facilitated biomarker discovery by coupling high-throughput techniques with novel nanosensors. In the present review, we focus on the study of label-based and label-free detection systems, as well as nanotechnology approaches, indicating their advantages and applications in biomarker discovery. In addition, several disease biomarkers are shown in order to display the clinical importance of the improvement of sensitivity and selectivity by using nanoproteomics approaches as novel sensors.
\end{abstract}

Keywords: biomarker; cancer; nanosensor; high-throughput techniques; microarray; proteomics

\section{Introduction}

Over the last decade, new-generation high-throughput (HT) methods have emerged and expanded in the field of proteomics, including next-generation sequencing and mass spectrometry technologies, 
which have enabled the study of increasing amounts of proteins with less sample requirements. Overall, this has translated into the possibility of performing multi-level studies of human diseases from the perspectives of genomics, transcriptomics and proteomics [1].

Proteomics research in human pathology has focused on the development of clinical applications for accurate diagnosis, early detection and prognostic assessment of human disease due to its potential utility in the identification of candidate biomarkers associated to disease status. Noteworthy, the elucidation of drugs' mechanisms of action by these approaches might lead to further characterization of new therapeutic targets. Hence, one of the most relevant applications of clinical proteomics is the identification and characterization of extremely-low abundance metabolites that might be disease-specific or even prognostic-associated. Therefore, the identification of biomarkers represents the ultimate tool for the improvement of early diagnostics, patient monitoring and for the evaluation of the safety and efficacy of therapeutic strategies [2,3].

Consequently the detection of such low-abundance biomarkers in biological fluids (e.g., blood, urine or saliva) requires HT detection techniques. In this sense, the integration of nanotechniques and proteomics has led to the development of nanoproteomics, which provides a robust analytical platform for real-time and sensitive detection of low-abundance proteins [4-6].

Therefore, nanoproteomics offers a real-time multiplexed analysis performed in a miniaturized assay, with low sample consumption and high sensitivity, thereby finding an increasing number of potential applications in research. Quantum dots, gold nanoparticles, carbon nanotubes and nanowires are few nanomaterials which have demonstrated potential to overcome the challenges of sensitivity faced by conventional proteomics for biomarker detection [7]. However, concerns regarding the toxicity and biocompatibility of nanotechniques still remain to be explored and much work is being carried out to ensure their safety for biological applications [8].

In this manuscript, we briefly describe the applications of nanoproteomics for biomarker discovery in various diseases focusing on neoplastic processes and also on auto-immune, metabolic and infectious diseases.

\section{Proteomics Technologies for Biomarker Discovery}

The advancement in proteomics techniques has provided a useful platform for the discovery of potential disease biomarkers, being protein microarrays one of the proteomics platforms involved jn biomarker discovery. Protein microarrays are miniaturized and parallelized array technology approaches for protein-protein interaction analysis and protein profiling $[9,10]$. Typically, thousands of proteins are printed and immobilized on functionalized glass slides, which can be simultaneously studied and analyzed in a HT fashion, thereby offering a high potential for characterizing the biology of a given cell of interest. To date, a number of microarray formats have been developed and recently implemented; all of them have tested as a versatile platform for many diverse applications [11]. Between them, there are DNA-microarrays or protein-chips which can use nanoporous alumina as substrate [12].

Together with the advances in microarray technologies, increasingly sensitive and reliable detection methodologies are being currently developed [4]. Such protein detection systems have progressively undergone a relevant transition from label-based to more sensitive label-free technologies. 
In general, label-based systems are mainly focused on the use of specific tags for target molecules as conventional fluorescent dyes and radioisotopes. In addition to the conventional labeling strategies other molecules are being gradually introduced for the improvement of detection methods such as quantum dots (QDs), gold nanoparticles (AuNPs) and carbon nanotubes (CNTs), among others. Moreover, dye-bead-based techniques such as flow-cytometry and magnetic bead-based detection strategies are currently being explored with promising results [4].

\subsection{Label-Based Detection Methods for Biomarker Discovery}

Enzyme-linked immunosorbent assay (ELISA) is the label-based reference method to identify and quantify biomarkers (Figure 1). However, this technique has some disadvantages: $(i)$ only one biomarker is measured per assay; (ii) 5 to $7 \mathrm{~h}$ are necessary to obtain the results; (iii) the valid range is only three orders of magnitude; (iv) two accurate antibodies are necessary. That is why in the last few years some variations on the classic ELISA have been appeared. Some examples are MesoScale ${ }^{\circledR}$, Searchlight ${ }^{\circledR}$, FASTQuant ${ }^{\circledR}$. These alternatives have reduced the final volumes needed from $200 \mu \mathrm{L}$ to $50-100 \mu \mathrm{L}$, as well as the time to three or four hours. Also, they can analyze 24 samples per assay and the range of detection has risen to four orders of magnitude [13].

Figure 1. Schematic description of ELISA experiments.

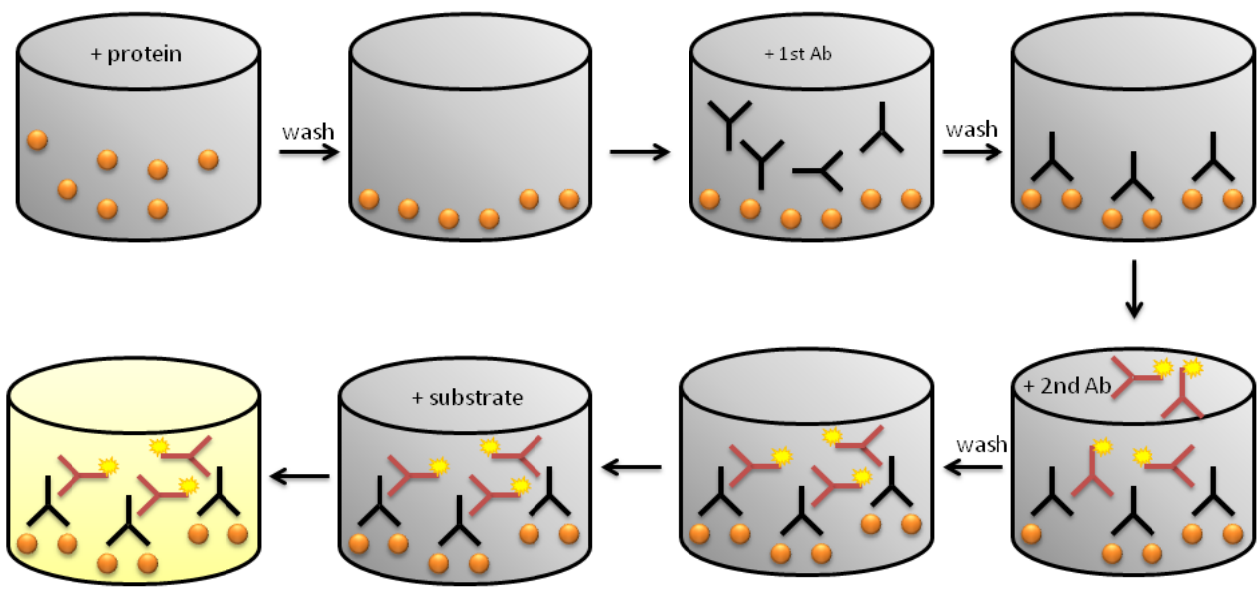

In this sense, protein microarrays have been employed as an alternative of conventional ELISA procedures, because of HT characteristics. Miller et al. have used antibody microarrays for discovery of serum biomarkers in prostate cancer, the most common solid organ malignancy affecting men [14]. The high-density antibody microarray containing 184 antibodies enabled the successful identification of five potential protein biomarkers; von Willebrand factor, IgM, $\alpha 1$-antic-hymotrypsin, villin, and IgG for prostate cancer.

In this regard, cyanine dyes (e.g., $\mathrm{Cy} 3$ and $\mathrm{Cy} 5$ ) are among the most common fluorochromes employed for protein microarray detection because of their brightness and the reduced complexity of labeling proteins with charged lysine residues. Srivastava et al. used conventional $\mathrm{Cy} 3$ and $\mathrm{Cy} 5$ fluorophores for the identification of serum protein profiles in cystic fibrosis [15]. Zhou et al. 
developed a innovative two-color protocol for the detection of different labeled proteins from parallel serum samples immobilized on antibody microarrays, in which detection limits are below femtomolar protein concentration [16].

During the last years, additional assays (for simultaneous detection of multiple analytes) have been developed based on multiplexed capture antibodies. For example, a recently developed approach allows detection of the highest number of proteins [17]. This novel platform is based on protein-G coated suspension beads array composed of about 300 unique particle subsets; in each subset antibodies are subsequently immobilized and properly orientated. In addition, this platform incorporates another analytical dimension, which is protein fractionation by size exclusion chromatography from plasma mononuclear cells and/or cell lines. The analysis of the results obtained for this two dimensional platform provides information about complex elution profiles and illustrates its potential in large scale protein complex identification; opening a new approach for assessment of molecular interactions studies [16]. Moreover bead-based arrays can also be used for the kinetic characterization as well as interaction of enzyme with multiple substrates in a multiplexed analysis [18].

Despite many different label-based methods detect variation in optical properties of fluorochromes or tags; notwithstanding other label-based methods have been developed on stable isotopic labeling in order to avoid problems expected with fluorochrome probes and their efficient conjugation with biomolecules, for example: fluorochrome-protein conjugates cannot affect specific groups of the antibody binding, binding procedures may decrease the fluorescence of fluorochromes such that the conjugate only show $15-30 \%$ of the fluorescence corresponding to a free dye, working $\mathrm{pH}$ (fluorescein at $\mathrm{pH} 8$ or rodamine at $\mathrm{pH} 7$ ) may also affect the results.

Stable isotope labeling with aminoacids in cell culture (SILAC) is a label technique which is analyzed by mass spectrometry (Figure 2). It is based on the metabolic incorporation of non-radioactive heavy isotopic forms of amino acids into the cellular proteins while cells are growing.

Figure 2. Schematic description of MS approaches used in biomarkers discovery. (A) SELDI-TOF; B) SILAC.

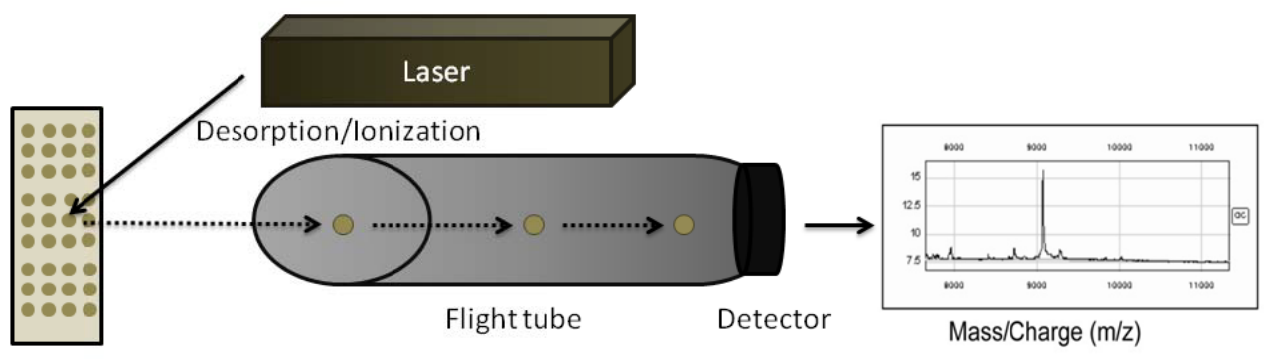

Chip 
Figure 2. Cont.

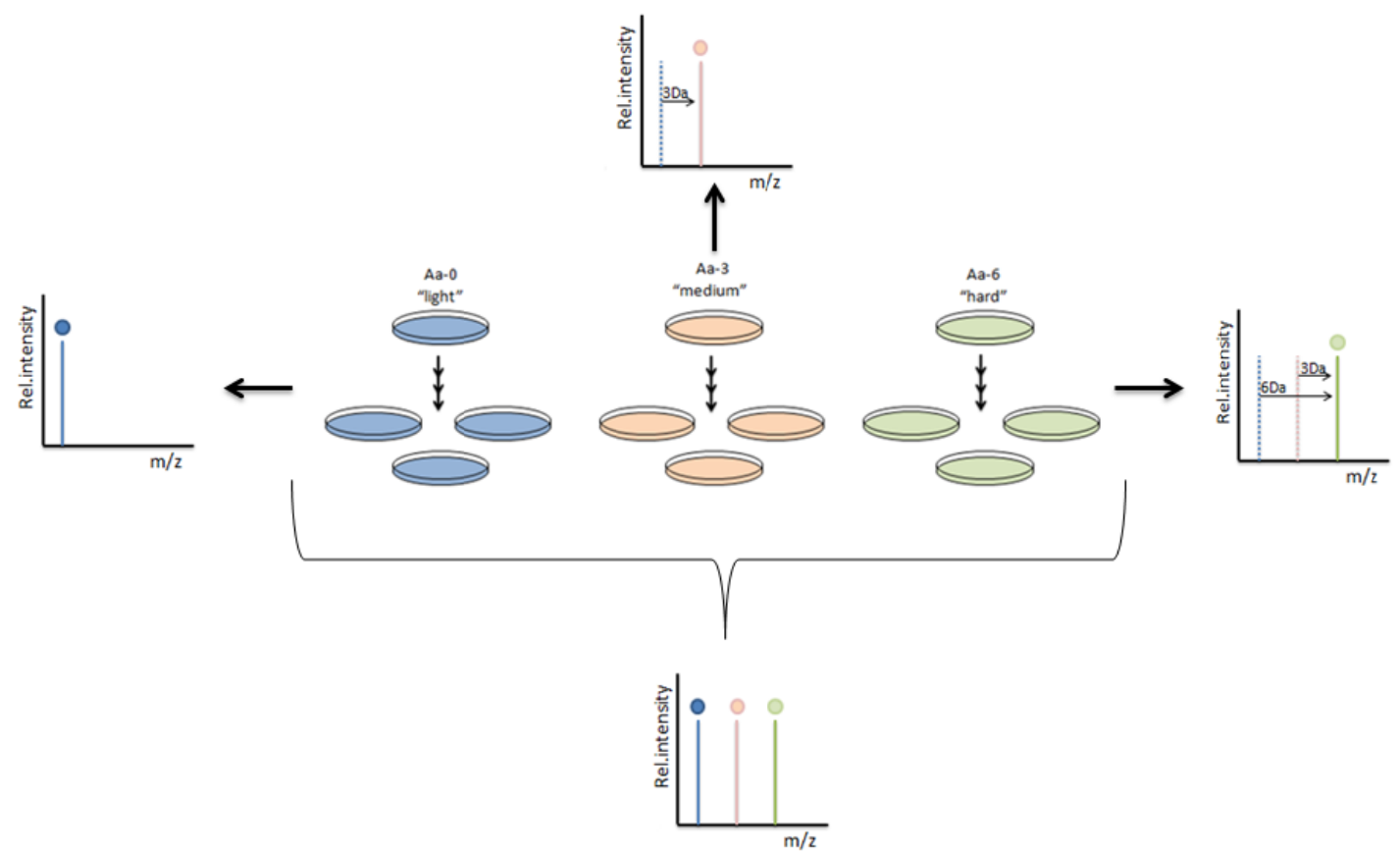

(B)

SILAC allows identifying cell surface proteins which are expressed in a different amount according to state, studying the protein-protein interaction, the identification of tyrosine kinase substrates or the membrane proteins and the temporal dynamics through SILAC for 5-plexing [19]. For example, isotope labeling has been successfully used for differential proteomics studies between normal and tumorogenic cells. By this approach, it has been found at least a 2-fold up-regulation of vimentin, ATP synthase, and $\alpha$-tubulin in prostate cancer cells exhibiting high tumorigenicity as compared with poorly tumorigenic cells. Their results suggest that these proteins may also be implicated in metastasis, showing SILAC ratios of 9.55, 5.92, and 2.17, respectively [20].

Waanders and collaborators have measured the signaling protein Growth factor Receptor-Bound protein 2 (Grb2), which is involved in signaling pathways. It is usually related to the Ras activation because of its $\mathrm{SH} 2$ domains, which allow it binding to phosphorylated tyrosins of kinase receptor, and SH3 domains, which allow it joining to the Ras-guanine exchange factor SOS [21].

\subsection{Label-Free Detection Methods for Biomarker Discovery}

Despite the wide use of the label-based techniques, researchers are increasingly using label-free techniques because they are cleaner, faster and simpler [22], but also because they usually are compatible with real-time detection [23].

There are several label-free methods, but all of them include three basic steps: (1) Sample preparation: protein extraction, reduction, alkylation and digestion; (2) Sample separation by liquid 
chromatography (LC or LC/LC) and analysis by tandem mass spectrometry (MS/MS); and (3) Data analysis including peptide/protein identification, quantification, and statistical analysis [22].

The most common label-free techniques widely used in proteomics, briefly described, are:

(i) Relative quantification by peak intensity of LC-MS: based on the lineal correlation between the area of the peaks in the LC-MS and the protein concentration.

(ii) Relative quantification by spectral count: in these methods, protein quantification is accomplished by comparing the number of identified MS/MS spectra from the same protein in each of the multiple LCMS/MS or LC/LC-MS/MS databases.

(iii) Absolute label-free quantification: it is used in the determination of absolute abundance proteins. This method gives the Protein Abundance Index (PAI), which is the number of identified peptides divided by the number of the theoretically observable tryptic peptides for each protein.

In general, the label-free techniques are proved to be useful for the study of real-time kinetics of biomolecular interactions, which are not hindered by interaction with tag molecules.

At present, there are many label-free detection strategies, such as surface plasmon resonance (SPR), CNTs, microelectromechanical cantilevers, surface-enhanced laser desorption ionization (SELDI)-time of flight (TOF)-MS, microfluidic purification chips (MPC), immunosensors based on channels of mesoporous silica (MPS), functionalized nanopipette probes, nanostructured electromechanical immunosensors featuring single-wall nanotubes (SWNT) forest and AuNPs [4,24-27]. Also, label-free protein-protein interactions were recently monitored using self-assembling protein arrays (named NAPPA microarrays) and atomic force microscopy (AFM), nanogravimetry, mass spectrometry and anodic porous alumina with the purpose of controlling the proteome alteration associated with cell proliferation, differentiation and neoplastic transformation [28-34].

Among other label-free techniques, SPR is a detection technique which analyzes molecular interactions onto a planar surface, based on the generation of surface plasmons (Figure 3). These are oscillations of free electrons that propagate in parallel to a metal/dielectric interface, which allow measuring changes in refractive index close to the sensor surface [35]. SPR enables accurate determination of kinetic parameters (association to dissociation rate) of the binding process between molecules as well as evaluate the strength of the binding and the specificity of the occurring interactions on large scale. As a consequence, it is possible to measure bimolecular interactions in real-time with a very high sensitivity [36].

Currently, SPR has been coupled with imaging to give the surface plasmon resonance imaging methods (SPRi). SPR $i$ can analyze hundreds of samples on a single array. It is possible to use whatever biomolecule and the probe molecule is immobilized onto a metal coated slide (commonly a gold thin layer: $<50 \mathrm{~nm}$ ). This technique is also based on the formation of surface plasmons. The polarized light is reflected depending on the interactions on the array and is collected to give an image. Ladd et al. made use of SPR $i$ techniques for the detection of candidate diagnostic biomarkers in cancer using antibody arrays. Interestingly, SPR $i$ is showing to be a potential useful technique for biomarker characterization in serum proteomic studies [37]. Noteworthy, additional studies have been reported the combination of SPR $i$ with a microfluidic chamber to obtain continuous flow of the analyte during the experiment. 
Finally, it is necessary to put emphasis on MPC, which was the first label-free system that used physiologic solutions, by detecting two biomarkers from a $10 \mu \mathrm{L}$ sample of whole blood in less than $20 \min [24]$.

Figure 3. Schematic description of Surface Plasmon Resonance.

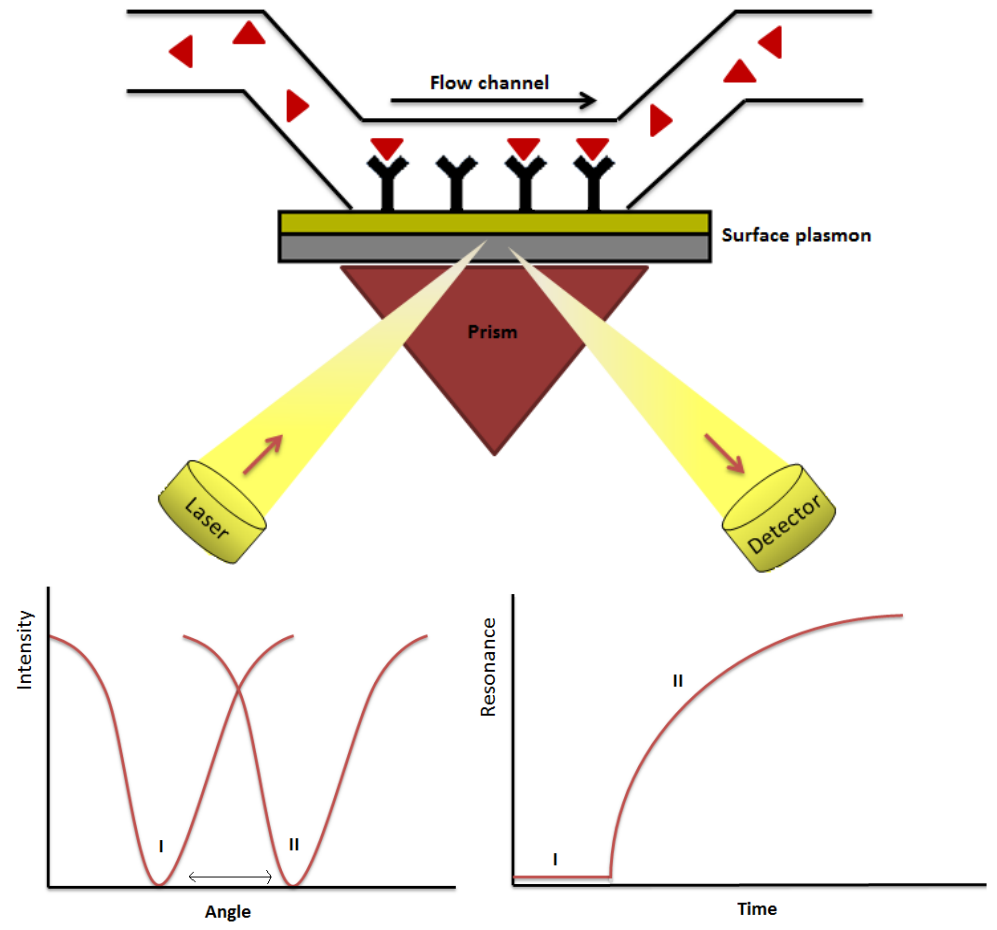

\subsection{Nanotechnology in Proteomics}

Recently, there has been a great interest in applying nanomaterial-based electrochemical biosensors for the sensitive detection of biomolecules [38]. During the past few years, the potential of nanotechniques and nanomaterials in biomarker discovery has been studied [4,5]. Such emerging approaches are advantageous due to their high sensitivity, minimum sample requirements, accuracy, real-time sensing, and simplicity of the instruments, low cost and potential HT applications. In summary, nanotechniques offer several advantages with respect to classic proteomic techniques such as the miniaturization with a low amount of sample which leads to a higher sensibility and easier protocols.

Nanoparticles show highly selective protein absorption and they can reach subcellular locations, which has a great impact on protein interactions and cellular behaviour.

Among other nanomaterials, QDs, AuNPs, CNTs and silicon nanowires are promising candidates for biomarker detection and discovery. In addition, there are other promising nanotechniques which include microcantilevers (Figure 4), microfluidics, gold nanowires or silver nanomechanical resonators [8]. The technological aspects and working principles of commonly used nanoproteomics techniques for biomarker discovery have been discussed in detail in other reviews [4,5]. On the other hand, QDs, semiconductor nanocrystals, are applicable for labeling biomolecules and present 
advantages compared with organic dyes [4], such as brighter fluorescence and photo-stability. Finally, CNTs have shown higher sensitivity than standard ELISA, providing detection limits superior to this classical technique [8].

Figure 4. Schematic description of microcantilevers detection systems used in biomarkers discovery.

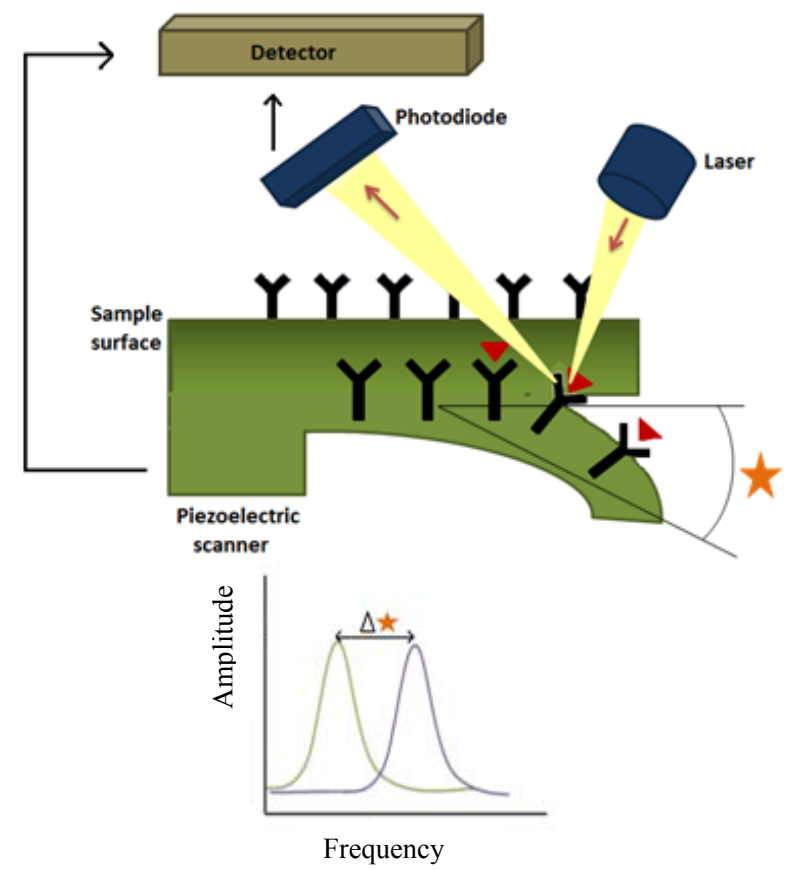

\subsubsection{Gold Nanoparticles}

AuNPs can be modified with simple organic capping reagents or with high molecular weight biomolecules. Their unique optical properties, as well as their high thermal and electrical conductivity, make these materials valuable as components of biosensors, in vitro cell imaging and in vivo imaging and therapy [39].

Among metal nanoparticles, AuNPs have immense potential for cancer diagnosis and therapy on account of their SPR enhanced light scattering and absorption. AuNPs, which have to be labeled with accurate biomolecules, present a deviation in emission spectrum of scattered light because of effective binding of the analyte of interest from a protein sample by specific biomolecular interactions. This approach has been successfully used in PSA detection [40].

\subsubsection{Quantum Dots}

QDs are semiconductors nanocrystals that exhibit unique electro-chemiluminiscent properties, strong light absorbance, bright fluorescence, size-tunable narrow emission spectra and provide excellent fluorescence quantum yields [4]. They are composed by elements from groups II-VI, III-V, or IV-VI of the periodic table, which can be attached to antibodies, aptamers, oligonucleotides, or peptides to be used to target cancer markers. These nanoparticles have many advantages such as their 
low toxicity, their biocompatibility, high quantum yields, diverse surface modification flexibility and they are used with different wavelengths of emission allowing the concurrent analysis of multiple biomarkers [41].

QDs are applicable for labeling of biomolecules such as peptides, proteins or oligonucleotides and considered as an attractive alternative of traditional organic dyes [4]. They can be employed to quantify biomarkers in assays based on fluorescence resonance energy transfer (FRET) or as acceptors in bioluminescence resonance energy transfer (BRET). QDs are bound to different antibodies and can label HER-2, which over-expresses on some human breast cancer and is quantified through FRET in vitro assays. But also, they are used as contrast agents for in-vivo cancer imaging and detection, for example in prostate cancer [41].

These nanoparticles have been used as biological probes for the simultaneous detection of multiple biomarkers directly from biological components [42]. During past years, several groups have reported the use of QDs for detection of different types of cancers. QD-antibody conjugates are also well suited for the multiplexing capabilities of semiconductor QDs, enabled the authors to detect four protein biomarkers (CD15, CD30, CD45 and Pax5) of Hodgkin's lymphoma from lymphoma tissues [8].

\subsubsection{Carbon Nanotubes}

Electronic bio-detection methods are rapidly emerging in diagnostics due to the technological advantages associated with sensitivity, signal amplification, low sample consumption, detection time and multiplexing capacity. CNTs have a high potential as electronic biosensors owing to their intrinsic electrical, thermal and spectroscopic properties [43]. Hence, CNTs are rapidly being adapted in clinical research and have shown considerable promise in cancer diagnosis and therapy. Furthermore, they have shown higher sensitivity than standard ELISA, providing detection limits superior to this classical technique [8].

Malthotra et al. constructed an electrochemical immunosensor using CNT arrays. They used secondary antibodies (HRP-labeled) for detection of low levels of IL-6 in experimental head and neck squamous cells carcionama cell lines [44]. CNTs have also been used as oxidase, dehydrogenase, peroxidase and catalase biosensors [45]. The use of CNT molecular wires offer great promise for achieving efficient electron transfer from electrode surfaces to the redox sites of enzymes. Better control of the chemical and physical properties of carbon nanotubes should lead to more efficient electrical sensing devices.

\subsubsection{Nanoparticle Biomarker Capture Technology}

Recently, a new strategy has been developed for the rapid detection of target protein biomarkers by MALDI-TOF mass spectrometry. The approach relies on selective sequestering of target proteins from complex media by engineered microgels, which select proteins by their size $(<30 \mathrm{kDa})$ and isoelectric points (protein $\mathrm{pI}<6.5$ ). In this case, protein extraction is not necessary [46]. Also, smart hydrogel particles have been developed in order to detect biomarkers present at low concentrations. With this purpose, an affinity bait molecule has been introduced into $\mathrm{N}$-isopropylacrylamide (NIPAm particles). This structure is capable of performing three independent functions within minutes, in one step, in 
solution: (a) molecular size sieving; (b) affinity capture of all solution phase target molecules; and (c) complete protection of harvested proteins from enzymatic degradation $[3,47]$.

\subsubsection{Nanocomposite Matrices for Sensors}

Nanocomposite matrices, characterized by the presence of at least one component with two or three dimensions of less than 100 nanometers, are a mixture of inorganic, organic and biological materials. One recently described example is the mixture of cytochrome P450 with anodic porous alumina. In fact, a cytochrome P450 thin film developed and characterised in order to be used as cholesterol biosensor, is the most succesful inorganic biosensor based on P450ssc and anodic porous alumina, and will be explained in detail in the Biomarker Discovery in Metabolic Diseases section [29,48]. On the other hand, nanocomposites have been successfully employed as matrices suitable for protein microarrays. Nucleic Acid Programmable Protein Arrays (NAPPA) have been combined with anodic porous alumina (APA); and a few macromolecules have been successfully detected by this technique [48].

Nanocomposites have also been combined with multiwalled carbon nanotubes (MWNTs) providing a new material for conductometric acid vapours sensors [49]. In this way, carbon nanotubes can be introduced in conduction polymers, which allow biosensors with enhanced chemical and physical properties, and conduction polymers can be placed onto carbon nanotubes arrays [49].

\section{Biomarker Discovery in Cancer}

As was described in the Introduction section, protein biomarkers (see Table 1) can be used to define a kind of cancer, the stage of the disease or select a treatment $[3,50]$.

Table 1. A list of cancer biomarkers detected by novel sensors based on nanoproteomics approaches.

\begin{tabular}{|c|c|c|}
\hline CANCER & TUMOR BIOMARKER & DETECTION TECHNIQUES \\
\hline \multirow{6}{*}{ Breast cancer } & BRCA1, BRCA2 & Protein Truncation Test (PTT) and western blotting \\
\hline & C-MYC & FISH \\
\hline & CA 15.3, CEA, HER2/neu & Immunohistochemistry (ELISA) \\
\hline & HER2/neu & Quantum dots (QD) and optofluidic ring resonator sensors \\
\hline & CEA & $\begin{array}{l}\text { Gold nanoparticles based techniques, quantum dots (QD) and } \\
\text { silicon photonic microring resonators }\end{array}$ \\
\hline & $\begin{array}{l}\text { Auto-antibodies against p53 or } \\
\text { heat shock protein } 60 \text { and } 90 \text { (hsp) }\end{array}$ & 2D-PAGE, ELISA or NAPPA arrays \\
\hline \multirow{3}{*}{ Colorectal cancer } & CEA, CA 19.9, CA 72.4 & Immunohistochemistry \\
\hline & CEA & $\begin{array}{l}\text { Gold nanoparticles based techniques, quantum dots (QD) and } \\
\text { silicon photonic microring resonators }\end{array}$ \\
\hline & $\begin{array}{l}\text { ANXA3, BMP4, LCN2, SPARC, } \\
\text { MMP7, MMP11 }\end{array}$ & Immunoblotting and tissue microarray analysis \\
\hline Epithelial neoplasia & CEA, CYFRA 21-1 & Immunohistochemistry \\
\hline \multirow[b]{2}{*}{ Gastric cancer } & CEA, CA 19.9 & Immunohistochemistry \\
\hline & CEA & $\begin{array}{l}\text { Gold nanoparticles based techniques, quantum dots (QD) and } \\
\text { silicon photonic microring resonators }\end{array}$ \\
\hline \multirow[b]{2}{*}{ Germ cell tumor } & hCG, AFP, LDH & Immunohistochemistry \\
\hline & AFP & $\begin{array}{l}\text { Gold nanoparticles based techniques, quantum dots (QD), } \\
\text { carbon nanotubes (CNTs) }\end{array}$ \\
\hline
\end{tabular}


Table 1. Cont.

\begin{tabular}{|c|c|c|}
\hline CANCER & TUMOR BIOMARKER & DETECTION TECHNIQUES \\
\hline \multirow[t]{3}{*}{ Head and neck cancer } & $\begin{array}{l}\text { Desmoglein-3, Cytokeratin 4, } \\
\text { Cytokeratin 16, Desmoplakin, } \\
\text { Vimentin }\end{array}$ & RPLC-MS/MS: MS-count of unique peptides per protein \\
\hline & $\begin{array}{l}\text { Keratin } 4 \text {, Keratin } 13 \text {, Cornulin, } \\
\text { Small proline-rich protein } 3\end{array}$ & 2D DIGE \\
\hline & $\begin{array}{l}\text { 14-3-3 sigma, 14-3-3 zeta/delta, } \\
\text { hnRNPK, S100-A7, PTHA }\end{array}$ & iTRAQ \\
\hline \multirow[t]{2}{*}{ Hepatocarcinoma } & AFP & $\begin{array}{l}\text { Immunohistochemistry, gold nanoparticles based } \\
\text { techniques, quantum dots (QD), carbon nanotubes (CNTs) }\end{array}$ \\
\hline & $\begin{array}{l}\text { Hsp27, Hsp70, and } \\
\text { glucose-regulated protein } 78\end{array}$ & 2-DE and MS/MS \\
\hline \multirow[t]{4}{*}{ Lung cancer } & CA125 & SELDI-TOF-MS \\
\hline & $\begin{array}{l}\text { HER2/neu, CYFRA 21-1, NSE, } \\
\text { CEA }\end{array}$ & Immunohistochemistry (ELISA) \\
\hline & HER2/neu & Quantum dots (QD) and optofluidic ring resonator sensors \\
\hline & CEA & $\begin{array}{l}\text { Gold nanoparticles based techniques, quantum dots (QD) } \\
\text { and silicon photonic microring resonators }\end{array}$ \\
\hline Lymphoma & LDH, $\beta 2$-microglobulin & Immunohistochemistry (ELISA) \\
\hline Myeloma & Ig, $\beta 2$-microglobulin & Immunohistochemistry (ELISA) \\
\hline \multirow{5}{*}{ Ovarian cancer } & CA- 125 & SELDI-TOF-MS \\
\hline & HER2/neu & Quantum dots (QD) and optofluidic ring resonator sensors \\
\hline & $\begin{array}{l}\text { LDH, CA 15.3, HER2/neu, CEA, } \\
\text { CA } 19.9\end{array}$ & Immunohistochemistry \\
\hline & CEA & $\begin{array}{l}\text { Gold nanoparticles based techniques, quantum dots (QD) } \\
\text { and silicon photonic microring resonators }\end{array}$ \\
\hline & $\begin{array}{l}\text { Tropomyosin family, actin family, } \\
\text { triosephosphate isomerase family, } \\
\text { Hsp60 }\end{array}$ & Peptide fragment matching and MS/MS \\
\hline Pancreatic cancer & CA 19.9, CA 72.4, MUC1 & Immunohistochemistry (ELISA) \\
\hline $\begin{array}{l}\text { Papillary and } \\
\text { follicular thyroid } \\
\text { carcinoma }\end{array}$ & Thyroglobulin & Immunohistochemistry and PCR-RT \\
\hline \multirow{4}{*}{ Prostate cancer } & PSA & $\begin{array}{l}\text { Gold nanoparticles based techniques, quantum dots (QD), } \\
\text { carbon nanotubes (CNTs), silicon nanowires and 2D } \\
\text { cantilever array chip }\end{array}$ \\
\hline & $\begin{array}{l}\text { PAP, PG, urinary calgranulin } \\
\text { B/MRP-14 }\end{array}$ & 2-DE MALDI-TOF-MS \\
\hline & Prostate cancer- 24 protein & SELDI-MS \\
\hline & HER2/neu & Quantum dots (QD) and optofluidic ring resonator sensors \\
\hline \multirow[t]{2}{*}{ Testicular cancer } & AFP & $\begin{array}{l}\text { Gold nanoparticles based techniques, quantum dots (QD), } \\
\text { carbon nanotubes (CNTs) }\end{array}$ \\
\hline & $\beta$-hCG & Immunohistochemistry \\
\hline Trophoblastic disease & Gonadotropin & Immunohistochemistry \\
\hline
\end{tabular}

Because of modern life style factors (sedentarism, nutritional habits, environmental contamination or life expectancy) some cancers are more prevalent, why it is necessary to find new biomarkers of the 
early stages to have more possibilities of earlier diagnostic of cancers [3,51]. Extracellular matrix proteins and elements secreted by a tumor can be diagnostic biomarker candidates. Secreted proteins are responsible for cell communication, so translating these signals into information could provide knowledge of the molecular mechanisms of neoplasia [51]. Also, modifications in glycosylation and the carbohydrate structure of proteins have been associated to cancer [52].

In the case of prostate cancer, Prostate Specific Antigen (PSA) is the biomarker usually used in the diagnostic of this pathology. PSA appears preferentially in the prostate, but it is produced by other tissues. Although it is a substance which is found in prostate, in patients it is localized at low concentrations in blood which are measured to make the diagnosis and the prognostics of cancer [51]. However, it is well known that PSA is not a biomarker as specific as it is necessary because the increase in PSA levels detected by 2D electrophoresis (2-DE) MALDI-TOF MS or SELDI Quadrupole-TOF (SELDI-qTOF) (Figure 3(A)) can be due to the age or prostatitis [52]. For this reason new biomarkers are needed [51].

Both prostatic acid phosphatase (PAP) and progastricsin (PG), which are overexpressed in prostate carcinoma, have been detected by 2-DE MALDI-TOF-MS. This technique has also identified a new potential biomarker: urinary calgranulin B/MRP-14. SELDI-MS has allowed detecting prostate cancer-24 protein, which appeared in $94 \%$ of prostate carcinomas and does not in normal cells. One of the most interesting lines which are being recently studied is likely biomarkers in prostatasomes, membranous vesicles secreted by the prostatic gland whose function is related with sperm motility and protection against female immunity in fecundation. Although more than 440 prostatasomes proteins have been recognized and categorized by LC-Electrospray ionisation/Mass Spectrometry (LC-ESIMS/MS) coupled with a gas phase fractionation (GPF), it is too soon to propose some new biomarkers. Also, metabolomics have identified a huge number of metabolites as potential biomarkers such as sarcosine, which is likely to indicate the progression to metastasis [52].

Breast cancer is the most prevalent cancer in women and the first cause of death, mostly because of the distant metastases. For this reason, it is necessary to identify the early stage biomarkers [51]. The lack of serum biomarkers drives to a too late detection of cancer, when surgery is no longer possible and/or metastasis processes are presented. An early detection might be possible only through both invasive and non-invasive techniques. Nowadays, a premature diagnosis is achieved by regular mammographies [53].

In breast cancer, many different mutations have been found, most of them in proto-oncogenes and/or tumor suppressor genes such as BRCA1, BRCA2, HER2-neu, C-MYC, and Cyclin D-1. As a result, auto-antibodies have been detected against the mutated genes such as $\mathrm{p} 53$ or heat shock protein 60 and 90 (hsp). 2D-PAGE, ELISA or NAPPA arrays have been some of the technologies used to try to detect breast cancer auto-antibodies. However, antibodies are not likely to be accurate biomarkers, unless they are into account together [53].

The most widely used serum marker in breast cancer diagnostics is CA 15-3, which is a soluble form of the mucin MUC1, which is in turn a marker of breast cancer. MUC1 is usually placed in the apical membrane of normal secretory epithelium, when malignant transformation has happened, MUC1 is translocated to the external plasmatic membrane, where is susceptible of suffering proteolytic cleavage. As a result, it is found as a soluble antigen which is usually detected by immunoassays. 
Unfortunately, as MUC1 changes its glycosylation pattern during neoplastic transformation, so it cannot be used as an early breast cancer biomarker [53].

In connection with glycoprotein and cancer, in breast cancer as in so many others, there are alterations in glycoproteins. The most known example is the Human Epidermal Growth Factor Receptor 2 (HER2/neu), which is a trans-membrane glycoprotein and whose overexpression means the malignant transformation of the tumor [53].

Ovarian cancer, one of the most aggressive and lethal cancers in women, lacks of a non-invasive diagnostic exam in order to detect it in the earliest stages [51]. Comparing samples from patients with ovarian cancer and healthy individuals, it was found that CA125 had the sensitivity of $60.7 \%$ and the specificity of $55 \%$ for distinguishing ovarian cancer from non-cancer samples. Moreover, four proteins were found, which are better biomarkers than CA125, using SELDI-TOF-MS protein chip technology; which is widely used to monitor the patients after the chemotherapy [54].

Pancreatic ductal adenocarcinoma (PDAC) is another of the most aggressive cancers and the problem lies in the fast metastasis [51]. This cancer has the worst prognosis and the mortality percentage is very similar to the rate of incidence. The best biomarker in pancreatic cancer is CA 19-9, which is a sialylated Lewis antigen of the MUC1 protein and is detected by serum immunoassay [55]. Although sensitivity is about an $80 \%$ and specificity about $90 \%$, this biomarker also appears in some diseases such as cirrhosis or chronic pancreatitis. That is why it cannot be used as an accurate biomarker. Most of the pancreatic cancers are discovered by computed tomography (CT) or magnetic resonance imaging [56].

Other kinds of cancer, for example colorectal or lung cancer, are not related with specific and accurate biomarkers because of problems such as low concentration or the masking by other proteins. Colorectal cancer is one of the most insidious cancers. The preferential treatment is surgery after neo-adjuvant treatment, but in most of cases metastases reappear some years later. Although biomarkers for metastasis are not known, researchers are making an effort to discover them. Lung cancer is the most prevalent and the major cause of death worldwide nowadays. Melanoma is a lower incidence dermatological cancer, but it is responsible of $80 \%$ of skin cancer death because of its fast metastasis to the brain [51].

\section{Biomarker Discovery in Autoimmune Diseases}

The importance of the detection of biomarkers for autoimmune diseases (see Table 2) lies in the need of an early detection of diseases, as well as the disease progression to disability and the response to therapy [57]. Autoimmune diseases appear in 3\% of the population and until, now the diagnosis is made through clinical examination, laboratory tests and imaging techniques. Since last decade, biomarkers for diagnostic of immune diseases employing different proteomics approaches have been studied [58].

A specific characteristic of this disease is the presence of autoantibodies in systemic circulation as well as in specific proximal fluids and tissues. The main problem appears as a consequence of the immunity against self-molecules, auto-antigens, which can be related with the alterations on the gene which regulate the self-tolerance paths [57]. Proteomics allow the study of the key events which happen in the protein level such as post-translational modifications or antibody production [57]. 
Table 2. A list of autoimmune biomarkers detected by novel sensors based on nanoproteomics approaches.

\begin{tabular}{|c|c|c|}
\hline AUTOINMUNE DISEASE & AUTOINMUNE BIOMARKER & DETECTION TECHNIQUES \\
\hline Diabetes & has & Magnetic relaxation nanosensors \\
\hline \multirow{4}{*}{ Behcet's disease } & $\alpha$-tropomyosin & IEC, SDS-PAGE and ESI-MS (sera) \\
\hline & Selenium-binding protein & 2-DE and immunoblot (sera) \\
\hline & $\alpha$ - enolase, Haptoglobin & 2-DE and MALDI-TOF-MS (sera) \\
\hline & Serum amyloid A & 2-DE and MALDI-TOF/TOF-MS (sera) \\
\hline \multirow{4}{*}{ Juvenile idiopathic arthritis } & $\begin{array}{l}\text { Transferrin, ceruloplasmin, } \\
\text { Serum amyloid A }\end{array}$ & $\begin{array}{l}\text { Chromatographic protein chips, } \\
\text { SELDI-TOF-MS (sera/urine). }\end{array}$ \\
\hline & $\begin{array}{l}\text { Serotransferin, GAPDH, } \\
\alpha-1 \text { anti-trypsin }\end{array}$ & IP of CIC's, 2DE, ESI-MS/MS (serum) \\
\hline & $\begin{array}{l}\text { Citrulinated fibrinogen, } \\
\text { complement } 3 \text {, complement } 1 \mathrm{q}\end{array}$ & IP of CIC's, SEC/LC, ESI-MS (serum) \\
\hline & $\begin{array}{l}\text { Complement } 3 \mathrm{c} \text {, apolipoprotein } \\
\text { AII,vitamin D binding protein }\end{array}$ & $\begin{array}{l}\text { DIGE, MALDI-TOF/TOF } \\
\text { (plasma, synovial fluid) }\end{array}$ \\
\hline Type 1 diabetes & GDC glutamate decarboxylase & Supramolecular protein nanoparticles \\
\hline \multirow{4}{*}{ Rheumatoid arthritis } & Cyclic citrulline peptide & $\begin{array}{l}\text { ELISA and Peptide-coated nanotube-based } \\
\text { biosensor }\end{array}$ \\
\hline & $\begin{array}{l}\text { peptides of C-reactive protein } \\
\text { (PCR) }\end{array}$ & $\begin{array}{l}\text { SDS-PAGE and triple quadrupole (TQ)-MS } \\
\text { by multiple-reaction monitoring (MRM) }\end{array}$ \\
\hline & p38 MAPK & Flow cytometry and Western blotting \\
\hline & $\mathrm{RF}$ & ELISA \\
\hline Wegener Granulomatosis & PR3 & Carbon nanotubes as multicolor Raman labels \\
\hline
\end{tabular}

In rheumatoid arthritis (RA), a systemic inflammatory disease related with alterations in human leukocyte antigen (HLA)-DRB1 locus, it has been necessary to find accurate biomarkers which identify the early stages of the disease, before cartilage damage ocurrs [59].

Diverse proteomic technologies have contributed to the discovery of biomarkers in autoimmune diseases, such as: (i) 2-DE and MS for auto-antigen discovery; (ii) autoantigen microarrays to typify autoantibody responses; (iii) antibody array technologies to profile cytokines and other biomolecules; (iv) reverse-phase protein arrays to analyze phosphoproteins; ( $v$ ) flow cytometric analysis of phosphoproteins $[57,60]$.

For example, Zhen and colleagues have developed microarrays which consist of putative and candidate genes printed by a robot over the array and probed against immune or control serum. The potential interaction is detected by fluorophore-conjugated anti-human secondary antibodies and they have found that the appearance of citrulline in RA means more severe disease and the detection of native and unmodified peptides is associated with mild disease [61].

Western blotting has allowed identifying some post-translational modifications variants of proteins have been characterized as auto-antigens such as citrullinated alpha-enolase in RA [57].

However, traditional MS or array-based proteomic assays face several limitations in the detection of multiple low abundance biomarkers from complex biological samples under clinically relevant conditions due to their sensitivity and specificity issues. Moreover, the detection process is very slow 
and it is often characterized by an unsuitable screening of large numbers of samples. These challenges of proteomics techniques prompted researcherd to apply different nanotechniques for biomarker discovery in auto-immune diseases.

Peptide-coated nanotubed are one of the recent approaches for the development of new immunosensors for diseases with specific serological autoantibodies, such as RA. Drouvalakis et al. determined cyclic citruline from patient serum in fentomolar (fM) range [62].

Wegener's granulomatosis is a rare auto-immune disease coupled with anti-neutrophil antibodies, which affect blood vessels as well as various other organs. Proteinase 3 (PR3) is a potential serum biomarker for this autoimmune disease and is used for routine diagnosis of the disease. Although it is difficult to detect such a low abundance protein in complex samples, Chen and collaborators have developed a nanoproteomics approach for detection, at $1 \mathrm{fM}$ level, of the target molecule by using antibodies conjugated with Raman tags for selective detection of PR3 [63]. In this case, the sensitivity which has been shown is higher than conventional fluorescence-based protein microarrays and traditional ELISA assays.

Biomarkers for systemic lupus erythematosus (SLE) and systemic sclerosis (SSc), both autoimmune connective tissue diseases, can be found using recombinant antibody microarrays. Carlsson and collaborators have developed a system in order to target mainly immunoregulatory proteins present in these autoimmune diseases. In this way, they found differentiation biomarkers between SLE and SSc. They also, observed differences increased with severity of SLE; thus, IL-2, IL-12 and IFN- $\gamma$ were detected [64]. Hence, proteomics has shown to be a great candidate to detect disease biomarkers and control the phenotypic subsets and activity of diseases.

\section{Biomarker Discovery in Infectious Diseases}

Besides various cancers and autoimmune diseases, serum proteome analysis has also been tested for many infectious diseases such as tuberculosis, leprosy and hepatitis, among others $[65,66]$.

Infectious diseases have become the leading cause of death in developing countries. That is one of the reasons why biomarkers (see Table 3) to achieve detection kits are needed [67]. New tools can help to identify the pathogen, evaluate the illness severity or establish the best treatment. Although lateral flow immunoassays, ELISA and the polymerase chain reaction (PCR) have been used with their limitations in the developed countries, these techniques frequently cannot be used in the developing countries. The World Health Organization has established the accurate characteristics to the diagnostic devices in the developing countries. They are summarized in the ASSURED criteria: A for Affordable, $\mathrm{S}$ for Sensitive, S for Specific, U for User-Friendly, R for Robust and Rapid, E for Equipment-Free and D for Deliverable to those who need them [68].

Among the potential biomarkers are products and targets with immunological memory of a pathogen, molecules which allow differentiating between infected and healthy individuals as well as assays, which recognize pathogen proteins and molecules. Until now, the main techniques used to detect the infectious individuals were serology and molecular methods. Although work on proteomic approaches is going on, the use of biomarkers will depend on our understanding of each infectious disease immunopathogenesis [67]. 
Table 3. A list of infectious biomarkers detected by novel sensors based on nanoproteomics approaches.

\begin{tabular}{|c|c|c|}
\hline INFECTIOUS DISEASE & INFECTIOUS BIOMARKER & DETECTION TECHNIQUES \\
\hline Anthrax & Anthrax protective antigen & Europium nanoparticlebased immunoassay \\
\hline Anthrax & Bacillus anthracis Protective antigen & Multichannel waveguides \\
\hline Candidiasis & D-arabinitol & One step electrodeposition \\
\hline $\begin{array}{l}\text { Chronic liver diseases, cirrhosis } \\
\text { and hepatocellular carcinoma }\end{array}$ & Hepatitis $\mathrm{B}$ and $\mathrm{C}$ virus antibodies & $\begin{array}{l}\text { Nano-gold immunological amplification on } \\
\text { protein chip }\end{array}$ \\
\hline Diptheria & Diphtheria antigen & Potentiometric immunosensor \\
\hline Food borne disease & Listeria monocytogenes & $\begin{array}{l}\text { Bioconjugated silica nanoparticles probe } \\
\text { with FITC }\end{array}$ \\
\hline Food borne illness & Salmonella & Bioconjugated nanoparticles \\
\hline Gonorrhea & Neisseria gonorrhoeae & Nano-structure zinc oxide film \\
\hline Hepatitis B & HBV virus & $\begin{array}{l}\text { Microfluidic device with microbead array } \\
\text { and QD }\end{array}$ \\
\hline \multirow[t]{2}{*}{ HIV-1 Infection } & HIV-1 p24 antigen & Nanoparticlebased immunoassay \\
\hline & HIV-1 p24 Gag protein & $\begin{array}{l}\text { Nanoparticle-based bio-barcode } \\
\text { amplification }\end{array}$ \\
\hline Parasitic disease & Schistosoma japonicum antibody & $\begin{array}{l}\text { Silver-enhanced colloidal gold } \\
\text { metalloimmunoassay }\end{array}$ \\
\hline Salmonellosis & Salmonella typhimurium antigen & Hybrid electrochemical/magnetic assay \\
\hline Tuberculosis & Protein amyloid A, transthyretin & $\begin{array}{l}\text { Surface-enhanced laser desorption } \\
\text { ionization time of flight (SELDI-TOF) } \\
\text { mass spectrometry }\end{array}$ \\
\hline
\end{tabular}

Agranoff and collaborators made use of SELDI-TOF-MS for identification of 20 most discriminatory proteins by comparing serum profiles from 179 tuberculosis subjects [69]. By MALDI-TOF-MS, both proteins amyloid $\mathrm{A}$ and transthyretin were demonstrated as potential serum biomarkers for early diagnosis of tuberculosis.

Another study identified differentially expressed proteins by MALDI-TOF and MALDI-TOF-MS/MS of leprosy patients and healthy individuals [70]. A significant increase in one of the isoforms of $2 \alpha$ chain of haptoglobin was determined in leprosy patients.

During the last years, several nanoproteomics studies have been conducted to study different types of infectious diseases. Tang et al. have demonstrated the selective detection of anthrax protective antigen from serum samples using a novel sensing approach based on europium nanoparticle-based immunoassay. This novel approach offered 100 -fold enhancement in detection limit $(0.01 \mathrm{ng} / \mathrm{mL})$ as compared to the traditional colorimetric development reagents of ELISA assays [71].

Another recently described approach allows the detection of dengue virus infection, based on a combination of integrated microfluidic system and magnetic beads. The designed strategy reaches high sensitivity levels $(21 \mathrm{pg})$ in a $30 \mathrm{~min}$ assay, indicating the potential of such sensing strategies for the development of rapid diagnostic test in infectious diseases [72].

Over the last two decades, anti-retroviral therapy (ART) has been successfully used reducing the morbidity and mortality of HIV-1. However, many patients have developed several immune abnormalities and their risk to suffer non-AIDS associated diseases has increased. Owing to that, it is 
necessary to find biomarkers which allow classifying patients into groups at risk of suffering nonAIDS diseases. HIV infected patients are also increasingly susceptible to suffering opportunistic pathogen infections, which is termed as immune restoration disease (IRD). One of the most frequent and severe IRDs is tuberculosis (TB). Usually, this combination highly increases the worsening of the pathology, particularly, the progression of extrapulmonary disease and lymphadenitis. Oliver and Price found in 2011 that CCL2 chemokine shows a decrease in its levels when a patient submitted to ART is going to develop TB $[67,73]$.

Prion diseases, such as Creutzfeldt-Jacob (CJD), are neurodegenerative diseases related to the transformation of the normal host cellular prion protein $\left(\operatorname{PrP}^{\mathrm{c}}\right)$ into the abnormal protease-resistant isoform $\left(\mathrm{PrP}^{\mathrm{Sc}}\right)$. The traditional diagnosis is based on the detection of proteinase $\mathrm{K}$ resistant, misfolded form (PrPSc) of cellular prion protein in the central nervous system (CNS). Biomarkers are needed to detect the disease in the early stages to avoid the progression of the disease over time. Sanchez et al. found a 13.4 KDa protein in cerebrospinal fluid (CSF), which was analyzed by cationic exchange chromatography, sodium dodecyl sulfate-polyacrylamide gel electrophoresis (SDS-PAGE), and LC-MS/MS and it was revealed that the protein was cystatin C [74]. This protein had been found by other researchers, also in blood, and it is known that its increase in CJD affected patients is related with the disease. Mabbott et al. have found dendritic cells and macrophages carrying $\operatorname{PrP}^{\mathrm{Sc}}$. Macrophages may even transport the abnormal protein in the absence of Follicular Dendritic Cells (FDCs) that is why the authors have considered the possibility that macrophages are a new structure in prion accumulation. On the other hand, dendritic cells can spread the infection towards other parts of the body [75].

\section{Biomarker Discovery in Metabolic Diseases}

Serum profiling has also provided biomarkers (see Table 4) for many other human diseases such as non-alcoholic fatty liver disease, diabetes, ischemic and hemorrhagic stroke [76]. Here, some of them are listed:

(i) Glucose biosensor: glucose levels can be monitored either in vivo or in vitro. Nowadays, there are biosensors based on conducting polymers, which have been shown to be useful for glucose estimation form 1 to $40 \mathrm{mM}$ and a stability of about 6 days. A novel glucose biosensor based on MWNTs have been developed improving upon the previous ones [29].

(ii) Lactate biosensor: until now, two different technologies have been approached for the development of nanosystems: film electrodes in combination with microdialysis systems and screen printed electrodes, which have shown a linear dynamic range from 0.2 to $1 \mathrm{mM}$ of lactate and a stability of about 3 weeks.

(iii) Urea and creatinine biosensors: most of them are based on detection of $\mathrm{NH}_{4}^{+}$or $\mathrm{HCO}_{3}{ }^{-}$ sensitive electrodes. A composite film of electropolymerized inactive polypyrrole and a poly ion complex has been developed.

(iv) Cholesterol biosensor: the measurement of cholesterol is based on an amperometric biosensor. This sensor responds even in presence of potential electrical interferences, as L-ascorbic acid, pyruvic acid and uric acid. The most successful cholesterol biosensor, recently described, is the one based on the P450-linked side chain cleaving enzyme (P450ssc), which consists of P450 cytochrome and 
adrenadoxin, a P450 reductant, and it has been used to make an amperometric biosensor to detect and measure the LDL-cholesterol in liquid solution. It is based on the Anodic Porous Alumina (APA), which is a specific size porous matrix, and in the organic poly-cationic poly-L-Lysine (PLL), which allows a molecular anchorage as well as a direct electron transfer. The APA layer is placed onto a rhodium-graphite screen-printed electrode (s.p.e.) and the P450ssc was immobilized through the PLL. The enzyme and analyte binding leads to a redox reaction, which can be translated into an electrical signal producing a direct electron transfer between the enzyme and the electrode. The cholesterol detection and measurement is made by cyclic voltammetry (CV). It is achieved a very good stability mainly because the enzyme was very strongly trapped in the APA/PLL matrix $[29,48]$.

(v) Uric acid biosensor: useful in gout, hyperuricaemia and Lesch-Nyhan syndrome.

Table 4. A list of metabolic biomarkers detected by novel sensors based on nanoproteomics approaches.

\begin{tabular}{|l|l|l|}
\hline METABOLIC DISEASE & METABOLIC BIOMARKER & DETECTION TECHNIQUES \\
\hline \multirow{2}{*}{ Diabetes mellitus } & Glucose & $\begin{array}{l}\text { Glucose sensors: electrostatic layer-by-layer (LBL) } \\
\text { nanoassembly of capsules composed of multi-layers } \\
\text { of polymer films, standard enzymatic } \\
\text { electrochemical and nanomaterial-based sensors }\end{array}$ \\
\cline { 2 - 3 } & $\begin{array}{l}\text { Extracellular glutathione } \\
\text { peroxidase, apo-lipoprotein E }\end{array}$ & Spectrophotometry and electrochemical techniques \\
\hline Gout & Uric acid & Spectrophotometry and electrochemical techniques \\
\hline Hyperuricaemia & Uric acid & Spectrophotometry and electrochemical techniques \\
\hline Lesch-Nyhan syndrome & Uric acid & Spectrophotometry and electrochemical techniques \\
\hline \multirow{2}{*}{ Chronic liver diseases } & $\begin{array}{l}\text { Fibrinogen B chain, } \\
\text { paraoxonase 1, prothrombin, } \\
\text { serum amyloid P component }\end{array}$ & Immunohistochemistry \\
\hline
\end{tabular}

Heart fatty acid-binding protein has been identified as a novel diagnostic serum biomarker for earlier diagnostic of stroke using a gel-based proteomic approach.

Serum proteomics have been also found to be a good alternative to liver biopsy for detection of common chronic liver diseases like non-alcoholic fatty liver disease. Recently, it has been described fibrinogen $\mathrm{B}$ chain, paraoxonase 1, prothrombin and serum amyloid $\mathrm{P}$ component as novel serum biomarkers [65] using a LC-MS/MS approach [76].

In $2007 \mathrm{Kim}$ et al. identified extracellular glutathione peroxidase and apo-lipoprotein E as potential serum biomarkers using 2D ESI-qTOF MS/MS approach, and verified their results by Western blotting and ELISA in diabetes mellitus patients. This represents an alternative to conventional finger-prick capillary blood glucose self-monitoring, which has several disadvantages: it is painful, it cannot be performed when the patient is sleeping or doing some activity and it is intermittent, which means it can miss dangerous fluctuations in blood glucose concentrations between tests. For all these reasons, the ideal blood glucose monitoring would therefore be continuous and non-invasive [77].

Measurement problems in diabetes can be solved with nano-approaches, such as biocompatible nanofilms, glucose nanosensors, quantum dots or gold nanoparticles [78].

The detection of glucose levels used as diabetes biomarker, can be made through encapsulation of glucose sensors that could be implanted in the body avoiding degradation and denaturation 
maintaining, at the same time, glucose access and detectable signal change. This kind of encapsulation can be carried out by the electrostatic layer-by-layer (LBL) nanoassembly of capsules composed of multi-layers of polymer films [78]. Also, nanotechnology has increased the surface area of sensors. So far, sensors in diabetes are based on electrochemical enzymatic measurements with screenprinted eletrodes. However, nanotechnology can offer higher surface area/volume ratios as well as enhanced optical properties (QDs, AuNPs, SERS) allowing improvements in accuracy, size, lifetime and usability of sensors for the treatment of diabetes [79].

The principal strategy used in diabetes is based on standard enzymatic electrochemical detection of glucose. In this way, we can use CNTs, nanowire arrays fabricated from ruthenium and gold, which increase surface area and improve electrochemical detection. On the other hand, nanomaterials allow the development of direct oxidation glucose sensors as replacements to biological recognition sensors. For this purpose, it can be used porous films, nanorods and nanoparticles composed of silver, gold, nickel and nickel/palladium.

It is also possible to design nanomaterial-based sensors to detect glucose through changes in $\mathrm{pH}$ or charge, such as field effect transitor (FET), which seems to be a good option. Finally, for in vivo continuous monitoring, fluorescence-based sensors offer several advantages. In this case, sensors would be implanted into the skin of the patient. They would have to be replaced weekly or monthly because of problems with signal degradation, however with this strategy, it is not necessary to take blood samples [79].

During the last decade, emerging nanotechniques have been using for biomarkers detection in metabolic diseases. Lin et al. have reported simultaneous label-free electrochemical detection of two cardiovascular biomarker proteins, CRP and myeloperoxidase directly in human serum. In this nanoproteomics approach, high-density nanowells were prepared on top of each electrode using nanoporous silica membrane to improve sensitivity and selectivity (down to $1 \mathrm{pg} / \mathrm{mL}$ ) [26].

\section{Concluding Remarks}

Proteomics research has revealed many novel disease biomarkers by applying various top-down and bottom-up approaches including gel-based techniques, MS, affinity separation and microarrays. Technological working aspects of different conventional proteomics techniques have been described in other reviews.

Despite the immense progress, biomarker discovery is still facing several biological and technological challenges such as the wide dynamic range of protein concentrations, difficulty of detection of low-abundance proteins and extreme variations between individuals.

During the last years, nanotechniques have undergone a significant progress for reliable handling the complexity of the cell proteome. Therefore a number of nanotechniques have been lately used for diverse applications such as biomarker discovery, label-free protein detection, study protein-protein interactions and printing protein microarrays. The advantages offered by these approaches have allowed to be successfully coupled with the rapidly expanding field of proteomics. Among other relevant emerging techniques, CNTs, QDs or AuNPs have drawn great attention due to their potential to minimize sample and reagent consumption. 
However, nanotechniques still face several limitations to be resolved for widespread application in biomarker discovery. Currently, new proteomics and nanotechnology disciplines are being progressively adopted by clinical researchers due to the availability of multiple-novel techniques and all the potential applications to deep into the knowledge of the pathophysiology of unresolved diseases. All the methodologies and techniques briefly described in this minireview, might eventually lead to the characterization of new molecular entities and/or disease-associated molecular modifications for improving diagnostic and prognostic stratification. Despite this, many efforts are still required to implement the current status of these approaches towards clinical standardization.

Nowadays, it is possible to anticipate a significant development in the near future that will make nano-proteomics for biomarkers discovery field more robust, sensitive, reliable and above all, biocompatible and environmentally friendly.

\section{Acknowledgments}

We gratefully acknowledge financial support from the Carlos III Health Institute of Spain (ISCIII, FIS PI081884) and JCYL-SAN10. María González-González is supported by a ISCIII FIS08/00721 PhD scholarship. Sara Paradinas is supported by a JCYL-EDU/1468/2008 PhD scholarship.

\section{References}

1. Wong, S.C.; Chan, C.M.; Ma, B.B.; Lam, M.Y.; Choi, G.C.; Au, T.C.; Chan, A.S.; Chan, A.T. Advanced proteomic technologies for cancer biomarker discovery. Expert Rev. Proteomics 2009, 6, 123-134.

2. Madu, C.O.; Lu, Y. Novel diagnostic biomarkers for prostate cancer. J. Cancer 2010, 1, 150-177.

3. Rakowska, P.D.; Ryadnov, M.G. Nano-enabled biomarker discovery and detection. Biomark. Med. 2011, 5, 387-396.

4. Gonzalez-Gonzalez, M.; Jara-Acevedo, R.; Matarraz, S.; Jara-Acevedo, M.; Paradinas, S.; Sayagues, J.M.; Orfao, A.; Fuentes, M. Nanotechniques in proteomics: Protein microarrays and novel detection platforms. Eur. J. Pharm. Sci. 2011, 45, 499-506.

5. Matarraz, S.; Gonzalez-Gonzalez, M.; Jara, M.; Orfao, A.; Fuentes, M. New Technologies in cancer. Protein microarrays for biomarker discovery. Clin. Transl. Oncol. 2011, 13, 156-161.

6. Xia, H.; Murray, K.; Soper, S.; Feng, J. Ultra sensitive affinity chromatography on avidin-functionalized PMMA microchip for low abundant post-translational modified protein enrichment. Biomed. Microdevices 2011, doi: 10.1007/s10544-011-9586-7.

7. Chandra, H.; Reddy, P.J.; Srivastava, S. Protein microarrays and novel detection platforms. Expert Rev. Proteomics 2011, 8, 61-79.

8. Ray, S.; Reddy, P.J.; Choudhary, S.; Raghu, D.; Srivastava, S. Emerging nanoproteomics approaches for disease biomarker detection: A current perspective. J. Proteomics 2011, 74, 2660-2681.

9. Tomizaki, K.Y.; Usui, K.; Mihara, H. Protein-protein interactions and selection: Array-based techniques for screening disease-associated biomarkers in predictive/early diagnosis. FEBS J. 2010, 277, 1996-2005. 
10. LaBaer, J.; Ramachandran, N. Protein microarrays as tools for functional proteomics. Curr. Opin. Chem. Biol. 2005, 9, 14-19.

11. Hu, Y.; Uttamchandani, M.; Yao, S.Q. Microarray: A versatile platform for high-throughput functional proteomics. Comb. Chem. High Throughput Screen. 2006, 9, 203-212.

12. Grasso, V.; Lambertini, V.; Ghisellini, P.; Valerio, F.; Stura, E.; Perlo, P.; Nicolini, N. Nanostructuring of a porous alumina matrix for a biomolecular microarray. Nanotechnology 2006, 17, 795-798.

13. Collings, F.B.; Vaidya, V.S. Novel technologies for the discovery and quantitation of biomarkers of toxicity. Toxicology 2008, 245, 167-174.

14. Meany, D.L.; Zhang, Z.; Sokoll, L.J.; Zhang, H.; Chan, D.W. Glycoproteomics for prostate cancer detection: Changes in serum PSA glycosylation patterns. J. Proteome Res. 2009, 8, 613-619.

15. Srivastava, M.; Eidelman, O.; Jozwik, C.; Paweletz, C.; Huang, W.; Zeitlin, P.L.; Pollard, H.B. Serum proteomic signature for cystic fibrosis using an antibody microarray platform. Mol. Genet. Metab. 2006, 87, 303-310.

16. Zhou, H.; Bouwman, K.; Schotanus, M.; Verweij, C.; Marrero, J.A.; Dillon, D.; Costa, J.; Lizardi, P.; Haab, B.B. Two-color, rolling-circle amplification on antibody microarrays for sensitive, multiplexed serum-protein measurements. Genome Biol. 2004, 5, R28.

17. Wu, W.; Slastad, H.; de la Rosa Carrillo, D.; Frey, T.; Tjonnfjord, G.; Boretti, E.; Aasheim, H.C.; Horejsi, V.; Lund-Johansen, F. Antibody array analysis with label-based detection and resolution of protein size. Mol. Cell. Proteomics 2009, 8, 245-257.

18. Blazer, L.L.; Roman, D.L.; Muxlow, M.R.; Neubig, R.R. Use of flow cytometric methods to quantify protein-protein interactions. Curr. Protoc. Cytom 2010, doi: 10.1002/0471142956.cy1311s51.

19. Harsha, H.C.; Molina, H.; Pandey, A. Quantitative proteomics using stable isotope labeling with amino acids in cell culture. Nat. Protoc. 2008, 3, 505-516.

20. Everley, P.A.; Krijgsveld, J.; Zetter, B.R.; Gygi, S.P. Quantitative cancer proteomics: Stable isotope labeling with amino acids in cell culture (SILAC) as a tool for prostate cancer research. Mol. Cell. Proteomics 2004, 3, 729-735.

21. Waanders, L.F.; Hanke, S.; Mann, M. Top-down quantitation and characterization of SILAC-labeled proteins. J. Am. Soc. Mass Spectrom. 2007, 18, 2058-2064.

22. Zhu, W.; Smith, J.W.; Huang, C.M. Mass spectrometry-based label-free quantitative proteomics. J. Biomed. Biotechnol. 2010, doi: 10.1155/2010/840518.

23. Kodoyianni, V. Label-free analysis of biomolecular interactions using SPR imaging. BioTechniques 2011, 50, 32-40.

24. Stern, E.; Vacic, A.; Rajan, N.K.; Criscione, J.M.; Park, J.; Ilic, B.R.; Mooney, D.J.; Reed, M.A.; Fahmy, T.M. Label-free biomarker detection from whole blood. Nat. Nanotechnol. 2010, 5, 138-142.

25. Umehara, S.; Karhanek, M.; Davis, R.W.; Pourmand, N. Label-free biosensing with functionalized nanopipette probes. Proc. Natl. Acad. Sci. USA 2009, 106, 4611-4616.

26. Lin, J.; Wei, Z.; Mao, C. A label-free immunosensor based on modified mesoporous silica for simultaneous determination of tumor markers. Biosens. Bioelectron. 2011, 29, 40-45.

27. Chikkaveeraiah, B.V.; Mani, V.; Patel, V.; Gutkind, J.S.; Rusling, J.F. Microfluidic electrochemical immunoarray for ultrasensitive detection of two cancer biomarker proteins in serum. Biosens. Bioelectron. 2011, 26, 4477-4483. 
28. Nicolini, C.; Pechkova, E. Nanoproteomics for nanomedicine. Nanomedicine (Lond.) 2010, 5, 677-682.

29. Nicolini, C.; Sivozhelezov, V.; Bavastrello, V.; Bezzerra, T.; Scudieri, D.; Spera, R.; Pechkova, E. Matrices for sensors from inorganic, organic, and biological nanocomposites. Materials 2011, 4, 1483-1518.

30. Maccioni, E.; Radicchi, G.; Erokhin, V.; Paddeu, S.; Facci, P.; Nicolini, C. Bacteriorhodopsin thin film as a sensitive layer for an anaesthetic sensor. Thin Solid Films 1996, 284-285, 898-900.

31. Paternolli, C.; Ghisellini, P.; Nicolini, C. Nanostructuring of heme-proteins for biodevice applications. IET Nanobiotechnol. 2007, 1, 22-26.

32. Paternolli, C.; Neebe, M.; Stura, E.; Barbieri, F.; Ghisellini, P.; Hampp, N.; Nicolini, C. Photoreversibility and photostability in films of octopus rhodopsin isolated from octopus photoreceptor membranes. J. Biomed. Mater. Res. A 2009, 88, 947-951.

33. Nicolini, C.; Pechkova, E. An overview of nanotechnology-based functional proteomics for cancer and cell cycle progression. Anticancer Res. 2010, 30, 2073-2080.

34. Nicolini, C.; LaBaer, J. Functional Proteomics \& Nanotechnology-Based Microarrays; Pan Stanford Series on Nanobiotechnology: Singapore, 2010; Volume 2, Chapters 1-12, pp. 1-347.

35. Ramachandran, N.; Larson, D.N.; Stark, P.R.; Hainsworth, E.; LaBaer, J. Emerging tools for real-time label-free detection of interactions on functional protein microarrays. FEBS J. 2005, 272, 5412-5425.

36. Torreri, P.; Ceccarini, M.; Macioce, P.; Petrucci, T.C. Biomolecular interactions by surface plasmon resonance technology. Ann. Ist. Super. Sanita 2005, 41, 437-441.

37. Ladd, J.; Taylor, A.D.; Piliarik, M.; Homola, J.; Jiang, S. Label-free detection of cancer biomarker candidates using surface plasmon resonance imaging. Anal. Bioanal. Chem. 2009, 393, 1157-1163.

38. Zhang, X.; Guo, Q.; Cui, D. Recent advances in nanotechnology applied to biosensors. Sensors 2009, 9, 1033-1053.

39. Zahavy, E.; Whitesell, J.K.; Fox, M.A. Surface effects in water-soluble shell-core hybrid gold nanoparticles in oligonucleotide single strand recognition for sequence-specific bioactivation. Langmuir 2010, 26, 16442-16446.

40. Bao, Y.P.; Wei, T.F.; Lefebvre, P.A.; An, H.; He, L.; Kunkel, G.T.; Muller, U.R. Detection of protein analytes via nanoparticle-based bio bar code technology. Anal. Chem. 2006, 78, 2055-2059.

41. Wagner, M.K.; Li, F.; Li, J.; Li, X.F.; Le, X.C. Use of quantum dots in the development of assays for cancer biomarkers. Anal. Bioanal Chem. 2010, 397, 3213-3224.

42. Yezhelyev, M.V. In situ molecular profiling of breast cancer biomarkers with multicolor quantum dots. Adv. Mater. 2007, 19, 3146-3151.

43. Sinha, N.; Yeow, J.T.-W. Carbon nanotubes for biomedical applications. IEE Trans. Nanobiosci. 2005, 4, 180-195.

44. Malhotra, R.; Patel, V.; Vaque, J.P.; Gutkind, J.S.; Rusling, J.F. Ultrasensitive electrochemical immunosensor for oral cancer biomarker IL-6 using carbon nanotube forest electrodes and multilabel amplification. Anal. Chem. 2010, 82, 3118-3123.

45. Wang, J. Carbon-nanotube based electrochemical biosensors: A review. Electroanalysis 2005, 17, 7-14. 
46. Cerasoli, E.; Rakowska, P.D.; Horgan, A.; Ravi, J.; Bradley, M.; Vincent, B.; Ryadnov, M.G. MiS-MALDI: Microgel-selected detection of protein biomarkers by MALDI-ToF mass spectrometry. Mol. Biosyst. 2010, 6, 2214-2217.

47. Luchini, A.; Geho, D.H.; Bishop, B.; Tran, D.; Xia, C.; Dufour, R.L.; Jones, C.D.; Espina, V.; Patanarut, A.; Zhou, W.; et al. Smart hydrogel particles: Biomarker harvesting: One-step affinity purification, size exclusion, and protection against degradation. Nano Lett. 2008, 8, 350-361.

48. Stura, E.; Bruzzese, D.; Valerio, F.; Grasso, V.; Perlo, P.; Nicolini, C. Anodic porous alumina as mechanical stability enhancer for LDL-cholesterol sensitive electrodes. Biosens. Bioelectron. 2007, 23, 655-660.

49. Bavastrello, V.; Stura, E.; Carrara, S.; Erokhin, V.; Nicolini, C. Poly(2,5-dimethylaniline)-MWNTs nanocomposite: A new material for conductometric acid vapours sensor. Sens. Actuat. B Chem. 2004, 98, 247-253.

50. Jokerst, J.V.; Raamanathan, A.; Christodoulides, N.; Floriano, P.N.; Pollard, A.A.; Simmons, G.W.; Wong, J.; Gage, C.; Furmaga, W.B.; Redding, S.W.; et al. Nano-bio-chips for high performance multiplexed protein detection: determinations of cancer biomarkers in serum and saliva using quantum dot bioconjugate labels. Biosens. Bioelectron. 2009, 24, 3622-3629.

51. Makridakis, M.; Vlahou, A. Secretome proteomics for discovery of cancer biomarkers. J. Proteomics 2010, 73, 2291-2305.

52. Goo, Y.A.; Goodlett, D.R. Advances in proteomic prostate cancer biomarker discovery. J. Proteomics 2010, 73, 1839-1850.

53. Misek, D.E.; Kim, E.H. Protein biomarkers for the early detection of breast cancer. Int. J. Proteomics 2011, doi: 10.1155/2011/343582.

54. Zhang, H.; Kong, B.; Qu, X.; Jia, L.; Deng, B.; Yang, Q. Biomarker discovery for ovarian cancer using SELDI-TOF-MS. Gynecol. Oncol. 2006, 102, 61-66.

55. Gold, D.V.; Modrak, D.E.; Ying, Z.; Cardillo, T.M.; Sharkey, R.M.; Goldenberg, D.M. New MUC1 serum immunoassay differentiates pancreatic cancer from pancreatitis. J. Clin. Oncol. 2006, 24, 252-258.

56. Buxbaum, J.L.; Eloubeidi, M.A. Molecular and clinical markers of pancreas cancer. JOP 2010, 11, 536-544.

57. Hueber, W.; Robinson, W.H. Proteomic biomarkers for autoimmune disease. Proteomics 2006, 6, 4100-4105.

58. Krenn, V.; Petersen, I.; Haupl, T.; Koepenik, A.; Blind, C.; Dietel, M.; Konthur, Z.; Skriner, K. Array technology and proteomics in autoimmune diseases. Pathol. Res. Pract. 2004, 200, 95-103.

59. Pinto, J.A.; Rego, I.; Rodriguez-Gomez, M.; Canete, J.D.; Fernandez-Lopez, C.; Freire, M.; Fernandez-Sueiro, J.L.; Sanmarti, R.; Blanco, F.J. Polymorphisms in genes encoding tumor necrosis factor-alpha and HLA-DRB1 are not associated with response to infliximab in patients with rheumatoid arthritis. J. Rheumatol. 2008, 35, 177-178.

60. Lee, S.; Serada, S.; Fujimoto, M.; Naka, T. Application of Novel Quantitative Proteomic Technologies to Identify New Serological Biomarkers in Autoimmune Diseases. Available online: http://www.intechopen.com/source/pdfs/20669/InTechApplication_of_novel_quantitative_proteo mic_technologies_to_identify_new_serological_biomarkers_in_autoimmune_diseases.pdf (accessed on 1 December 2011). 
61. Li, Q.Z.; Xie, C.; Wu, T.; Mackay, M.; Aranow, C.; Putterman, C.; Mohan, C. Identification of autoantibody clusters that best predict lupus disease activity using glomerular proteome arrays. J. Clin. Invest. 2005, 115, 3428-3439.

62. Drouvalakis, K.A.; Bangsaruntip, S.; Hueber, W.; Kozar, L.G.; Utz, P.J.; Dai, H. Peptide-coated nanotube-based biosensor for the detection of disease-specific autoantibodies in human serum. Biosens. Bioelectron. 2008, 23, 1413-1421.

63. Chen, Z.; Tabakman, S.M.; Goodwin, A.P.; Kattah, M.G.; Daranciang, D.; Wang, X.; Zhang, G.; Li, X.; Liu, Z.; Utz, P.J.; et al. Protein microarrays with carbon nanotubes as multicolor raman labels. Nat. Biotechnol. 2008, 26, 1285-1292.

64. Carlsson, A.; Wuttge, D.M.; Ingvarsson, J.; Bengtsson, A.A.; Sturfelt, G.; Borrebaeck, C.A.; Wingren, C. Serum protein profiling of systemic lupus erythematosus and systemic sclerosis using recombinant antibody microarrays. Mol. Cell. Proteomics 2011, doi: 10.1074/mcp.M110.005033.

65. Bell, C.; Smith, G.T.; Sweredoski, M.J.; Hess, S. Characterization of the mycobacterium tuberculosis proteome by liquid chromatography mass spectrometry-based proteomics techniques: A comprehensive resource for tuberculosis research. J. Proteome Res. 2012, 11, 119-130.

66. Liu, T.; Xue, R.; Huang, X.; Zhang, D.; Dong, L.; Wu, H.; Shen, X. Proteomic profiling of hepatitis B virus-related hepatocellular carcinoma with magnetic bead-based matrix-assisted Laser desorption/ionization time-of-flight mass spectrometry. Acta Biochim. Biophys. Sin. (Shanghai) 2011, 43, 542-550.

67. Gaudieri, S. Biomarkers that reflect immune activation or dysfunction will be important in the management of infectious diseases. Biomark. Med. 2011, 5, 109-112.

68. Hauck, T.S.; Giri, S.; Gao, Y.; Chan, W.C. Nanotechnology diagnostics for infectious diseases prevalent in developing countries. Adv. Drug Deliv. Rev. 2010, 62, 438-448.

69. Agranoff, D.; Fernandez-Reyes, D.; Papadopoulos, M.C.; Rojas, S.A.; Herbster, M.; Loosemore, A.; Tarelli, E.; Sheldon, J.; Schwenk, A.; Pollok, R.; et al. Identification of diagnostic markers for tuberculosis by proteomic fingerprinting of serum. Lancet 2006, 368, 1012-1021.

70. Gupta, N.; Shankernarayan, N.P.; Dharmalingam, K. Alpha1-acid glycoprotein as a putative biomarker for monitoring the development of the type II reactional stage of leprosy. J. Med. Microbiol. 2010, 59, 400-407.

71. Tang, S.; Moayeri, M.; Chen, Z.; Harma, H.; Zhao, J.; Hu, H.; Purcell, R.H.; Leppla, S.H.; Hewlett, I.K. Detection of anthrax toxin by an ultrasensitive immunoassay using europium nanoparticles. Clin. Vaccine Immunol. 2009, 16, 408-413.

72. Lee, Y.F.; Lien, K.Y.; Lei, H.Y.; Lee, G.B. An integrated microfluidic system for rapid diagnosis of dengue virus infection. Biosens. Bioelectron. 2009, 25, 745-752.

73. Oliver, B.G.; Price, P. The search for biomarkers of immune restoration disease associated with mycobacterium tuberculosis in HIV patients beginning antiretroviral therapy. Biomark. Med. 2011, 5, 149-154.

74. Sanchez, J.C.; Guillaume, E.; Lescuyer, P.; Allard, L.; Carrette, O.; Scherl, A.; Burgess, J.; Corthals, G.L.; Burkhard, P.R.; Hochstrasser, D.F. Cystatin C as a potential cerebrospinal fluid marker for the diagnosis of creutzfeldt-jakob disease. Proteomics 2004, 4, 2229-2233.

75. Mabbott, N.A.; Mackay, F.; Minns, F.; Bruce, M.E. Temporary inactivation of follicular dendritic cells delays neuroinvasion of scrapie. Nat. Med. 2000, 6, 719-720. 
76. Ray, S.; Reddy, P.J.; Jain, R.; Gollapalli, K.; Moiyadi, A.; Srivastava, S. Proteomic technologies for the identification of disease biomarkers in serum: Advances and challenges ahead. Proteomics 2011, 11, 2139-2161.

77. Kim, H.J.; Cho, E.H.; Yoo, J.H.; Kim, P.K.; Shin, J.S.; Kim, M.R.; Kim, C.W. Proteome analysis of serum from type 2 diabetics with nephropathy. J. Proteome Res. 2007, 6, 735-743.

78. Pickup, J.C.; Zhi, Z.L.; Khan, F.; Saxl, T.; Birch, D.J. Nanomedicine and its potential in diabetes research and practice. Diabetes Metab. Res. Rev. 2008, 24, 604-610.

79. Cash, K.J.; Clark, H.A. Nanosensors and nanomaterials for monitoring glucose in diabetes. Trends Mol. Med. 2010, 16, 584-593.

(C) 2012 by the authors; licensee MDPI, Basel, Switzerland. This article is an open access article distributed under the terms and conditions of the Creative Commons Attribution license (http://creativecommons.org/licenses/by/3.0/). 

ORIGINAL RESEARCH

Enhanced Citotoxic activity by nanoparticles's conjugation

Sánchez-Paradinas et al

\title{
Enhanced cytotoxic activity of bile acid cisplatin
}

\section{derivatives by conjugation with gold nanoparticles}

\author{
Sara Sánchez-Paradinas ${ }^{1}$ \\ Martín Pérez-Andrés ${ }^{2}$ \\ María Jesús Almendral-Parra ${ }^{1}$ \\ Emilio Rodríguez-Fernández ${ }^{3}$ \\ Alberto Orfao ${ }^{2}$ \\ Julio J. Criado ${ }^{3}$ \\ Manuel Fuentes ${ }^{2}$
}

1 Departamento de Química Analítica, Nutrición y Bromatología, Facultad de Ciencias Químicas, Universidad de Salamanca, Plaza de la Merced s/n, Salamanca 37008, Spain

${ }^{2}$ Centro de Investigación del Cáncer (CIC; IBMCC CSIC/USAL), Servicio de Citometría, Departamento de Medicina and IBSAL, Universidad de Salamanca, Salamanca 37007, Spain

${ }^{3}$ Departamento de Química Inorgánica, Facultad de Farmacia, Universidad de Salamanca, Campus "Miguel de Unamuno", Salamanca 37007, Spain

Correspondence: Manuel Fuentes

Centro de Investigación del Cáncer (CIC; IBMCC CSIC/USAL), Servicio de Citometría, Departamento de Medicina and IBSAL, Universidad de Salamanca, Salamanca 37007, Spain

Tel + 34923294811

Fax +34923294743

Email mfuentes@usal.es 


\section{Abstract:}

Purpose: This article explores the potencial cytotoxic activity of Bile-acid cisplatin derivatives like bisursodeoxycholate(ethylenediamine)platinum(II), PtU2, when conjugated with gold nanoparticles, being a promising alternative to cisplatin in the treatment of cancer due to their lower toxicity.

Methods: We analyzed the intracellular delivery ability of these compounds after conjugation with 20-nm gold nanoparticles (PtU2-AuNPs) in the MG63 (osteosarcoma) cell line.

Results: Same platinum uptake after incubation with PtU2 and PtU2-AuNPs-derivatives is associated with a higher cytotoxic activity in case of the platinum-gold nanoparticle conjugate, the overall IC50 of PtU2 being reduced more than 10 fold for these new conjugates.

Conclusion: When conjugated with gold nanoparticles, this bile-acid derivative is more efficient than the platinum compound alone in terms of their cytotoxic activity.

Keywords: Bile-acid cisplatin derivatives; gold nanoparticles; cytotoxic activity; drug delivery.

\section{Introduction}

The platinum compounds have clinical utility as antitumoral drugs because of their cytotoxic activity, cisplatin (CDDP) being one of the most widely used anticancer agents for the treatment of various solid tumors. ${ }^{1}$ Its side effects (nephrotoxicity, myelotoxicity, neurotoxicity, nausea, and vomiting) and the development of resistance by targeted cells have been drawbacks which have fostered the development of new cisplatin analogues, including bile acid-cisplatin derivatives. ${ }^{2}$ These derivatives have potential cytotoxic activity and reduced toxicity, owing to their lower lability and their amphipathic character, making them a suitable alternative for CDDP, as antitumoral drugs. Also the square-planar platinum(II) complex bearing two ursodeoxycholate (UDC) ligands used in this study and synthesized by our group presents intrinsic fluorescence, which may contribute to a better understanding of drug activity, metabolic pathways and transport mechanism. ${ }^{3}$ 
Gold nanoparticles (AuNPs) have recently emerged as an attractive candidate for drug delivery applications. ${ }^{4}$ AuNPs dramatically improve therapeutic outcomes of multiple drug-related therapies based on drug delivery, which attract the attention of "NanoMedicine". ${ }^{5-7}$ The gold core is essentially inert, non-toxic (in short- and medium-term direct assays), biocompatible and provides stability, making it an ideal starting point for carrier construction. ${ }^{8}$ A wide range of conjugation chemistries (self-assembled monolayers) provide versatility on chemical functional groups that can be used to bound distinct compounds. As a consequence of such versatility, AuNPs offer the diversity to incorporate multiple therapeutic drugs or biomacromolecules by covalent and non-covalent conjugation on the surface of a NP. ${ }^{9}$ Such drug delivery systems have proven to improve solubility and stability in complex biological media compared to the corresponding free drugs. ${ }^{10}$

In this work, we show an enhanced cytotoxic activity of UDC-cisplatin conjugated to AuNPs in an osteosarcoma cell line (MG63), a model for one of the most untreatable and painful malignant tumors whose standard treatment requires radical surgery and neoadjuvant therapy. ${ }^{11}$

\section{Material and methods}

\section{Chemicals}

All chemical reagents were of analytical grade and used as purchased with no additional purification. Dichloro(ethylenediamine)platinum(II), cisplatin, HUDC (ursodeoxycholic acid) and gold nanoparticles (gold colloidal solution) were purchased from Sigma-Aldrich (St. Louis, MO). Gold nanoparticles were characterized with UV-Vis absorption spectroscopy and TEM, showing an absorption band at $520 \mathrm{~nm}$ and an average size of $20 \mathrm{~nm}$. Annexin V-FITC, propidium iodide Staining Solution and annexin V Binding Buffer 10X were purchased from Immunostep (Salamanca, Spain). Penicillin/Streptomycin, trypsin, fetal bovine serum, L-glutamine and phosphate buffered saline (PBS) were obtained from GIBCO (Carlsbad, CA). Dimethylsulfoxide was obtained from Merck (Darmstadt, Germany). 
The bisursodeoxycholate(ethylenediamine)-platinum(II), [Pt(UDC) $\left.)_{2}(\mathrm{en})\right]$, PtU2 compound was synthesized as previously described by Pérez-Andrés et al. ${ }^{3}$ PtU2 solutions were prepared by dissolving the solid compound in ultrapure water. The conjugates of PtU2 with gold nanoparticles (PtU2-AuNP) were prepared by mixing the solid PtU2 compound directly in the colloidal solution of the nanoparticles. All the solutions were vortexed for at least twenty minutes and then stored at $4^{\circ} \mathrm{C}$ until use in cell cultures. The conjugates were characterized by absorption spectroscopy, fluorescence emission spectroscopy, transmission electron microscopy (TEM) and scanning electron microscopy (SEM).

\section{Cell line}

The MG63 cell line was cultured in RPMI (Invitrogen, CA, USA) supplemented with $10 \%$ calf fetal serum, $1 \% \mathrm{~L}$-glutamine and $2 \%$ penicillin/streptomycin, at $37^{\circ} \mathrm{C}$ in a $5 \% \mathrm{CO}_{2}$ humid atmosphere, in the presence of different concentrations $(0-150 \mu \mathrm{M})$ of PtU2, AuNPs and PtU2-AuNPs for the analysis of the cytotoxic activity and the carrier activity. Cells were cultured for 24 and $48 \mathrm{~h}$ in the different conditions evaluated. When necessary, cells were counted using Neubauer counting chamber. All the experiments were performed on exponentially growing cells, with a doubling time between 24 and $36 \mathrm{~h}$.

\section{Carrier activity measurements}

In order to study the carrier activity of the conjugates, the medium and the cells were collected separately, and metal content (platinum and gold) was determined in each fraction by inductively coupled plasma mass spectrometry (ICP-MS) at the central facility of Chemical Analysis (“Servicio General de Análisis Químico") of the University of Salamanca (Salamanca, Spain) with an Inductively Coupled Plasma-Mass Spectrometer Elan 6000 model from Perkin-Elmer (Waltham, MA) calibrated from 10 to $1000 \mathrm{ppb}$ with solutions of platinum and gold standard (Panreac, Barcelona, Spain). In all assays, the sensitivity detection limit was of $<0.3 \mathrm{ppb}$ and of $<5 \mathrm{ppb}$ for the Pt and Au metals, respectively. Platinum and gold containing samples were mixed with $5 \mathrm{~mL}$ of concentrated $\mathrm{HNO}_{3}$, added with $20 \mathrm{ppb}$ of holmium. After treatment in microwave 
oven for 15 minutes, clear solutions of the samples were analyzed for total platinum and gold. Concentration values $(\mathrm{ppb})$ were corrected with respect to holmium signal.

\section{Cytotoxic activity measurements}

The cytotoxic activity of the PtU2 and the PtU2-AuNPs conjugates was evaluated by flow cytometry (FACSCalibur flow cytometer, Becton/Dickinson Biosciences, San Jose, CA, USA) after a 24 and $48 \mathrm{~h}$ incubation under the above described culture conditions. Harvested cells were centrifuged ( $5 \mathrm{~min}$. at $540 \mathrm{~g}$ ) and resuspended at a concentration of $10^{5}$ cells were washed once in a PBS solution. Afterward, cells were stained with the Annexin V-FITC Apoptosis detection kit (Immunostep SL, Salamanca, Spain) according to the manufacturer's instructions. A minimum of $5 \times 10^{4}$ cells were acquired within 1 hour. Percentage of death cells were analyzed using Infinicyte software 1.5 (Cytognos, Spain). All experiments were repeated, at least three times. The Mann-Whitney $U$ test was used to estimate the statistical significance of the differences observed between groups of experiments. In all cases, $p$ values $\leq 0.05$ were considered to be associated with statistical significance.

\section{Results and Discussion}

AuNPs-citrate nanostructures were coated with the PtU2 compound through non-covalent interactions between the citrate molecules and moieties of the bile-acid cisplatin derivatives. The formation of the complexes in a non-covalent way is more convenient than a covalent conjugation mainly because of easier drug release as intracellular processing of the prodrug is not required, ${ }^{12,13}$ together with an easier production and a controllable loading efficiency. The ${ }^{1} \mathrm{H}$ NMR spectrum in $\mathrm{D}_{2} \mathrm{O}$ of the PtU2 compound shows three signals (s, singlet) at $0.6550 \mathrm{ppm}$, $0.8507 \mathrm{ppm}$ and $0.9230 \mathrm{ppm}$, which are attributed to the methyl groups C18, C19 and C21, respectively (Figure 1(A)). After the formation of the adducts, the corresponding signals slightly shifted to $0.5500 \mathrm{ppm}, 0.7878 \mathrm{ppm}$ and $0.8530 \mathrm{ppm}$, respectively.

The morphological characterization of the conjugates was performed by transmission electron microscopy (TEM) and scanning electron microscopy (SEM) (Figure 1(B) and (C)). Based on 
TEM images, at first glance, it is possible to distinguish a clear zone surrounding the core of AuNPs, which corresponds to an element with a lower electron density, in our case the platinum compound (Figure 1(B)). In turn, the SEM images (Figure 1(C)) showed surface of AuNPs with a rough appearance. The bile-acid platinum compounds tested in this study have an amphipathic micelles-forming character, as it was previously described by Criado et al. ${ }^{2}$ Thus, it could be assumed that an interaction between the micelles and the hydrophobic surface of the AuNPs existed.

At first sight, AuNPs aggregation is observed in both the TEM and SEM images; this rather than being a limitation might be beneficial. As previously reported, most tumors present intercellular spaces (100 to $1200 \mathrm{~nm}) \cdot{ }^{14,15}$ All particles with less than $100 \mathrm{~nm}$ could be eliminated through transvascular transport. Bearing this in mind, it could be proposed that the observed PtU2-AuNPs aggregates, being small enough to move through the intracellular space, could increase the attraction for getting solid tumor neoplastic cells than not aggregated derivatives.

In order to evaluate the intracellular contents of both PtU2-AuNP and AuNPs related to the cytotoxic activity observed, the amount of Au and Pt per $7 \times 10^{6}$ cells was measured as described in Materials and Methods. As shown in Figure 2(A.i), it is observed a direct relationship between the amounts of intracellular Au uptake and increasing concentrations of both AuNPs or conjugate PtU2-AuNP. Interestingly, the overall intracellular amount of Au was higher when cells were incubated under identical conditions with PtU2-AuNP versus AuNPs alone. In this sense, the highest ratio [Au] intracellular PtU2-AuNPs/[Au] intracellular AuNPs (eg 2.5) was reached the highest concentration of PtU2-AuNP $(150 \mu \mathrm{M})$; indicating that endocytosis capacity of the cells have not change independently of AuNPs or PtU2-AuNP.

The overall amount of platinum taken up by the cells increased almost linearly with increasing concentrations of PtU2 and PtU2-AuNPs, but no differences founded when incubating with the bulk compound and the conjugate, neither between the amount of platinum measured in the extracellular not in the intracellular medium (Figure 2(A)). Therefore, the intracellular concentration of Pt did not increase when cells were incubated with different concentrations of the 
PtU2-AuNP conjugate (range: 0 to $150 \mu \mathrm{M}$ ) neither higher differences reached at higher concentration (ratio [Pt]intracellular: 1.7 at $150 \mu \mathrm{M}$ ).

Overall, the PtU2-AuNP complex exerted an important cytotoxic activity against MG63 osteosarcoma cells which was already clearly detectable after $48 \mathrm{~h}$ of culture (Figure 2(B)). The amount of apoptotic cells detected after incubation with this newly-synthesized Platinum-AuNP complex was significantly higher $(p \leq 0.05)$ at doses of between 10 and $150 \mu \mathrm{M}$, versus that obtained with the PtU2 compound. Experiments performed to assay the activity of free PtU2 demonstrated that this compound was unable to exert almost any cytotoxic activity even at the highest (e.g. $150 \mu \mathrm{M})$ concentration of the drug (Figure 2(B)). As a consequence, the percentage of dead cells caused by PtU2 and PtU2-AuNPs was significantly different, even if there was no significant difference in the amount of Pt inside the cells (Figure 2(C)), as mentioned above.

\section{Conclusion}

Taking into account all the above-mentioned arguments, it could be concluded that under the same in vitro conditions, bile-acid derivatives attached to AuNPs are more efficient than the platinum compound alone in terms of their cytotoxic activity, e.g. as anticancer agents. Such increased cytotoxic activity is specific for the PtU2-AuNPs complex, since no cytotoxic activity was detected when the cells were incubated with the AuNPs alone in volumes of nanoparticle solution equivalent to those used with the PtU2-AuNPs complexes for a drug concentration between 0 and $30 \mu \mathrm{M}$. The precise mechanisms by which the presence of AuNPs increases the cytotoxic activity of the drug remain elusive and require further investigations.

\section{Acknowledgments/Disclosures}

The author reports no conflicts of interest in this work. This work has been supported by grants from the Fondo de Investigación Sanitaria (FIS) of the Instituto de Salud Carlos III (ISCIII), Madrid, Spain (ISCIII, FIS PI1102114) and Junta Castilla-León (SA198A12-2); Sara SánchezParadinas is supported by a PhD fellowship from the Junta de Castilla y León (Orden EDU/1486/2008, de 30 de Julio BOCyL 18/08/2008). The author ERF thanks the grant from 
"Fundación Samuel Solórzano Barruso 2012". We would like to thank Noelia Dasilva, Fernando Palacio and Ángel Millán for their critical comments of the manuscript.

\section{References}

1. Wong E, Giandomenico CM. Current Status of Platinum-Based Antitumor Drugs. Chem Rev. 1999;99:2451-2466.

2. Criado JJ, Rodríguez-Fernández E, Manzano JL, et al. Intrinsically Fluorescent Cytotoxic Cisplatin Analogues as DNA Marker Molecules. Bioconjug Chem 2005;16:275-282.

3. Pérez-Andrés M, Benito JJ, Rodríguez-Fernández E, et al. Bisursodeoxycholate(ethylenediamine)platinum(II): a new autofluorescent compound. Cytotoxic activity and cell cycle analysis in ovarian and hematological cell lines. Dalton Trans. 2008;6159-6164.

4. Rana S, Bajaj A, Mout R, Rotello V. Monolayer coated gold nanoparticles for delivery applications. Advanced Drug Delivery Reviews 2012;64:200-216.

5. Pissuwan D, Niidome T, Cortie MB. The forthcoming applications of gold nanoparticles in drug and gene delivery systems. Journal of Controlled Release 2011;149:65-71.

6. Gonzalez-Gonzalez M, Jara-Acevedo R, Matarraz S, et al. Nanotechniques in proteomics: Protein microarrays and novel detection platforms. European Journal of Pharmaceutical Sciences 2012;45(4):499-506.

7. Dasilva N, Díez P, Matarraz S, et al. Biomarker Discovery by Novel Sensors Based on Nanoproteomics Approaches. Sensors 2012;12:2284-2308.

8. Di Guglielmo C, De Lapuente J, Porredon C, Ramos-López D, Sendra J, Borràs M. In vitro safety toxicology data for evaluation of gold nanoparticles-chronic cytotoxicity, genotoxicity and uptake, J Nanosci Nanotechnol 2012;12(8):6185-6195.

9. Templeton AC, Wuelfing MP, Murray RW. Monolayer-protected cluster molecules. Acc. Chem. Res. 2000;33:27-36.

10. Algar WR, Prasuhn DE, Stewart MH, et al. The Controlled Display of Biomolecules on Nanoparticles: A Challenge Suited to Bioorthogonal Chemistry. Bioconjug Chem 
2011;22:825-858.

11. Xue Z, Lin M, Zhu J, Zhang J, Lia Y, Guo Z. Platinum(II) compounds bearing bonetargeting group: synthesis, crystal structure and antitumor activity. Chem Commun 2010;46:1212-1214.

12. Saha K, Agasti SS, Kim C, Li X, Rotillo VM. Gold Nanoparticles in Chemical and Biological Sensing. Chem Rev 2012;112:2739-2779.

13. Tomuleasa C, Soritau O, Orza A, et al.. Gold nanoparticles conjugated with cisplatin/doxorubicin/capecitabine lower the chemoresistance of hepatocellular carcinoma-derived cancer cells. J Gastrointestin Liver Dis 2012;21:187-196.

14. Hobbs SK, Monsky WL, Yuan F, et al. Regulation of transport pathways in tumor vessels: Role of tumor type and microenvironment. Proc. Natl. Acad. Sci. USA 1998;95:46074612.

15. Yuan F, Dellian M, Fukumura D, et al. Vascular Permeability in a Human Tumor Xenograft: Molecular Size Dependence and Cutoff Size. Cancer Research 1995;55:37523756. 
Figure $1(\mathrm{~A}){ }^{1} \mathrm{H}-\mathrm{NMR}$ spectra of the platinum compound (i) and its incubation adduct with gold nanoparticles (ii). HUDC= ursodeoxycholic acid. TEM (B) and SEM (C) images of the PtU2AuNPs conjugate drug complex in water.

A

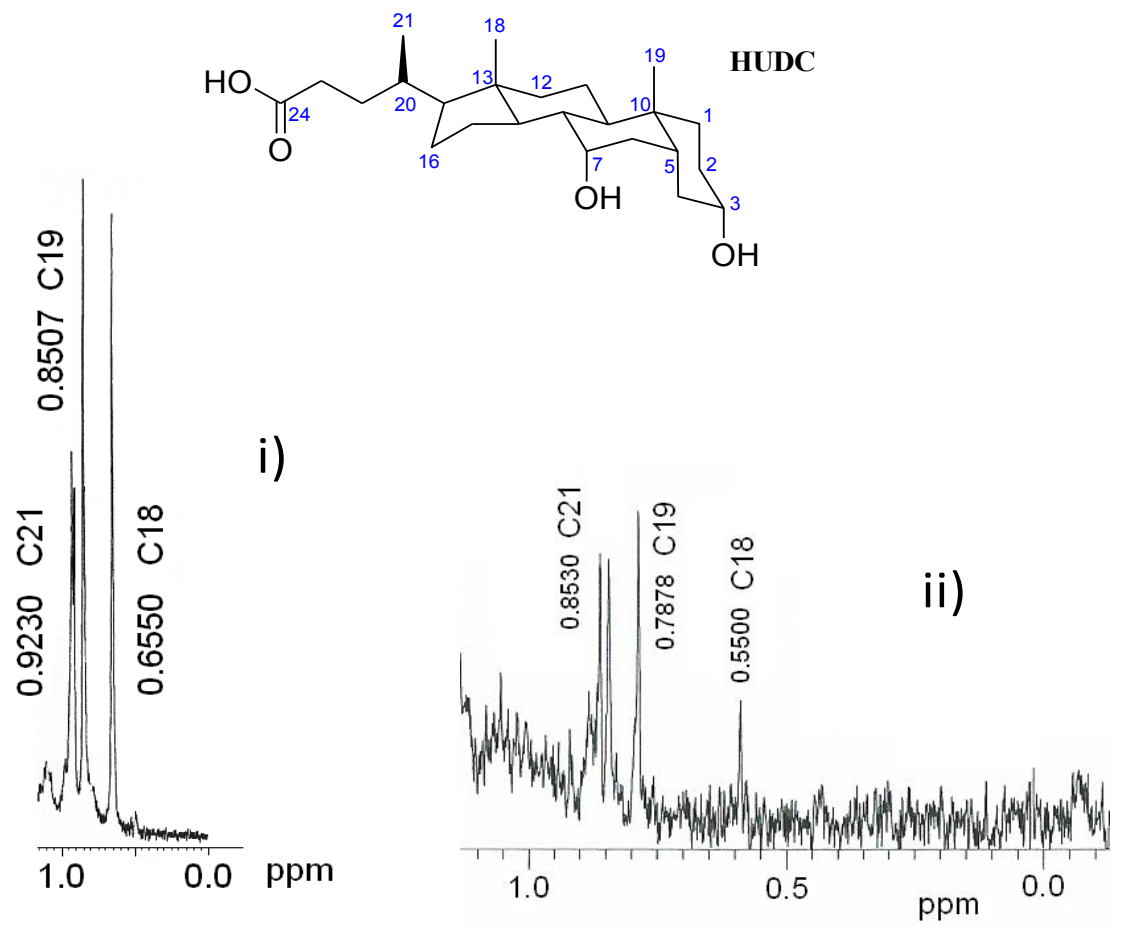

\section{B}

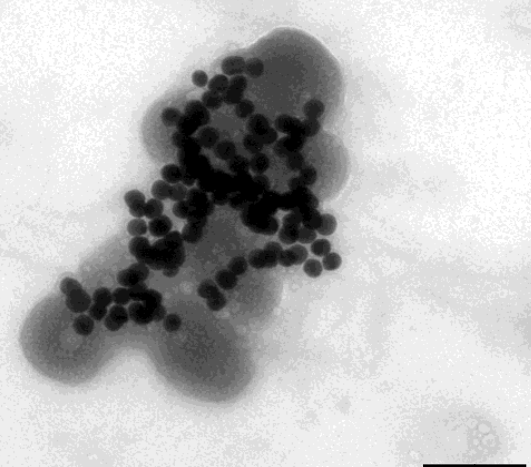

$50 \mathrm{~nm}$

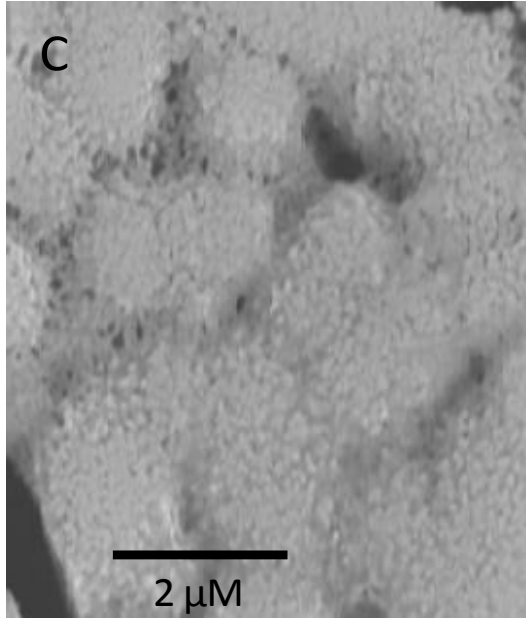


Figure 2 A) Metal contents after $48 \mathrm{~h}$ continuous exposure (0-150 $\mu \mathrm{M})$ determined by ICP-MS. i) Intracellular metal contents after incubation with AuNPs, PtU2 and PtU2-AuNP. ii) Extracellular metal contents after incubation with AuNPs, PtU2 and PtU2-AuNP. B) Cytotoxic activity of the PtU2 compound (green line) and the newly-synthesized PtU2-AuNP complex (red line) against MG63 (osteosarcoma) cells, after culturing these cells in the presence of different amounts of each of the two compounds, for $48 \mathrm{~h}$. Results are expressed as median percentage of surviving MG63 cells (vertical lines correspond to $95 \%$ confidence interval). ${ }^{*} p \leq 0.05$. C) Median percentage of dead cells with respect to intracellular platinum content when incubating with PtU2 (green line) and PtU2-AuNPs (red line).

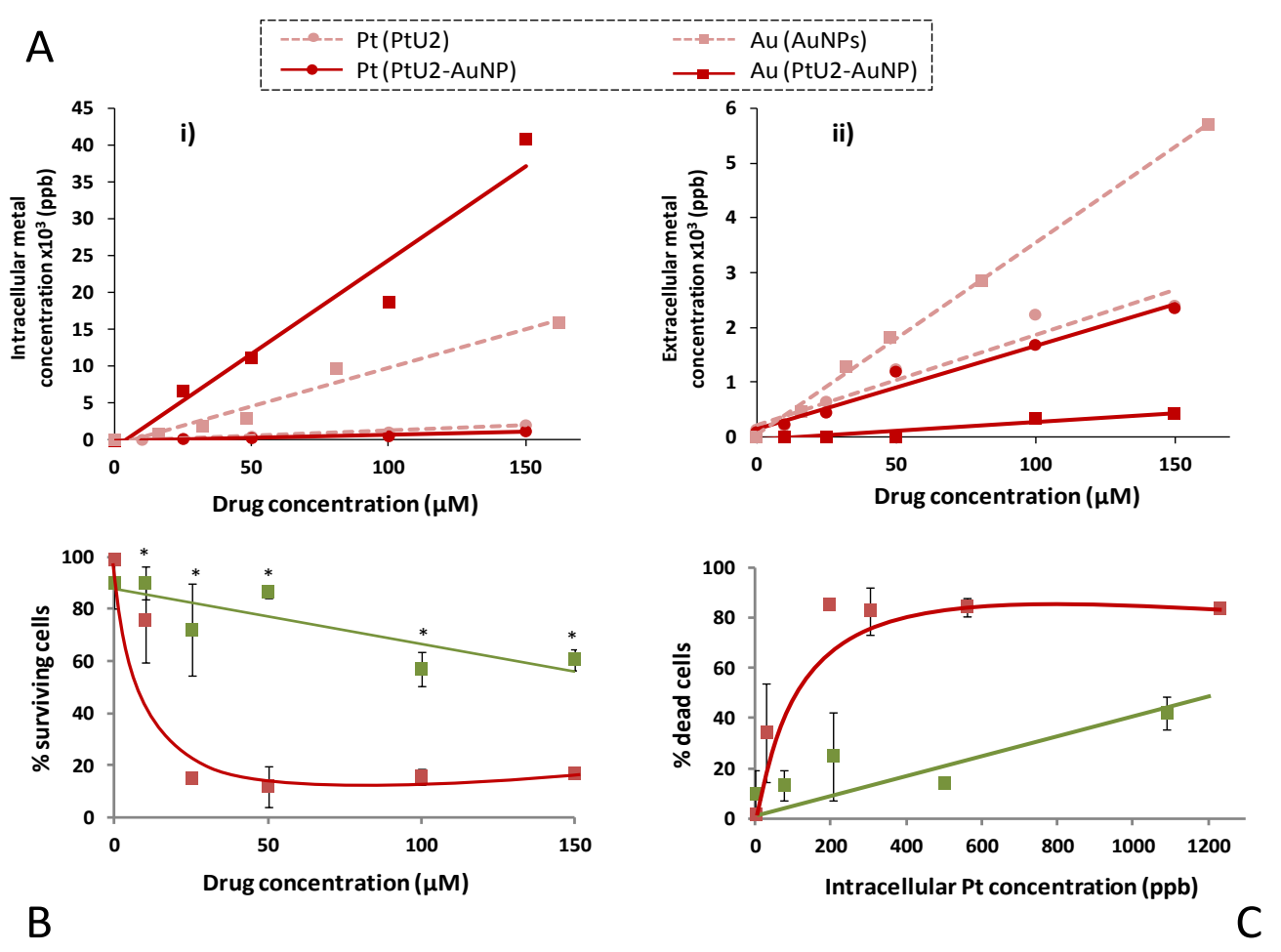



Anexo II: Informes sobre el trabajo realizado

Appendix II: Reports on the developed work 

Philipps University of Marburg

FB Physics

Biophotonics Group

Universidad de Salamanca

Facultad de Ciencias Químicas

Departamento de Química Analítica

February 26, 2013

\section{Report on Thesis summary of Sara Sánchez Paradinas}

The thesis "Nanoparticles as tolos in bio-chemical processes. Synthesis, characterization, functionalization and applications" consists of six chapters. In the first chapter Sara Sánchez Paradinas gives a general introduction of why Nanotechnology could be applied in molecular Biology. Then, in the second chapter she explained the general aims of her research as PhD student. The third chapter deals with the synthesis and application of quantum dots: inorganic nanoparticles able to act as labels and sensors in biological applications. This work led to a publication. Chapter four is focused in the application of gold nanoparticles as carrier systems and the fifth in the application in the field of proteomics. The last chapter collects the general conclusions of the thesis. The thesis is based on three papers published in highly ranked journals and one that has been recently submitted.

Sara Sánchez Paradinas has developed new methods to produce quantum dots in aqueous media which important to minimize costs in the production and ensure stability of the particles in biological environments. She has also improved the delivery of a drug of medical interest and she was involved in the new field of nanoproteomics.

The thesis is well written and describes perfectly the instrumentation used and the methods applied for the research work done by Sara Sánchez Paradinas. In my opinion the thesis is of high quality. The work is interdisciplinary and therefore, the effort of combining analytical chemistry with molecular biology deserves special attention. I strongly recommend that her thesis would be accepted as part of the requirements for receiving the PhD degree in the Department of Analytical Chemistry in the University of Salamanca.

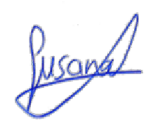

\section{Dra. Susana Carregal Romero}

Dra. Susana Carregal Romero, phone: +4964212824179; fax:+4964212827034; e-mail: Susana.carregalromero@physik.uni-marburg.de 

Universidad de Salamanca

Facultad de Ciencias Químicas

Departamento de Química Analítica

NANOPARTICLES AS TOOLS IN BIO-CHEMICAL PROCESSES. SYNTHESIS, CHARACTERIZATION, FUNCTIONALIZATION AND APPLICATIONS - Ph.D. thesis summary of Sara Sánchez Paradinas

The thesis summary entitled "NANOPARTICLES AS TOOLS IN BIO-CHEMICAL PROCESSES. SYNTHESIS, CHARACTERIZATION, FUNCTIONALIZATION AND APPLICATIONS" is organized within three main chapters as Introduction, General Aims and General Conclusions, all well supported with new literature data on 97 pages. In the first two chapters Sara Sánchez Paradinas gives general information about nanotechnology, quantum dots and modification of these nanoparticles. Further, general aims of the thesis are clearly defined and described, and aimed at the field of analysis and using of quantum dots. In the following chapters she primarily describes the aim of each part and the main conclusions of the results. Chapter 3 (QDs) clearly describes the aim of this part of the thesis and the results obtained. The work is published in J. Fluorescence (IF 2.1) and Sara Sánchez Paradinas is the third author. Chapter 4 (Metal nanoparticles), the aim and the results obtained are briefly defined and there is article submitted for publication, where Sara Sánchez Paradinas is the first author. Chapter 5 (Nanoparticles in proteomics), the aim and the results are briefly described. The work is published in European Journal of Pharmaceutical Sciences (IF 3.2), Sara Sánchez Paradinas as the fifth author and in review published Sensors (IF 1.7) summarizing results from the field of the interest, Sara Sánchez Paradinas is the fifth author. The general conclusions of the work are described in the final chapter.

Novelty of the thesis can be defined in the fact that Sara Sánchez Paradinas has developed a new method for the synthesis of Quantum dots in aqueous media. The in-depth knowledge of their characteristics and particular phenomena is an important aspect of this part of the work, and it will encourage and facilitate their use as analytical tools in biological applications. This chapter resulted in a publication in J Fluoresc (2012) 22:59-69.

In the second part, Sara Sánchez Paradinas show her work in one of the most important and current fields of Nanoscience, the transport of drugs with nanoparticles. She has demonstrated the potential toxicity of new cisplatin derivatives when conjugated with gold nanoparticles. The publication of this part has been recently submitted. 
And finally, she has participated in the elaboration of several works that show the tremendous potential of nanoparticles in the field of proteomics, one in European Journal of Pharmaceutical Sciences 45 (2012) 499-506 and another in Sensors 2012, 12, 2284-2308.

The summary is well written, the content well organized and logically presented and shows the high quality of the research work done by Sara Sánchez Paradinas.

In my conclusion I would like to stress that this Thesis has significant degree of scientific novelty and represents real contribution to analytical chemistry and nanoscience. I can recommend the thesis to be defended, and after the successful defending, to obtain scientific degree of Ph.D.

Prof. Ing. René Kizek, Ph.D.
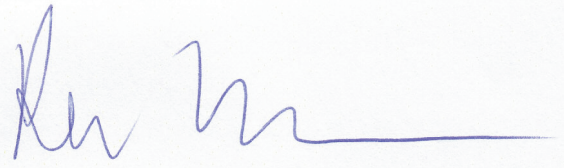

The Head of Laboratory of Metallomics and Nanotechnology, Department of Chemistry and Biochemistry, Mendel University in Brno and Research Group Leader in Central European Institute of Technology, Brno University of Technology 